Prepared for the U. S. Army Fort Bliss Environmental Division

under a Related Services Agreement with the

U.S. Department of Energy under contract DE-AC05-76RL01830

\title{
Dust Plume Modeling from Ranges and Maneuver Areas on Fort Bliss and the White Sands Missile Range: Final Report
}

(Contract No. 55363A)

$\begin{array}{ll}\text { EG Chapman } & \text { MS Pekour } \\ \text { JC Barnard } & \text { JP Rishel } \\ \text { FC Rutz } & \text { WJ Shaw }\end{array}$

May 2009 


\title{
DISCLAIMER
}

This report was prepared as an account of work sponsored by an agency of the United States Government. Neither the United States Government nor any agency thereof, nor Battelle Memorial Institute, nor any of their employees, makes any warranty, express or implied, or assumes any legal liability or responsibility for the accuracy, completeness, or usefulness of any information, apparatus, product, or process disclosed, or represents that its use would not infringe privately owned rights. Reference herein to any specific commercial product, process, or service by trade name, trademark, manufacturer, or otherwise does not necessarily constitute or imply its endorsement, recommendation, or favoring by the United States Government or any agency thereof, or Battelle Memorial Institute. The views and opinions of authors expressed herein do not necessarily state or reflect those of the United States Government or any agency thereof.

\author{
PACIFIC NORTHWEST NATIONAL LABORATORY \\ operated by \\ BATTELLE \\ for the \\ UNITED STATES DEPARTMENT OF ENERGY \\ under Contract DE-AC05-76RL01830 \\ Printed in the United States of America
Available to DOE and DOE contractors from the
Office of Scientific and Technical Information,
P.O. Box 62, Oak Ridge, TN 37831-0062;
ph: (865) 576-8401
fax: $(865) 576-5728$
email: reports@adonis.osti.gov \\ Available to the public from the National Technical Information Service, \\ U.S. Department of Commerce, 5285 Port Royal Rd., Springfield, VA 22161 \\ ph: (800) 553-6847 \\ fax: (703) 605-6900 \\ email: orders@ntis.fedworld.gov \\ online ordering: http://www.ntis.gov/ordering.htm
}

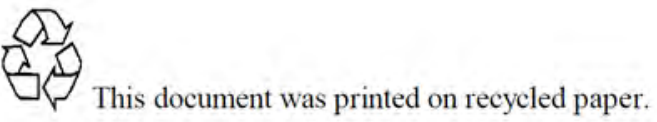

$(9 / 2003)$ 


\title{
Dust Plume Modeling from Ranges and Maneuver Areas on Fort Bliss and the White Sands Missile Range: Final Report
}

(Contract No. 55363A)

\author{
EG Chapman MS Pekour \\ JC Barnard JP Rishel \\ FC Rutz WJ Shaw
}

May 2009

Prepared for the U. S. Army Fort Bliss Environmental Division under a Related Services Agreement with the U.S. Department of Energy under contract DE-AC05-76RL01830

Pacific Northwest National Laboratory

Richland, Washington 99352 



\section{Summary}

The potential for air quality impacts from heavy mechanized vehicles operating on and between the unpaved main supply routes at Fort Bliss and White Sands Missile Range was investigated. This report details work performed by the staff of Pacific Northwest National Laboratory for the Fort Bliss Environmental Division in this investigation. Dust emission and dispersion from typical move-out activities occurring on the installations were simulated using the atmospheric modeling system DUSTRAN. Major assumptions associated with designing the modeling scenarios are summarized, and results of simulations conducted under these assumptions are presented for four representative meteorological periods.

Modeling results represent contributions from military vehicular activity alone. Background particulate concentrations in an incoming air mass and particulates generated via wind erosion and from disturbed soils are not included in the predicted values. Model predictions are referred to as concentration contributions to emphasize this point.

Results of these baseline simulations indicate that low wind-speed days generally resulted in higher 24-hour-average $\mathrm{PM}_{10}$ concentration contributions over a larger local area than high wind-speed days. Under low wind-speed conditions, lofted particulates stay in the area of generation and are not readily dispersed, leading to the higher concentration contributions. Of the six move-out routes studied, the route extending from the White Sands Missile Range (WSMR) through Oro Grande to the McGregor Range Camp consistently demonstrated the largest regions of 24-hour average $\mathrm{PM}_{10}$ concentration contributions ( $500 \mu \mathrm{g} / \mathrm{m}^{3}$ or more). The greater range of high-concentration contribution is attributed to the proximity of two parallel "legs" along the route. The doubling back of the convoy as it traverses these parallel legs increases vehicular activity and the associated dust emission source strength in the area, leading to higher 24-hour concentration contributions. Baseline simulations for move-out routes involving travel over the same subset of roads and trails were similar for a given day. For example, predicted hourly and 24-hour average concentration contributions for a move-out from WSMR to Range 40 were similar to predictions for a move-out from WSMR to the Dona Ana Range Camp. Simulations of move-outs from WSMR to the Oro Grande Base Camp and from WSMR to the Short-Range Air Defense (SHORAD) range also tended to be similar.

A series of sensitivity tests was conducted to examine the individual and combined effects of moveout start time and reduced vehicle speed. The sensitivity simulations suggest that, under certain circumstances, delaying the start of move-out maneuvers from early morning until mid-morning may decrease the size of the dust plume from military operations and thus reduce local $\mathrm{PM}_{10}$ concentrations. The decrease is related to meteorological changes in both boundary layer depth and wind speed that affect mixing and dispersion processes. However, on move-out routes with long travel times, decreased contributions may not materialize if the delay causes vehicle travel to extend significantly into the afternoon decay phase of the diurnally varying atmospheric boundary layer and/or periods of decreased winds. The sensitivity simulations also indicate that reductions in vehicle speed may not automatically produce improvements in 24-hour average $\mathrm{PM}_{10}$ concentration contributions. Reducing vehicle speed directly reduces the magnitude of the vehicle dust emission source strength. However, it also increases travel time. Depending on the overall distance that must be traveled, this increase in travel time may push a portion of emissions into a time of day with more shallow boundary layer depths and/or decreased wind speeds, similar to delaying the move-out start time on long travel routes. The trade-off between decreased emission source strengths and increased travel times needs to be assessed in such situations. 



\section{Acknowledgments}

The authors thank Larry Berg for helpful comments on the draft manuscript, and Ruth Keefe, Sheila Bennett, and Mike Parker for their efforts in editing and producing this report. We especially appreciate their care in handling the large number of figures included in this document. The authors also recognize and thank Dr. K. Jerry Allwine, now retired, whose vision, perseverance, and leadership led to the development of DUSTRAN. Without him, this work would not have been possible. 



\section{Acronyms and Abbreviations}

$\begin{array}{ll}\text { ARS } & \text { Armed Reconnaissance Squadron } \\ \text { BRAC } & \text { Base Realignment and Closure } \\ \text { BSB } & \text { Brigade Support Battalion } \\ \text { BSTB } & \text { Brigade Special Troops Battalion } \\ \text { CAB } & \text { Combined Arms Battalion } \\ \text { CALGRID } & \text { California photochemical GRID model } \\ \text { CALMET } & \text { California Meteorological model } \\ \text { CALPUFF } & \text { California PUFF model } \\ \text { DUSTRAN } & \text { Dust Transport model } \\ \text { DoD } & \text { U.S. Department of Defense } \\ \text { DRI } & \text { Desert Research Institute } \\ \text { EPA } & \text { U.S. Environmental Protection Agency } \\ \text { ESRI } & \text { Environmental System Research Institute } \\ \text { GIS } & \text { Geographical Information System } \\ \text { HBCT } & \text { Heavy Brigade Combat Team } \\ \text { HC BCT } & \text { Brigade Headquarters } \\ \text { MST } & \text { Mountain Standard Time } \\ \text { PM } & \text { Particulate Matter with an aerodynamic diameter of 10 microns or less } \\ \text { PNNL } & \text { Pacific Northwest National Laboratory } \\ \text { SERDP } & \text { Strategic Environmental Research and Development Program } \\ \text { SHORAD } & \text { Short-Range Air Defense } \\ \text { UTC } & \text { Coordinated Universal Time } \\ \text { WSMR } & \text { White Sands Missile Range }\end{array}$





\section{Contents}

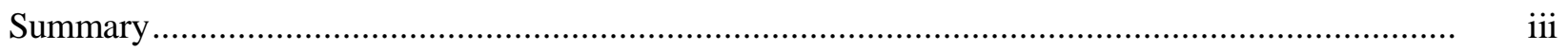

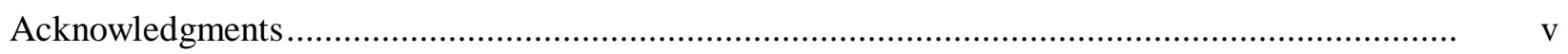

Acronyms and Abbreviations............................................................................................. vii

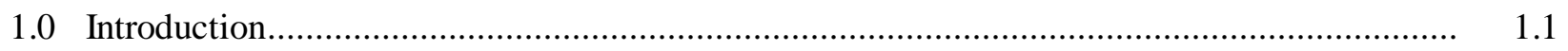

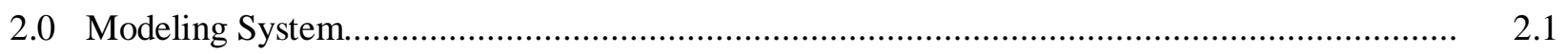

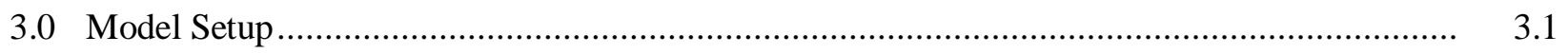

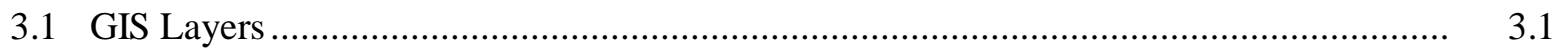

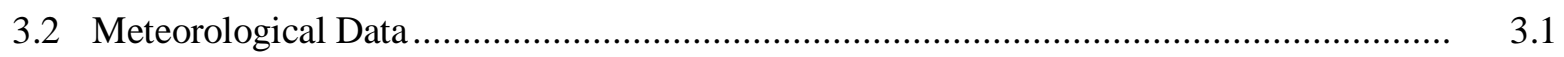

3.3 Vehicle Types ................................................................................................. 3.3

3.4 Move Out Scenarios: Routes and Assumptions ........................................................... 3.3

3.5 Modeling Domain ..........................................................................................

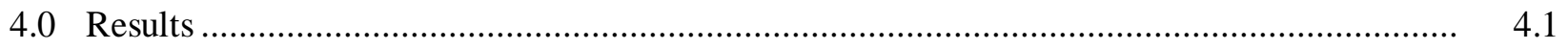

4.1 Baseline Simulations ........................................................................................ 4.1

4.2 Wheeled Vehicle Versus Tracked Vehicle Emission Factors ......................................... 4.4

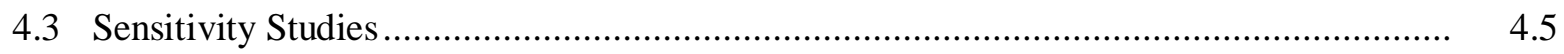

4.3.1 Move-out Start Time................................................................................ 4.5

4.3.2 Vehicle Speed...................................................................................... 4.10

4.3.3 Combined Effect of Move-out Start Time and Vehicle Speed ............................. 4.13

5.0 List of Persons and Organizations Consulted ................................................................. 5.1

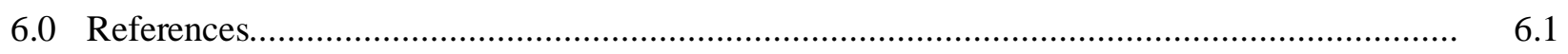

Appendix A - Vehicle Categorization for a Heavy Brigade Combat Team (HBCT) ...................... A.1

Appendix B - Simulated $\mathrm{PM}_{10}$ Concentrations for the Move-out from White Sands Missile Range to Dona Ana Range Camp

Appendix C - Simulated $\mathrm{PM}_{10}$ Concentrations for the Move-out from White Sands Missile Range to Range 40

Appendix D - Simulated $\mathrm{PM}_{10}$ Concentrations for the Move-out from White Sands Missile Range to McGregor Range Camp via Dona Ana.....

Appendix E - Simulated $\mathrm{PM}_{10}$ Concentrations for the Move-out from White Sands Missile Range to Oro Grande Base Camp

Appendix F - Simulated $\mathrm{PM}_{10}$ Concentrations for the Move-out from White Sands Missile Range to SHORAD.

Appendix G - Simulated $\mathrm{PM}_{10}$ Concentrations for the Move-out from White Sands Missile Range to McGregor Range Camp via Oro Grande..... 


\section{Figures}

3.1 Meteorological Stations in the Vicinity of Fort Bliss ......................................................... 3.2

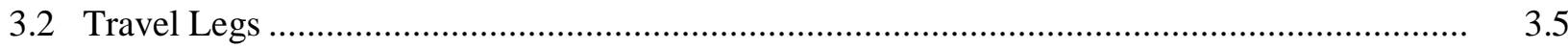

4.1 24-Hour-Average $\mathrm{PM}_{10}$ Concentration Contributions on March 15, 2005, for the Move-out from WSMR to Dona Ana; WSMR to Range 40; WSMR to Oro Grande; WSMR to SHORAD; and WSMR to McGregor Range Camp via Oro Grande.

4.2 24-Hour Average $\mathrm{PM}_{10}$ Concentration Contributions on November 25, 2005, for the Moveout from WSMR to Oro Grande and WSMR to SHORAD

4.3 24-Hour-Average $\mathrm{PM}_{10}$ Concentration Contributions on March 12, 2005, for a Move-out from WSMR to Oro Grande

4.4 Hourly $\mathrm{PM}_{10}$ Concentration Contributions on March 12, 2005, for a Move-out from WSMR to Oro Grande.

4.5 Delayed Start Sensitivity Test: 24-Hour-Average PM $_{10}$ Concentration Contributions on April 27, 2005, for a Move-out from WSMR to Oro Grande. move-out starts at 1000 MST......

4.6 Delayed Start Sensitivity Test: Hourly PM $_{10}$ Concentration Contributions on April 27, 2005, for a Move-out from WSMR to Oro Grande. 0800-0900 MST when the move-out starts at 0600 MST and 1200-1300 MST when the move-out starts at 1000 MST

4.7 Delayed Start Sensitivity Test: 24-Hour-Average PM $_{10}$ Concentration Contributions on November 28, 2005, for a Move-out from WSMR to McGregor Range Camp via Oro Grande when the move-out starts at 0600 MST and when the move-out starts at 1000 MST.....

4.8 Reduced Speed Sensitivity Test: Move-out from WSMR to Oro Grande on March 12, 2005 ....

4.9 Reduced Speed Sensitivity Test: 24-Hour-Average $\mathrm{PM}_{10}$ Concentration Contributions on March 14, 2005 for a Move-out from WSMR to Range 40

4.10 Reduced Speed Sensitivity Test: 24-Hour-Average $\mathrm{PM}_{10}$ Concentration Contributions on November 28, 2005 for a Move-out from WSMR to Range 40

4.11 Combined Delayed Start and Reduced Speed Sensitivity Test 4.14

\section{Tables}

3.1 Periods in 2005 Selected for DUSTRAN Simulations

3.2 HBCT: Vehicles Included in Current DUSTRAN Simulations

3.3 Move-out Routes and Assumptions 


\subsection{Introduction}

The purpose of this investigation is to evaluate the dust concentrations generated by heavy mechanized tracked and wheeled military vehicles in the vicinity of Fort Bliss and the White Sands Missile Range (WSMR). In 2005, Base Realignment and Closure (BRAC) transformed the Fort Bliss installation into a heavy mechanized training facility. The environmental impacts to air quality resulting from uplifted fugitive dust and fine particulates $\left(\mathrm{PM}_{10}\right.$; i.e., particulates with an aerodynamic diameter less than 10 microns) from vehicular movement on unpaved roads are of potential concern. Fugitive dust emissions have the potential to migrate toward the south and west of the City of El Paso, over Highways 54 and 264 that run through Fort Bliss, and toward small communities along Highway 54. Any of these occurrences could result in violations of air quality regulations for the States of Texas or New Mexico.

In 2006, the Fort Bliss Directorate of Environment (now the Fort Bliss Environmental Division) contracted with Pacific Northwest National Laboratory (PNNL) to prepare the DUSTRAN dust plume modeling system for the Fort Bliss area and to use the model to simulate fugitive dust emissions from representative training and tactical vehicle maneuvers. The 2006 study focused on move-outs from the Fort Bliss main cantonment to the Dona Ana and McGregor range camps, and on combat training activities within the Dona Ana, McGregor, and South training areas (Chapman et al. 2006a, 2006b). The current investigation extends this previous work to simulations of move-out scenarios from the WSMR main cantonment to various destinations within Fort Bliss.

This report summarizes results of the current investigation. We begin by briefly reviewing the DUSTRAN modeling system. We then describe the model configuration tasks specific to this investigation, including establishment of move-out routes, scenario design, and inherent assumptions made in developing the scenarios. Results are summarized by providing screen shots with $\mathrm{PM}_{10}$ contours from simulations of various move-out routes for climatologically representative periods. Various moveout routes are briefly discussed, and the results of sensitivity studies, including move-out timing and reduced vehicle speed, are presented. 



\subsection{Modeling System}

The dust plume modeling system DUSTRAN was developed under the U.S. Department of Defense (DoD) Strategic Environmental Research and Development Program (SERDP) to develop an atmospheric dispersion modeling system to assist the DoD in addressing particulate air quality issues at military training and testing ranges (Allwine et al. 2006, 2007; Shaw et al. 2008). DUSTRAN is a comprehensive dispersion modeling system consisting of a diagnostic meteorological model, emissions models, and dispersion models that is integrated into the ArcMap Geographical Information System (GIS), commercial software developed by the Environmental System Research Institute (ESRI). DUSTRAN functions as a console application within ArcMap and allows the user to interactively create a release scenario and run the underlying models. Using data layering, the model domain, sources, and results, including the calculated wind vector field and plume contours, can be displayed with other spatial and geophysical data sources to aid in analysis and interpretation of the scenario.

The core components within DUSTRAN for simulating vehicle-generated dust are the CALPUFF modeling system and a dust-emissions-factor module. The CALPUFF modeling system consists of a suite of models for simulating the effects of time- and space-varying meteorological conditions on pollution transport, transformation, and removal. Source-term information is generated by DUSTRAN's dust-emission-factors module, which includes factors for various wheeled military vehicles (Gillies et al. 2005a; 2005b). The experiments to derive the Gillies et al. (2005a; 2005b) emissions factors were conducted at Fort Bliss during the spring of 2001 and the spring of 2002. They indicated that the major two variables significantly affecting $\mathrm{PM}_{10}$ wheeled military vehicle emission factors for unpaved roads are vehicle weight and vehicle speed.

Dr. Gillies and his colleagues at the Desert Research Institute (DRI) are conducting a multi-year, multi-location study to attempt to deduce $\mathrm{PM}_{10}$ emission factors for tracked military vehicles. It is anticipated that their study eventually will identify major variables affecting tracked vehicle emission factors and yield installation-independent relationships that can be incorporated into DUSTRAN for a variety of tracked vehicles. However, no generally applicable tracked vehicle emission factors exist at this time (telephone conversation between E. Chapman and J. Gillies, November 18, 2008; email correspondence between W. Shaw and J. Gillies, December 19, 2008). The current set of simulations thus was conducted using the wheeled vehicle emission factor estimates of Gillies et al. (2005a, 2005b) for all military vehicles.

The CALPUFF modeling system includes the CALMET meteorological model (Scire et al. 2000b) and the CALPUFF dispersion model (Scire et al. 2000a). In the most general sense, CALMET creates gridded fields of wind and boundary-layer parameters from observed meteorological data. These gridded fields are then supplied to CALPUFF, which performs the plume transport, deposition, and diffusion calculations. A second dispersion model, called CALGRID (Scire et al. 1989), is also integrated into DUSTRAN. CALGRID is useful for applications where source emissions can be characterized over a gridded area, such as the modeling of wind-blown dust, whereas CALPUFF is most applicable for discrete source emissions, such as dust emissions from vehicles.

To simplify input data requirements, numerous data preprocessors interface CALMET, CALPUFF, and CALGRID to available terrain elevation and land-use datasets for use in model calculations. All of the model components are dynamically linked by the DUSTRAN interface. For the current application, 
staff from WSMR and the Fort Bliss Environmental Division provided reference data layers (e.g., roads, tank trails, installation boundaries, training areas, control points, etc.) and high-resolution GIS land-cover data layers. 


\subsection{Model Setup}

Model setup involved incorporating relevant site-specific GIS layers into DUSTRAN; selecting and preparing hourly meteorological data files for the specific time periods to be simulated; determining the number, type, and weight of vehicles to be included in the various simulations; specifying move-out parameters (e.g., routes, vehicle speeds, timing, etc.); and selecting the model domain and resolution. Work performed in each of these areas is summarized here.

\subsection{GIS Layers}

For the 2006 investigation, staff from the Fort Bliss Environmental Division provided reference data layers (e.g., roads, tank trails, installation boundaries, training areas, control points) and high-resolution GIS land-cover data layers for Fort Bliss. In July 2008, PNNL staff confirmed with Fort Bliss staff that these layers were still the most current (email correspondence between J. Moncada and E. Chapman, July 7, 2008, including a forwarded email from S. Sanchez to J. Moncada, July 7, 2008). Fort Bliss staff also assisted PNNL in obtaining equivalent data layers for WSMR from WSMR staff. The WSMR-supplied data layers covered not only WSMR, but also portions of Fort Bliss. The layers were incorporated into DUSTRAN and tests conducted to evaluate the congruency of overlapping data layers. These tests did not identify any conflicts or discrepancies between the data sets in the areas of overlap; however, as a precaution, Fort Bliss data layers were designated as primary in all overlapping regions.

\subsection{Meteorological Data}

Meteorological conditions are important in dust simulations because they govern the transport, diffusion, and deposition of dust particles released into the atmosphere. Previous work (Chapman et al. 2006a) identified climatologically representative periods where both higher and lower ambient dust concentrations were likely throughout the entire Fort Bliss region, and where high-quality, multi-day measurements from local surface and upper-air meteorological stations were available. These same periods, shown in Table 3.1, are used in the current investigation. Year 2005 data from the WSMR Oro Grande meteorological station had been provided by WSMR staff during the late stages of the 2006 study, too late for use in that work. However, these data were incorporated into the meteorological data files used in the present investigation. Telephone conversations with WSMR meteorological office staff confirmed that no other meteorological sites with the necessary measurements exist on WSMR. Meteorological stations used in this study are indicated in Figure 3.1.

Table 3.1. Periods in 2005 Selected for DUSTRAN Simulations

\begin{tabular}{ccccc}
\hline & \multicolumn{2}{c}{ Start } & \multicolumn{2}{c}{ End } \\
\cline { 2 - 5 } Period & Date (2005) & Time (MST) ${ }^{(\mathrm{a})}$ & Date (2005) & Time (MST) \\
\hline 1 & March 12 & 0000 & March 16 & 2400 \\
2 & April 25 & 0000 & April 30 & 2400 \\
3 & July 20 & 0000 & July 24 & 2400 \\
4 & November 25 & 0000 & November 29 & 2400 \\
\hline
\end{tabular}

(a) Mountain Standard Time (MST = UTC -7 hours). 


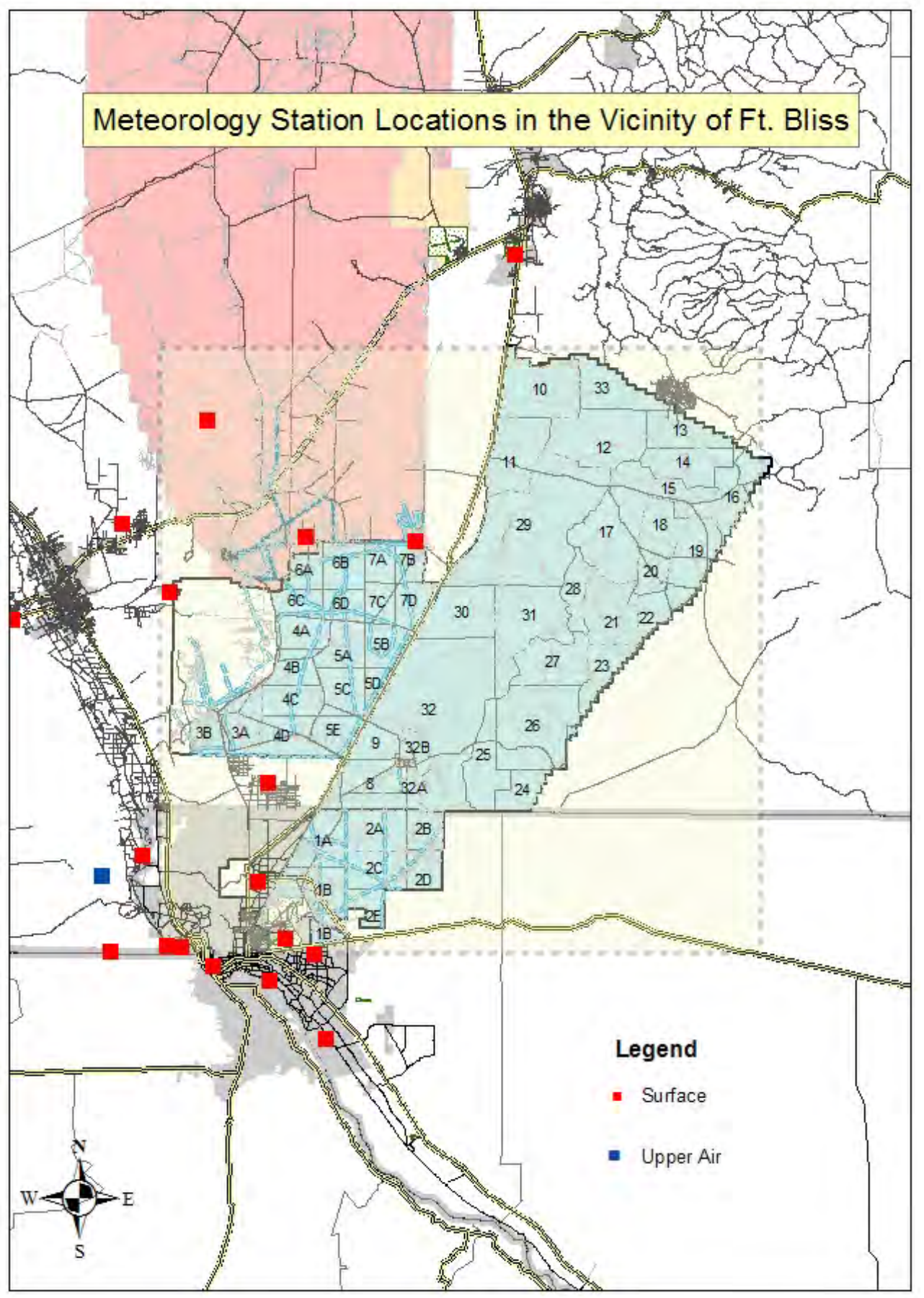

Figure 3.1. Meteorological Stations in the Vicinity of Fort Bliss. The DUSTRAN modeling domain is shown in light yellow, surrounded by the gray dashed box. Fort Bliss is shown in blue-gray and WSMR in pink.

The meteorological periods indicated in Table 3.1 represent a wide range of stability classes, wind speeds, and wind directions. Further information on the meteorology of the Fort Bliss area, including selected hourly plots of 10-m meteorological wind fields for the periods in Table 3.1, can be found in Chapter 3 and Appendixes H, I, J, and K of Chapman et al. (2006a). 


\subsection{Vehicle Types}

Fort Bliss staff provided a report (Booz Allen Hamilton 2006) that included a spreadsheet summarizing the number and type of vehicles typically included in a heavy brigade combat team (HBCT). The report included vehicles associated with brigade headquarters (HC BCT), Brigade Special Troops Battalion (BSTB), Armed Reconnaissance Squadron (ARS), Combined Arms Battalion (CAB), Fires Battalion, and Brigade Support Battalion (BSB). This report was used to generate a list of vehicle numbers, types, and weights to be included in all DUSTRAN simulations for this investigation. This list is summarized in Table 3.2. Appendix A discusses how specific vehicles in the Booz Allen Hamilton (2006) report were classified to generate Table 3.2. Based on this activity, 888 wheeled vehicles and 356 tracked vehicles are included in the DUSTRAN simulations.

Table 3.2. HBCT Vehicles Included in Current DUSTRAN Simulations

\begin{tabular}{ccrr}
\hline Category & Type & Weight (kg) & Number \\
\hline HMMWV & Wheeled & 2445 & 500 \\
LMTV & Wheeled & 8060 & 78 \\
HEMMT & Wheeled & 17727 & 120 \\
MTV & Wheeled & 13608 & 110 \\
M923 & Wheeled & 13490 & 2 \\
PLSTrans & Wheeled & 32500 & 61 \\
ASV & Wheeled & 13408 & 3 \\
FKLFT & Wheeled & 15200 & 7 \\
CRANE & Wheeled & 27300 & 1 \\
SEE & Wheeled & 7300 & 4 \\
M93 & Wheeled & 17800 & 2 \\
M113 & Tracked & 12349 & 86 \\
Bradley & Tracked & 29937 & 132 \\
M1A1 & Tracked & 60909 & 70 \\
M88 & Tracked & 70000 & 30 \\
M9 & Tracked & 23300 & 6 \\
CATV & Tracked & 26000 & 16 \\
M109 & Tracked & 27600 & 16 \\
\hline
\end{tabular}

In the 2006 study, HCBT military vehicles were mapped to the limited set of comparable vehicle types then available within DUSTRAN. Upgrades to DUSTRAN since that time allow a user to specify a list of vehicles with accompanying weights and to eliminate this mapping step.

\subsection{Move Out Scenarios: Routes and Assumptions}

Fort Bliss staff provided PNNL with general travel routes for the move-out of a full HBCT from the WSMR main cantonment to various destinations (correspondence between J. Moncada and E. Chapman, finalized in an August 6, 2008 email from J. Moncada to E. Chapman). Destinations included the 
Oro Grande Base Camp within WSMR and the Short Range Air Defense (SHORAD) range, Dona Ana Range Camp, Range 40, and McGregor Range Camp within Fort Bliss. Some destinations involved travel over the same subset of roads and trails; for example, a move-out from the WSMR main cantonment to SHORAD includes the route for a move-out from the WSMR main cantonment to the Oro Grande Base Camp. Twelve travel legs were thus identified that can be combined in different ways to produce different move-out routes. Figure 3.2 illustrates the 12 individual travel legs, while Table 3.3 summarizes the various combinations needed for the six move-out routes studied in this investigation.

Move-out activities are simulated as line sources in DUSTRAN. In addition to specifying routes and the number and weight of vehicles traveling the route, use of DUSTRAN requires input of vehicle speeds and the timing and duration of vehicular activity. For this investigation it was assumed that move-out activities involved all vehicles in a HBCT (Table 3.2) traveling exclusively on unpaved road surfaces at the times and speeds indicated in Table 3.3, with vehicle types uniformly mixed throughout the convoy. Based on information provided by Fort Bliss staff in developing scenarios for the 2006 study (Chapman et al. 2006a), a move-out start time of 0600 MST was used in all baseline simulations for all routes.

In modeling move-out scenarios, DUSTRAN does not simulate individual vehicles but takes a "bulk" approach to dust emissions from vehicle activities. That is, dust emissions from all vehicles active on a roadway over a specified time are assumed to be released uniformly from the road at a constant rate throughout the duration of the activity. In terms of the 24-hour-average $\mathrm{PM}_{10}$ contribution computed within DUSTRAN, treating a move-out as multiple linked legs with vehicular activity staggered in time produces the same result as treating the same move-out as one long route as long as meteorological conditions change minimally in time. However, using the multiple linked legs more realistically represents the timing and spatial distribution of vehicle movement and thus the associated dust emissions that are generated along the route. (For a detailed discussion of this topic, see Chapman et al. 2006a, particularly Section 4.2 and Figure 4.2.) Setting the length of a given leg to the approximate distance likely to be traveled in one hour maximizes the temporal precision of a given simulation and was done where possible.

In selecting the segment lengths and vehicle speeds shown in Table 3.3, factors such as existing speed limits on base roads, terrain, likely road conditions, maximum capable speeds of various military vehicles, and the structure of a typical move-out were all considered. For example, Leg 1 of Table 3.3 runs through an area with a slight elevation gradient. The leg is approximately $13 \mathrm{~km}$ long, and the selected average vehicle speed is $13 \mathrm{~km}$ per hour (kph). Leg 2 is longer but goes through an essentially flat area; thus the leg is longer (approximately $19 \mathrm{~km}$ ), and the specified vehicle speed is higher (19 kph). Leg 3 connects the main traverse route to Dona Ana Range Camp. It is quite short (3 km), but again goes through relatively flat terrain, and it is probable that a given vehicle will traverse this leg in less than an hour. The version of DUSTRAN used in this study requires input of whole hours for vehicular activity. We account for a period of "zero velocity" by reducing the average vehicle speed to $10 \mathrm{kph}$. For Leg 4 (continuation through Dona Ana Base Camp to Range 40), the terrain gradient increases and the route uses a rougher road than those used on the previous three legs. Leg 4 is $5 \mathrm{~km}$ long, and again a given vehicle will likely traverse it in less than an hour. To account for both the rougher terrain and the short distance, the average vehicle speed is set at $5 \mathrm{kph}$. We note that specified vehicle speeds for all travel legs except 3 and 4 are higher than the $11 \mathrm{kph}$ (7 mph) used in studies to estimate vehicular exhaust emissions (Booz-AllenHamilton 2006). 


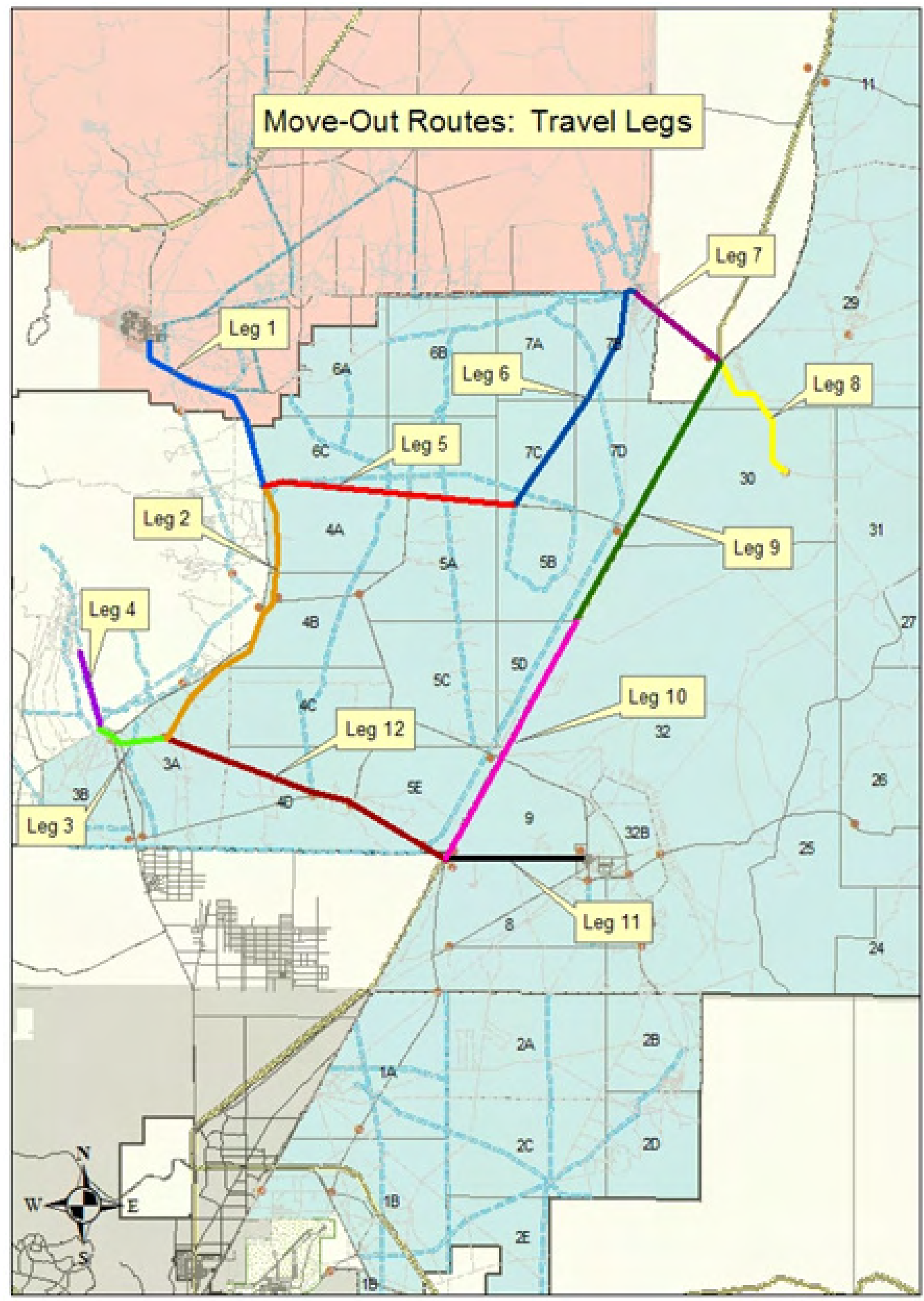

Figure 3.2. Travel Legs. Travel legs are combined as described in Table 3.3 to yield specific move-out routes from WSMR to various points within Fort Bliss. 
Table 3.3. Move-out Routes and Assumptions

\begin{tabular}{|c|c|c|c|c|}
\hline & $\begin{array}{l}\text { Time of Day Vehicles } \\
\text { on Leg (MST) }\end{array}$ & Distance $(\mathrm{km})$ & $\begin{array}{l}\text { Average Vehicle } \\
\text { Speed (kph) }\end{array}$ & $\begin{array}{c}\text { Duration of } \\
\text { Vehicles on Leg (hr) }\end{array}$ \\
\hline $\begin{array}{l}\text { WSMR to Dona Ana Range } \\
\text { Camp }\end{array}$ & & 35 & & 7 \\
\hline $\begin{array}{l}\text { Leg } 1 \text { (WSMR to Control Point } \\
\text { near 4A-6C) }\end{array}$ & 0600 through 1100 & 13 & 13 & 5 \\
\hline $\begin{array}{l}\text { Leg } 2 \text { (Control Point near 4A-6C } \\
\text { to Control Point in } 3 \mathrm{~A} \text { ) }\end{array}$ & 0700 through 1200 & 19 & 19 & 5 \\
\hline $\begin{array}{c}\text { Leg } 3 \text { (Control Point in 3A to } \\
\text { Dona Ana Range Camp) }\end{array}$ & 0800 through 1300 & 3 & 10 & 5 \\
\hline WSMR to Range 40 & & 40 & & 8 \\
\hline $\begin{array}{l}\text { Leg } 1 \text { (WSMR to Control Point } \\
\text { near 4A-6C) }\end{array}$ & 0600 through 1100 & 13 & 13 & 5 \\
\hline $\begin{array}{l}\text { Leg } 2 \text { (Control Point near 4A-6C } \\
\text { to Control Point in 3A) }\end{array}$ & 0700 through 1200 & 19 & 19 & 5 \\
\hline $\begin{array}{c}\text { Leg } 3 \text { (Control Point in } 3 \text { A to } \\
\text { Dona Ana Range Camp) }\end{array}$ & 0800 through 1300 & 3 & 10 & 5 \\
\hline $\begin{array}{l}\text { Leg } 4 \text { (Dona Ana Base Camp to } \\
\text { Range 40) }\end{array}$ & 0900 through 1400 & 5 & 5 & 5 \\
\hline $\begin{array}{l}\text { WSMR to Oro Grande Range } \\
\text { Camp }\end{array}$ & & 35 & & 7 \\
\hline $\begin{array}{l}\text { Leg } 1 \text { (WSMR to Control Point } \\
\text { near 4A-6C) }\end{array}$ & 0600 through 1100 & 13 & 13 & 5 \\
\hline $\begin{array}{l}\text { Leg } 5 \text { (Control Point near 4A-6C } \\
\text { to Control Point at 7C-5B) }\end{array}$ & 0700 through 1200 & 16 & 16 & 5 \\
\hline $\begin{array}{c}\text { Leg } 6 \text { (Control Point at 7C-5B to } \\
\text { Oro Grande Range Camp) }\end{array}$ & 0800 through 1300 & 16 & 16 & 5 \\
\hline WSMR to SHORAD & & 61 & & 9 \\
\hline $\begin{array}{l}\text { Leg } 1 \text { (WSMR to Control Point } \\
\text { near 4A-6C) }\end{array}$ & 0600 through 1100 & 13 & 13 & 5 \\
\hline $\begin{array}{l}\text { Leg } 5 \text { (Control Point near 4A-6C } \\
\text { to Control Point at 7C-5B) }\end{array}$ & 0700 through 1200 & 16 & 16 & 5 \\
\hline $\begin{array}{c}\text { Leg } 6 \text { (Control Point at 7C-5B to } \\
\text { Oro Grande Range Camp) }\end{array}$ & 0800 through 1300 & 16 & 16 & 5 \\
\hline $\begin{array}{l}\text { Leg } 7 \text { (Oro Grande Range Camp } \\
\text { to Highway Intersection at 29) }\end{array}$ & 0900 through 1400 & 7 & 16 & 5 \\
\hline $\begin{array}{l}\text { Leg } 8 \text { (Highway Intersection at } 29 \\
\text { to SHORAD) }\end{array}$ & 1000 through 1500 & 9 & 16 & 5 \\
\hline
\end{tabular}


Table 3.3. (contd)

\begin{tabular}{|c|c|c|c|c|}
\hline & $\begin{array}{l}\text { Time of Day } \\
\text { Vehicles on Leg } \\
\text { (MST) }\end{array}$ & $\begin{array}{l}\text { Distance } \\
(\mathrm{km})\end{array}$ & $\begin{array}{l}\text { Average Vehicle } \\
\text { Speed (kph) }\end{array}$ & $\begin{array}{c}\text { Duration of } \\
\text { Vehicles on Leg } \\
\text { (hr) }\end{array}$ \\
\hline $\begin{array}{l}\text { WSMR to McGregor via } \\
\text { Oro Grande }\end{array}$ & & 97 & & 11 \\
\hline $\begin{array}{l}\text { Leg } 1 \text { (WSMR to Control Point } \\
\text { near 4A-6C) }\end{array}$ & 0600 through 1100 & 13 & 13 & 5 \\
\hline $\begin{array}{l}\text { Leg } 5 \text { (Control Point near 4A-6C } \\
\text { to Control Point at 7C-5B) }\end{array}$ & 0700 through 1200 & 16 & 16 & 5 \\
\hline $\begin{array}{c}\text { Leg } 6 \text { (Control Point at 7C-5B to } \\
\text { Oro Grande Range Camp) }\end{array}$ & 0800 through 1300 & 16 & 16 & 5 \\
\hline $\begin{array}{l}\text { Leg } 7 \text { (Oro Grande Range Camp } \\
\text { to Highway intersection at 29) }\end{array}$ & 0900 through 1400 & 7 & 16 & 5 \\
\hline $\begin{array}{c}\text { Leg } 9 \text { (Highway Intersection at } \\
29 \text { to Boundary of 5B-5D) }\end{array}$ & 1000 through 1500 & 19 & 19 & 5 \\
\hline $\begin{array}{l}\text { Leg } 10 \text { (Boundary of 5B-5D to } \\
\text { intersection near Control } \\
\text { Point 5E-8-9) }\end{array}$ & 1100 through 1600 & 17 & 18 & 5 \\
\hline $\begin{array}{l}\text { Leg } 11 \text { (Intersection near Control } \\
\text { Points at 5E-8-9 to McGregor } \\
\text { Range Camp) }\end{array}$ & 1200 through 1700 & 9 & 16 & 5 \\
\hline $\begin{array}{l}\text { WSMR to McGregor via } \\
\text { Dona Ana }\end{array}$ & & 61 & & 8 \\
\hline $\begin{array}{l}\text { Leg } 1 \text { (WSMR to Control Point } \\
\text { near 4A-6C) }\end{array}$ & 0600 through 1100 & 13 & 13 & 5 \\
\hline $\begin{array}{l}\text { Leg } 2 \text { (Control Point near 4A-6C } \\
\text { to Control Point in 3A) }\end{array}$ & 0700 through 1200 & 19 & 19 & 5 \\
\hline $\begin{array}{l}\text { Leg } 12 \text { (Control Point in 3A to } \\
\text { Intersection near Control } \\
\text { Points at 5E-8-9) }\end{array}$ & 0800 through 1300 & 20 & 20 & 5 \\
\hline $\begin{array}{l}\text { Leg } 11 \text { (Intersection near Control } \\
\text { Points at 5E-8-9 to McGregor } \\
\text { Range Camp) }\end{array}$ & 0900 through 1400 & 9 & 16 & 5 \\
\hline
\end{tabular}

Another constraint in defining and combining travel legs arises from the CALPUFF dispersion model employed within DUSTRAN. CALPUFF requires that the total number of line source segments in a given simulation be 20 or less, where a segment is defined as one straight-line section. Handling a single road curve may require two or more segments; Leg 2 of Figure 3.2, for example, requires eight line segments because of the winding nature of the road. The legs shown in Figure 3.2, when combined as indicated in Table 3.3 to produce the move-out routes of interest, comply with this modeling constraint.

Selected vehicle speeds and timing of vehicle activities can have a significant effect on model results. The parameters shown in Table 3.3 reflect the project goal of conducting simulations under realistic move-out conditions while still capturing worst-case situations. 


\subsection{Modeling Domain}

Fort Bliss staff expressed a preference for using the same modeling domain as the 2006 study (Chapman et al. 2006a) to facilitate integration of results from the two investigations. All six of the current specified move-out routes lie within this domain. Domain suitability was examined by conducting a set of preliminary simulations. Results suggested that the 2006 domain location and extent would be sufficient to capture major contours of predicted $\mathrm{PM}_{10}$ concentration contribution plumes in the current investigation. The modeling domain used in this investigation thus is coincident with that used in the 2006 study and consists of a 100- by 100-km grid with individual grid cells 2 by $2 \mathrm{~km}$ in extent. Six vertical layers were geometrically spaced to extend from the surface to $3300 \mathrm{~m}$. All simulations were initiated at midnight MST and run for 24 hours so the 24-hour average $\mathrm{PM}_{10}$ concentration contribution could be calculated. 


\subsection{Results}

This section summarizes the results of DUSTRAN simulations for $\mathrm{PM}_{10}$ concentration contributions for the meteorological periods and travel routes given in Section 3. In addition to these baseline simulations, the potential effect of using wheeled vehicle emissions factors as a surrogate for tracked vehicles is discussed relative to the most current research on tracked vehicle emission factors. Finally, the sensitivity of simulation results to parameters most directly under the control of Fort Bliss staff, such as the time of day that move-out maneuvers begin and average vehicle speed, are discussed relative to baseline simula-

tion results. For convenience and ease of comparison, some figures from the appendixes are duplicated in this section.

\subsection{Baseline Simulations}

Simulation results for the WSMR to Dona Ana move-out, WSMR to Range 40 move-out, WSMR to McGregor Range Camp via Dona Ana move-out, WSMR to Oro Grande Range Camp move-out, WSMR to SHORAD move-out, and WSMR to McGregor Range Camp via Oro Grande move-out are summarized in Appendixes B, C, D, E, F, and G, respectively. Results are presented as plots of 24-hour average $\mathrm{PM}_{10}$ concentration contributions and selected instantaneous hourly values for each day in the meteorological periods identified in Table 3.1. In all plots, $10 \mu \mathrm{g} / \mathrm{m}^{3}$ contours are shown in gold, $50 \mu \mathrm{g} / \mathrm{m}^{3}$ contours in red, $150 \mu \mathrm{g} / \mathrm{m}^{3}$ contours in purple, and $500 \mu \mathrm{g} / \mathrm{m}^{3}$ contours in black.

The results represent contributions from military vehicular activity alone. Background particulate concentrations in an incoming air mass and particulates generated via wind erosion and from disturbed soils also contribute to total ambient $\mathrm{PM}_{10}$ concentrations but are not accounted for in these simulations. Model predictions are referred to as concentration contributions to emphasize this point.

Results of this investigation were consistent with findings from the 2006 study. Both hourly and 24hour average concentration contributions tended to exhibit similar maximum contour levels $\left(\sim 500 \mu \mathrm{g} / \mathrm{m}^{3}\right)$; however, the size and location of areas affected by the vehicle dust plume varied from day to day. Low wind-speed days generally resulted in higher 24-hour-average $\mathrm{PM}_{10}$ concentration contributions over a larger area than high wind-speed days because under low wind-speed conditions, lofted particulates stay in the area of generation and are not readily dispersed. The angle of the prevailing wind direction relative to a move-out route determined which locations experienced higher or lower concentrations.

Of the six move-out routes studied, the WSMR to McGregor Range Camp via Oro Grande route (Appendix G) consistently demonstrated the largest regions with $\mathrm{PM}_{10}$ concentration contributions of $500 \mu \mathrm{g} / \mathrm{m}^{3}$ or more. This is illustrated in Figures 4.1a-f, where 24-hr average concentration contributions for the six routes are displayed for the arbitrarily chosen date of March 15, 2005. On this day, winds were relatively steady from the north-northwest at about $2 \mathrm{~m} / \mathrm{s}$ in the early morning hours, increasing slightly to $3 \mathrm{~m} / \mathrm{s}$ from the north by mid-afternoon (see Chapman et al. 2006a, Appendix H). 

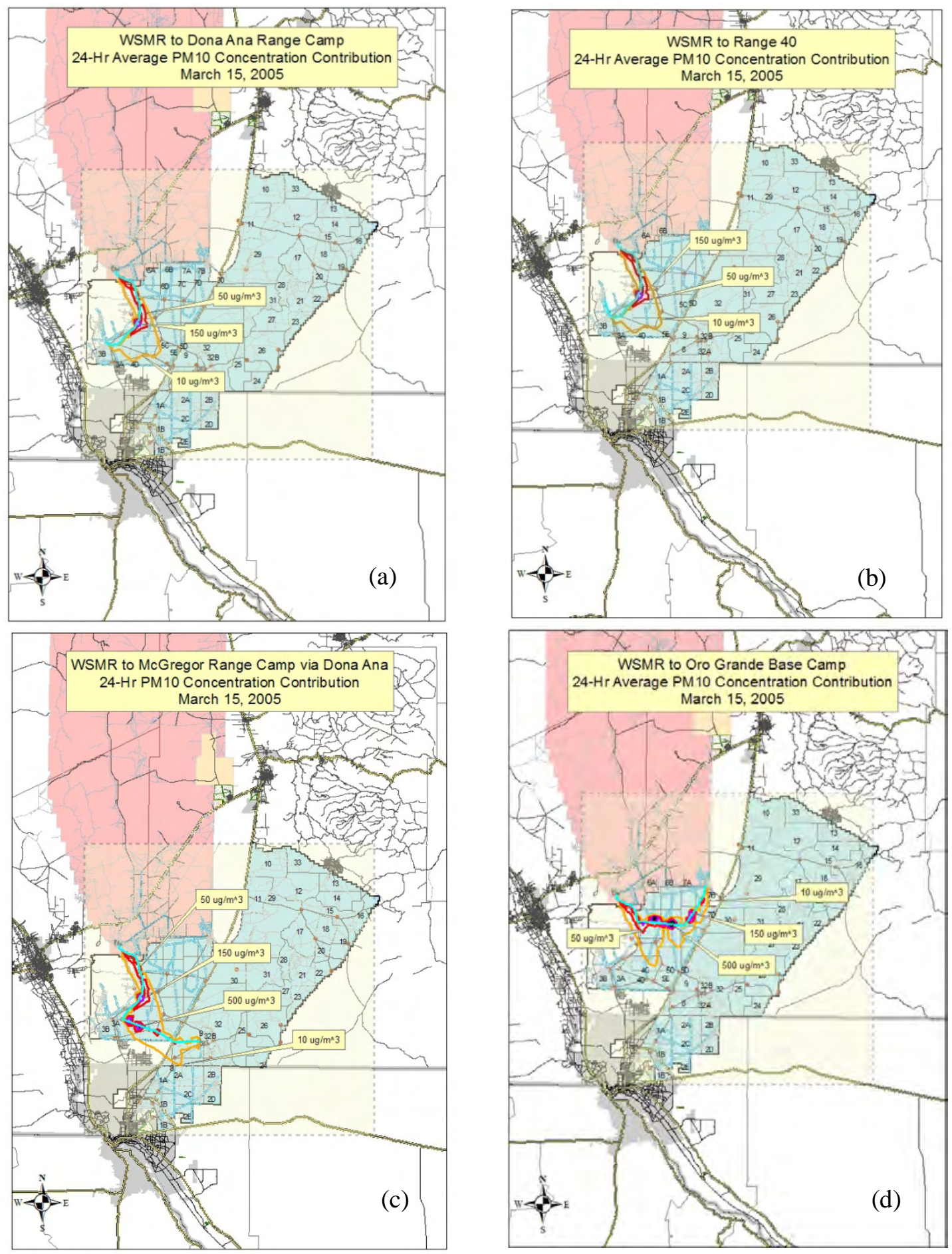

Figure 4.1. 24-Hour-Average $\mathrm{PM}_{10}$ Concentration Contributions on March 15, 2005, for the Move-out from (a) WSMR to Dona Ana; (b) WSMR to Range 40; (c) WSMR to McGregor Range Camp via Dona Ana; (d) WSMR to Oro Grande; (e) WSMR to SHORAD; and (f) WSMR to McGregor Range Camp via Oro Grande. Move-out travel routes are indicated in light blue. 

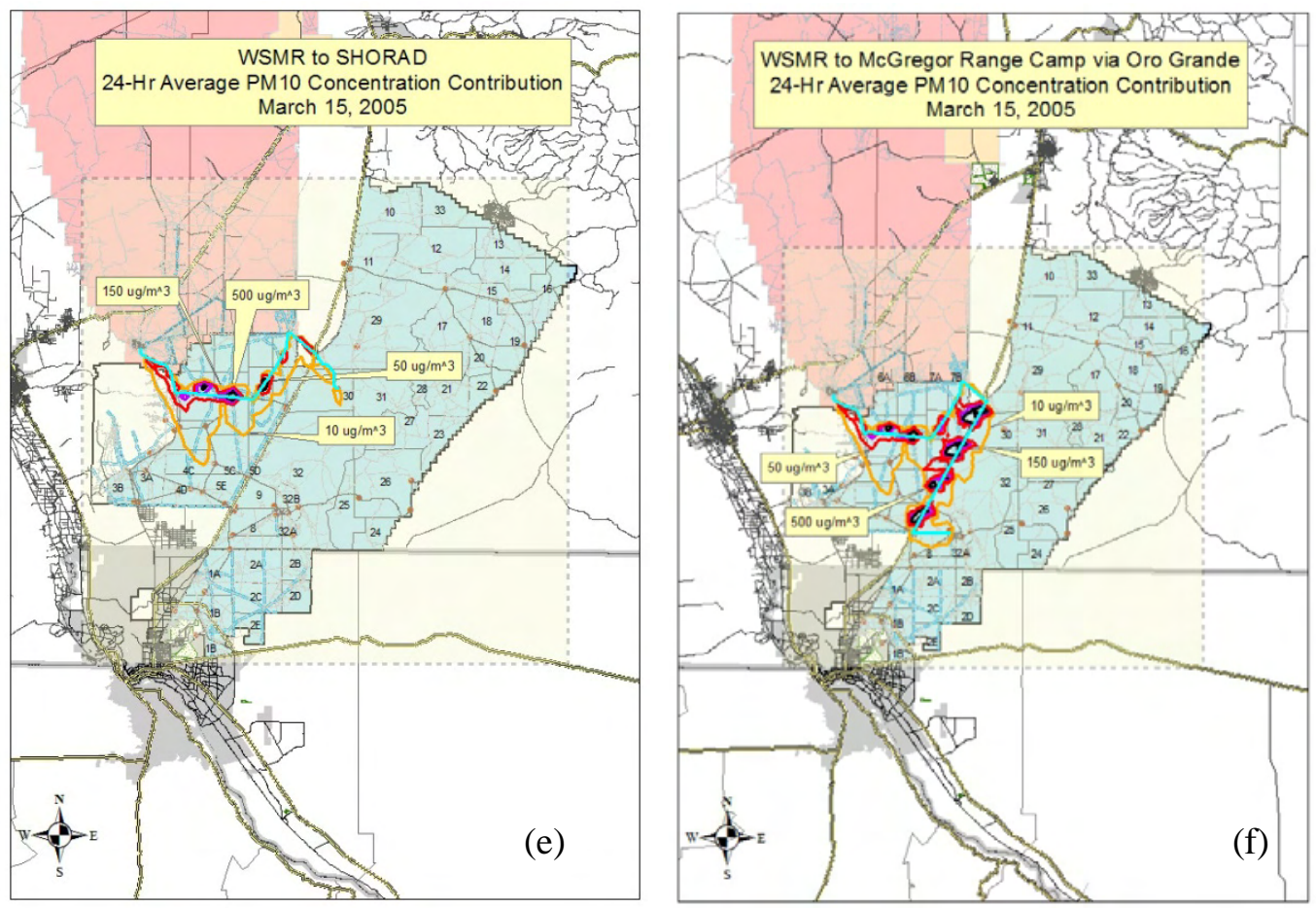

Figure 4.1. (contd)

As shown in Figure 4.1f, the $500 \mu \mathrm{g} / \mathrm{m}^{3}$ contribution regions are congregated mainly along U.S. Route 54 because travel legs 9 and 10 (Figure 3.2) parallel this road. The higher levels relative to other move-out routes result from the higher assumed vehicle speeds (19 and $18 \mathrm{kph}$ ) along these two long, straight travel legs and from the proximity of travel legs 6 and 9. These two legs essentially parallel each other for about $16 \mathrm{~km}$, separated only by distances of 6 to $7 \mathrm{~km}$. This doubling back of the convoy increases vehicular activity and the associated dust emission source strength in the area, leading to higher 24-hour concentration contributions.

Results for move-out routes involving travel over the same subset of roads and trails are similar for a given day, as expected. For example, simulation results for the WSMR to Range 40 move-out shown in Figure 4.1b tend to be very similar to those for the WSMR to Dona Ana Range Camp move-out in Figure 4.1a. As indicated in Table 3.3, the first three travel legs of the Range 40 move-out compose the Dona Ana route. The fourth leg is short (5 km), with low assumed vehicle speeds (5 kph). Thus it is not surprising that vehicle activity between WSMR and Dona Ana dominates the $\mathrm{PM}_{10}$ concentration contributions in the WSMR to Range 40 simulations.

WSMR to Oro Grande Base Camp (Figure 4.1d) and WSMR to SHORAD (Figure 4.1e) move-out simulations also tend to be similar because the SHORAD move-out route is an extension of the Oro Grande route. The extension involves two additional travel legs totaling $16 \mathrm{~km}$ with assumed vehicle speeds of $16 \mathrm{kph}$. Depending on meteorological conditions, dispersion of dust from the additional legs can combine with dust generated during travel to Oro Grande, leading to higher concentration contributions. A clear example of this is shown in Figure 4.2. Here weak north-northeasterly winds on the morning of November 25 caused enough mixing of dust generated along the various SHORAD travel legs to raise the 24-hr average $\mathrm{PM}_{10}$ concentration contributions to $500 \mu \mathrm{g} / \mathrm{m}^{3}$ and above in a small area of the WSMR to Oro Grande route. 

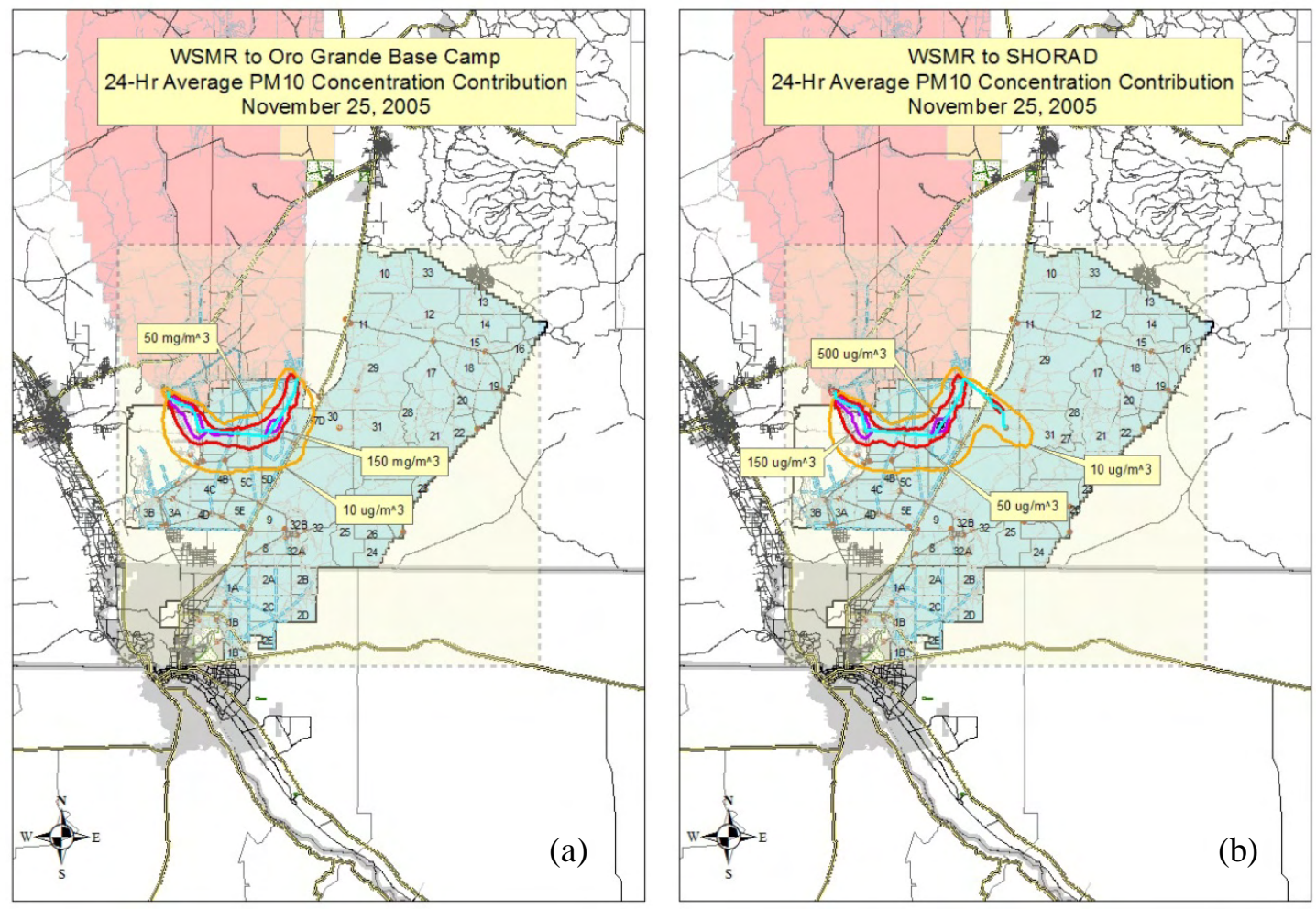

Figure 4.2. 24-Hour Average $\mathrm{PM}_{10}$ Concentration Contributions on November 25, 2005, for the Moveout from (a) WSMR to Oro Grande and (b) WSMR to SHORAD. Dust generated along the extended SHORAD route has raised the maximum concentrations along the entry road to Oro Grande to above $500 \mu \mathrm{g} / \mathrm{m}^{3}$. Move-out travel routes are indicated in light blue.

\subsection{Wheeled Vehicle Versus Tracked Vehicle Emission Factors}

As discussed in Section 2, simulations in this investigation were conducted using wheeled vehicle emissions factors from Gillies et al. (2005a, 2005b) for all vehicles because no generally applicable tracked vehicle emissions factors exist. Wheeled vehicle emissions factors have been found to be a linear function of vehicle weight and speed; the substantial weight of tracked vehicles such as the M1A1 and M88 means that source strengths computed using the wheeled vehicle function are very large.

Dr. Gillies and his colleagues have been conducting a SERDP-sponsored study aimed at deriving emissions factors for tracked vehicles. Preliminary results from experiments involving the M113, Bradley, and M1A1 tracked vehicles (email correspondence between W. Shaw and J. Gillies, December 19,2008 ) suggest that source strengths derived from $\mathrm{PM}_{10}$ tracked vehicle emission factors will be less than those computed using tracked vehicle weights in wheeled vehicle functions. If Gillies' initial results can be extended to all types of tracked vehicles on all types of dry unpaved surfaces, the true emission factors for individual tracked vehicles will be on the order of $20 \%$ less than those used in this investigation. The composite source strength for an entire HCBT (i.e., the source strength involving all wheeled and tracked vehicles shown in Table 3.2) would be reduced by approximately 15\%. Dust dispersion and transport processes are such that a 15\% reduction in source strength will scale approximately to a $15 \%$ reduction in predicted concentration contributions. Until Dr. Gillies and his colleagues have completed their study, this extension of their preliminary results and subsequent analysis must be considered 
speculative. However, based on current information, it appears that using wheeled vehicle emission factors for all vehicles in an HCBT is a conservative approach that is more likely to slightly overestimate, rather than underestimate, the overall contribution of vehicle-generated dust to ambient $\mathrm{PM}_{10}$ concentrations.

\subsection{Sensitivity Studies}

The baseline simulations presented in Appendixes B-G use scenario parameters consistent with general information on how move-out operations are conducted, as obtained from Fort Bliss staff for the 2006 study (Chapman et al. 2006a). The time of day at which move-out operations begin and the average permitted vehicle speed are two parameters that Fort Bliss staff have the ability to influence. Simulations were conducted to investigate the sensitivity of predicted $\mathrm{PM}_{10}$ concentration contributions to these two parameters individually and in combination. To more easily evaluate results, all sensitivity studies included the March 12, 2005, move-out from WSMR to the Oro Grande Base Camp. This route runs near the borders of the WSMR and Fort Bliss installations, and the baseline simulation for this date indicates a potential for dust from move-out activities to drift near two public highways: U. S. Route 54, which runs through Fort Bliss, and U.S. Route 70, which runs through WSMR. Other move-out routes on other dates were included in the sensitivity studies to provide results for a variety of overall distances, topography, and meteorological conditions.

Results of the sensitivity studies indicated that delaying move-out start times, reducing vehicle speeds, or a combination of both did not greatly influence the maximum magnitude $\left(\sim 500 \mu \mathrm{g} / \mathrm{m}^{3}\right)$ of the 24-hour-average $\mathrm{PM}_{10}$ concentration contributions. However, in some situations, altering these parameters could significantly influence the size and location of the areas affected by the vehicular dust plume. The following sections discuss the conditions under which such influences were noted.

\subsubsection{Move-out Start Time}

In the first sensitivity simulation, the start time of the March 12, 2005 move-out from WSMR to the Oro Grande Base Camp was altered from 0600 MST to 1000 MST. The first vehicle thus was assumed to leave the WSMR main cantonment at 1000 MST and the last vehicle to reach the Oro Grande Base Camp just before 1700 MST. All other scenario parameters (travel route, vehicle types, vehicle speeds, duration of vehicles on a given travel leg, etc.) were the same as those in the baseline simulations.

Figure 4.3a shows the 24-hour average $\mathrm{PM}_{10}$ concentration contributions for the baseline $0600 \mathrm{MST}$ start time, while Figure 4.3b shows 24-hour average $\mathrm{PM}_{10}$ concentration contributions for the sensitivity 1000 MST start time. Figure 4.4a shows simulated concentration contributions occurring for the period 0800-0900 MST, two hours into the baseline move-out, while Figure 4.4b shows simulated concentration contributions for the period 1200-1300 MST, two hours into the sensitivity move-out. Note that all plots show areas with $\mathrm{PM}_{10}$ concentration contributions of $500 \mu \mathrm{g} / \mathrm{m}^{3}$; however, the total areas with such contributions are much smaller in the sensitivity run. As can be seen in these plots, the geographic areas contained by the various concentration contribution contours are all substantially smaller for the 1000 MST move-out start time than for the 0600 MST start time, except for the hourly (Figure $4.4 \mathrm{ab}) 10 \mu \mathrm{g} / \mathrm{m}^{3}$ contour. Here the areas enclosed by the two $10 \mu \mathrm{g} / \mathrm{m}^{3}$ contours are closer in size, but locations have shifted. For the later start time, the area within the $10 \mu \mathrm{g} / \mathrm{m}^{3}$ contour lies mainly on the Fort Bliss installation. 

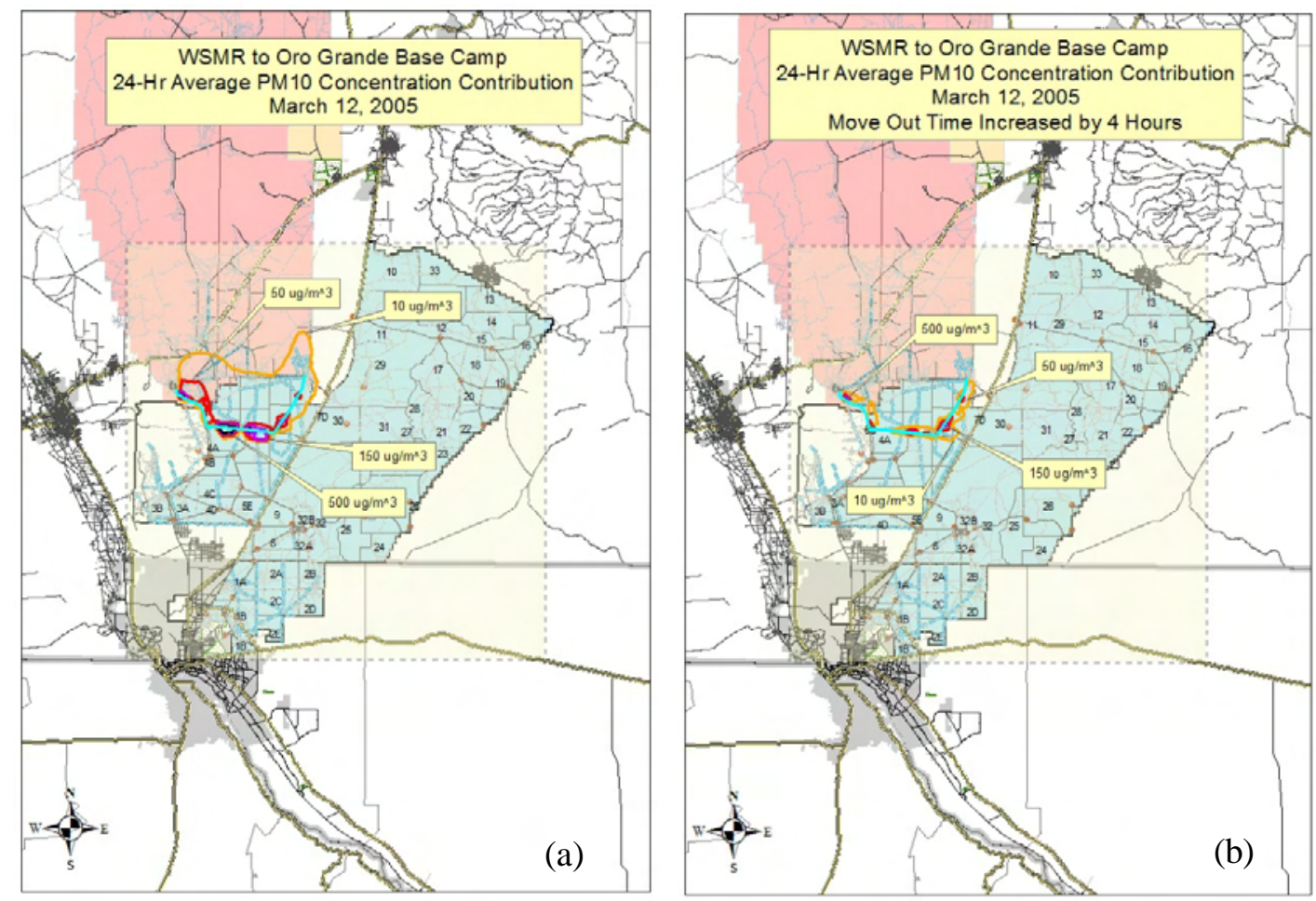

Figure 4.3. 24-Hour-Average $\mathrm{PM}_{10}$ Concentration Contributions on March 12, 2005, for a Move-out from WSMR to Oro Grande. (a) Move-out starts at 0600 MST and (b) move-out starts at 1000 MST. Move-out travel routes are indicated in light blue.
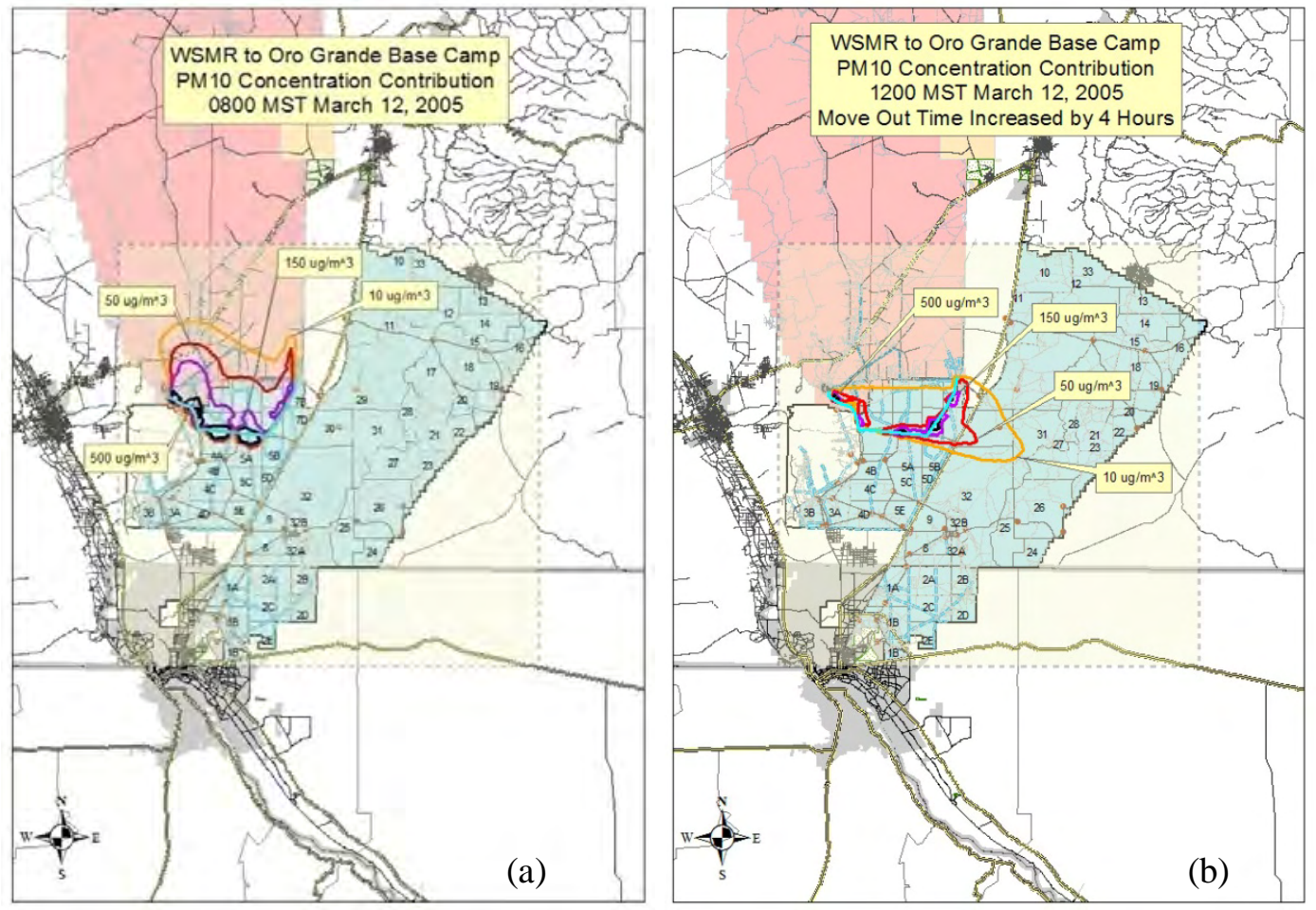

Figure 4.4. Hourly $\mathrm{PM}_{10}$ Concentration Contributions on March 12, 2005, for a Move-out from WSMR to Oro Grande. (a) 0800-0900 MST when move-out starts at 0600 and (b) 12001300 MST when move-out starts at 1000. Move-out travel routes indicated in light blue. 
The reasons for the decrease and shift in affected areas are meteorological in nature. The depth of the boundary layer (i.e., the air layer near the ground affected by turbulent transfer of heat, moisture, or momentum to or from the surface) increases during the day, generally reaching a peak in the mid- to late afternoon. Turbulence then begins to decay, and the boundary layer decreases in depth as solar heating declines. Boundary layer depth essentially governs the volume of air throughout which emitted material will mix; the greater the boundary layer depth, the greater the mixing volume, and, for a fixed source strength, lowering the resulting concentration. Additionally, climatological studies of the Fort Bliss area suggest that, in the absence of terrain-induced effects, there is a distinctive diurnal variation in springtime wind speeds: spring daytime wind roses show strong westerly winds, whereas spring nighttime wind roses suggest much weaker winds (Chapman et al. 2006a). This situation occurred on the March 12, 2005, date simulated in Figures 4.3 and 4.4; the light (1 m/s or less) southerly winds at 0700 MST had changed to steady 3 to $5 \mathrm{~m} / \mathrm{s}$ westerly winds by 1300 MST (see Chapman et al. 2006a, Appendix H). As discussed in Section 4.1, under low wind-speed conditions, lofted dust particles stay in the area of generation and are not readily dispersed, leading to higher near-source concentration contributions.

Figures 4.5 (24-hour average) and 4.6 (hourly) illustrate the effect of delaying the move-out start time by four hours on April 27, 2005, for the same WSMR to Oro Grande move-out route. Here again, the later start time results in smaller affected areas relative to the baseline simulation, this time even for the $10-\mu \mathrm{g} / \mathrm{m}^{3}$ contour. Winds on this day were steady from the west-southwest at approximately $3 \mathrm{~m} / \mathrm{s}$ at 0700 MST, shifting slightly to the south-southwest by 1300 MST and increasing to about $5 \mathrm{~m} / \mathrm{s}$ by 1600 MST.
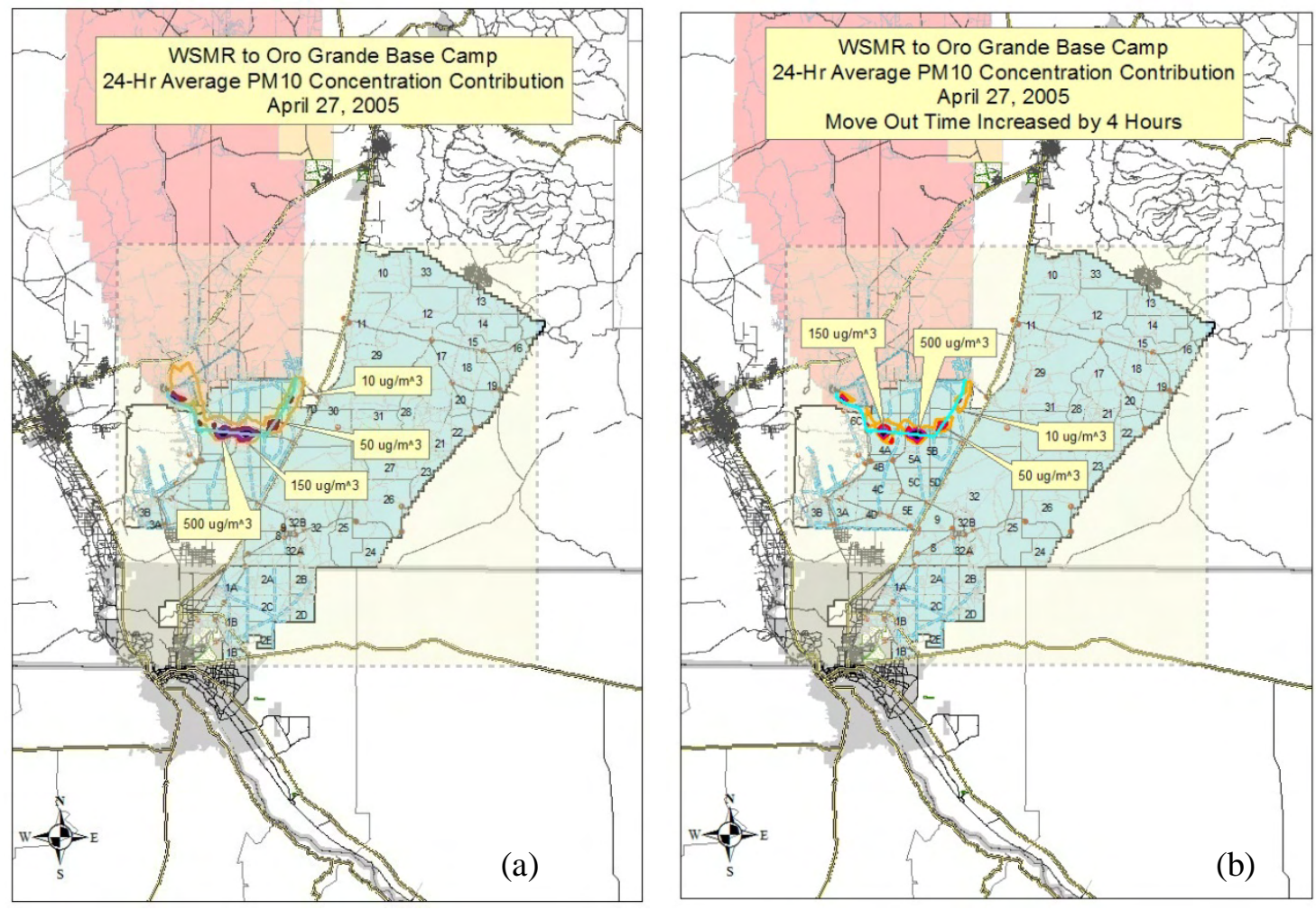

Figure 4.5. Delayed Start Sensitivity Test: 24-Hour-Average $\mathrm{PM}_{10}$ Concentration Contributions on April 27, 2005, for a Move-out from WSMR to Oro Grande. (a) Move-out starts at 0600 MST and (b) move-out starts at 1000 MST. Move-out travel routes are indicated in light blue. 

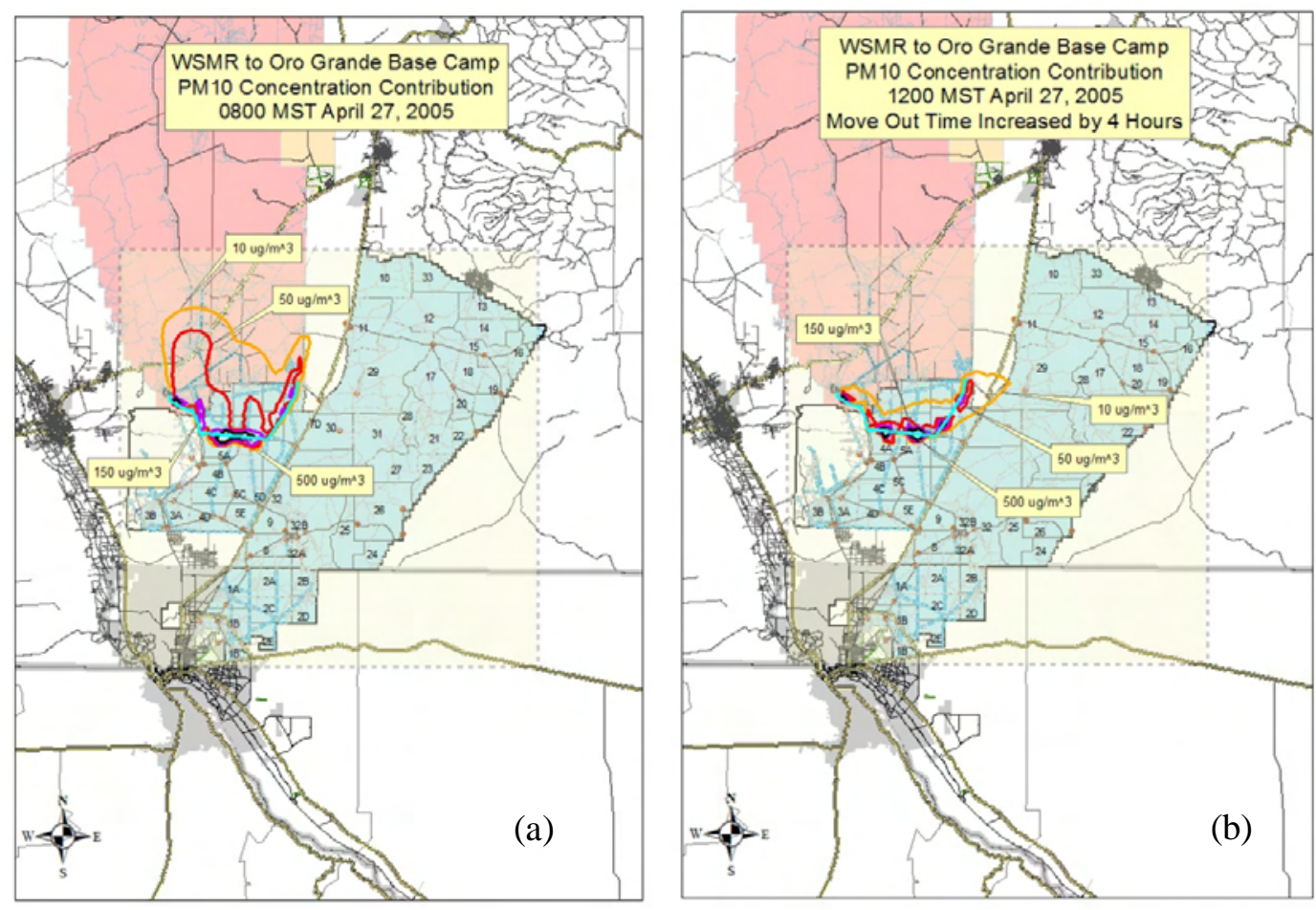

Figure 4.6. Delayed Start Sensitivity Test: Hourly $\mathrm{PM}_{10}$ Concentration Contributions on April 27, 2005, for a Move-out from WSMR to Oro Grande. (a) 0800-0900 MST when the move-out starts at 0600 MST and (b) 1200-1300 MST when the move-out starts at 1000 MST. Time periods shown represent the first hour vehicles are present on the entire travel route. Move-out travel routes are indicated in light blue.

The WSMR to Oro Grande move-out route extends approximately $35 \mathrm{~km}$. Move-out activities last a total of seven hours in both the baseline and sensitivity simulations. For longer routes, delaying the start of a move-out may simply transfer vehicular dust emissions from a shallow morning boundary layer to a shallow evening boundary layer with little effect on 24-hour average $\mathrm{PM}_{10}$ concentration contributions. If too much activity is transferred to the decay portion of the diurnal boundary layer cycle and/or to periods with decreased winds, an increase in $\mathrm{PM}_{10}$ concentration contributions or an increase in the size of the area affected by the dust plume may result. An example of this is shown in Figure 4.7 for the WSMR to McGregor Range Camp via Oro Grande move-out route on November 28, 2005. This route is approximately $97 \mathrm{~km}$ long, and in the baseline simulation lasts 11 hours (0600 to $1700 \mathrm{MST}$ ).

In a sensitivity simulation, the move-out start time was delayed four hours, with vehicle activity lasting 11 hours (1000 to $2100 \mathrm{MST}$ ). On this day, winds were about $2 \mathrm{~m} / \mathrm{s}$ and varying in direction early in the morning, increasing to about 3 to $4 \mathrm{~m} / \mathrm{s}$ from the west-northwest by $1000 \mathrm{MST}$, then gradually reducing to about 2 to $3 \mathrm{~m} / \mathrm{s}$ from the north-northwest by 1900 MST. Sunrise occurred at approximately 0646 MST and sunset at 1702 MST. Substantially more of the vehicle travel thus was moved to nighttime hours, when wind speeds were lower and boundary layer depths typically decreasing. A comparison of baseline (Figure 4.7a) and sensitivity results (Figure 4.7b) shows that the extent of the various 24-hour average contour areas has increased. 

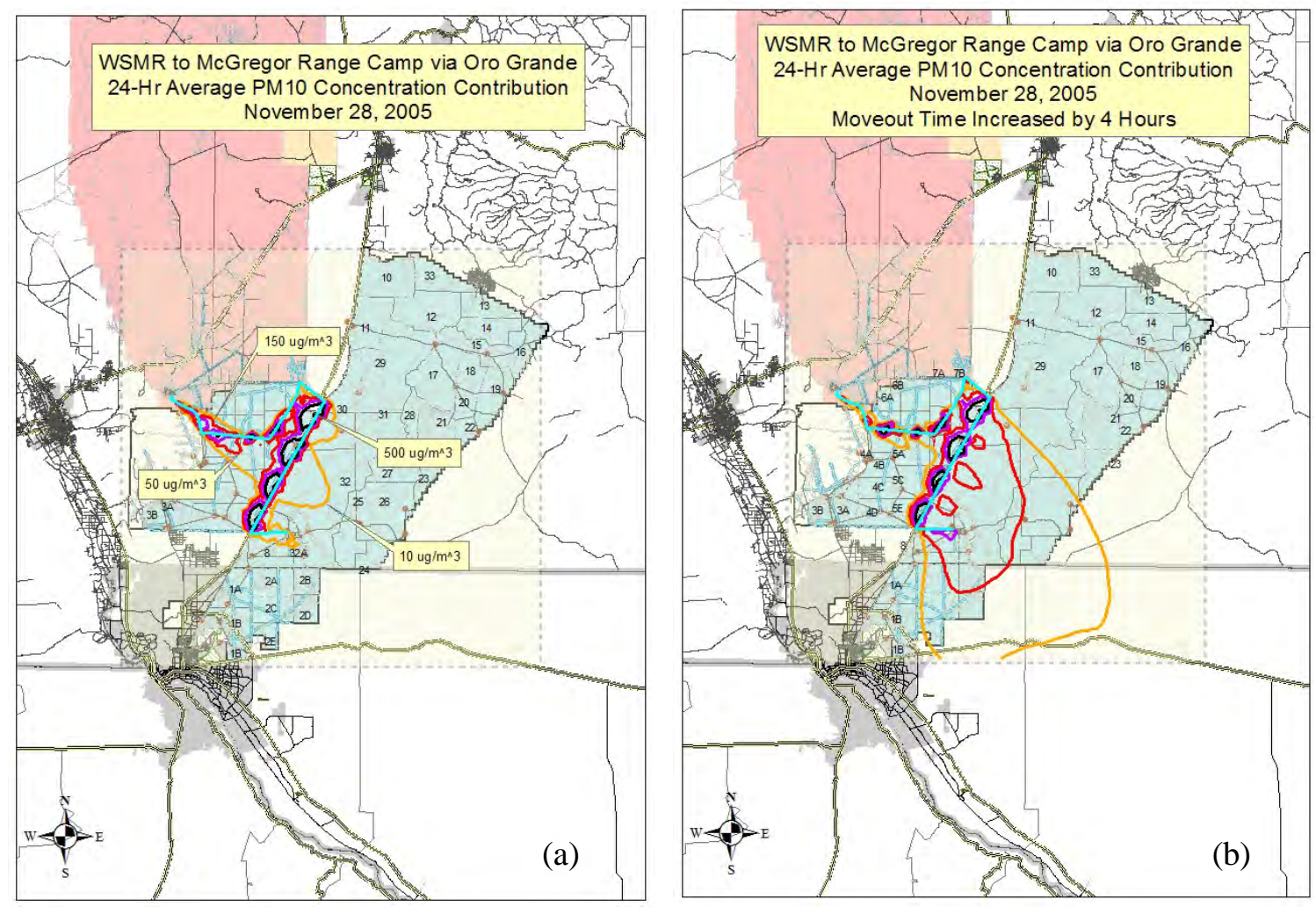

Figure 4.7. Delayed Start Sensitivity Test: 24-Hour-Average $\mathrm{PM}_{10}$ Concentration Contributions on November 28, 2005, for a Move-out from WSMR to McGregor Range Camp via Oro Grande. (a) Move-out starts at 0600 MST and (b) move-out starts at 1000 MST. Move-out travel routes are indicated in light blue.

These sensitivity simulations suggest that delaying the start of move-out maneuvers from early until mid-morning along selected routes may help decrease the contribution of military operations to local $\mathrm{PM}_{10}$ concentrations due to meteorological changes in both boundary layer depth and wind speed. This strategy may be particularly useful in the spring, when, on a climatological basis, diurnal variations in wind speed are more likely to occur in the Fort Bliss-WSMR area. However, on longer routes, decreased contributions may not materialize if the delay causes the move-out to encompass periods of decreased winds and/or the decay phase of the diurnally varying atmospheric boundary layer. It also must be emphasized that in these baseline and sensitivity model runs, DUSTRAN simulated the expected contributions from specified military vehicle activities alone; background particulate concentrations in an incoming air mass and particulates generated via wind erosion and from disturbed soils are not included with the vehicle-generated predictions. Separate estimates of wind blown $\mathrm{PM}_{10}$ concentration contributions can be obtained by using the wind-blown dust module in DUSTRAN and manually adding grid cell concentrations to those from the vehicle simulations. (The current version of DUSTRAN does not permit the automatic combining of vehicle and wind-blown dust estimates.) In short, when total ambient particulate concentrations are of interest instead of just vehicle-generated dust contributions, the impact of delaying move-out start times on background air mass particulate concentrations and on particulates generated via wind erosion and from disturbed soils also should be considered. 


\subsubsection{Vehicle Speed}

In sensitivity tests of vehicle speed, average vehicle speeds for selected routes were cut in half, rounding to the nearest whole number. This reduction caused concurrent changes in activity timing and duration because the overall move-out takes longer to complete. For example, consider the WSMR to Oro Grande Base Camp move-out route composed of travel legs 1, 5, and 6 (Table 3.2). In the sensitivity tests, average vehicle speeds on these legs were reduced to 7, 8, and $8 \mathrm{kph}$, respectively. Although the move-out still begins at 0600 MST, vehicles reach the start of travel leg 5 at 0800 MST instead of 0700 , and the start of travel leg 6 at 1000 MST instead of 0800. Vehicle activity on each leg now lasts 10 hours instead of five.

The influence of reducing average vehicle speed on $\mathrm{PM}_{10}$ concentration contributions for the March 12, 2005, WSMR to Oro Grande Base Camp move-out route can be seen by comparing the 24-hour average contribution in Figure 4.8a with that of the baseline simulation in Figure 4.3a. Plotted contours for given concentrations are all reduced in area, although the reduction is most noticeable for the 10 and $50 \mu \mathrm{g} / \mathrm{m}^{3}$ contours. Figure $4.8 \mathrm{~b}$ shows hourly $\mathrm{PM}_{10}$ concentration contributions for 1000 to 1100 MST, the first hour for which vehicles are present on all three travel legs in the sensitivity simulation. It can be compared to Figure 4.4a, where the 0800-0900 MST hourly $\mathrm{PM}_{10}$ concentration contributions represent the first hour that vehicles are present on all legs in the baseline study. Areas of all plotted contours are reduced, although the reduction in the $10 \mu \mathrm{g} / \mathrm{m}^{3}$ region is less pronounced.
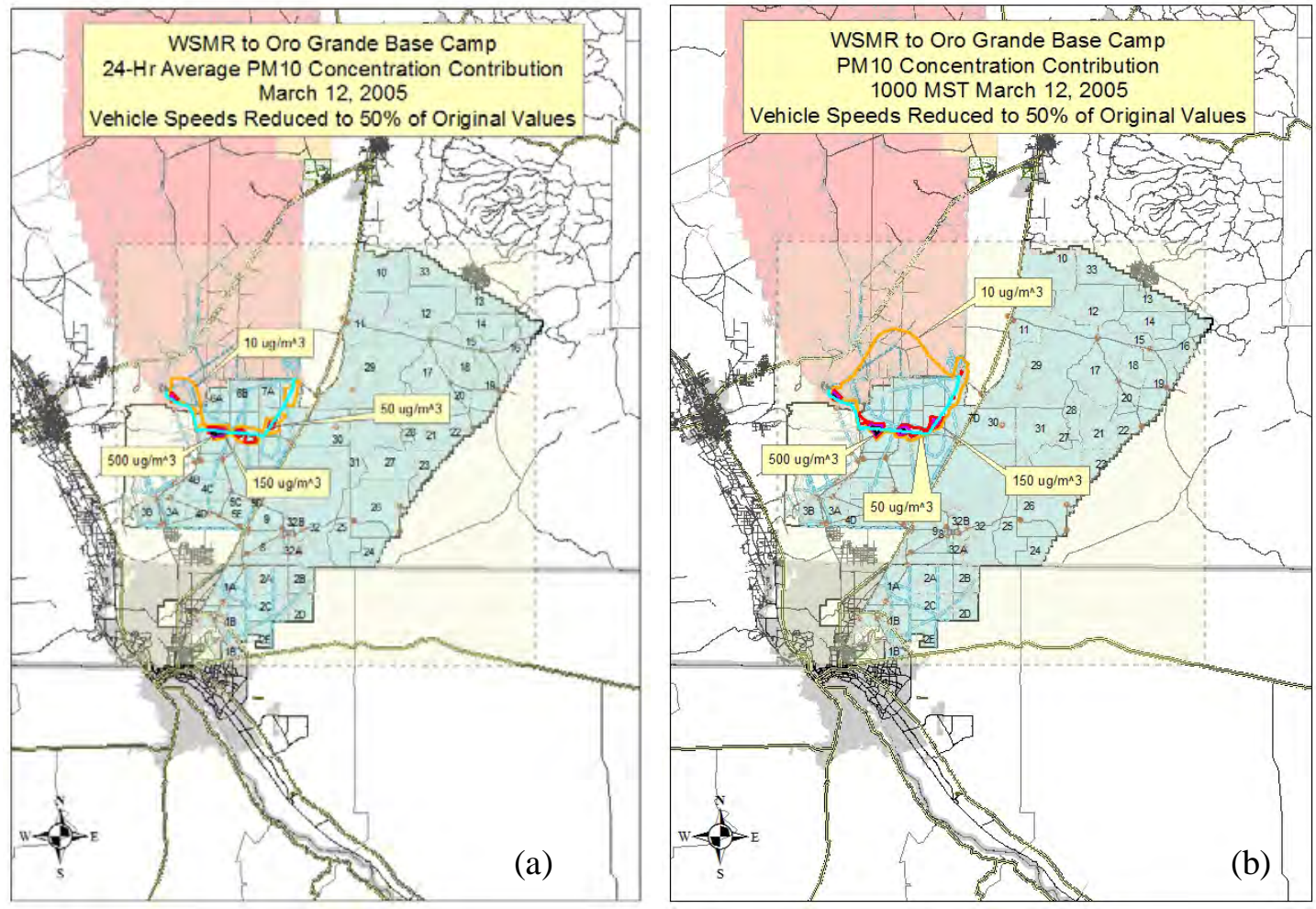

Figure 4.8. Reduced Speed Sensitivity Test: Move-out from WSMR to Oro Grande on March 12, 2005. (a) 24-hour average $\mathrm{PM}_{10}$ concentration contributions and (b) hourly $\mathrm{PM}_{10}$ concentration contributions for the time period 1000-1100 MST. Compare with baseline 24-hour average and hourly results shown in Figures 4.3a and 4.4a, respectively. Move-out travel routes are indicated in light blue. 
Reducing vehicle speed directly reduces the magnitude of the dust emission source strength in DUSTRAN. It also increases travel time. Depending on the route, this may push some emissions into a time of day with either lesser or greater boundary layer depths and decreased or increased wind speeds, similar to delaying the move-out start time. This in turn suggests that reducing vehicle speeds on shorter move-out routes, when there is less time for significant changes in meteorological conditions to occur, will have a greater likelihood of reducing $\mathrm{PM}_{10}$ concentration contributions.

The WSMR to Range 40 move-out is relatively short, totaling approximately $40 \mathrm{~km}$. Comparing simulated baseline (Figure 4.9a) and reduced speed sensitivity (Figure 4.9b) for this route on March 14, 2005, indicates that for 24-hour average $\mathrm{PM}_{10}$ concentration contributions the dust plume generated with lower vehicle speeds covers a smaller area. In contrast, reduced speeds on the longer WSMR to McGregor Range Camp via Oro Grande move-out route for November 28, 2005 do not produce clear improvements in 24-hour average $\mathrm{PM}_{10}$ concentration contributions. Figure 4.10a shows baseline simulation results for this date. Figure 4.10b shows November 28 simulation results when vehicle speeds are cut in half while maintaining the 0600 MST move-out start time. Concentration contributions in both figures are calculated for the 24-hour period beginning at 0000 MST November 28, consistent with the convention that 24-hour averages are calculated from midnight to midnight. Note, however, that with the 0600 MST start, the reduced speed move-out is not completed until 0400 MST November 29.

Figure 4.10b thus does not reflect all vehicle-generated dust emissions associated with the move-out. If the maneuver start time is changed to 0200 MST November 28, the reduced-speed-move-out can be completed by 0000 MST November 29. Figure 4.10c shows the results of the reduced speed simulation with the 0200 MST move-out start time and suggests limited, if any, reductions over baseline results.
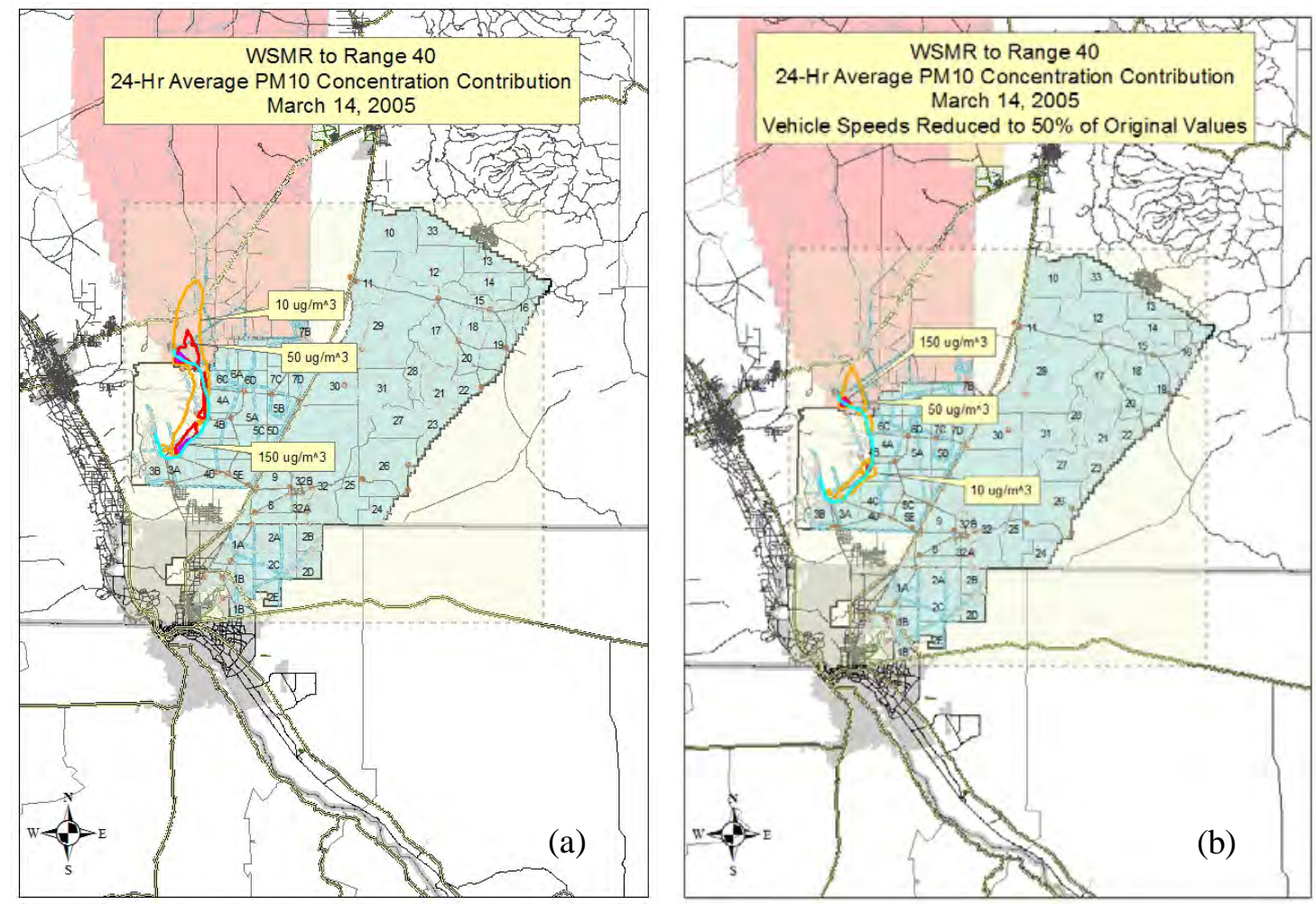

Figure 4.9. Reduced Speed Sensitivity Test: 24-Hour-Average $\mathrm{PM}_{10}$ Concentration Contributions on March 14, 2005, for a Move-out from WSMR to Range 40. (a) Baseline case and (b) vehicle speeds reduced to $50 \%$ of baseline levels. Move-out travel routes are indicated in light blue. 

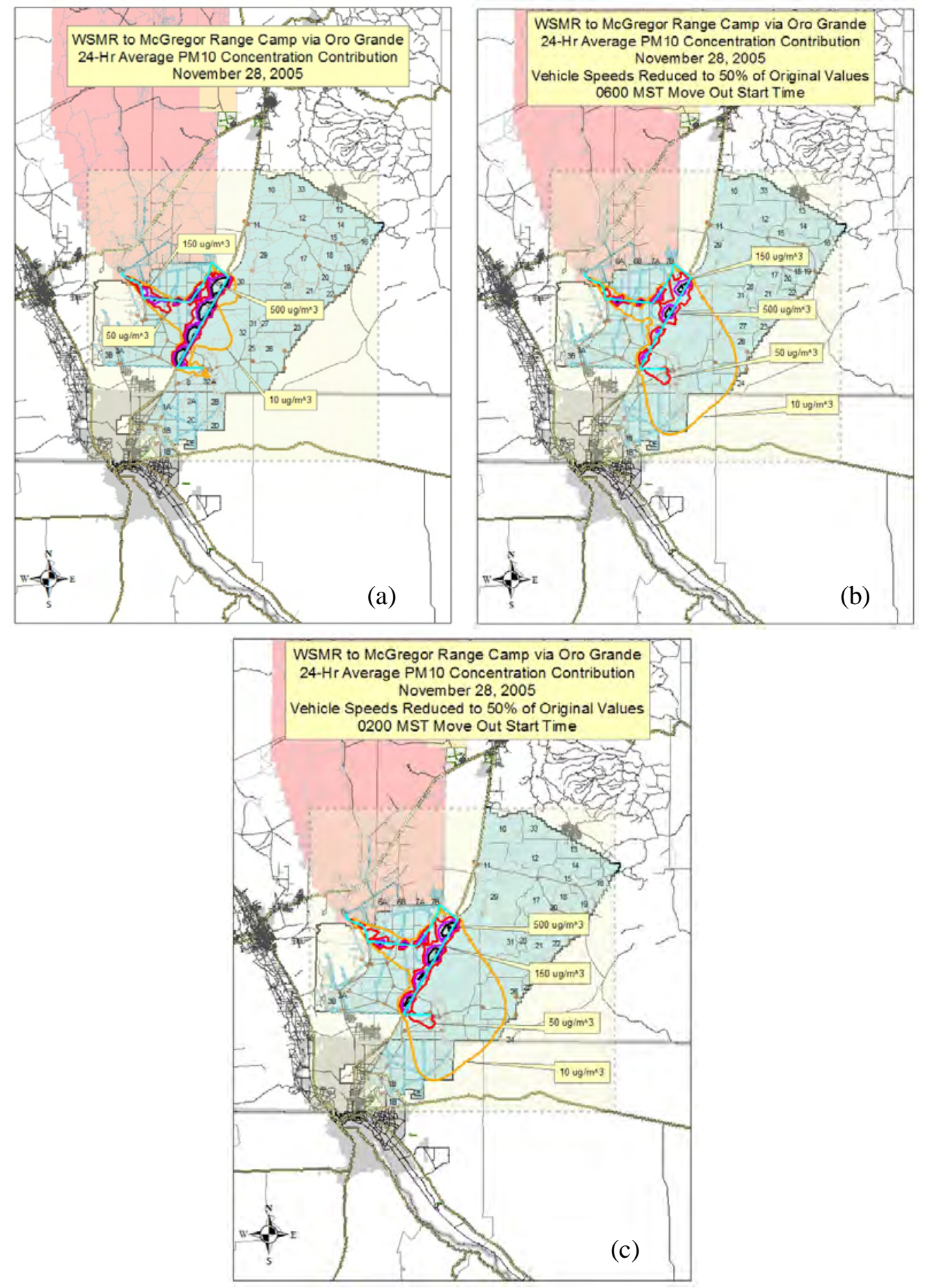

Figure 4.10. Reduced Speed Sensitivity Test: 24-Hour-Average $\mathrm{PM}_{10}$ Concentration Contributions on November 28, 2005, for a Move-out from WSMR to Range 40. (a) Baseline case;

(b) vehicle speeds reduced to 50\% of baseline levels and 0600 MST move-out start time; (c) vehicle speeds reduced to 50\% of baseline levels and 0200 MST move-out start time. Move-out travel routes are indicated in light blue. 
The results of these sensitivity tests indicate that reductions in vehicle speed may not automatically produce improvements in 24-hour average $\mathrm{PM}_{10}$ concentration contributions. When vehicles must travel between set locations, as in move-out maneuvers, the trade-off between decreased emission source strengths and increased travel times should be assessed. If meteorological changes such as slower winds or reduced boundary layer depths are likely to accompany the increase in travel time, it is unlikely that reduced vehicle speeds will significantly lessen the contribution of military activities to local $\mathrm{PM}_{10}$ concentrations or the area covered by the vehicle-generated dust plume. However, if higher winds or increased boundary layer depths are likely to accompany the increase in travel time, reducing vehicle speeds may reduce the size of the area with high $\mathrm{PM}_{10}$ concentration contributions.

\subsubsection{Combined Effect of Move-out Start Time and Vehicle Speed}

The combined effect of delaying move-out start times and reducing vehicle speeds was evaluated for a March 12, 2005 move-out from WSMR to the Oro Grande Base Camp. The move-out began at 1000 MST, four hours later than in the baseline run. Vehicle speeds on each travel leg were cut in half, with concurrent adjustments of activity timing and duration. The 24-hour average $\mathrm{PM}_{10}$ concentration contributions shown in Figure 4.11a cover substantially less area than the baseline simulation in Figure 4.3a and are slightly less than the individual sensitivity results for delayed move-out time (Figure 4.3b) and reduced speed (Figure 4.8b), particularly on the first travel leg. The $\mathrm{PM}_{10}$ concentration contributions at 1400 to $1500 \mathrm{MST}$, the first hour for which vehicles are present on the entire route, are shown in Figure 4.11b. At this hour, there is only a small plume centered on the travel route. This sharply contrasts with Figure 4.4a, which shows baseline $\mathrm{PM}_{10}$ concentration contributions for 0800 to $0900 \mathrm{MST}$, the first hour that vehicles cover the entire route in the baseline case. There, both the 10 and $50 \mu \mathrm{g} / \mathrm{m}^{3}$ contours extend past U. S. Route 70 . The $10 \mu \mathrm{g} / \mathrm{m}^{3}$ contour in Figure $4.11 \mathrm{~b}$ also covers much less area than the corresponding contour in the delayed-move-out-time simulation (Figure 4.4b) and the reduced-speed simulation (Figure 4.8b) for hours that correspond to the first instance vehicles covering the entire travel route. However, as indicated in these figures, the time of day varies for all travel legs that have vehicles on them: 0800 to 0900 MST for the baseline case, 1200 to 1300 MST for the delay move-out start time case, 1000 to 1100 MST for the reduced speed case, and 1400 to 1500 MST for the combined time delay and reduced speed case. Meteorological conditions were not constant throughout this time; as noted previously, light (1 m/s or less) southerly winds at 0700 MST changed to steady 3 to $5 \mathrm{~m} / \mathrm{s}$ westerly winds by 1300 MST. Additionally, in spring in the El Paso area, the boundary layer likely neared its maximum depth somewhere in the period of 1400 to 1600 MST. Under such changing conditions, comparison of 24-hour average $\mathrm{PM}_{10}$ concentration contributions is more useful for assessing the sensitivity of model results to specific input parameters.

Figure 4.10c, presented and discussed in Section 4.3.2, shows the combined effect of altered moveout time and reduced speed on the longer WSMR to McGregor Range Camp via Oro Grande route for November 28, 2005. As noted, reduced vehicle speed increased the duration of this long move-out to the point that to capture true 24-hour average concentration contributions the move-out time had to be changed to 0200 MST. On this longer route, no substantial improvement in the magnitude or area influenced by vehicle-generated $\mathrm{PM}_{10}$ concentration contributions is noticeable. 

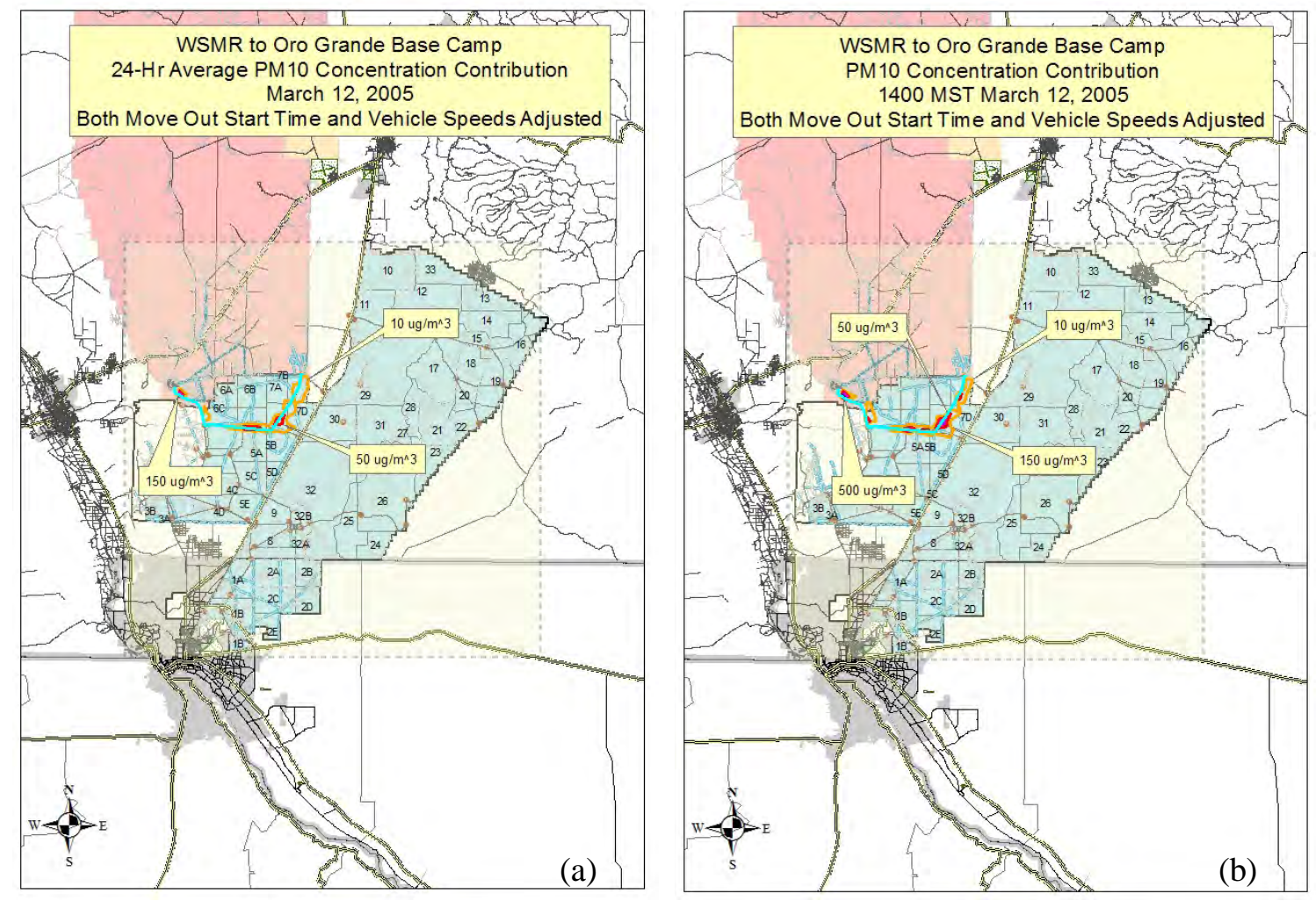

Figure 4.11. Combined Delayed Start and Reduced Speed Sensitivity Test: Move-out from WSMR to Oro Grande on March 12, 2005, with Vehicle Speeds Reduced to 50\% of Baseline Levels and 1000 MST Move-out Start Time. (a) 24-hour average $\mathrm{PM}_{10}$ concentration contributions and (b) hourly $\mathrm{PM}_{10}$ concentration contributions for the 1400-1500 MST period.

Compare (a) with Figures 4.3a (baseline), 4.3b (delayed move-out time), and 4.8a (reduced speed) and (b) with Figures 4.4a (hourly baseline), 4.4b (hourly delayed move-out time), and $4.8 \mathrm{~b}$ (hourly reduced speed), respectively. Move-out travel routes are indicated in light blue. 


\subsection{List of Persons and Organizations Consulted}

Dr. Jack Gillies, Desert Research Institute

Dr. Hampden Kuhns, Desert Research Institute

Ms. Lilia Lenhart, Fort Bliss

Meteorological Office, White Sands Missile Range

Mr. Jesse Moncada, Fort Bliss

Ms. Carol Placchi, White Sands Missile Range

Mr. Steven Sanchez, Fort Bliss 



\subsection{References}

Allwine KJ, FC Rutz, WJ Shaw, JP Rishel, BG Fritz, EG Chapman, BL Hoopes and TE Seiple. 2007. Final Technical Report: Development of the DUSTRAN GIS-Based Complex Terrain Model for Atmospheric Dust Dispersion. PNNL-16588, Pacific Northwest National Laboratory, Richland, Washington.

Allwine KJ, FC Rutz, WJ Shaw, JP Rishel, BG Fritz, EG Chapman, BL Hoopes and TE Seiple. 2006. DUSTRAN 1.0 User's Guide: A GIS-Based Atmospheric Dust Dispersion Modeling System.

PNNL-16055, Pacific Northwest National Laboratory, Richland, Washington.

Booz Allen Hamilton. 2006. Preliminary Prevention of Significant Deterioration (PSD) Analysis of Ft. Bliss Emissions. McLean, Virginia.

Chapman EG, JP Rishel, FC Rutz, TE Seiple, RK Newsom and KJ Allwine Jr. 2006a. Dust Plume Modeling at Fort Bliss: Move-out Operations, Combat Training and Wind Erosion. PNNL-16123, Pacific Northwest National Laboratory, Richland, Washington.

Chapman EG, JP Rishel, FC Rutz, TE Seiple, RK Newsom and KJ Allwine Jr. 2006b. Dust Plume Modeling at Fort Bliss: Full Training Scenario. PNNL-15935, Pacific Northwest National Laboratory, Richland, Washington.

Gillies JA, V Etyemezian, H Kuhns, D Nikolic, and DA Gillette. 2005a. "Effect of Vehicle Characteristics on Unpaved Road Dust Emissions.” Atmos. Environ. 39:2341-2347.

Gillies JA, WP Arnott, V Etyemezian, H Kuhns, H Moosmuller, D DuBois, M Abu-Allaban, G Schwemmer, DA Gillette, WG Nickling, R Varma, T Wilkerson, and R Varma. 2005b. Characterizing and Quantifying Local and Regional Particulate Matter Emissions from Department of Defense Installations. Prepared for the Strategic Environmental Research and Development Program by the Desert Research Institute, Reno, Nevada, under Project CP-1191.

Scire JS, DG Strimaitis, and RJ Yamartino. 2000a. A User's Guide for the CALPUFF Dispersion Model (Version 5). Earth Tech, Inc., Concord, Massachusetts.

Scire JS, FR Robe, ME Fernau, and RJ Yamartino. 2000b. A User's Guide for the CALMET Meteorological Model (Version 5). Earth Tech, Inc., Concord, Massachusetts.

Scire JS, RJ Yamartino, GR Carmichael, and YS Chang. 1989. CALGRID: A Mesoscale Photochemical Grid Model Volume II - User’s Guide. California Resources Board, Sacramento, California.

Shaw WJ, KJ Allwine, BG Fritz, FC Rutz, JP Rishel, and EG Chapman. 2008. "An Evaluation of the Wind Erosion Module in DUSTRAN.” Atmos. Environ. 42(8):1907-1921. 

Appendix A

Vehicle Categorization for a Heavy Brigade Combat Team (HBCT) 



\section{Appendix A}

\section{Vehicle Categorization for a Heavy Brigade Combat Team (HBCT)}

The following table summarizes the assignment of specific HBCT vehicles, as presented in a BoozAllen-Hamilton (2006) report, to general vehicle categories used in the DUSTRAN simulations. These assignments provide the basis for Table 3.2.

Table A.1. Heavy Brigade Combat Team: Vehicle Categorization

\begin{tabular}{|c|c|c|}
\hline & No. Sources & Assigned \\
\hline \multicolumn{3}{|l|}{ Wheeled Vehicle--HC BCT } \\
\hline M998 A1 (HMMWV) & 30 & HMMWV \\
\hline M1097A2 W/E (HMMWV) & 2 & HMMWV \\
\hline M1113 W/E (HMMWV) & 3 & HMMWV \\
\hline M1078 W/E (LMTV) & 4 & LMTV \\
\hline M1083 W/E (MTV) & 2 & MTV \\
\hline \multicolumn{3}{|l|}{ Wheeled Vehicle--BSTB } \\
\hline M997 A1 W/E (AMBULENCE 4 LITTER) (HMMWV) & 1 & HMMWV \\
\hline M998 A1 (HMMWV) & 52 & HMMWV \\
\hline M1025 (HMMWV) & 8 & HMMWV \\
\hline M1097A2 W/E (HMMWV) & 12 & HMMWV \\
\hline M1113 W/E (HMMWV) & 15 & HMMWV \\
\hline M1114 W/E (HMMWV) & 11 & HMMWV \\
\hline M1078 W/E (LMTV) & 3 & LMTV \\
\hline M1083 W/E (MTV) & 7 & MTV \\
\hline M1117 ARMORED SECURITY VEHICLE: WHEELED W/MOUNT (ASV) & 3 & ASV \\
\hline M923 A2 W/E (TRK, CGO 5T 6x6) & 2 & M923 \\
\hline M977 W/LT CRANE (HEMMT) & 2 & HEMMT \\
\hline M978 W/W (HEMMT) & 2 & HEMMT \\
\hline M984 W/W (HEMMT) & 1 & HEMMT \\
\hline NBCRS-FOX (M93A1) & 2 & M93 \\
\hline \multicolumn{3}{|l|}{ Wheeled Vehicles--ARS } \\
\hline M997 A1 W/E (AMBULENCE 4 LITTER) (HMMWV) & 10 & HMMWV \\
\hline M998 A1 (HMMWV) & 29 & HMMWV \\
\hline M1025 (HMMWV) & 1 & HMMWV \\
\hline M1097A2 W/E (HMMWV) & 4 & HMMWV \\
\hline M1113 W/E (HMMWV) & 4 & HMMWV \\
\hline M1114 W/E (HMMWV) & 33 & HMMWV \\
\hline M1078 W/E (LMTV) & 3 & LMTV \\
\hline M1083 W/E (MTV) & 5 & MTV \\
\hline KNIGHT M707 FSV (HMMWV) & 3 & HMMWV \\
\hline
\end{tabular}


Table A.1. (contd)

\begin{tabular}{|c|c|c|}
\hline & No. Sources & Assigned \\
\hline \multicolumn{3}{|l|}{ Wheeled Vehicles--CAB } \\
\hline M998 A1 (HMMWV) & 64 & HMMWV \\
\hline M1097A2 W/E (HMMWV) & 4 & HMMWV \\
\hline M1113 W/E (HMMWV) & 2 & HMMWV \\
\hline M1114 W/E (HMMWV) & 10 & HMMWV \\
\hline KNIGHT M707 FSV (HMMWV) & 2 & HMMWV \\
\hline M1078 W/E (LMTV) & 6 & LMTV \\
\hline M1083 W/E (MTV) & 12 & MTV \\
\hline M985 W/MED CRANE (HEMMT) & 4 & HEMMT \\
\hline SMALL EMPL EXCAV (SEE) & 4 & SEE \\
\hline \multicolumn{3}{|l|}{ Wheeled Vehicles--FIRES } \\
\hline M997 A1 W/E (AMBULENCE 4 LITTER) (HMMWV) & 3 & HMMWV \\
\hline M998 A1 (HMMWV) & 31 & HMMWV \\
\hline M1038 A1 (HMMWV) & 12 & HMMWV \\
\hline M1097A2 W/E (HMMWV) & 4 & HMMWV \\
\hline M1113 W/E (HMMWV) & 4 & HMMWV \\
\hline M1074 (PLS TRANSPORTER) W/MHE & 12 & PLSTrans \\
\hline M1078 W/E (LMTV) & 6 & LMTV \\
\hline M1083 W/E (MTV) & 5 & MTV \\
\hline \multicolumn{3}{|l|}{ Wheeled Vehicles--BSB } \\
\hline M997 A1 W/E (AMBULENCE 4 LITTER) (HMMWV) & 6 & HMMWV \\
\hline M998 A1 (HMMWV) & 100 & HMMWV \\
\hline M1038 A1 (HMMWV) & 1 & HMMWV \\
\hline M1097A2 W/E (HMMWV) & 2 & HMMWV \\
\hline M1113 W/E (HMMWV) & 37 & HMMWV \\
\hline M978 (HEMMT) & 46 & HEMMT \\
\hline M984 W/W (HEMMT) & 9 & HEMMT \\
\hline M1075 PLS TRANSPORTER & 49 & PLSTrans \\
\hline M1078 W/E (LMTV) & 34 & LMTV \\
\hline M1079 W/E (LMTV) & 22 & LMTV \\
\hline M1083 W/E (MTV) & 56 & MTV \\
\hline M1087 W/E (MTV) & 6 & MTV \\
\hline M1088 W/E (MTV) & 13 & MTV \\
\hline M1089 W/W W/E (MTV) & 4 & MTV \\
\hline CRANE: WHEEL MOUNTED HYDRAULIC 25 TON ALL TERRAIN & 1 & CRANE \\
\hline XM1120 (HEMMT) & 56 & HEMMT \\
\hline FORKLIFT-VAR REACH & 7 & FKLFT \\
\hline TOTAL WHEELED VEHICLES & 888 & \\
\hline
\end{tabular}


Table A.1. (contd)

\begin{tabular}{|c|c|c|}
\hline & No. Sources & Assigned \\
\hline \multicolumn{3}{|l|}{ HC BCT Tracked Vehicles: } \\
\hline M2 A3 IFV & 2 & Bradley \\
\hline M1068 CARRIER ARMORED CP: FULL TRACKED & 5 & M113 \\
\hline \multicolumn{3}{|l|}{ BSTB Tracked Vehicles: } \\
\hline M2 A3 IFV & 2 & Bradley \\
\hline M1068 CARRIER ARMORED CP: FULL TRACKED & 1 & M113 \\
\hline M88 A1 RCVY VEH (MED) & 1 & M88 \\
\hline \multicolumn{3}{|l|}{ ARS Tracked Vehicles: } \\
\hline M3 A3 CFV & 23 & Bradley \\
\hline M7 BFIST & 3 & Bradley \\
\hline M286 120 MM MTR & 6 & M113 \\
\hline \multicolumn{3}{|l|}{ CAB Tracked Vehicles: } \\
\hline M1 A2 SEP & 70 & M1A1 \\
\hline M2 A3 IFV & 76 & Bradley \\
\hline M3 A3 CFV & 6 & Bradley \\
\hline M7 BFIST & 20 & Bradley \\
\hline M113 A3 CARRIER PERSONEL FULL TRACKED ARMD RISE & 30 & M113 \\
\hline M548 CARRIER CARGO TRCKD 6T & 4 & M113 \\
\hline M9 ACE & 6 & M9 \\
\hline M1064 CARRIER 120 MM MORTAR: SELF PROPELLED & 8 & M113 \\
\hline M1068 CARRIER ARMORED CP: FULL TACKED & 6 & M113 \\
\hline M577 A2 CARRIER COMMAND POST LIGHT TRACKED & 8 & M113 \\
\hline \multicolumn{3}{|l|}{ FIRES Tracked Vehicles: } \\
\hline M1068 CARRIER ARMORED CP: FULL TACKED & 8 & M113 \\
\hline CARRIER AMMUNITION: TRACKED VEHICLE (CATV) & 16 & CATV \\
\hline M109A6 PALADIN & 16 & M109 \\
\hline \multicolumn{3}{|l|}{ BSB Tracked Vehicles: } \\
\hline M113 A3 CARRIER PERSONEL FULL TRACKED ARMD RISE & 6 & M113 \\
\hline M577 A2 CARRIER COMMAND POST LIGHT TRACKED & 4 & M113 \\
\hline M88 A2 (RCVY VEH TRCKD HVY) & 17 & M88 \\
\hline M88 A1 RCVY VEH (MED) & 12 & M88 \\
\hline TOTAL TRACKED VEHICLES & 356 & \\
\hline
\end{tabular}





\section{Appendix B}

Simulated $\mathrm{PM}_{10}$ Concentrations for the Move-out from White Sands Missile Range to Dona Ana Range Camp 



\section{Appendix B}

\section{Simulated $\mathrm{PM}_{10}$ Concentrations for the Move-out from White Sands Missile Range to Dona Ana Range Camp}

The following pages present contour maps of simulated PM10 concentrations contributed by WSMR to Dona Ana Range Camp move-out operations to air quality in and around Fort Bliss and WSMR for the 21 days (March 12-16, April 25-30, July 20-24, and November 25-29, 2005) studied in this investigation. For each day, the contour map of the 24-hour-average PM10 concentration contribution is shown first, followed by a contour map of PM10 concentration contributions for a specific hour. The hour listed in the figure header represents the start of the hour, e.g., 1000 MST means the hour from 1000 MST to 1100 MST. Move-out scenario assumptions are summarized in Section 3 of this report. 


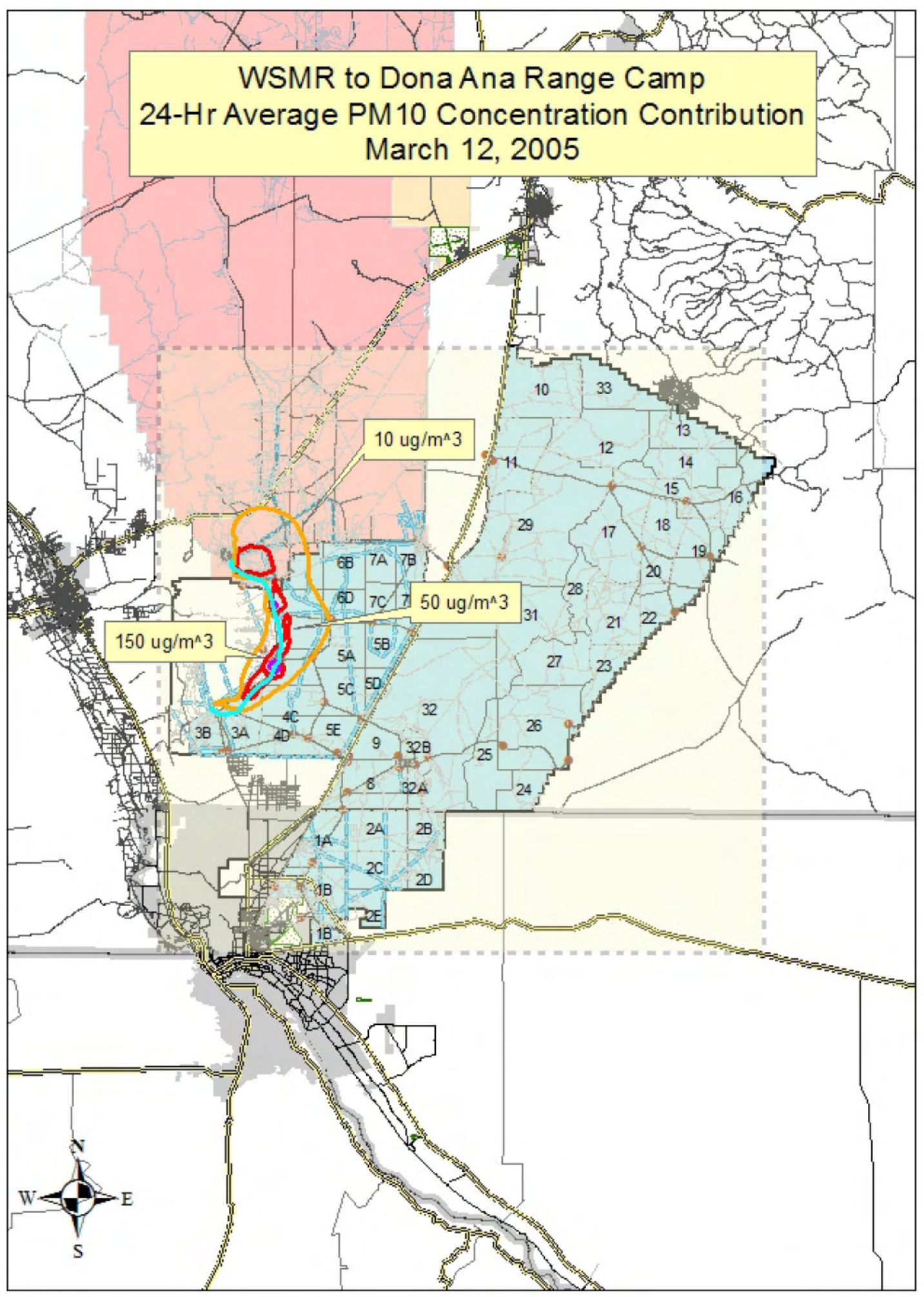




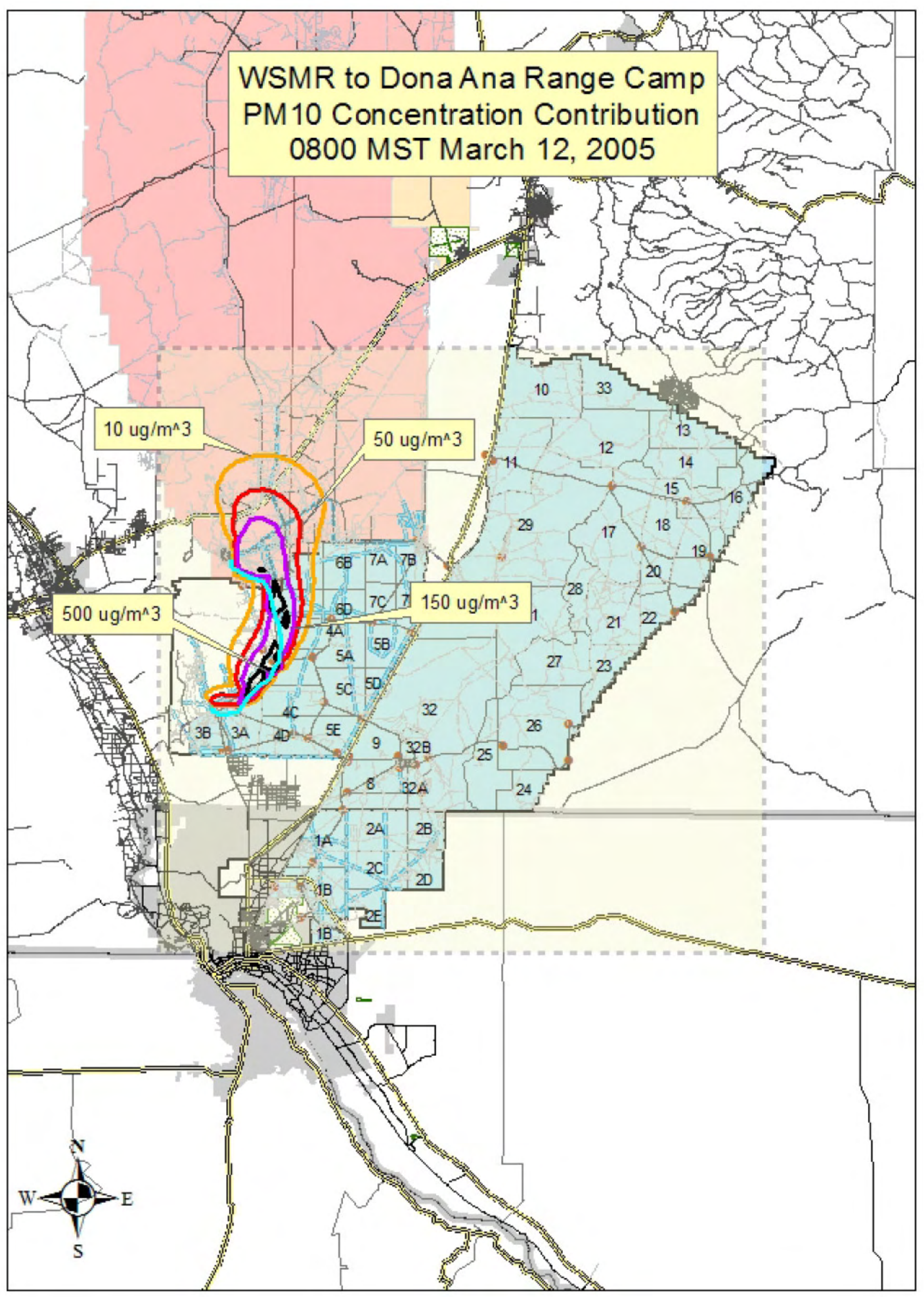




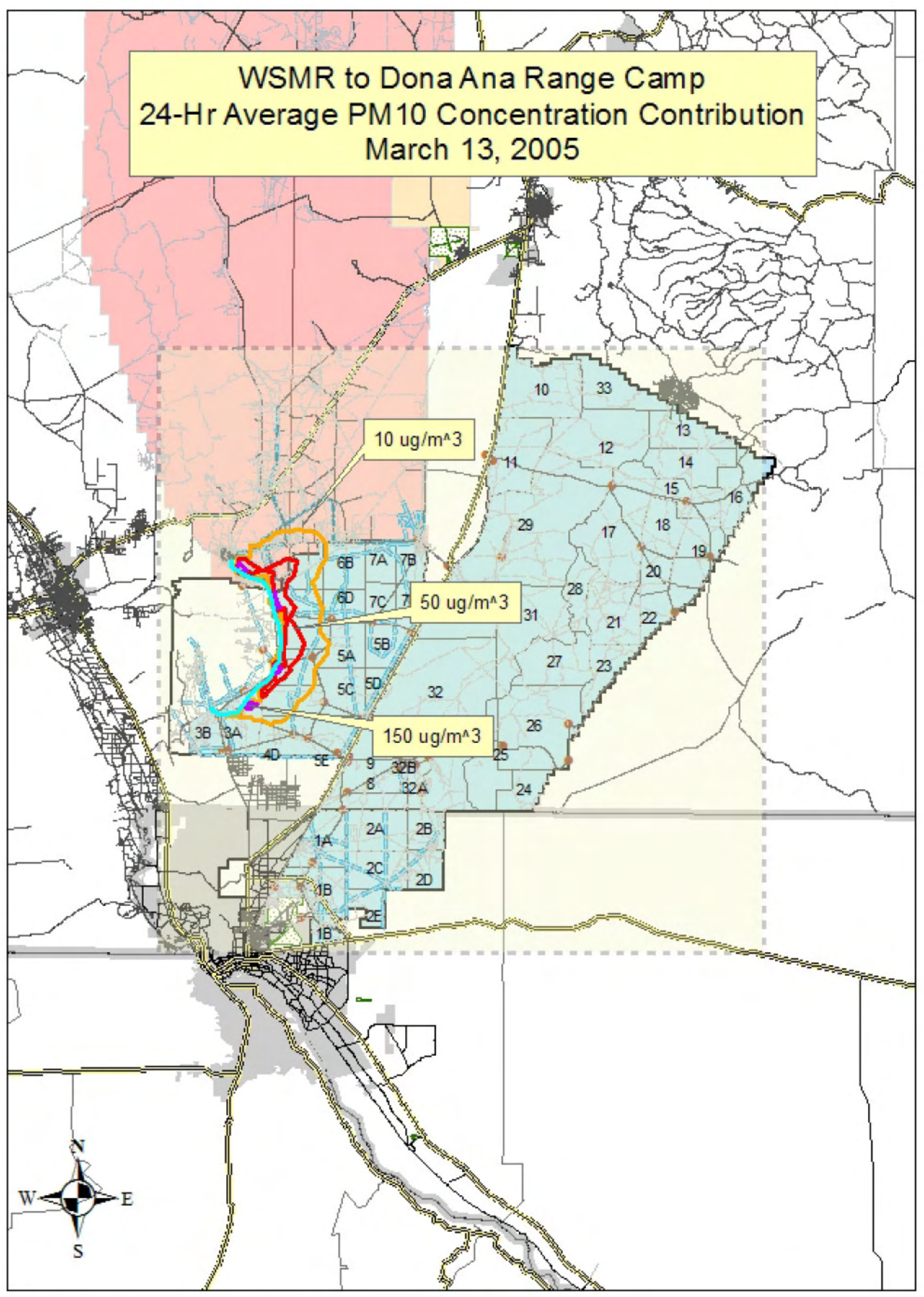




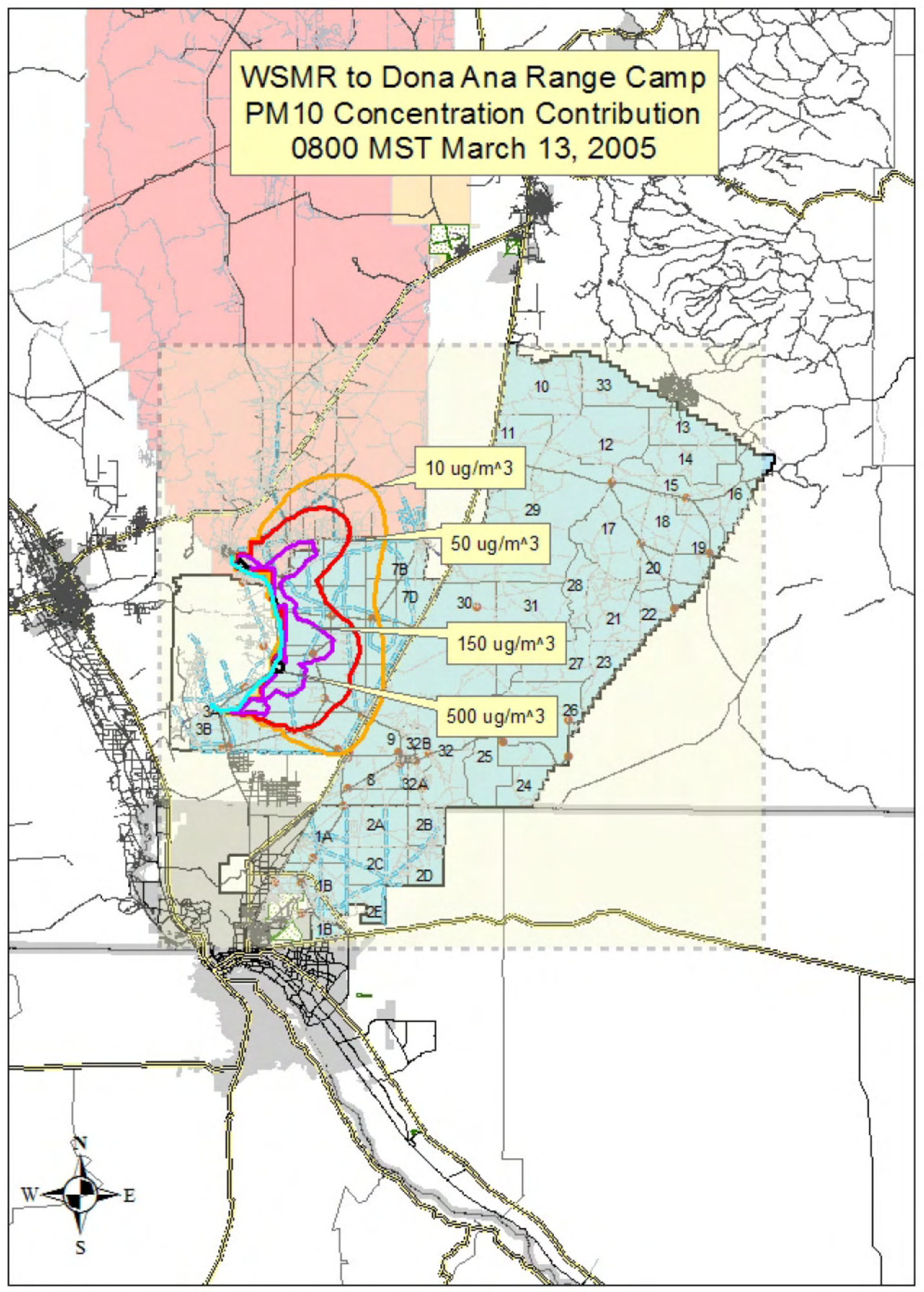




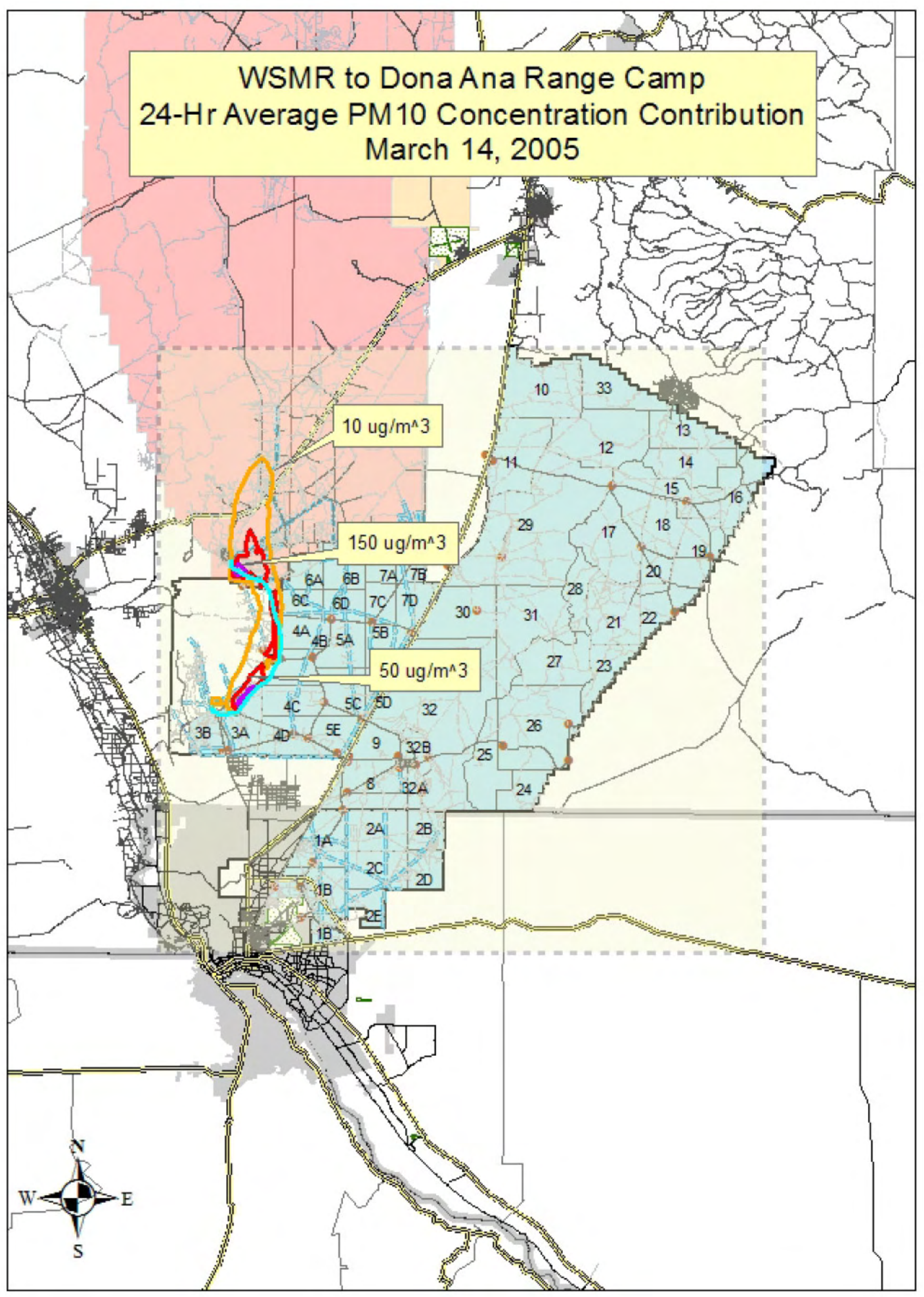




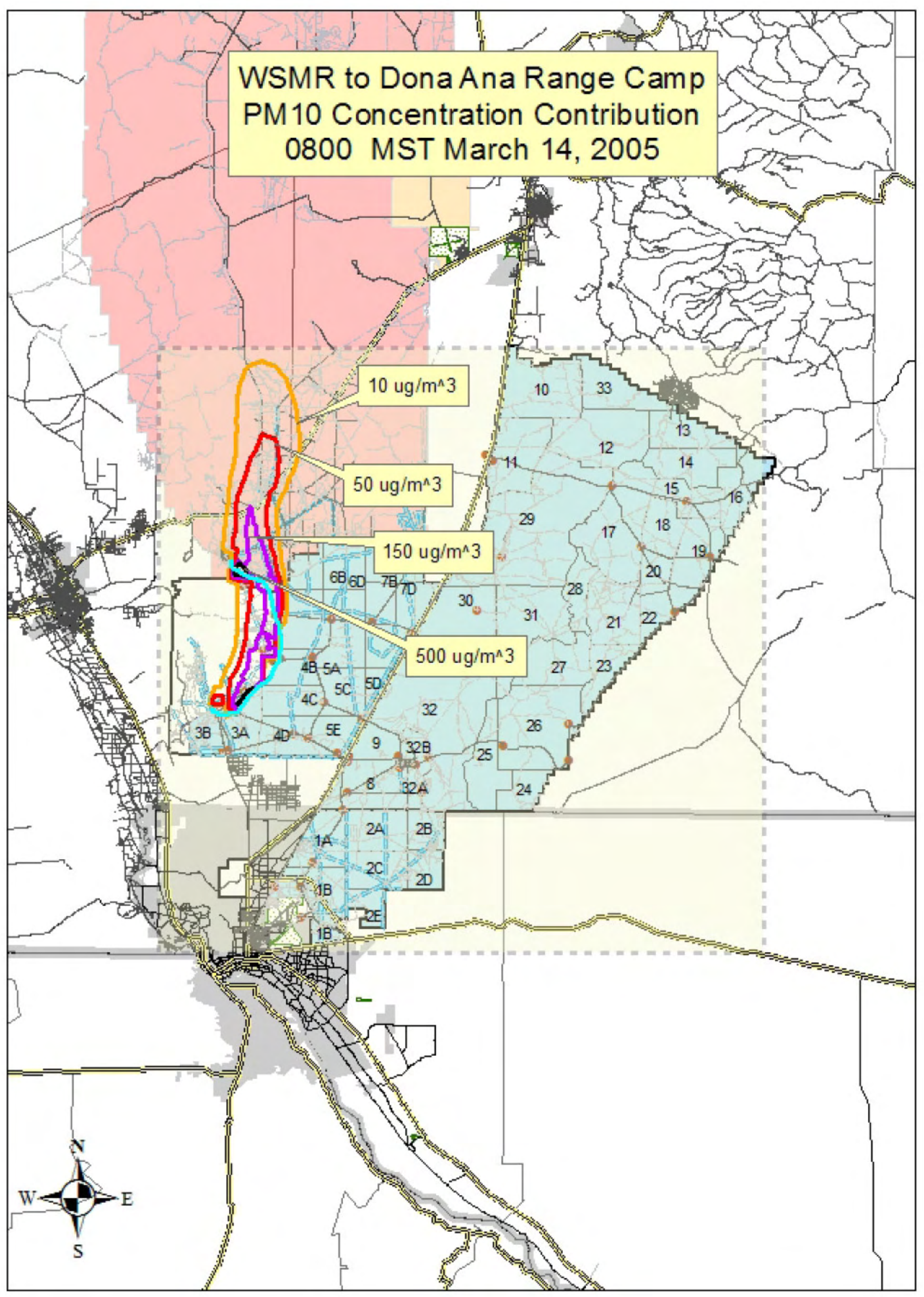




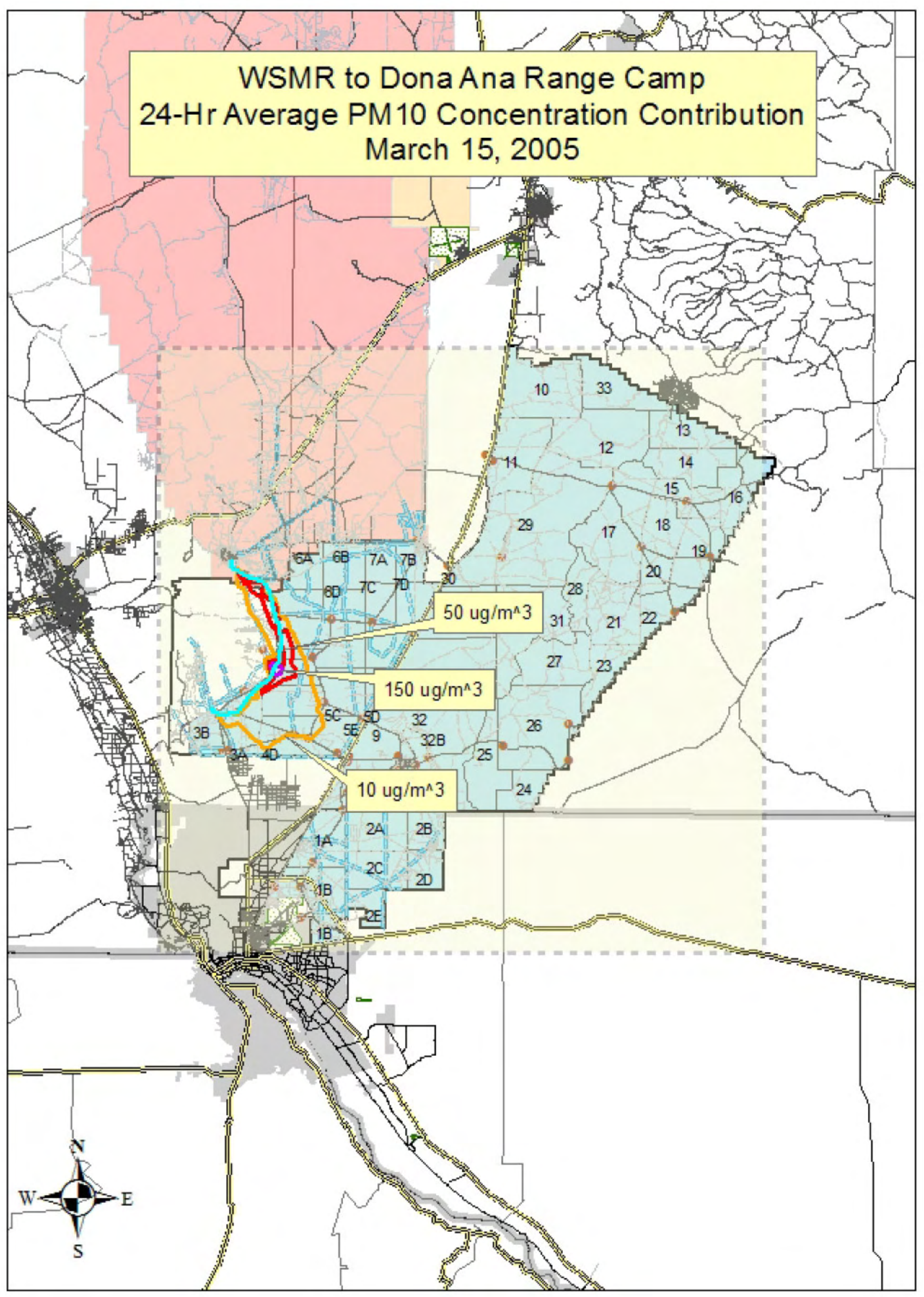




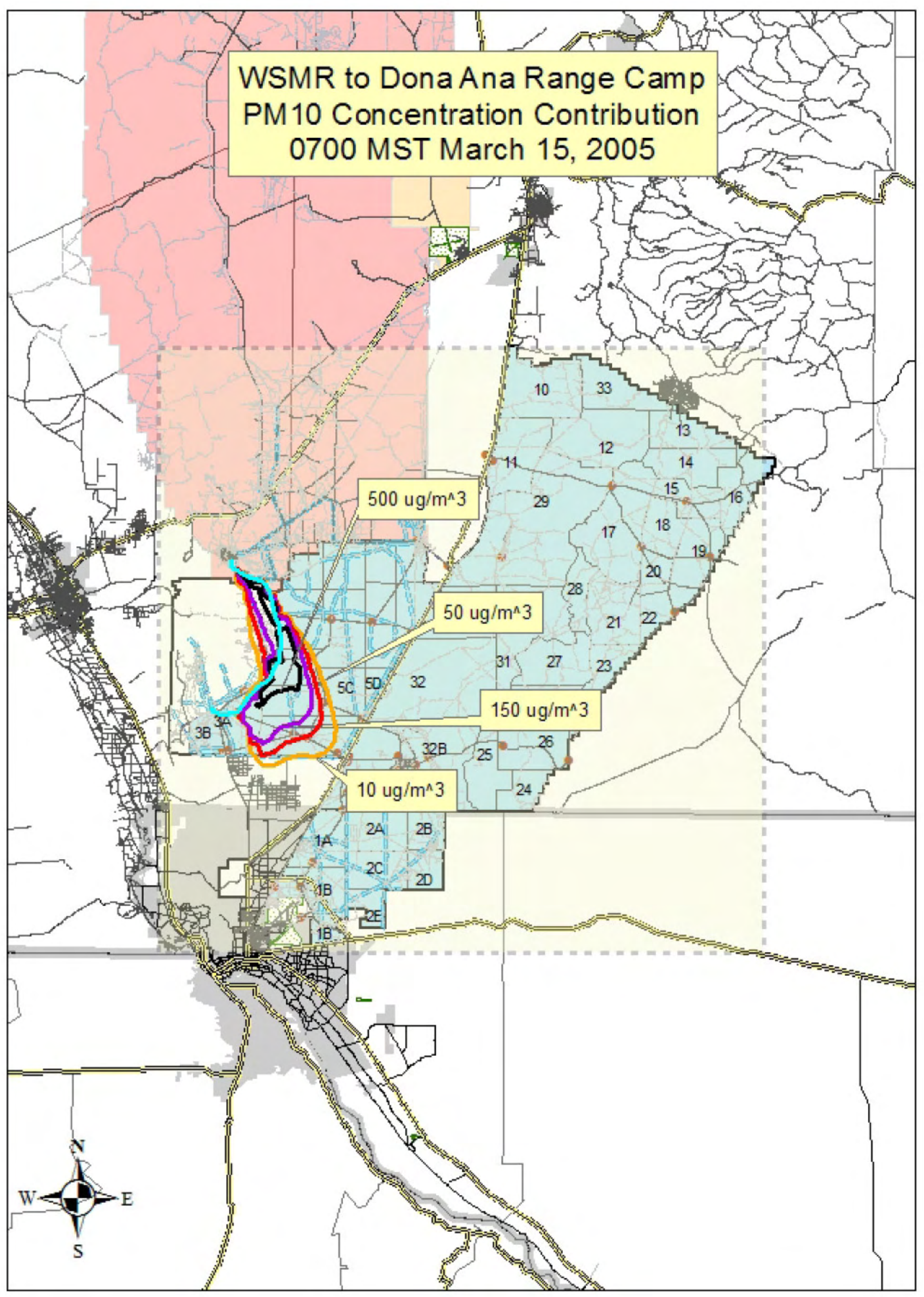




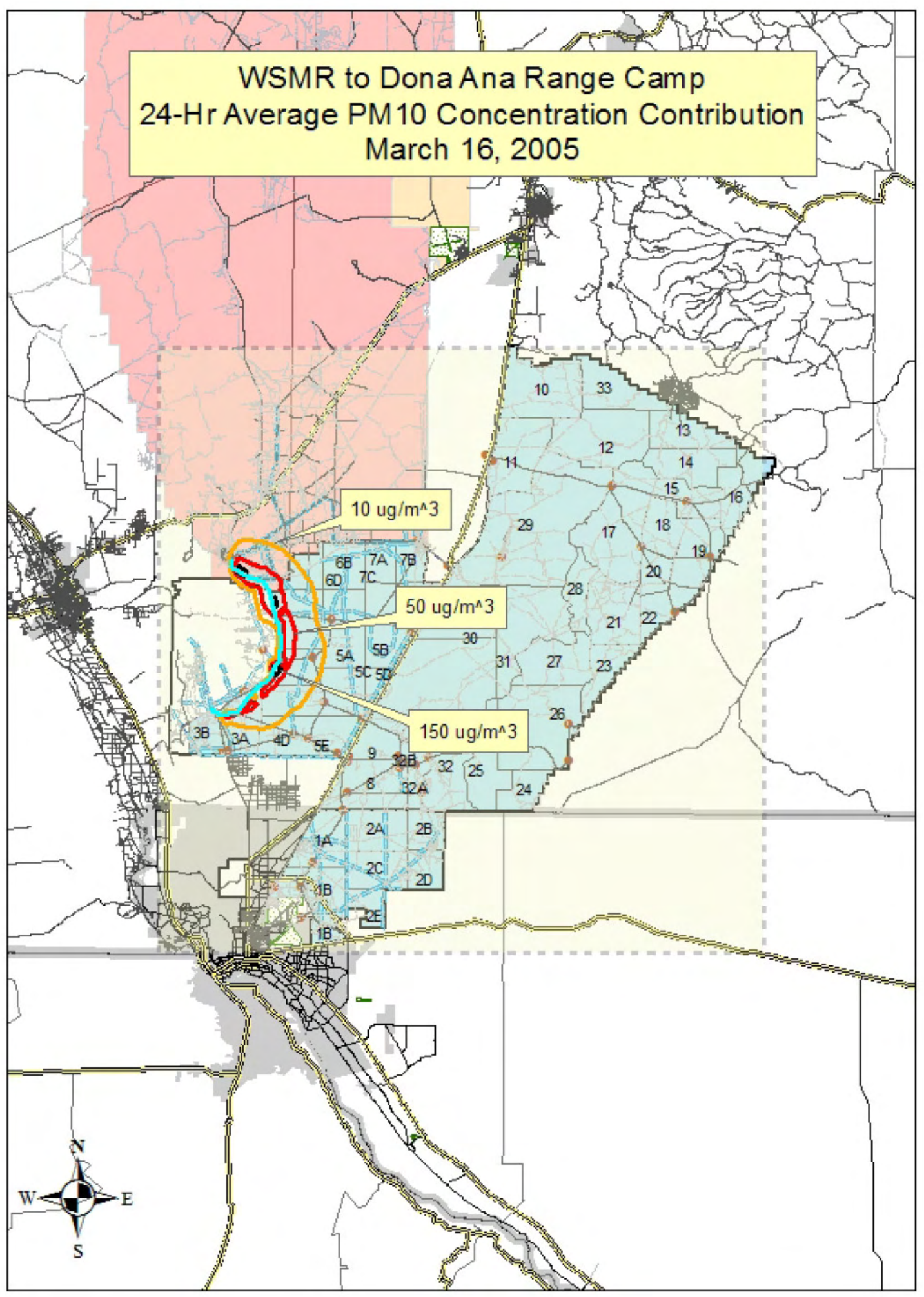

B.10 


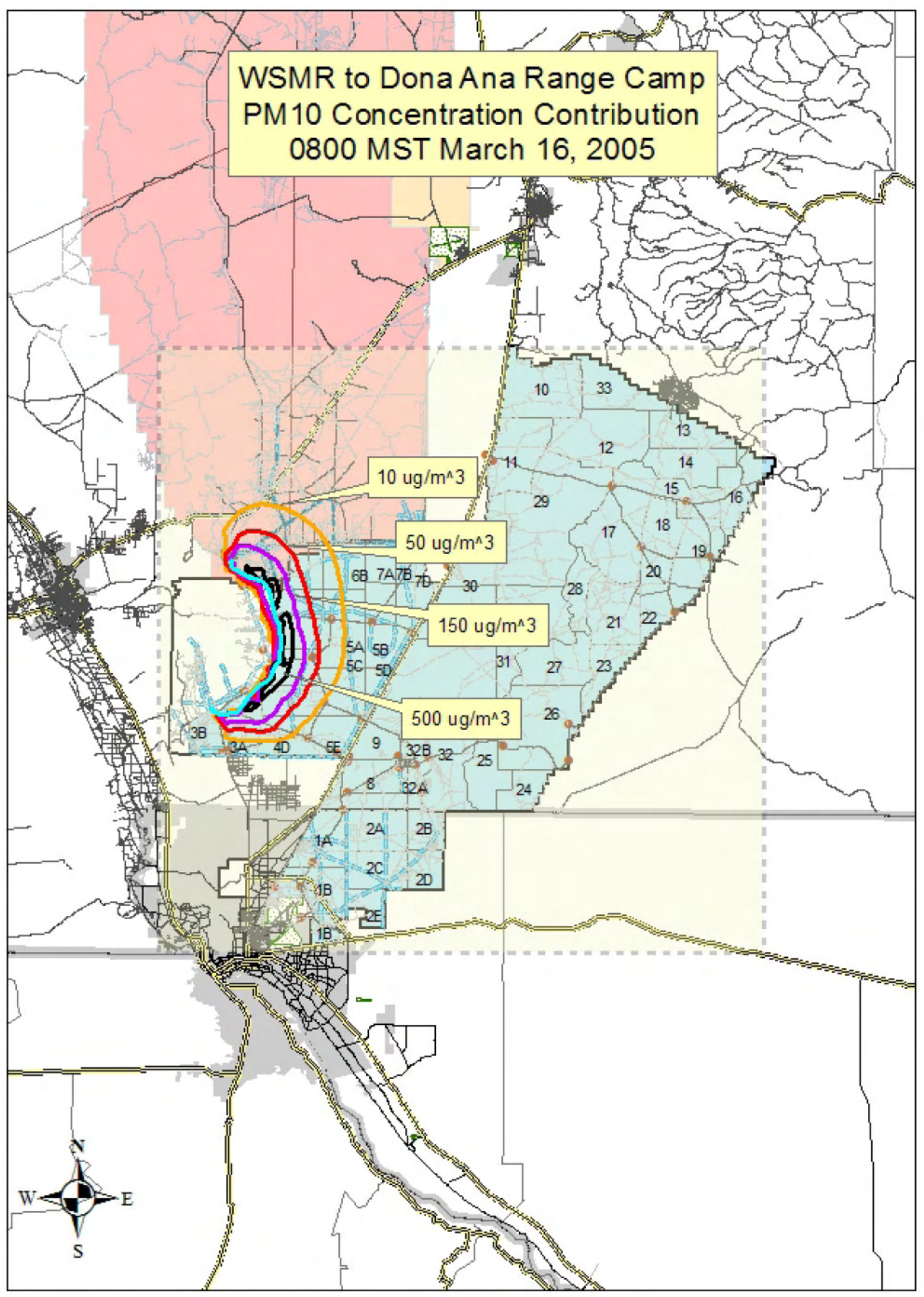




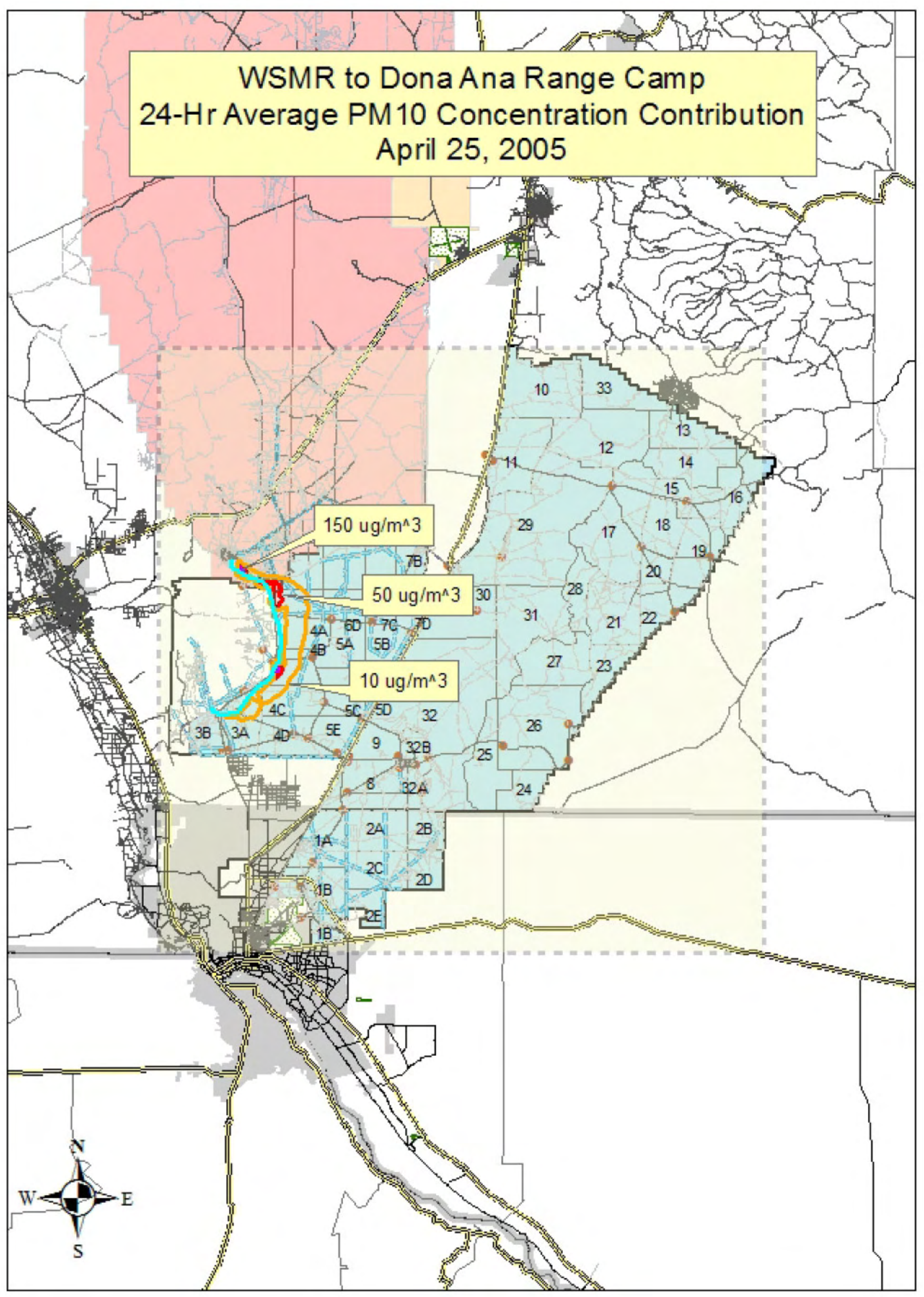




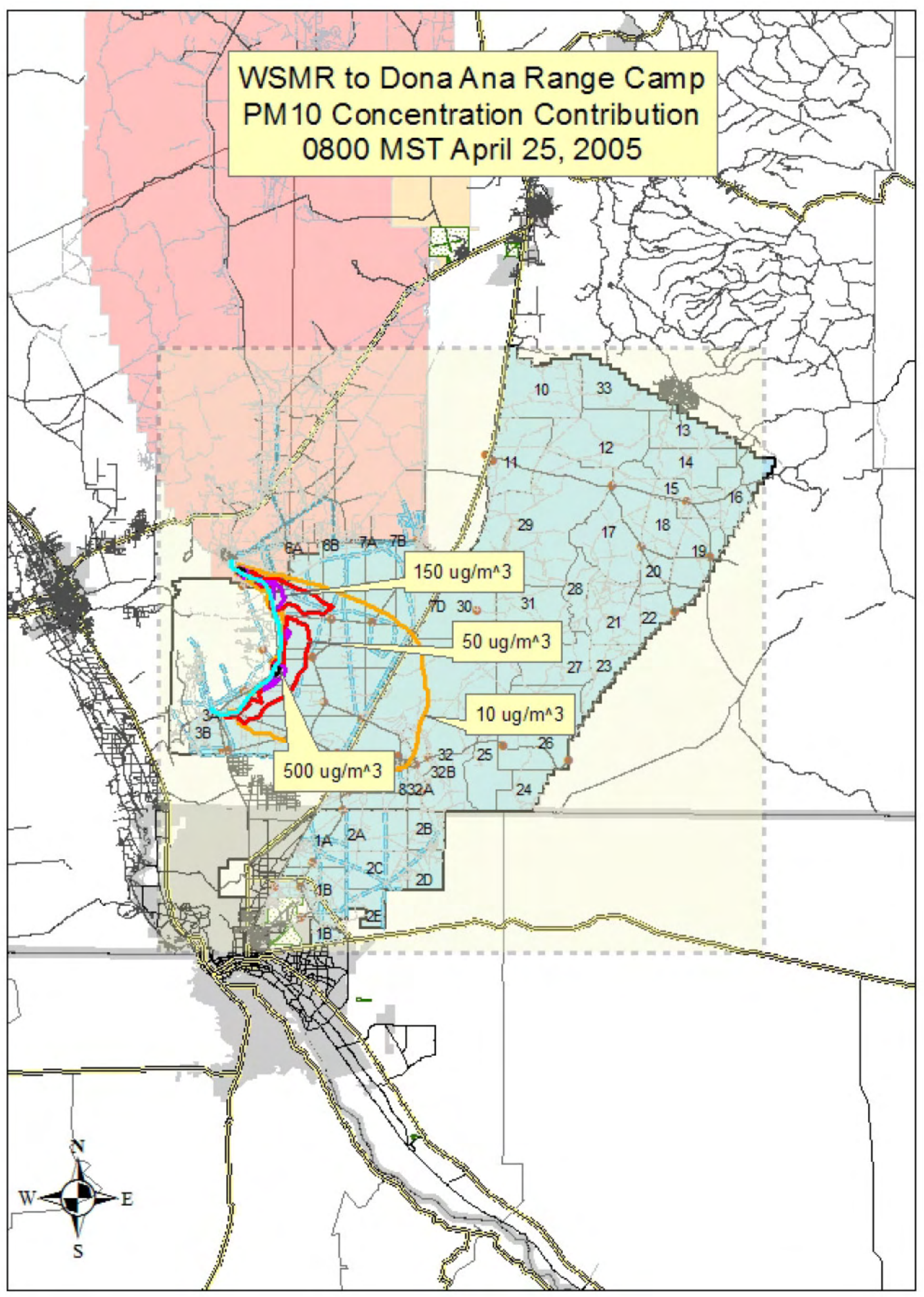




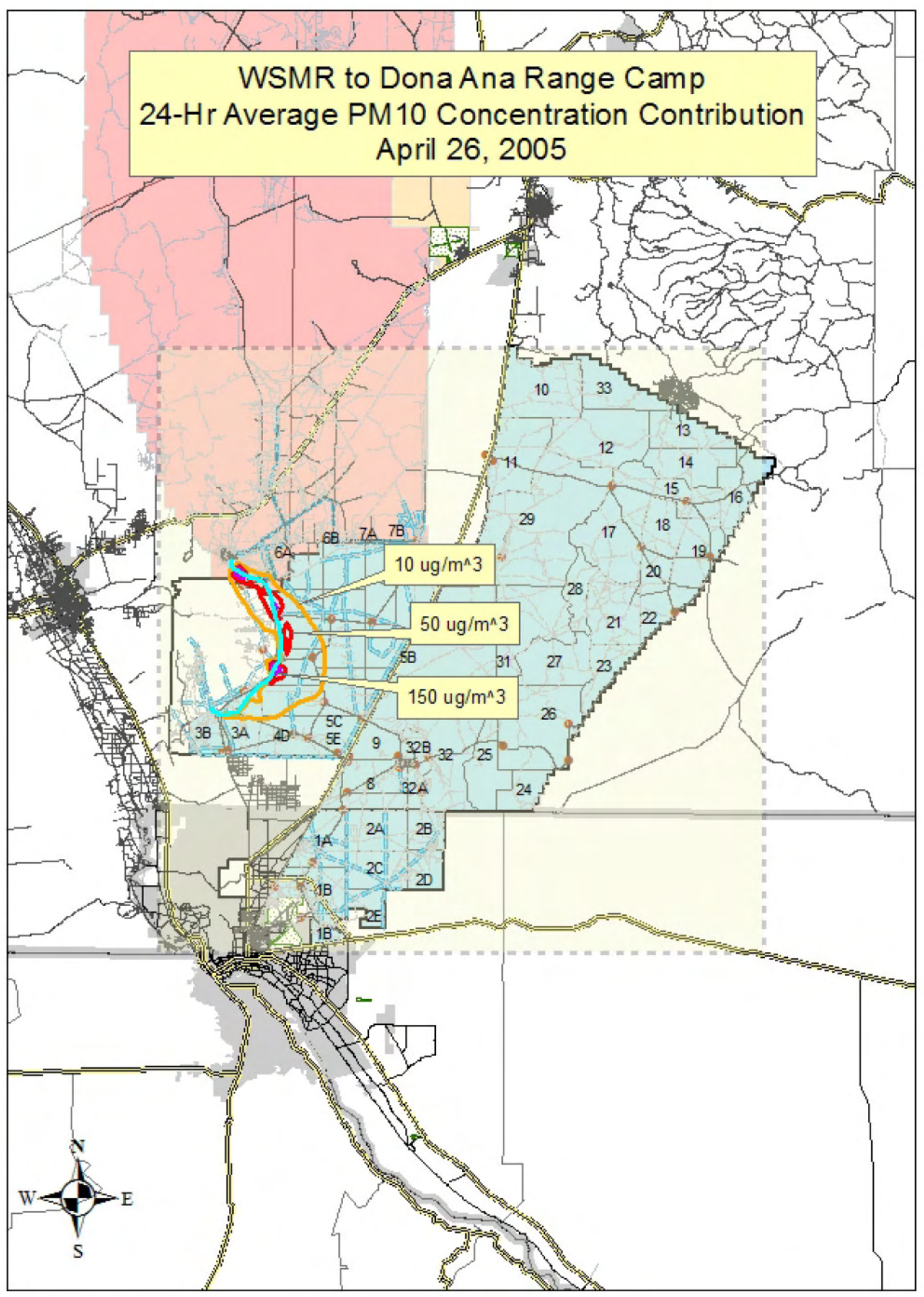




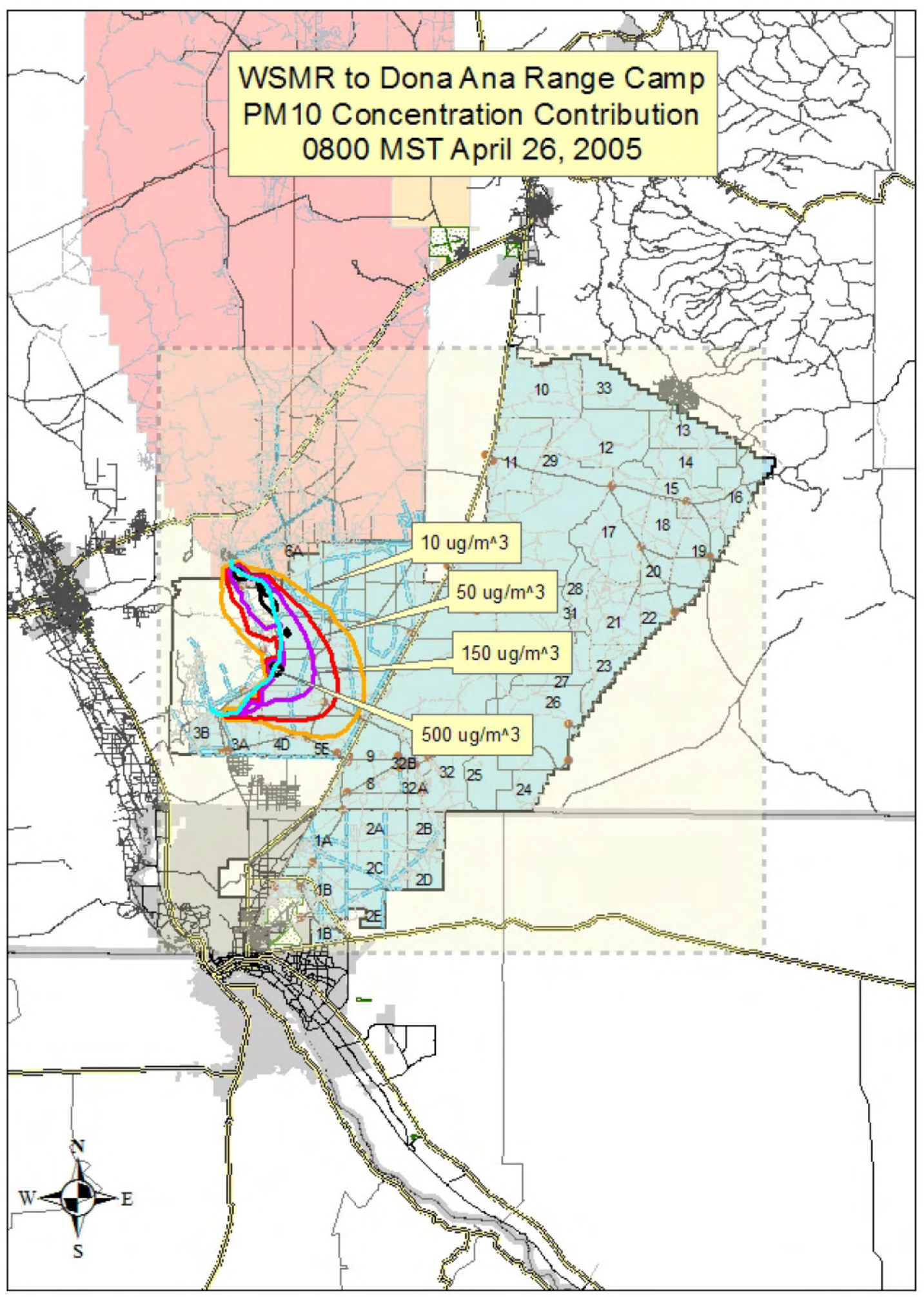




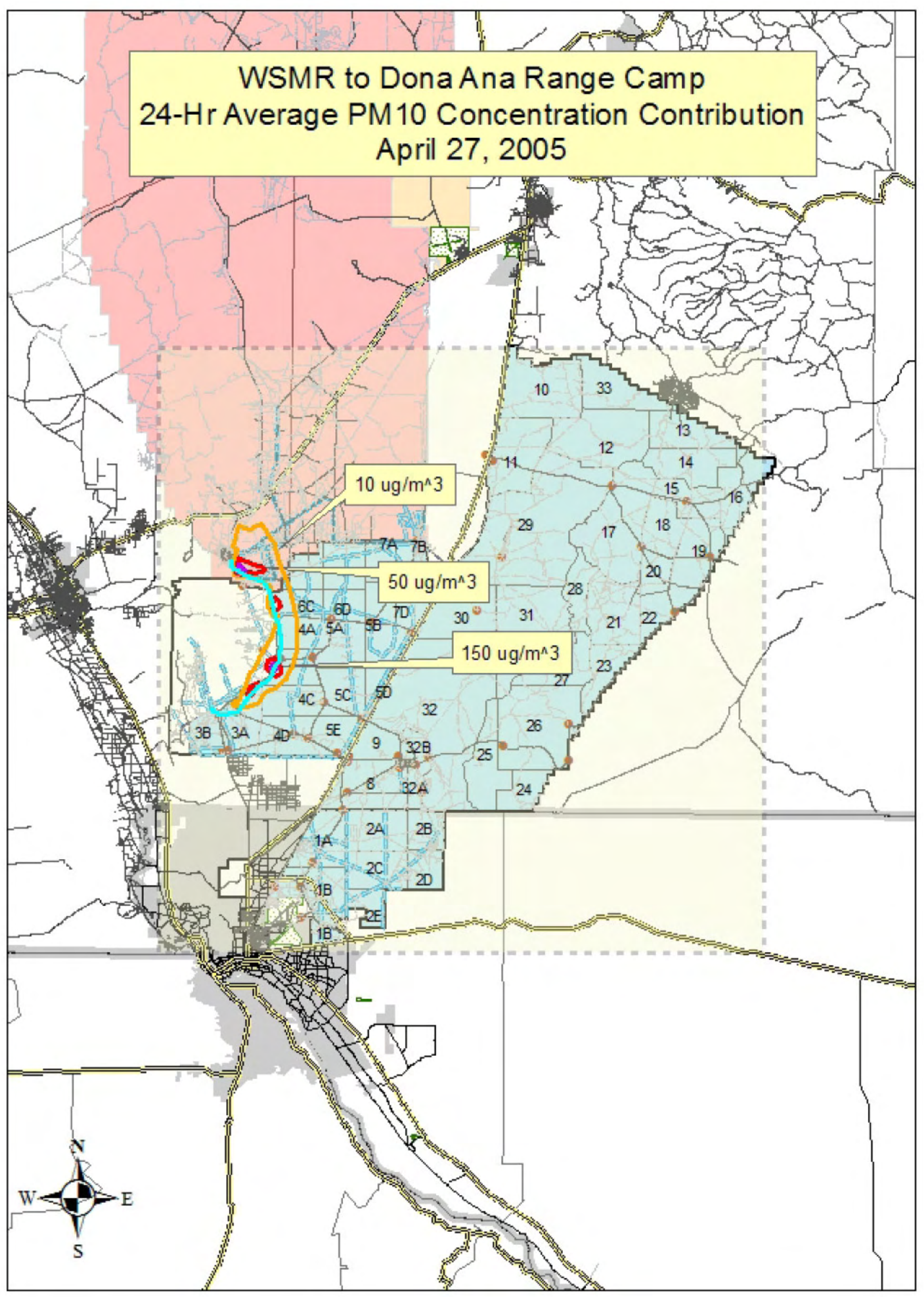




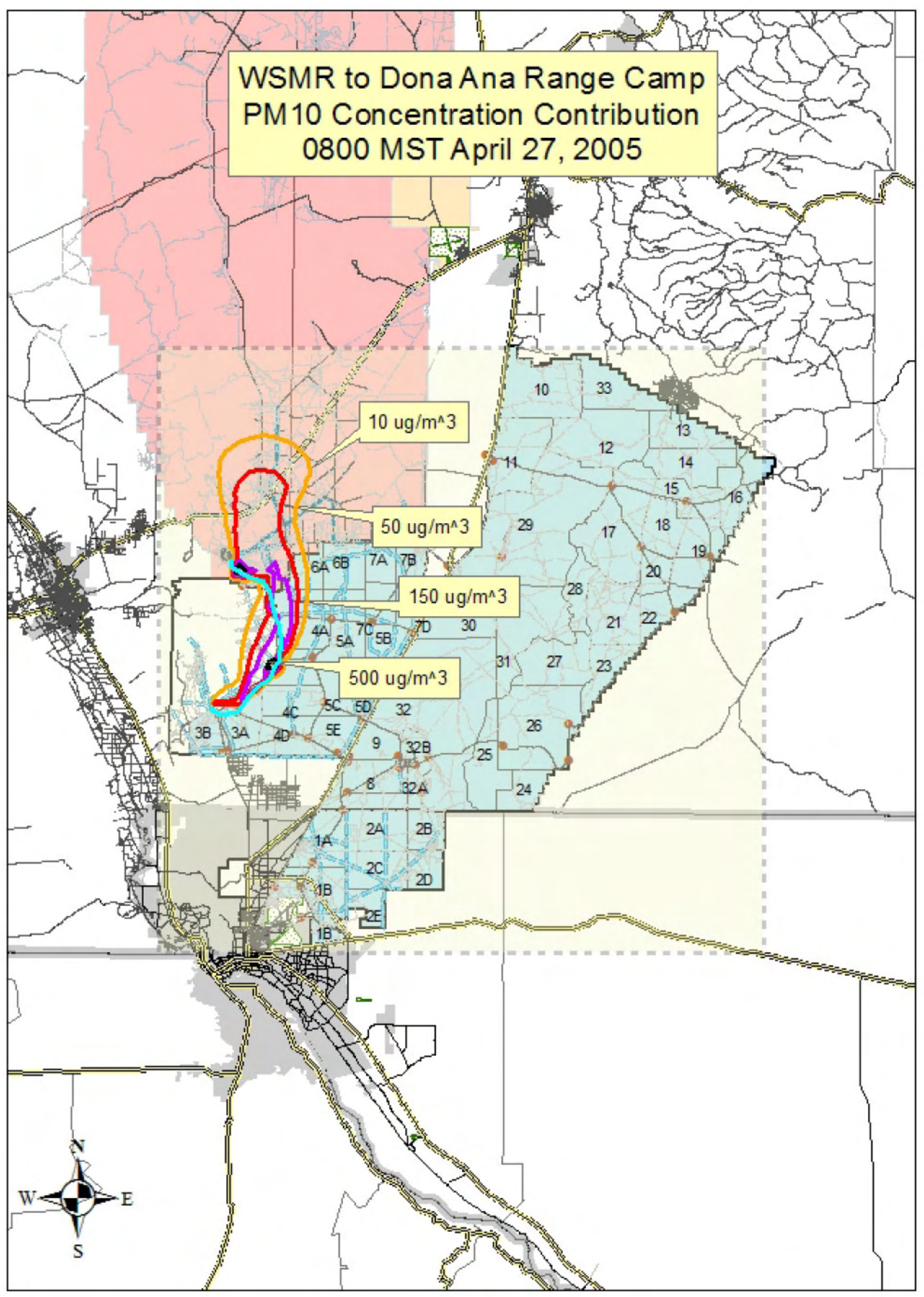




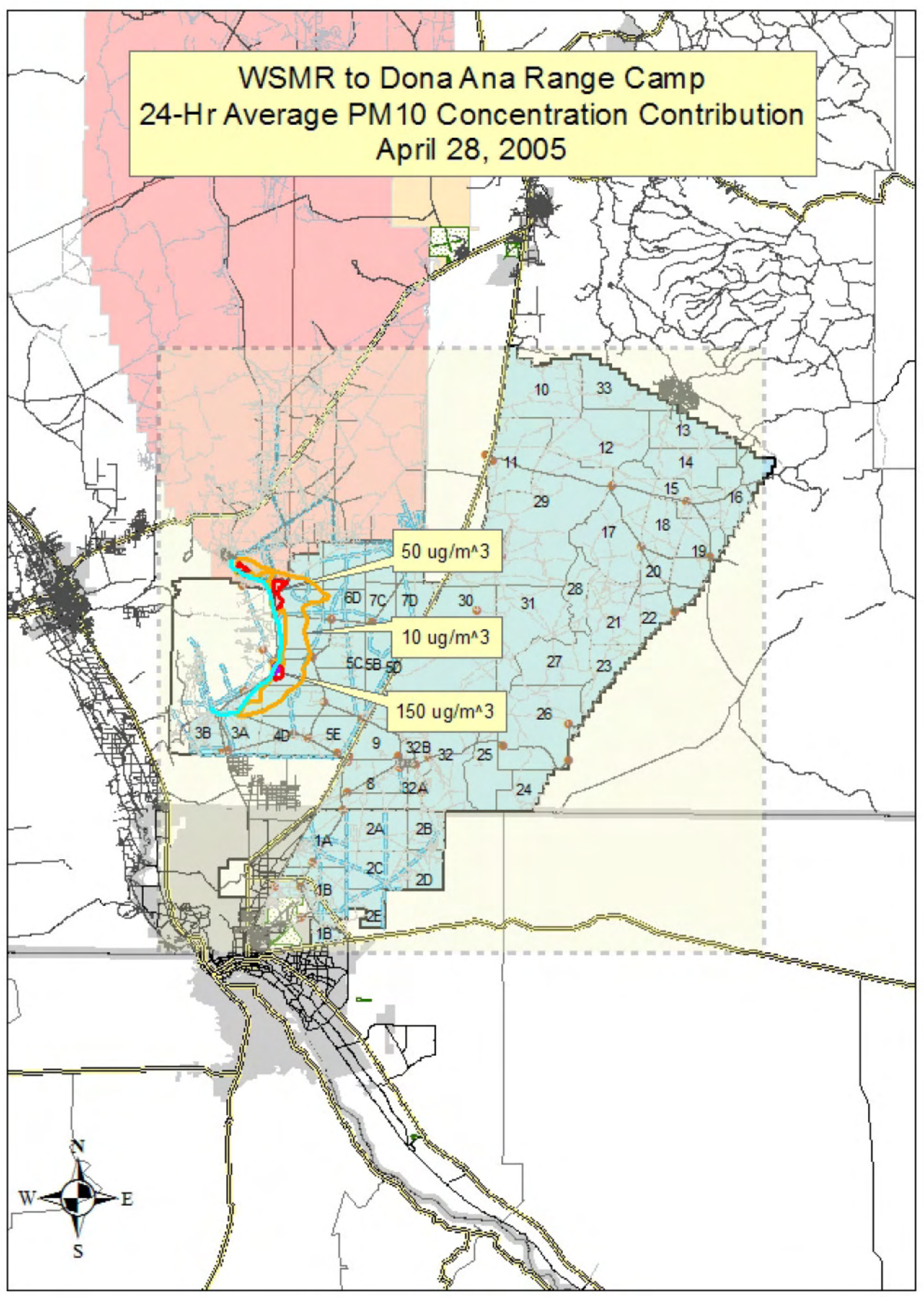




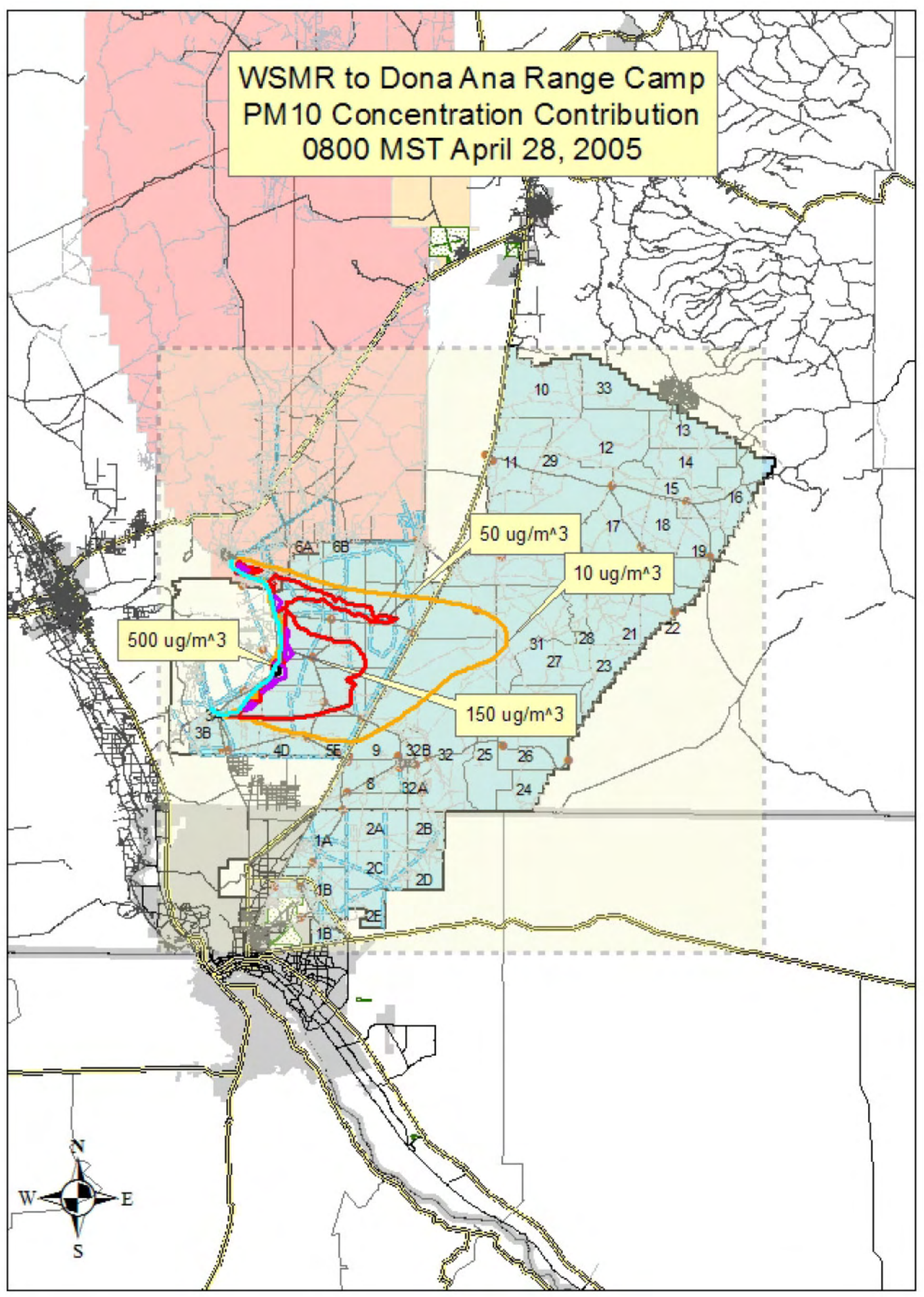




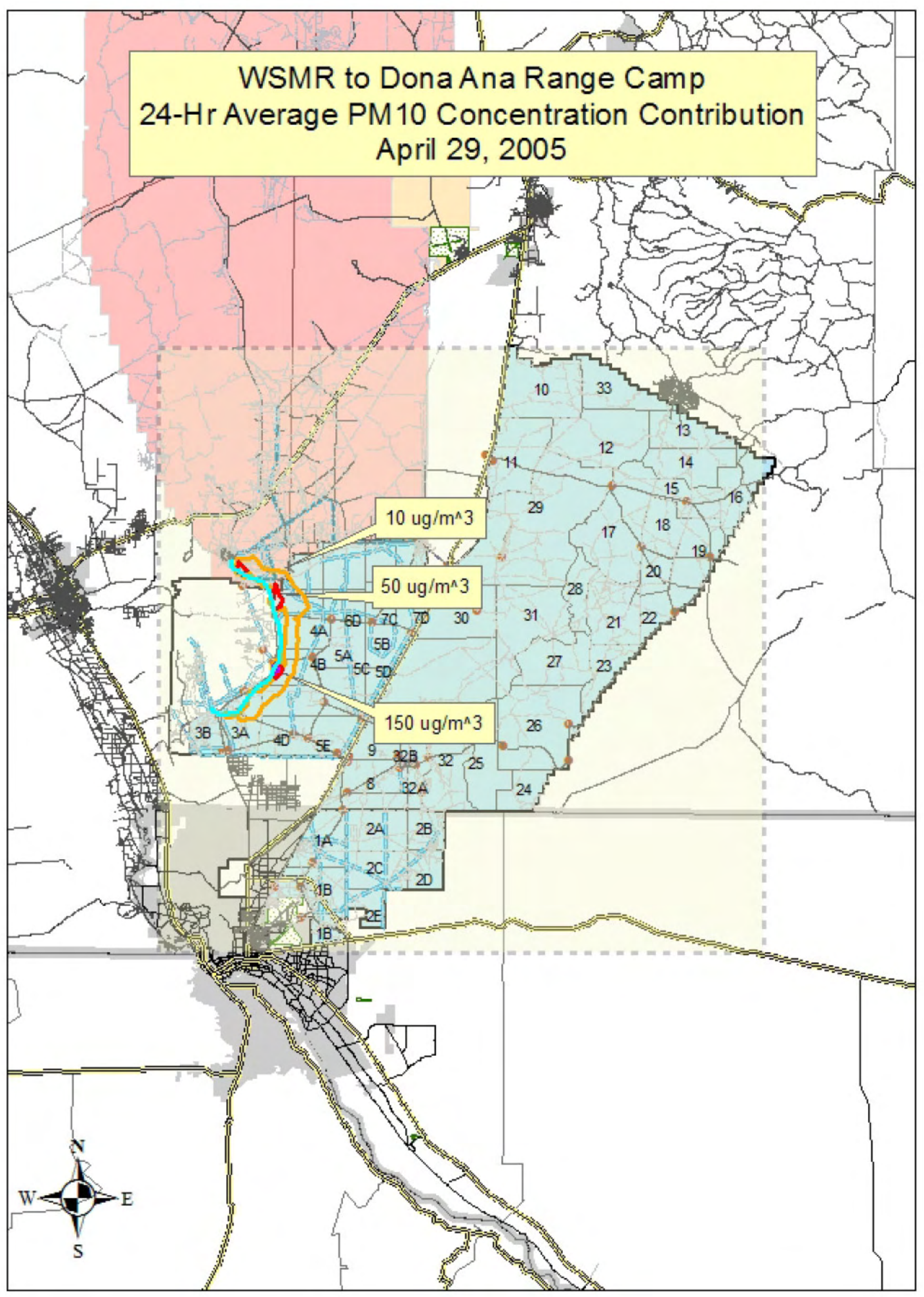




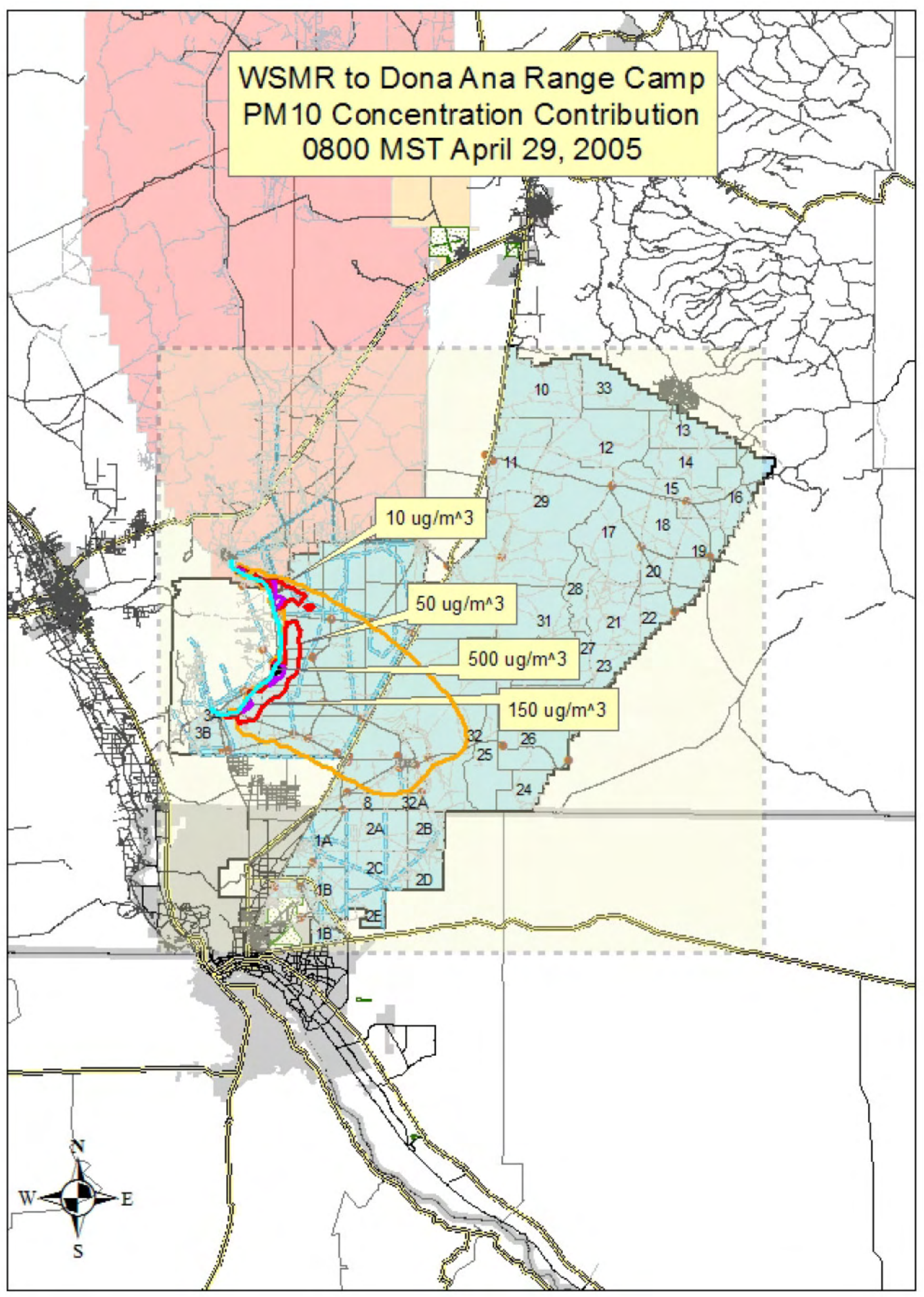




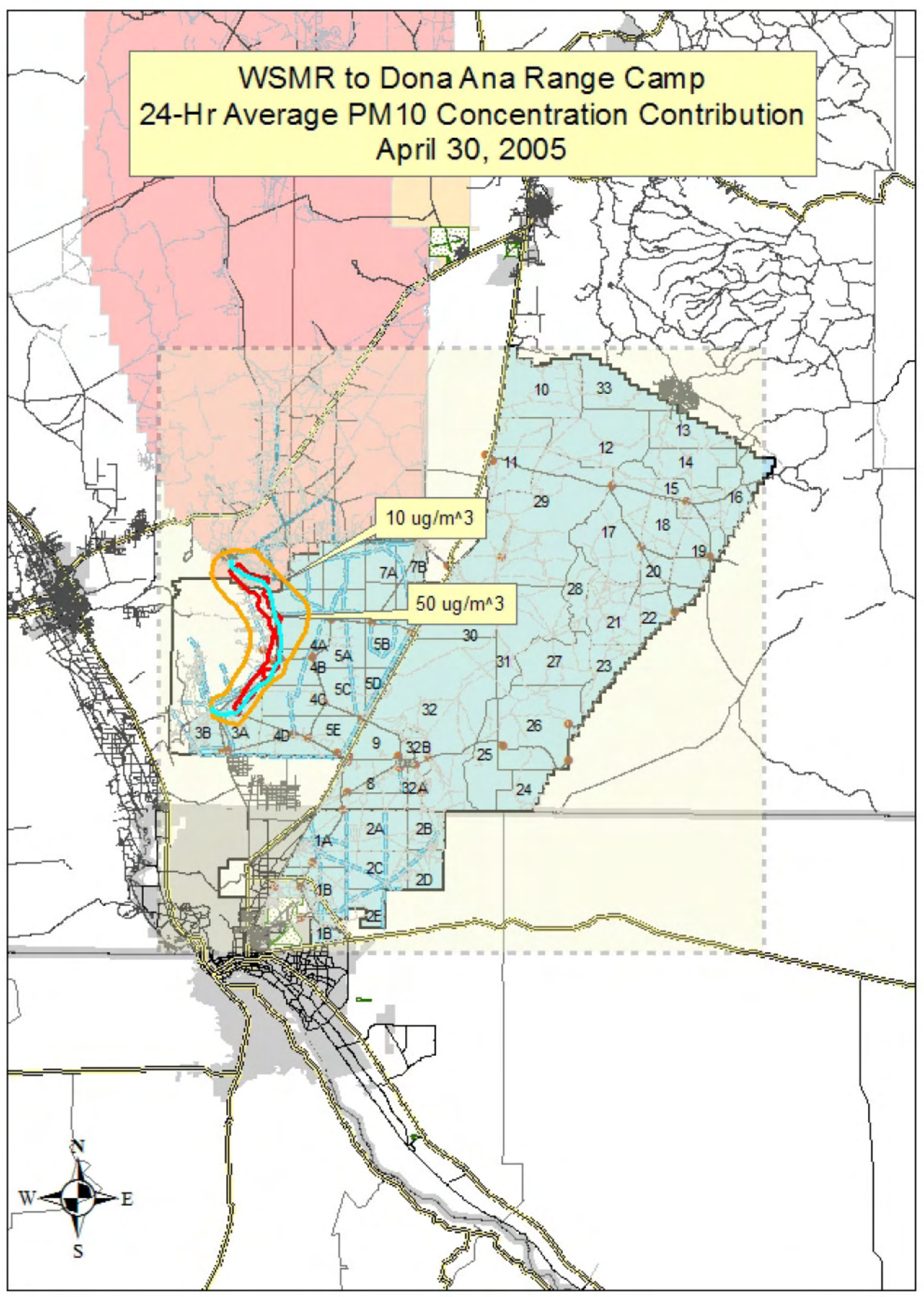




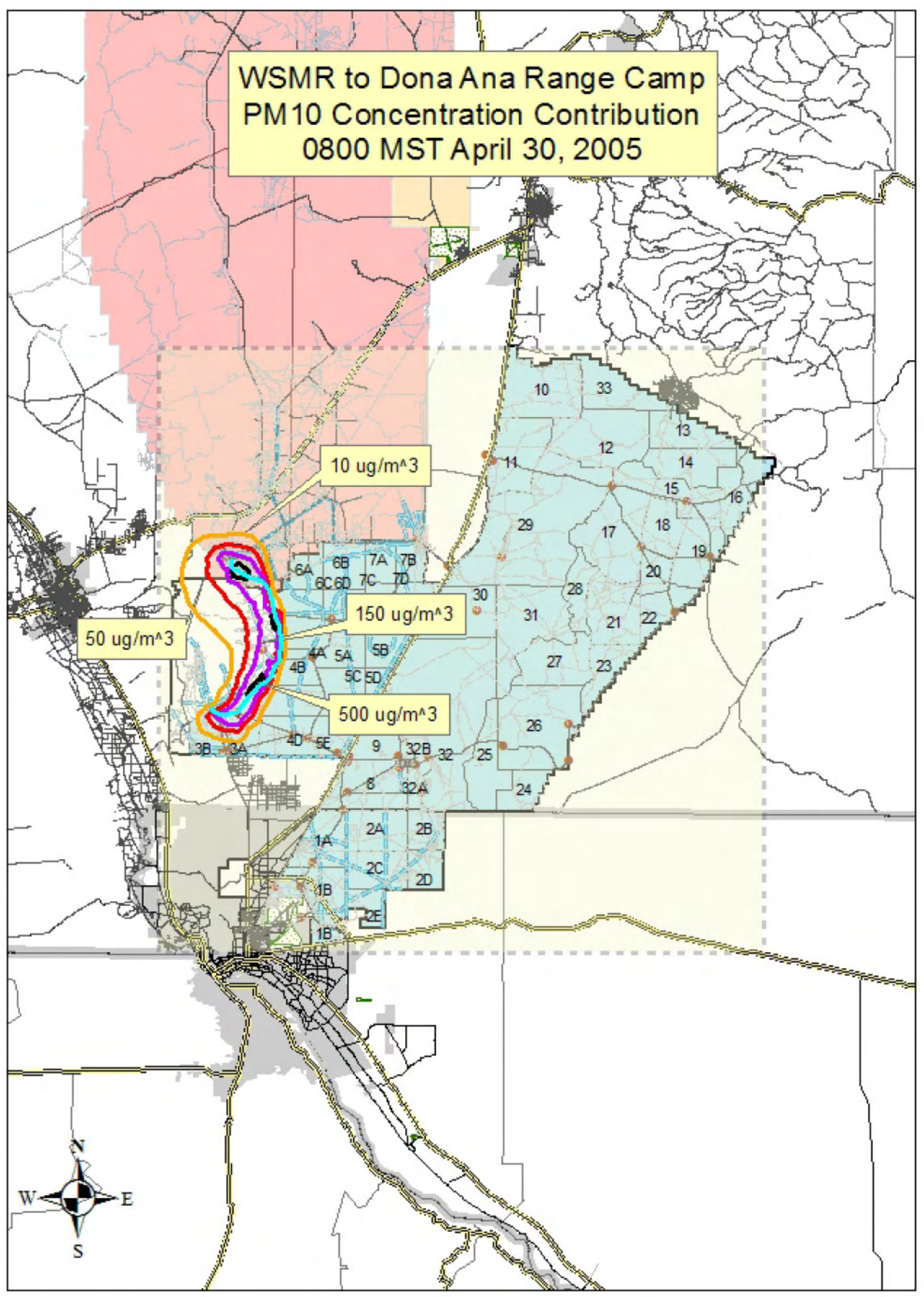




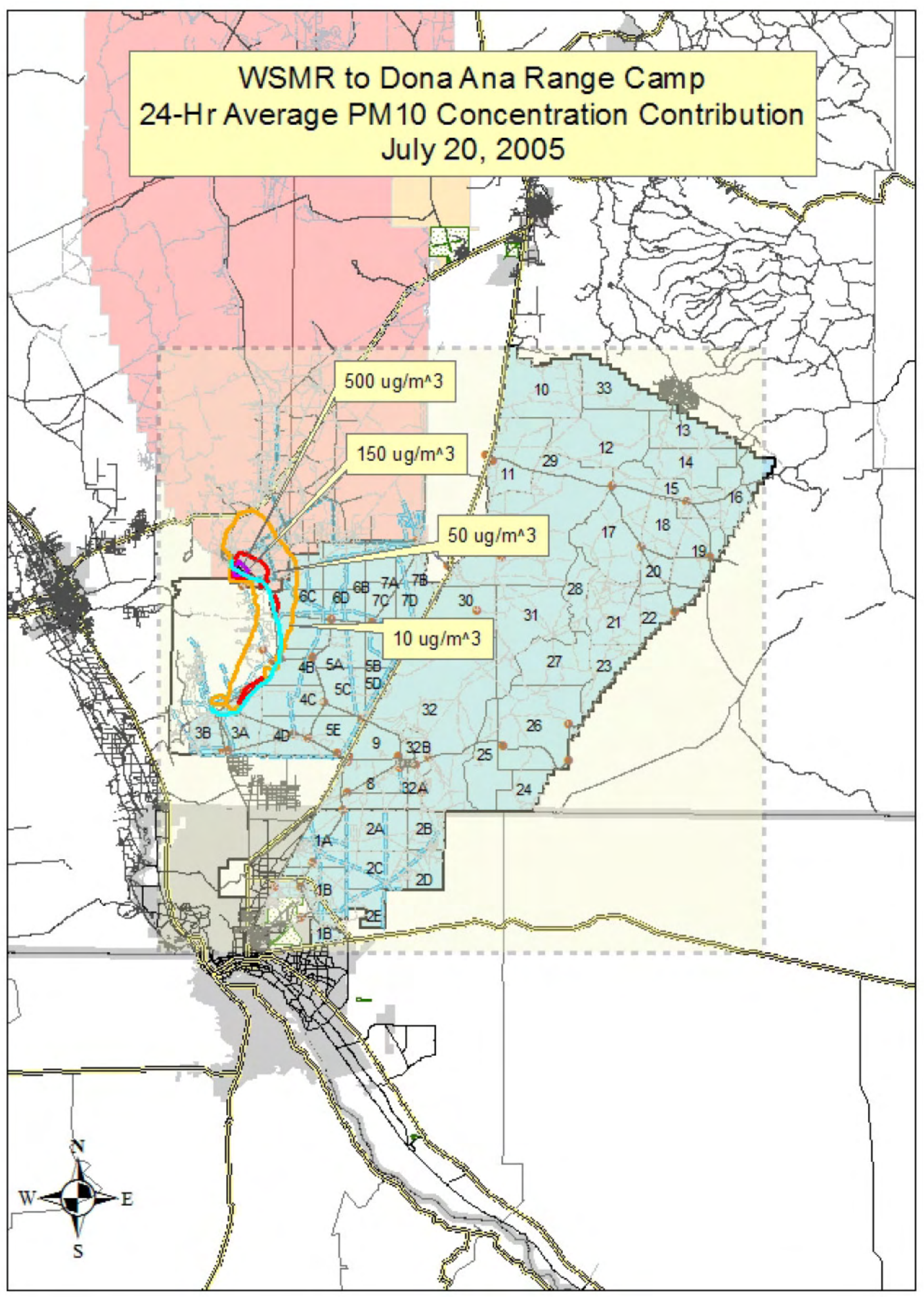




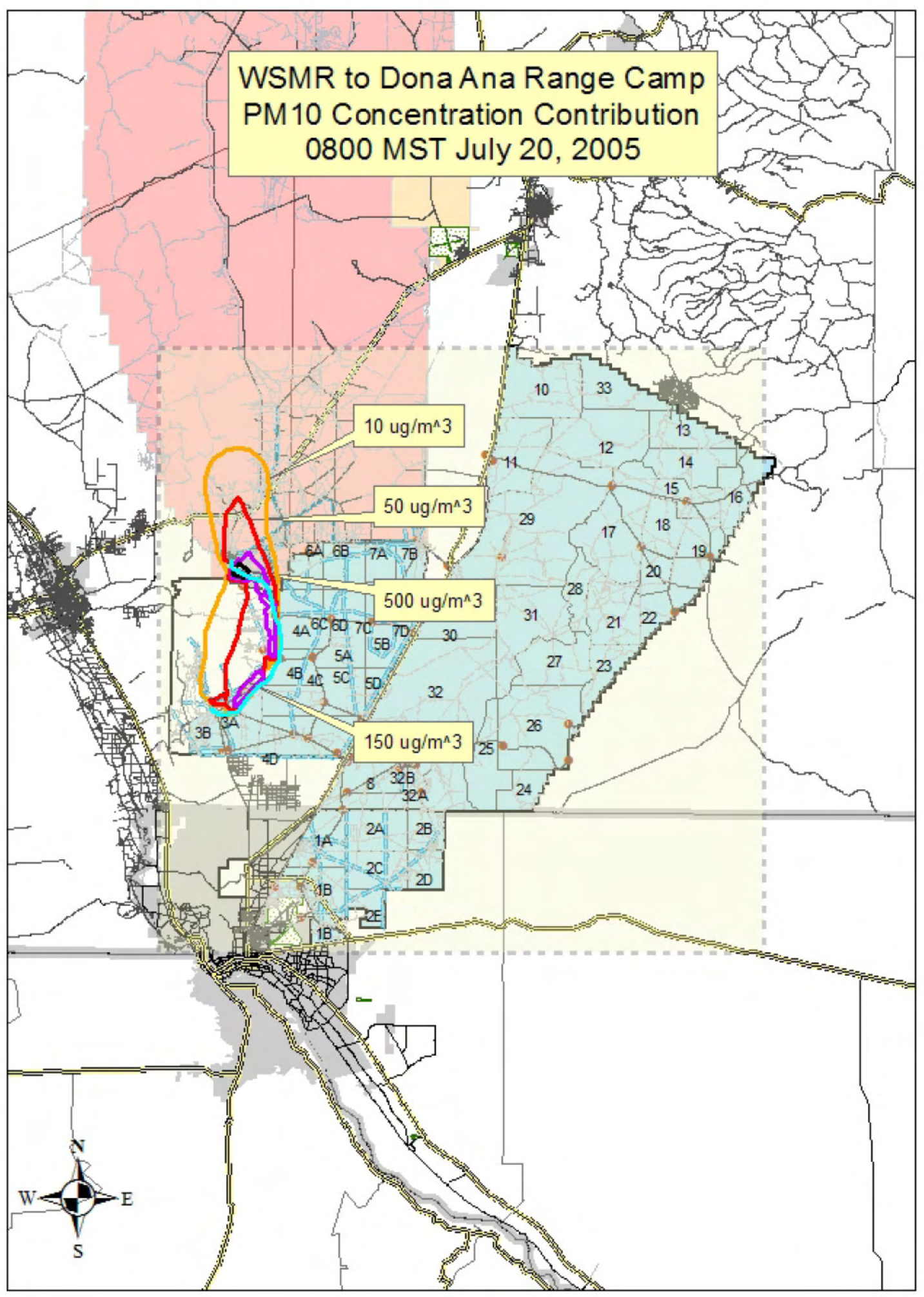




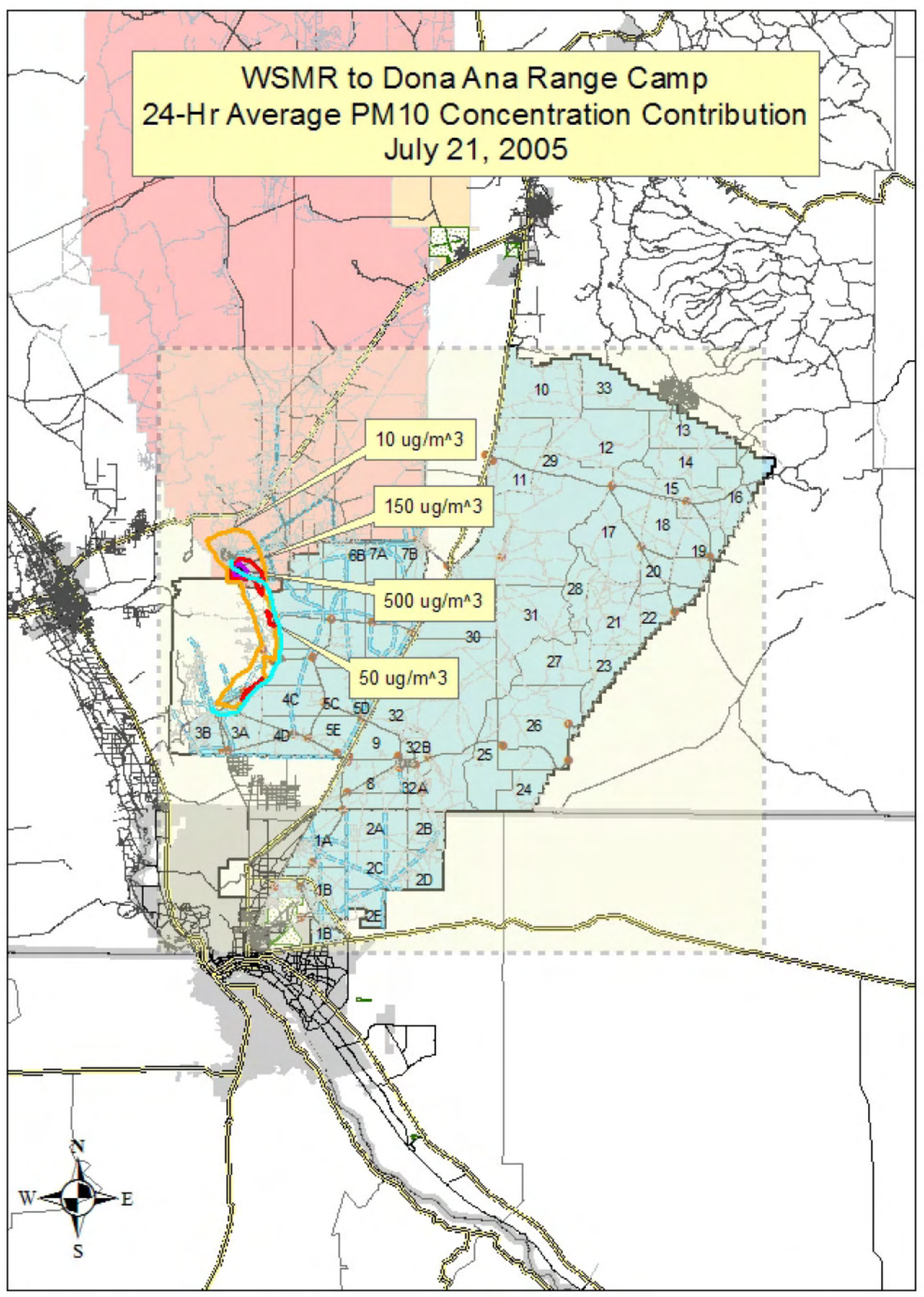




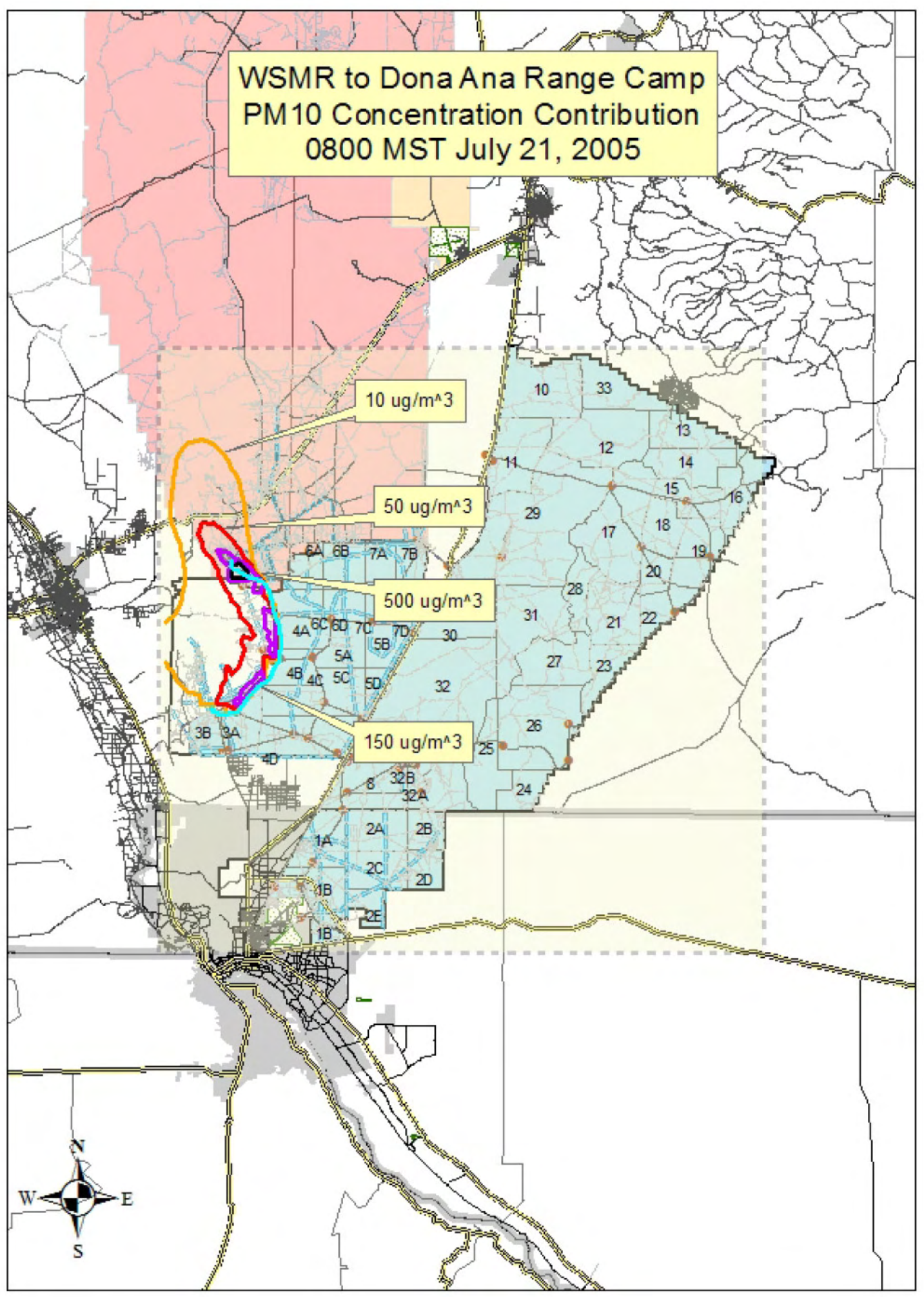




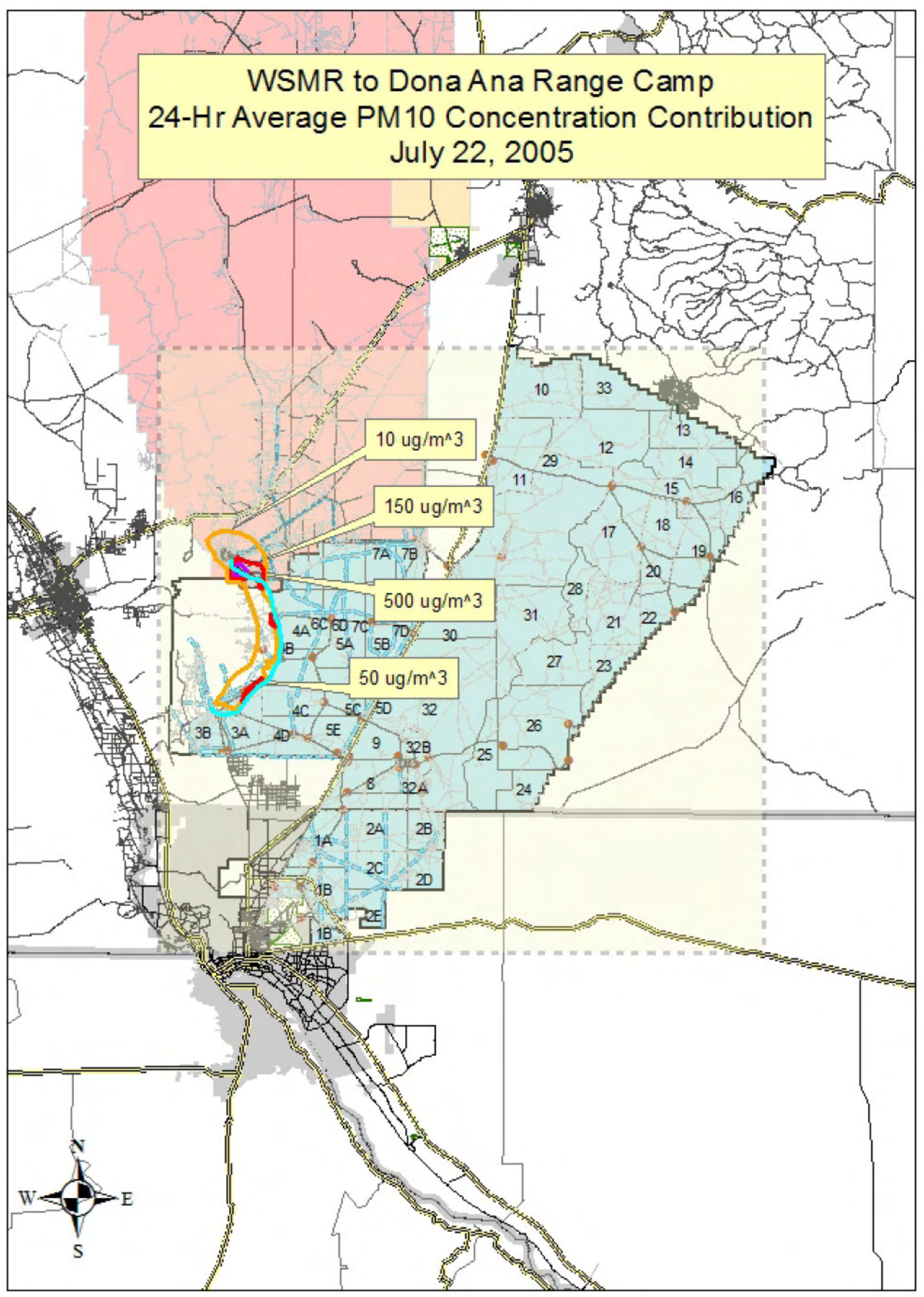




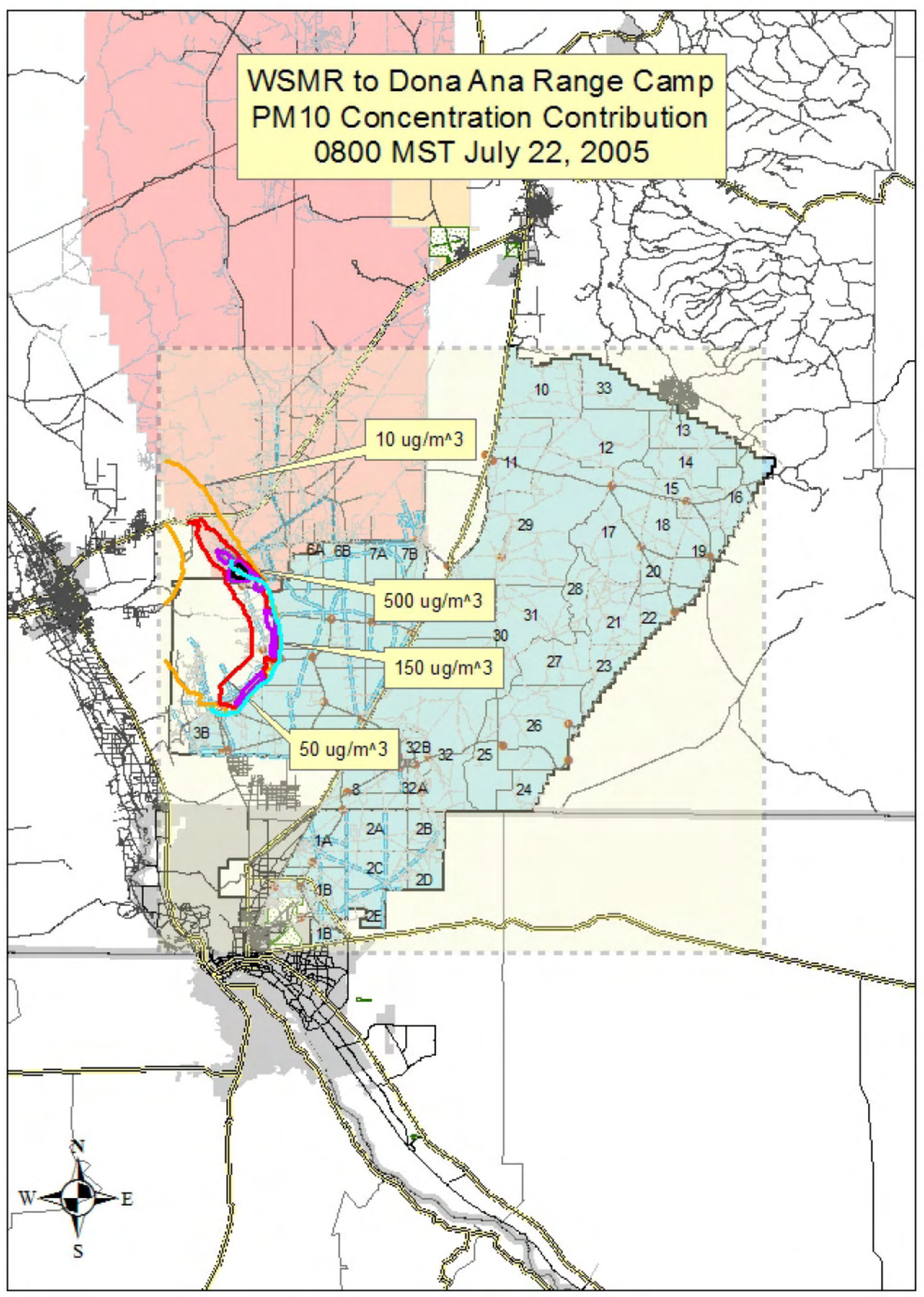




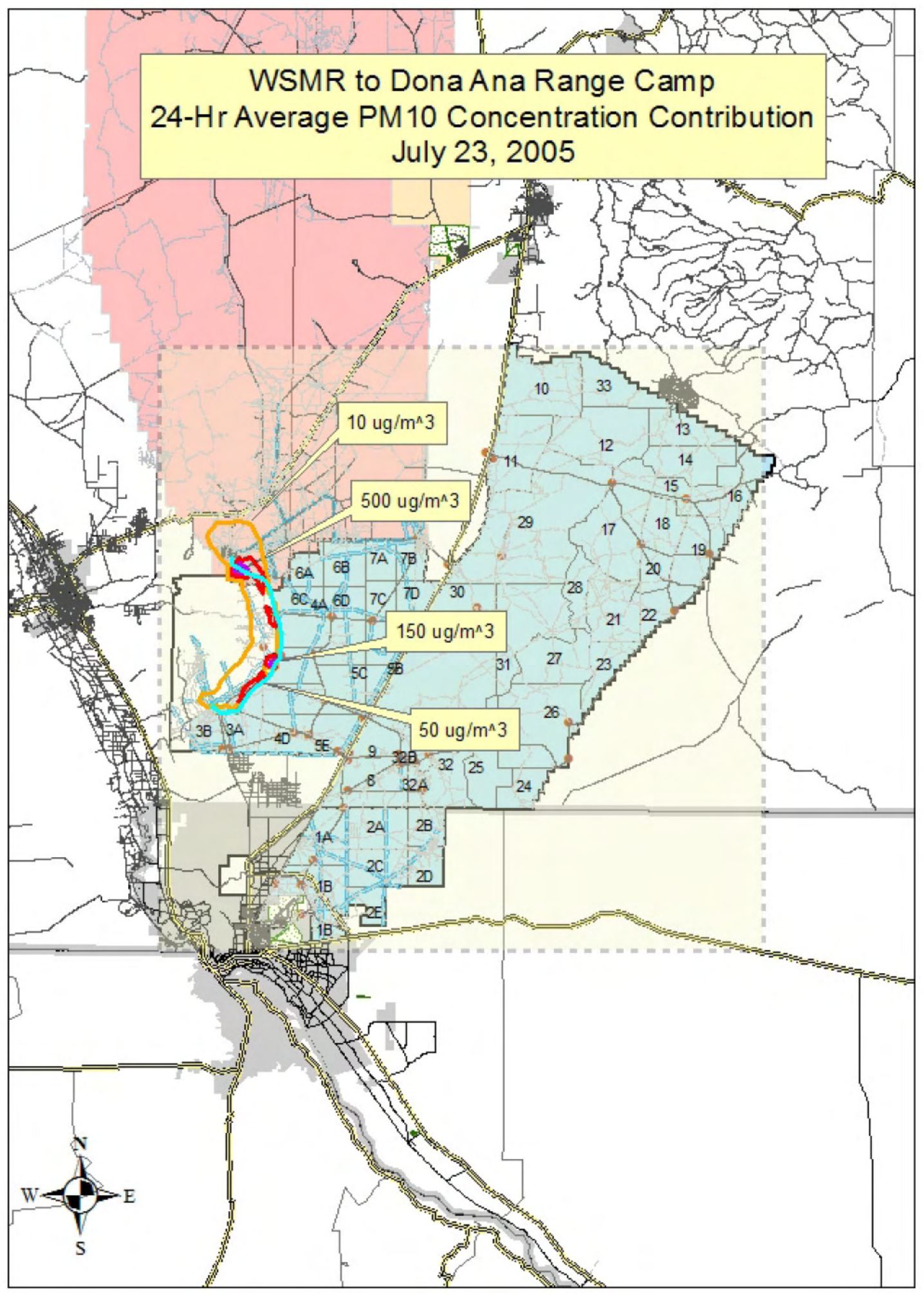




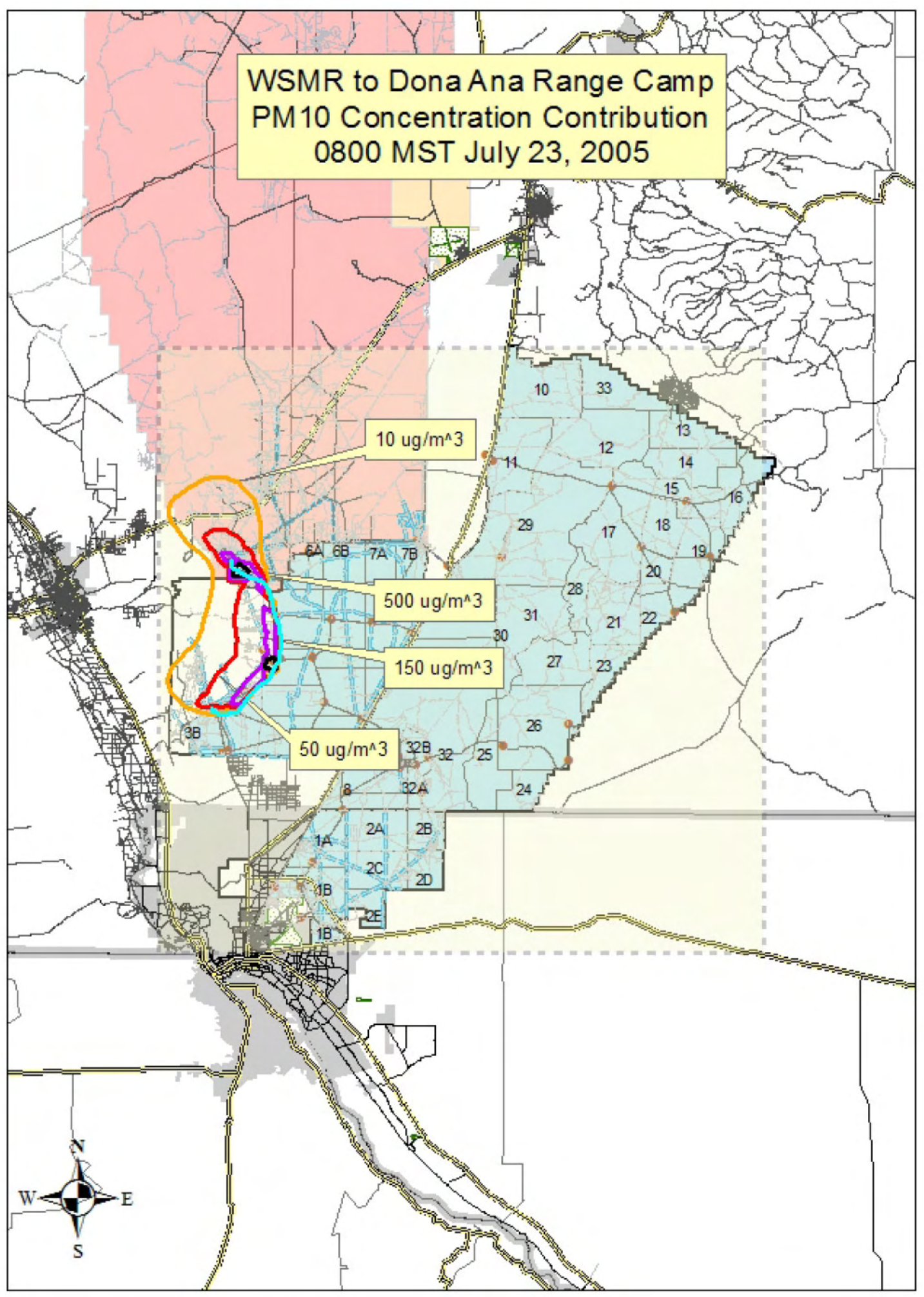




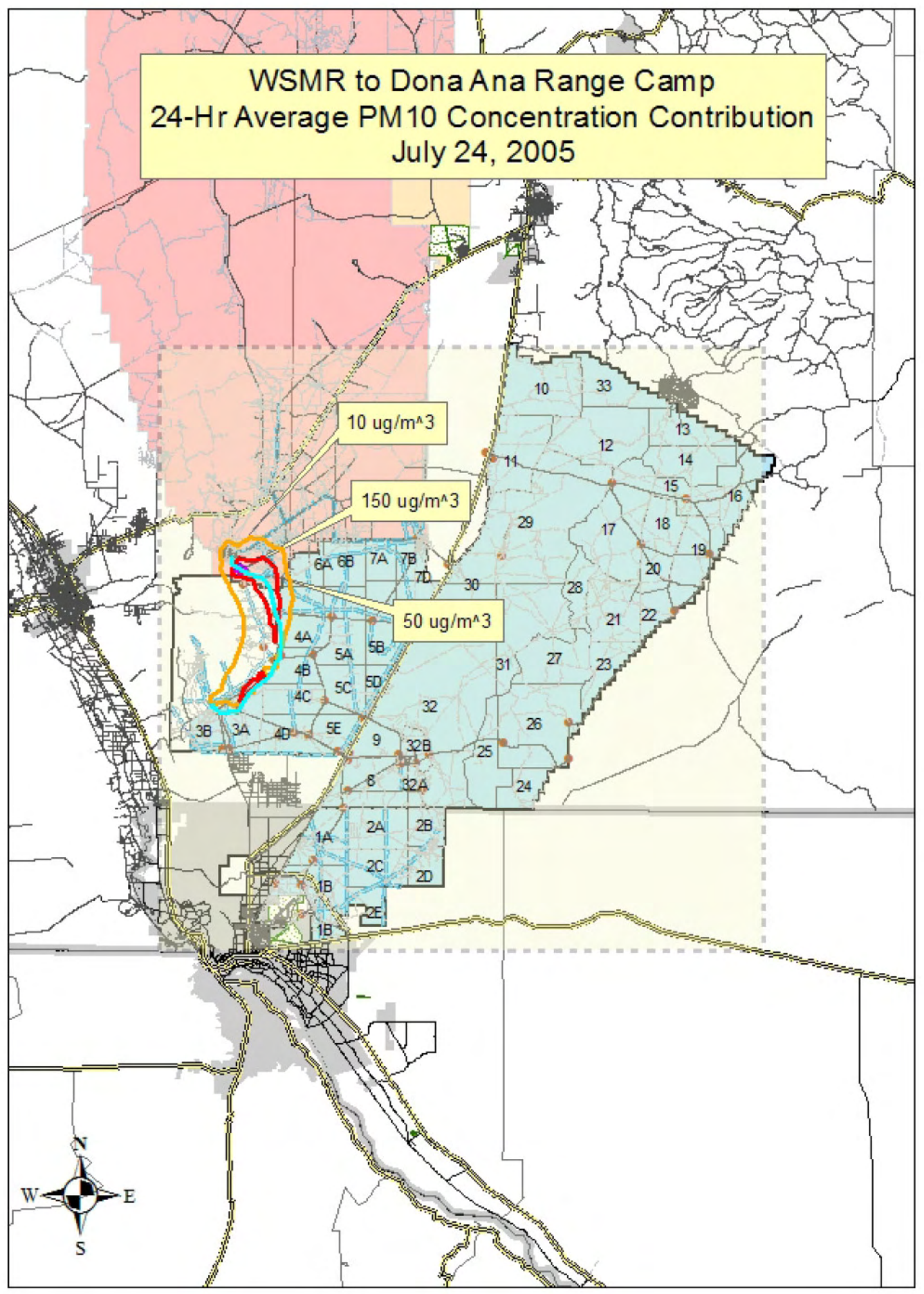




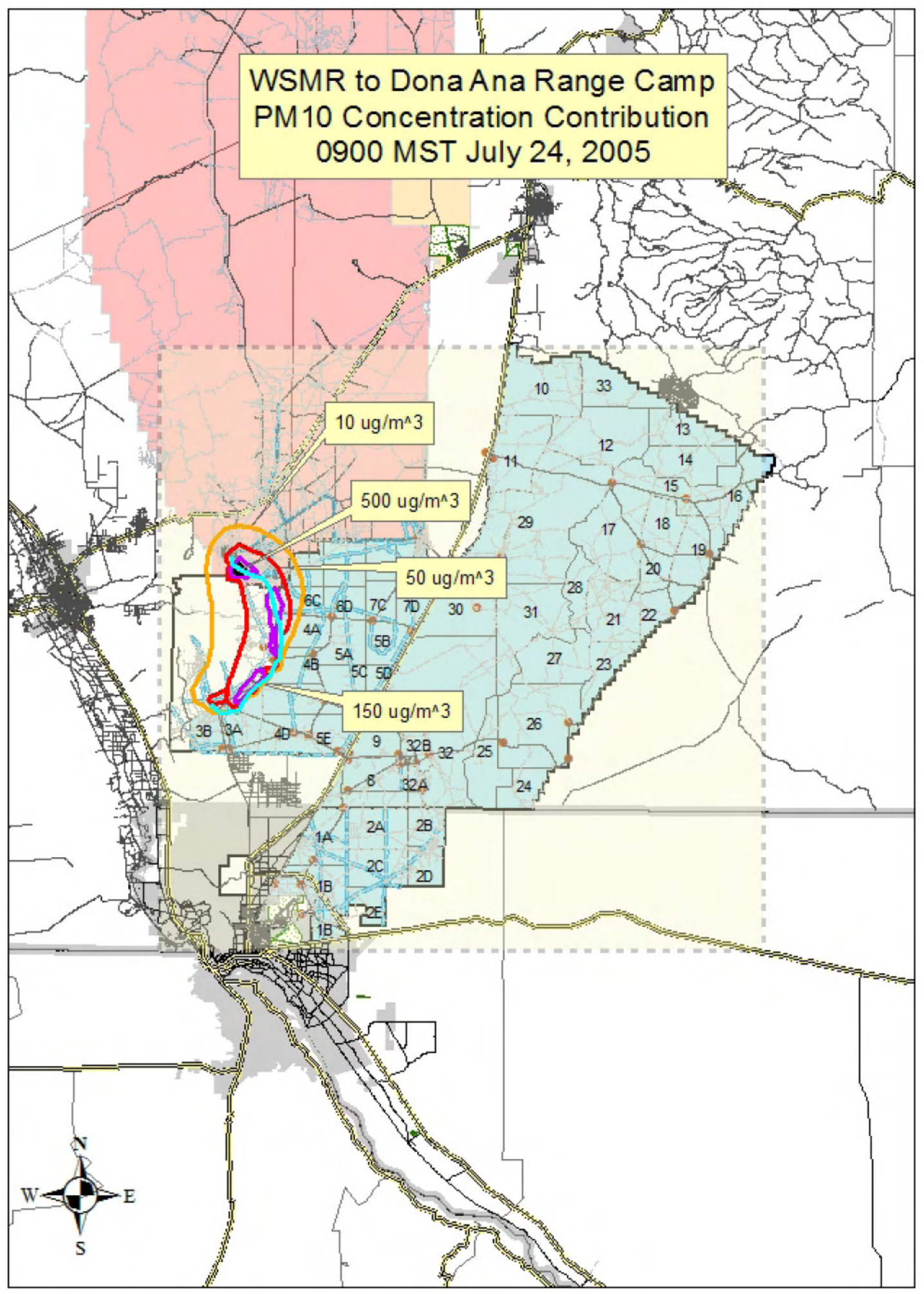




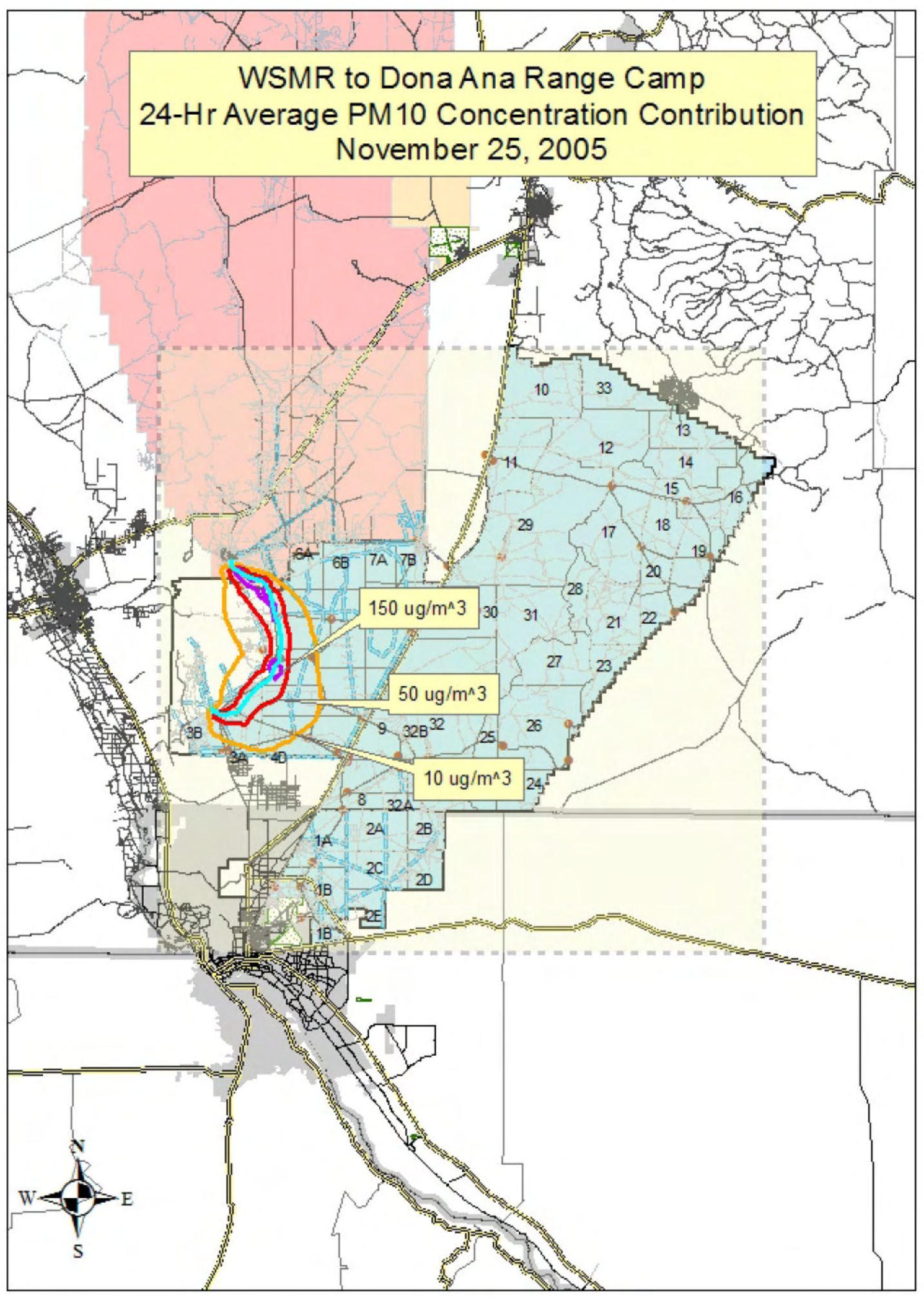




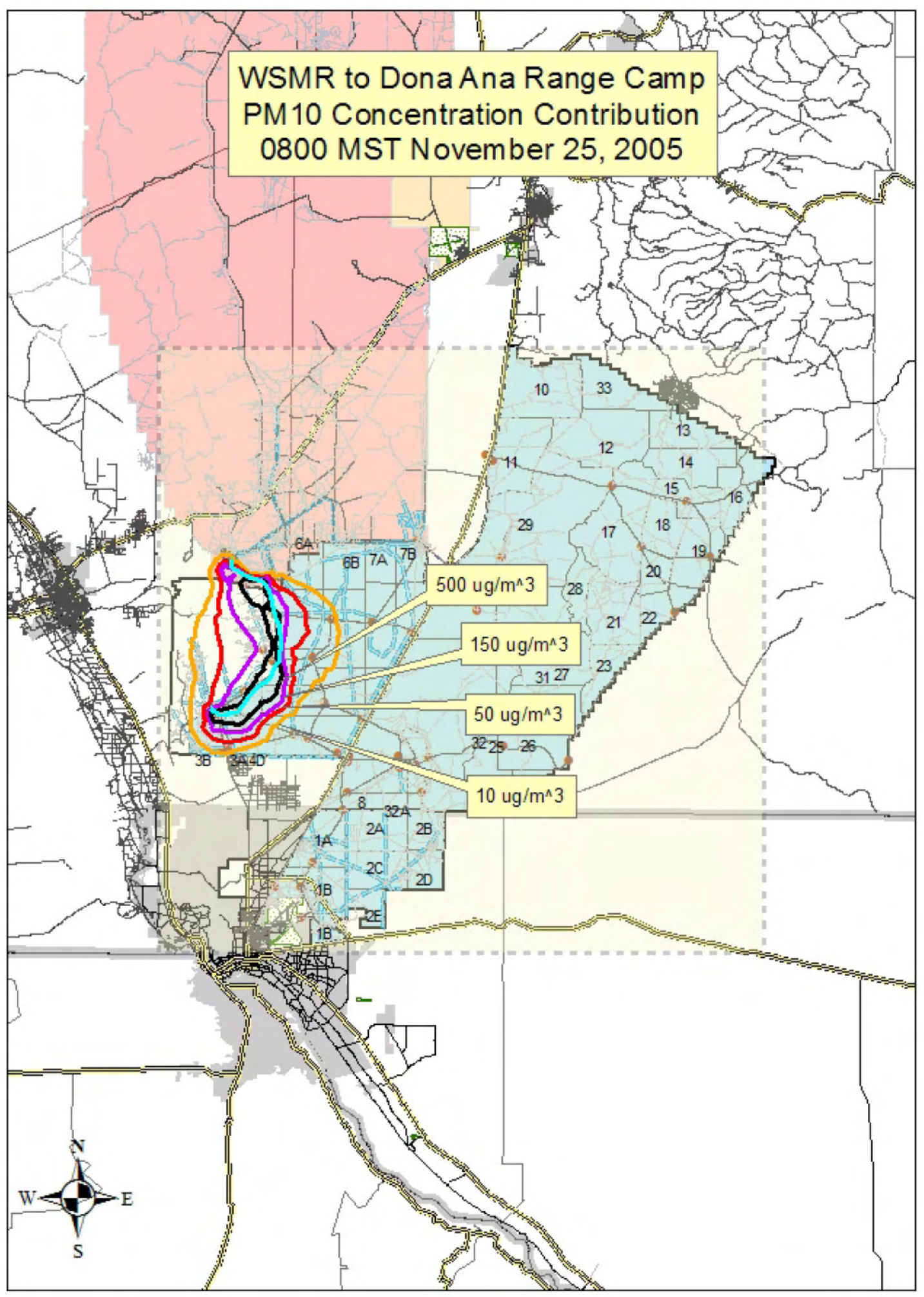




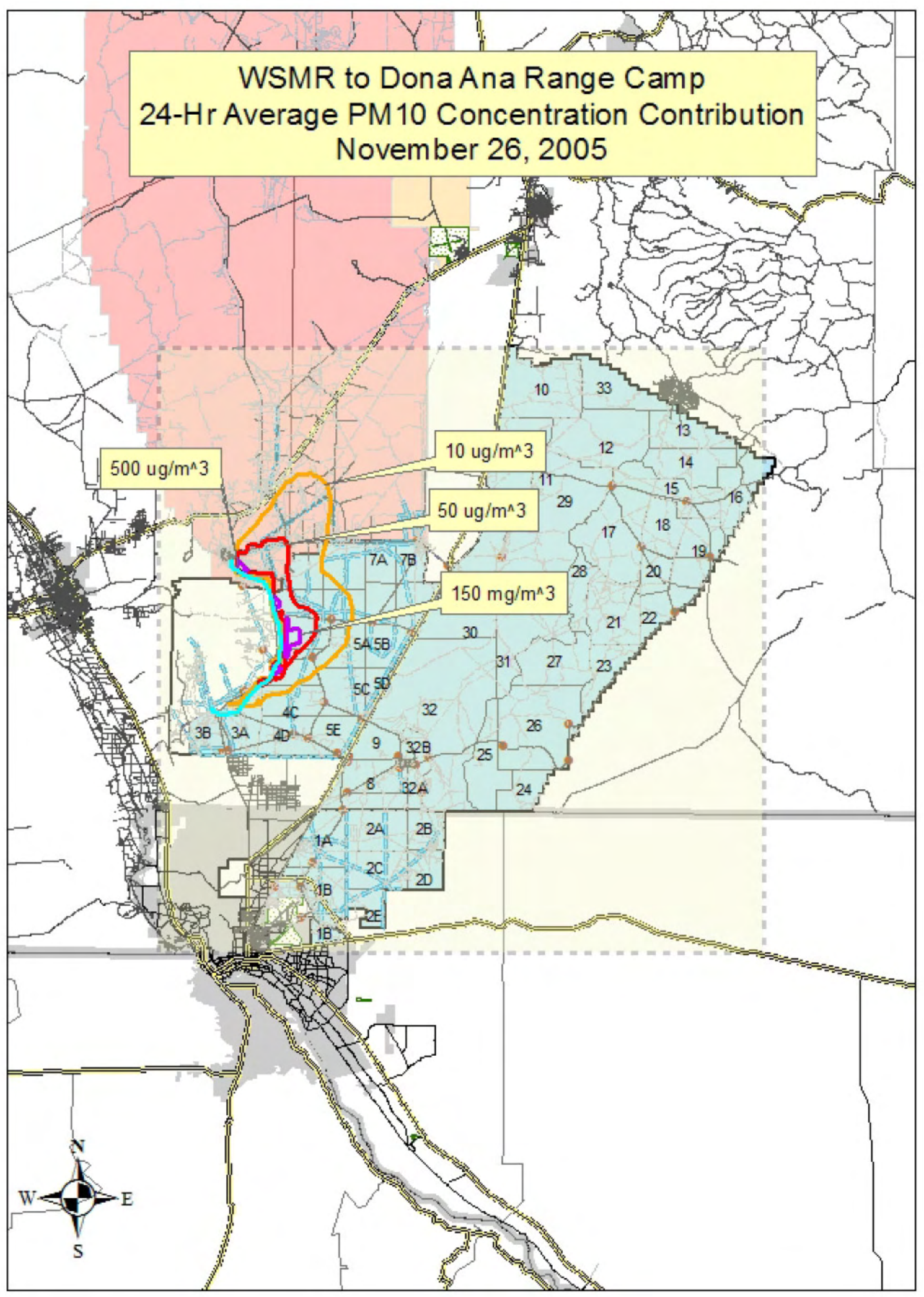




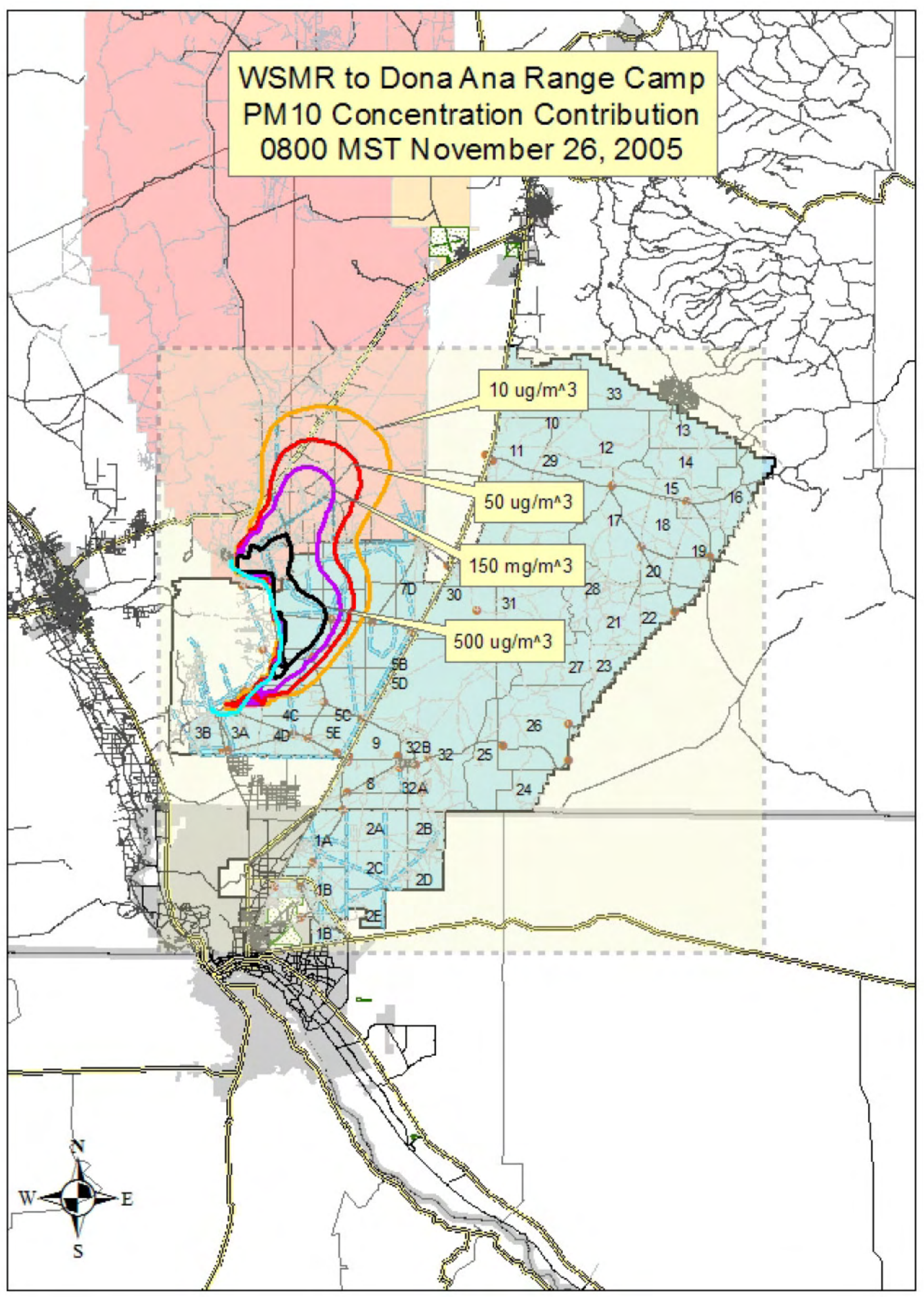




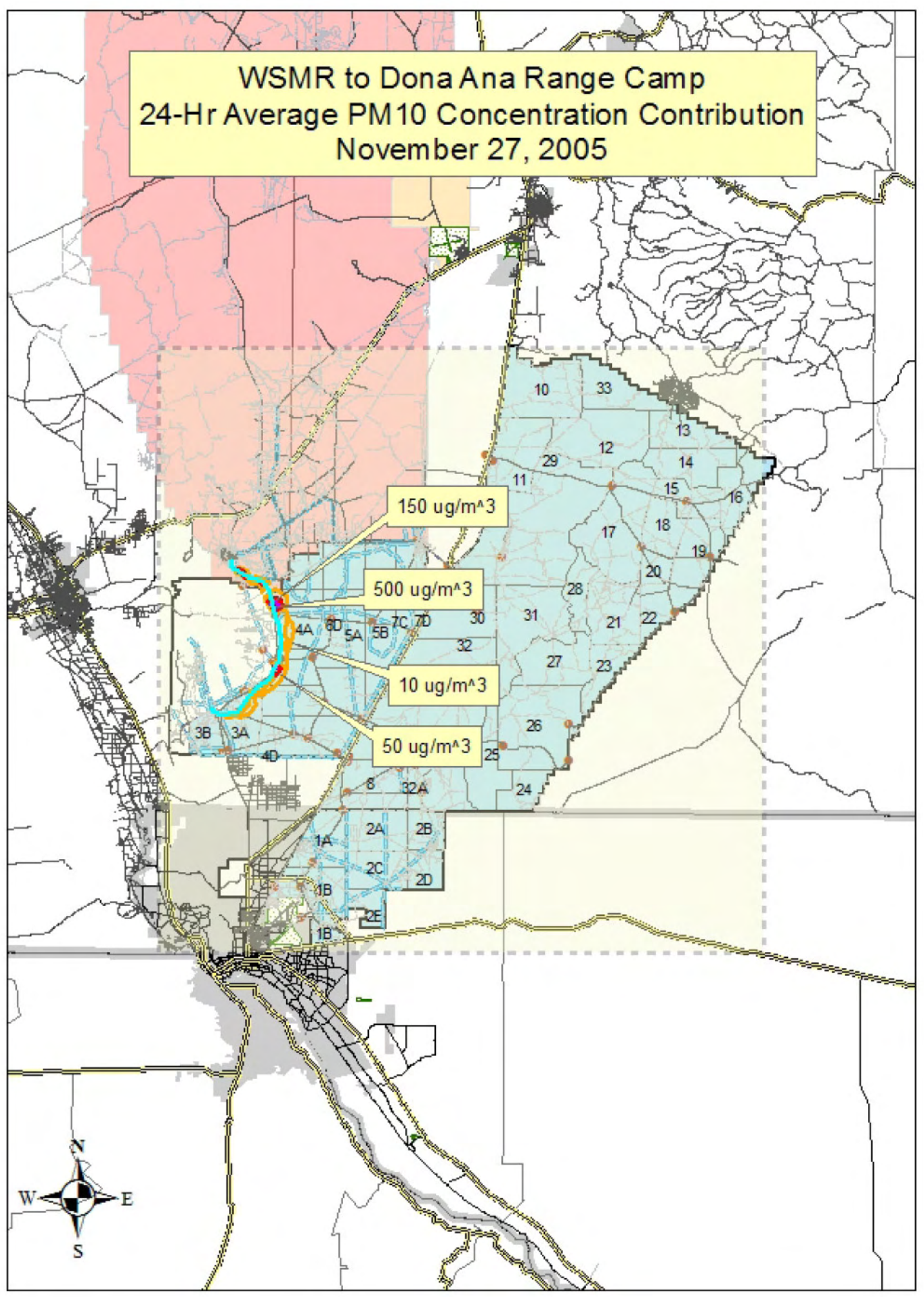




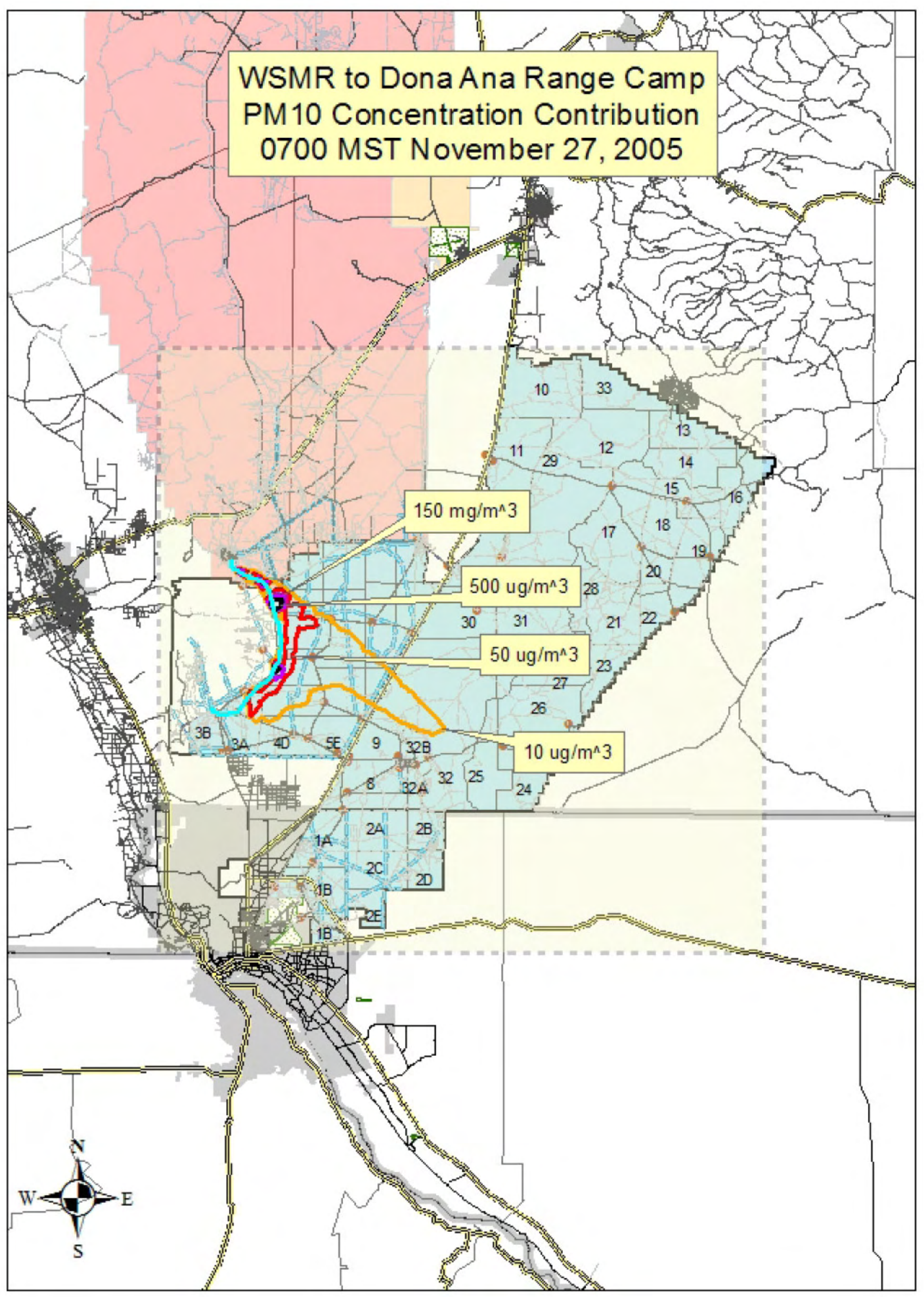




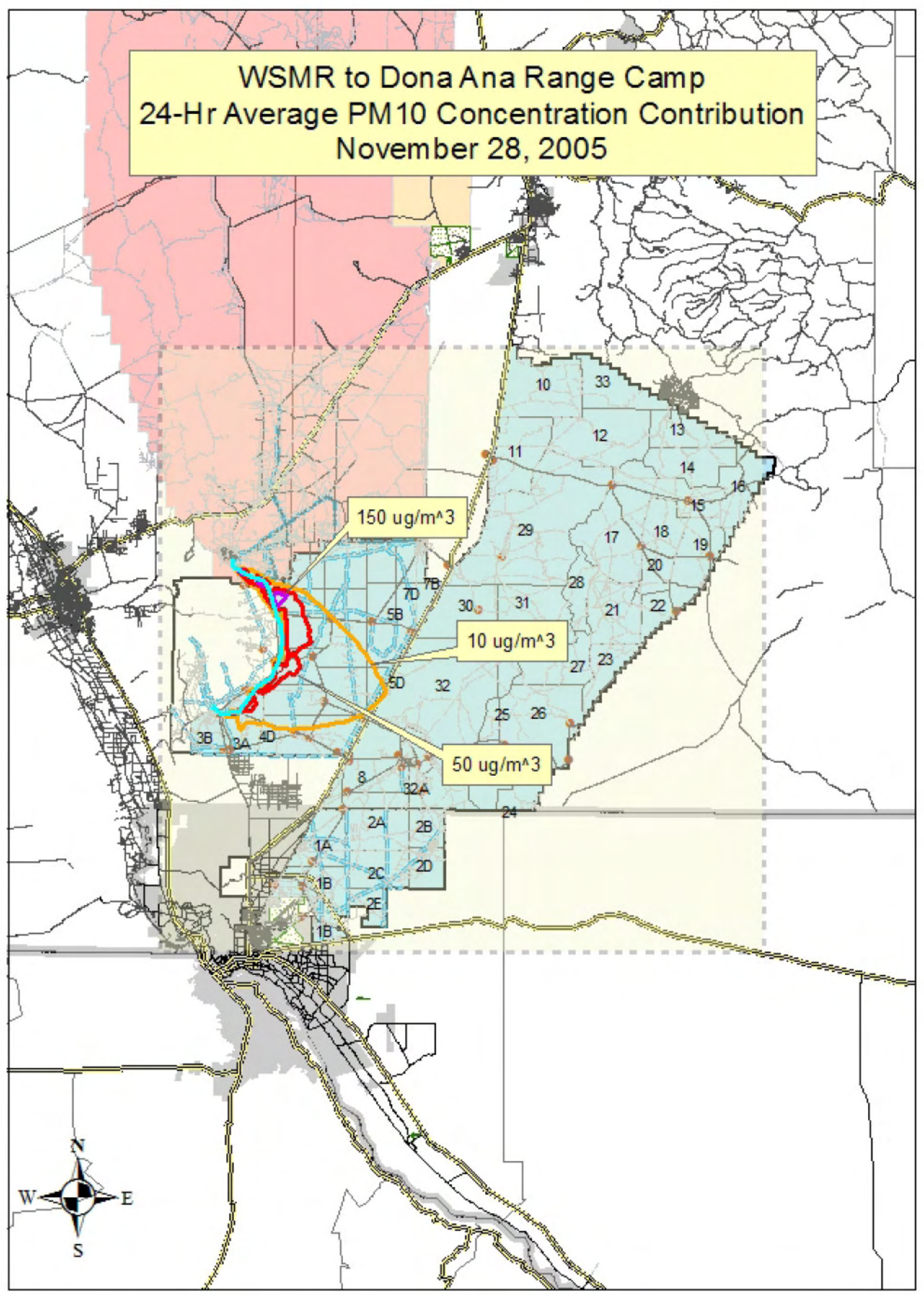




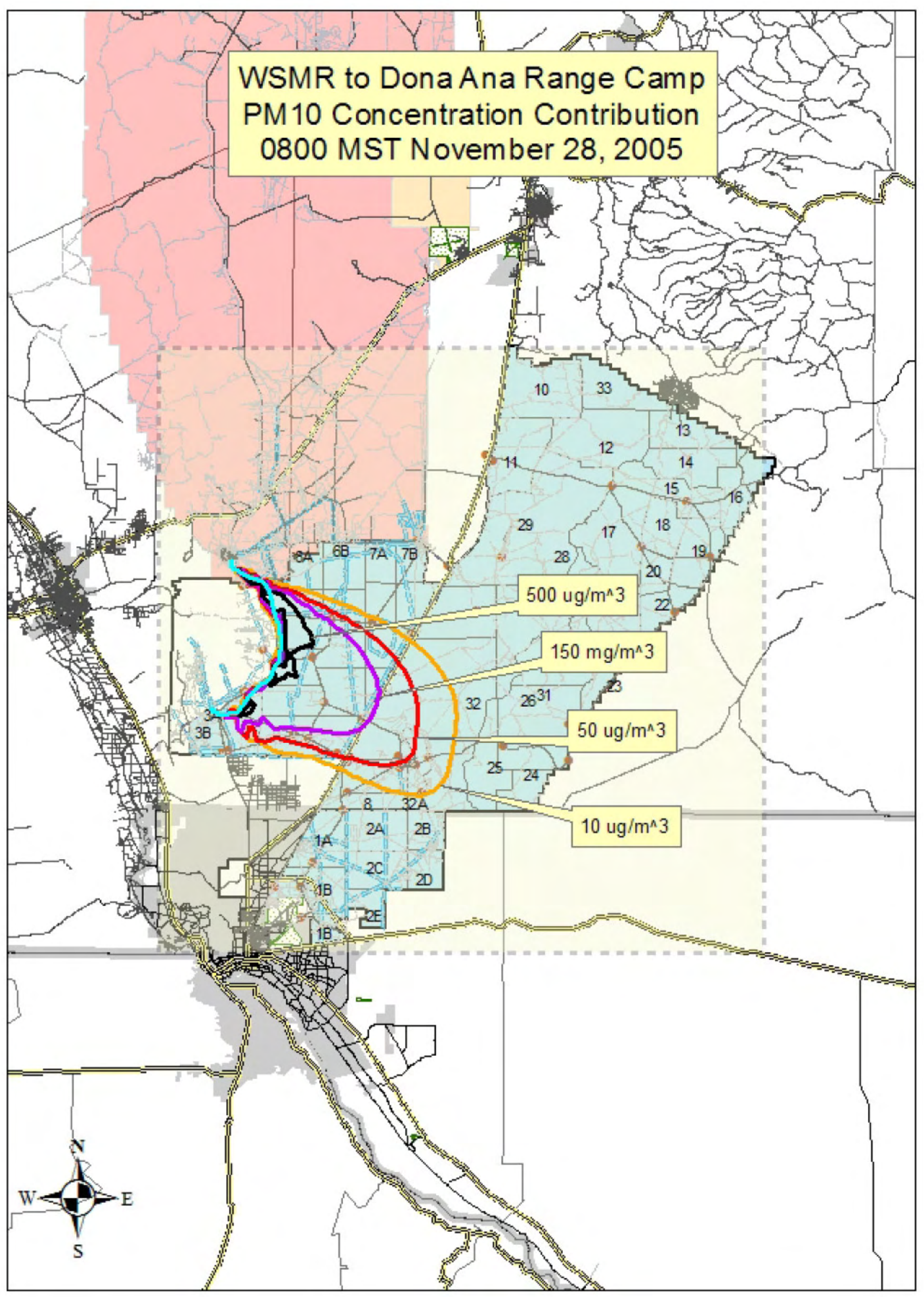




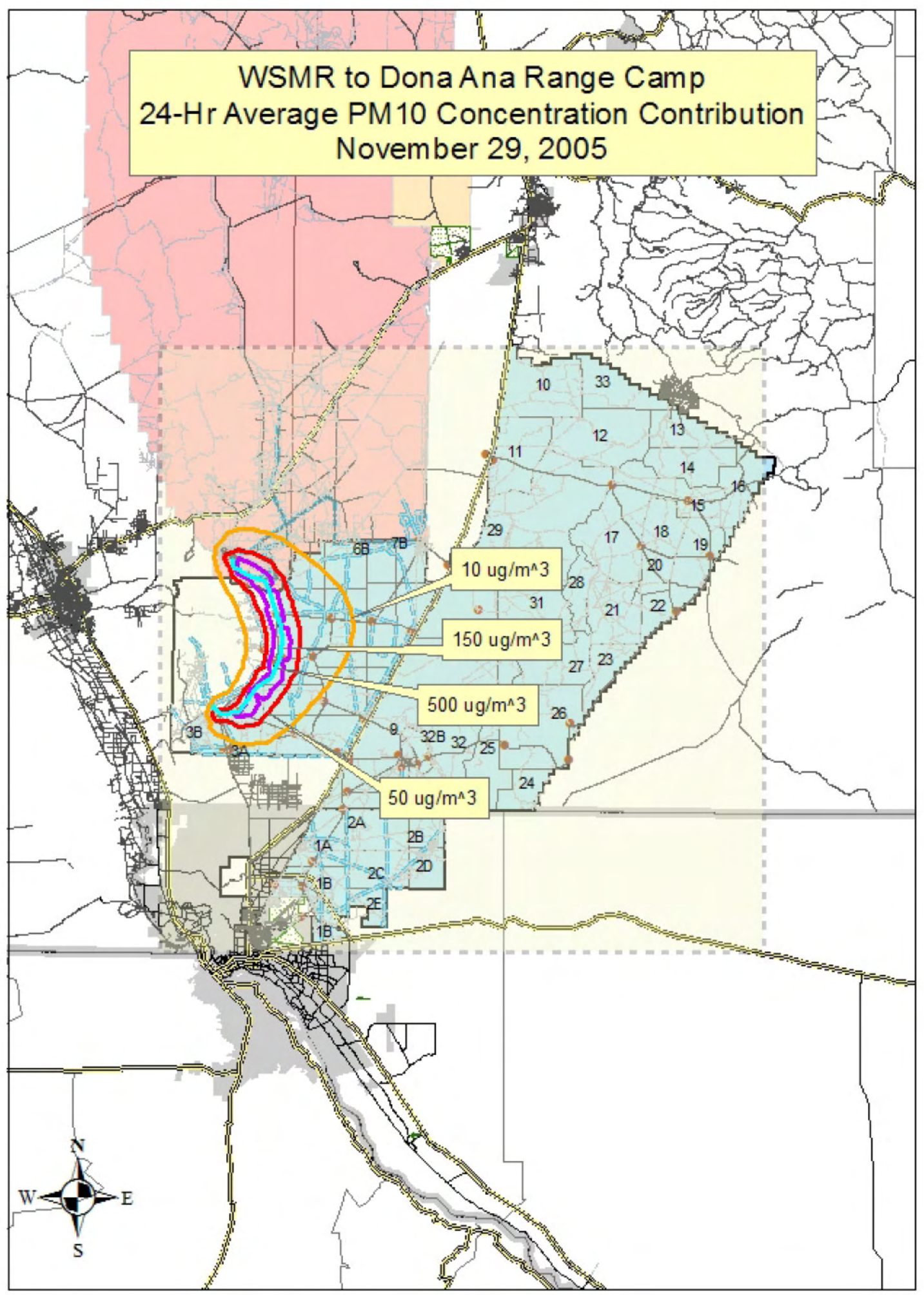




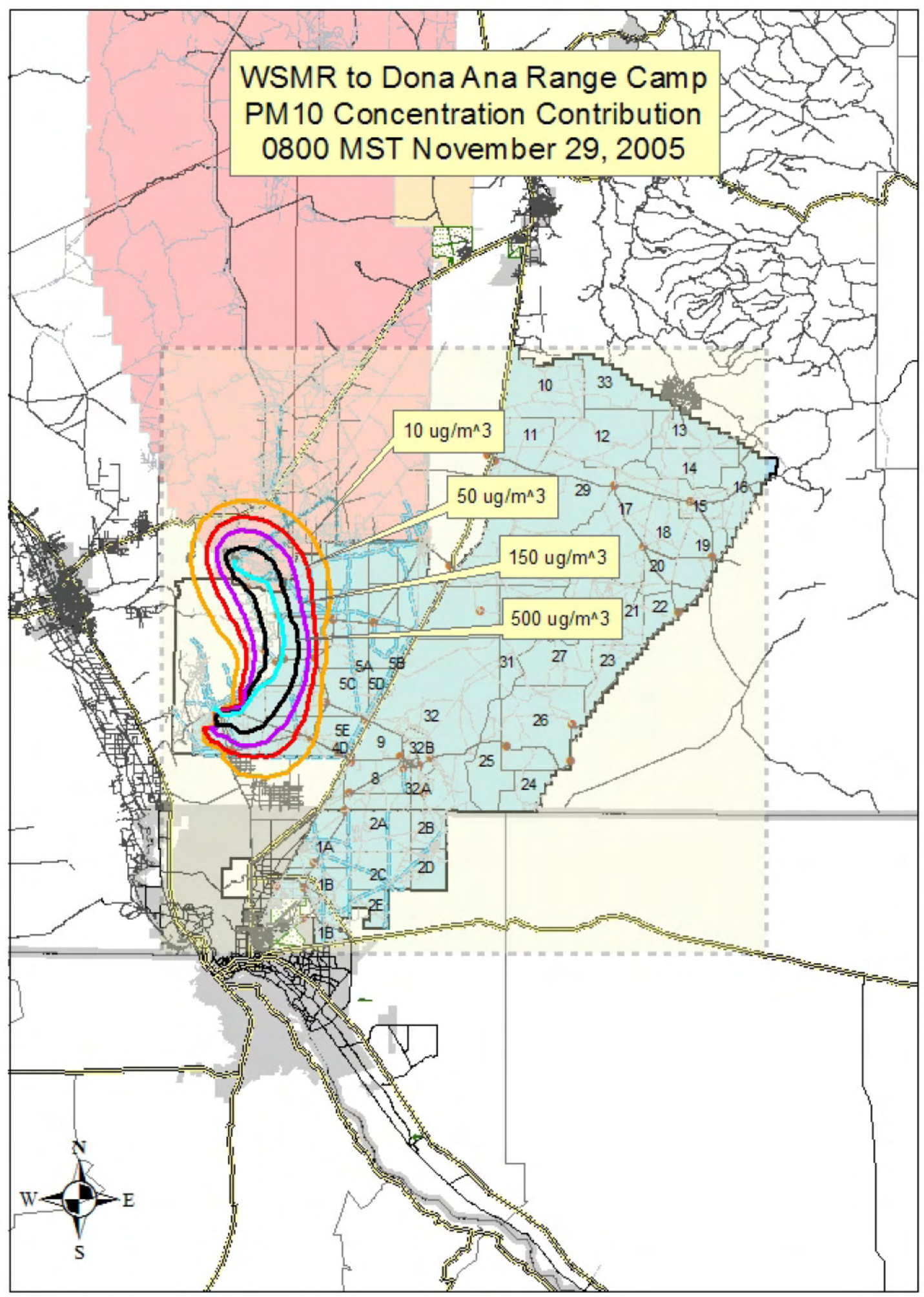





\section{Appendix C}

Simulated $\mathrm{PM}_{10}$ Concentrations for the Move-out from White Sands Missile Range to Range $\mathbf{4 0}$ 



\section{Appendix C}

\section{Simulated $\mathrm{PM}_{10}$ Concentrations for the Move-out from White Sands Missile Range to Range $\mathbf{4 0}$}

The following pages present contour maps of simulated PM10 concentrations contributed from WSMR to Range 40 move-out operations to air quality in and around Fort Bliss and WSMR for the 21 days (March 12-16, April 25-30, July 20-24, and November 25-29, 2005) studied in this investigation. For each day, the contour map of the 24-hour-average PM10 concentration contribution is shown first, followed by a contour map of PM10 concentration contributions for a specific hour. The hour listed in the figure header represents the start of the hour, e.g., 1000 MST means the hour from 1000 MST to 1100 MST. Move-out scenario assumptions are summarized in Section 3 of this report. 


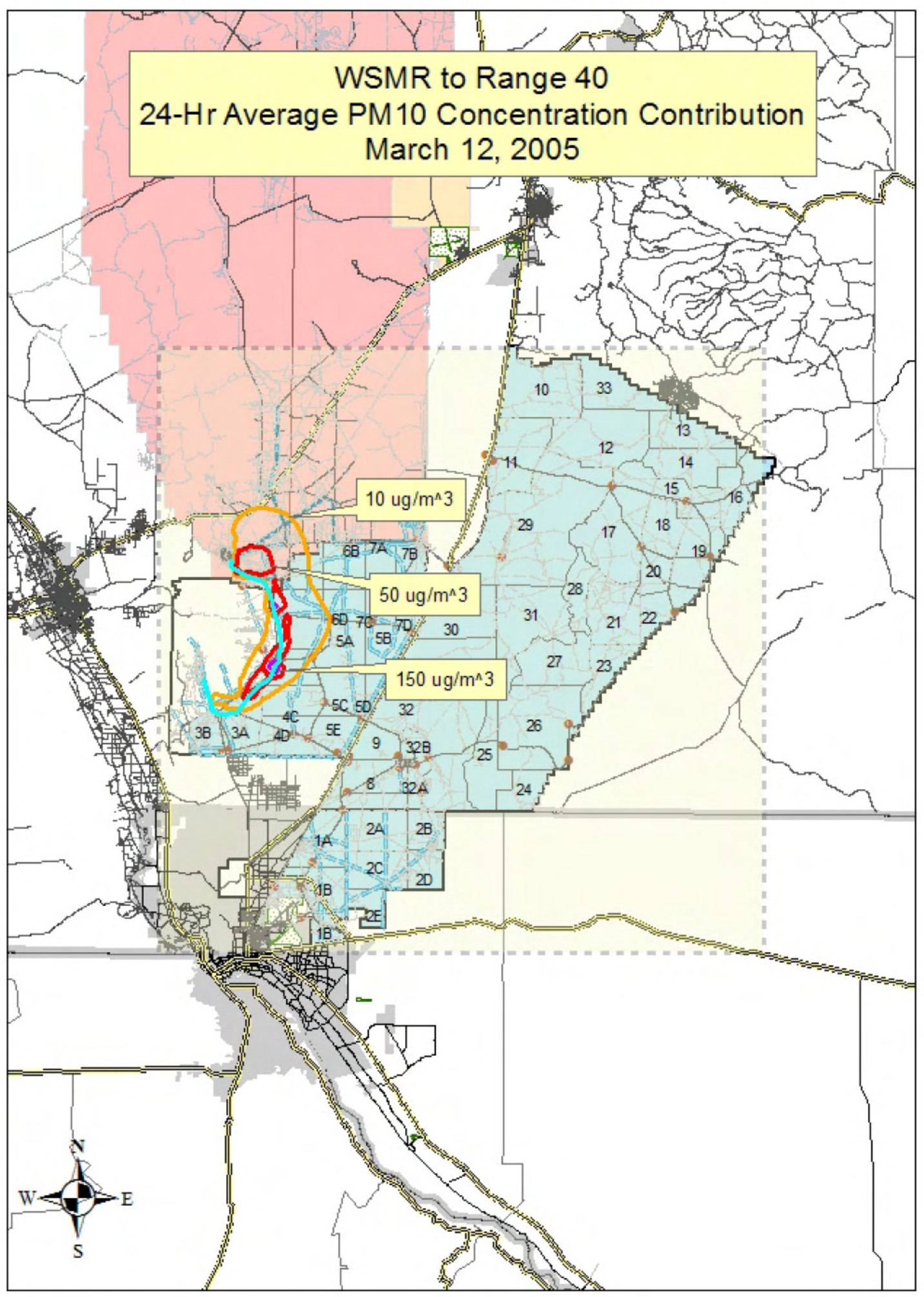




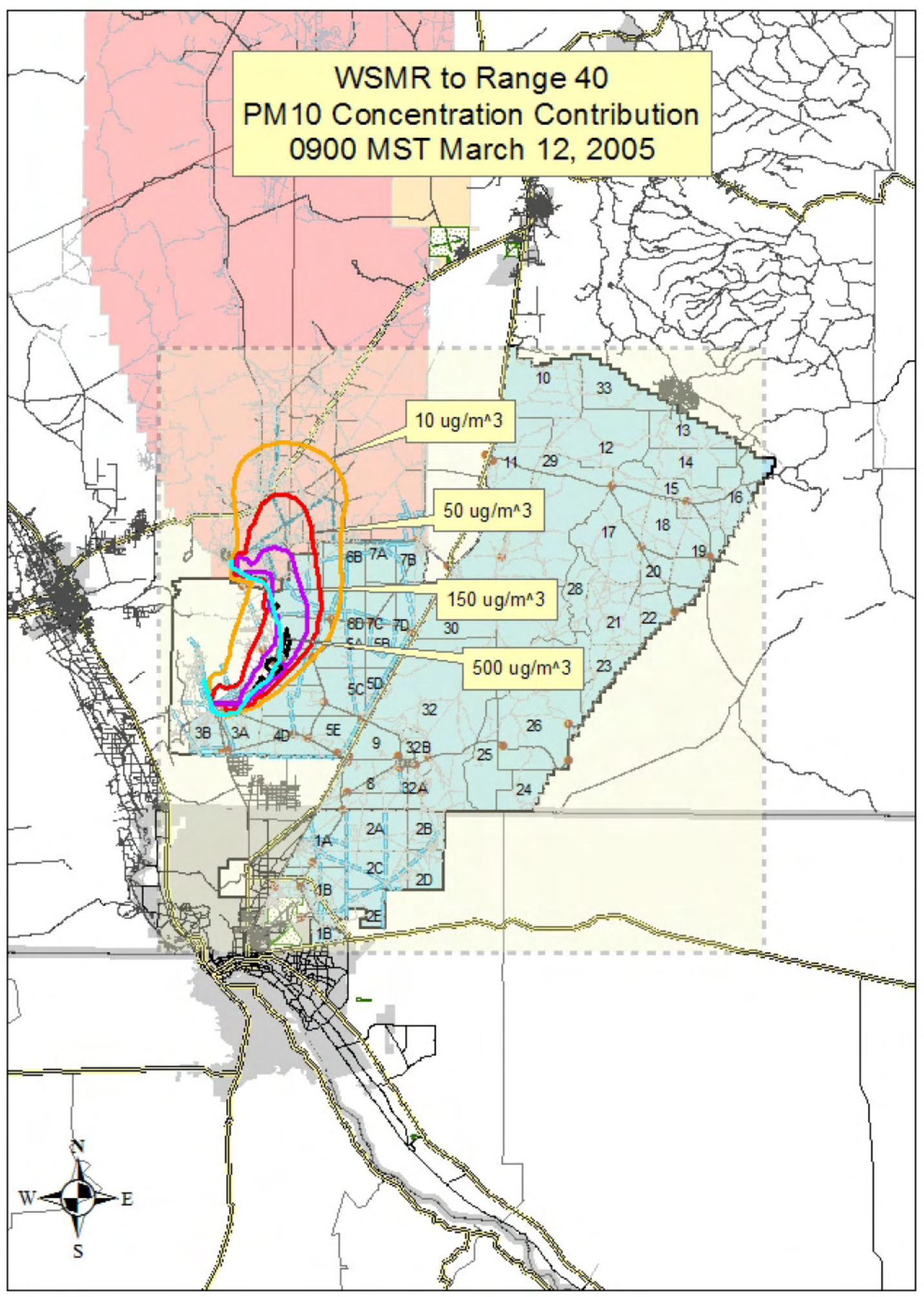




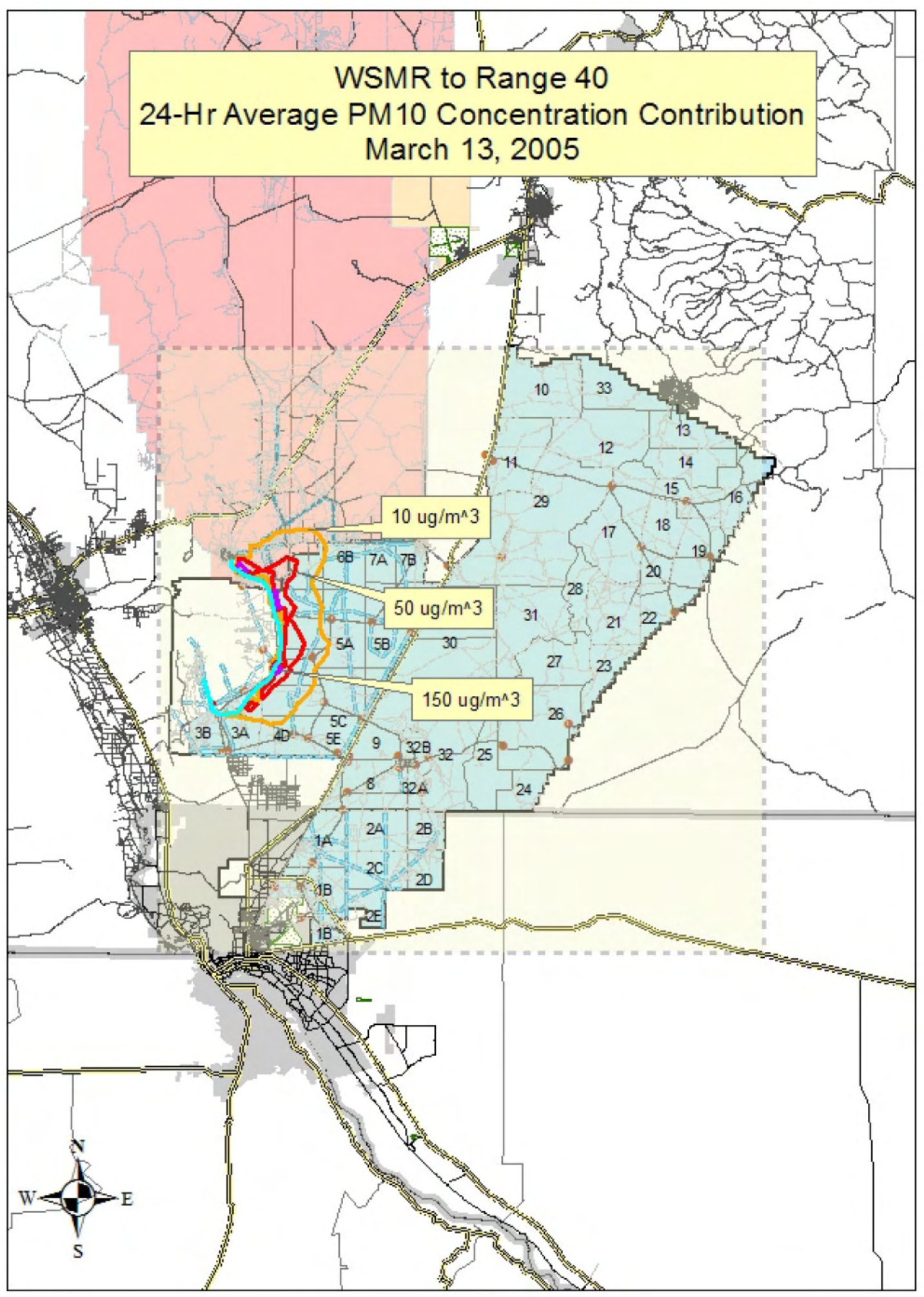




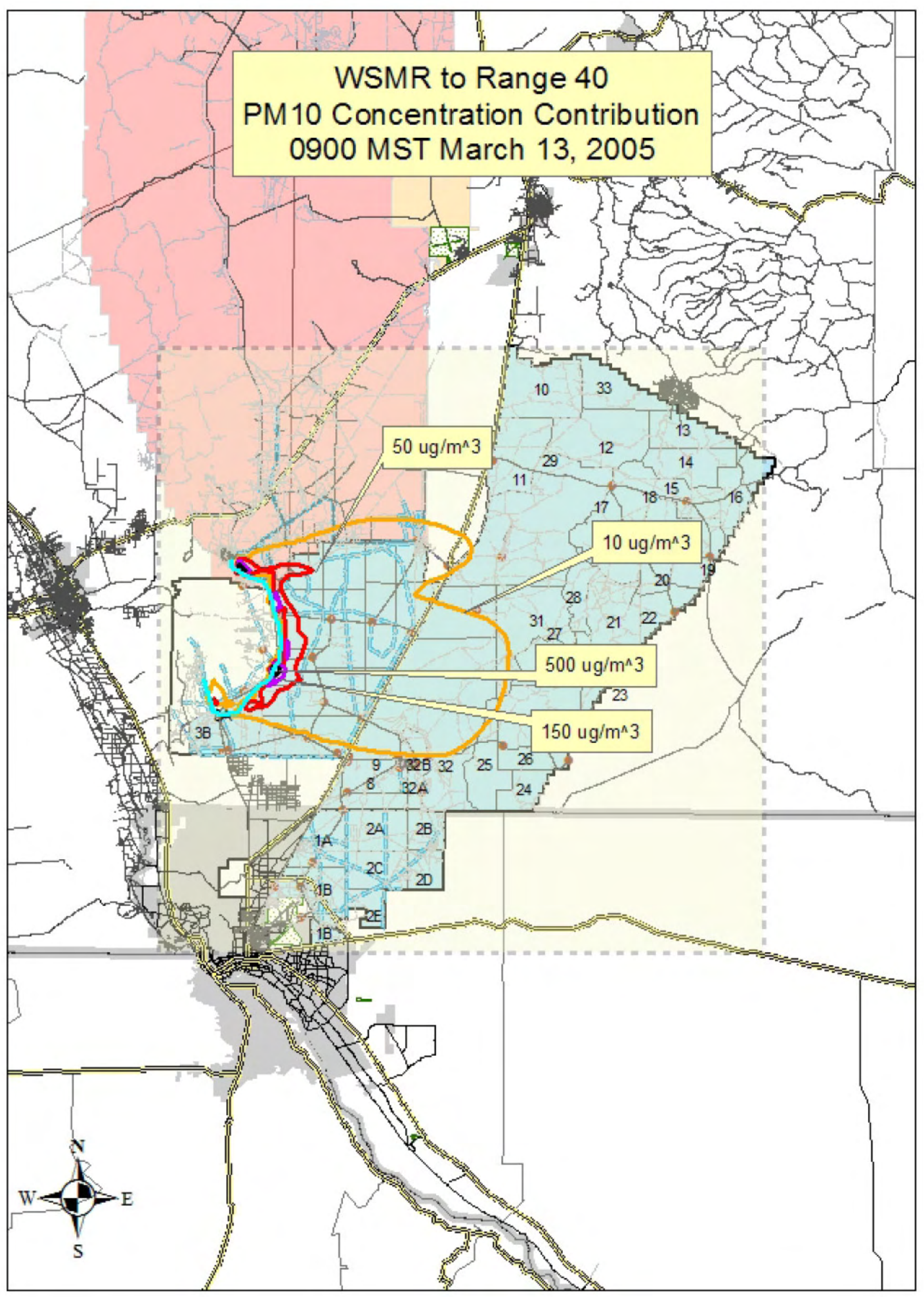




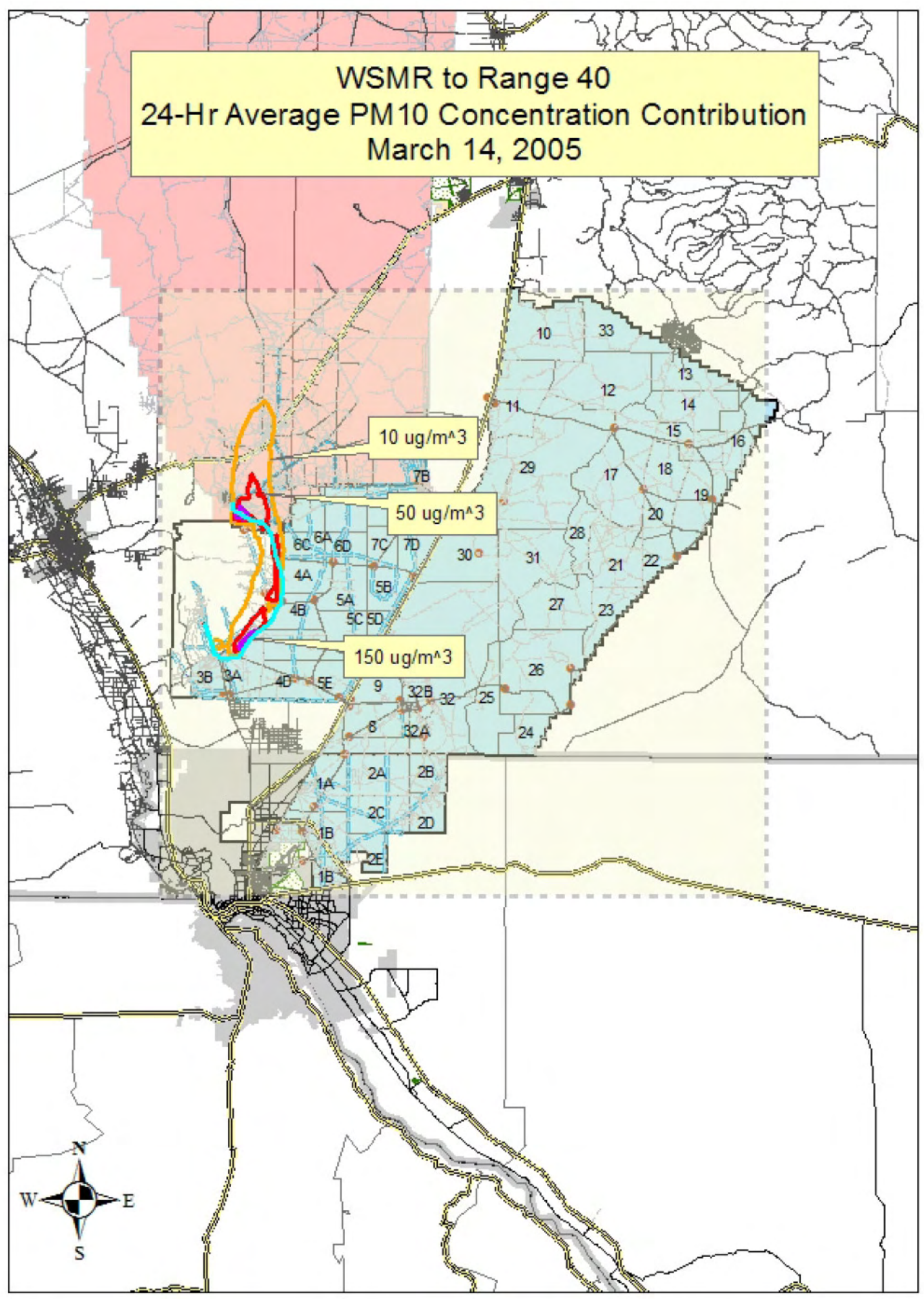

C.6 


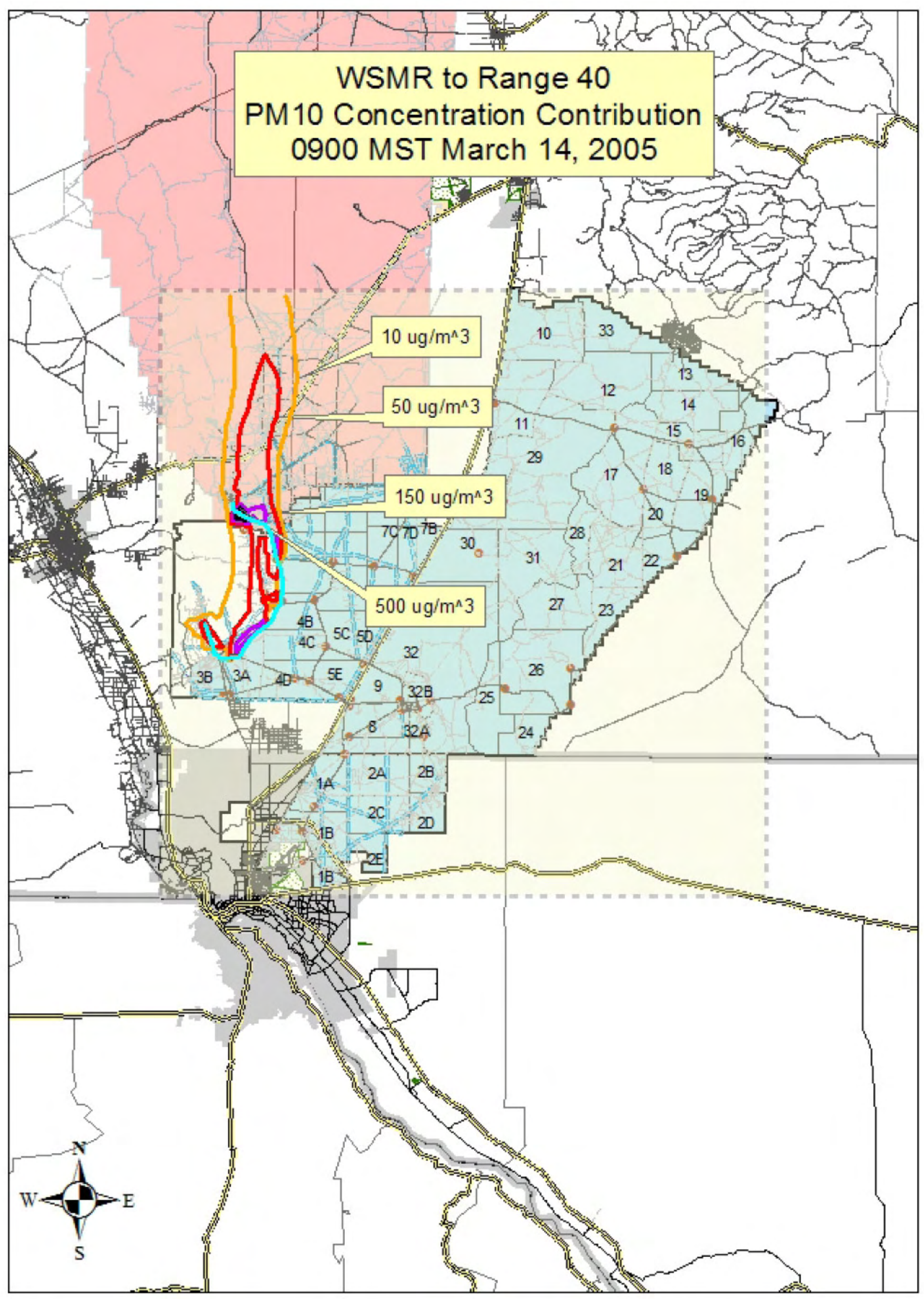

C.7 


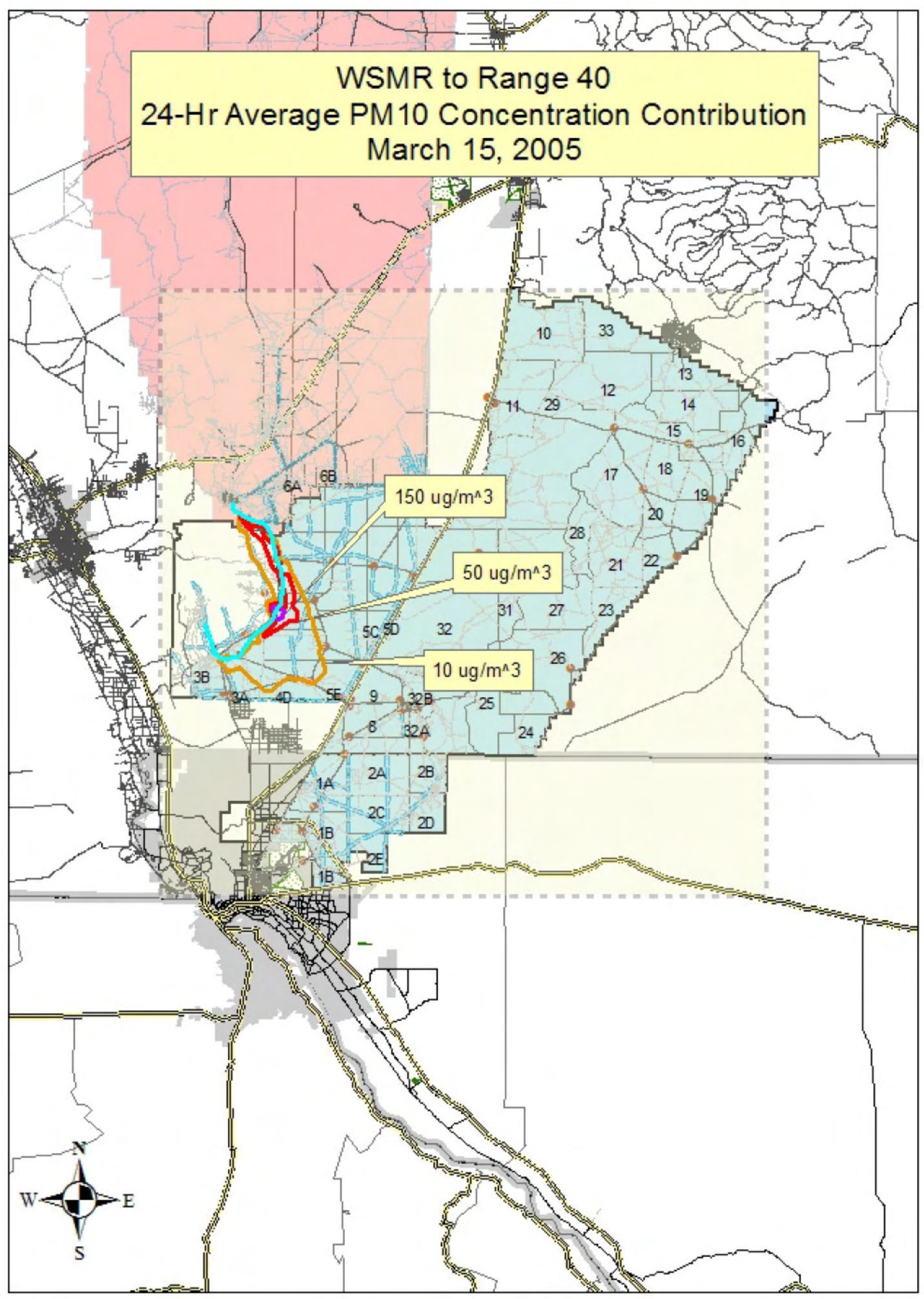




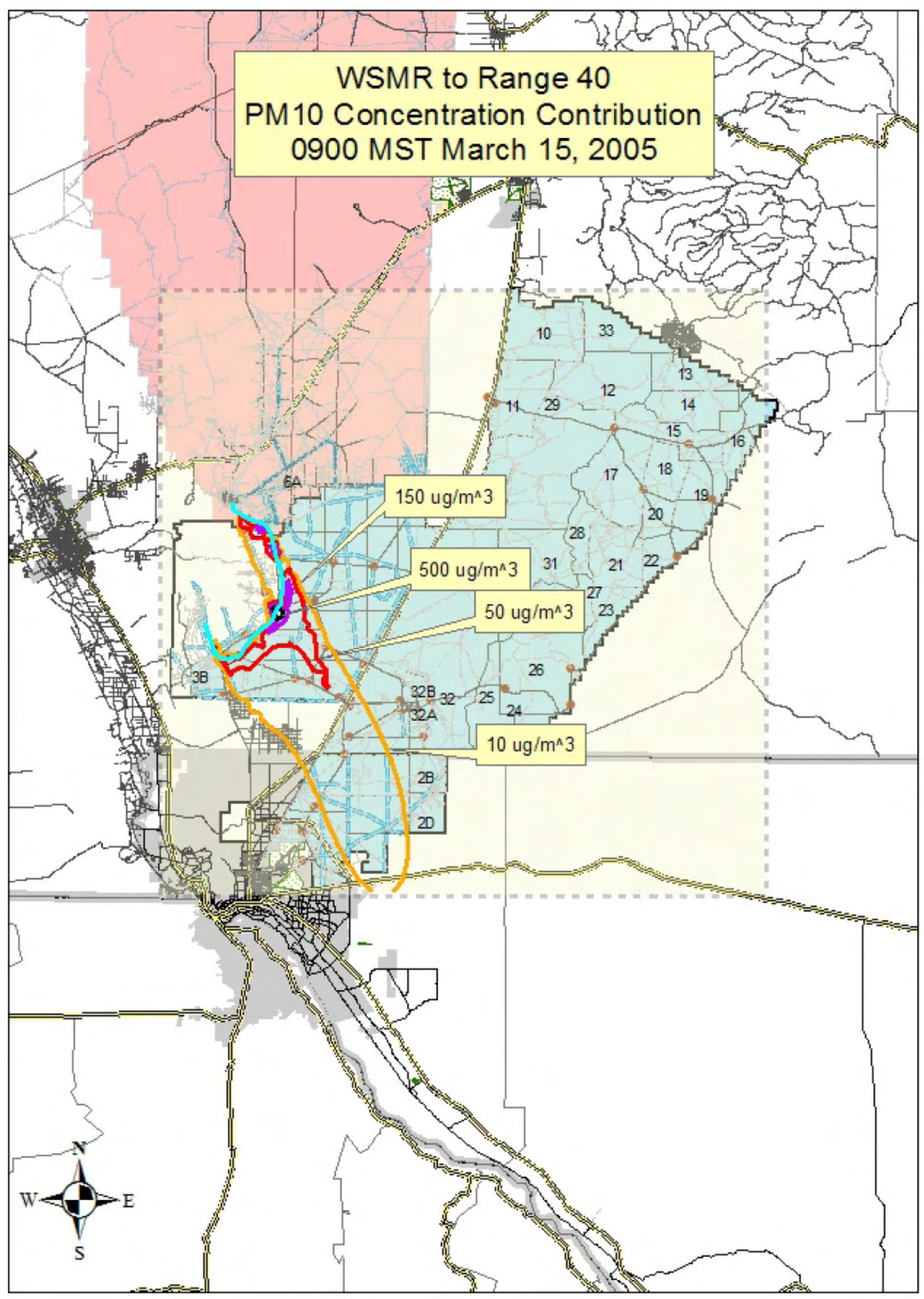




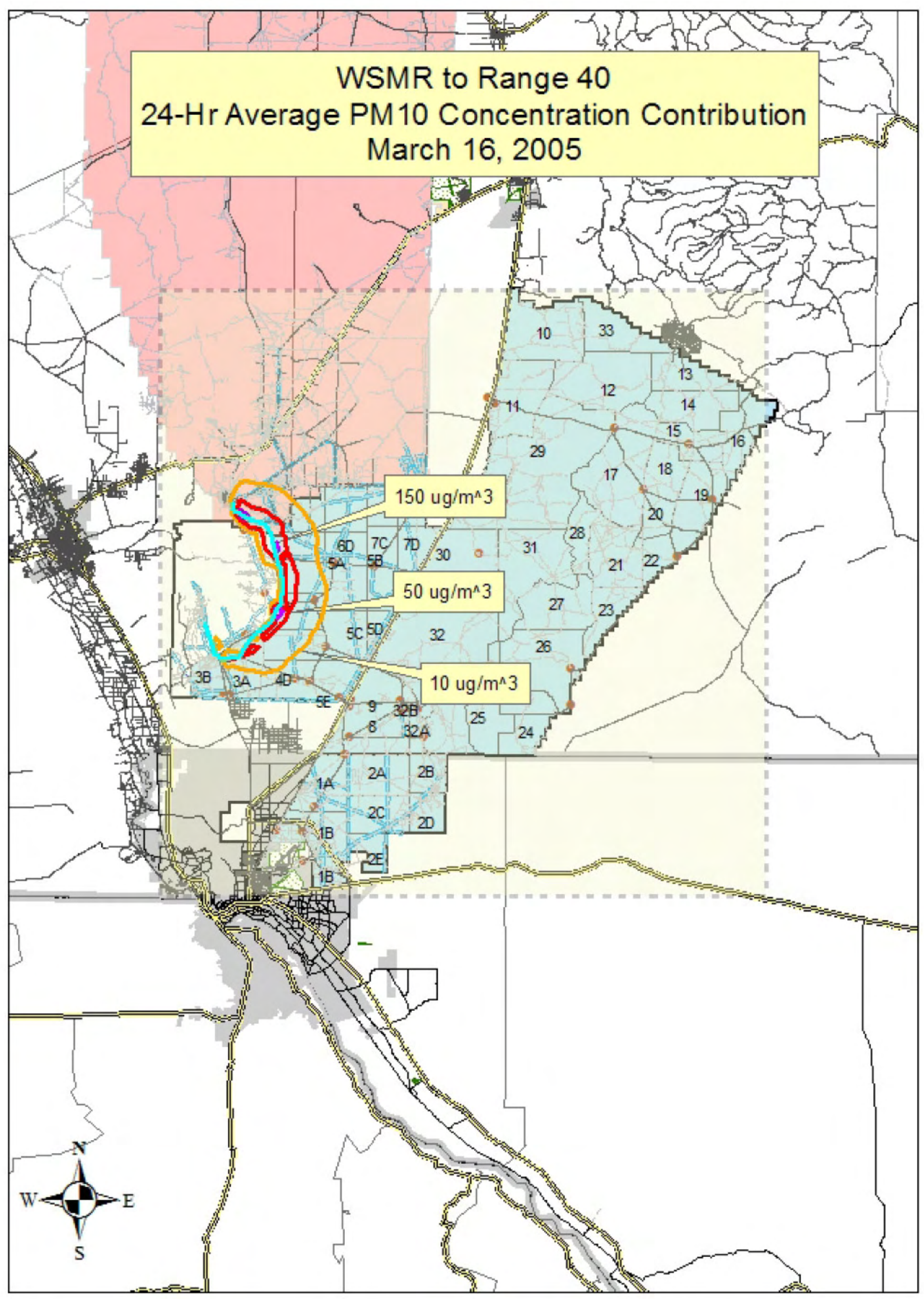




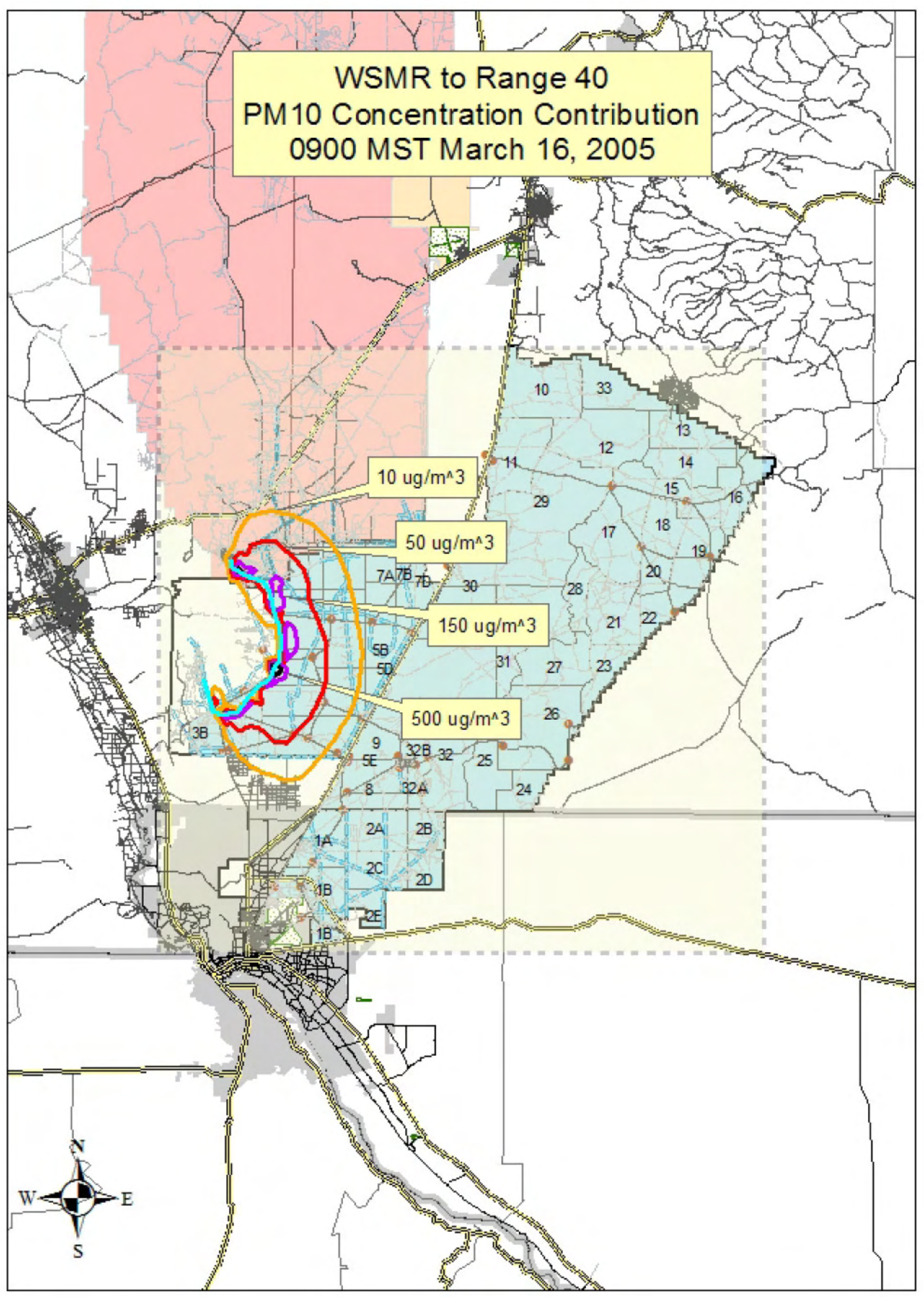




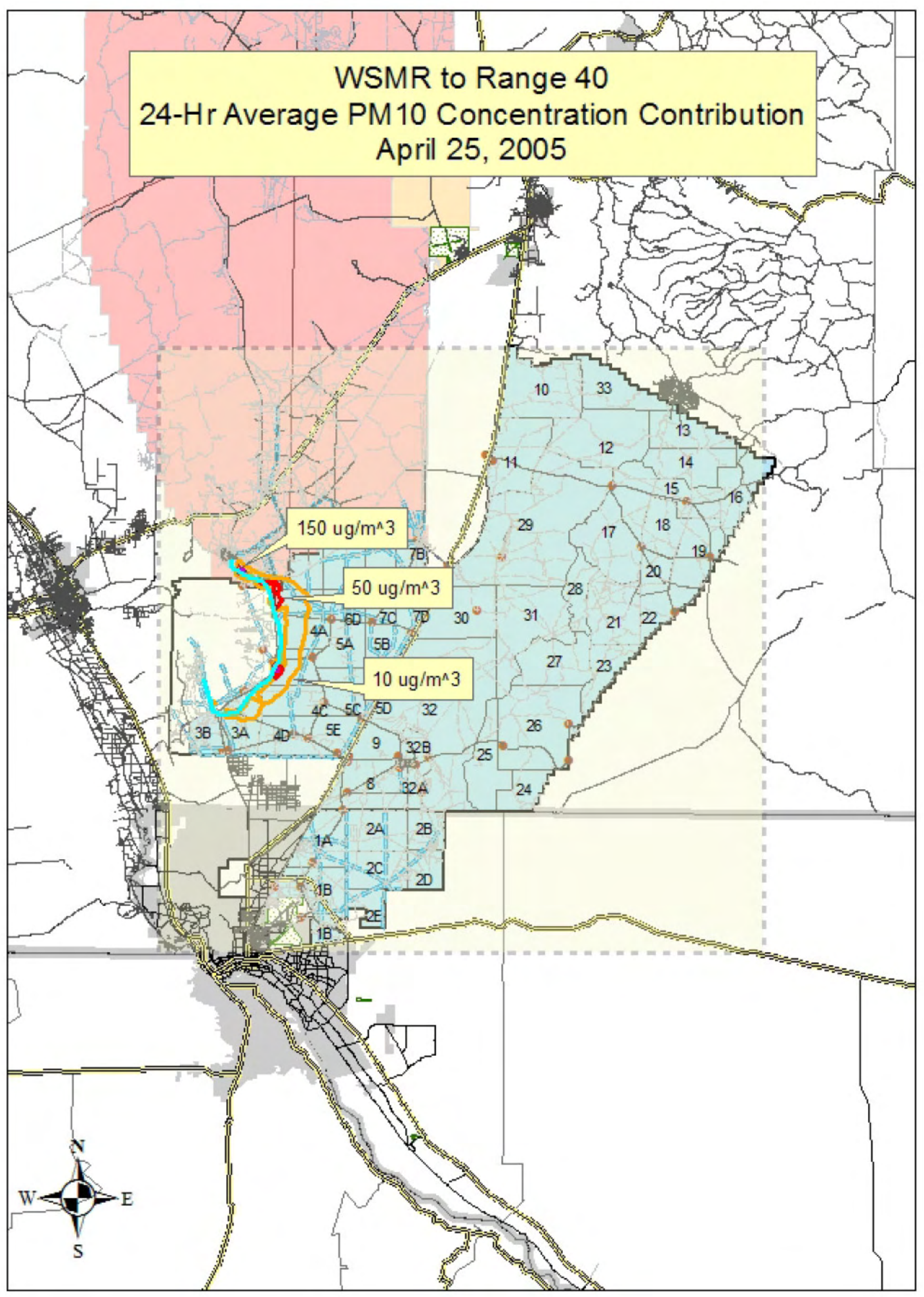

C.12 


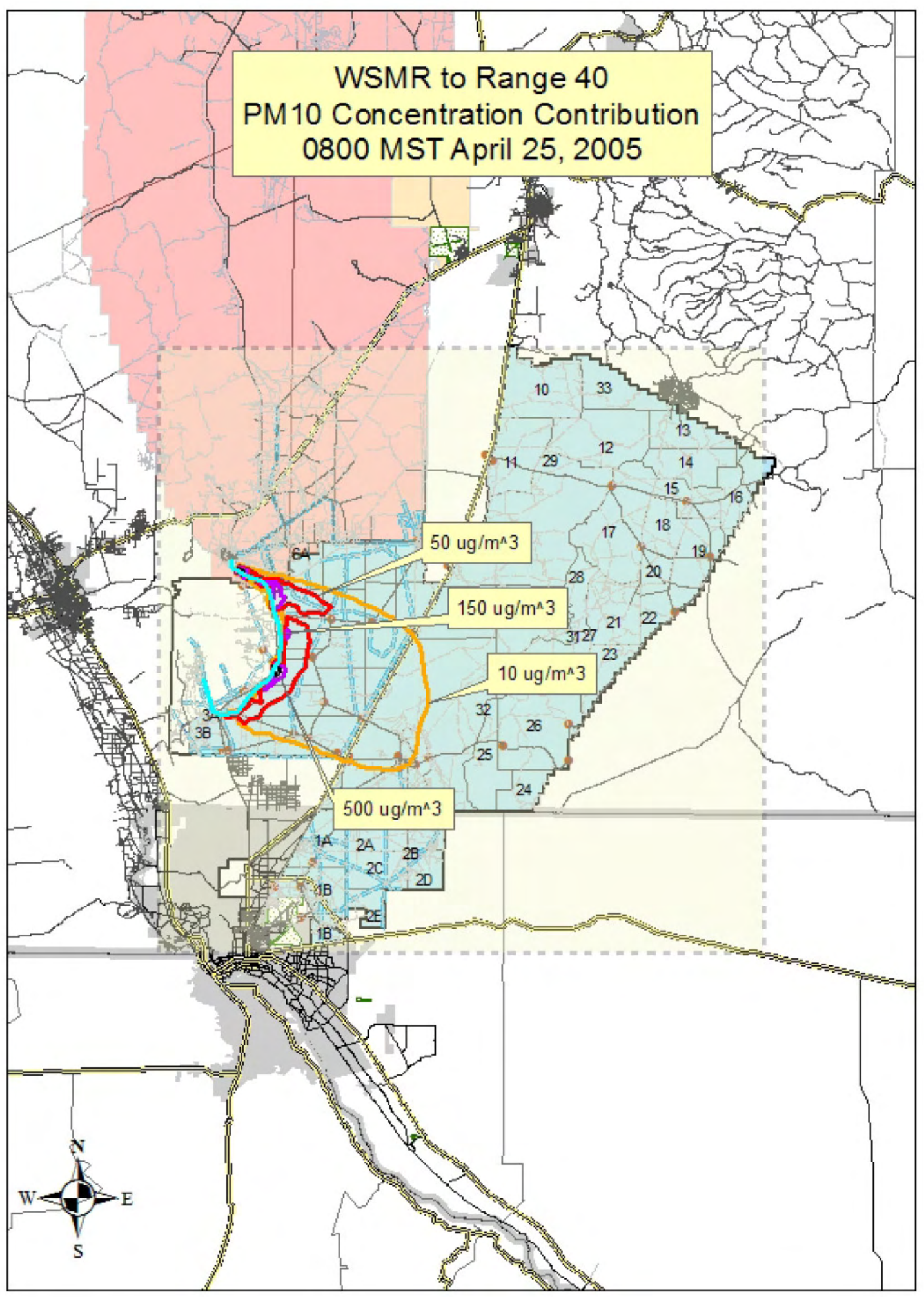




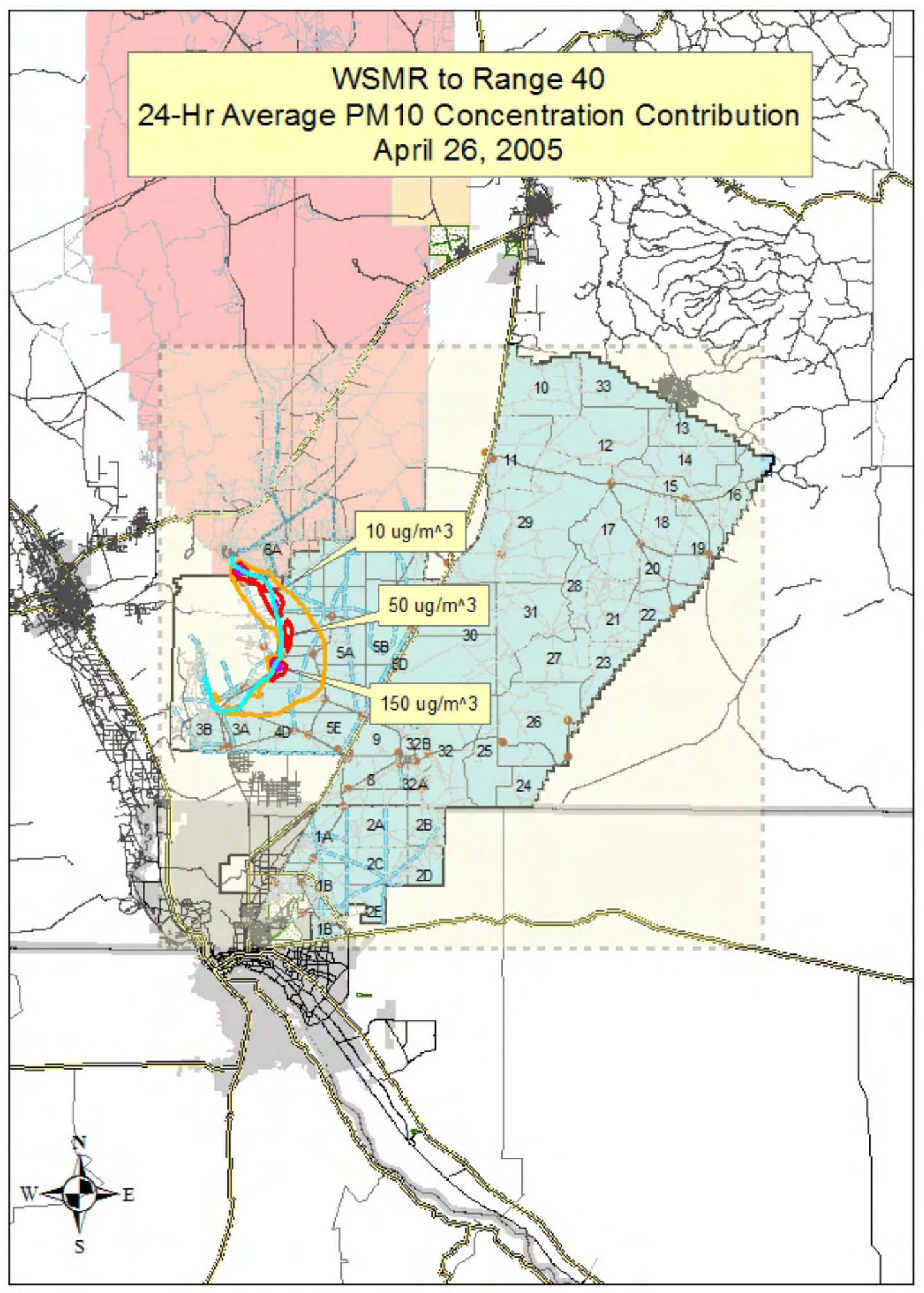




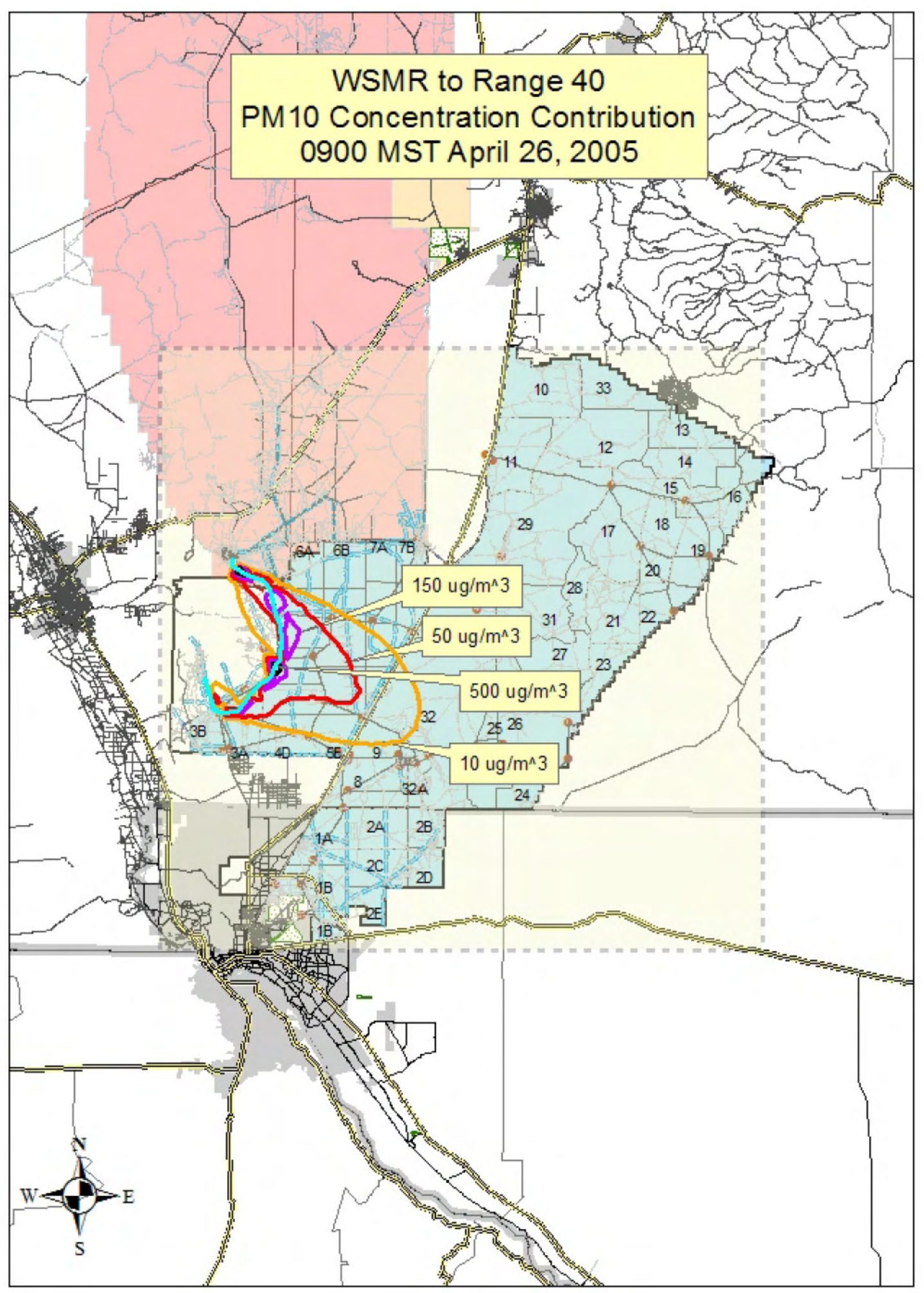




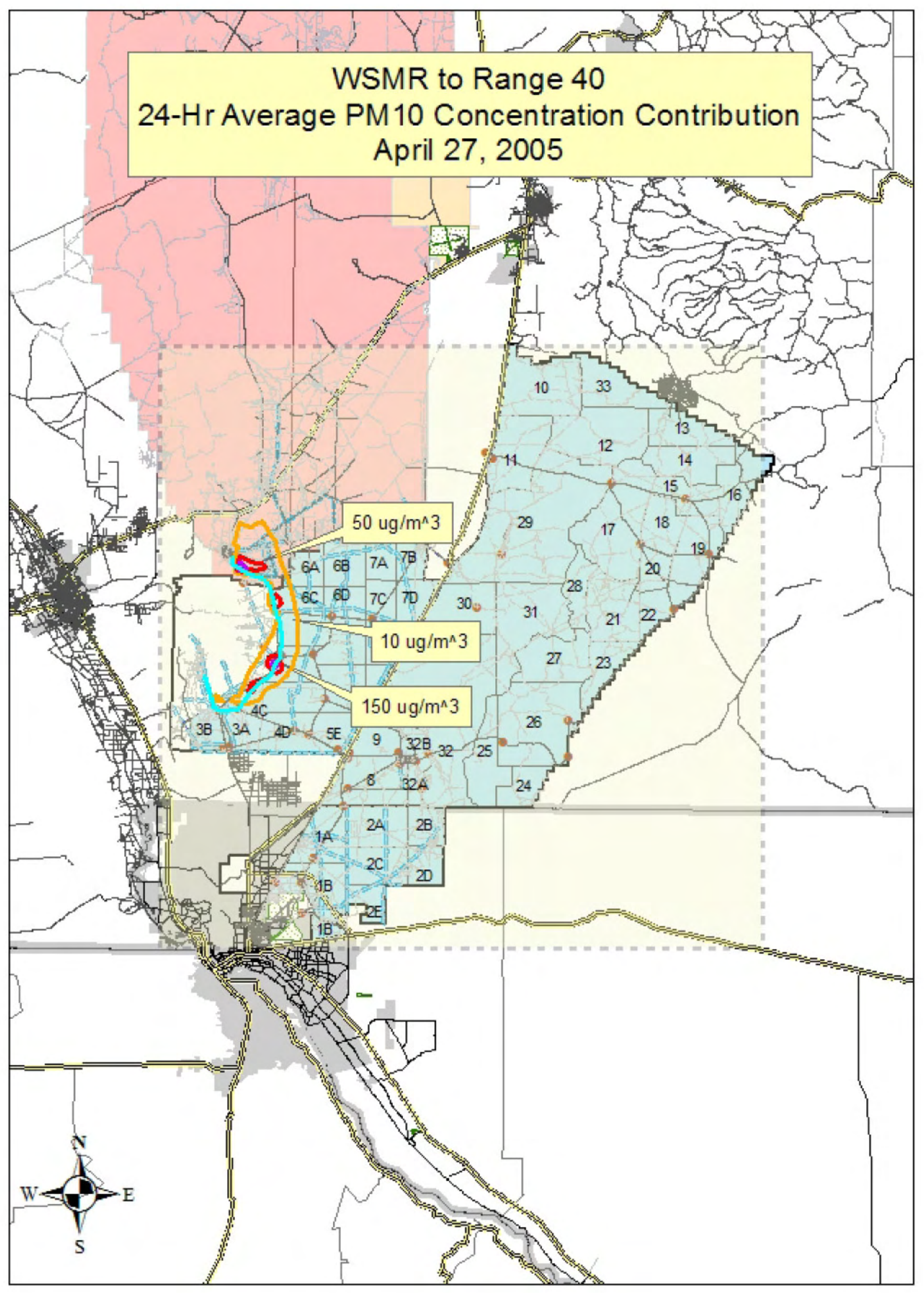




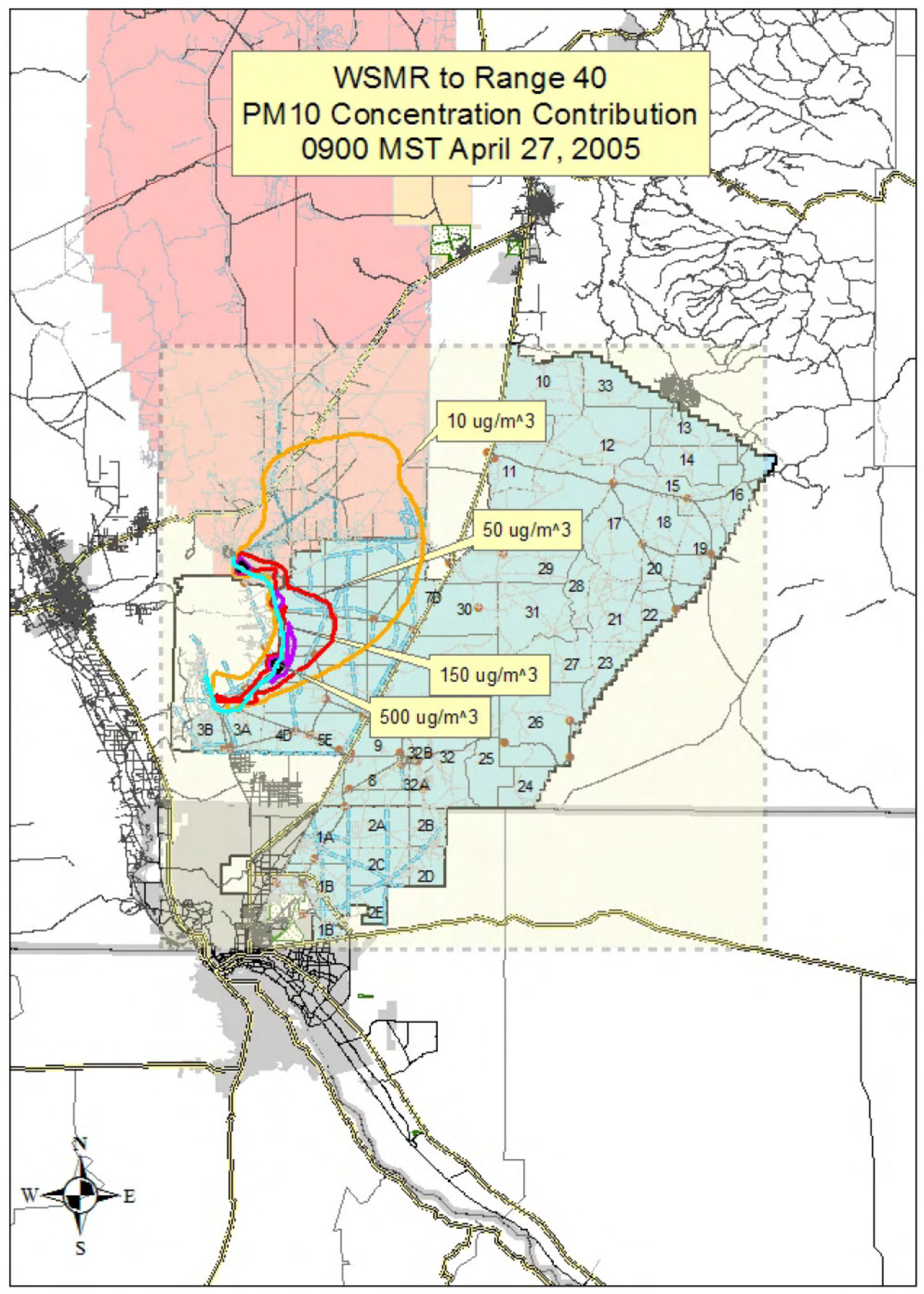




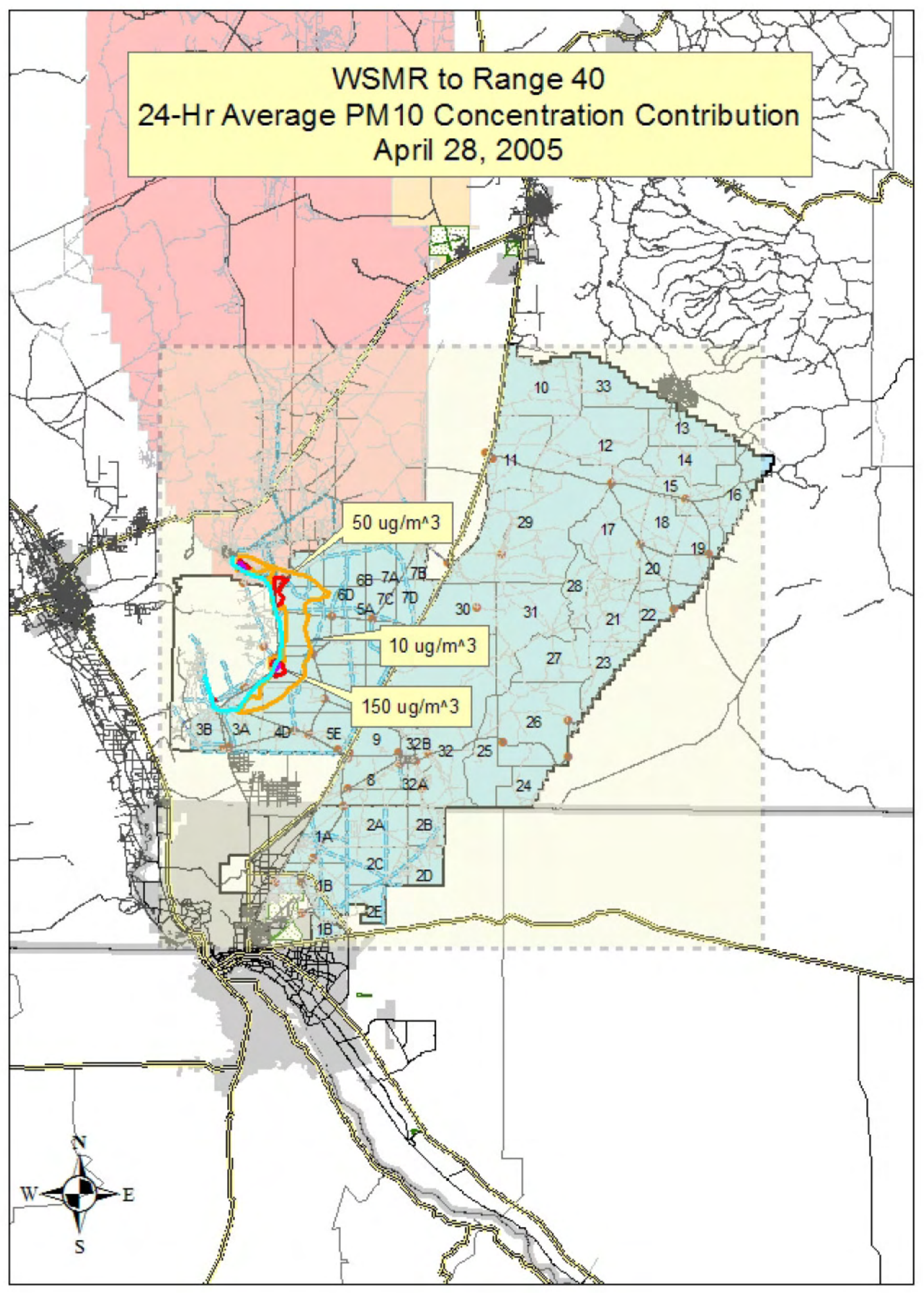




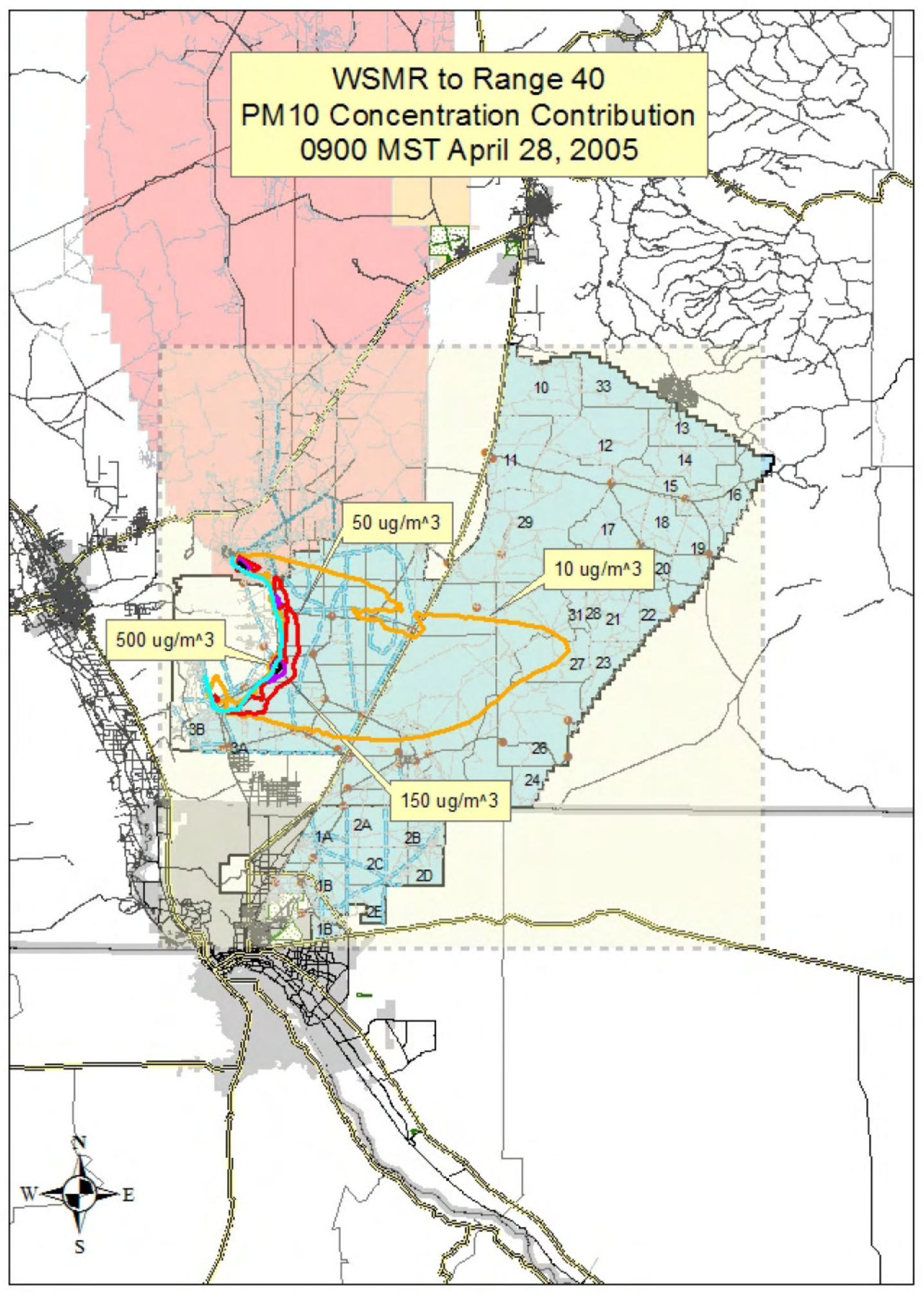




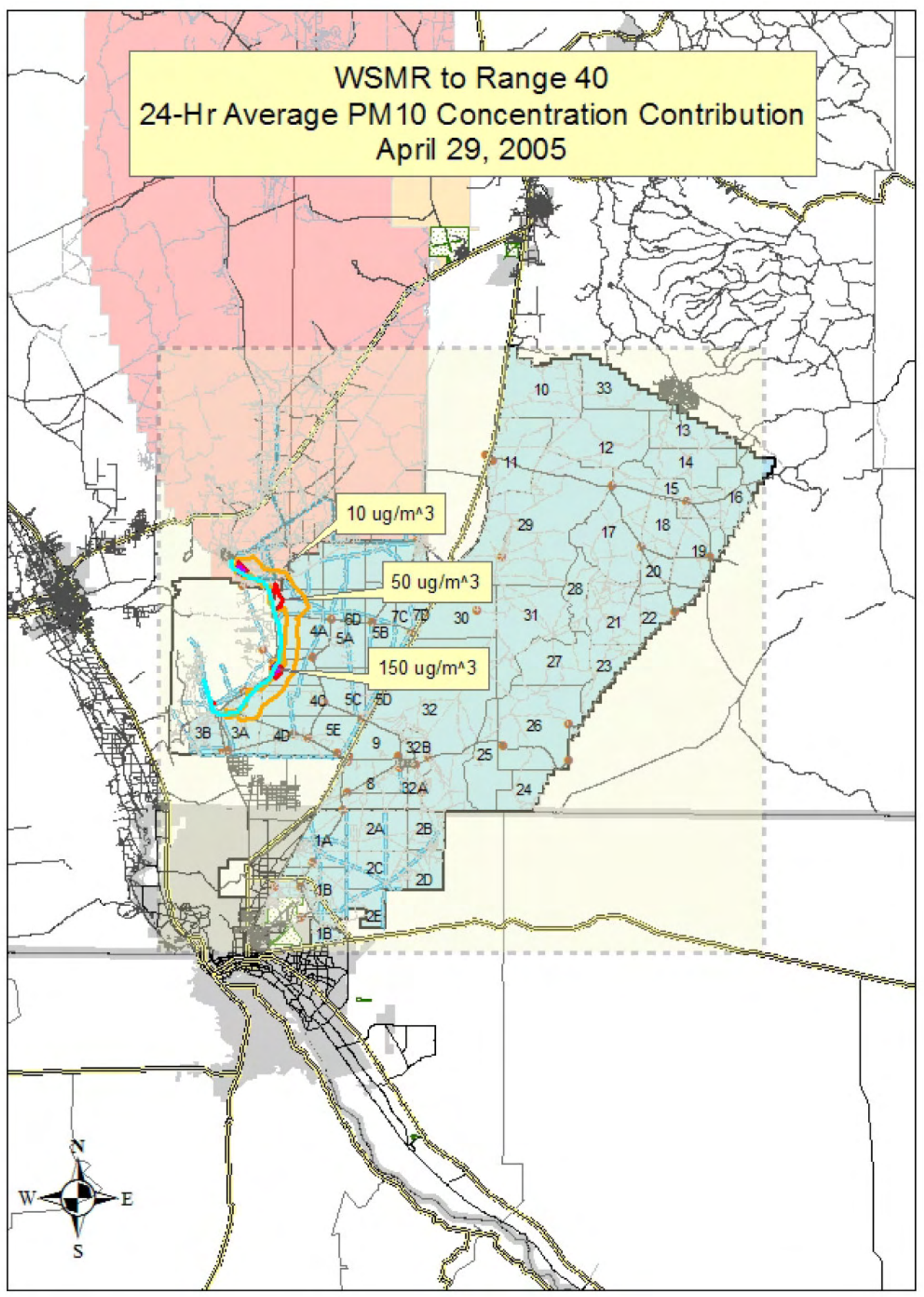




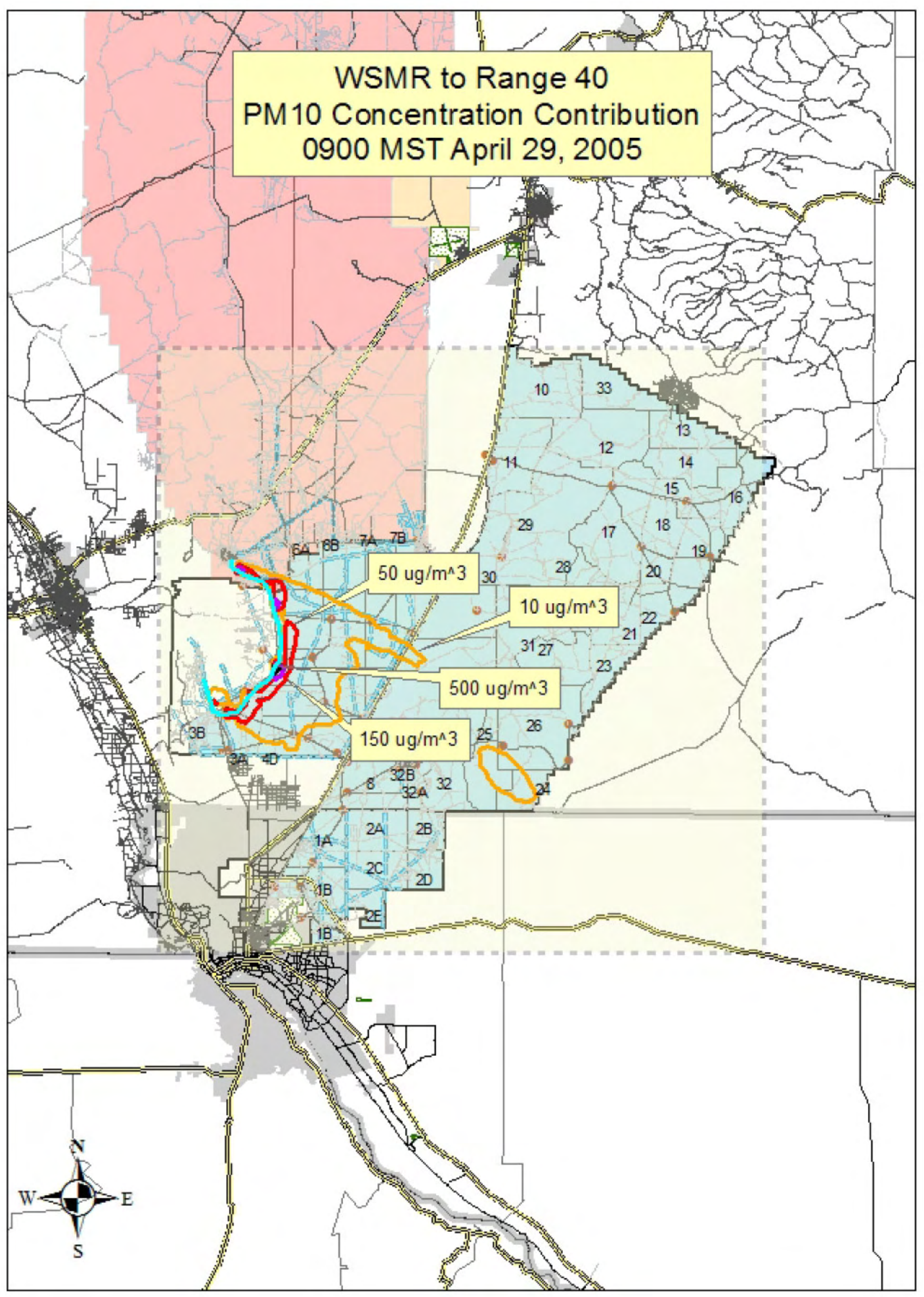




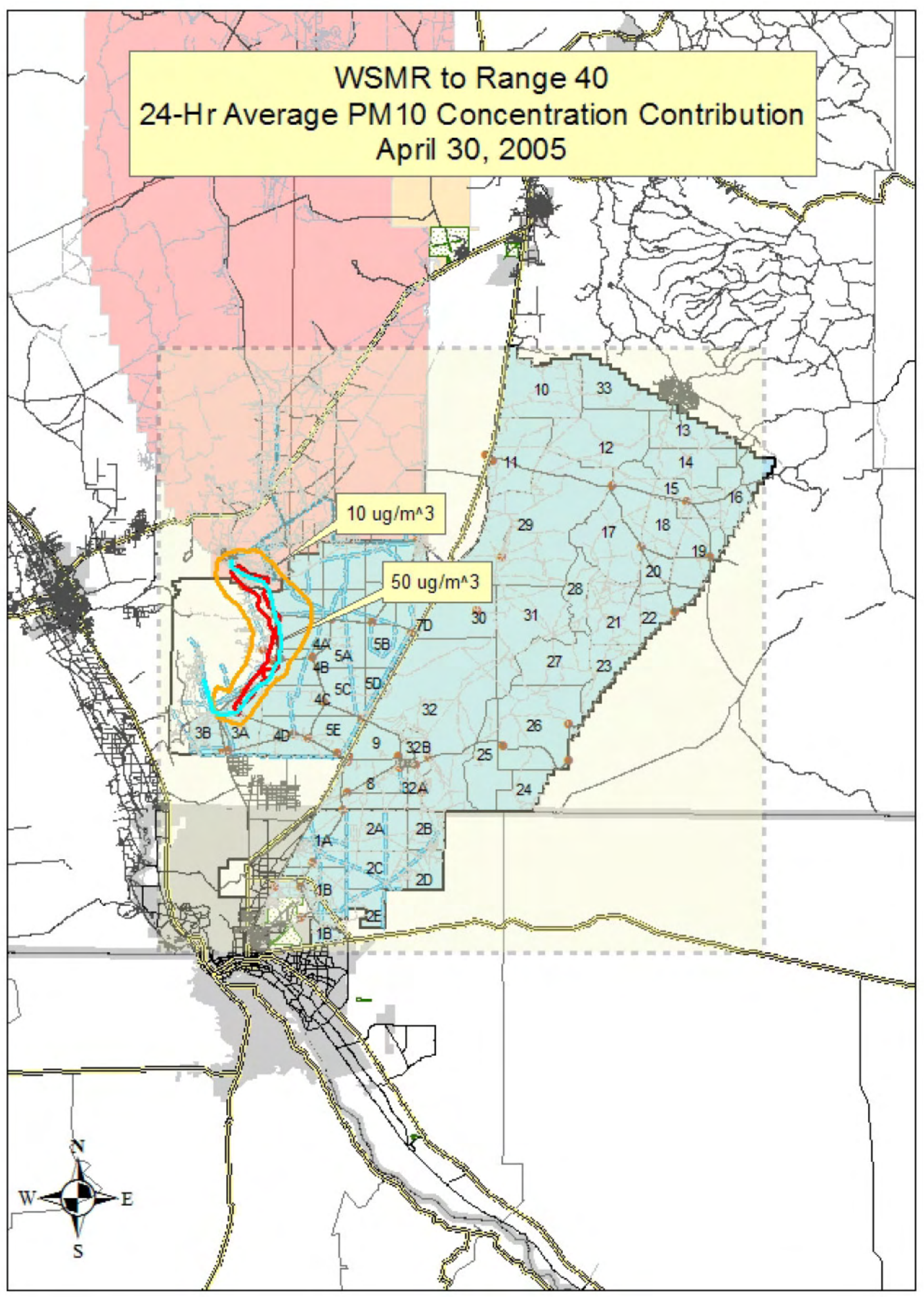




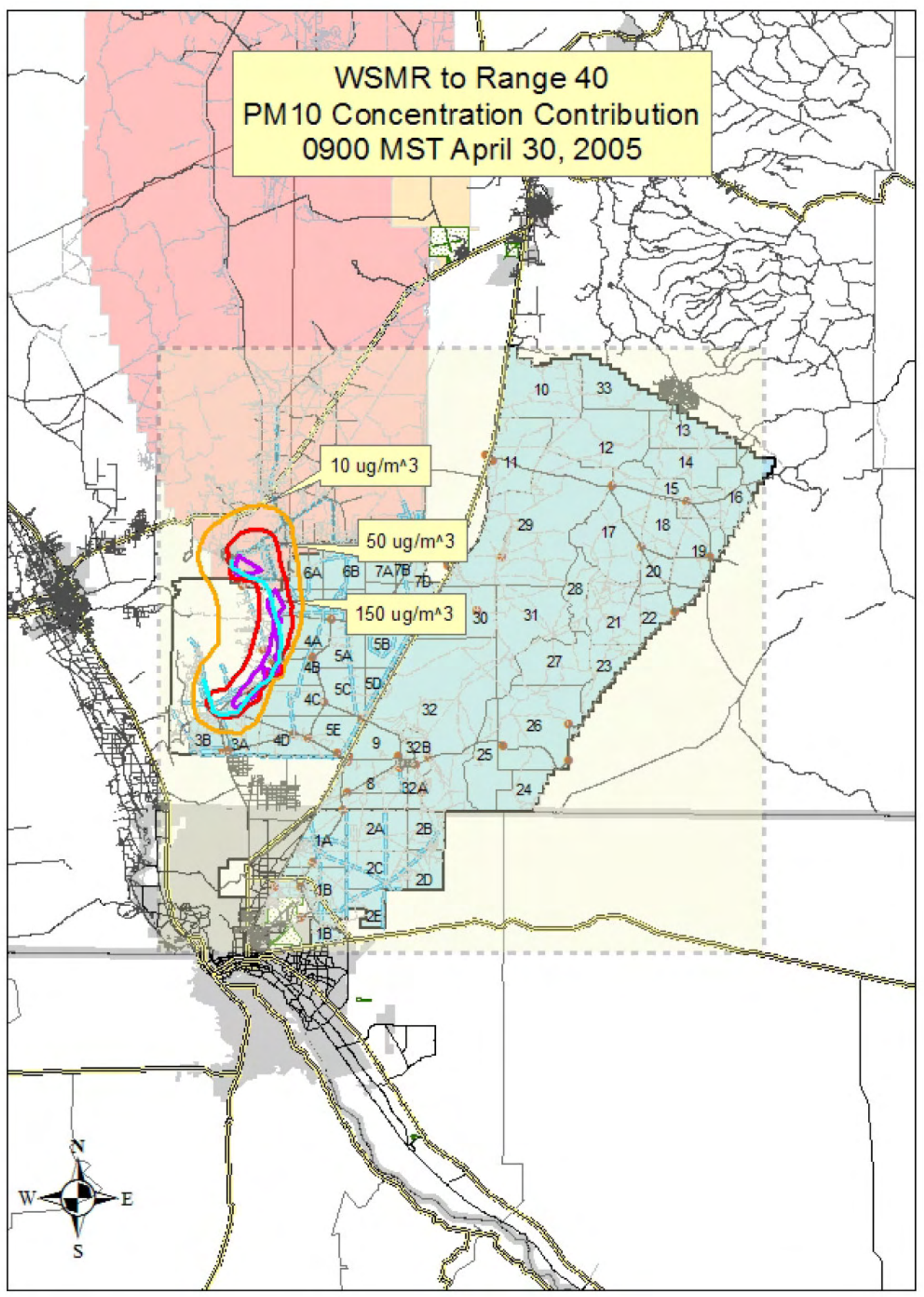




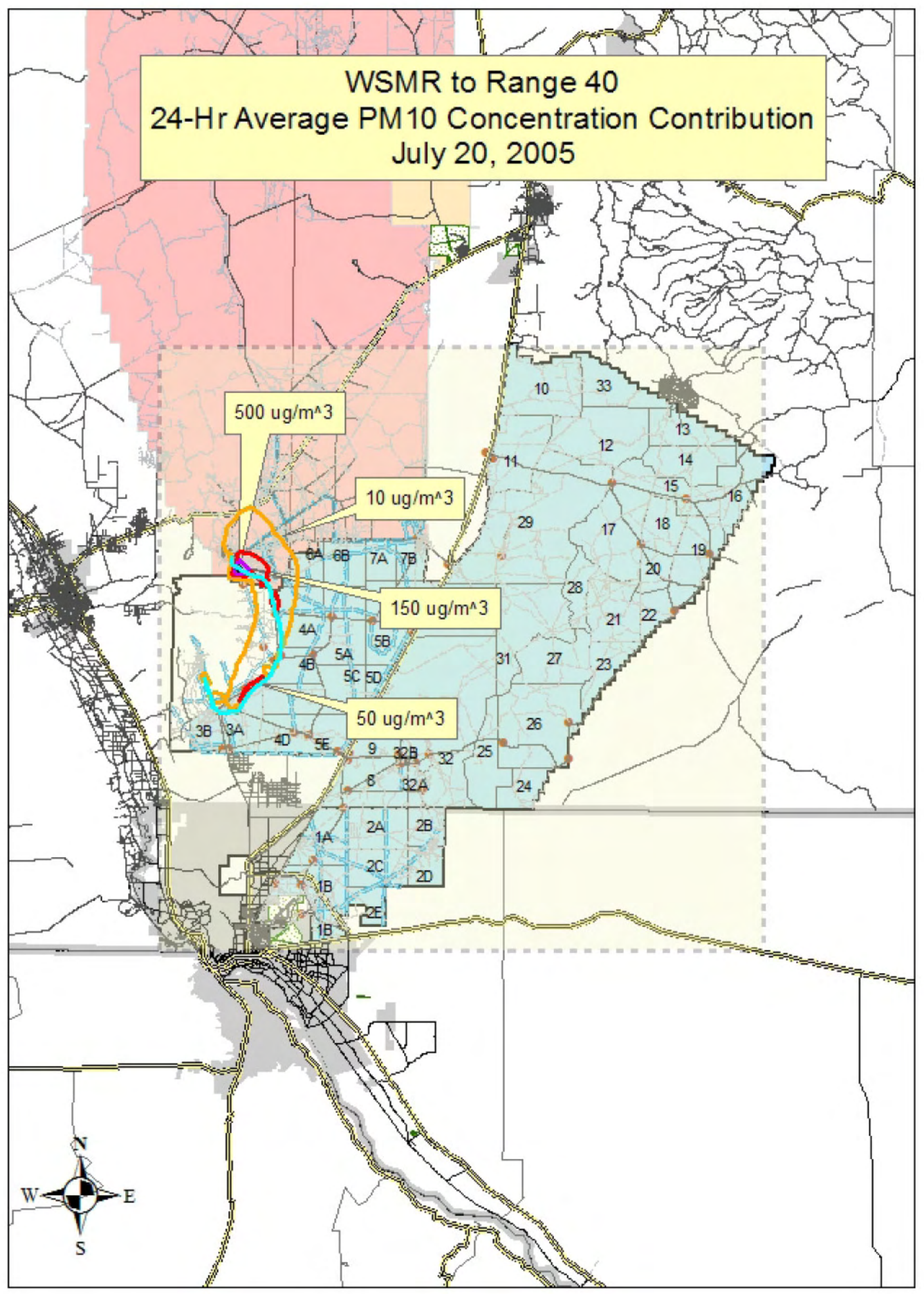




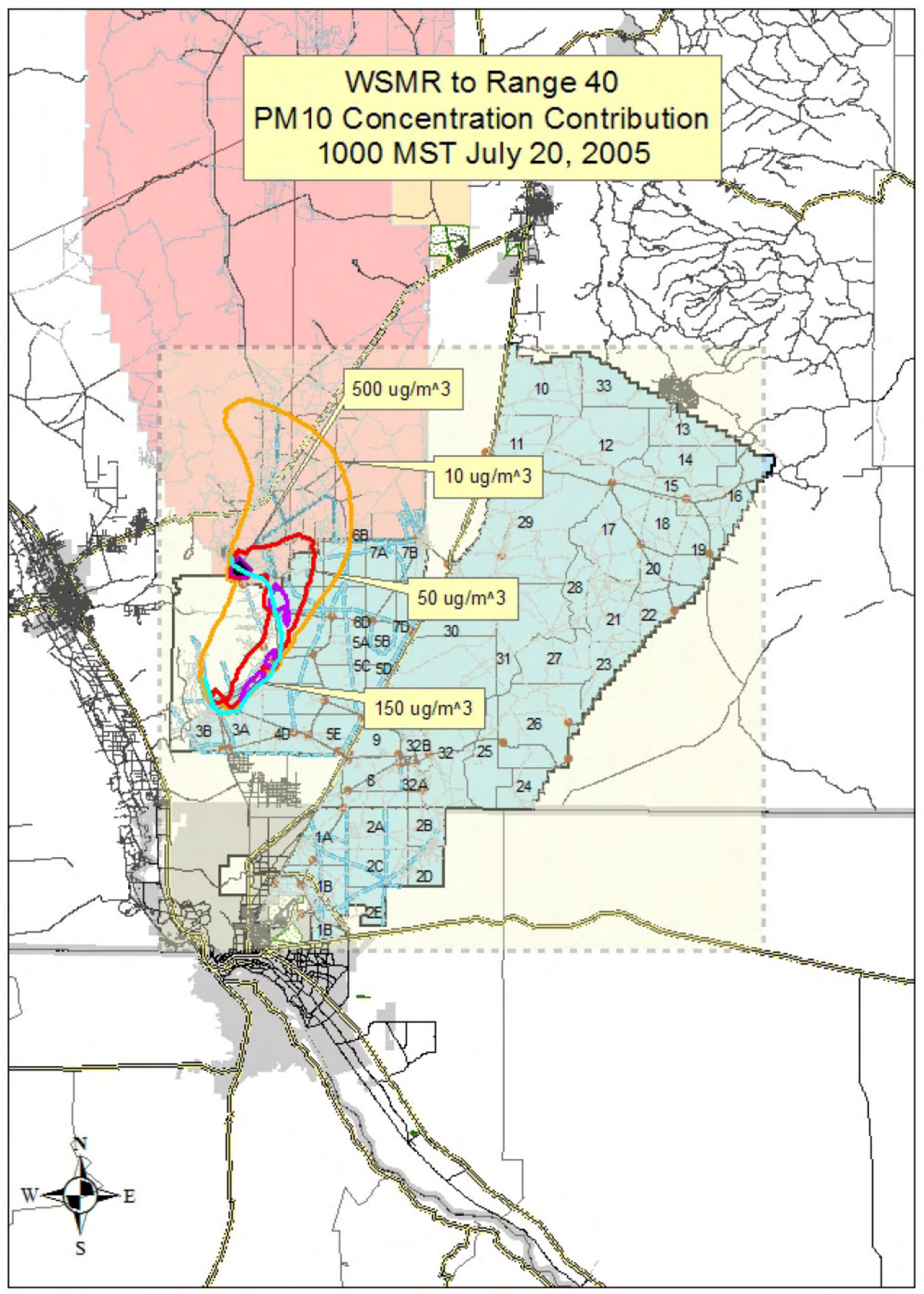




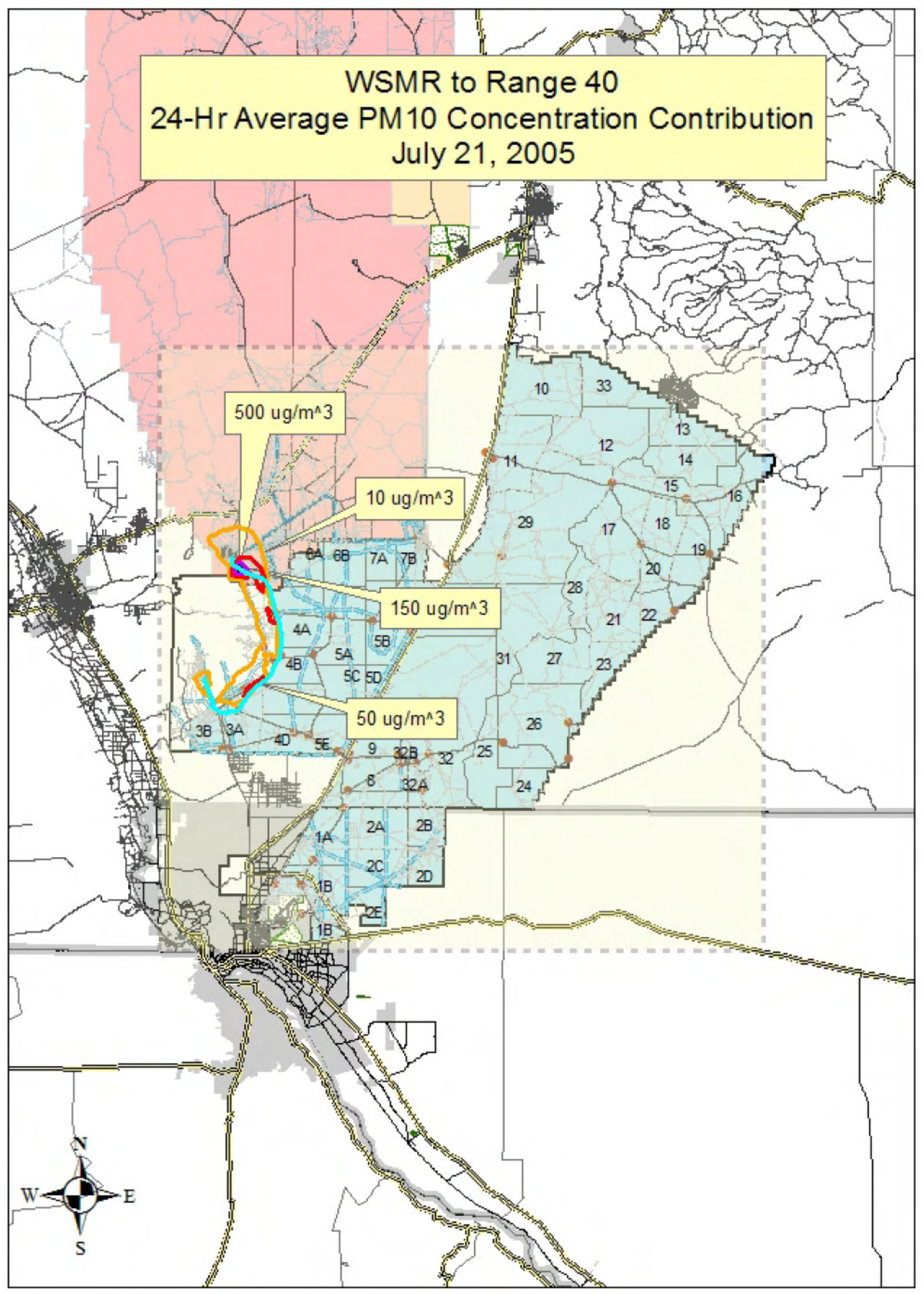




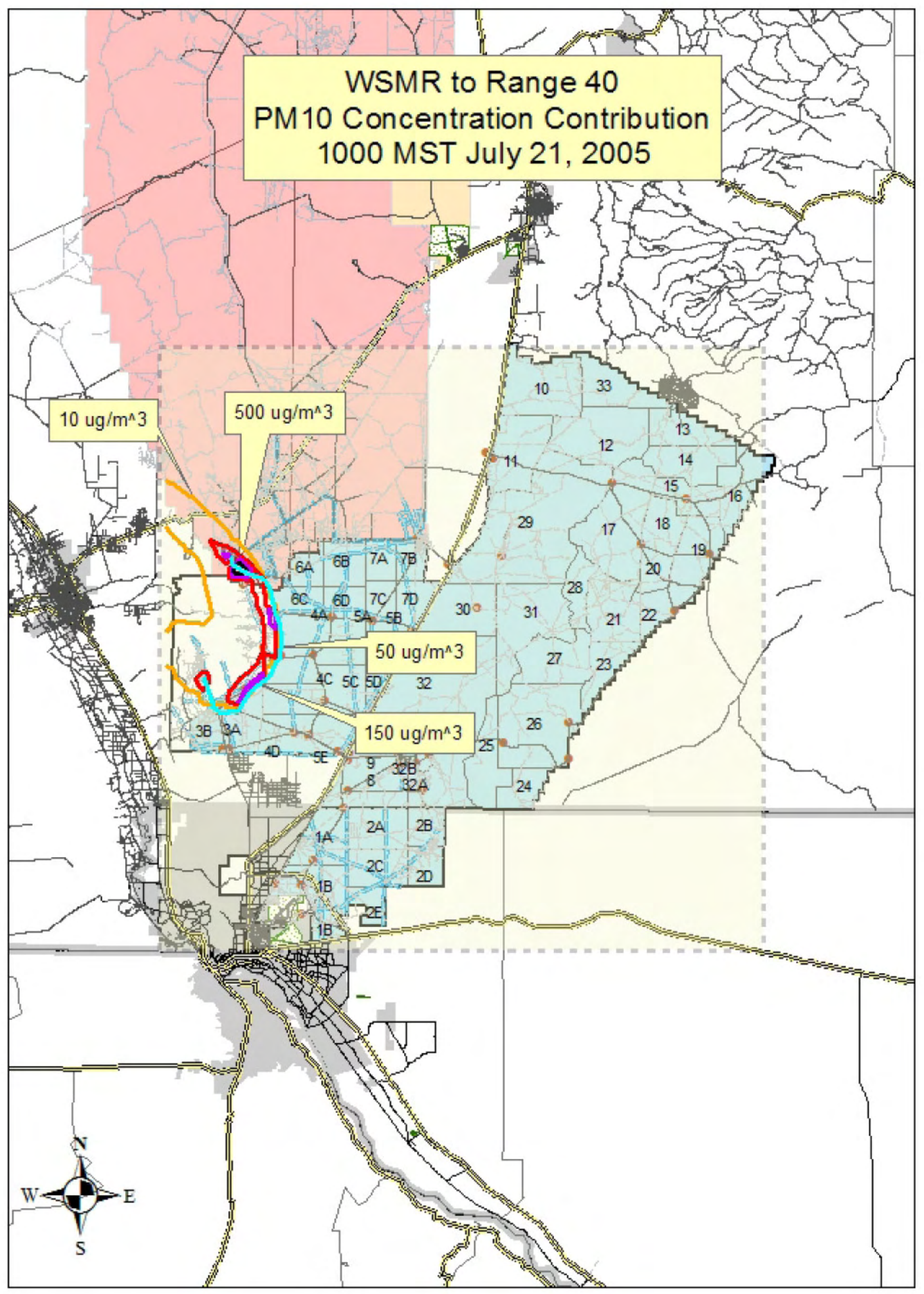




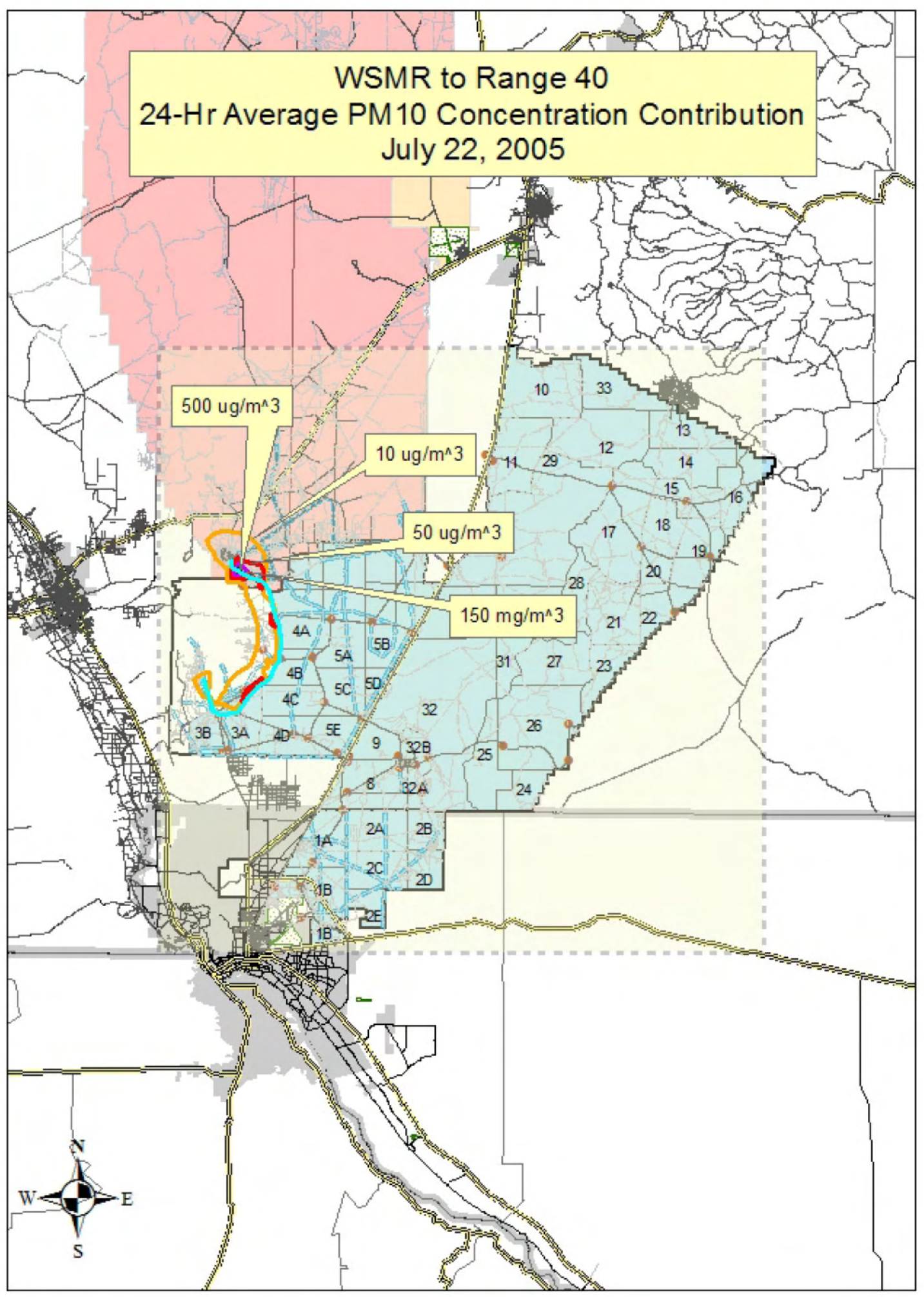




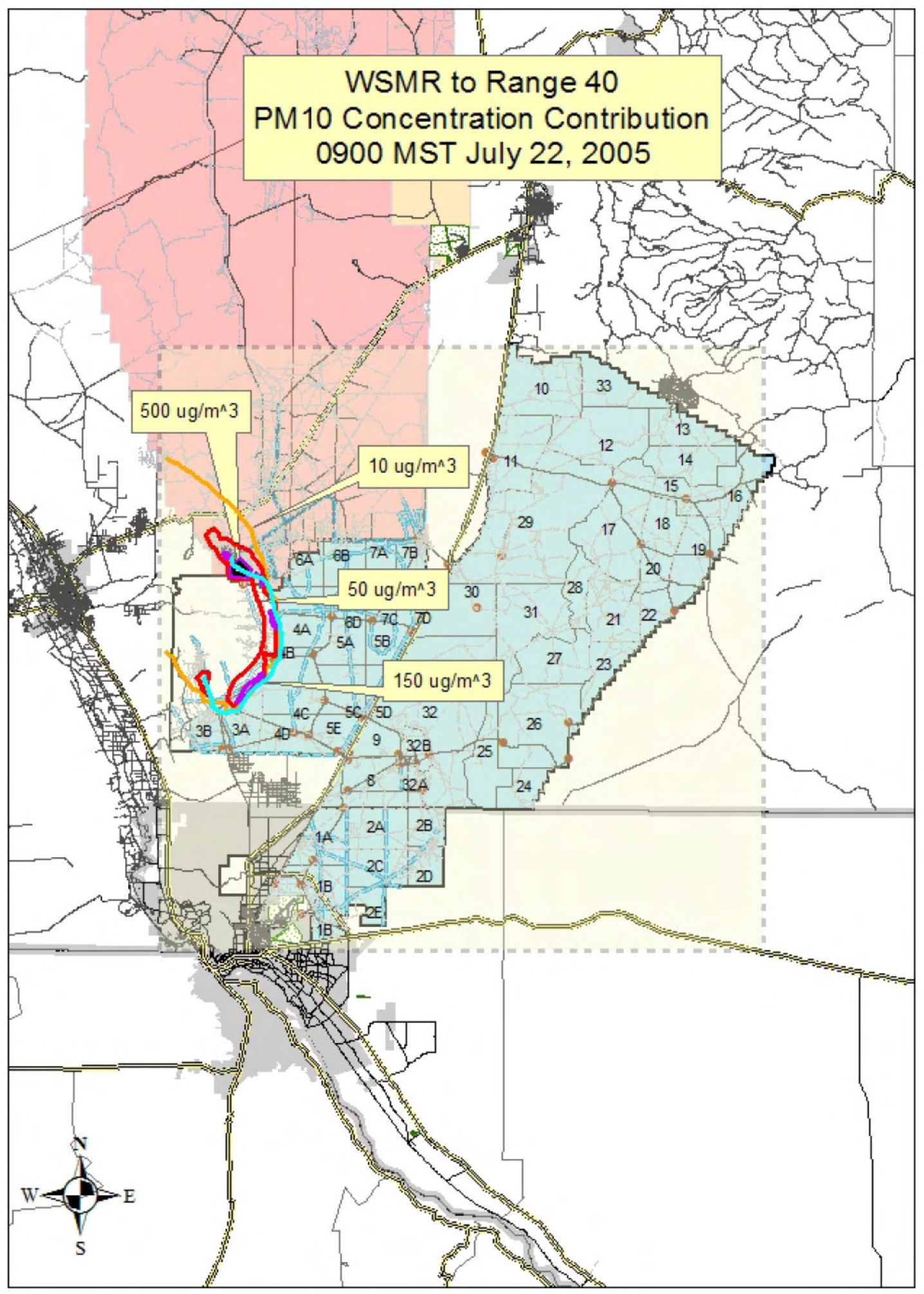




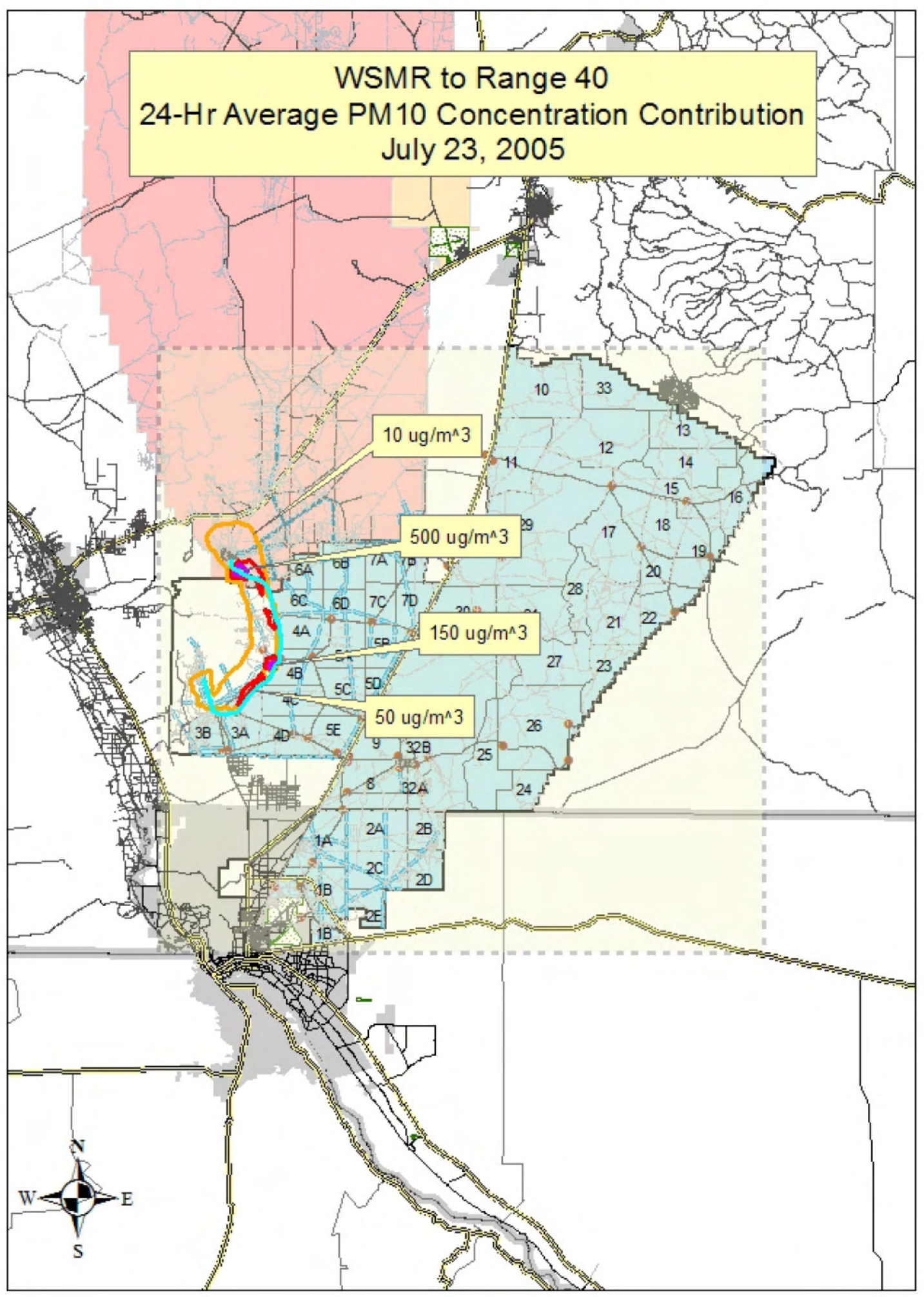




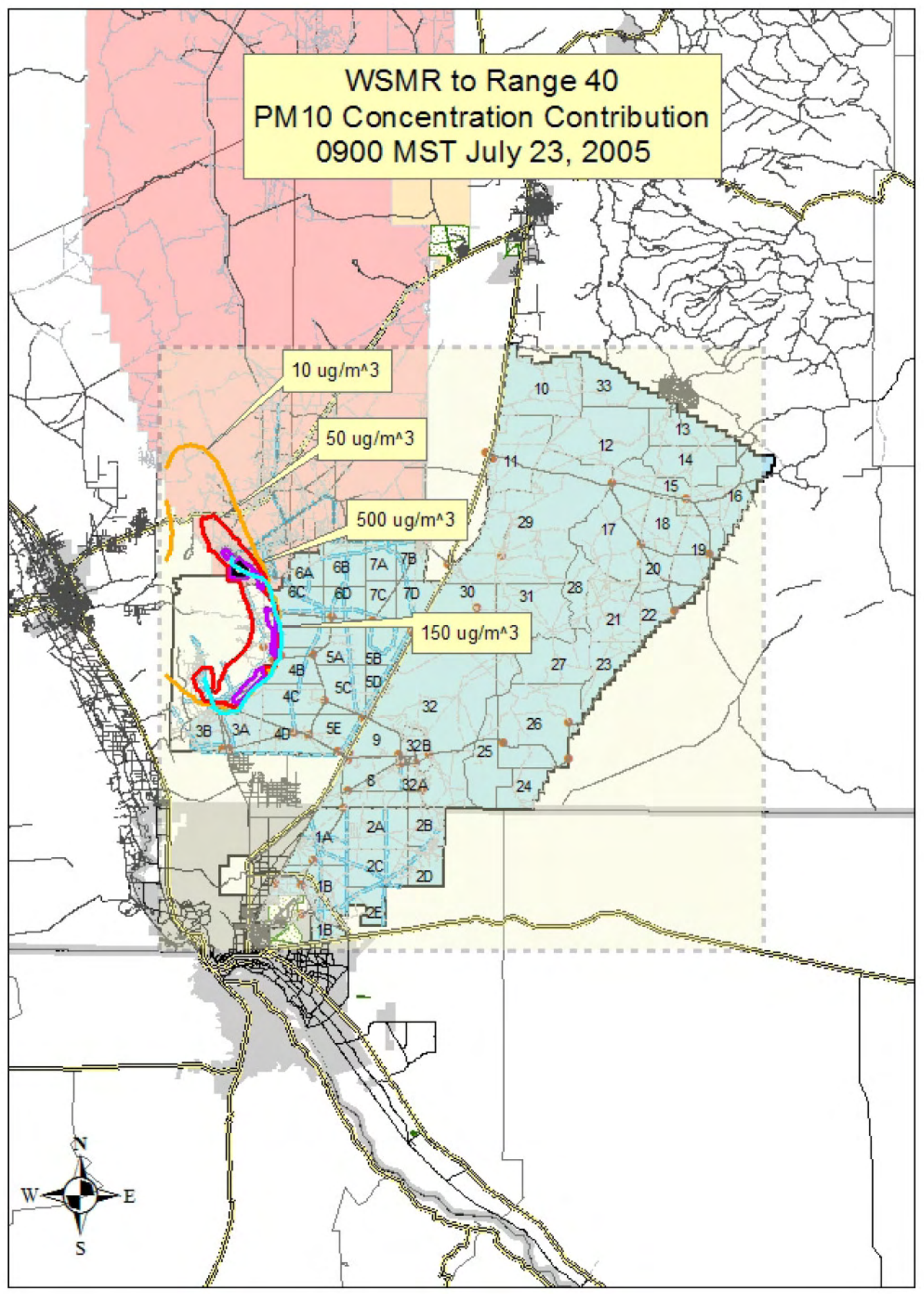




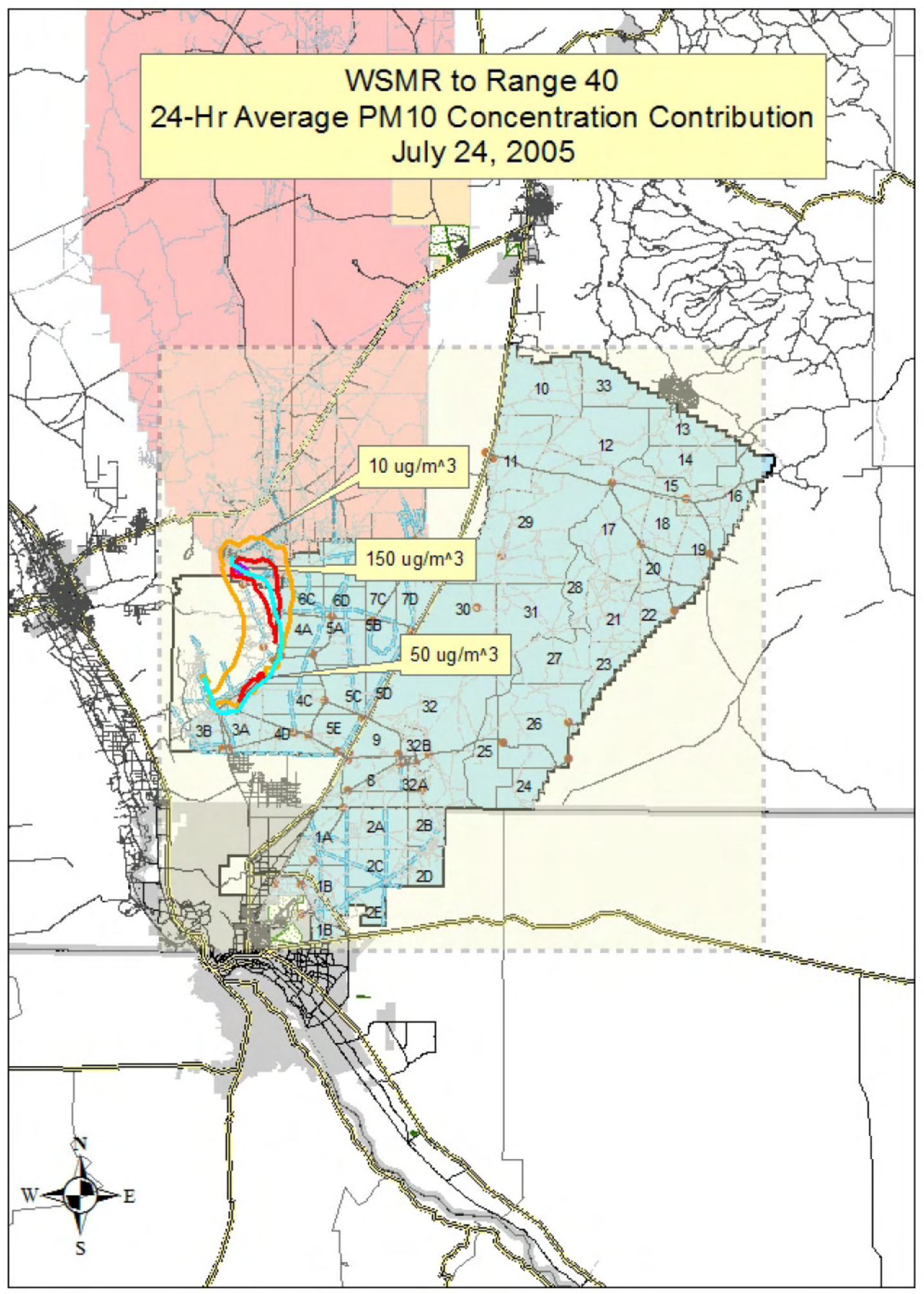




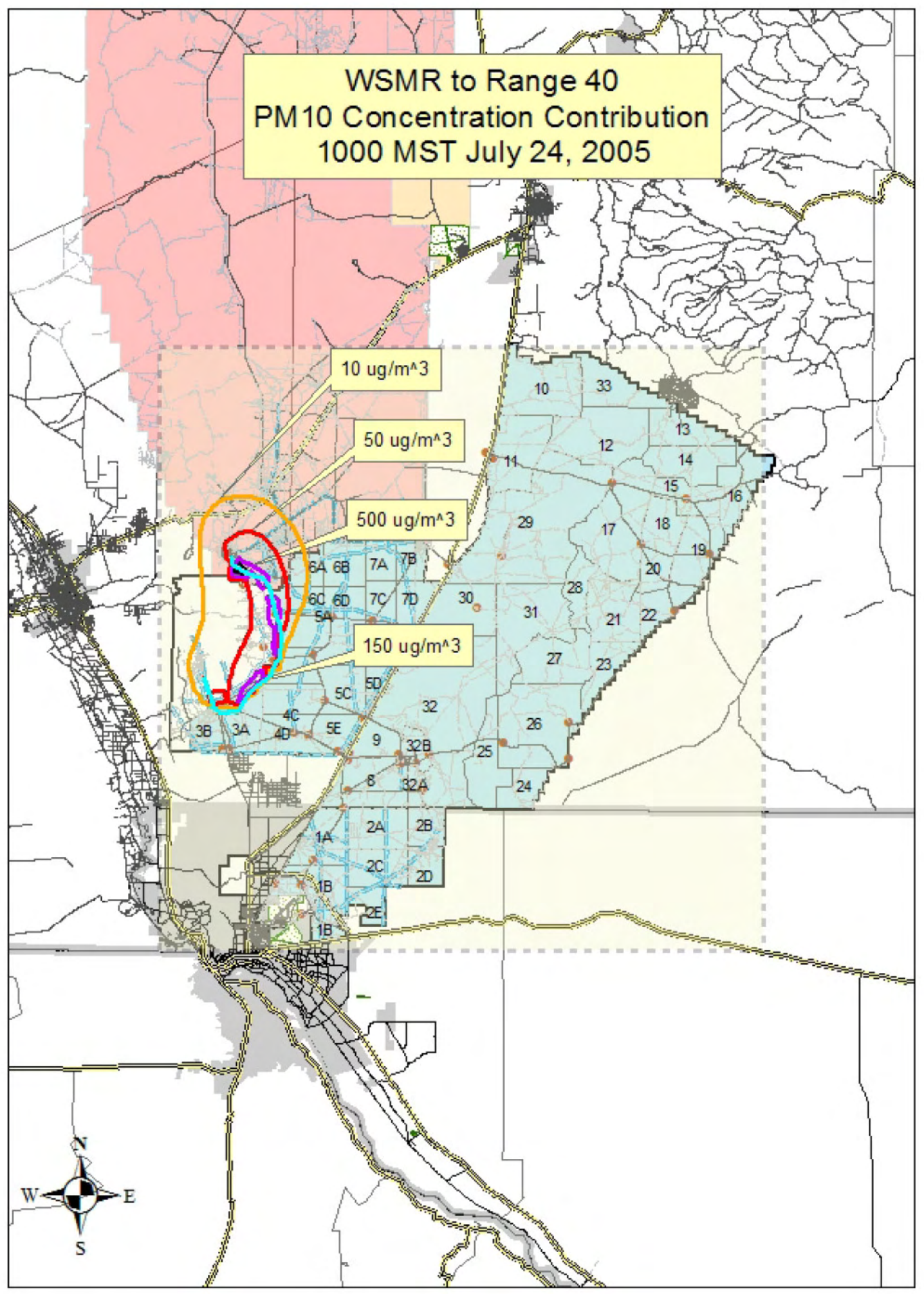




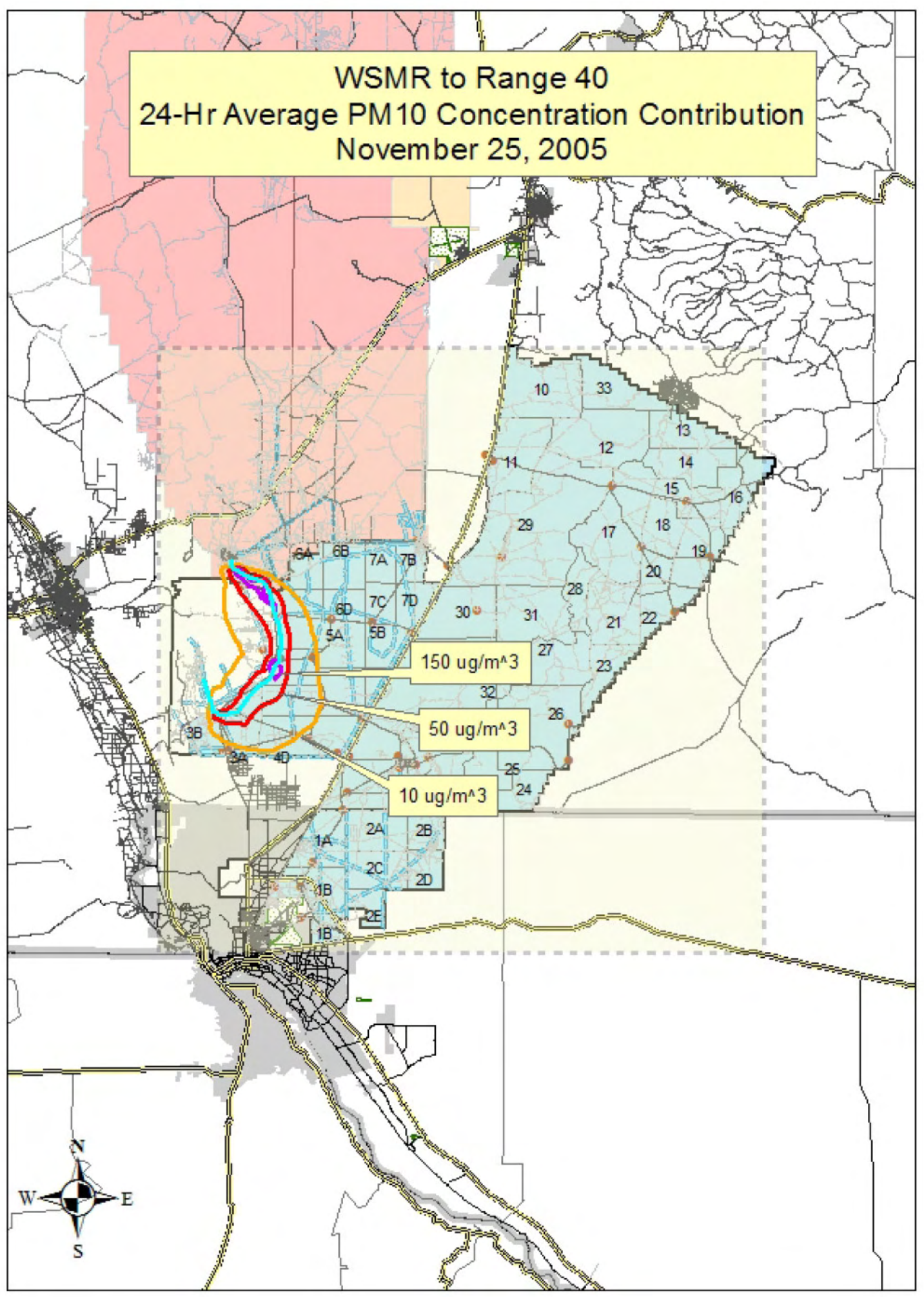




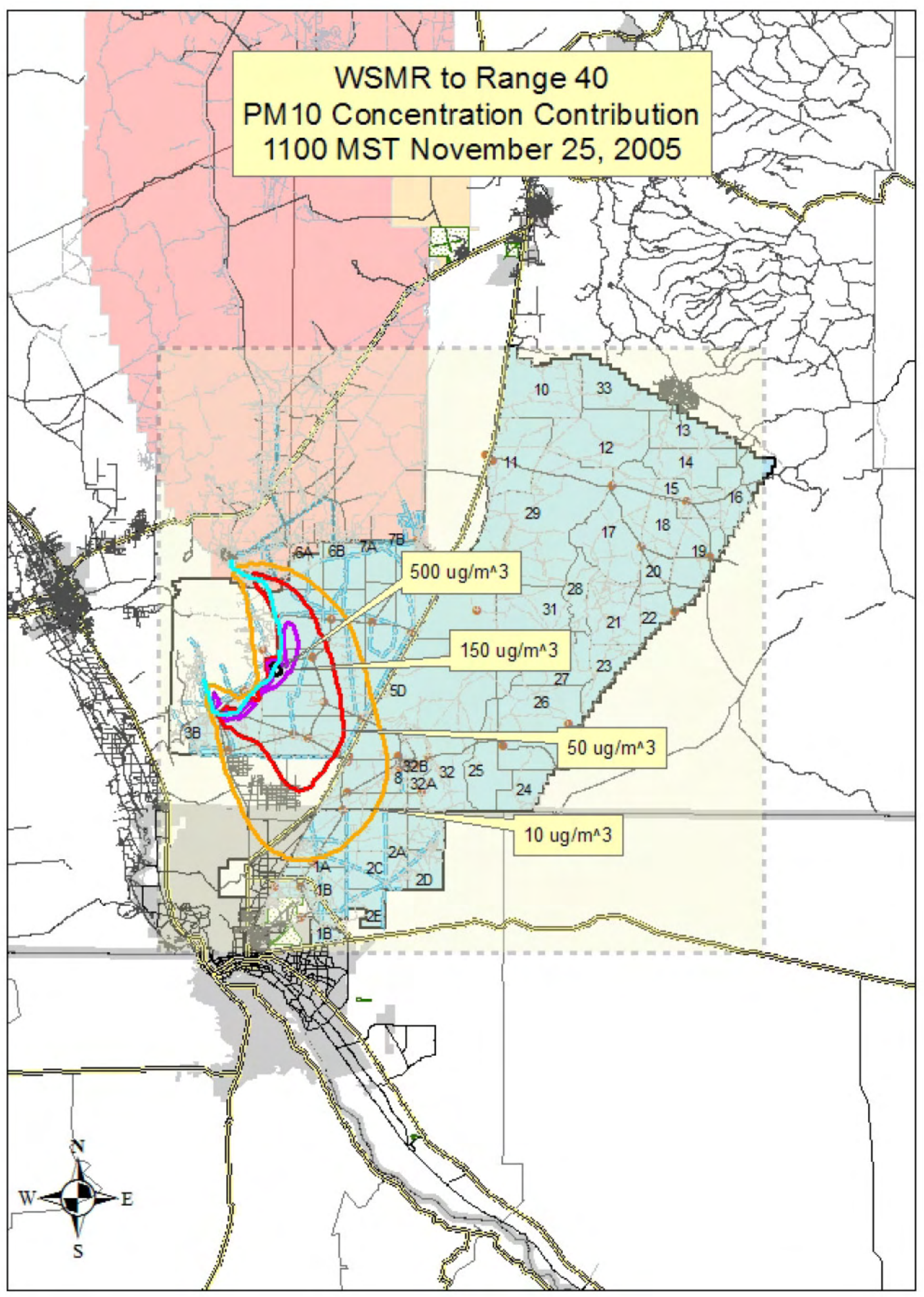




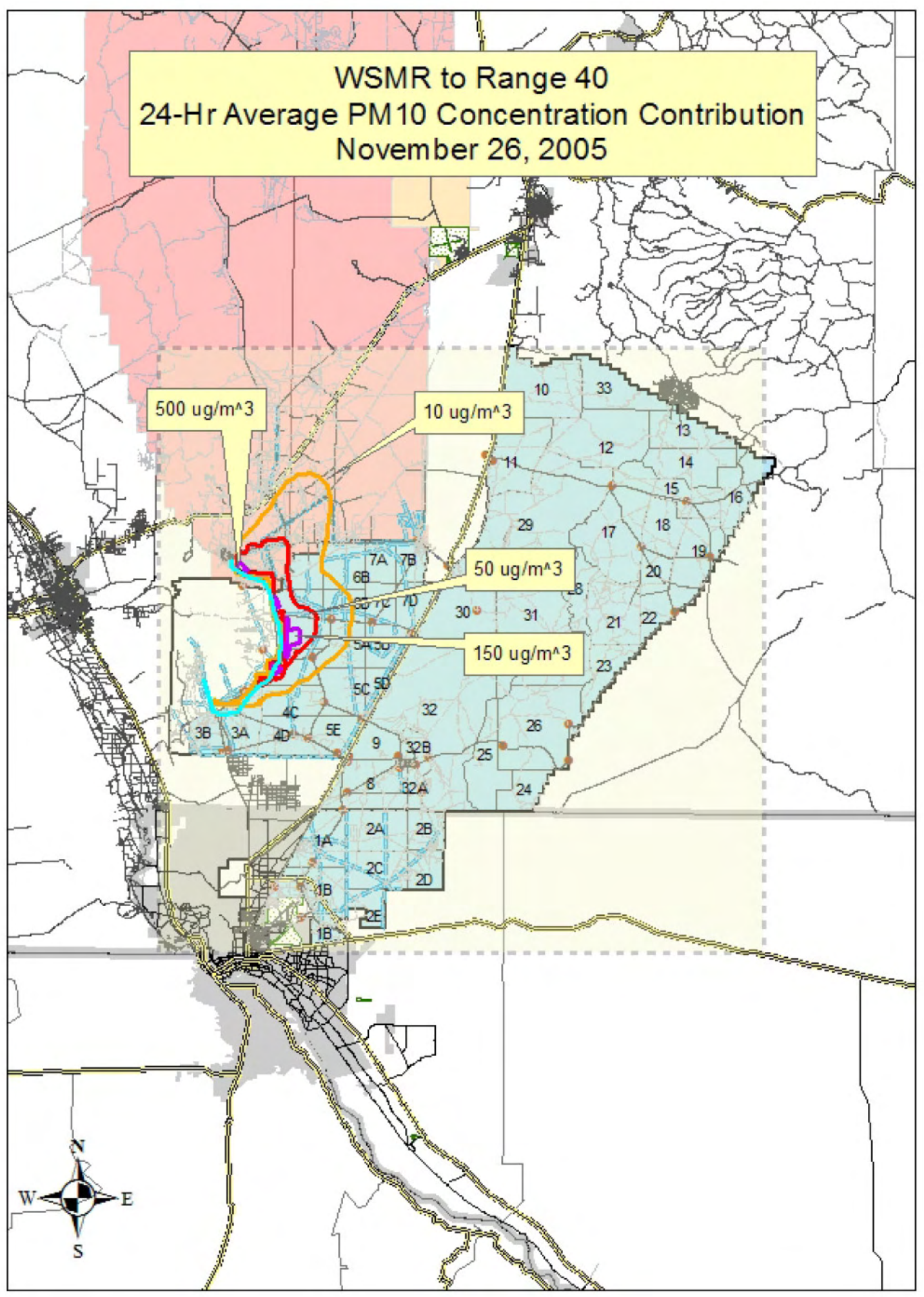




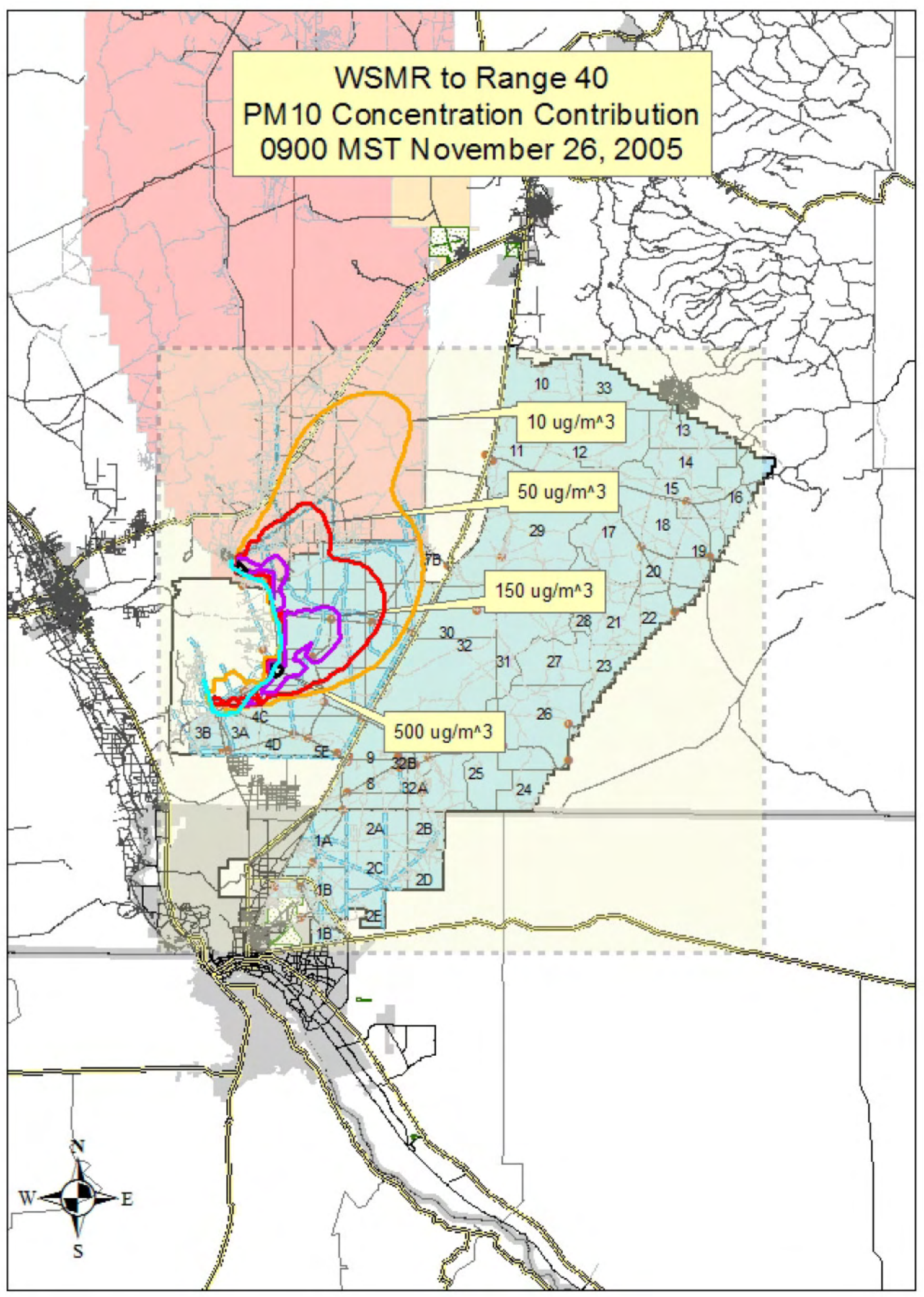




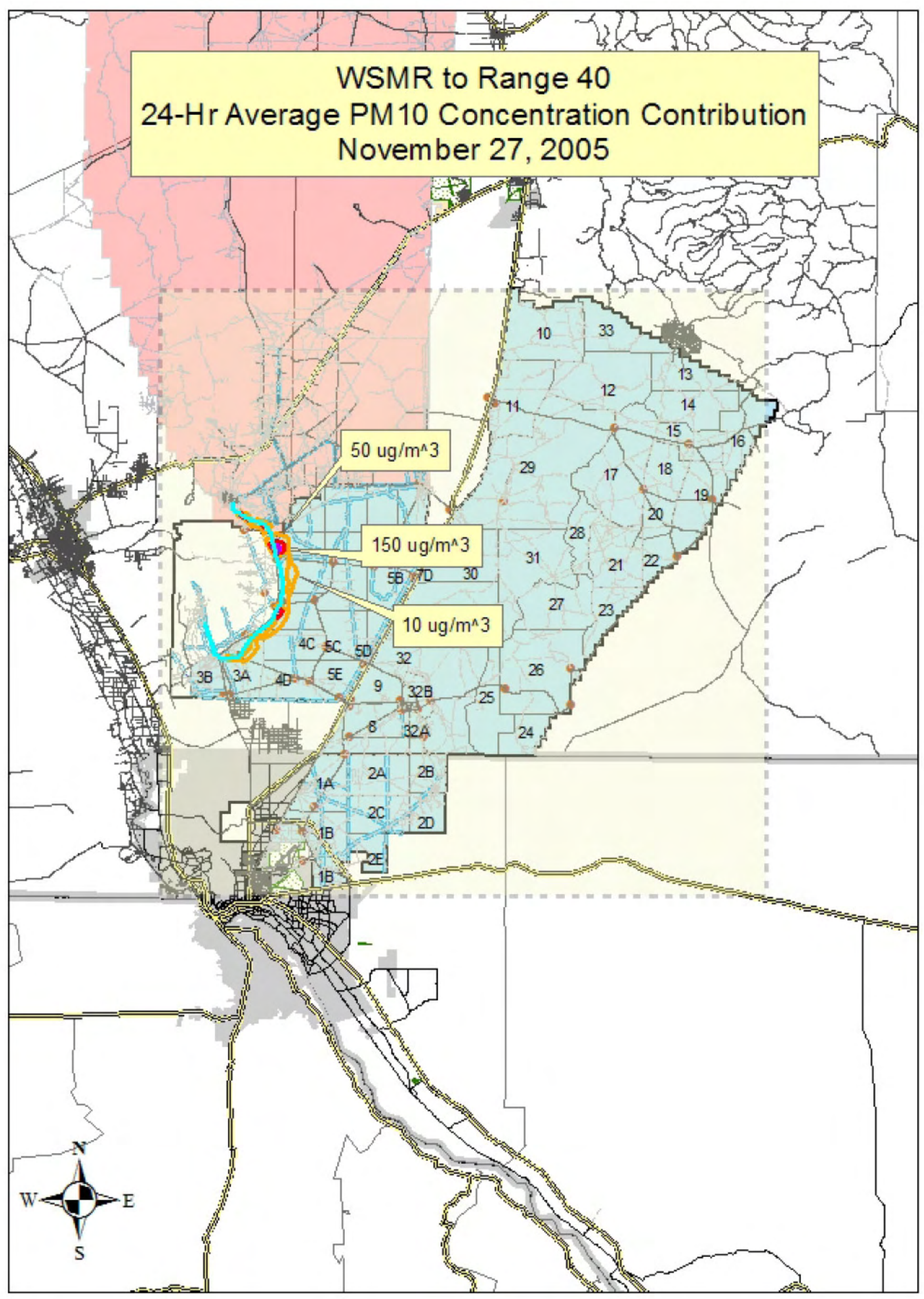




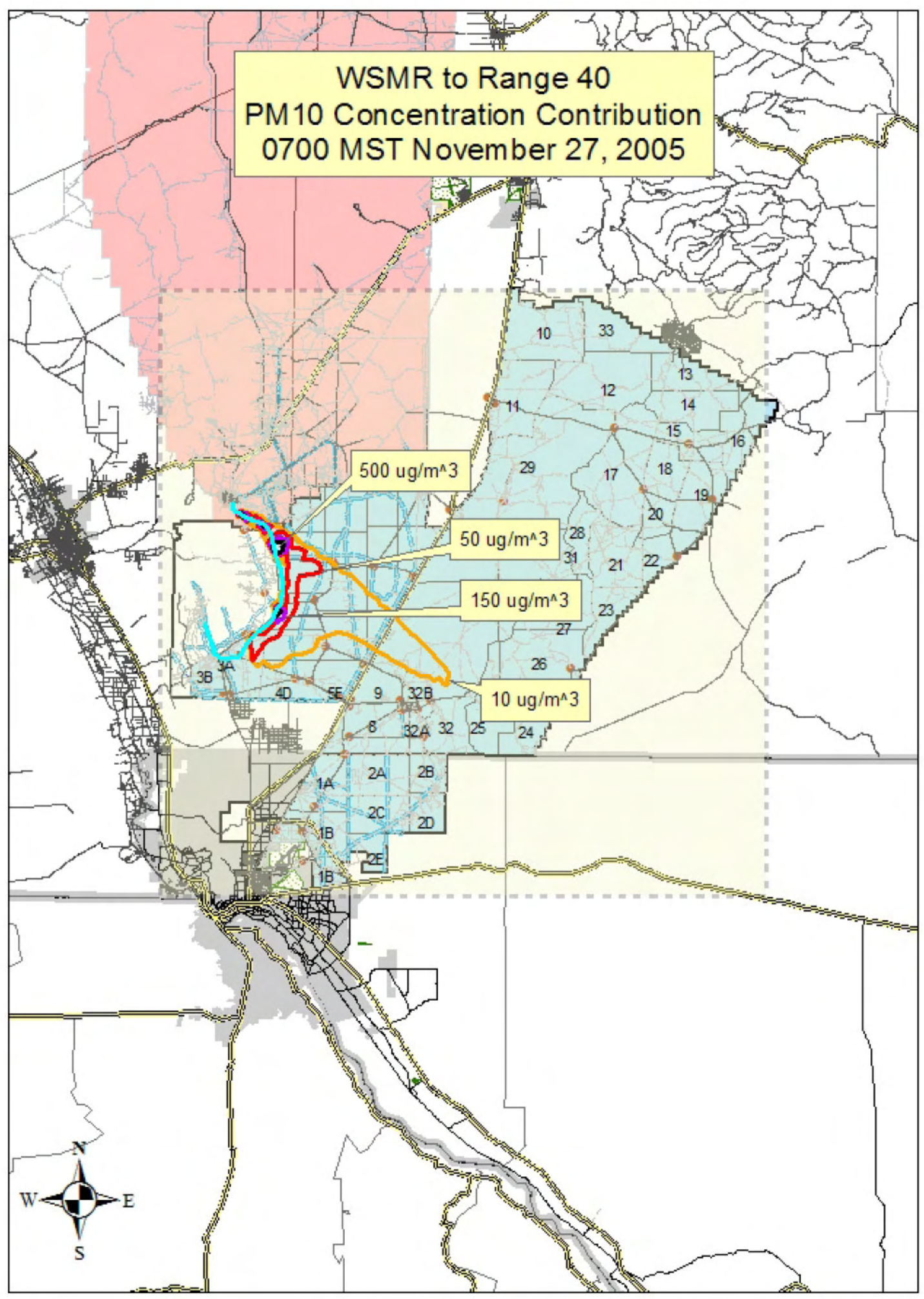




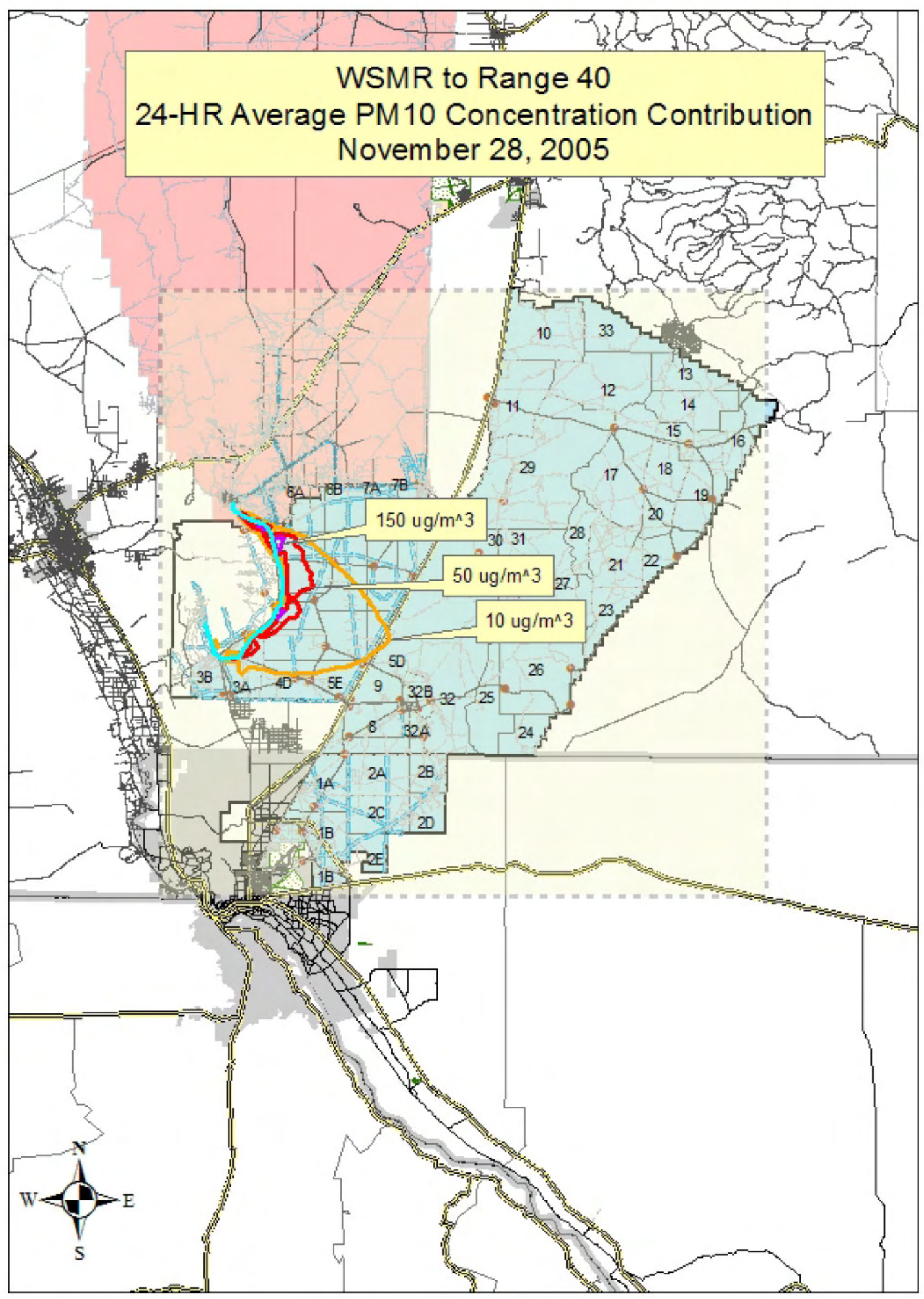




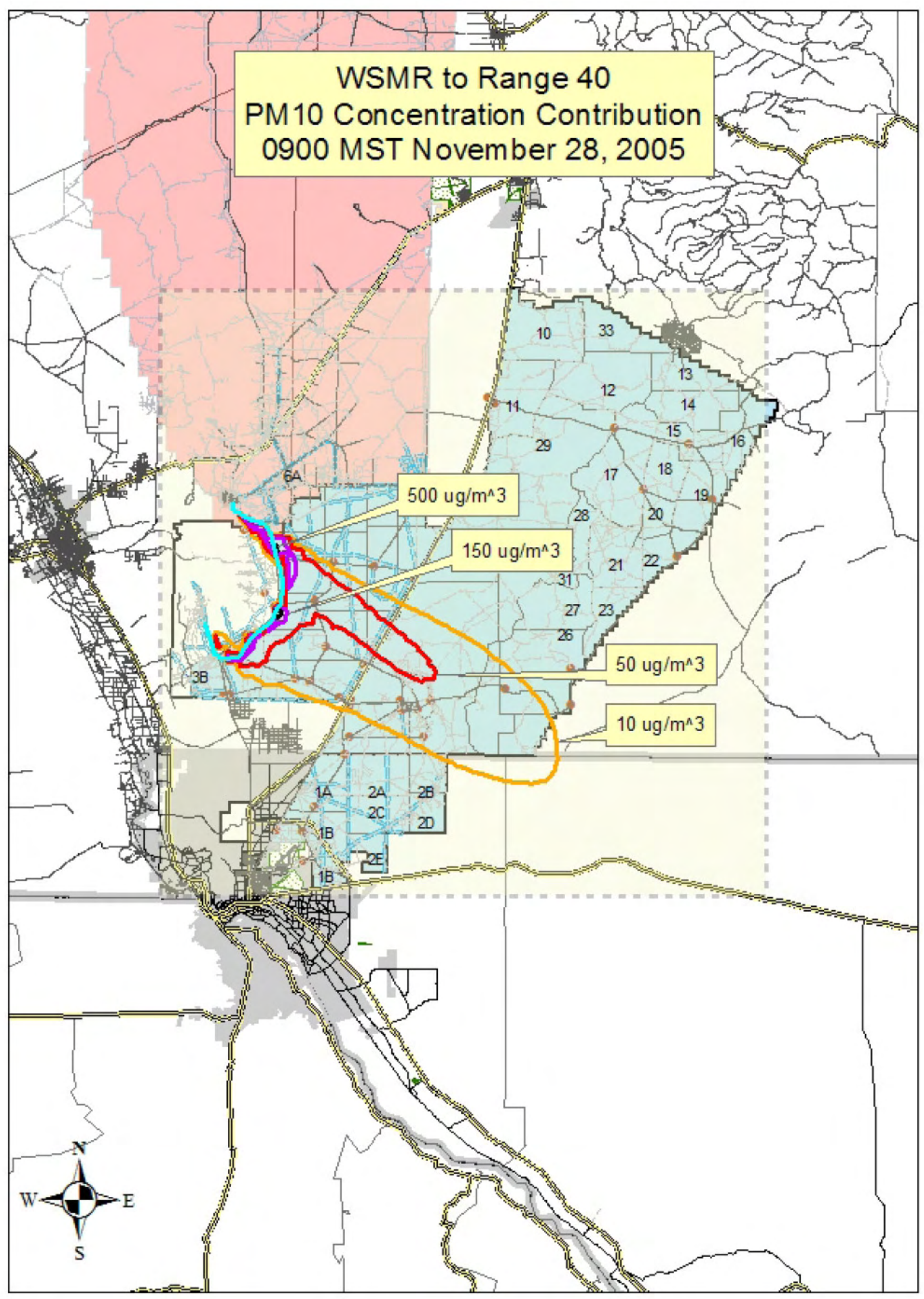




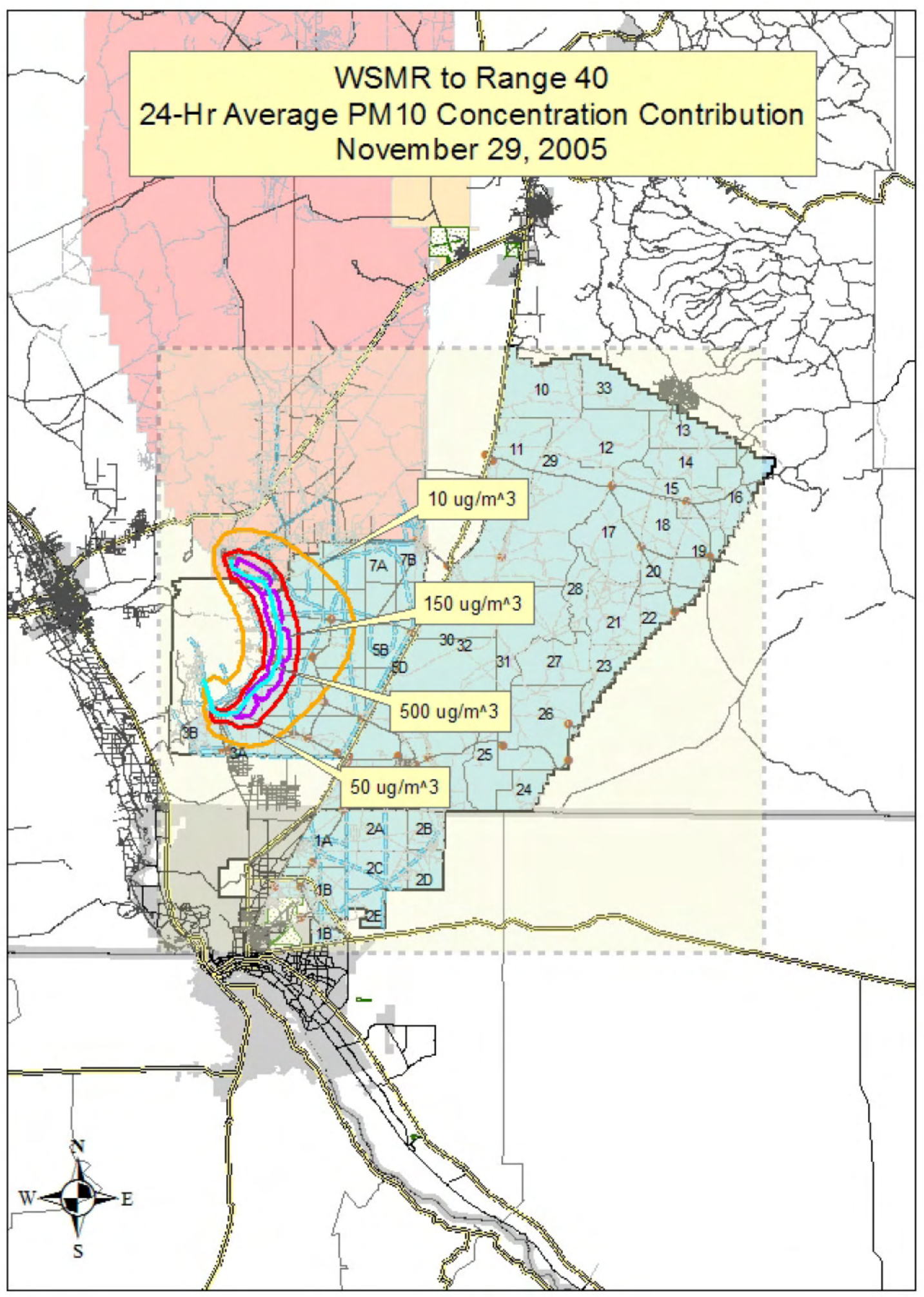




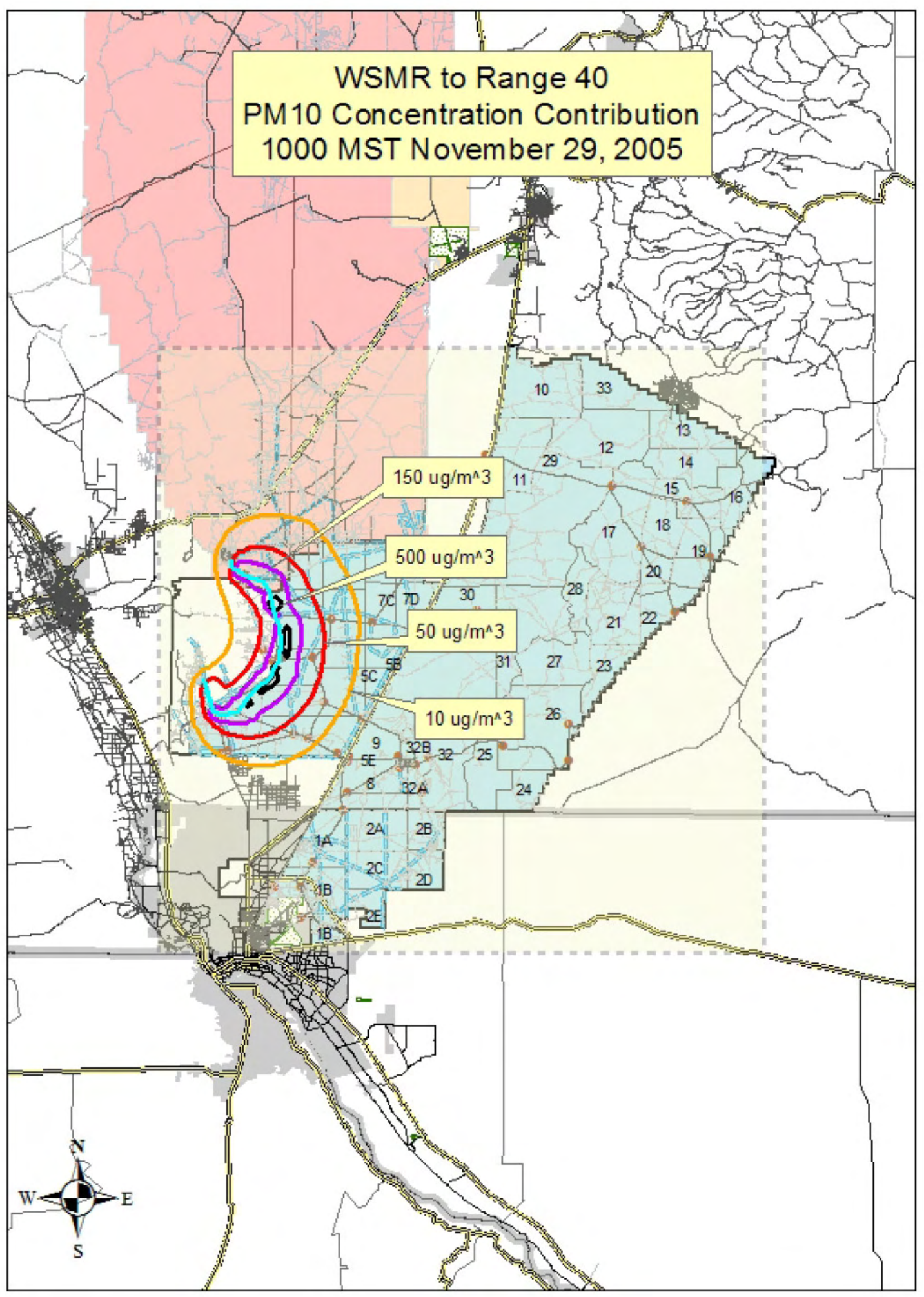





\section{Appendix D}

Simulated $\mathrm{PM}_{10}$ Concentrations for the Move-out from White Sands Missile Range to McGregor Range Camp via Dona Ana 



\section{Appendix D}

\section{Simulated $\mathrm{PM}_{10}$ Concentrations for the Move-out from White Sands Missile Range to McGregor Range Camp via Dona Ana}

The following pages present contour maps of simulated PM10 concentrations contributed by WSMR to McGregor Range via Camp Dona Ana move-out operations to air quality in and around Fort Bliss and WSMR for the 21 days (March 12-16, April 25-30, July 20-24, and November 25-29, 2005) studied in this investigation. For each day, the contour map of the 24-hour-average PM10 concentration

contribution is shown first, followed by a contour map of PM10 concentration contributions for a specific hour. The hour listed in the figure header represents the start of the hour, e.g., 1000 MST means the hour from 1000 MST to 1100 MST. Move-out scenario assumptions are summarized in Section 3 of this report. 


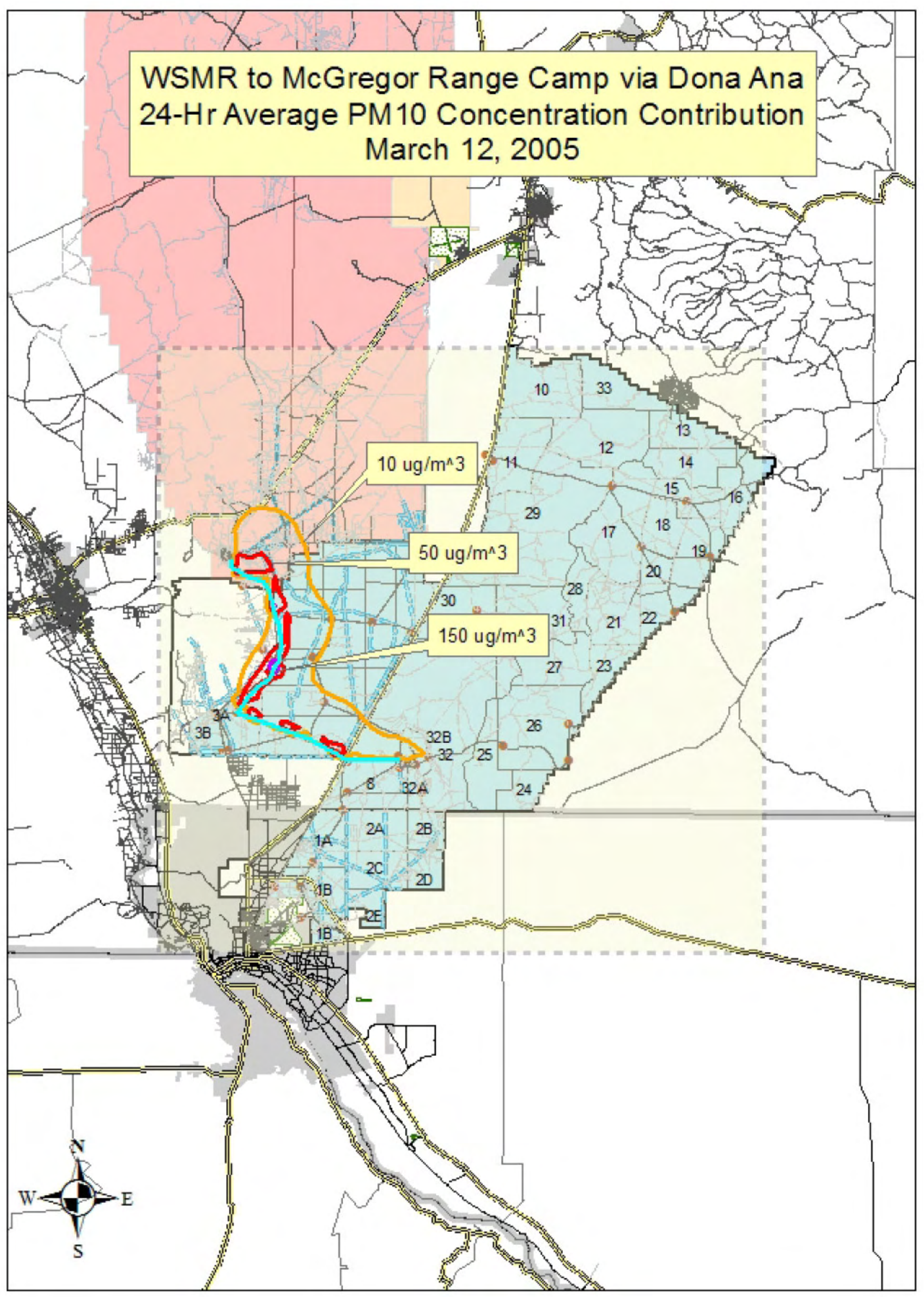




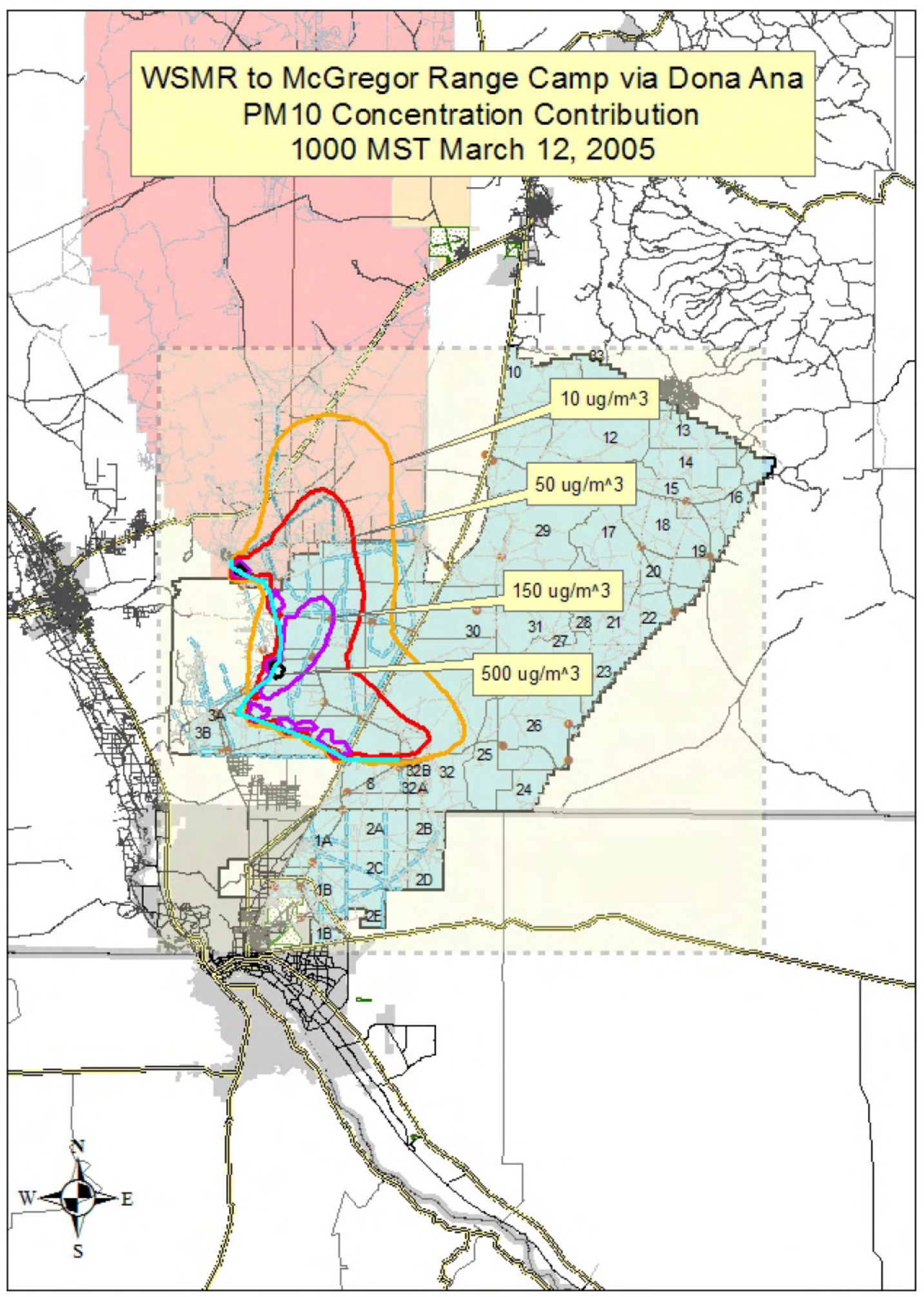




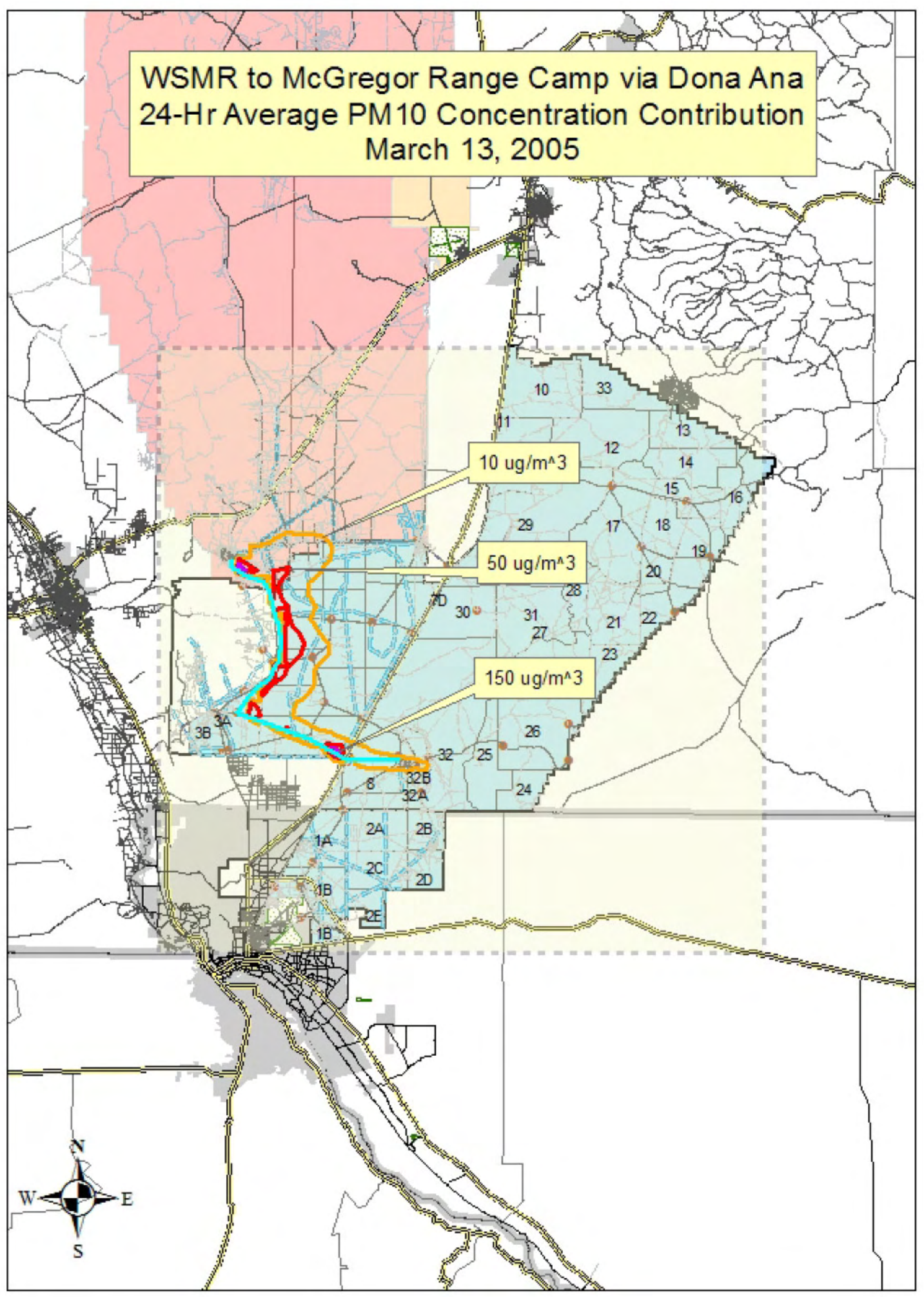




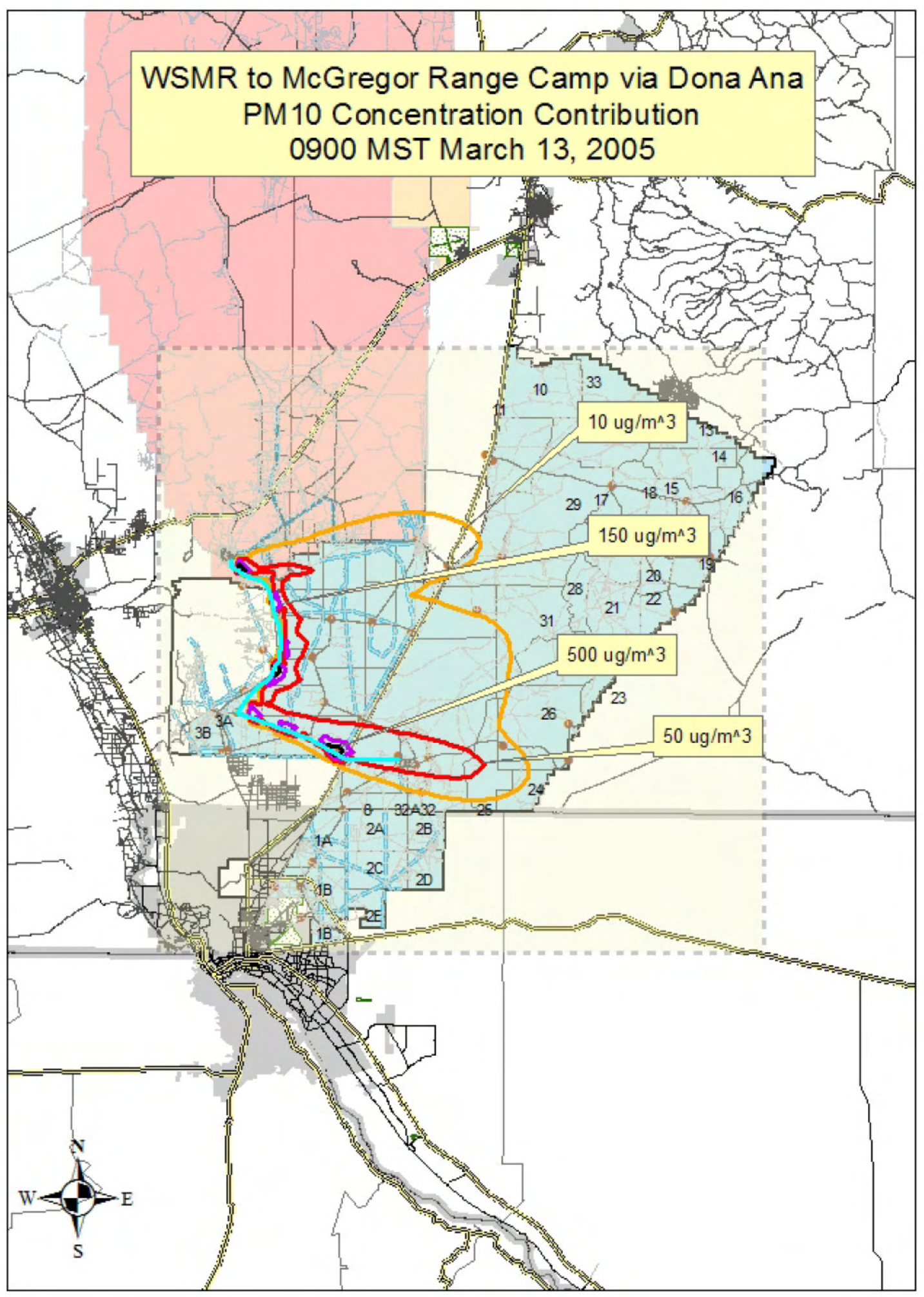

D. 5 


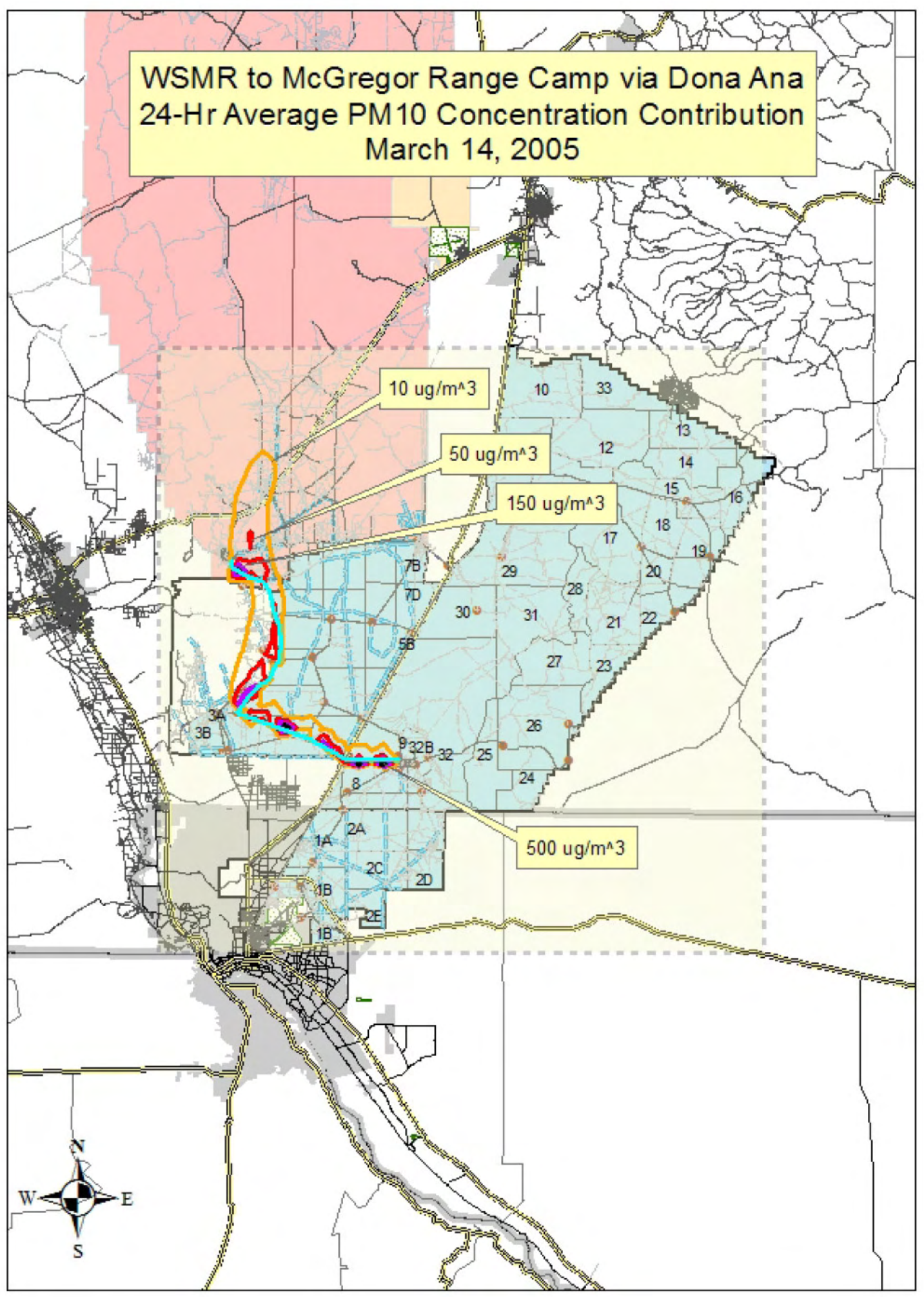

D. 6 


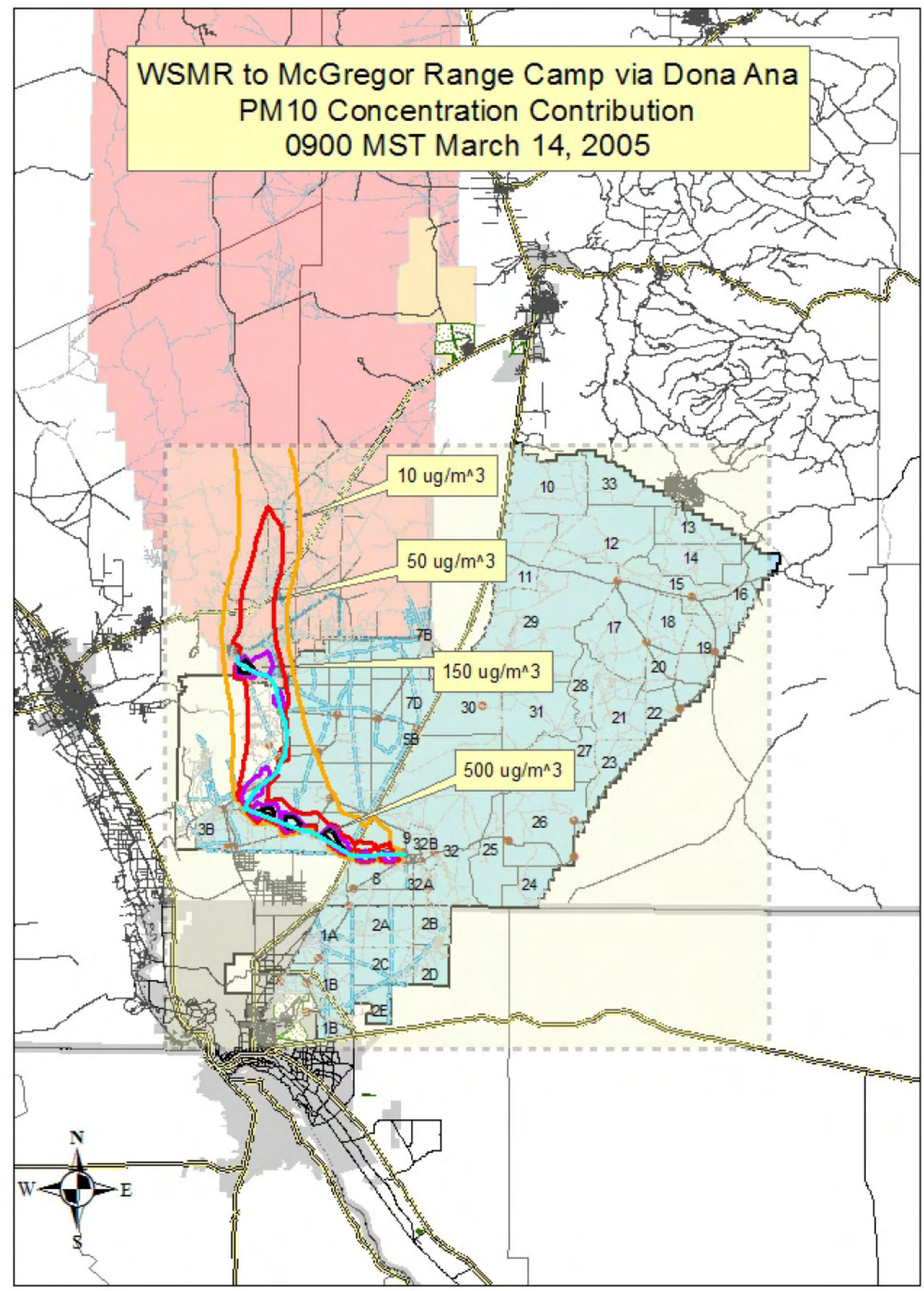

D. 7 


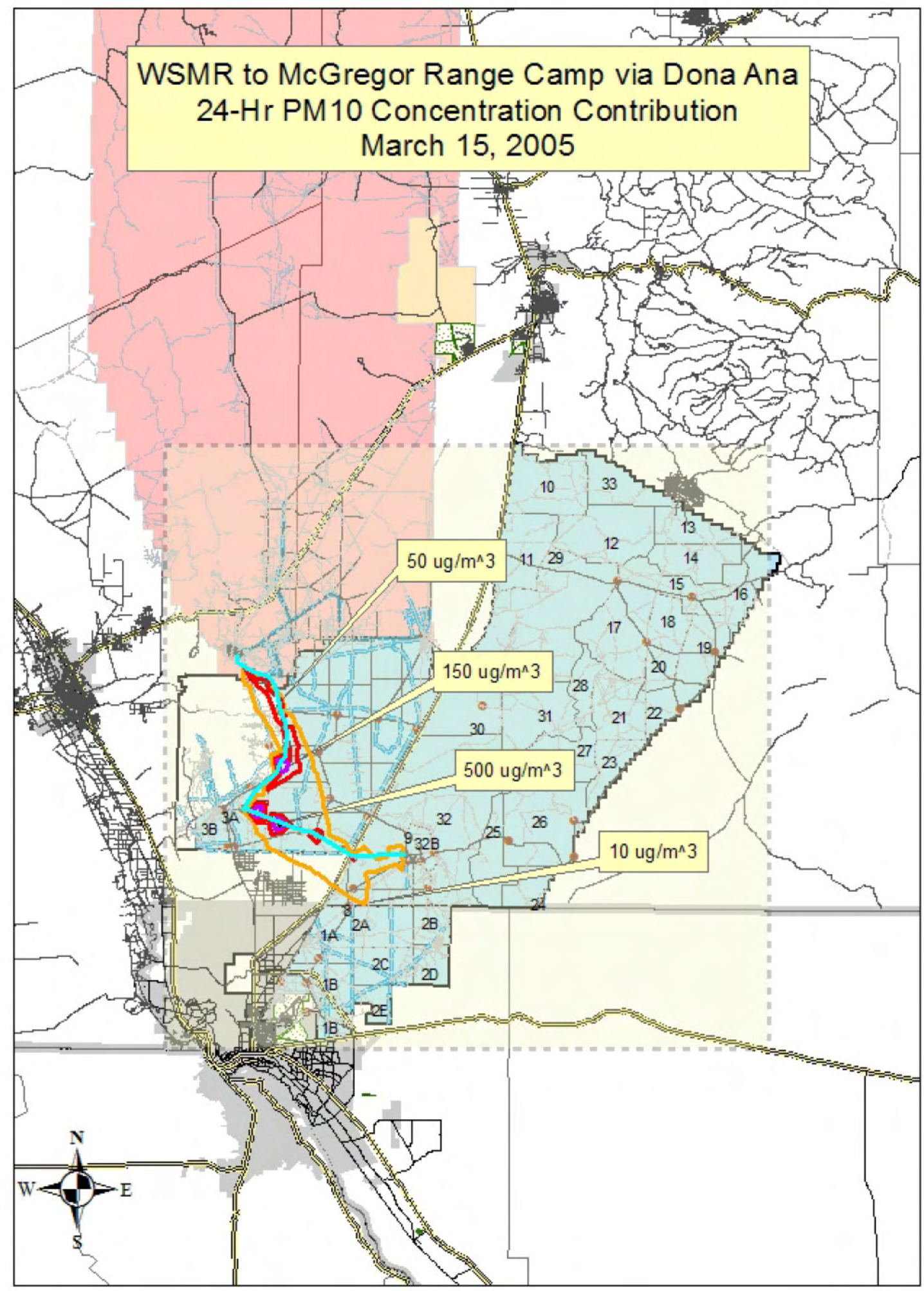




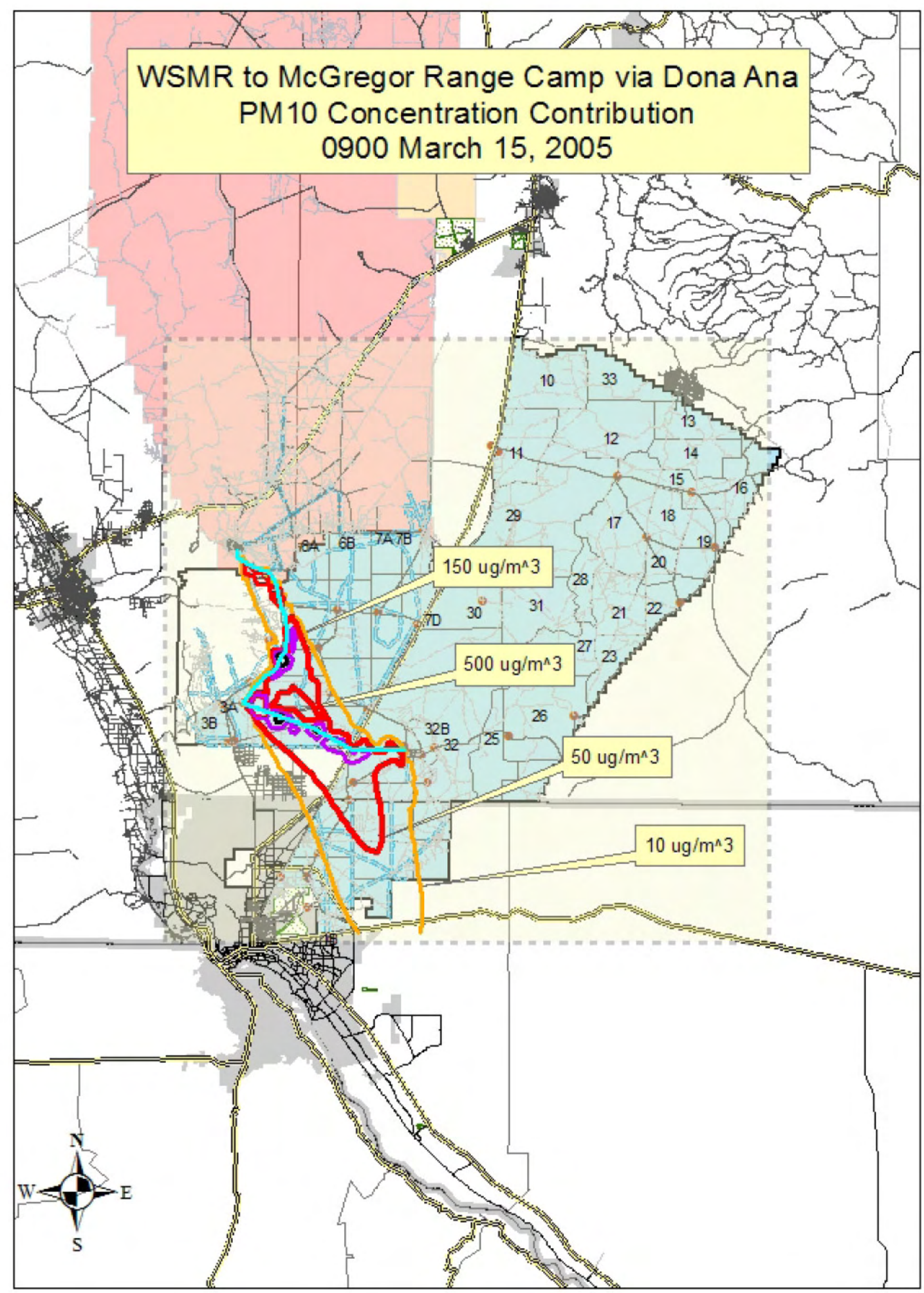




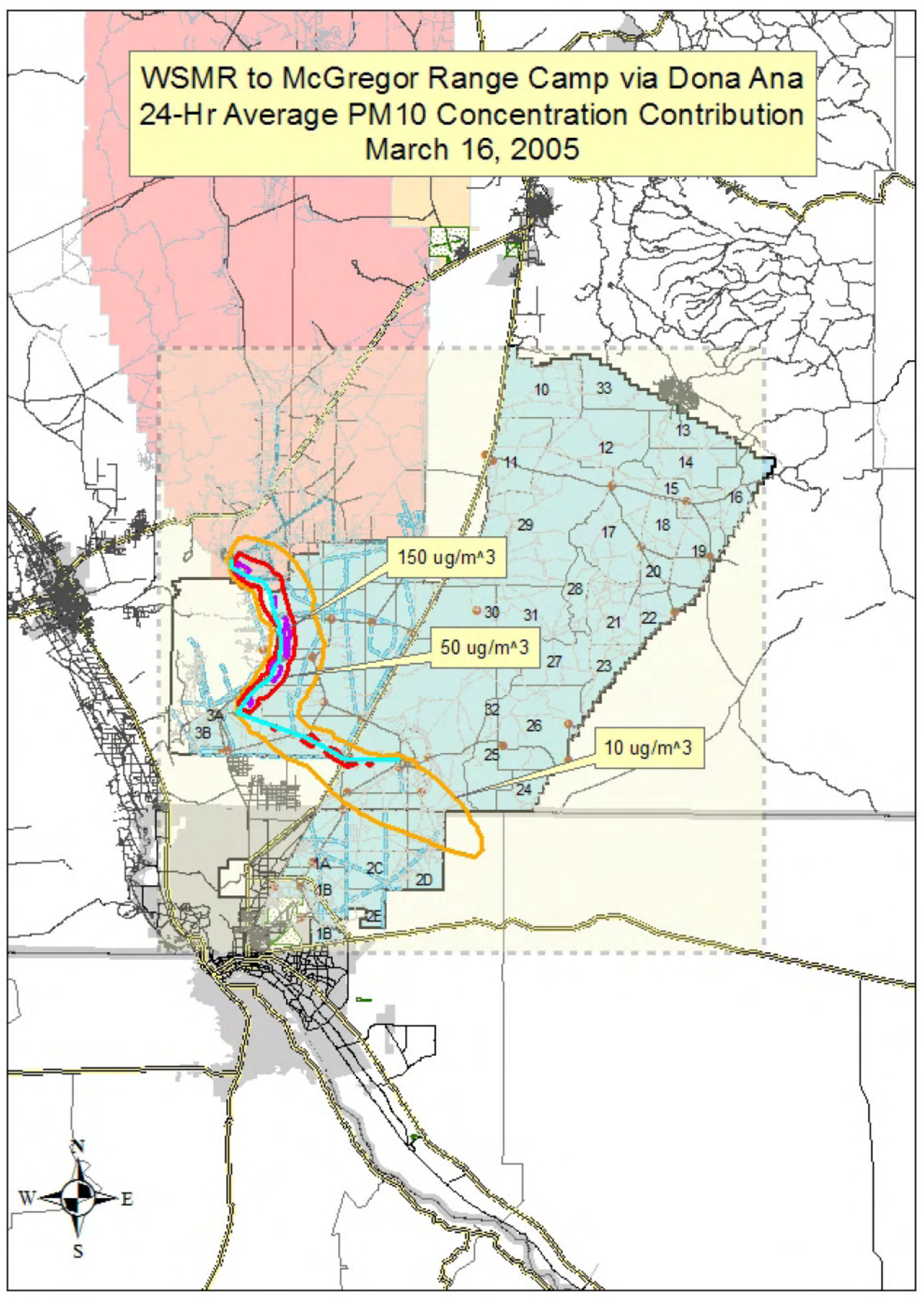

D.10 


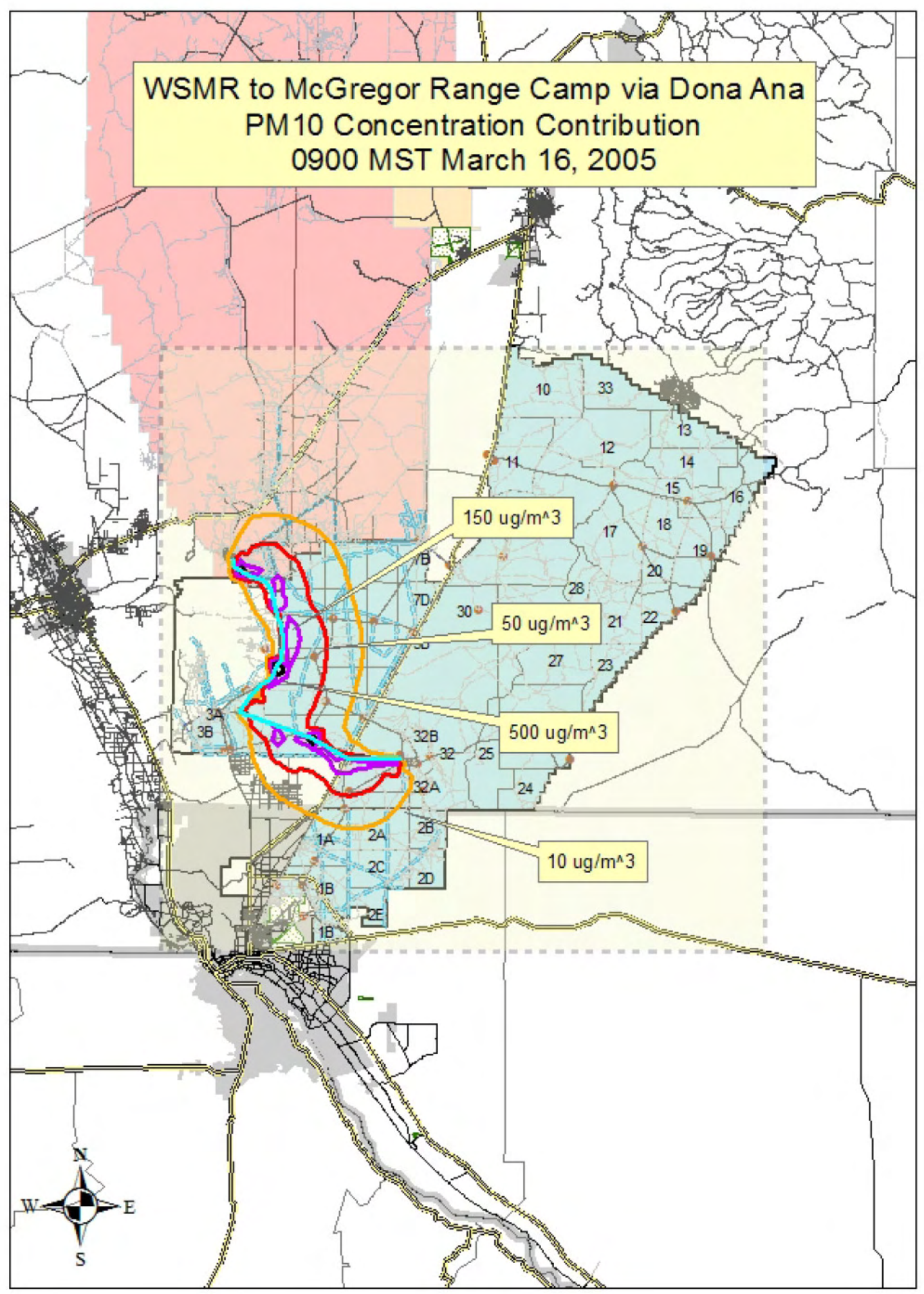

D.11 


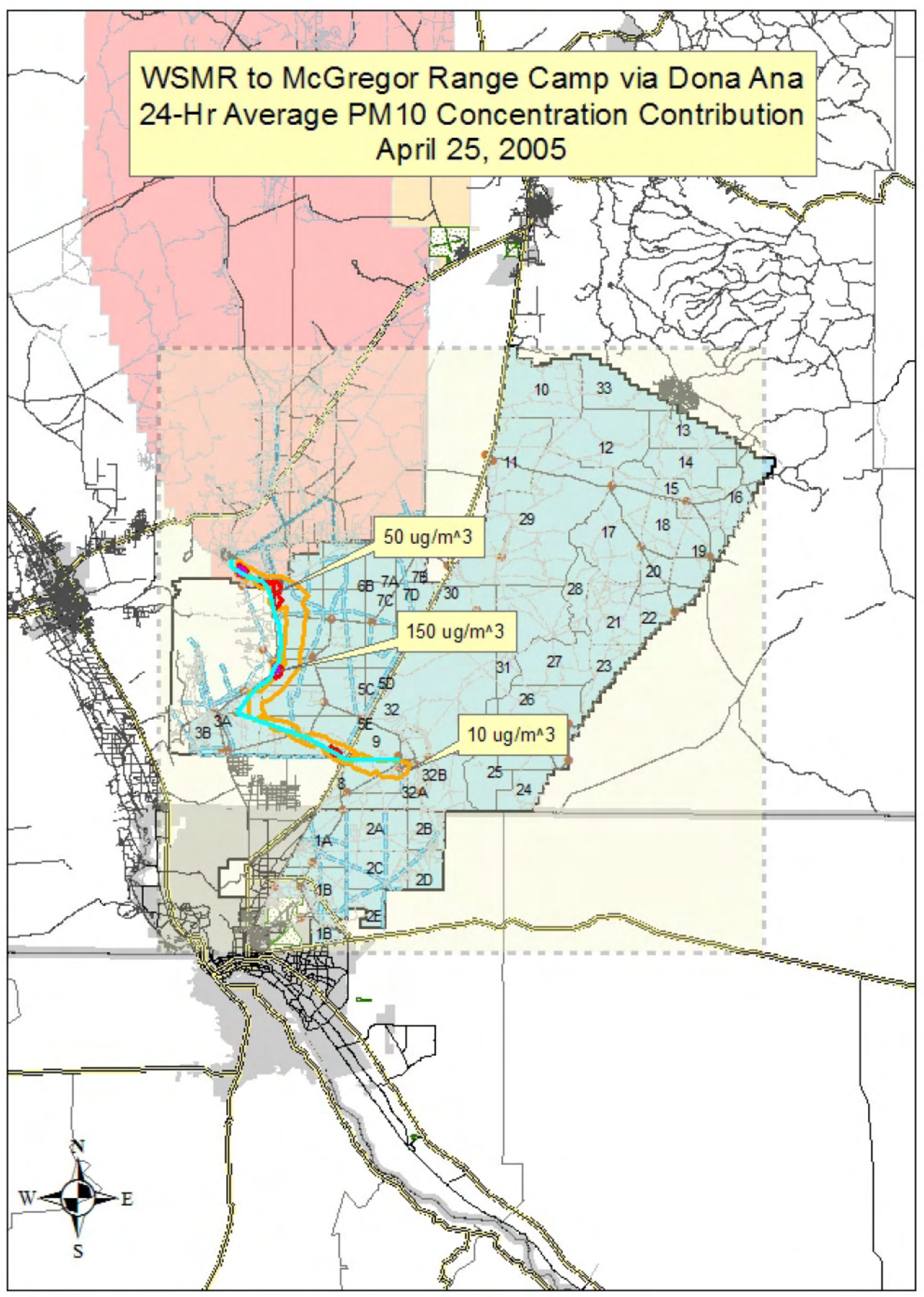

D.12 


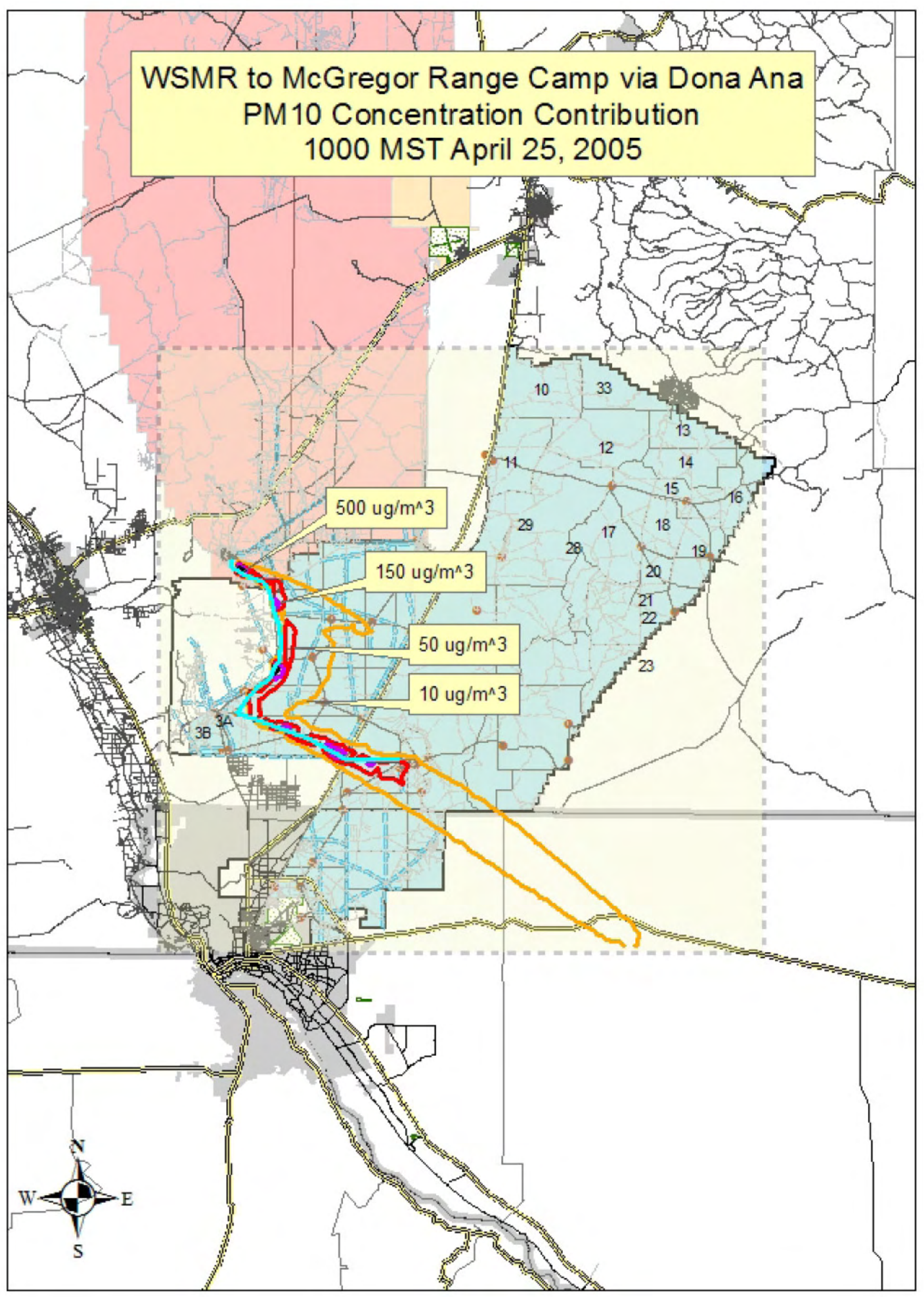

D.13 


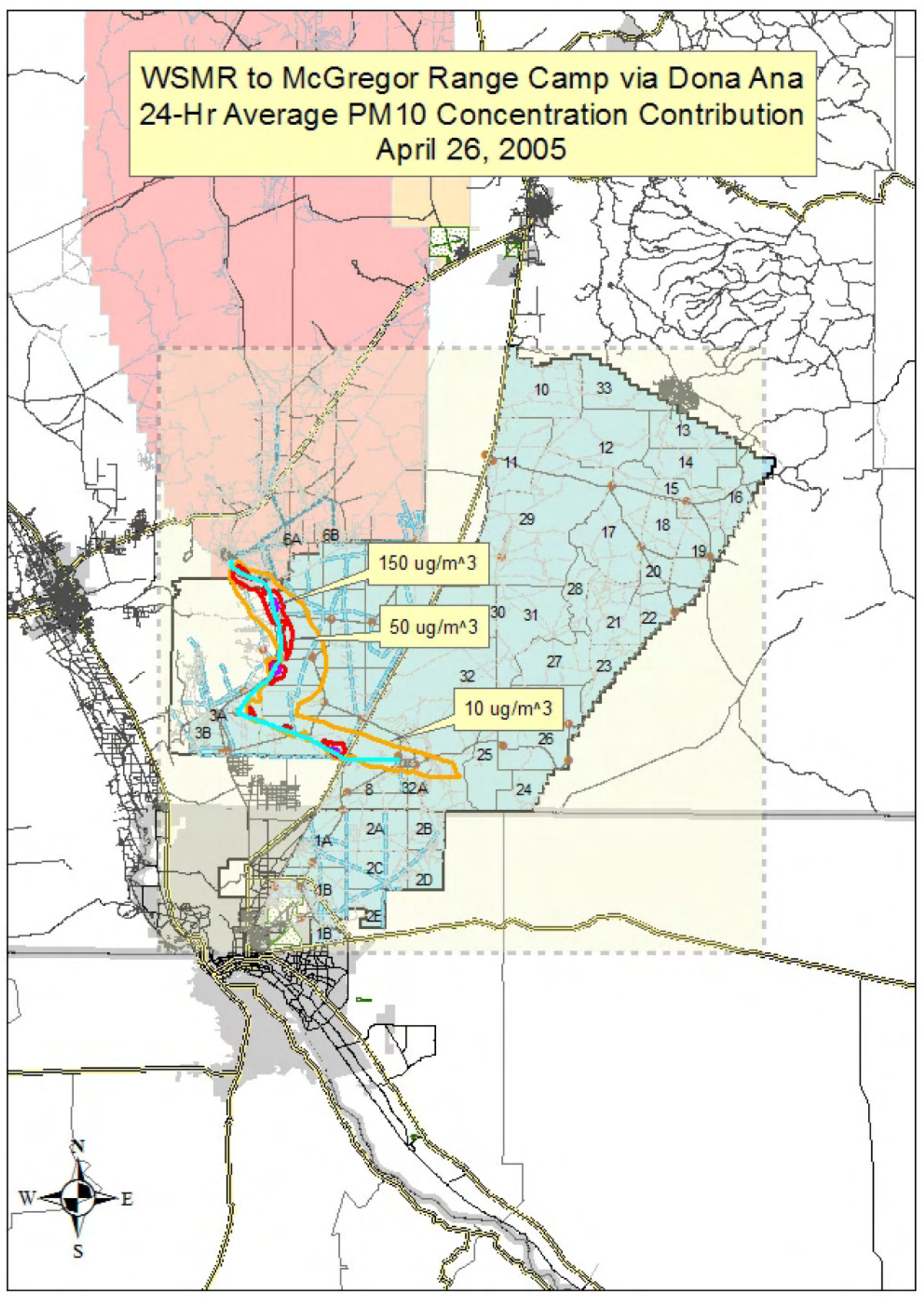

D.14 


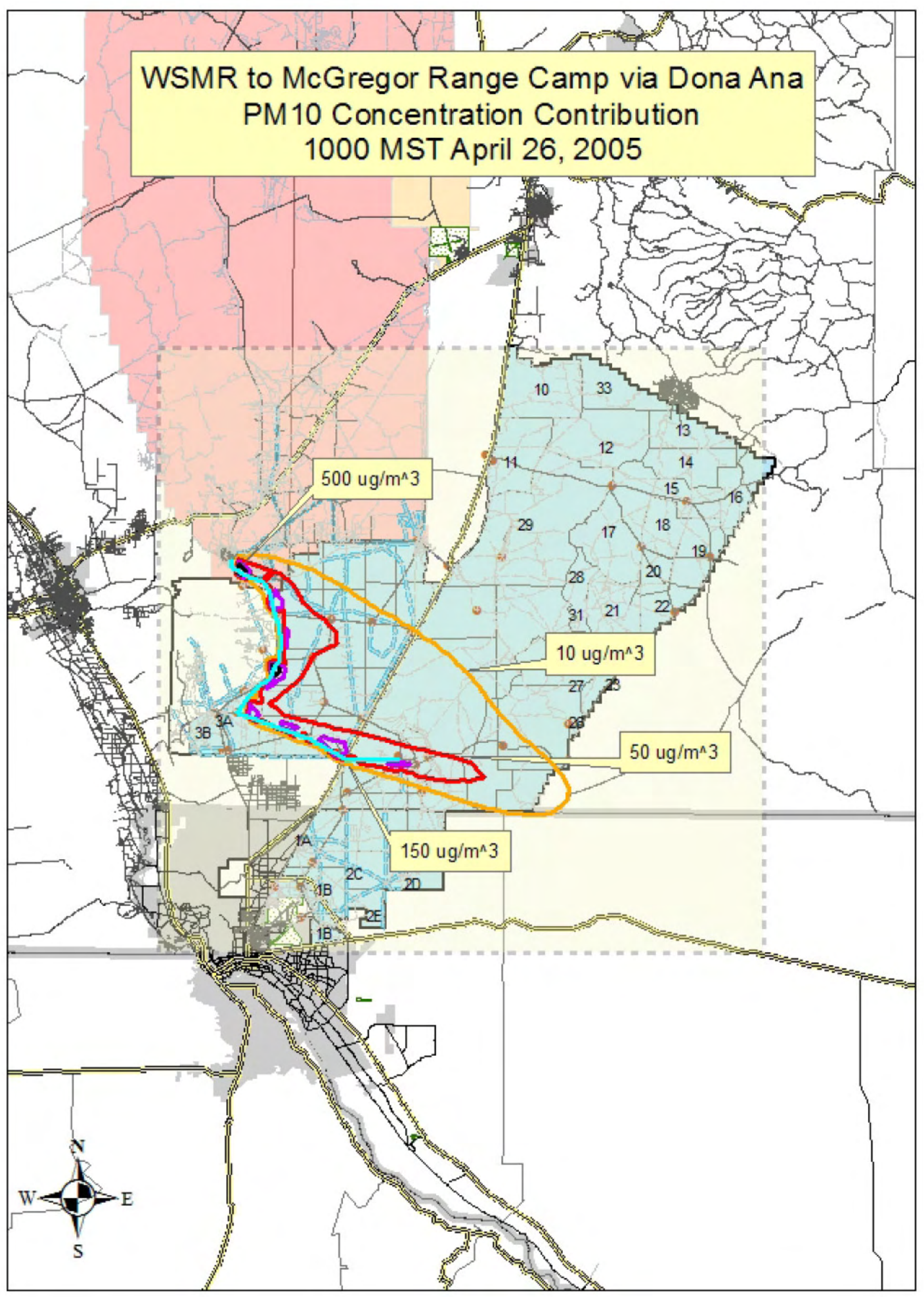

D.15 


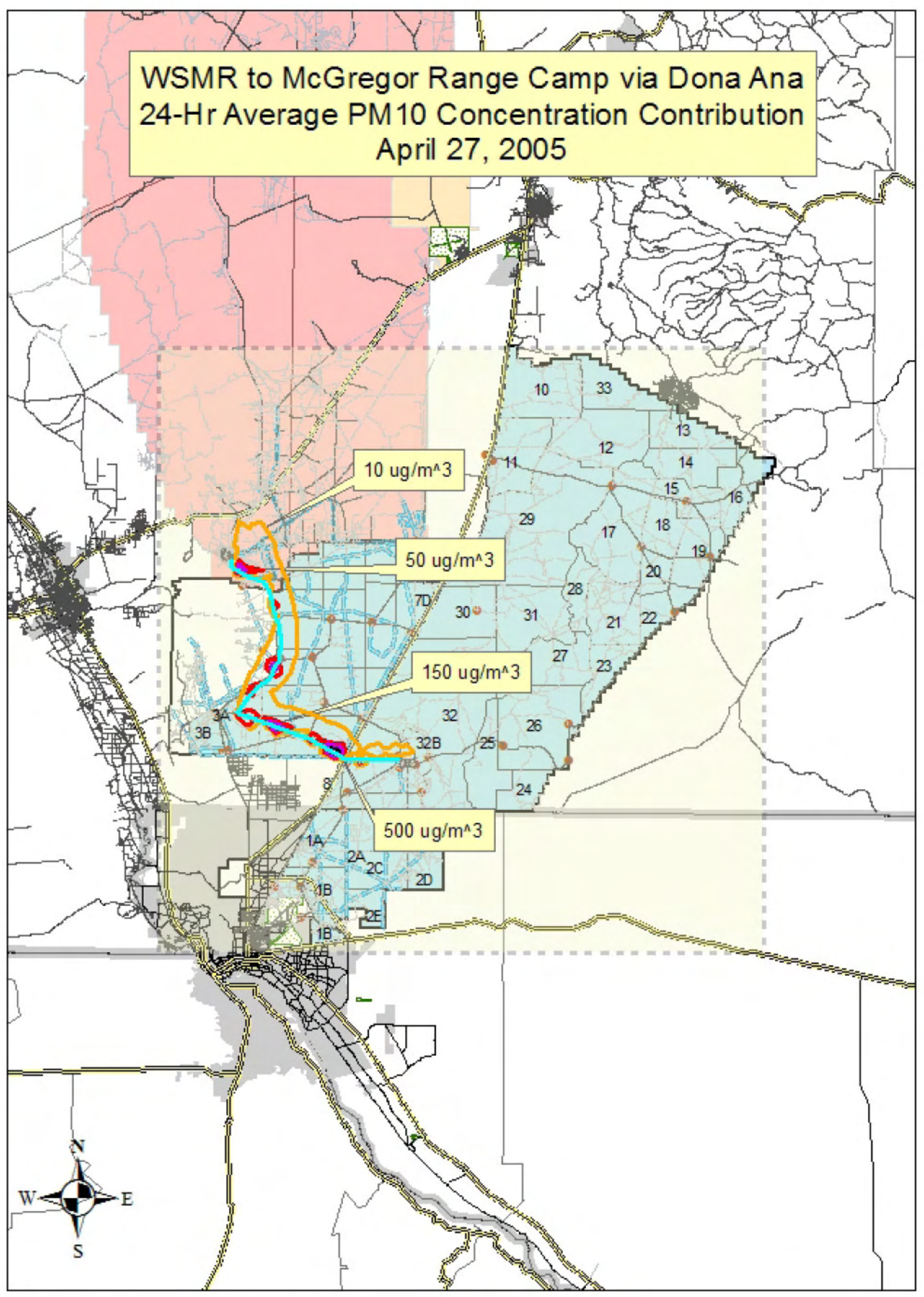

D.16 


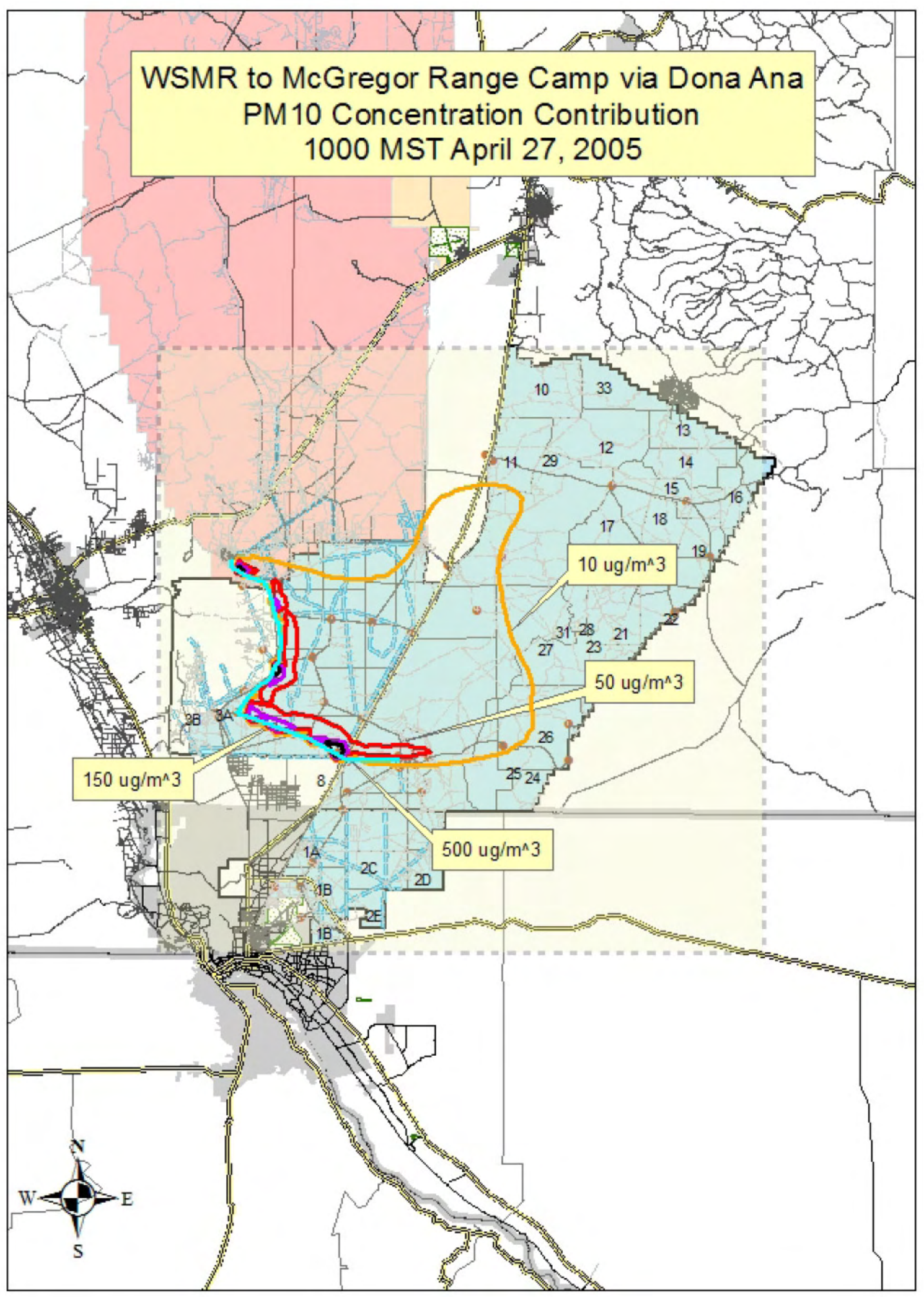

D.17 


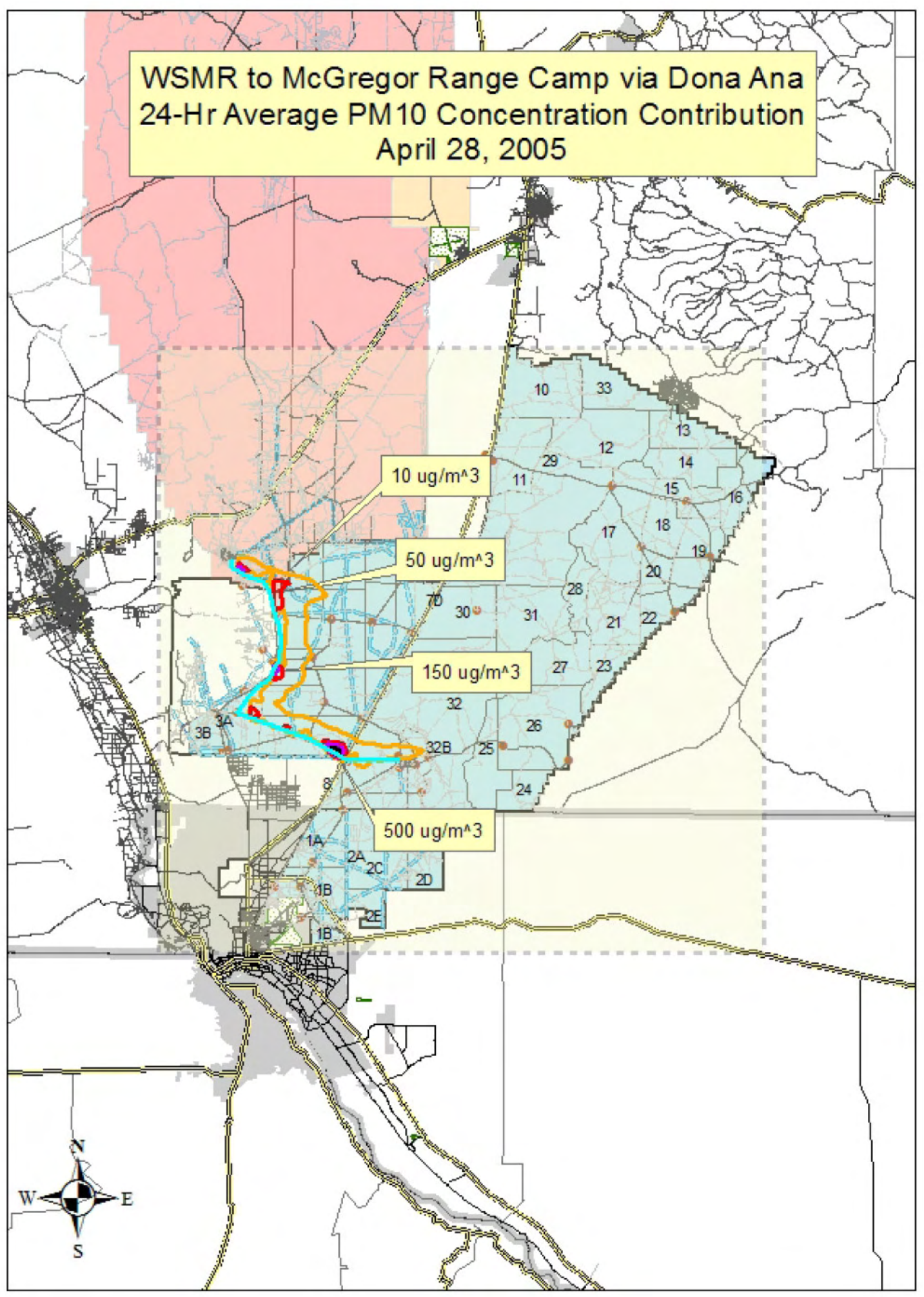

D.18 


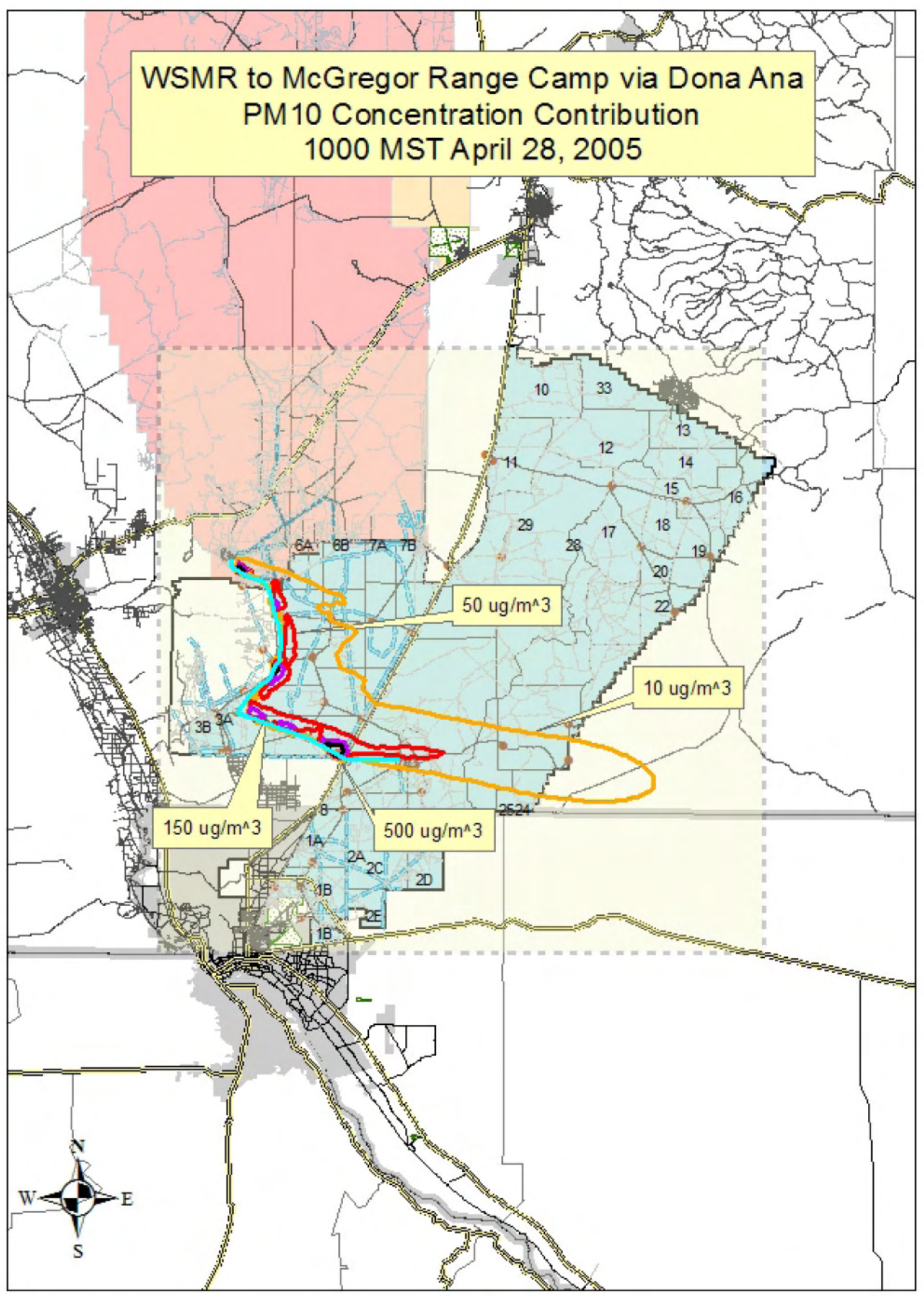

D.19 


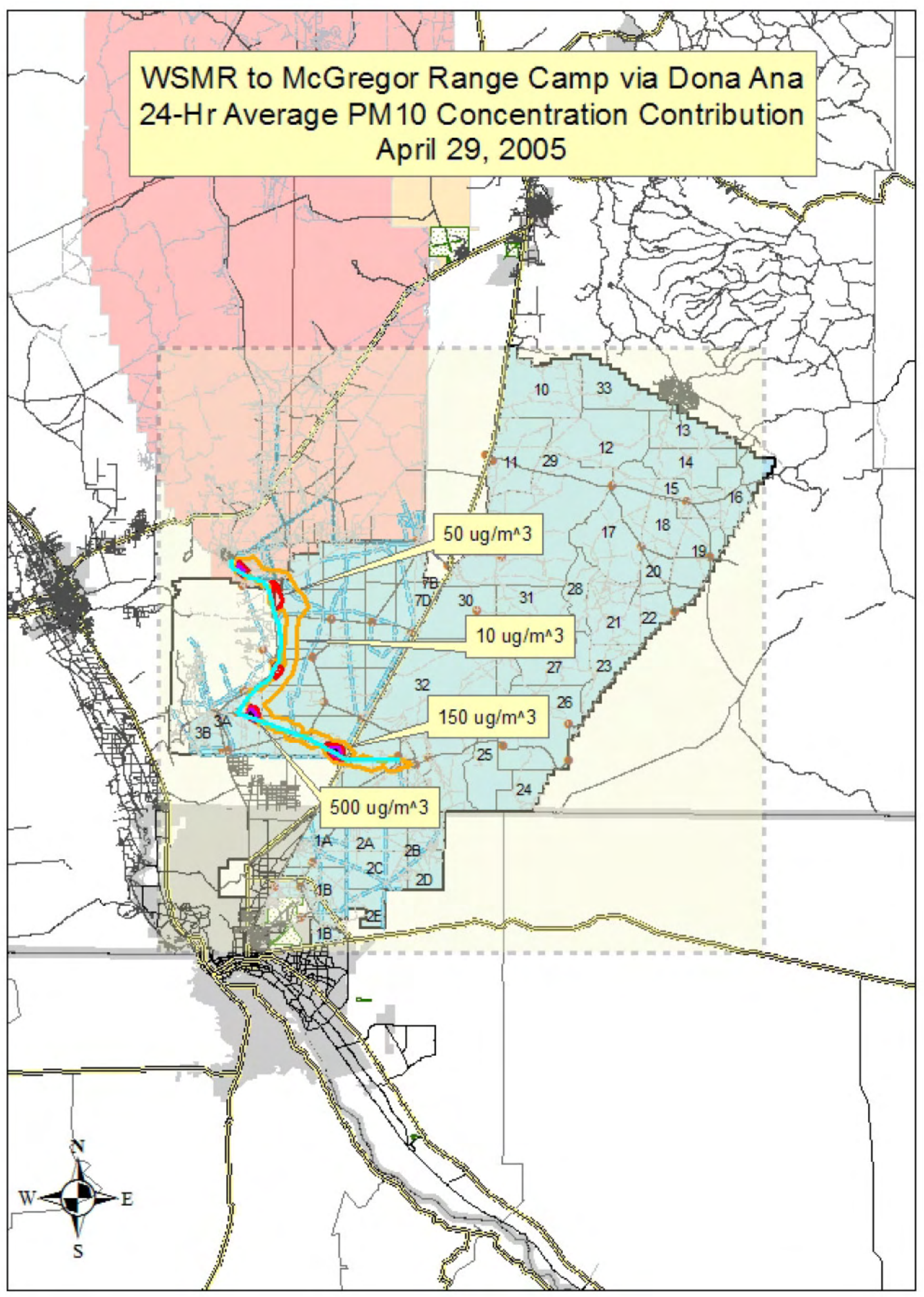

D.20 


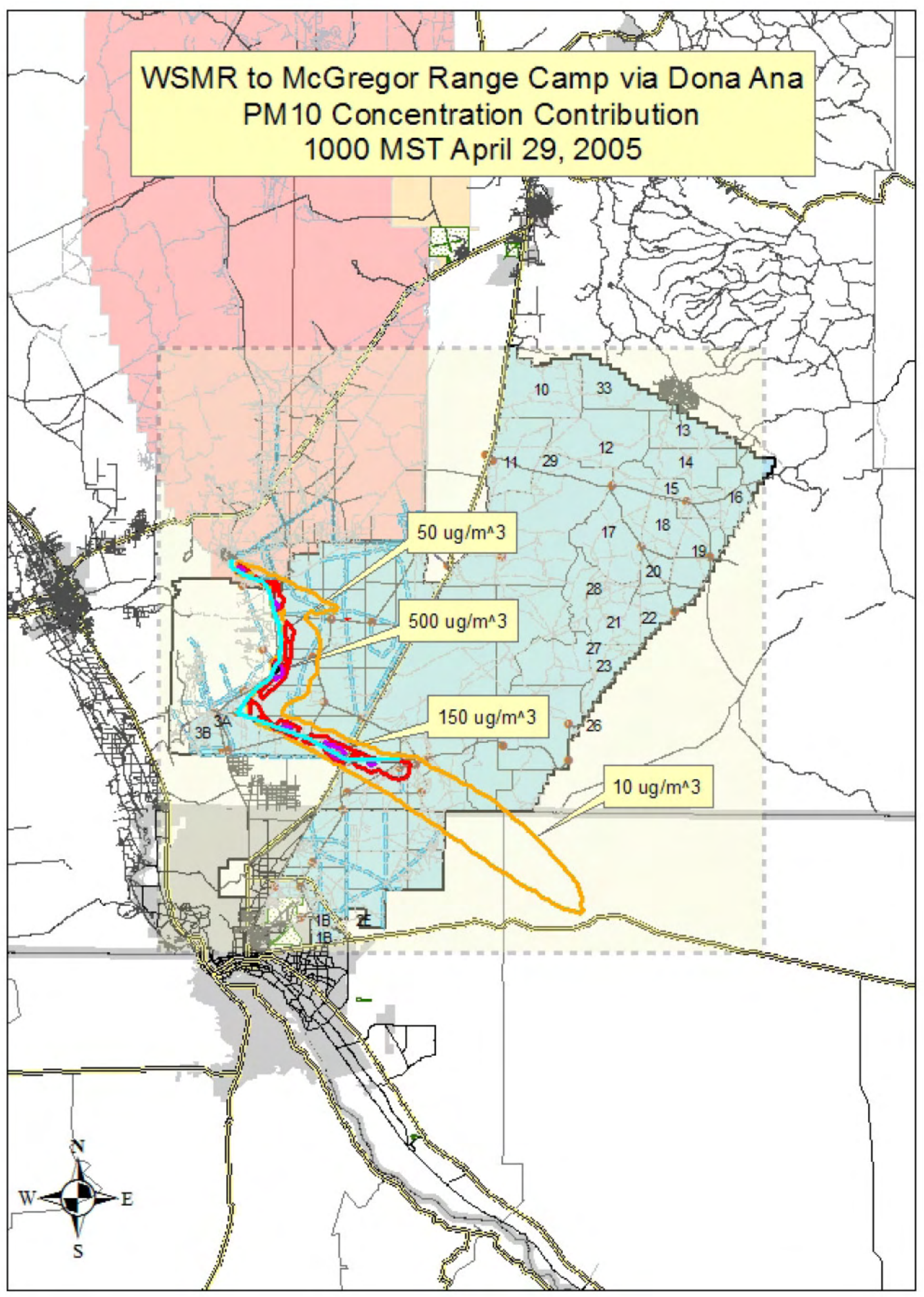

D.21 


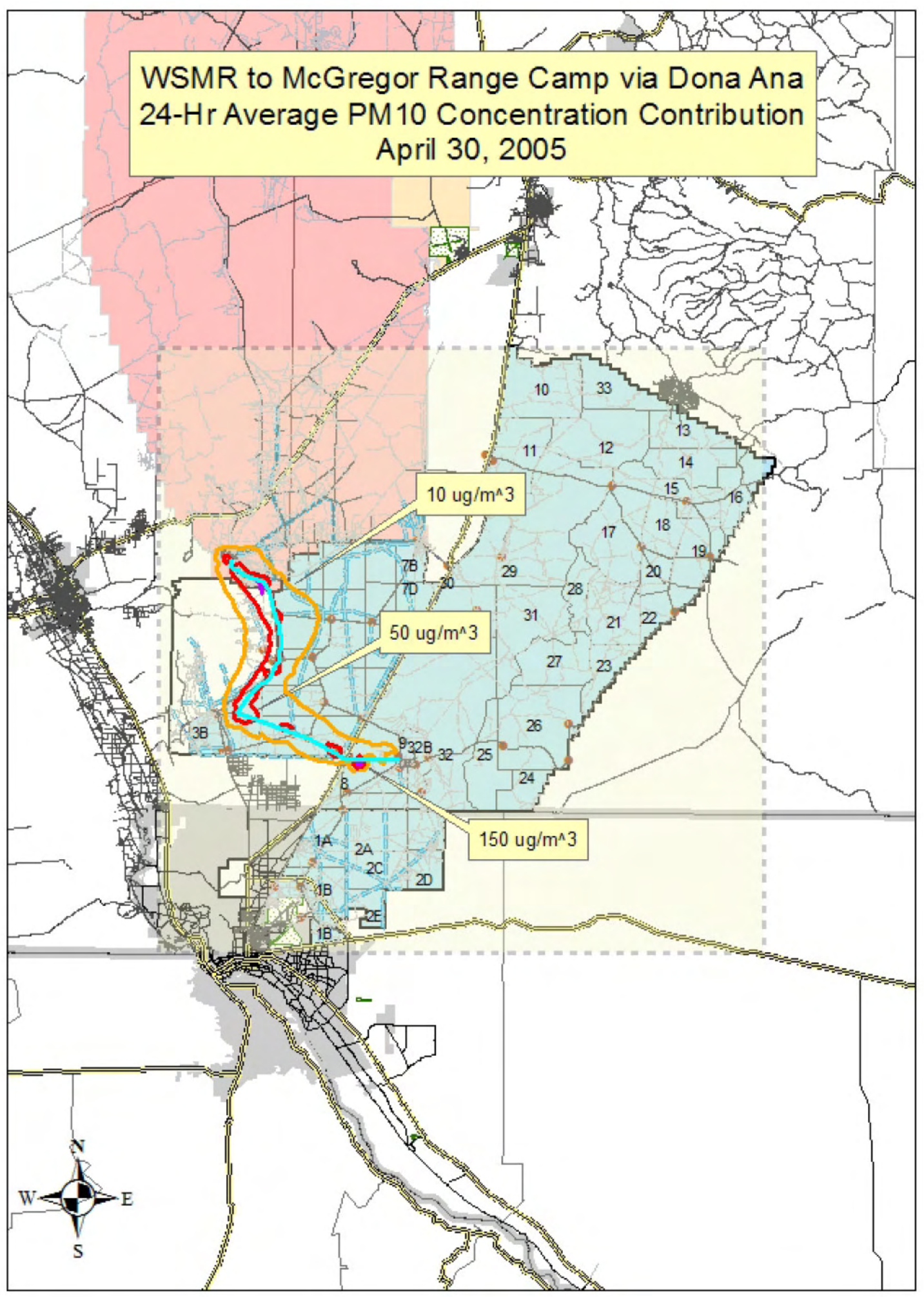

D.22 


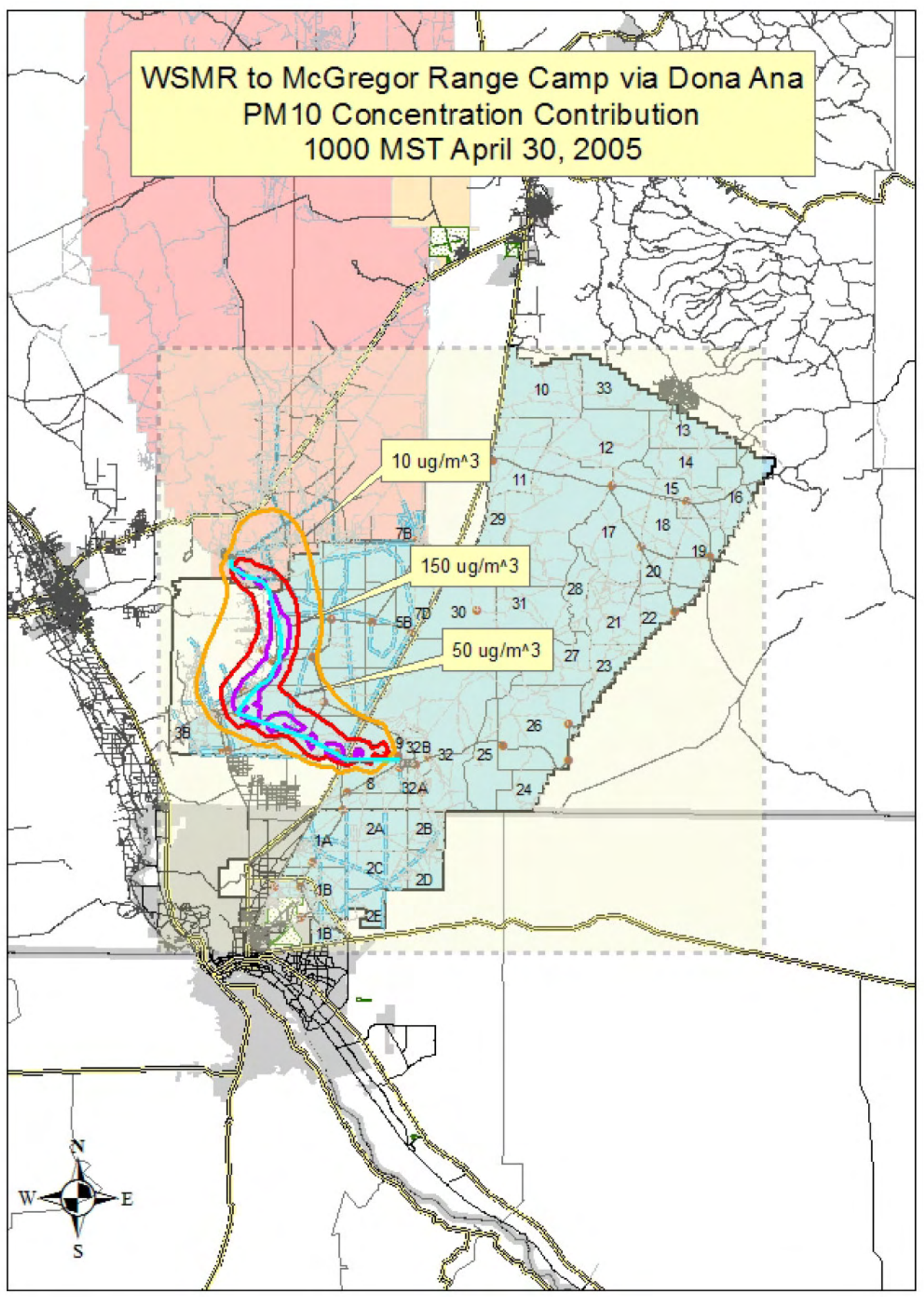

D.23 


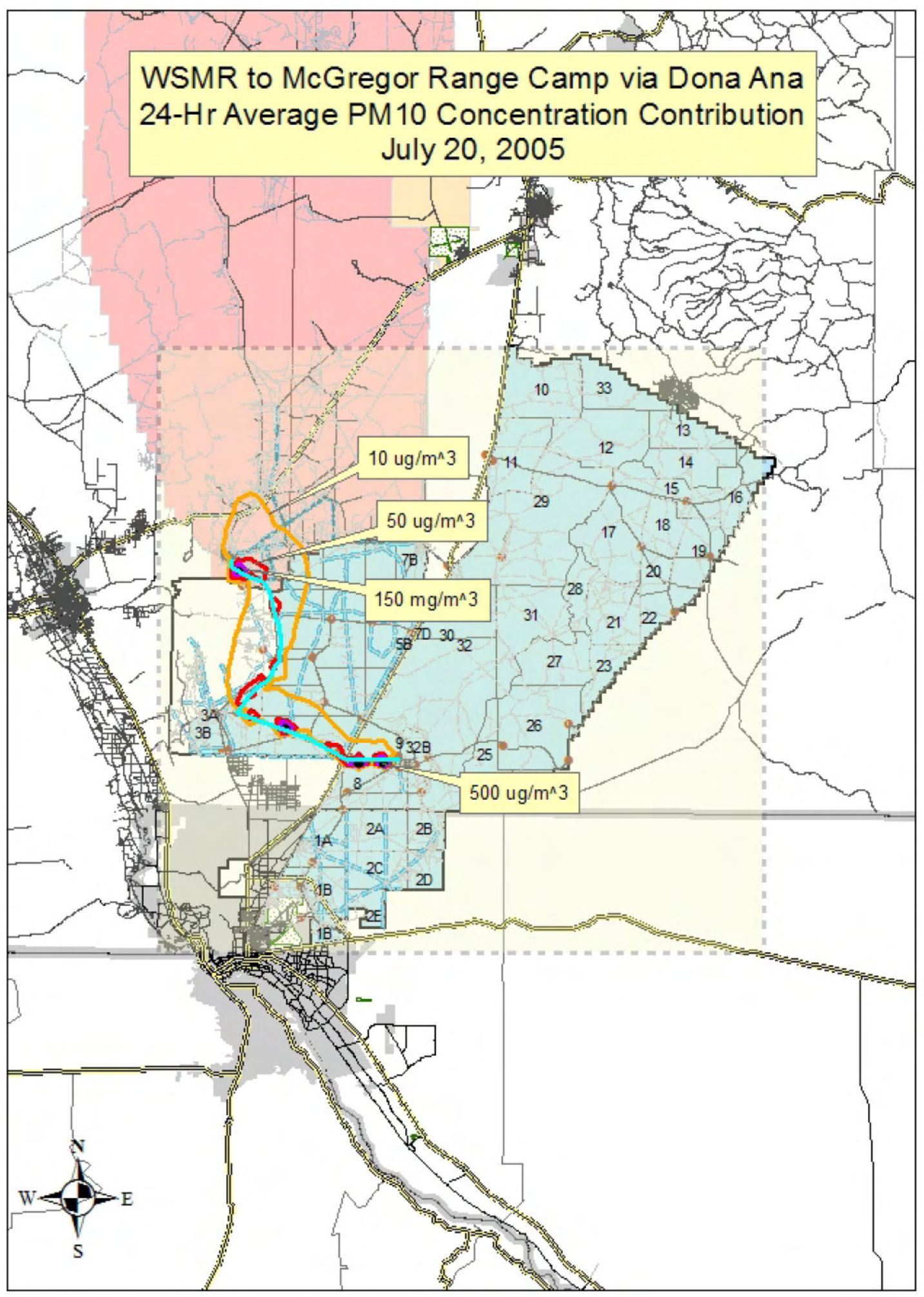




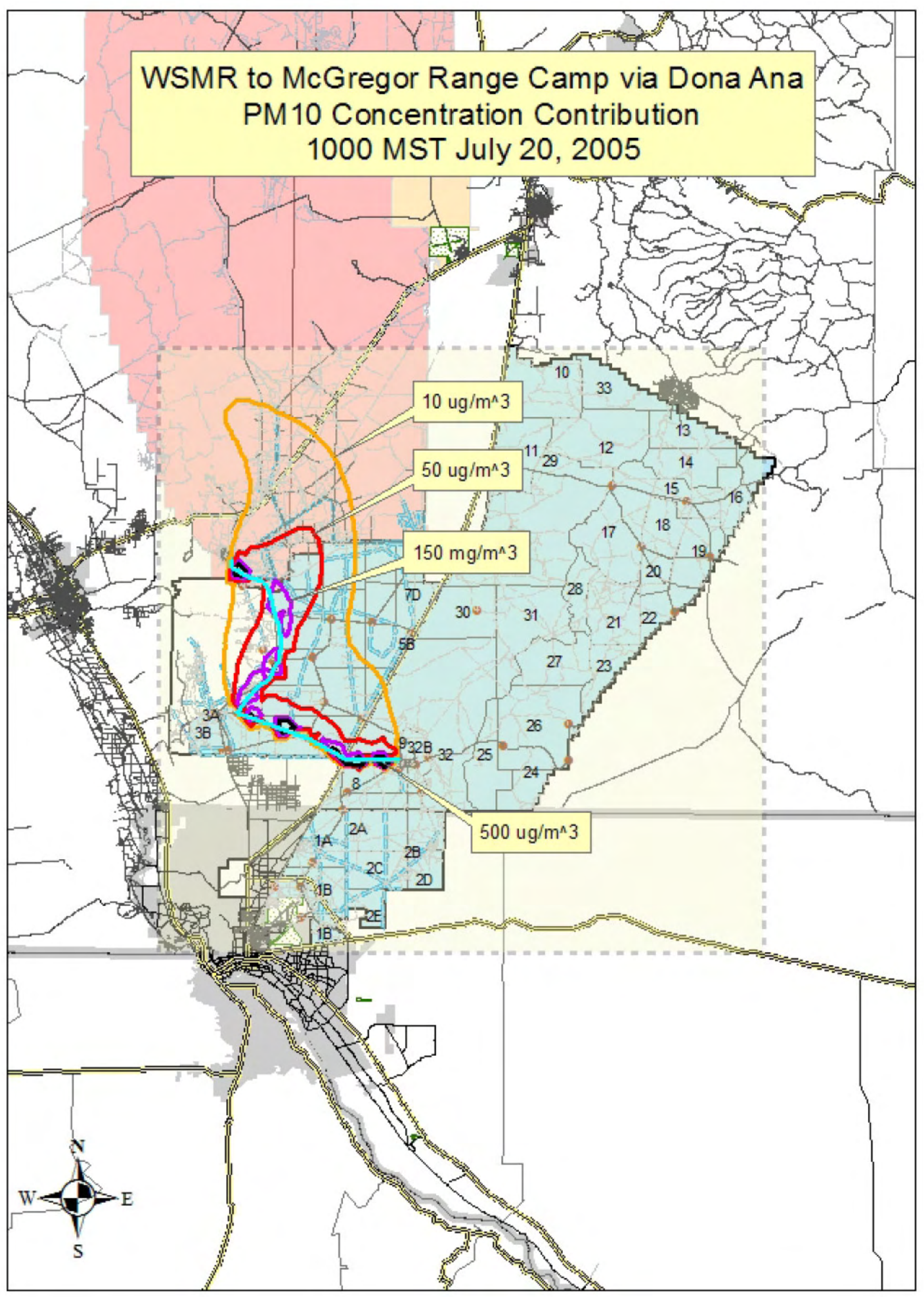




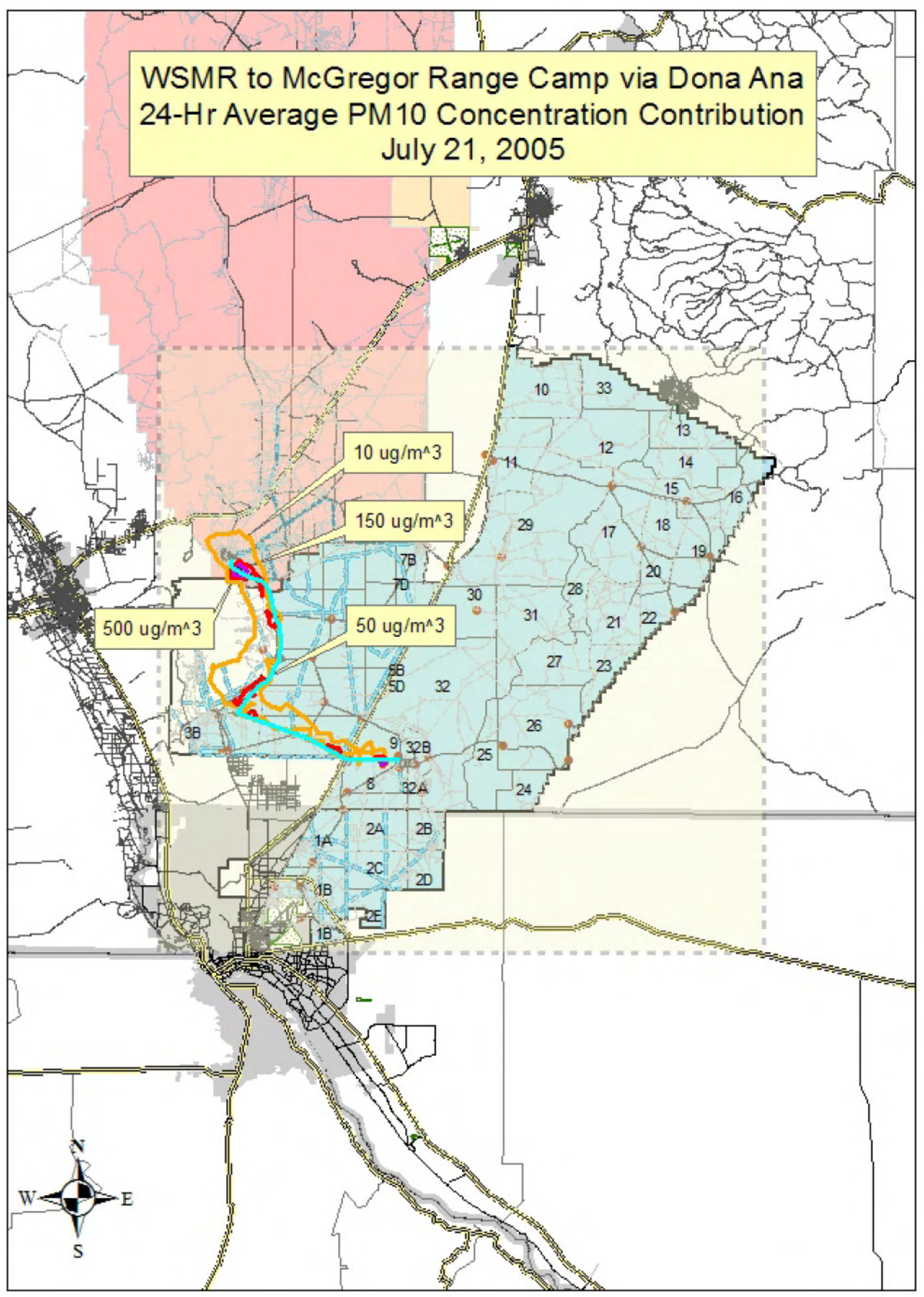




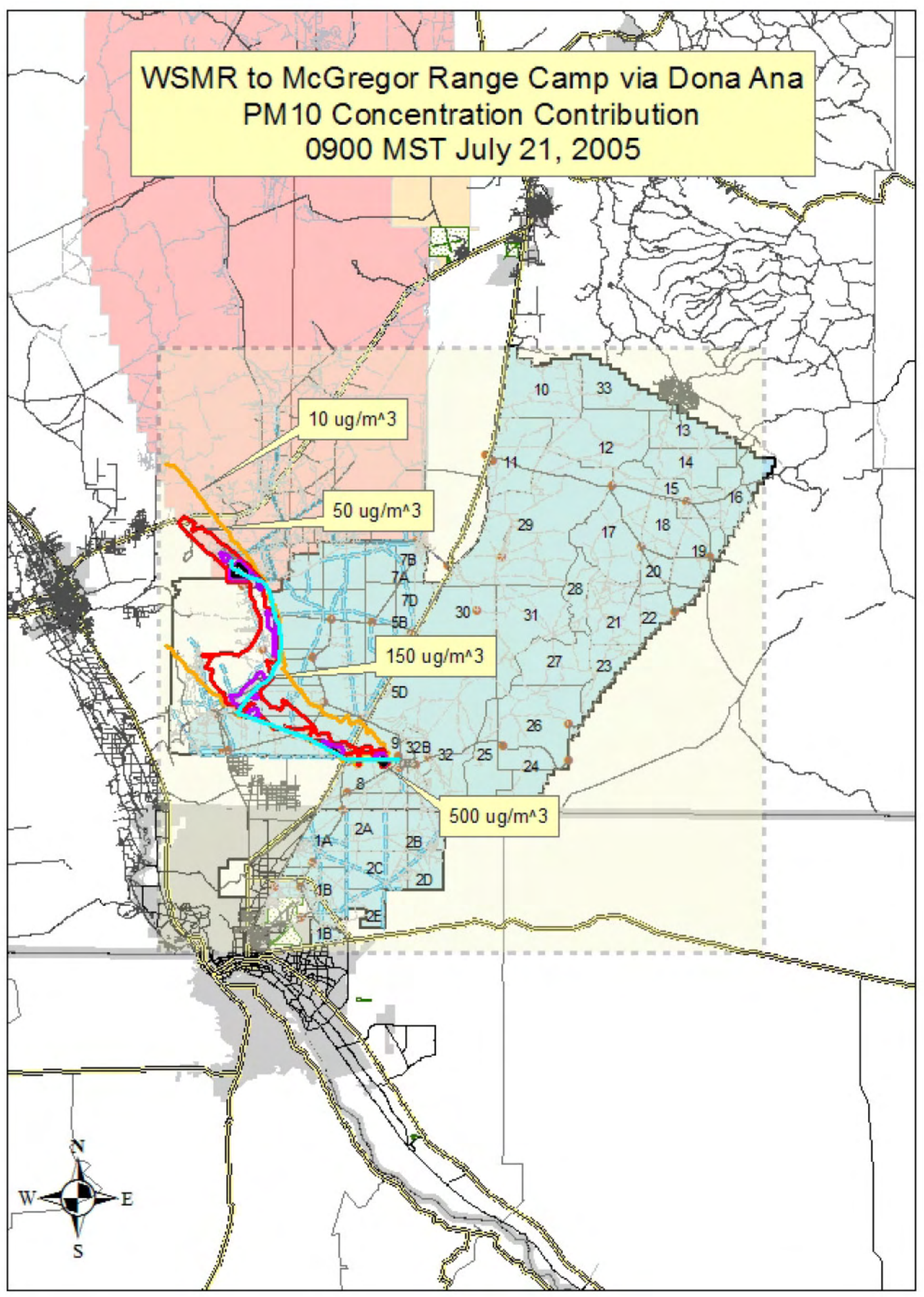




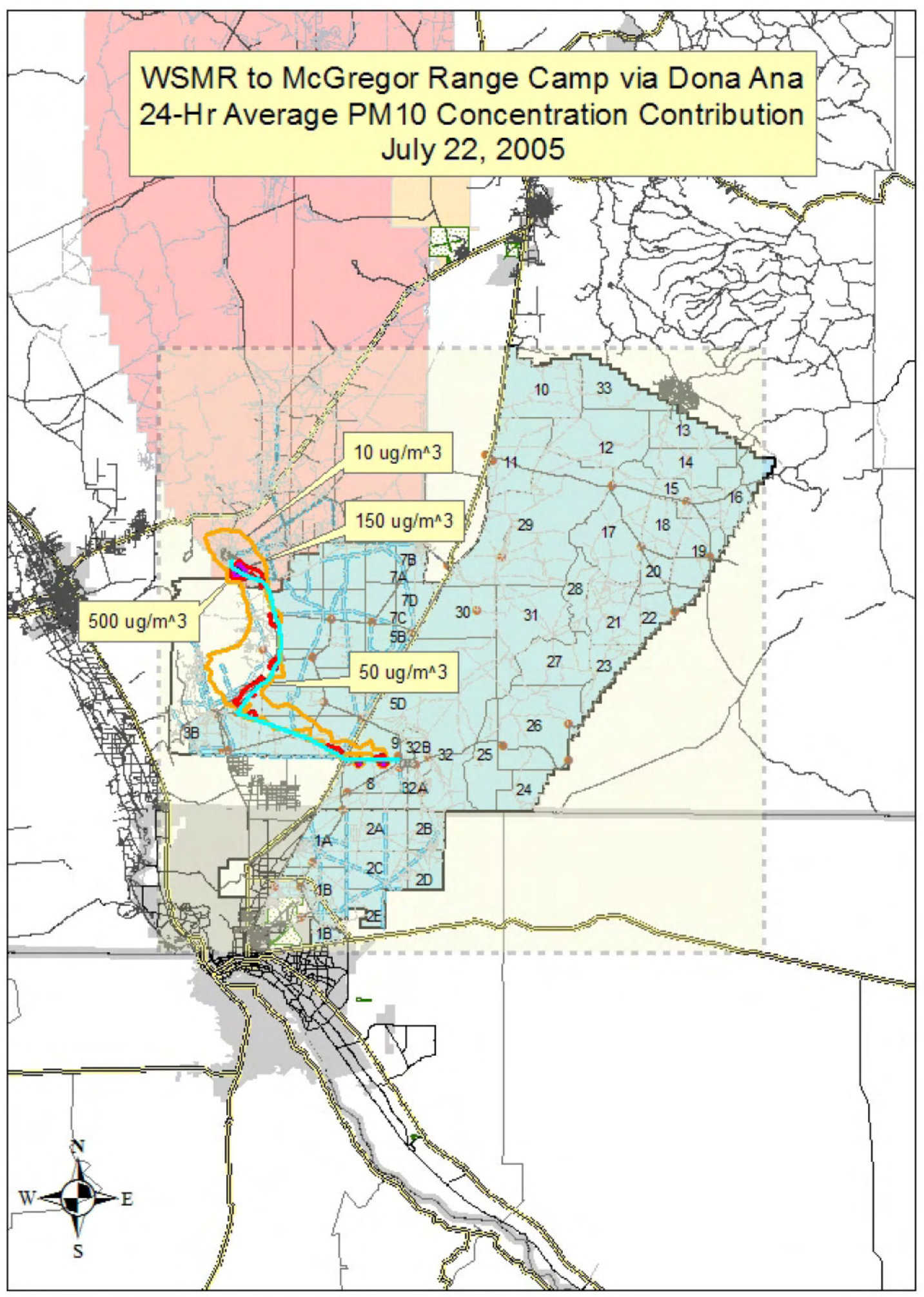




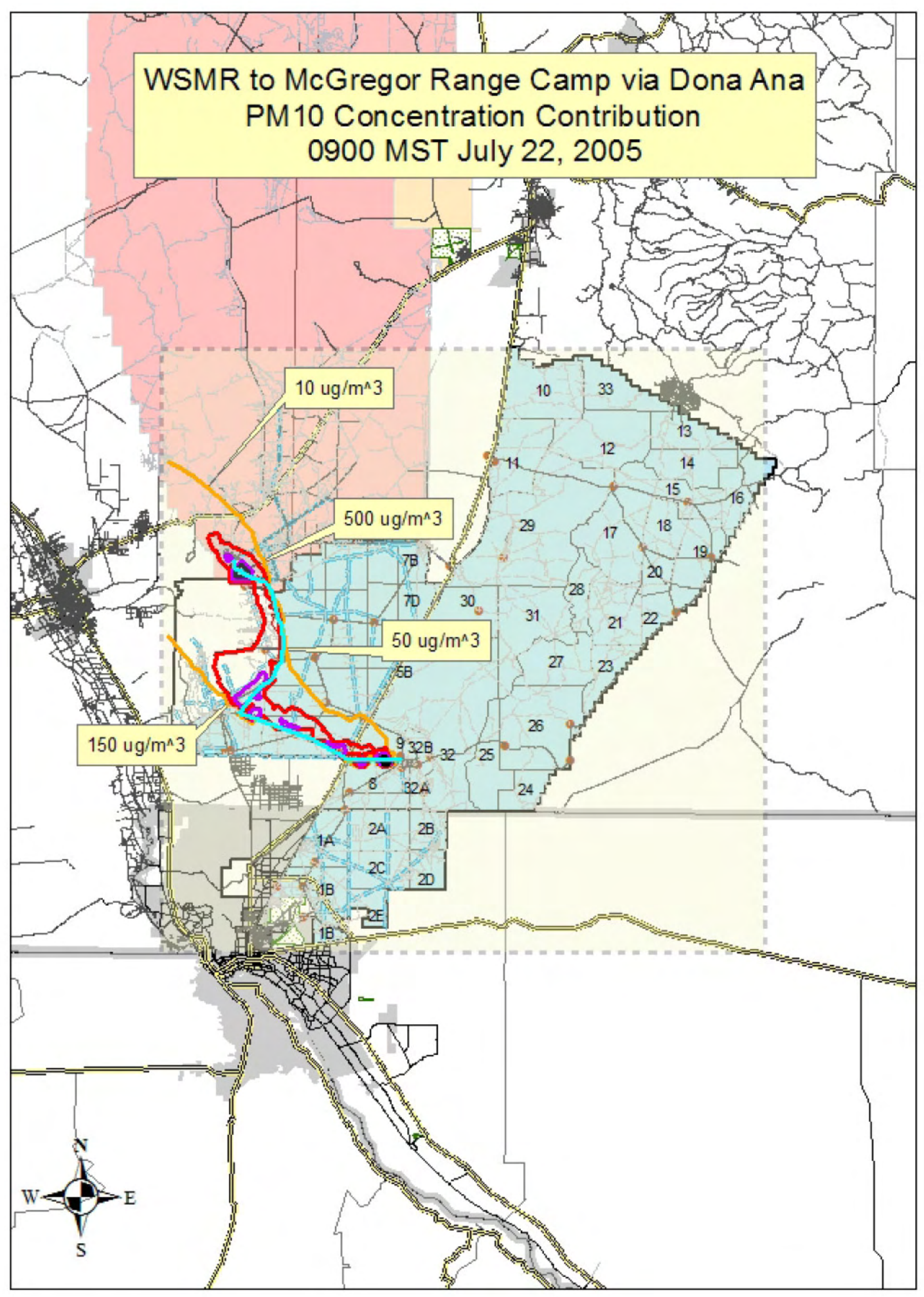




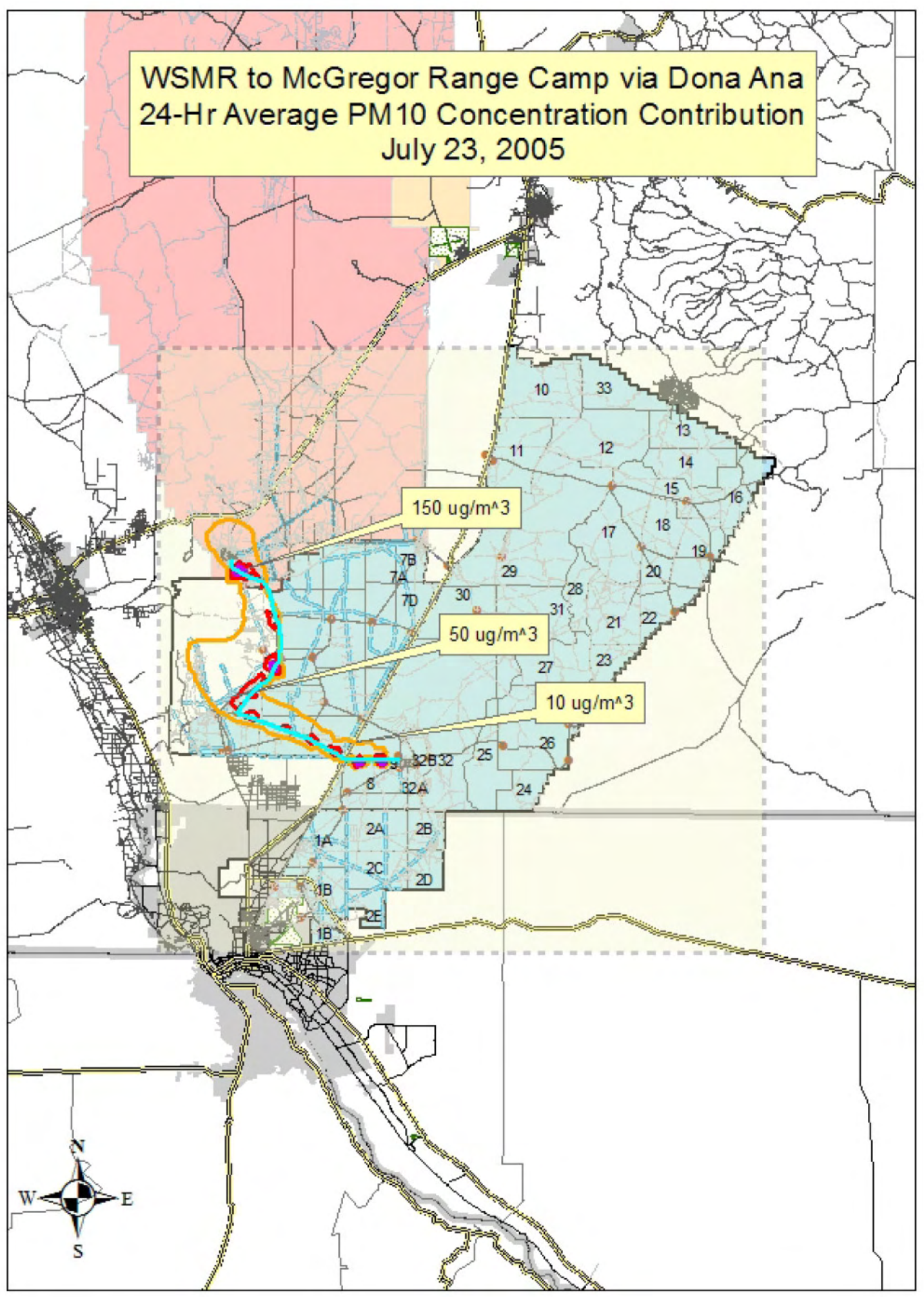

D.30 


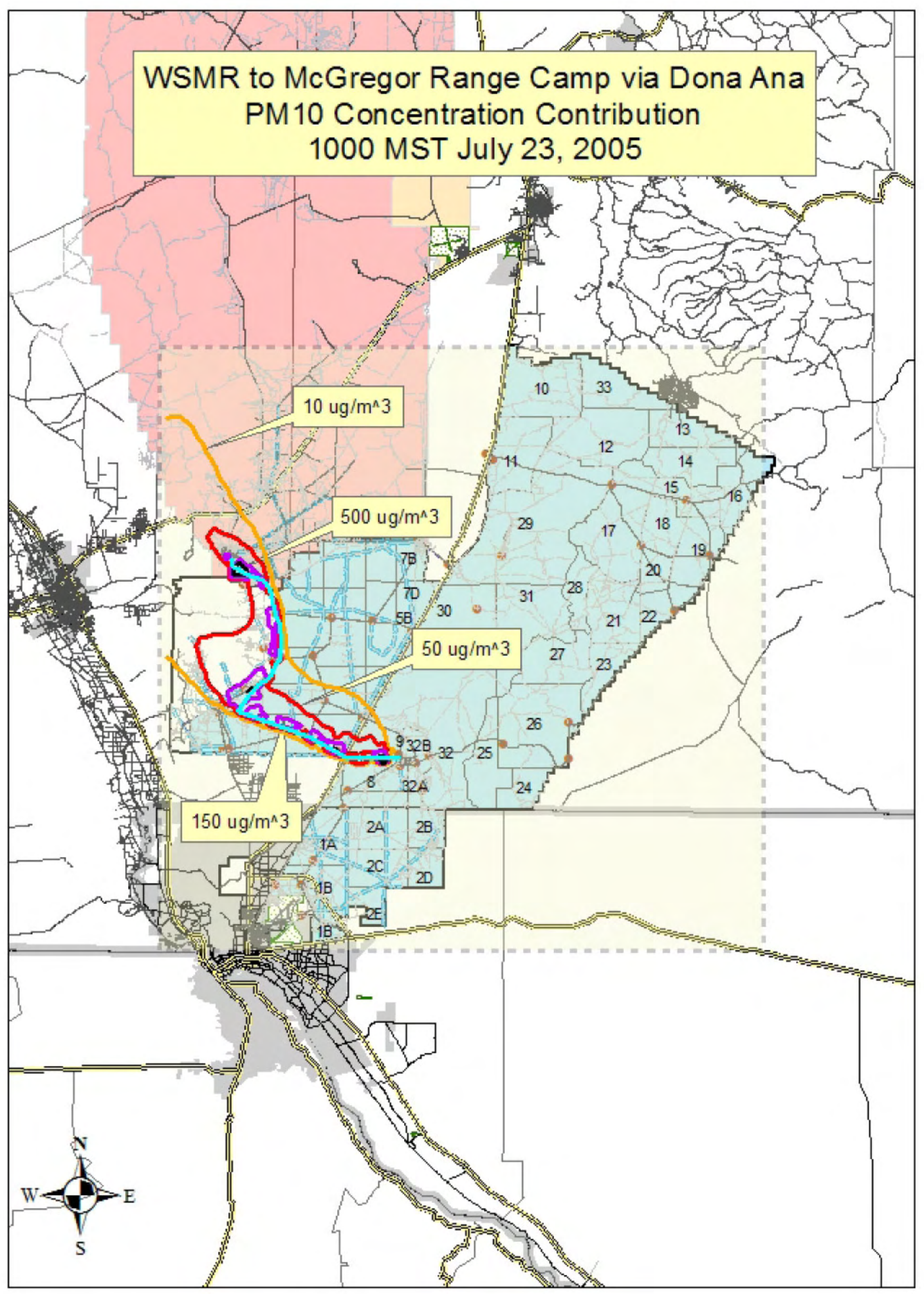

D.31 


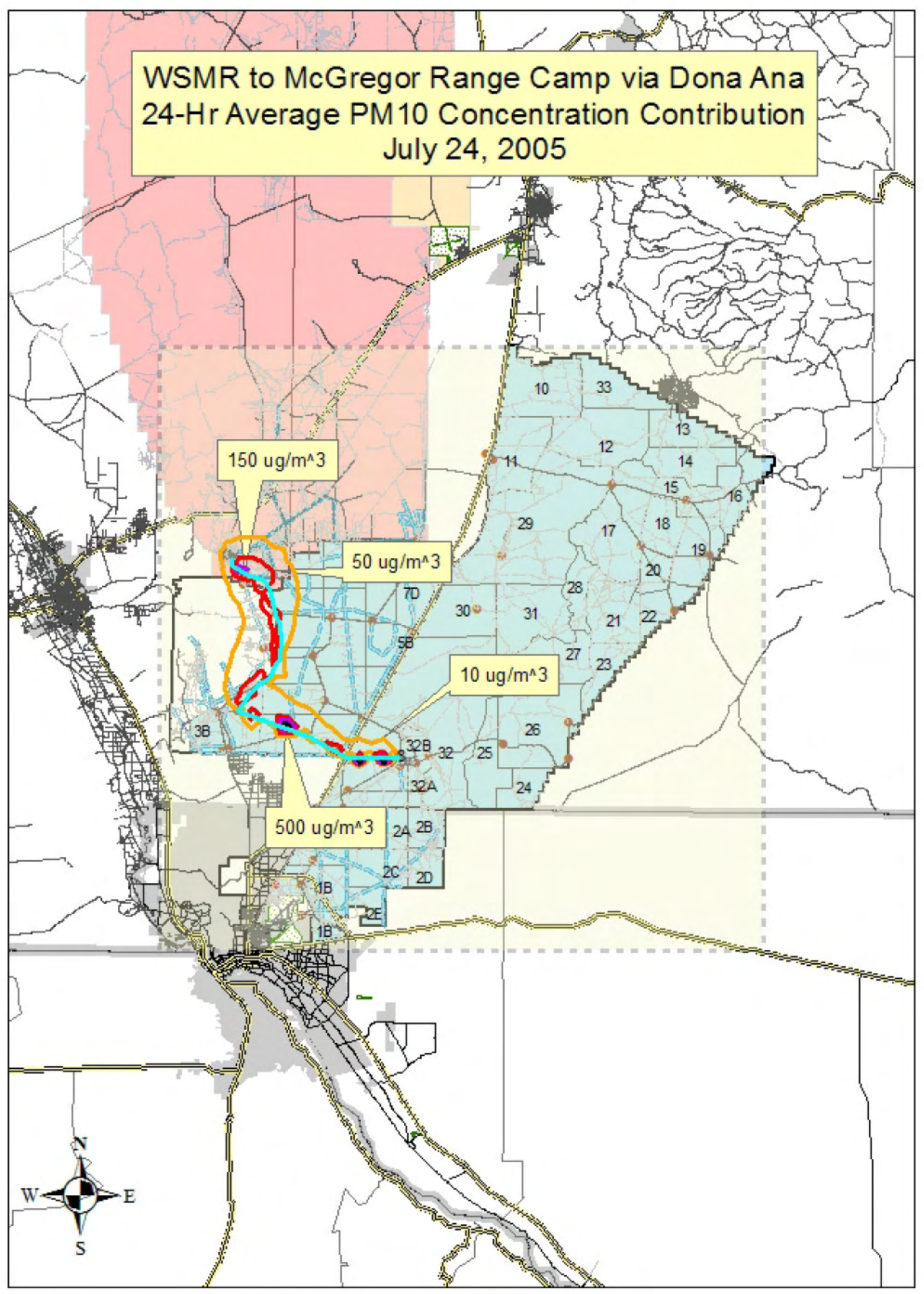

D.32 


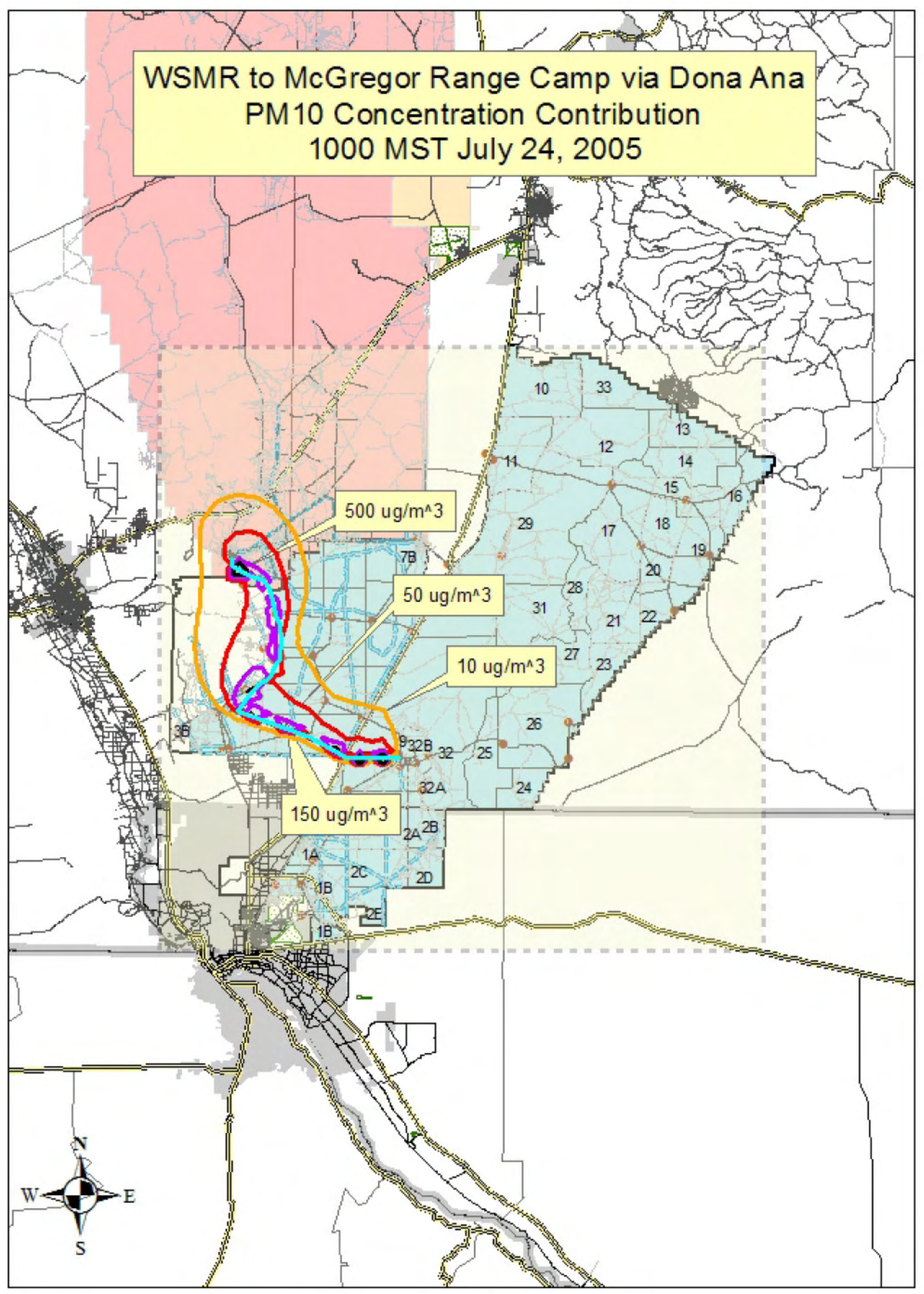

D.33 


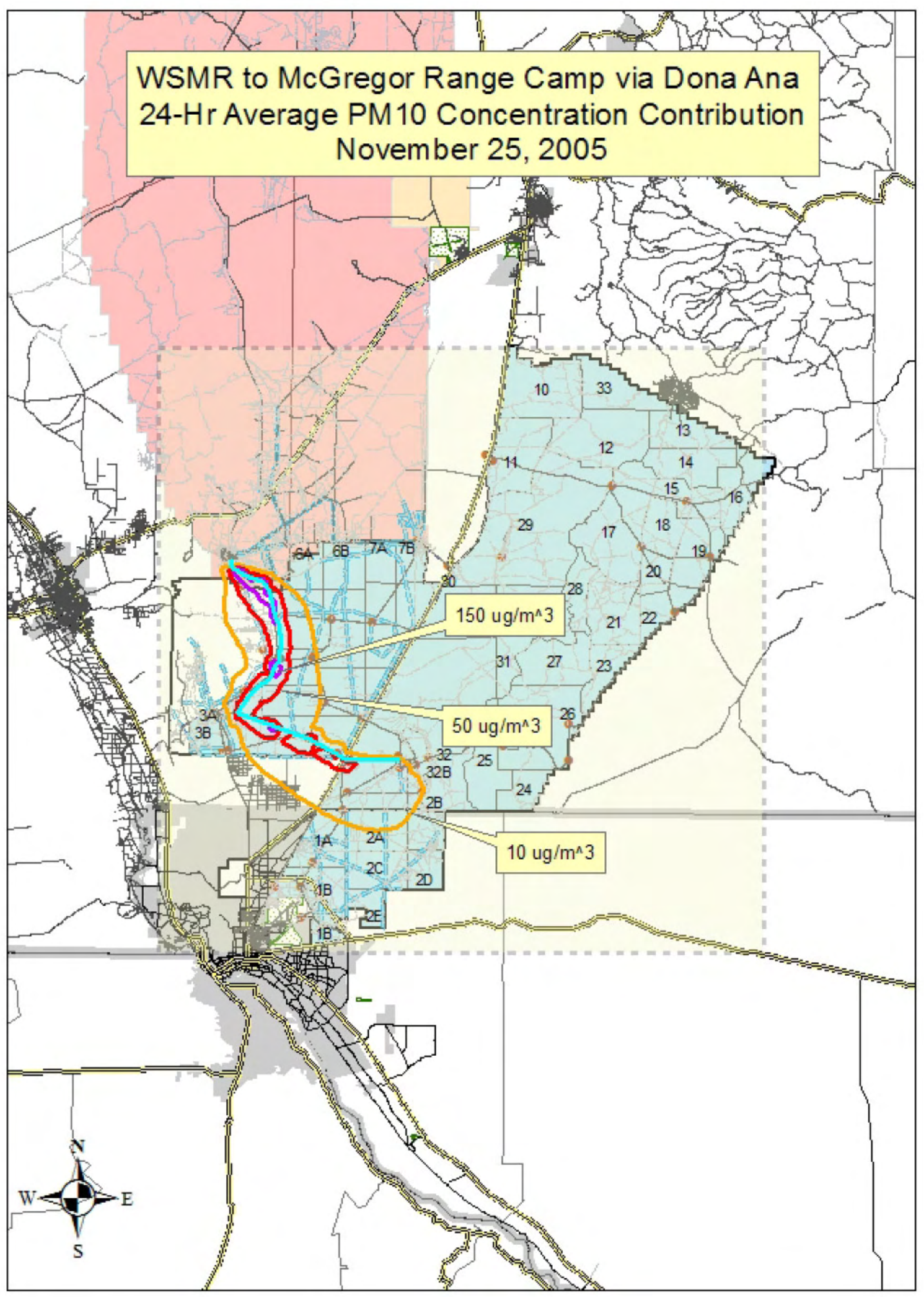




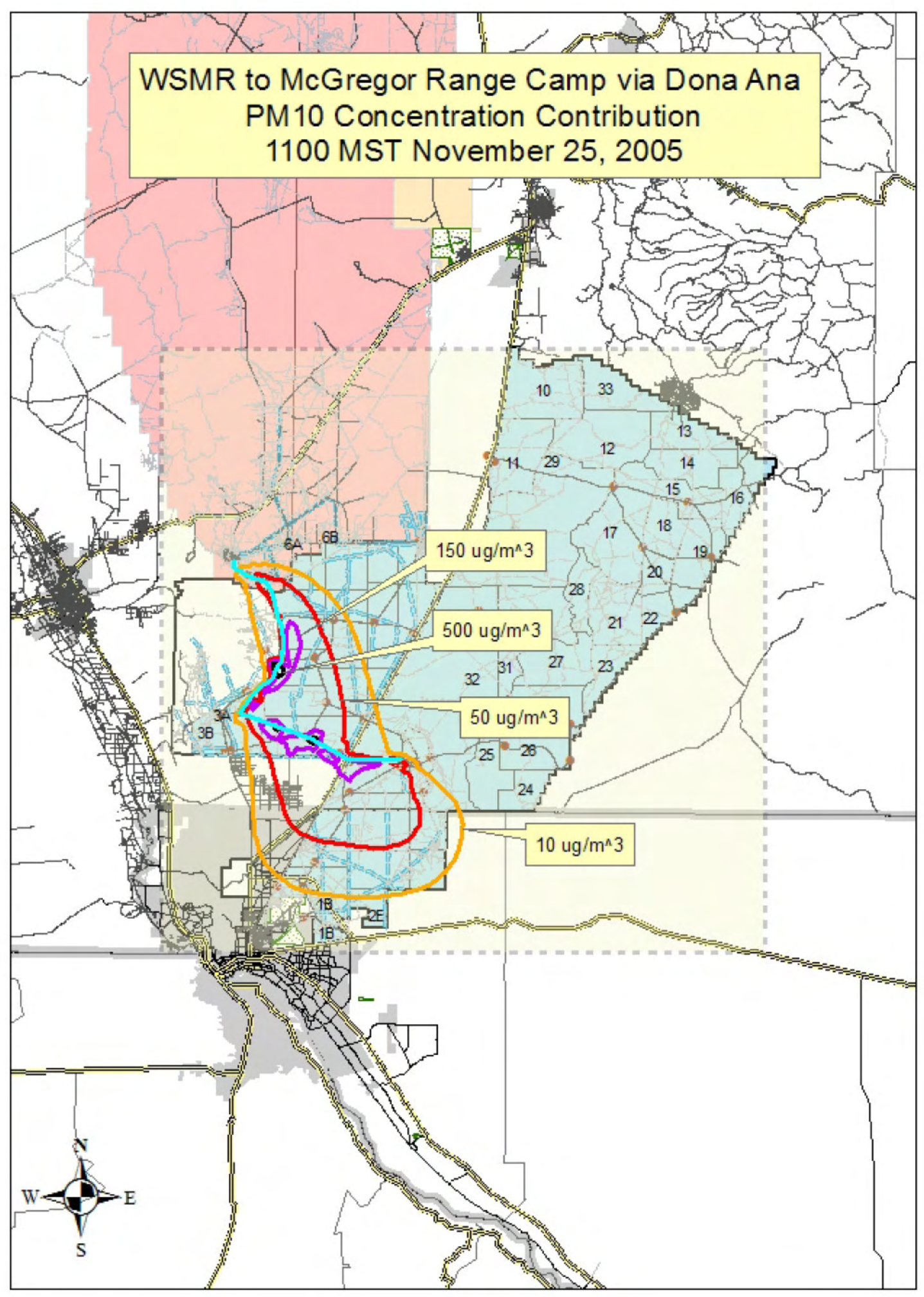

D.35 


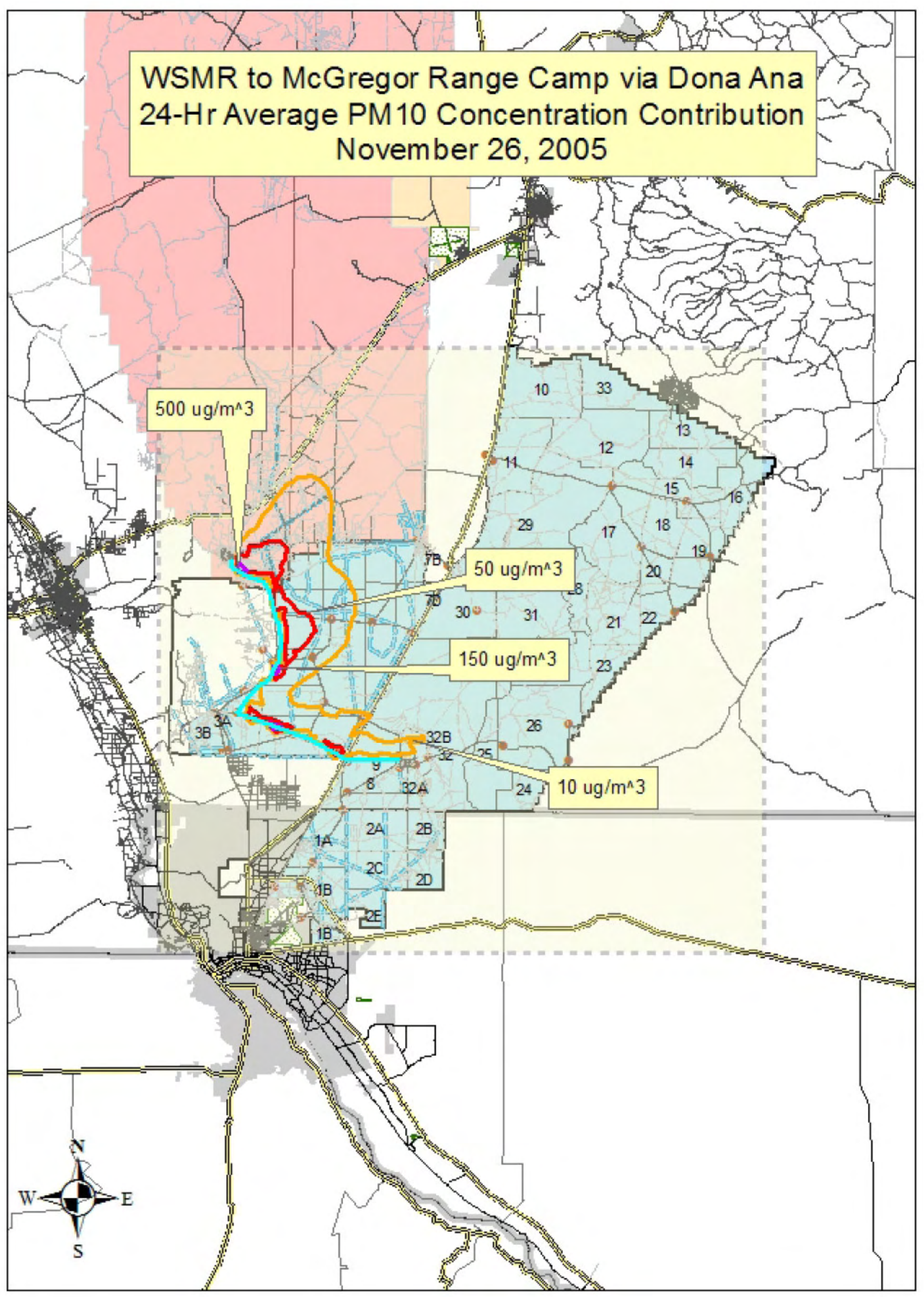

D.36 


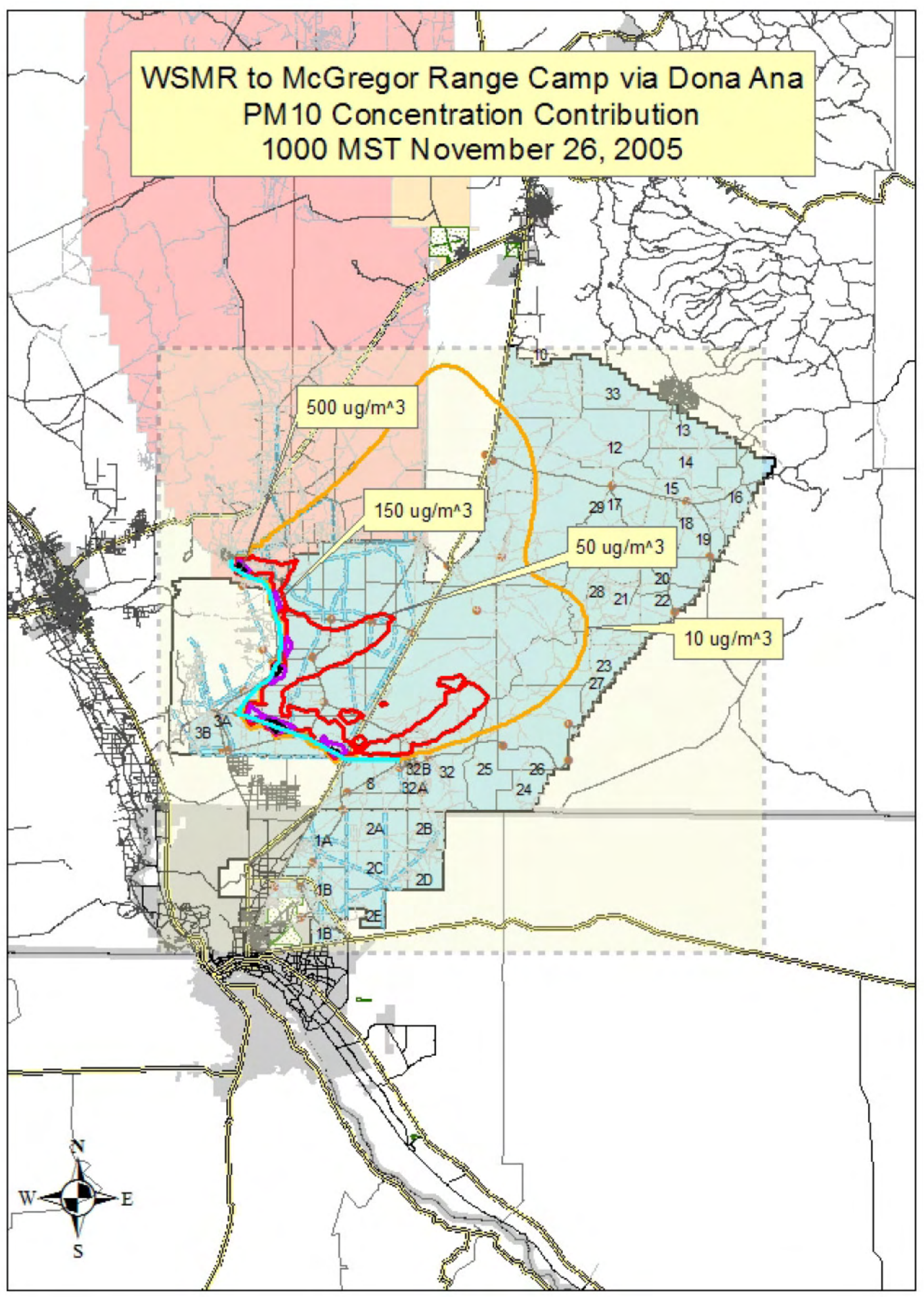

D.37 


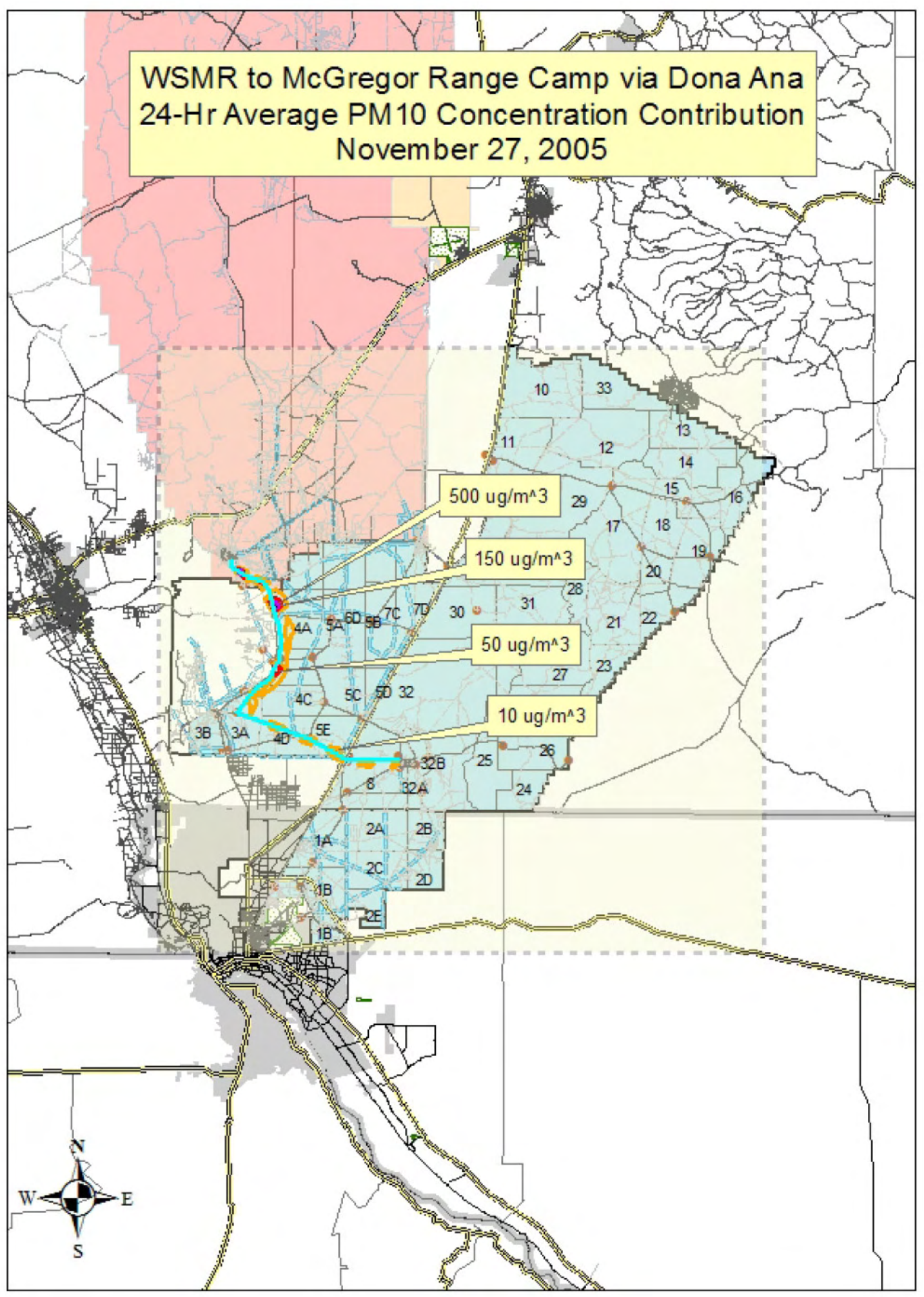

D.38 


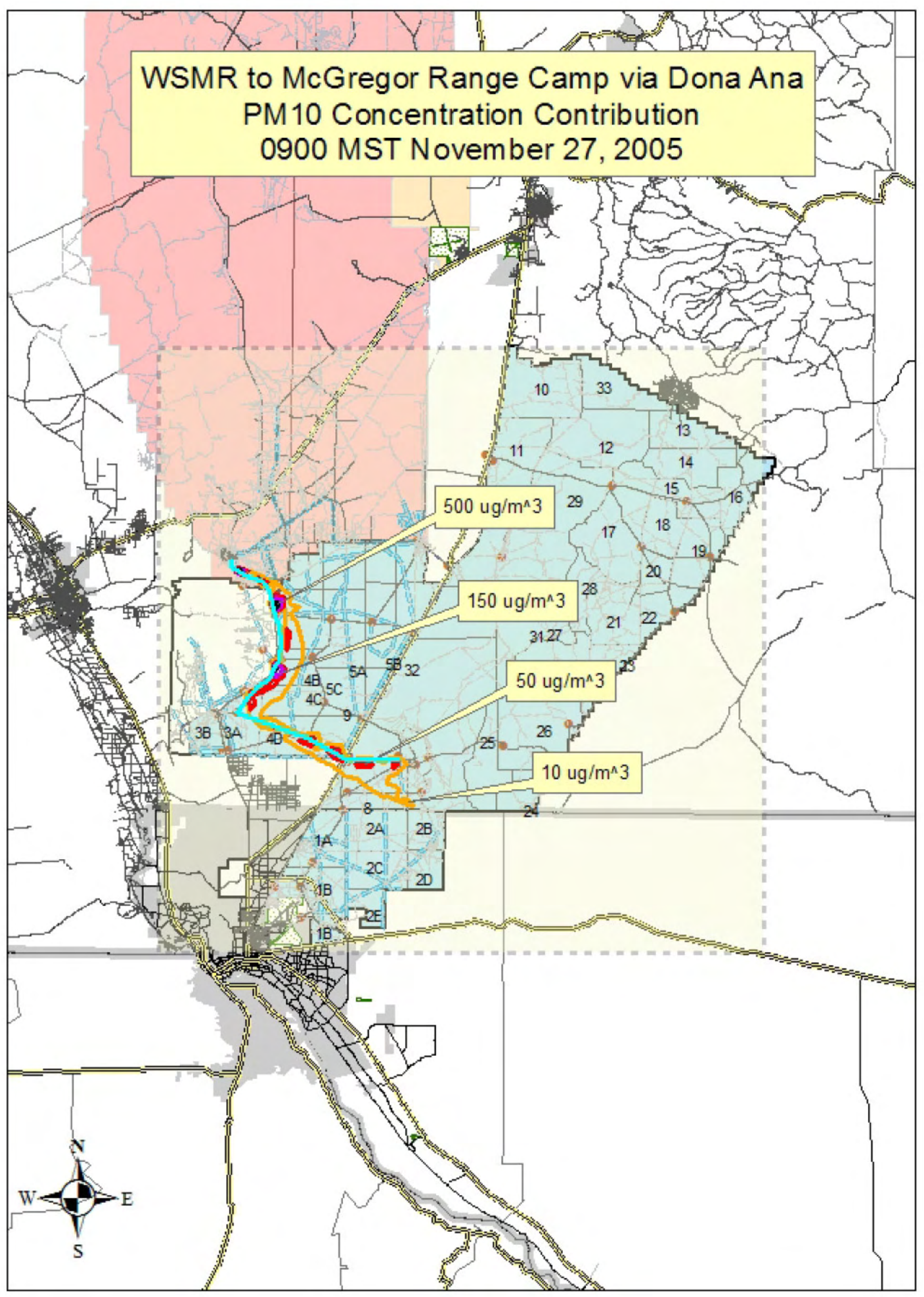

D.39 


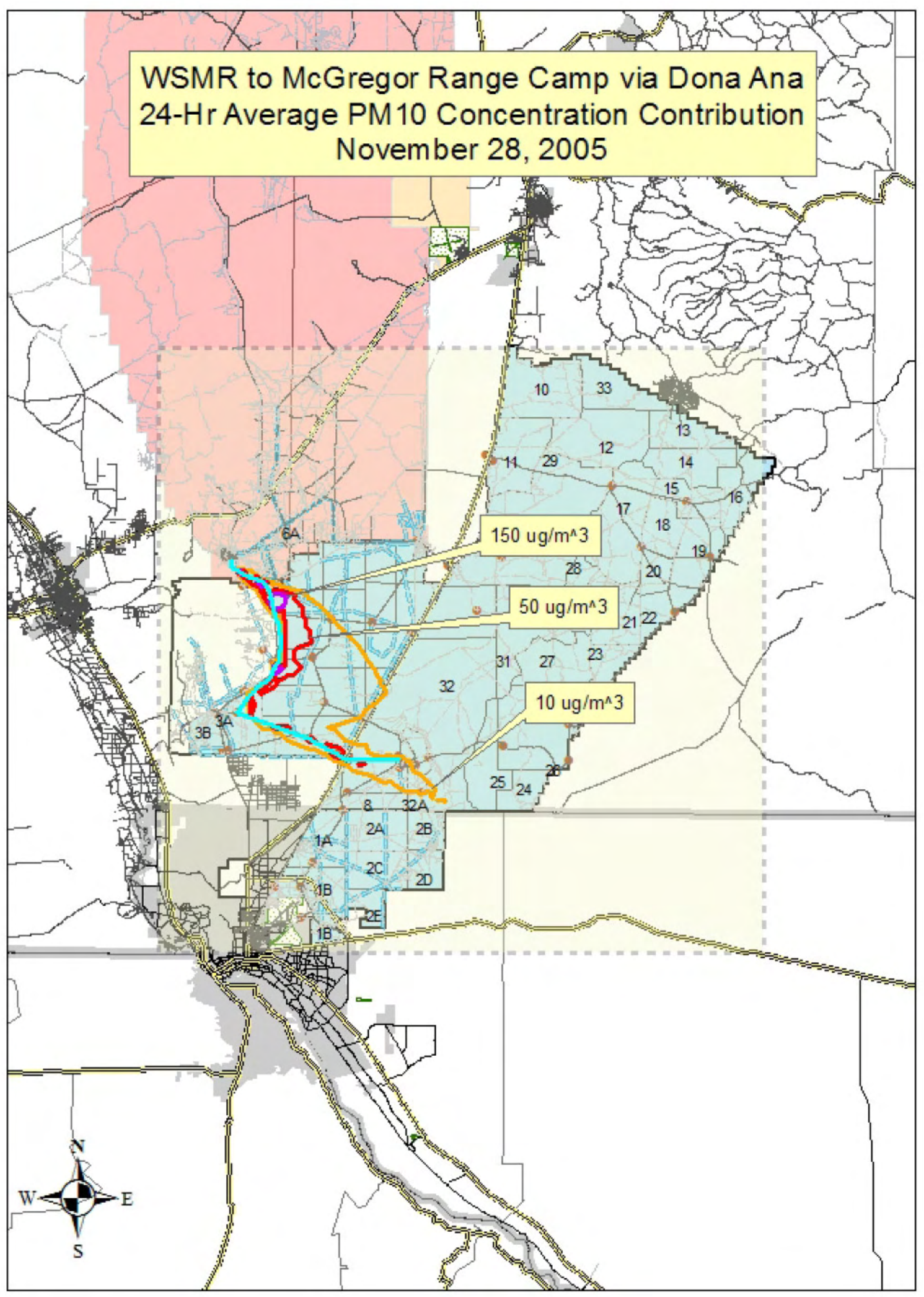




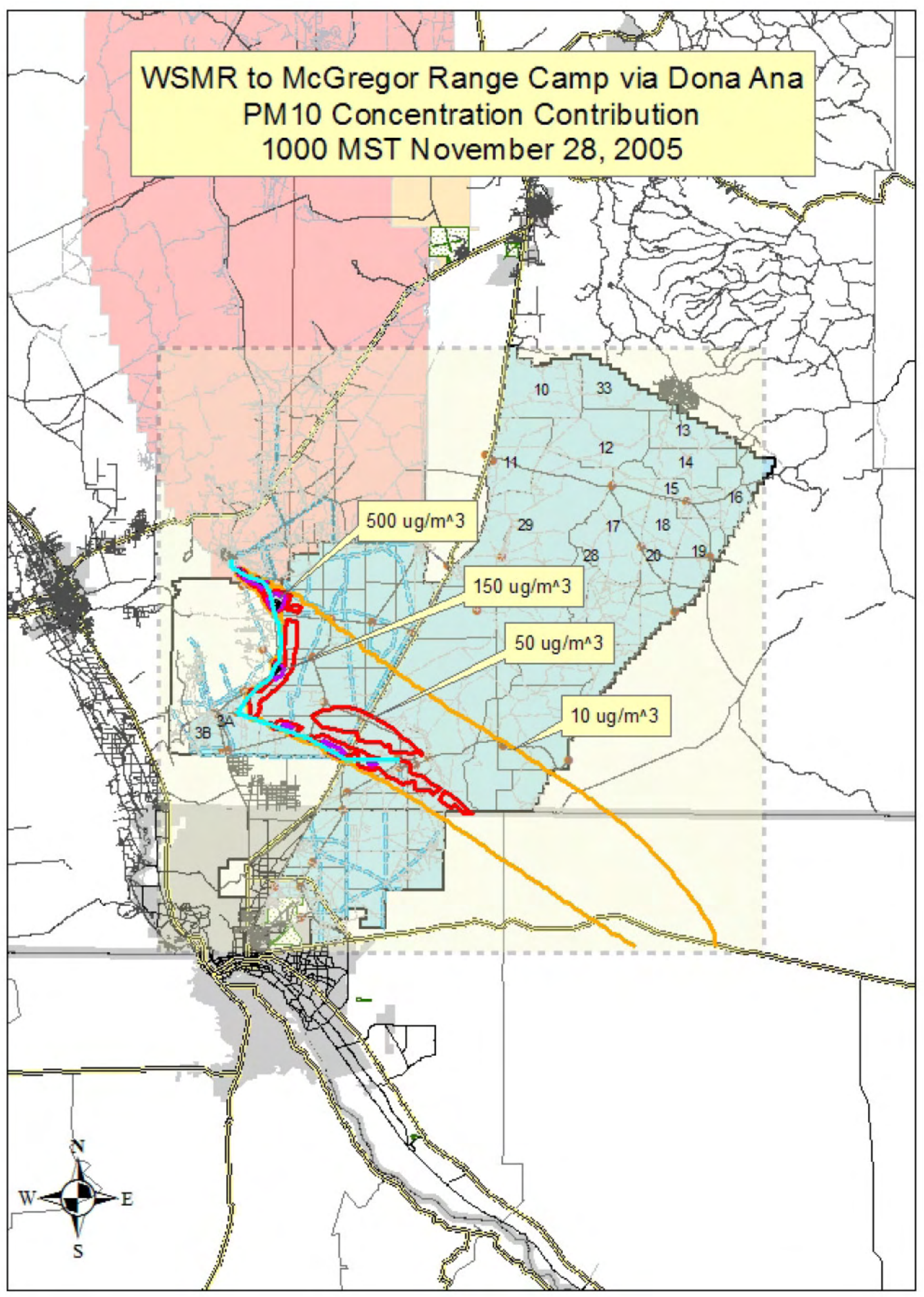




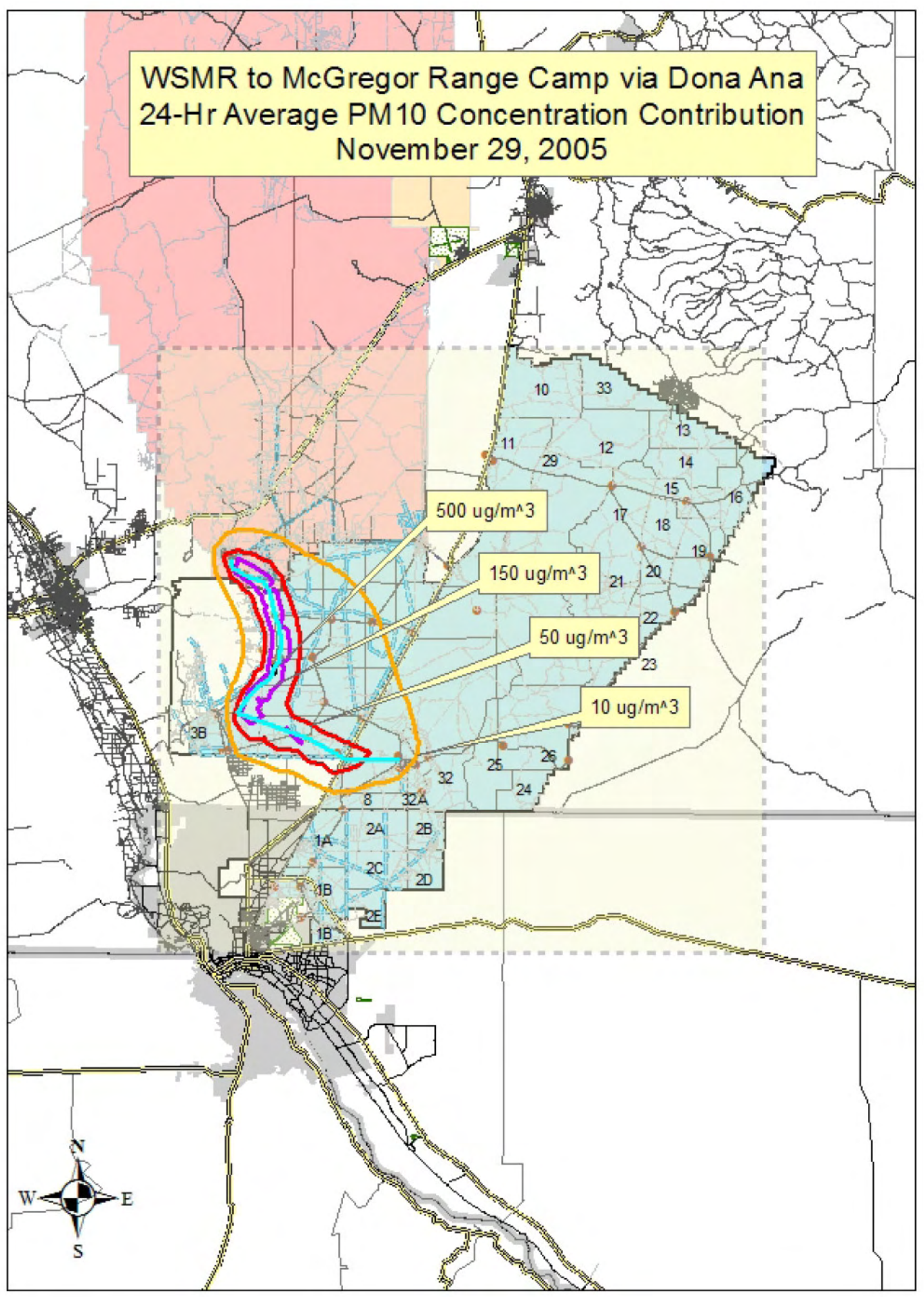




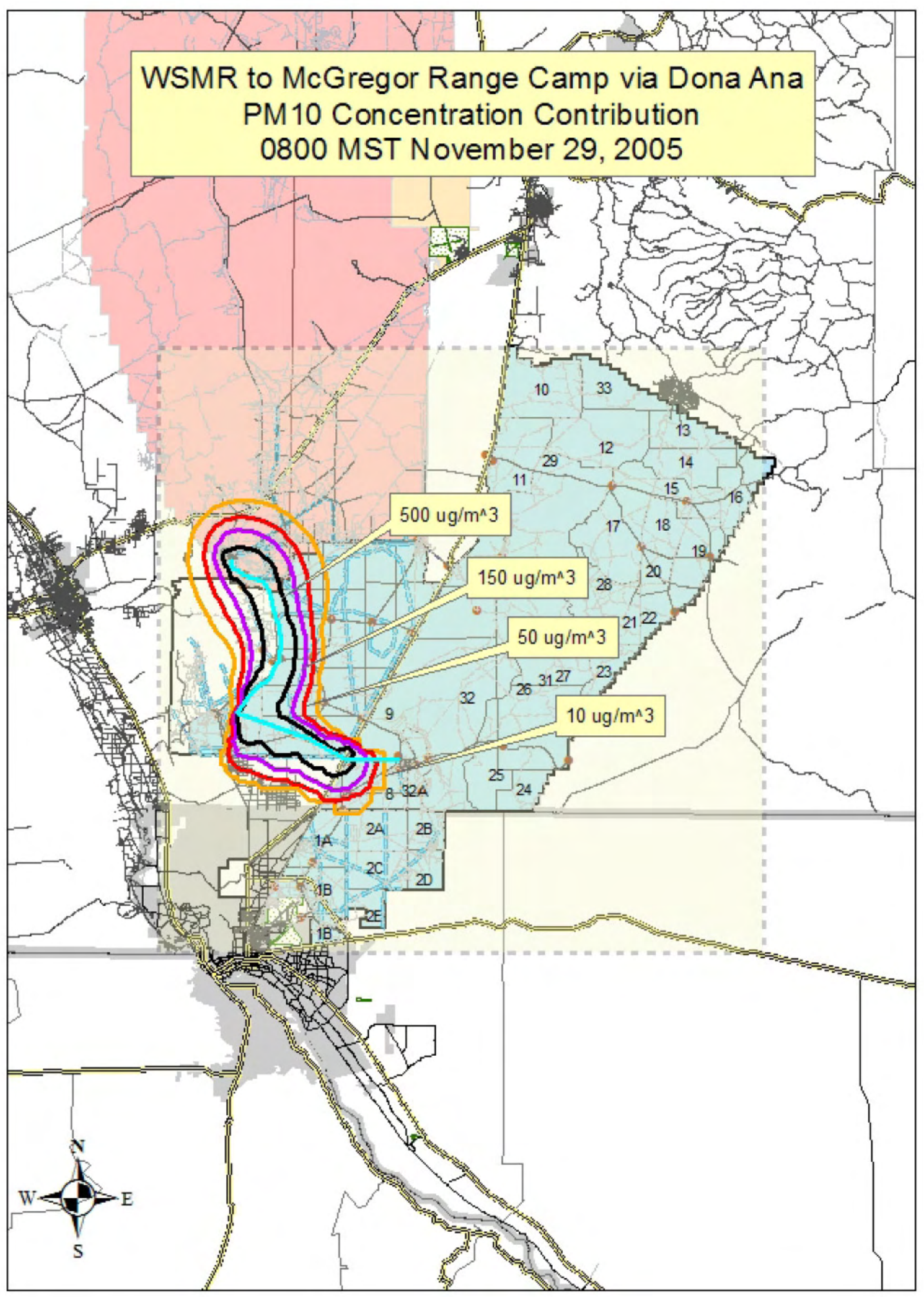





\section{Appendix E}

Simulated $\mathrm{PM}_{10}$ Concentrations for the Move-out from White Sands Missile Range to Oro Grande Base Camp 



\section{Appendix E}

\section{Simulated $\mathrm{PM}_{10}$ Concentrations for the Move-out from White Sands Missile Range to Oro Grande Base Camp}

The following pages present contour maps of simulated PM10 concentrations contributed by WSMR to Oro Grande Base Camp move-out operations to air quality in and around Fort Bliss and WSMR for the 21 days (March 12-16, April 25-30, July 20-24, and November 25-29, 2005) studied in this investigation. For each day, the contour map of the 24-hour-average PM10 concentration contribution is shown first, followed by a contour map of PM10 concentration contributions for a specific hour. The hour listed in the figure header represents the start of the hour, e.g., 1000 MST means the hour from 1000 MST to 1100 MST. Move-out scenario assumptions are summarized in Section 3 of this report. 


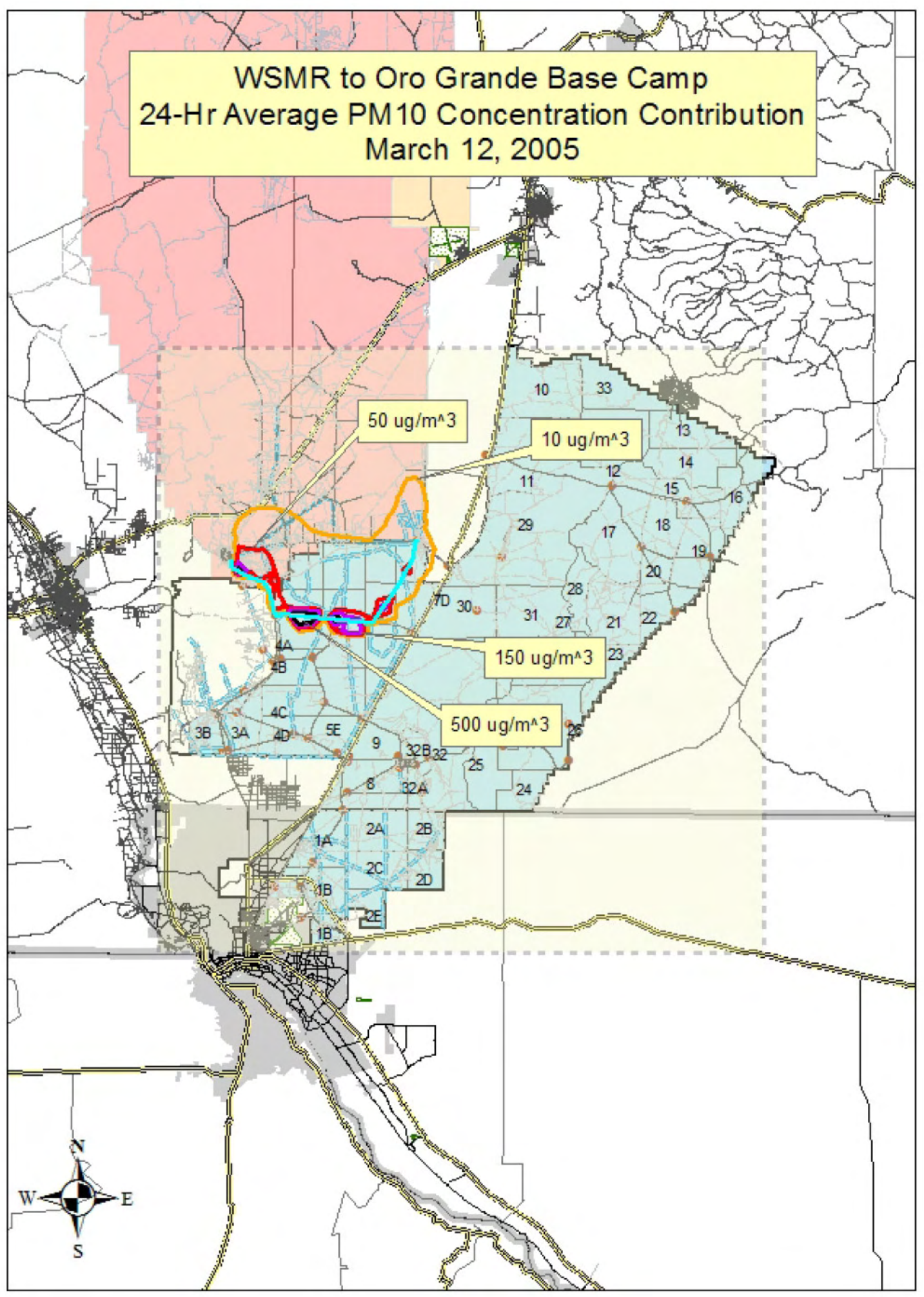




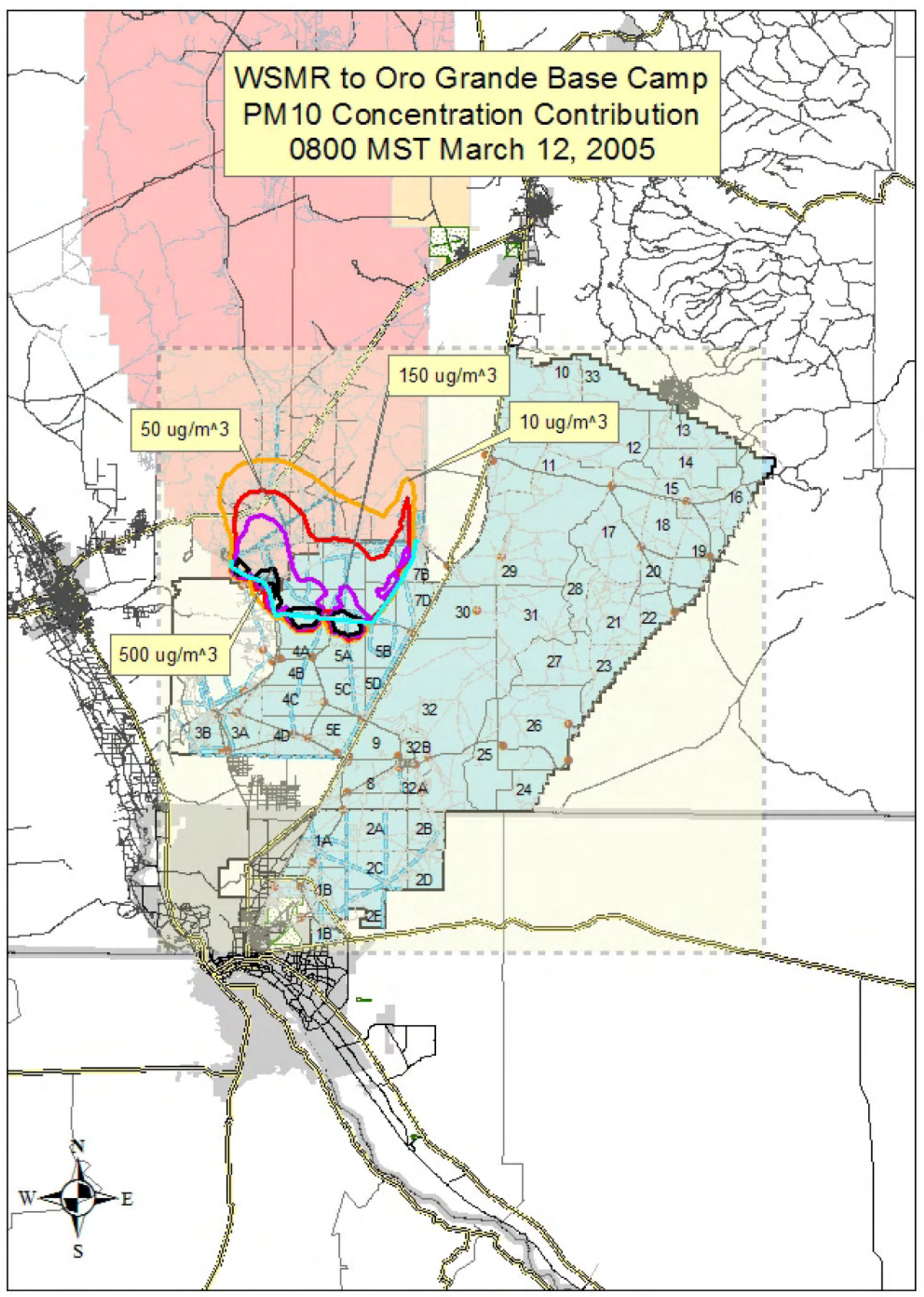




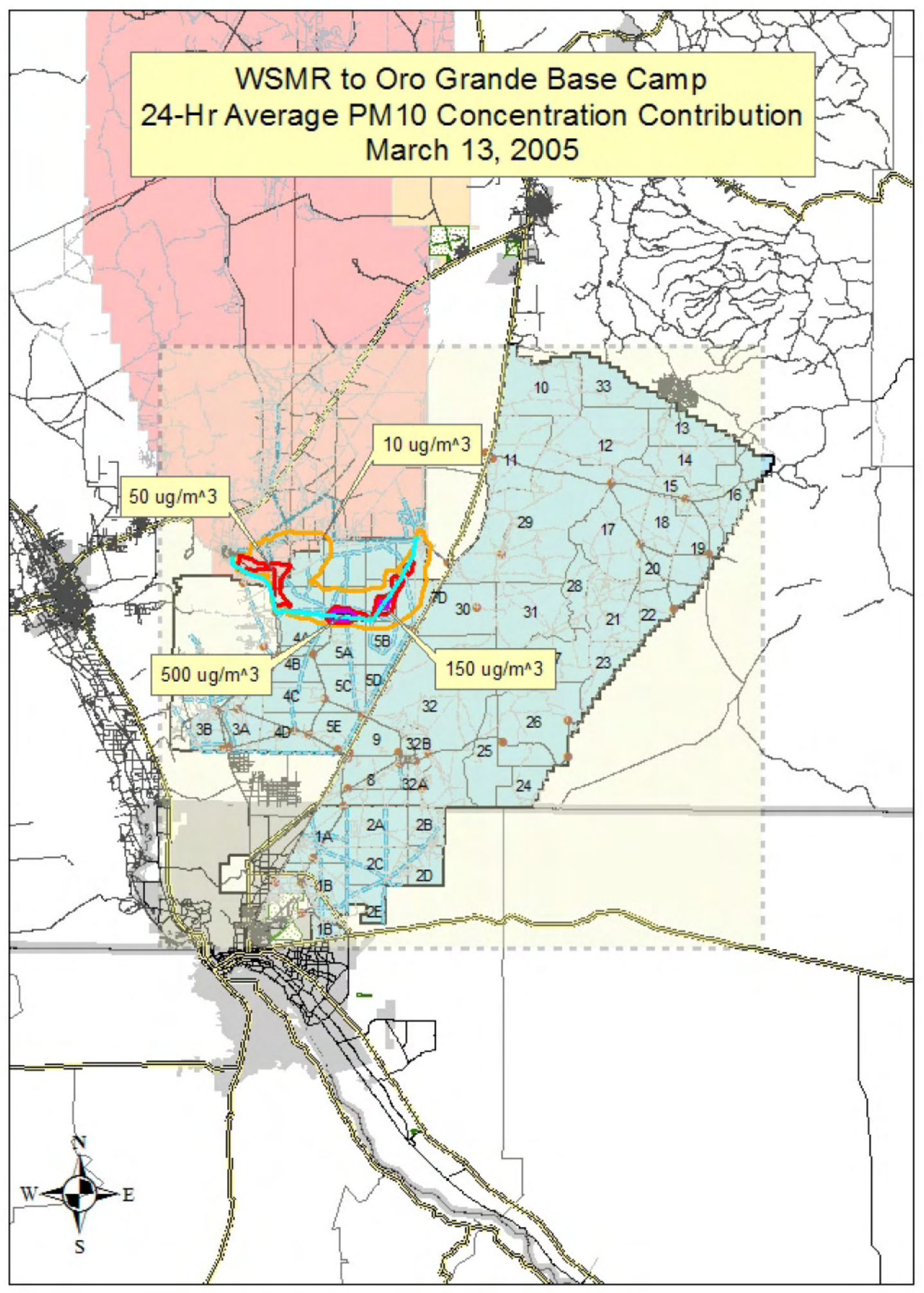




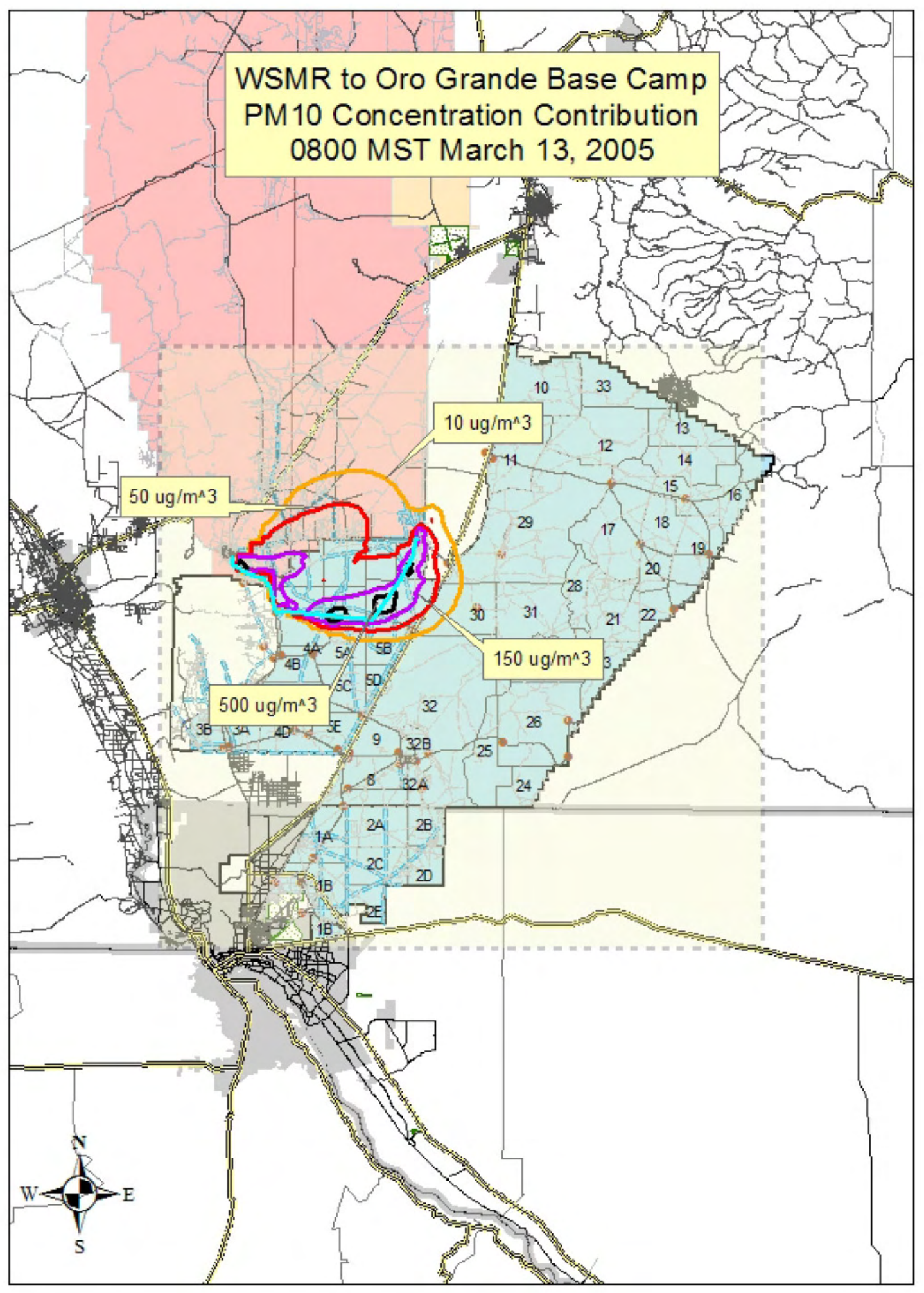




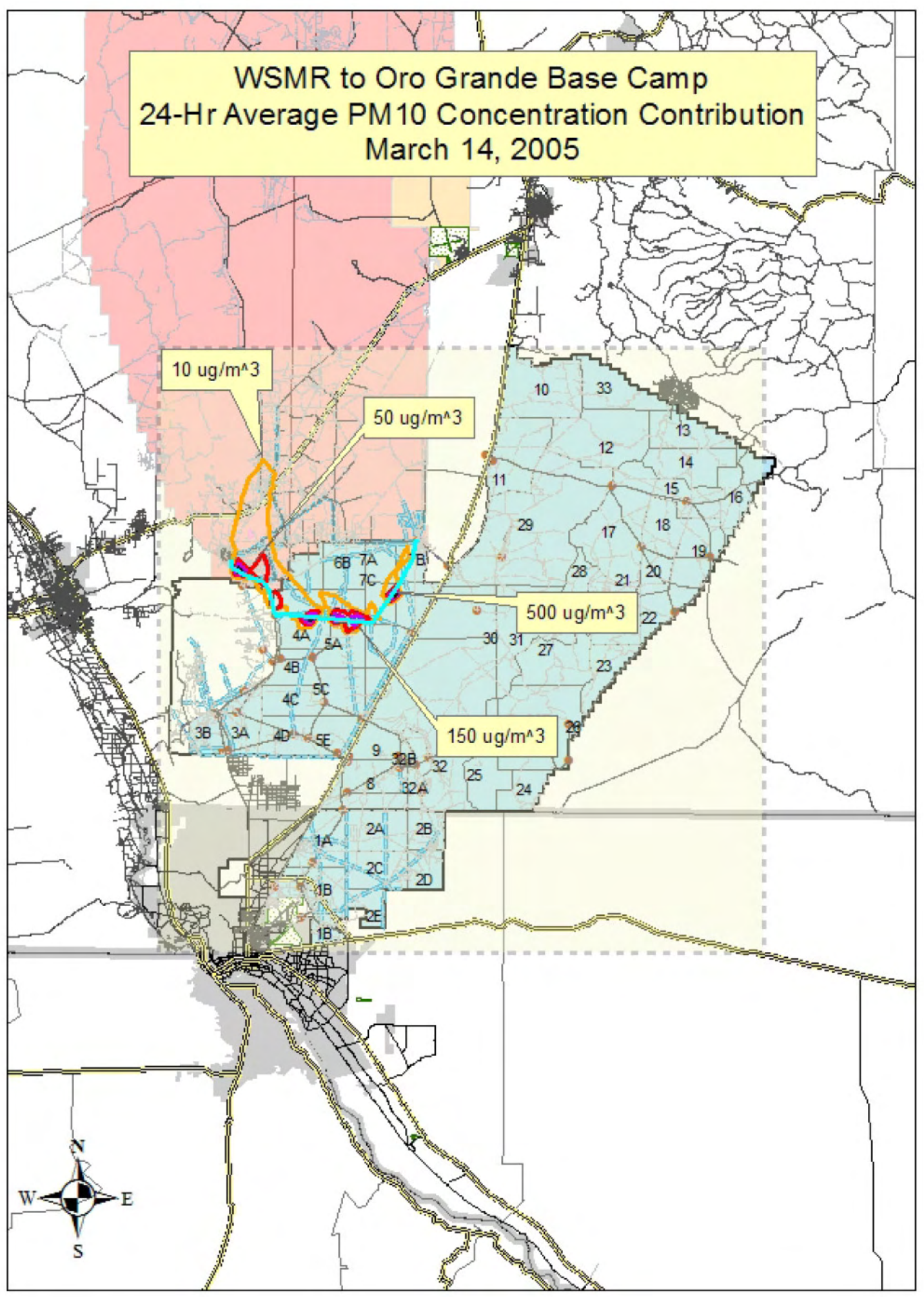

E.6 


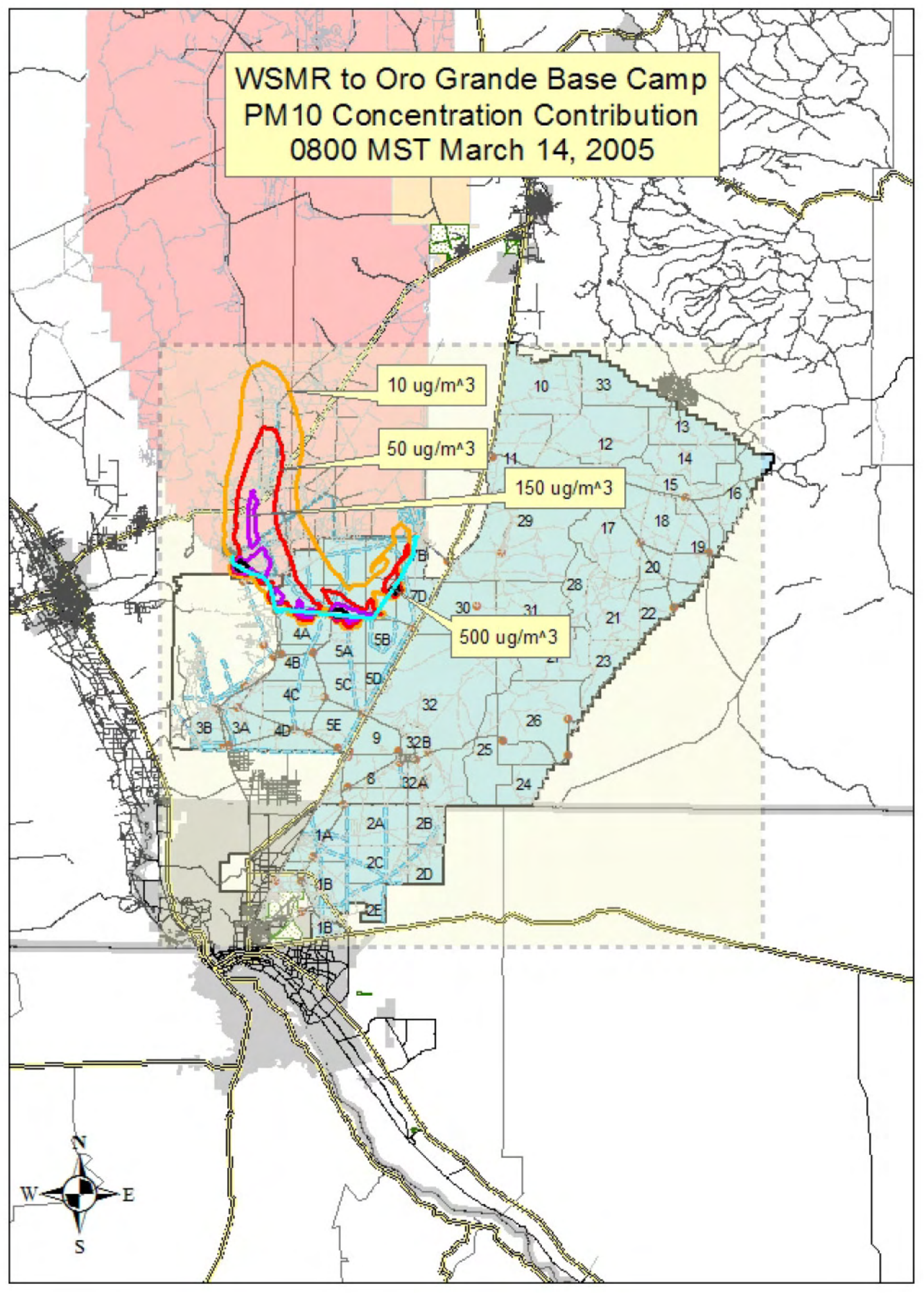




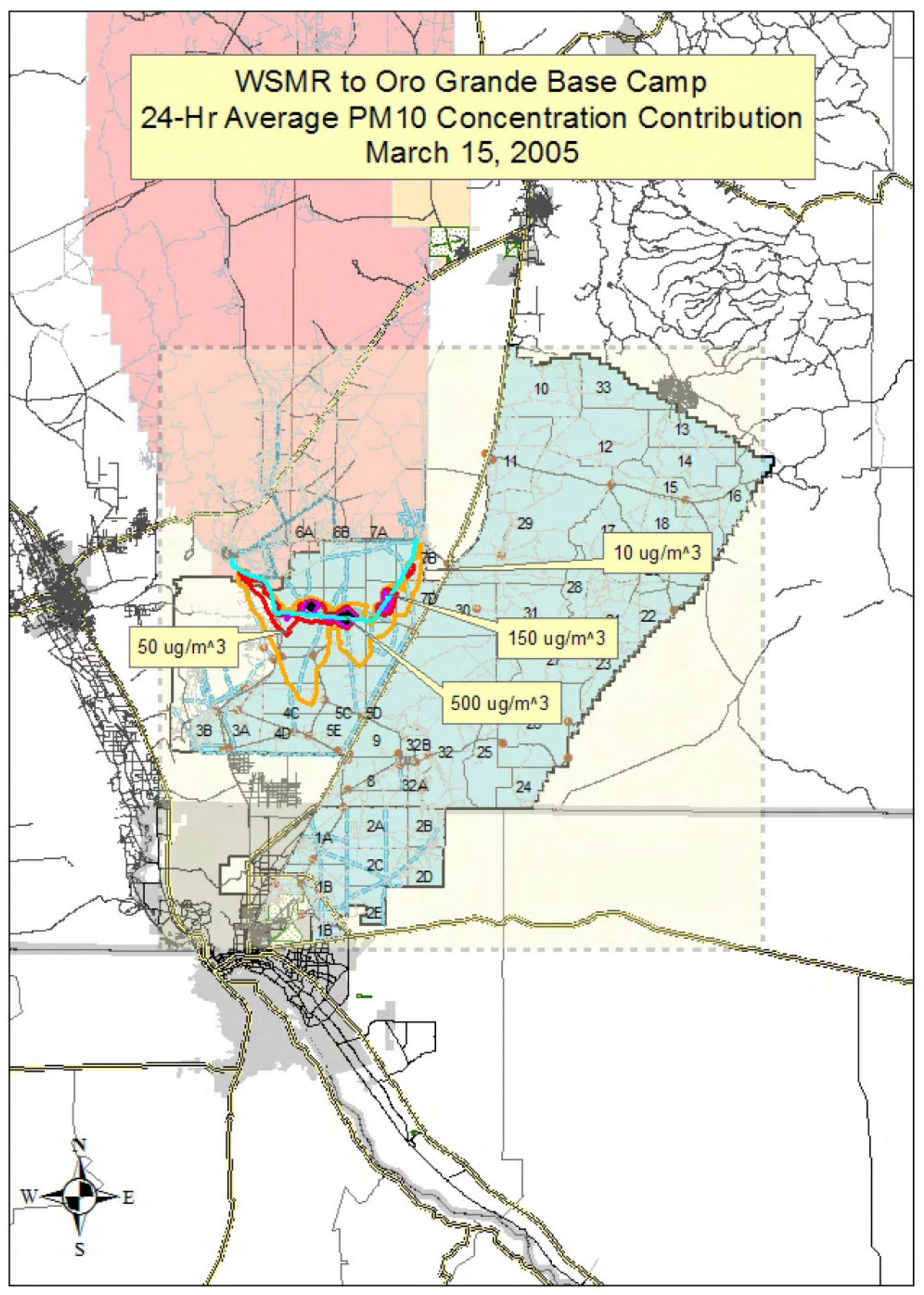




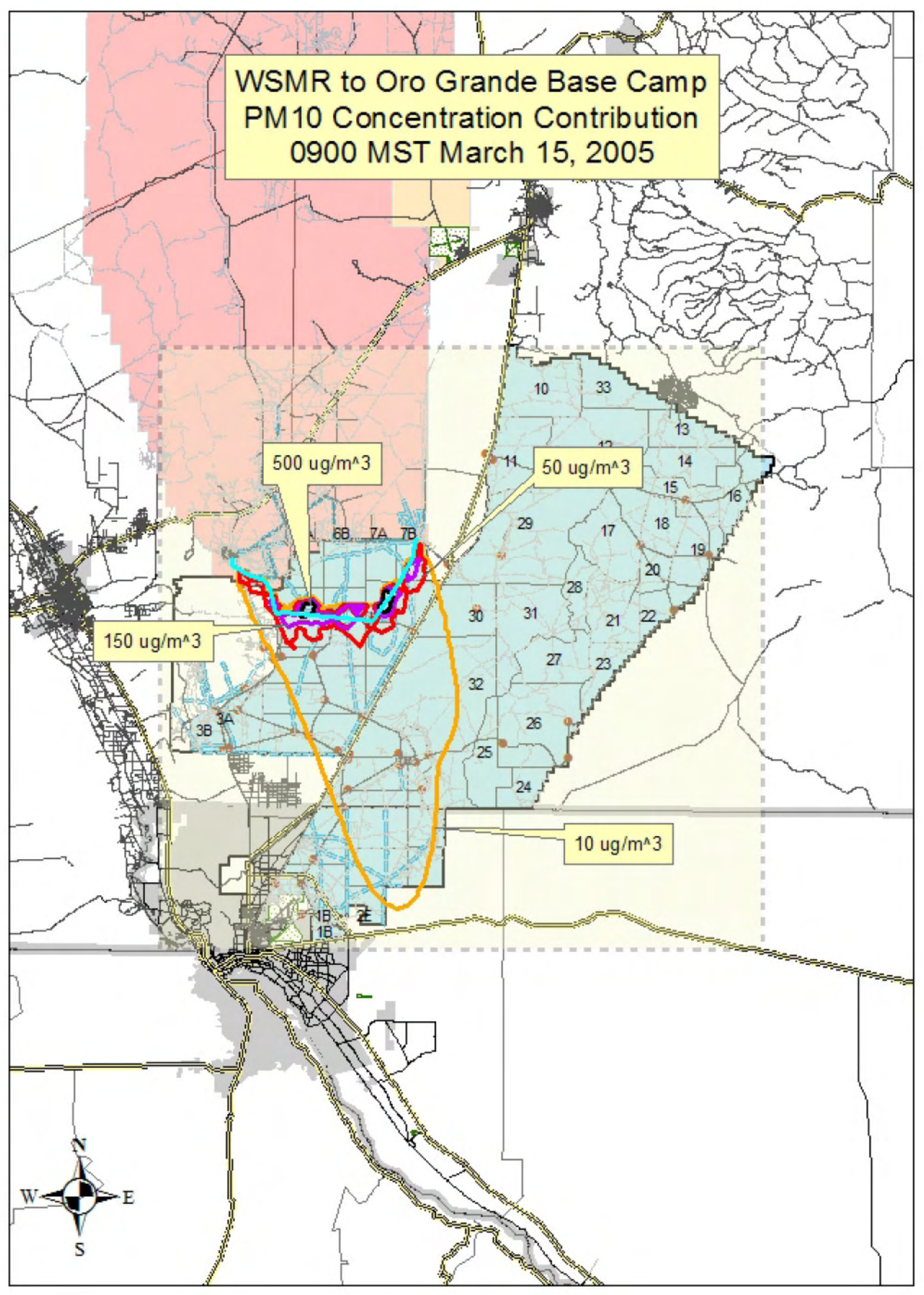




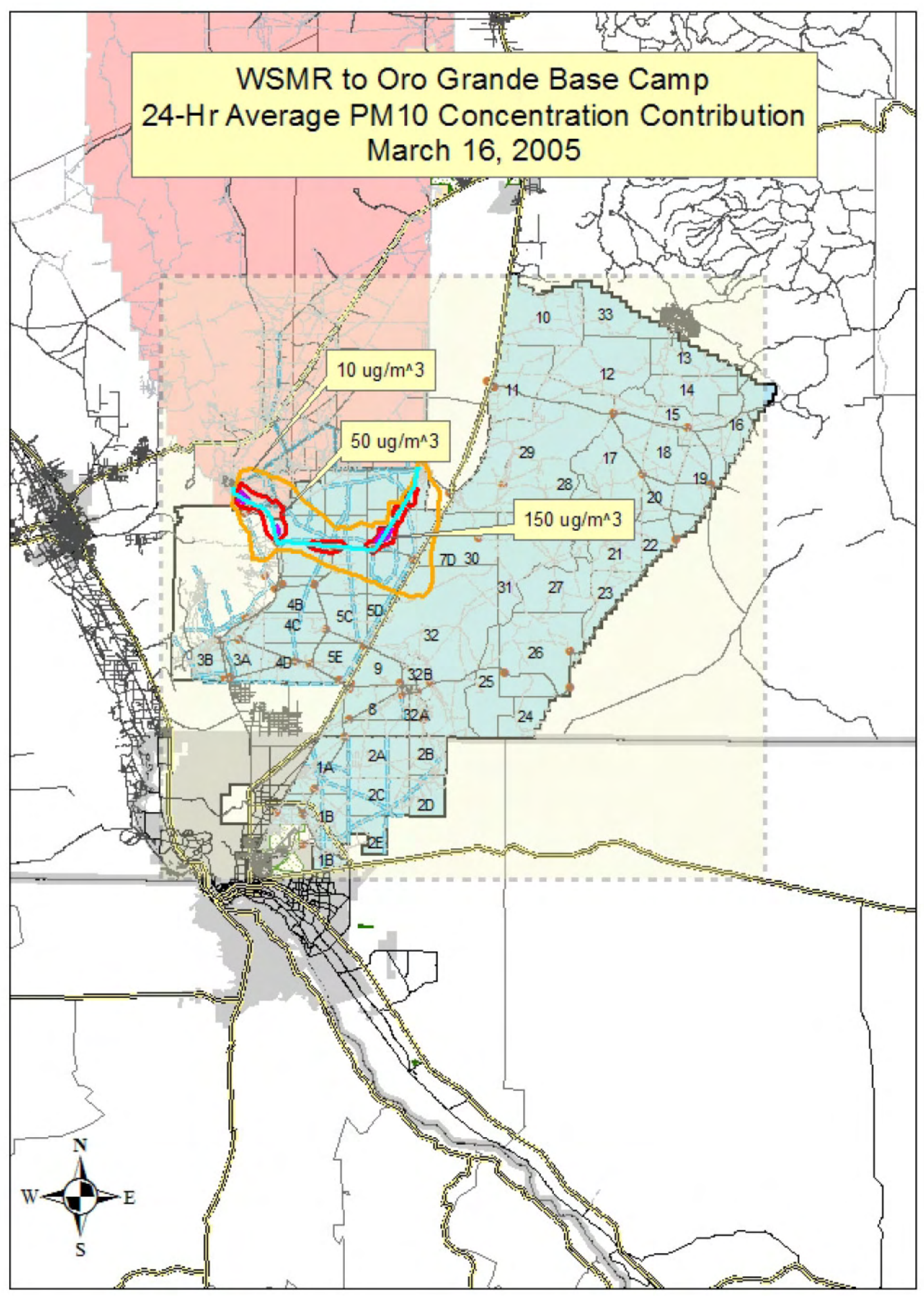




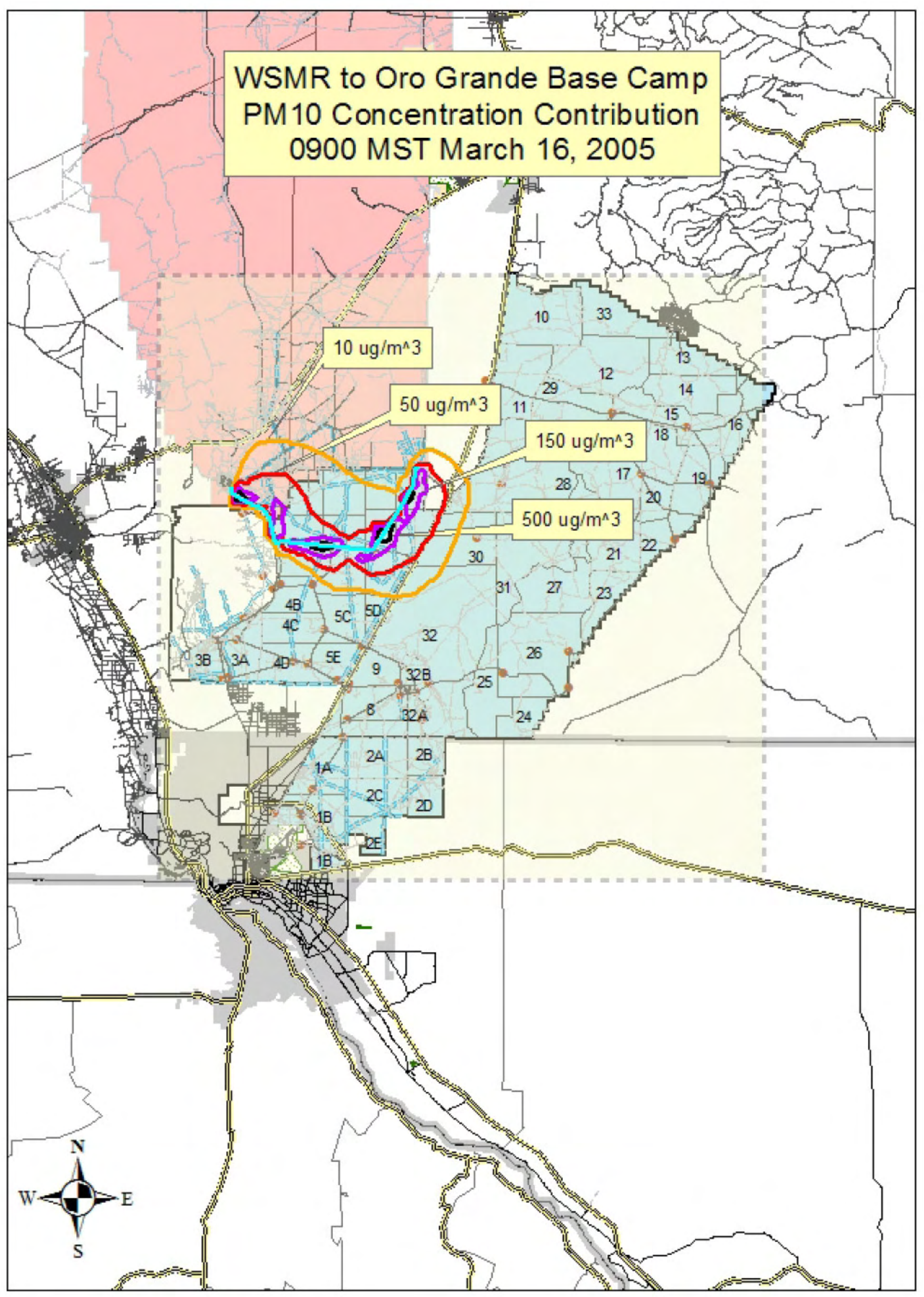




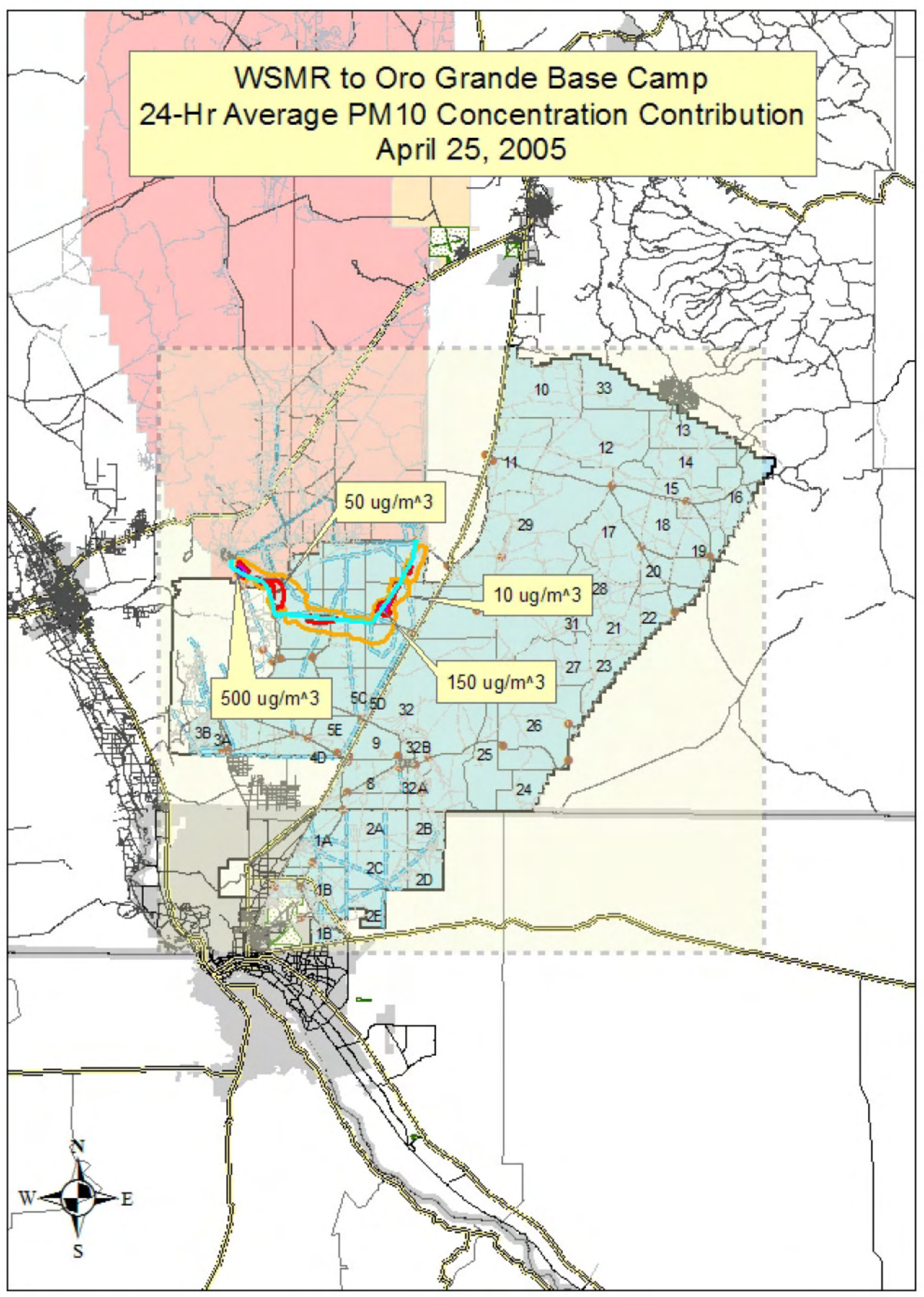

E.12 


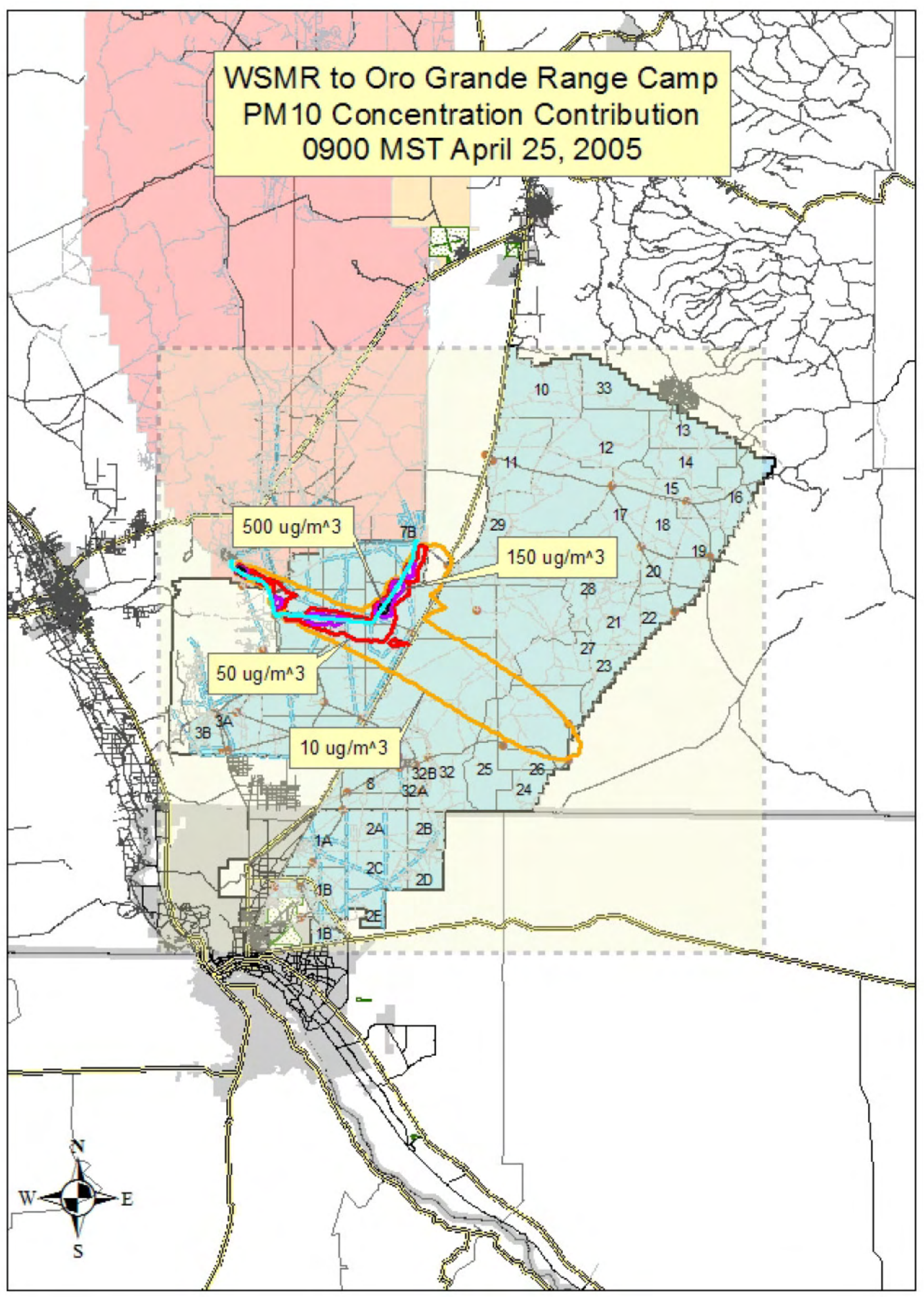




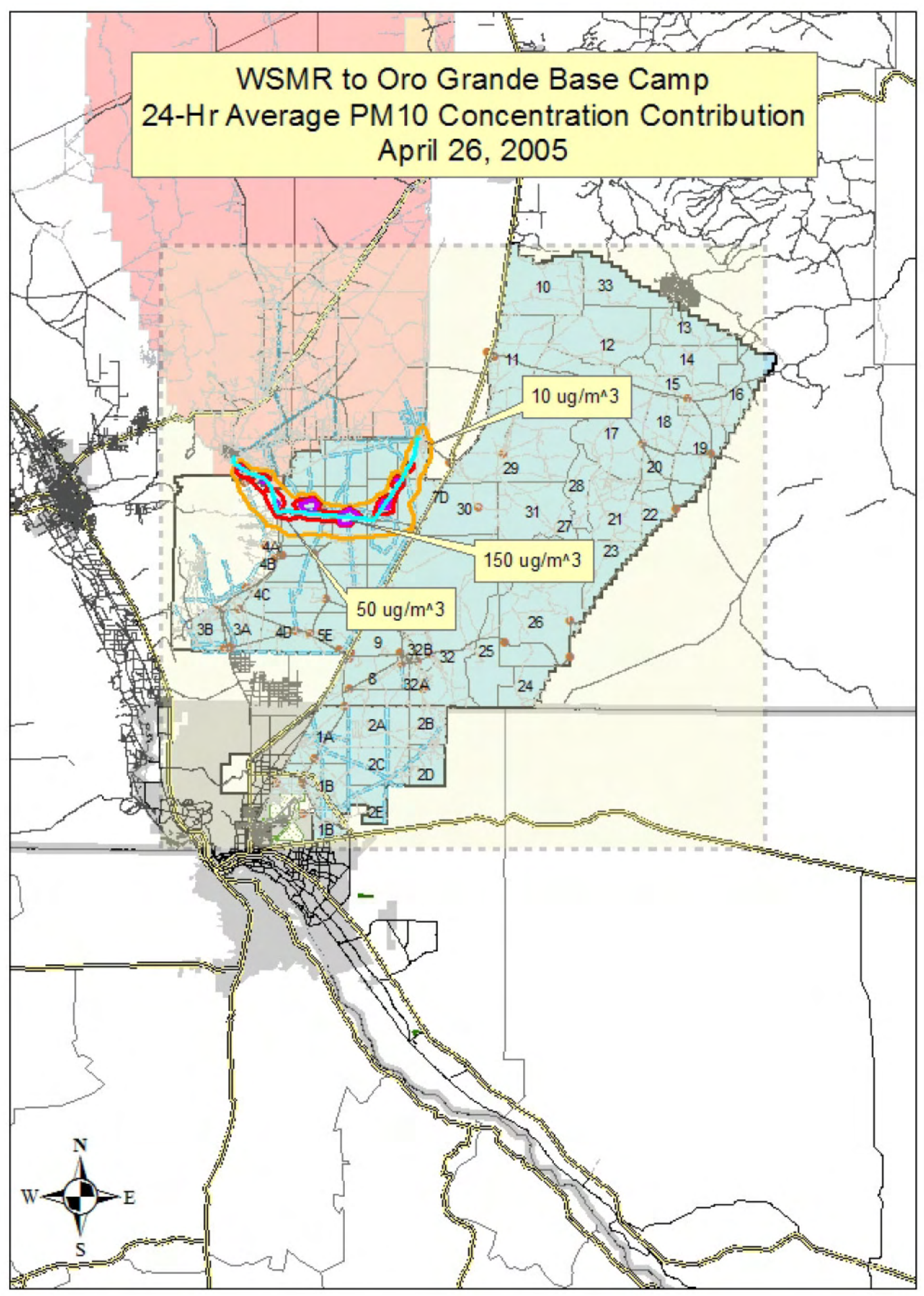




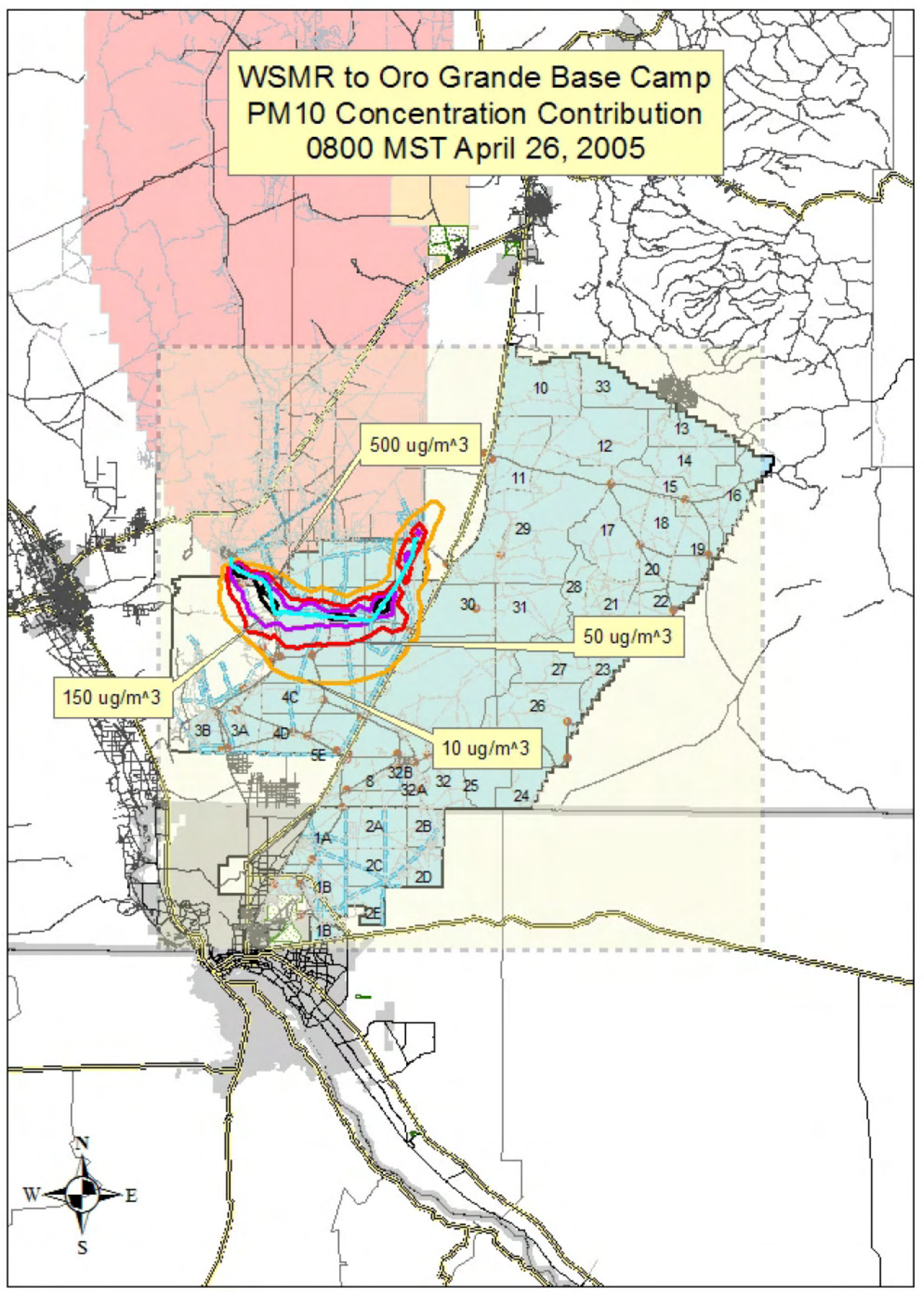




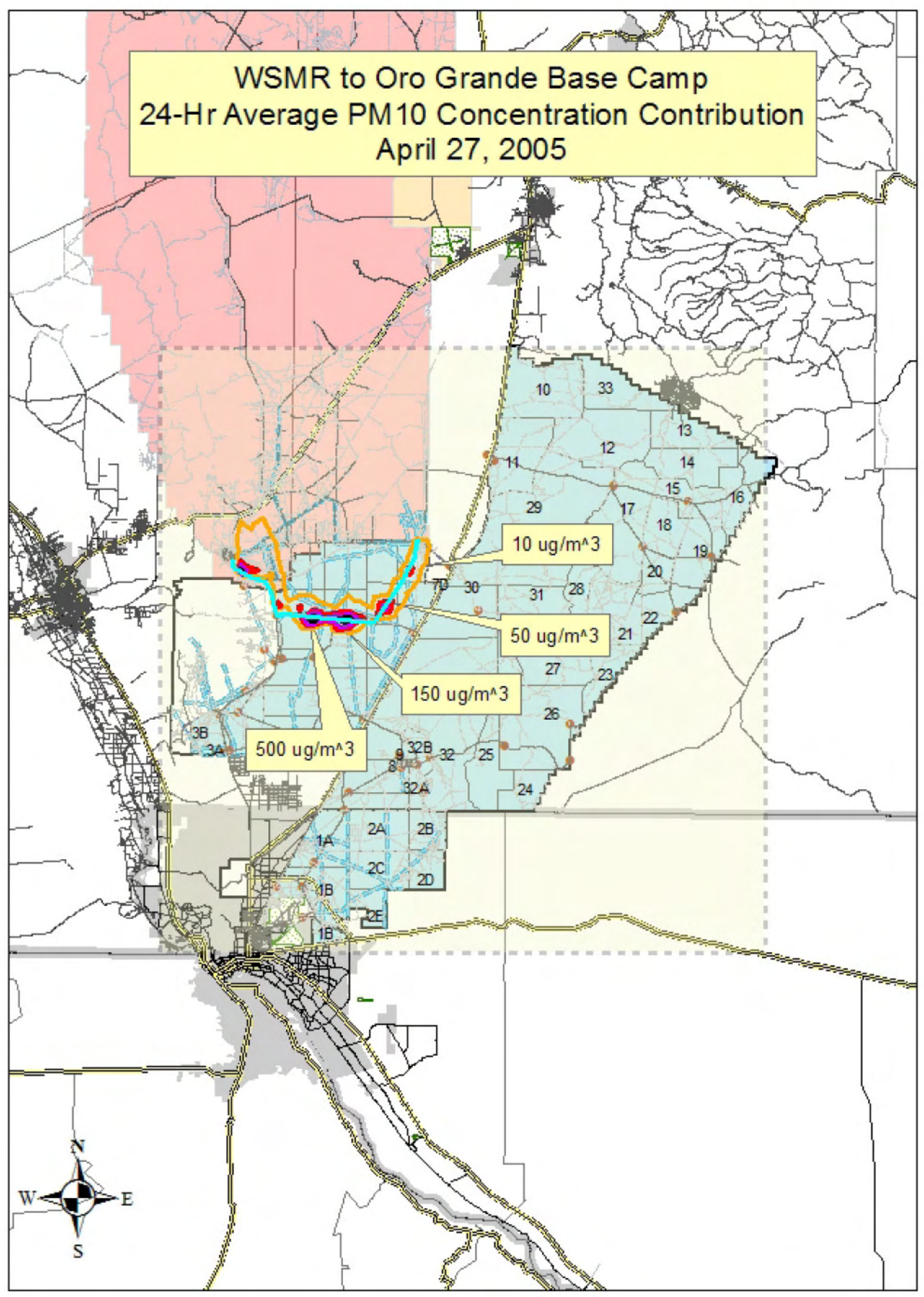




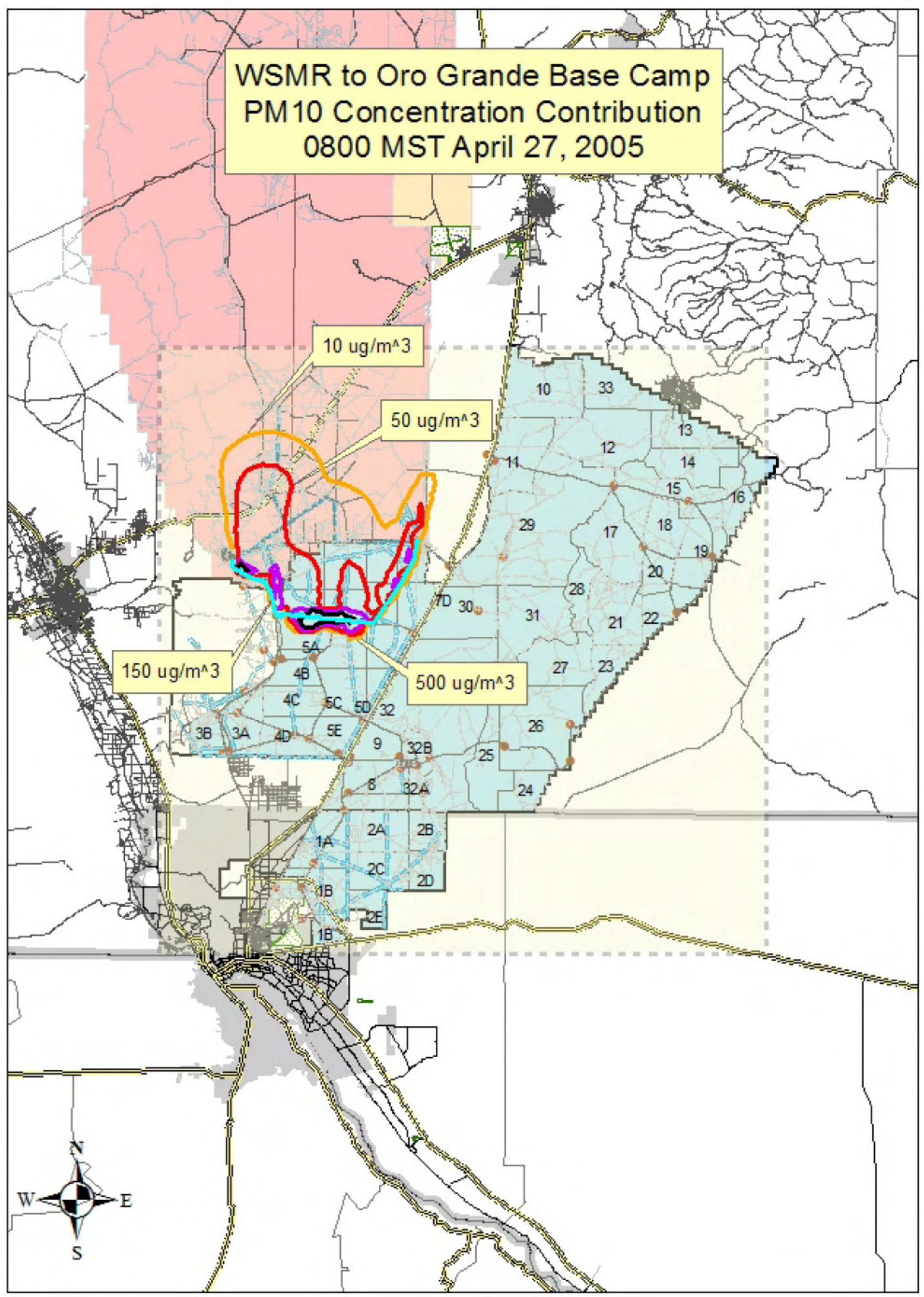

E.17 


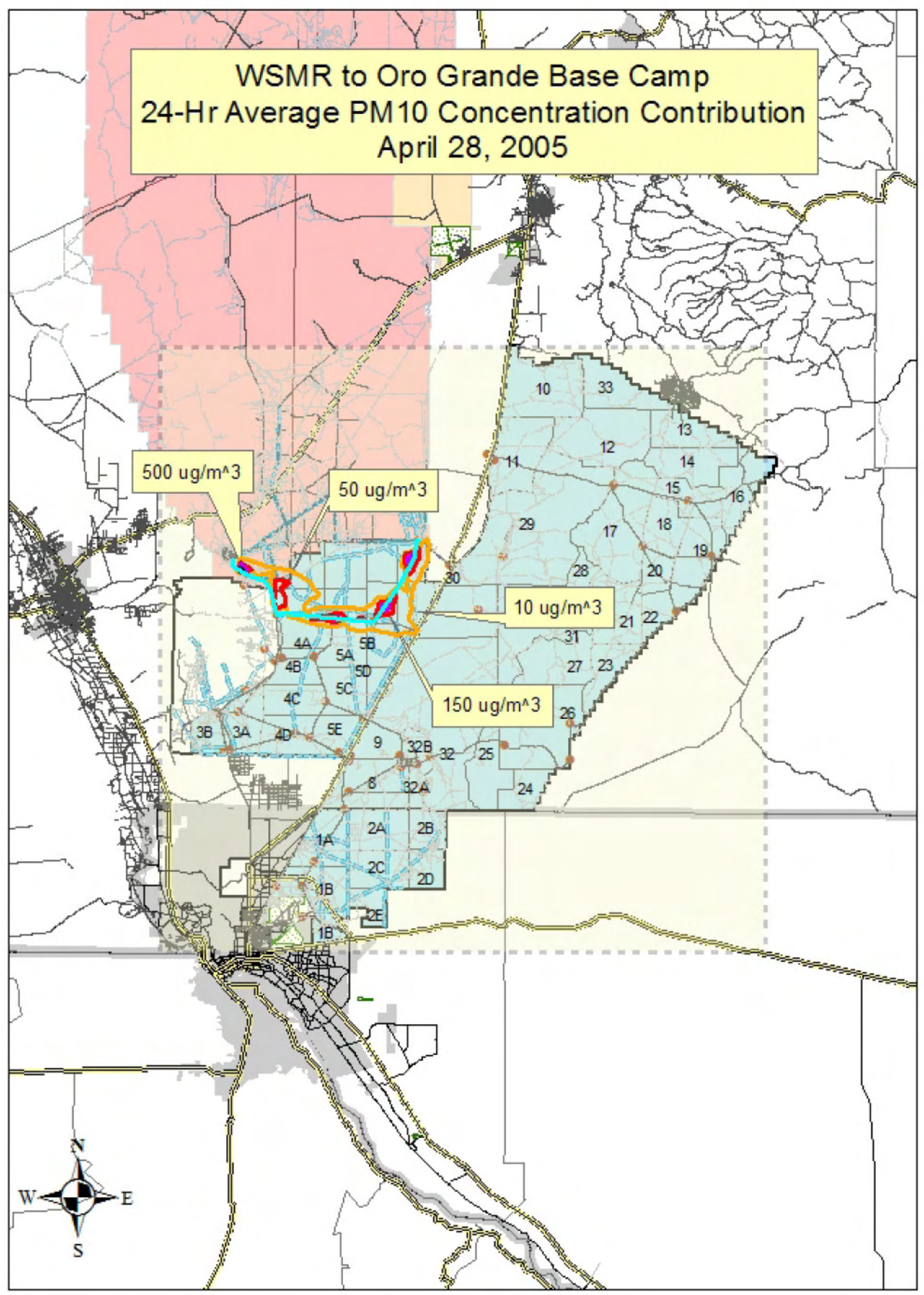




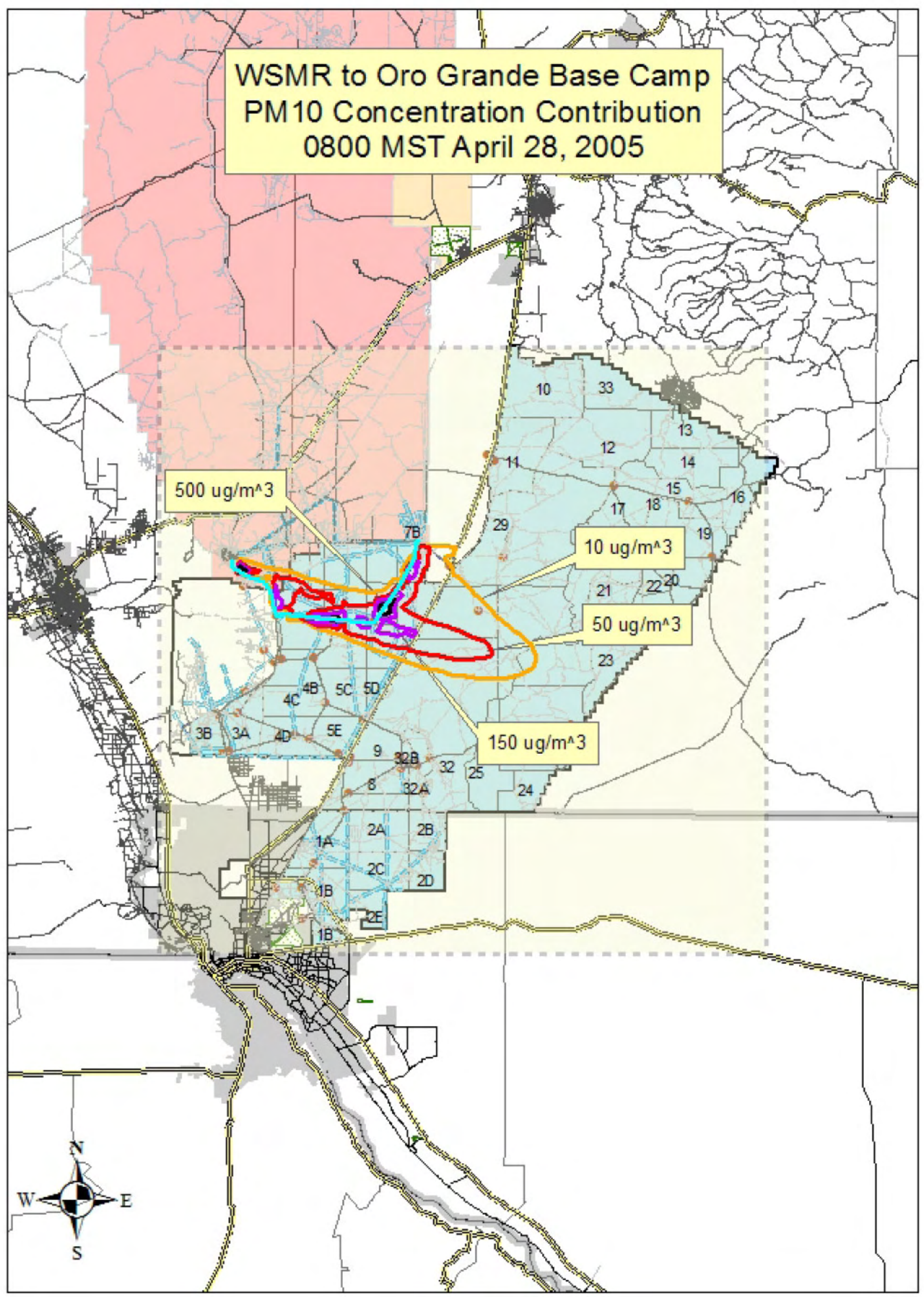




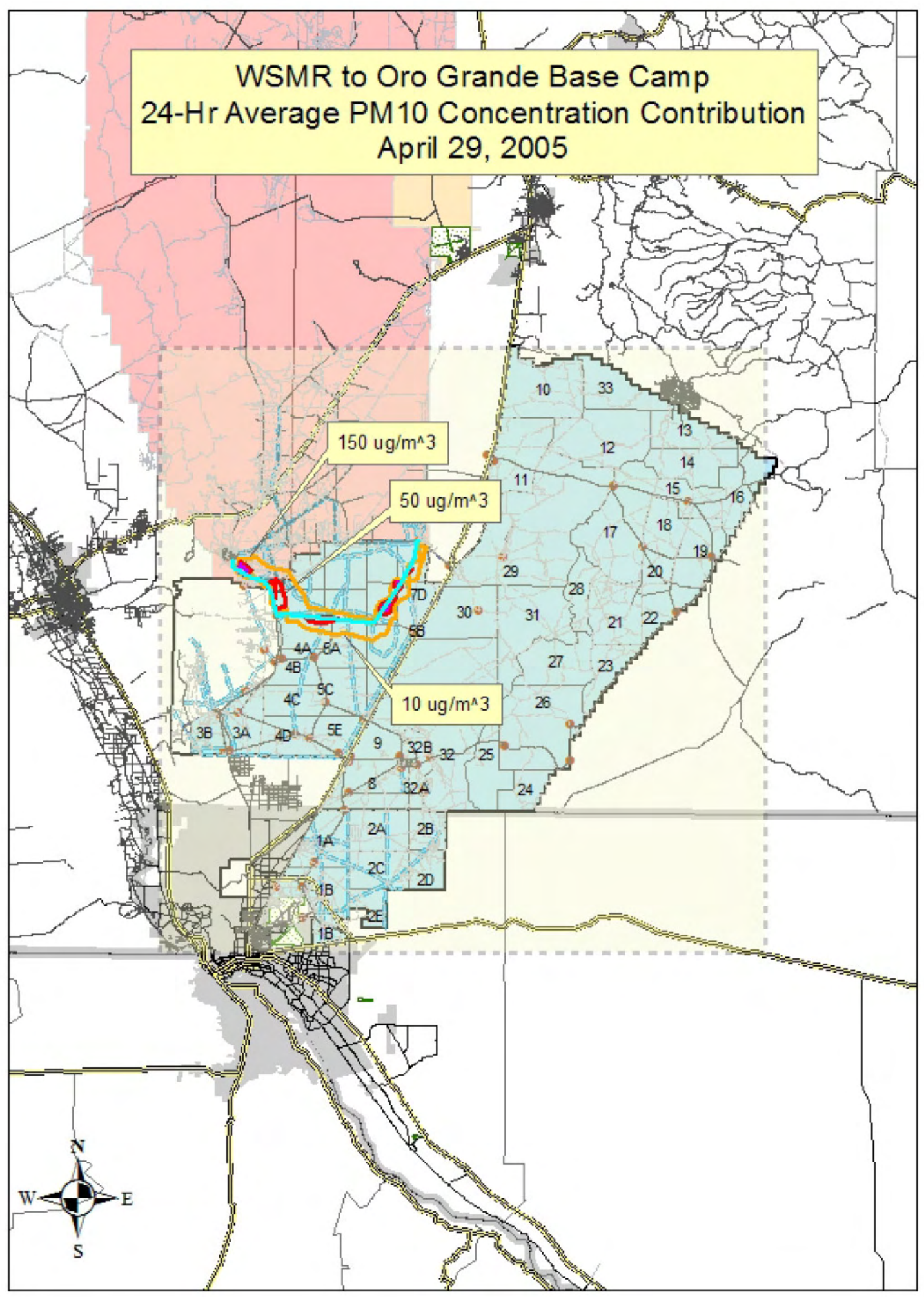




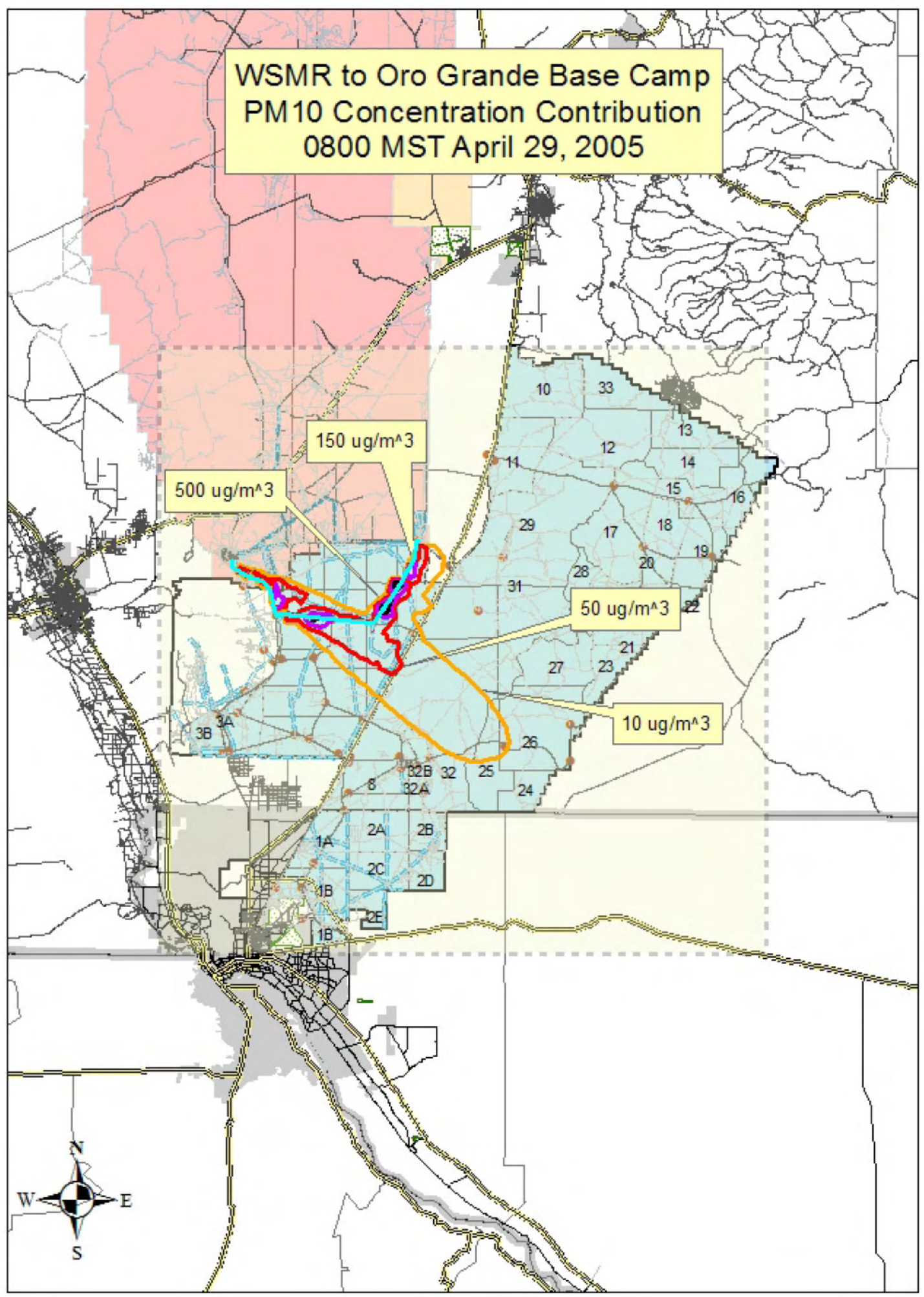




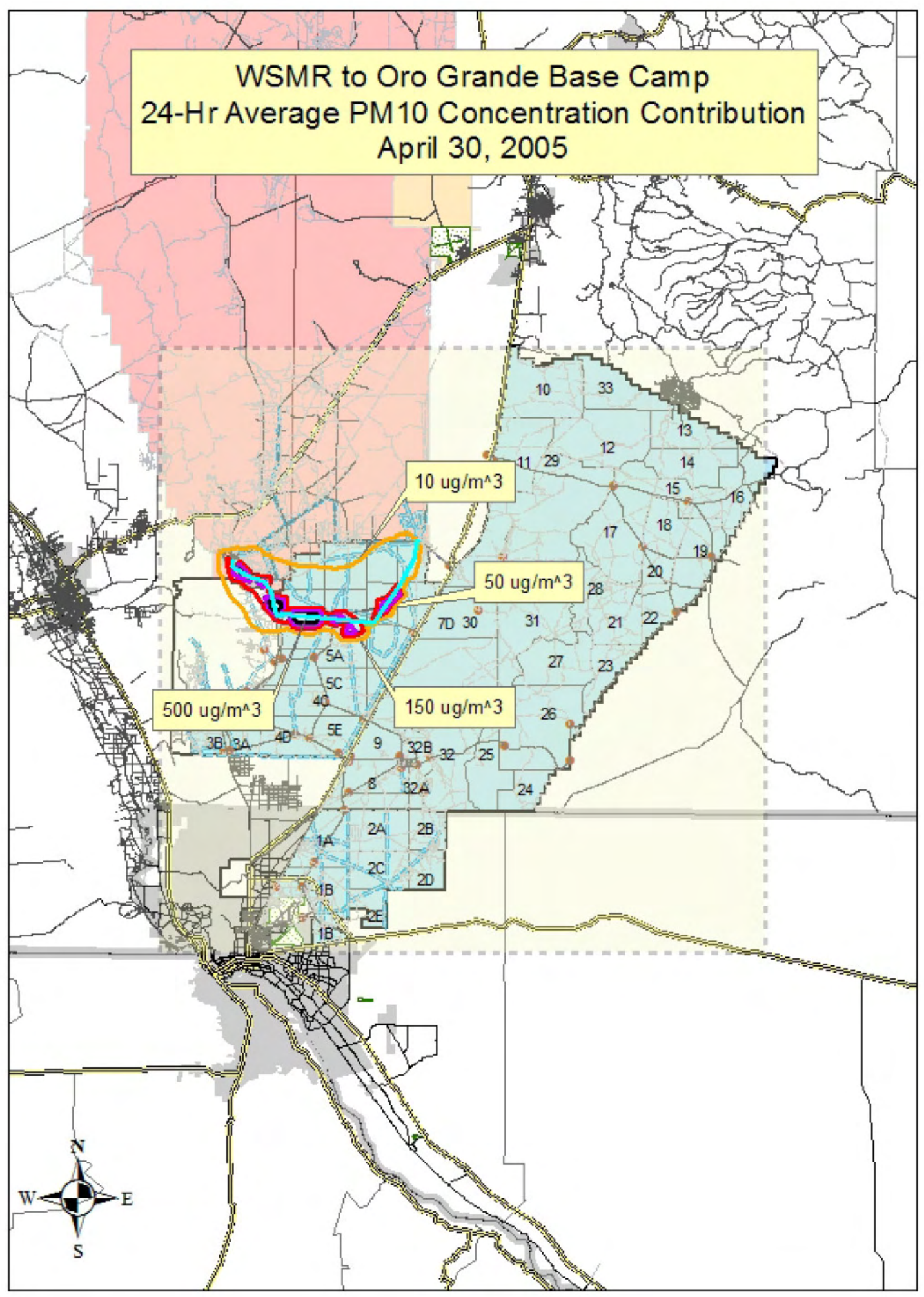




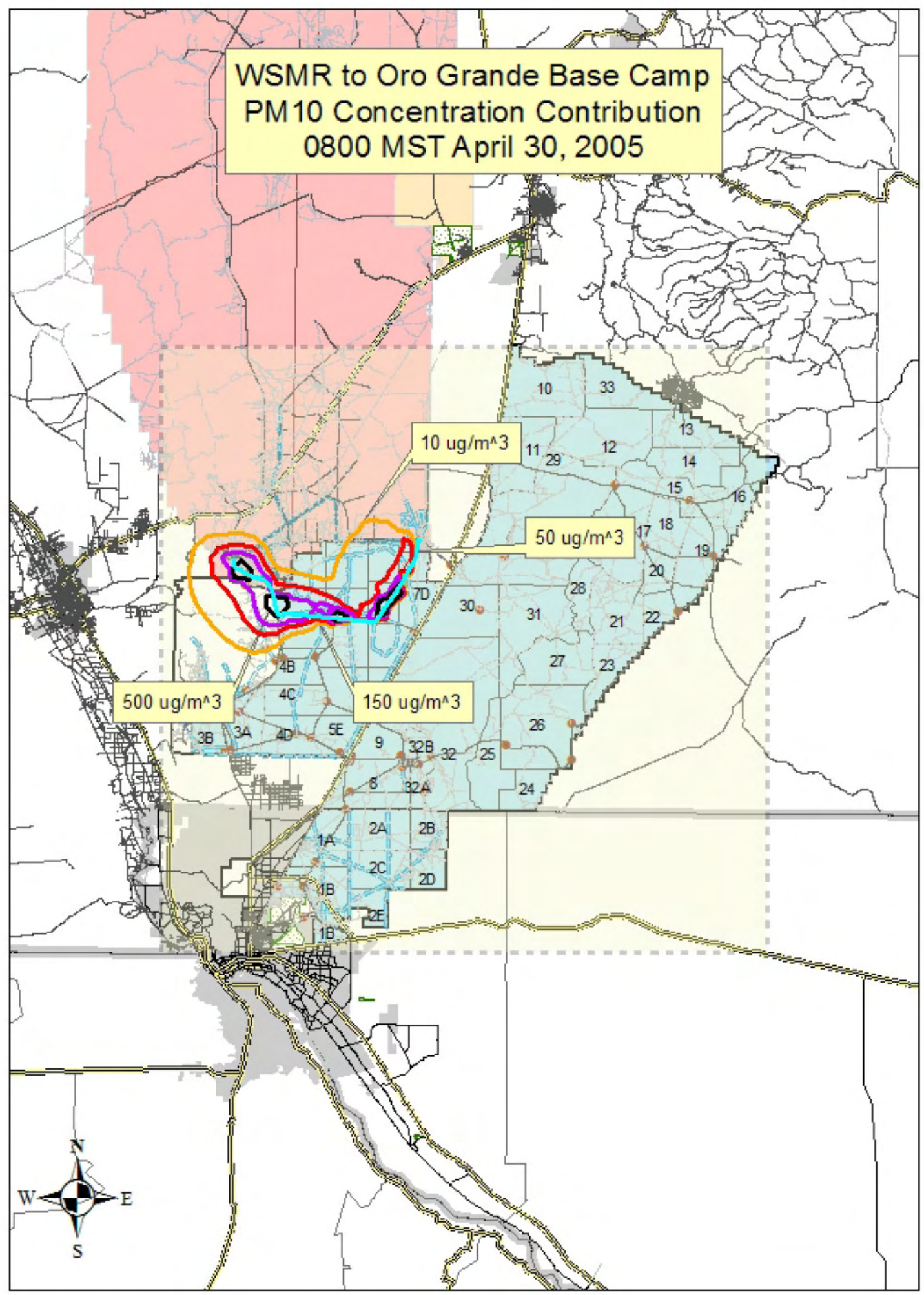




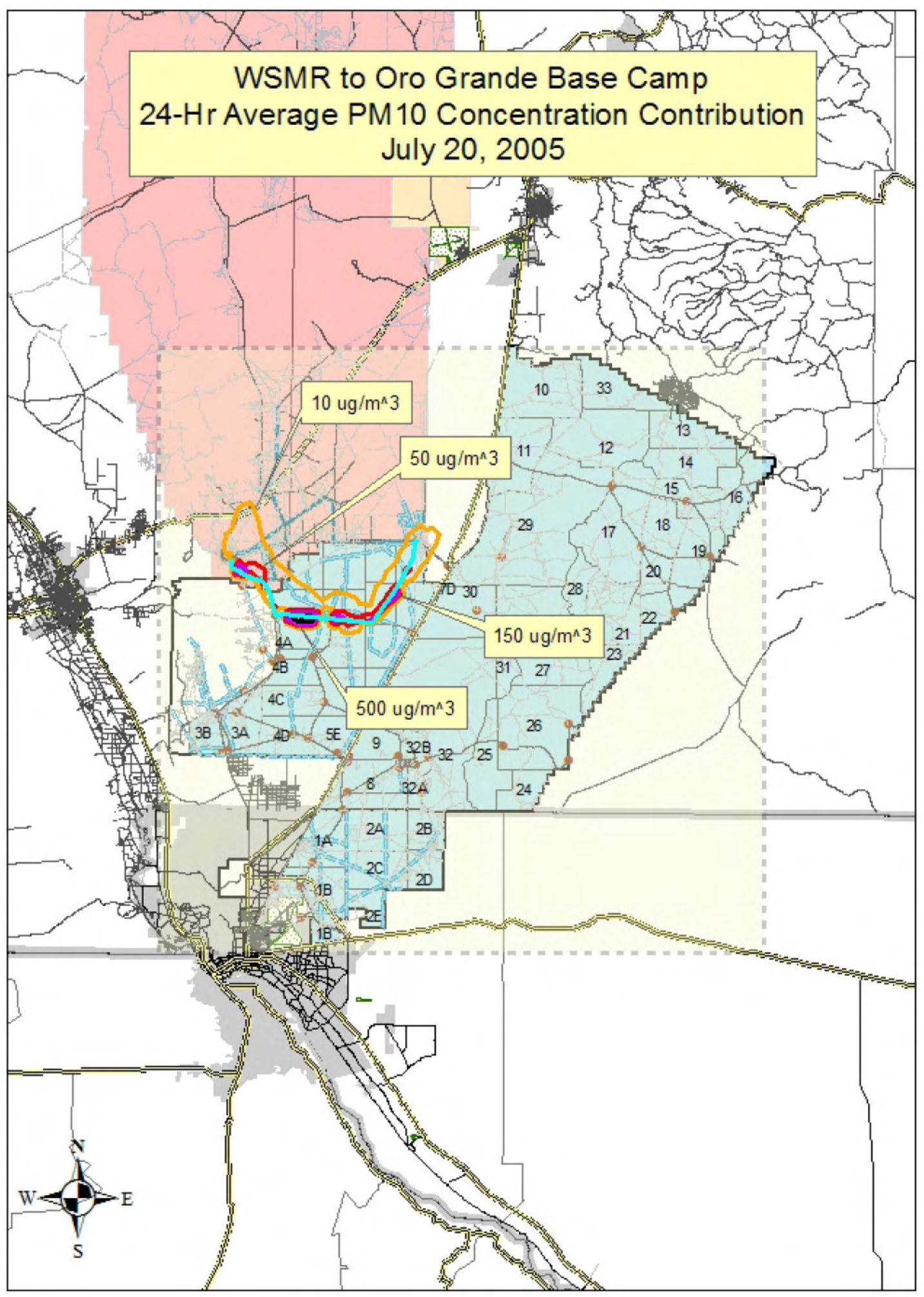




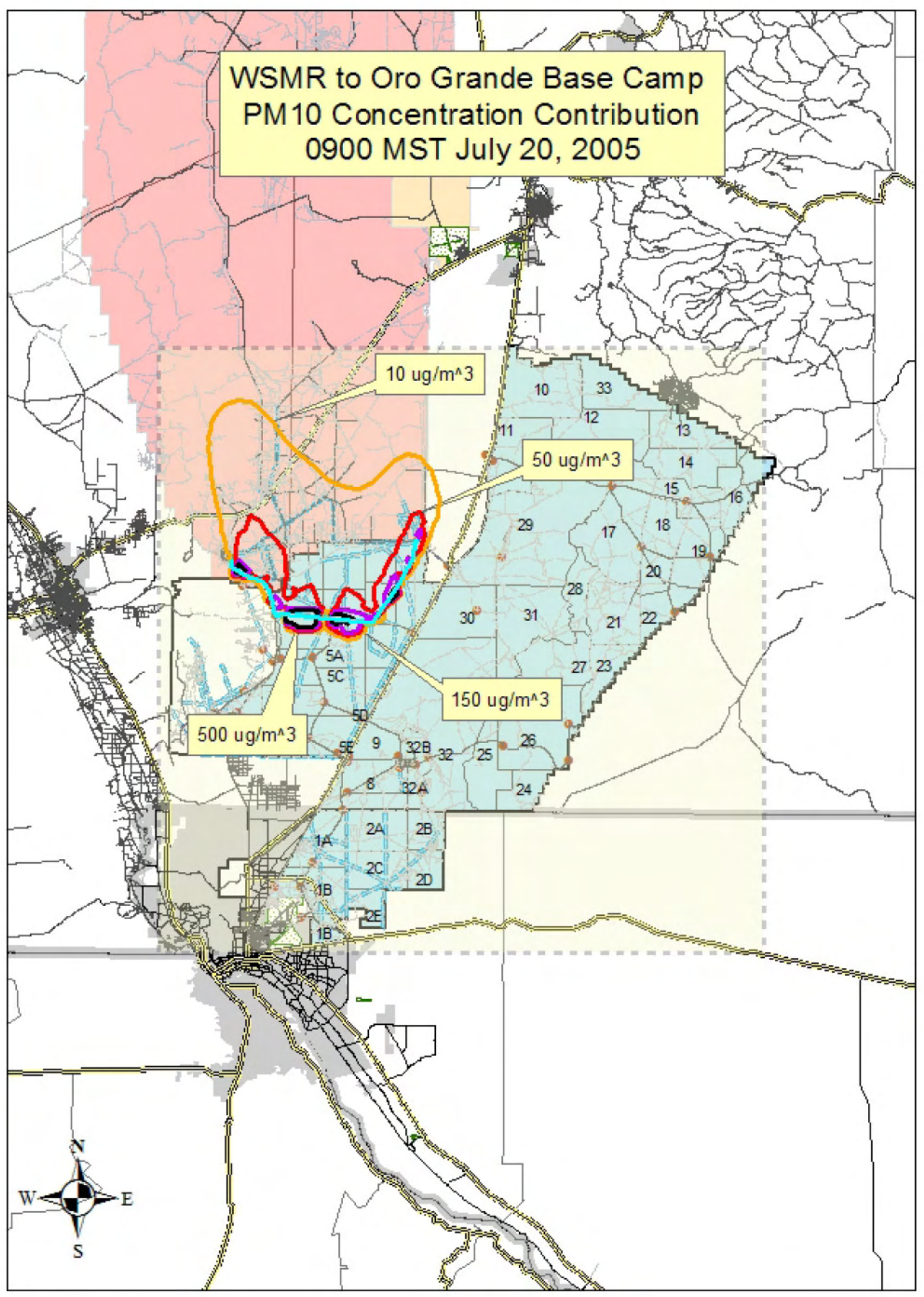




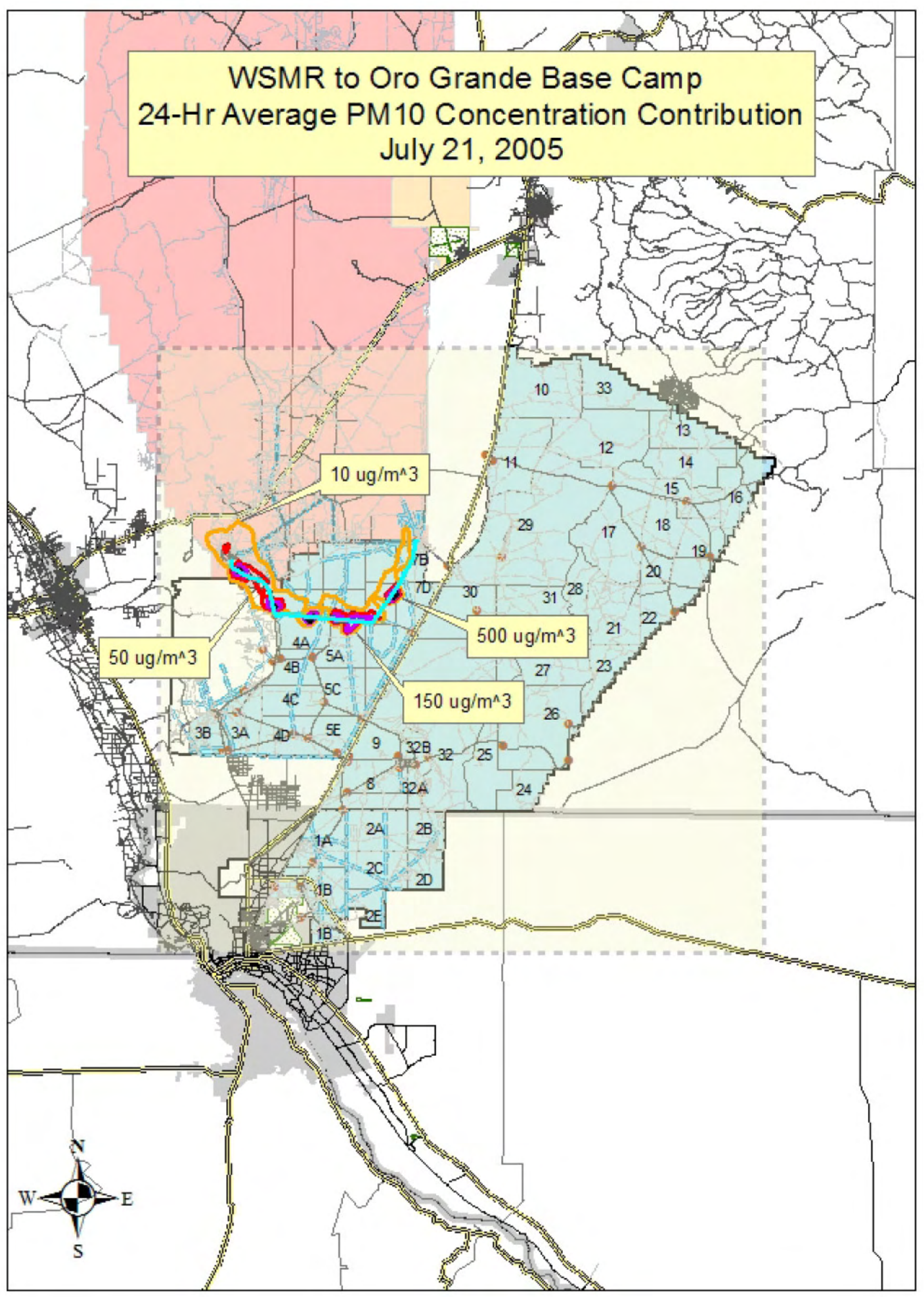




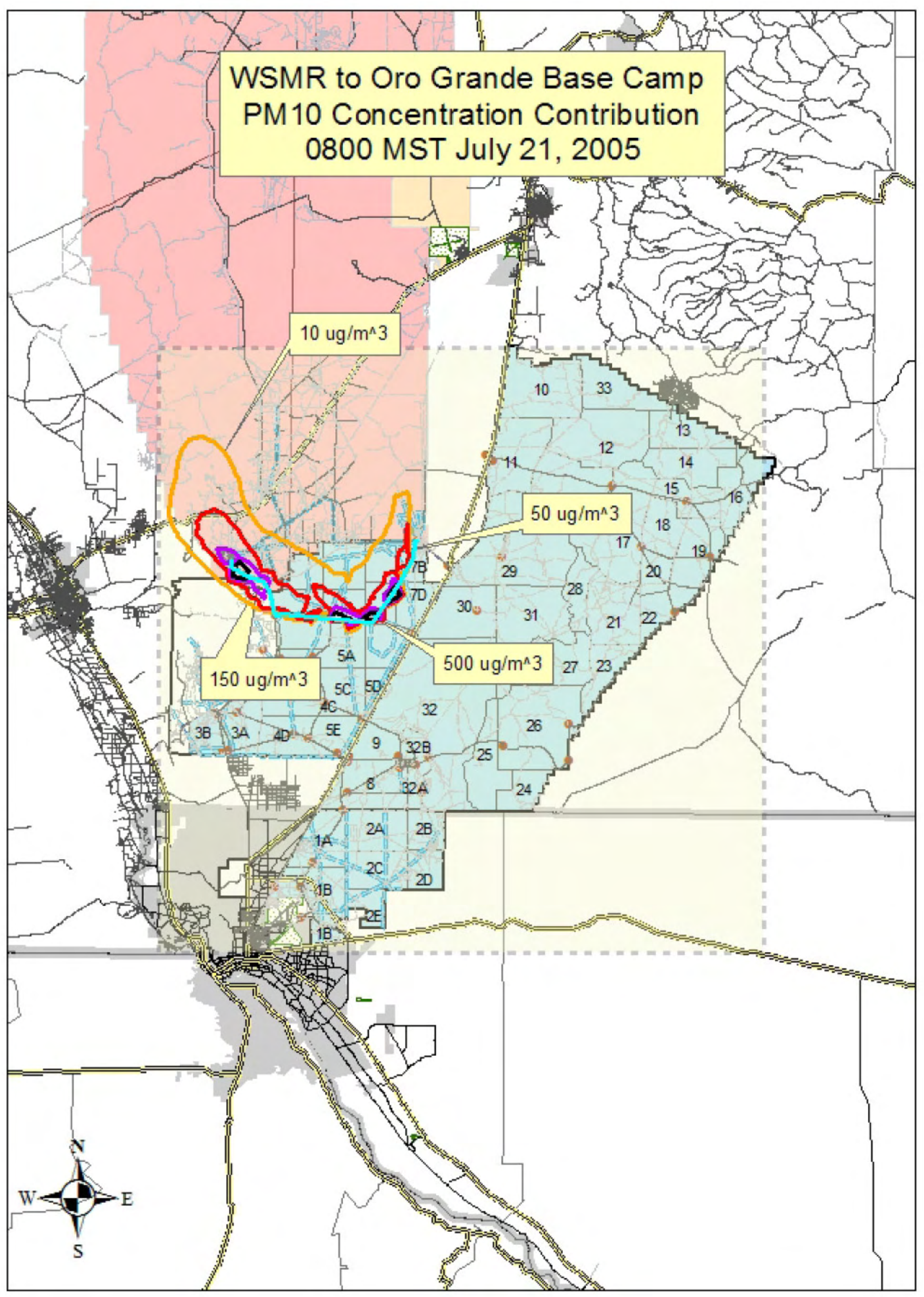




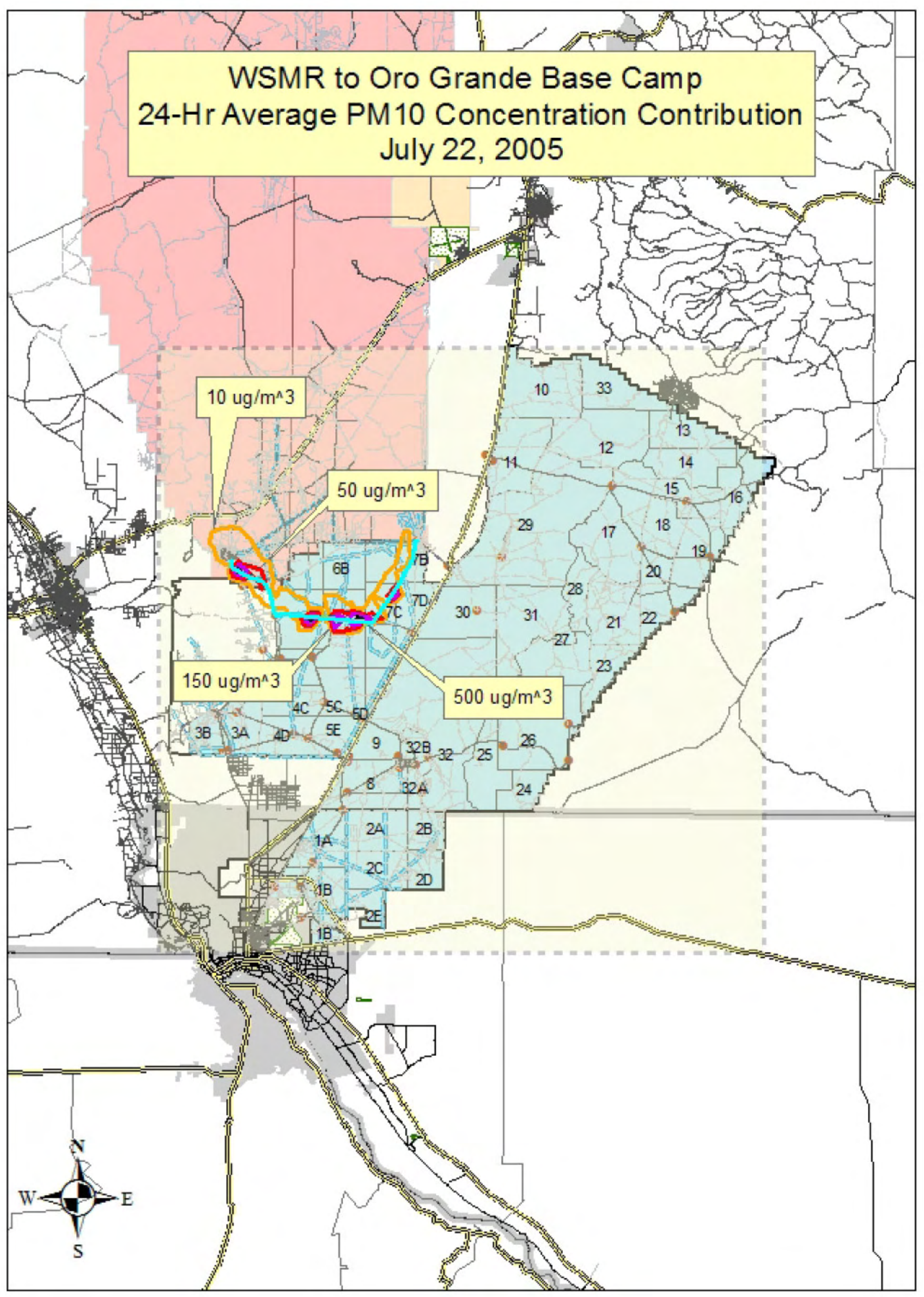




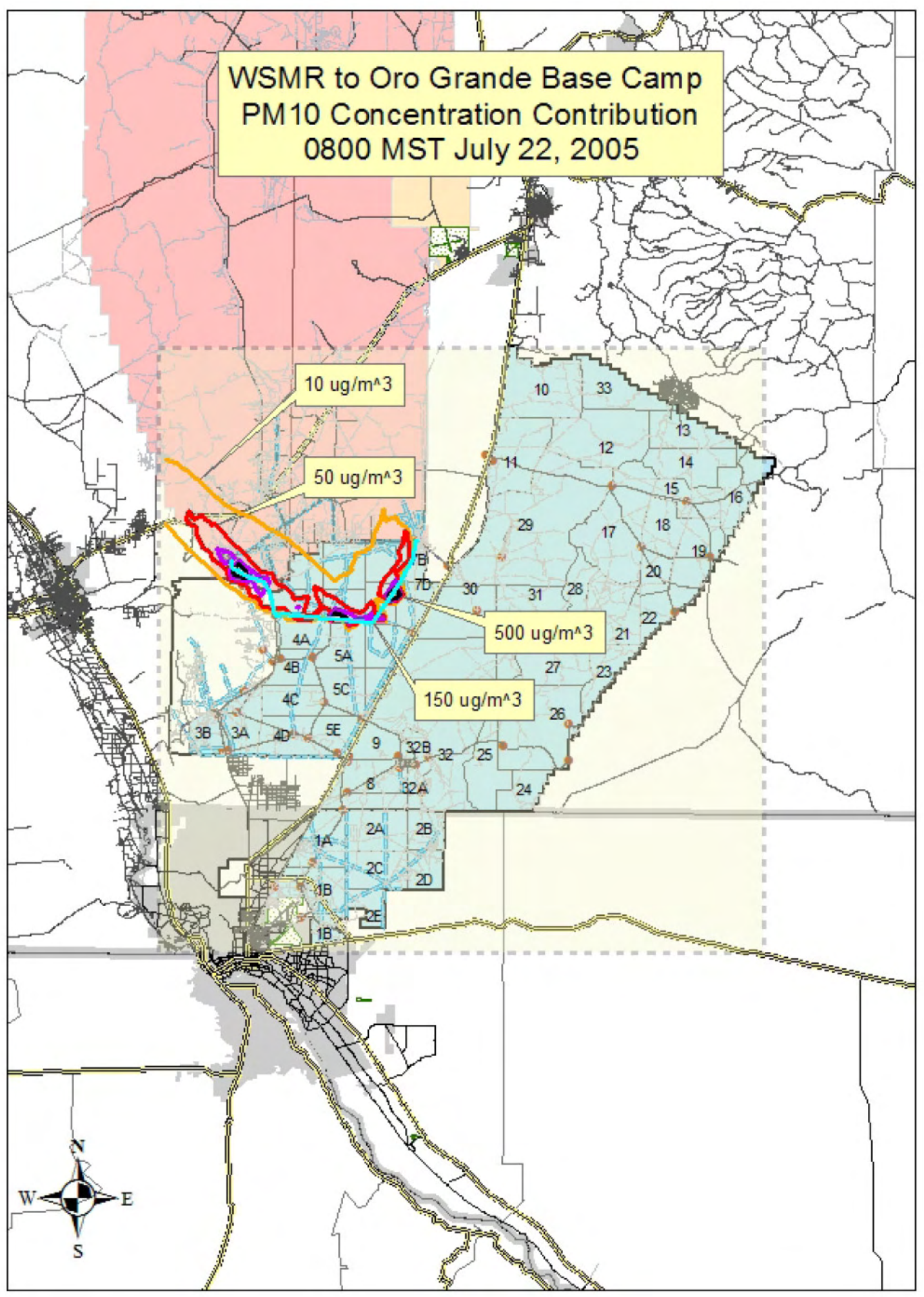




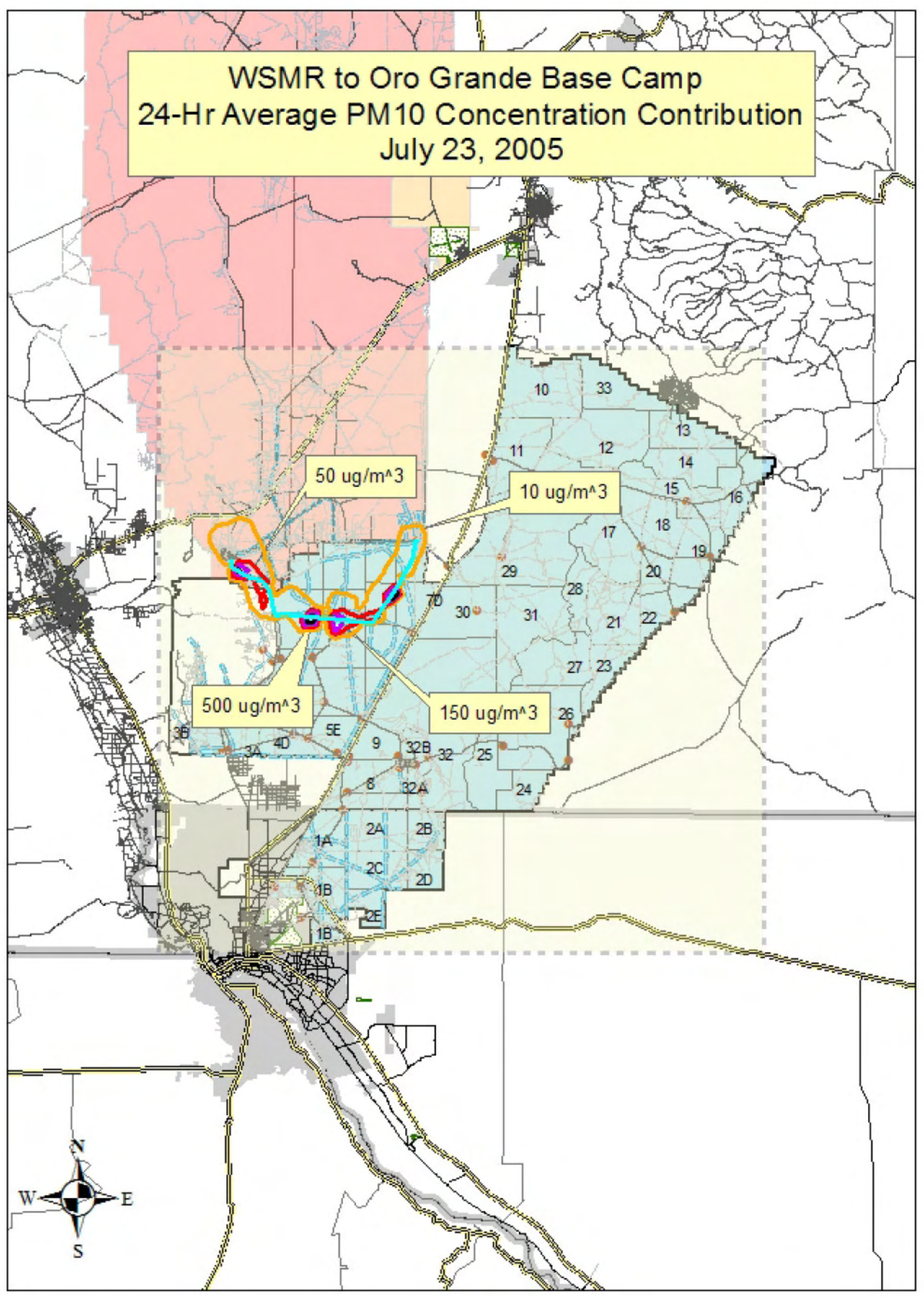




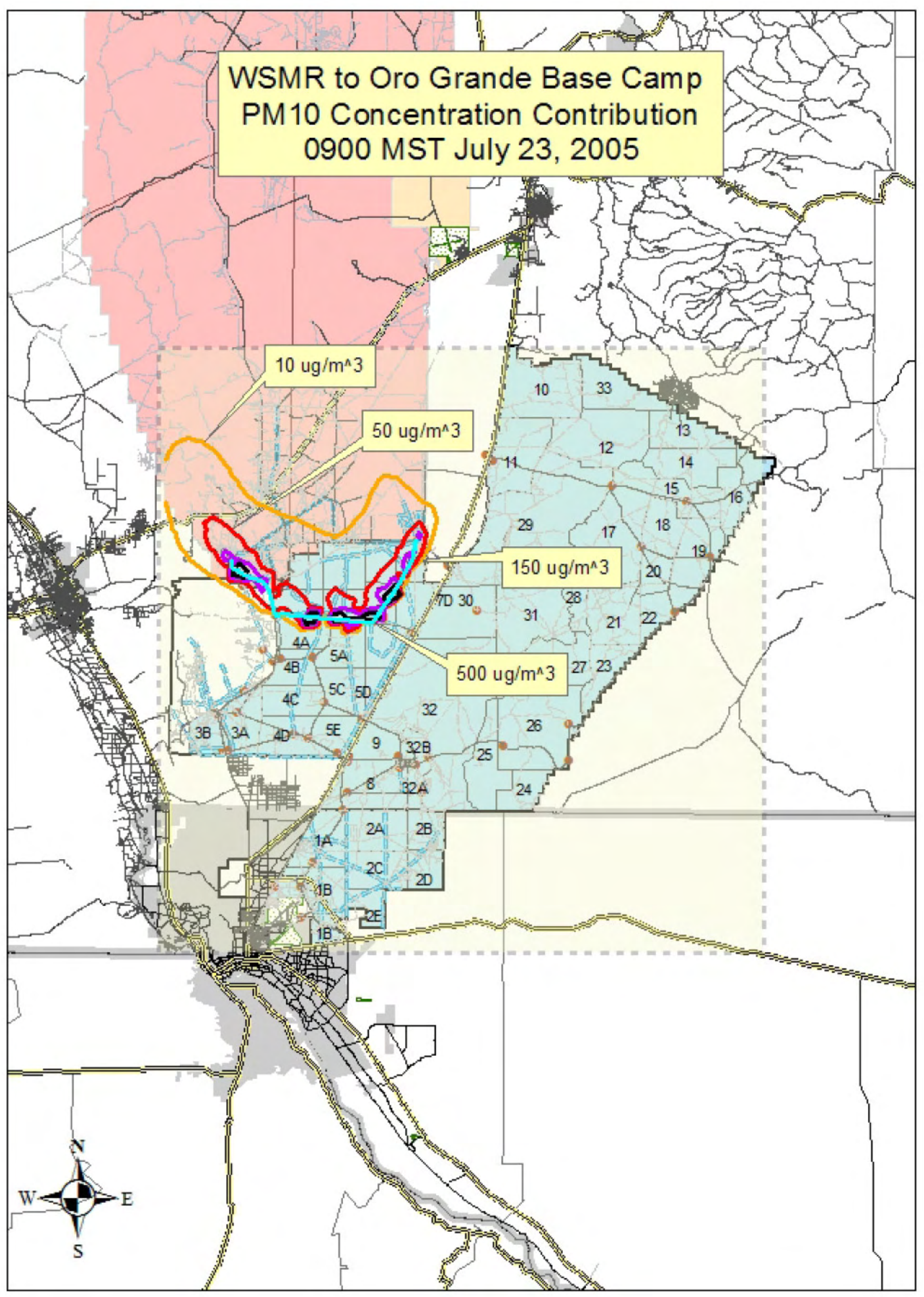




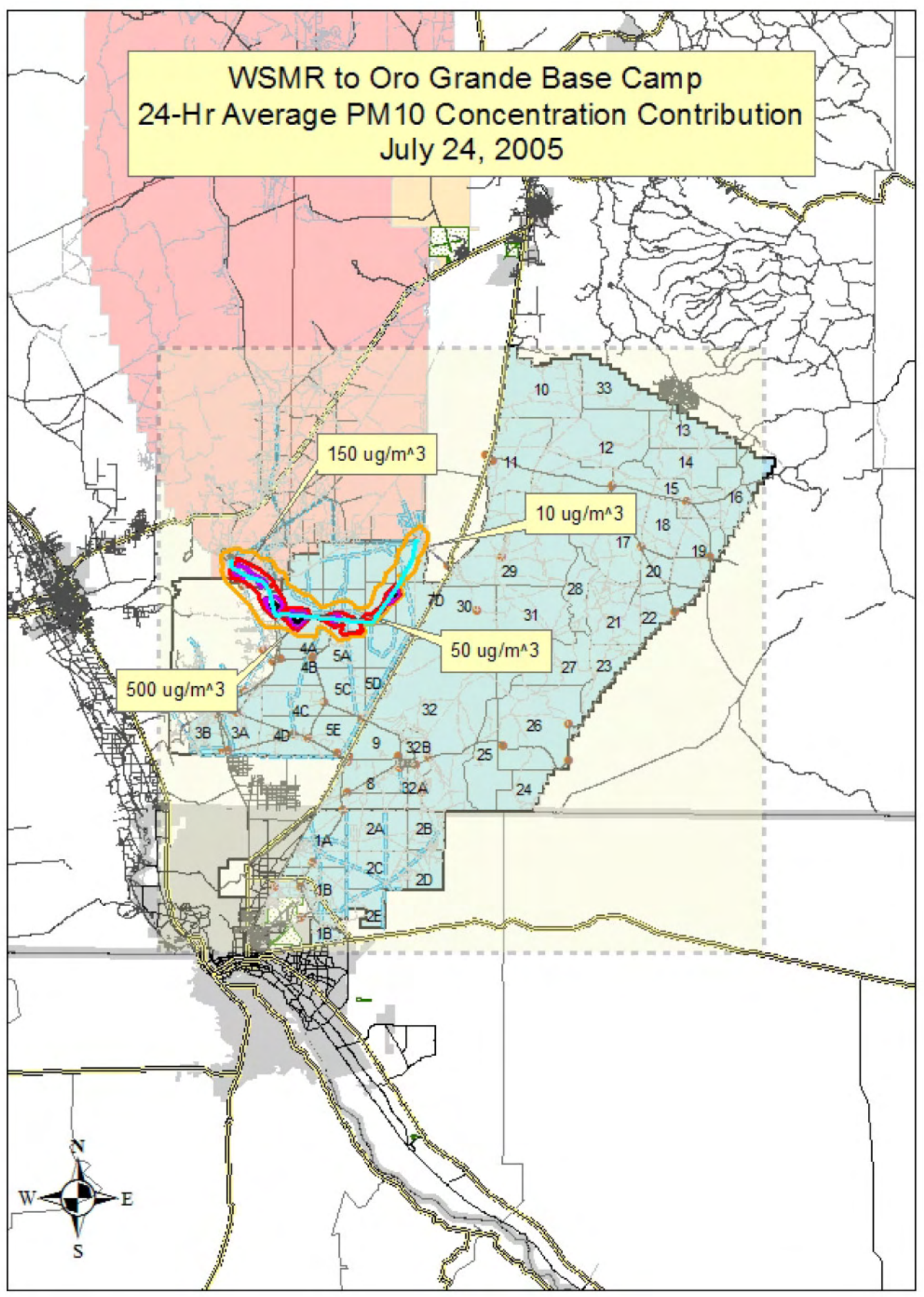




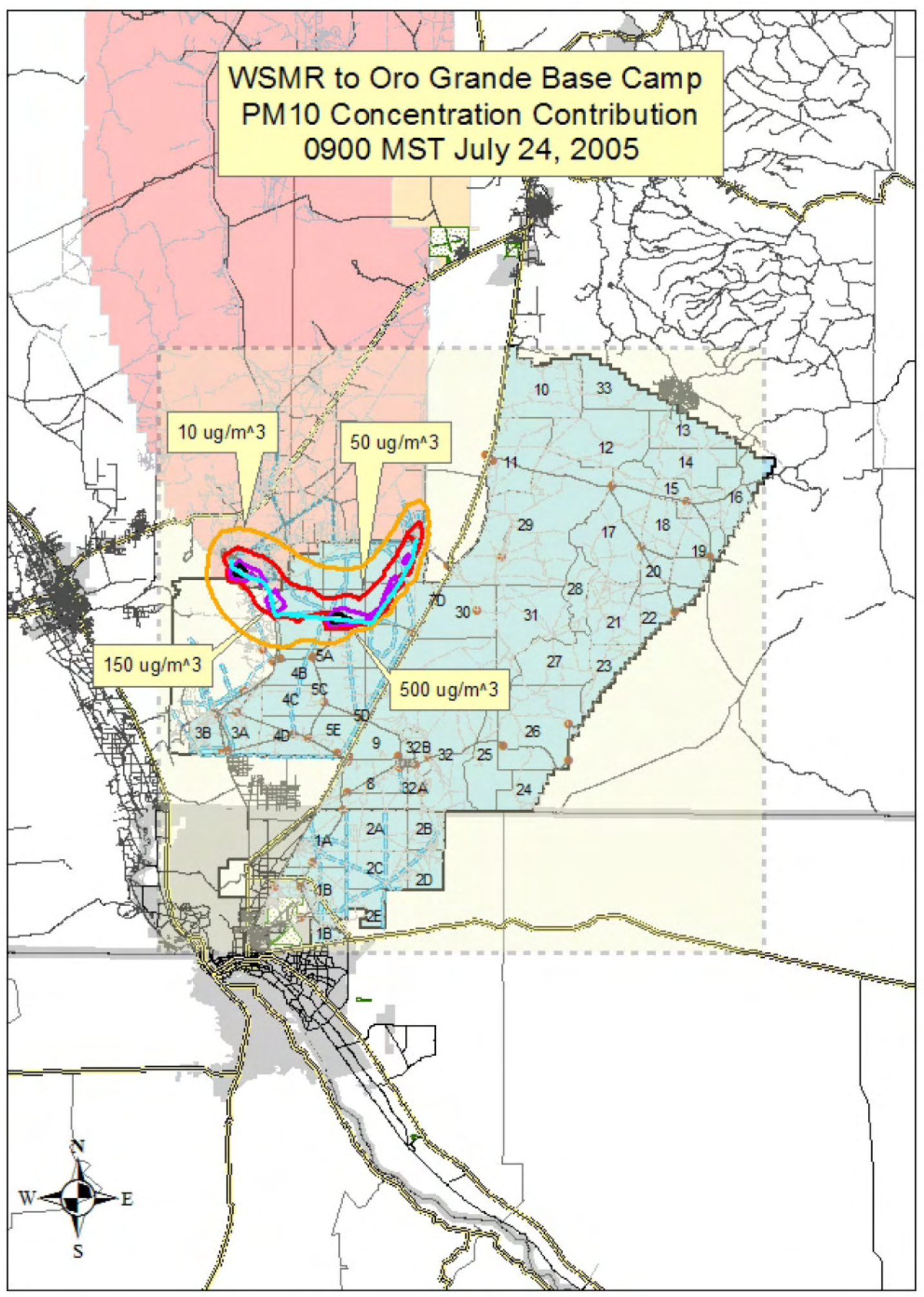




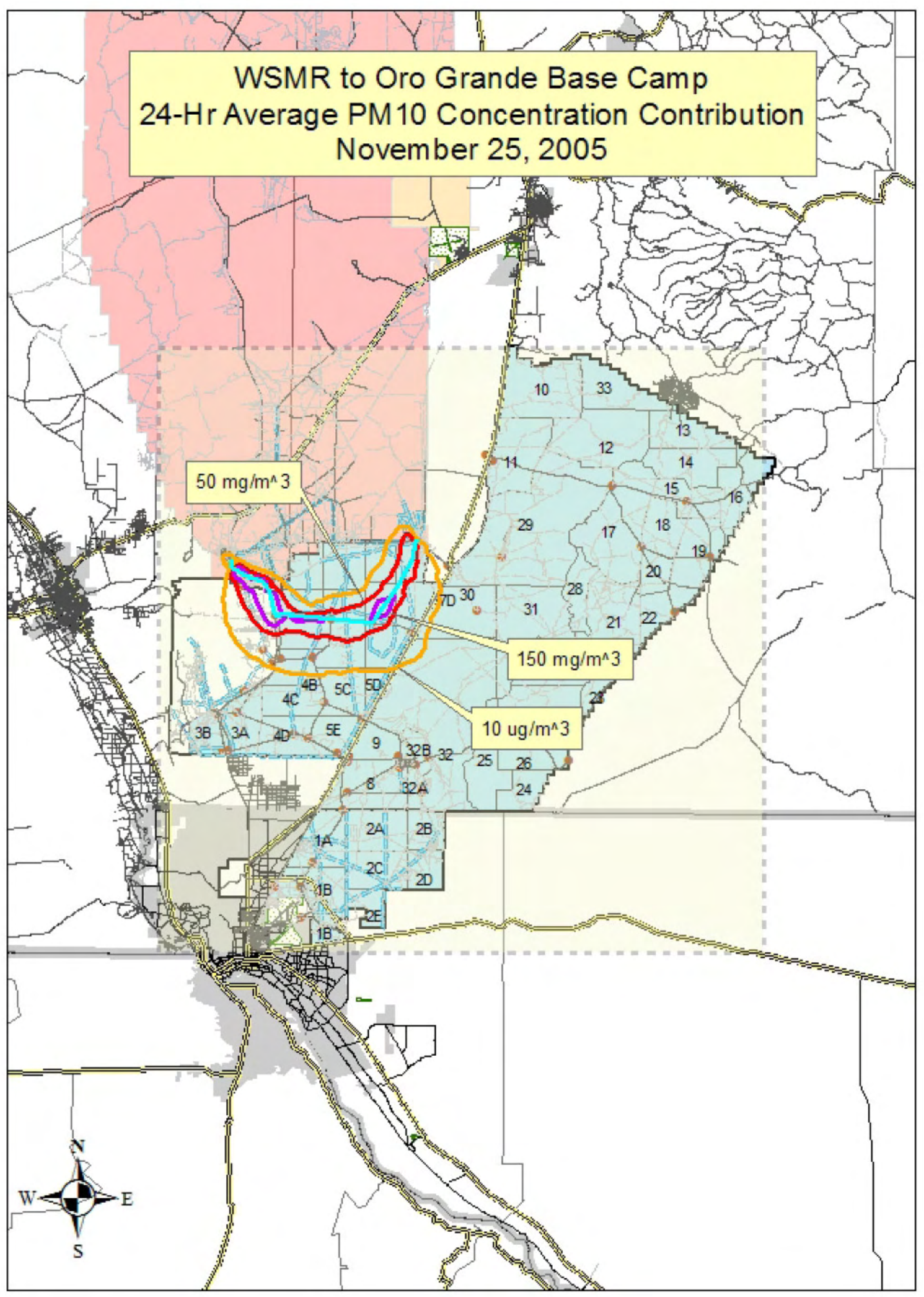




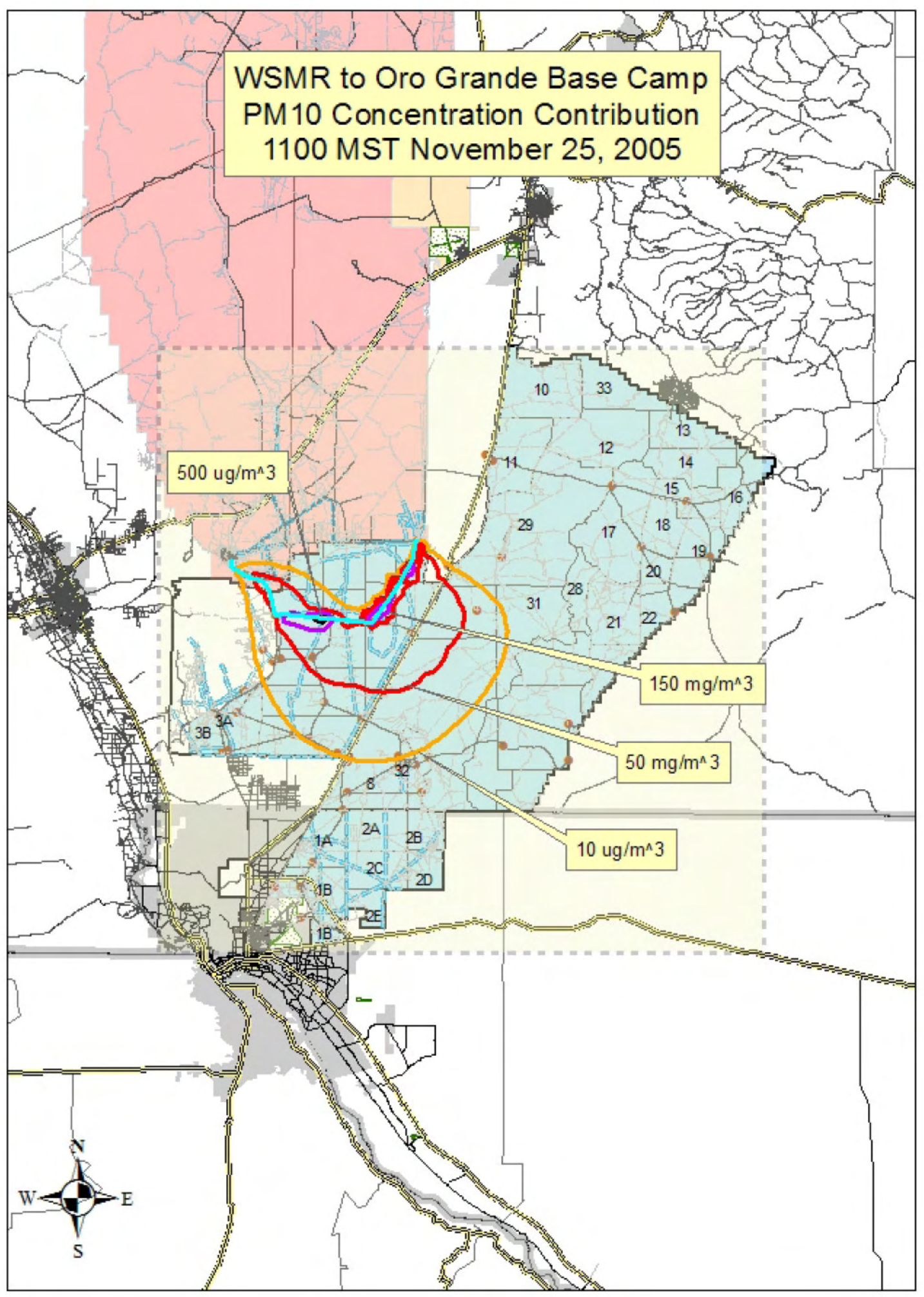




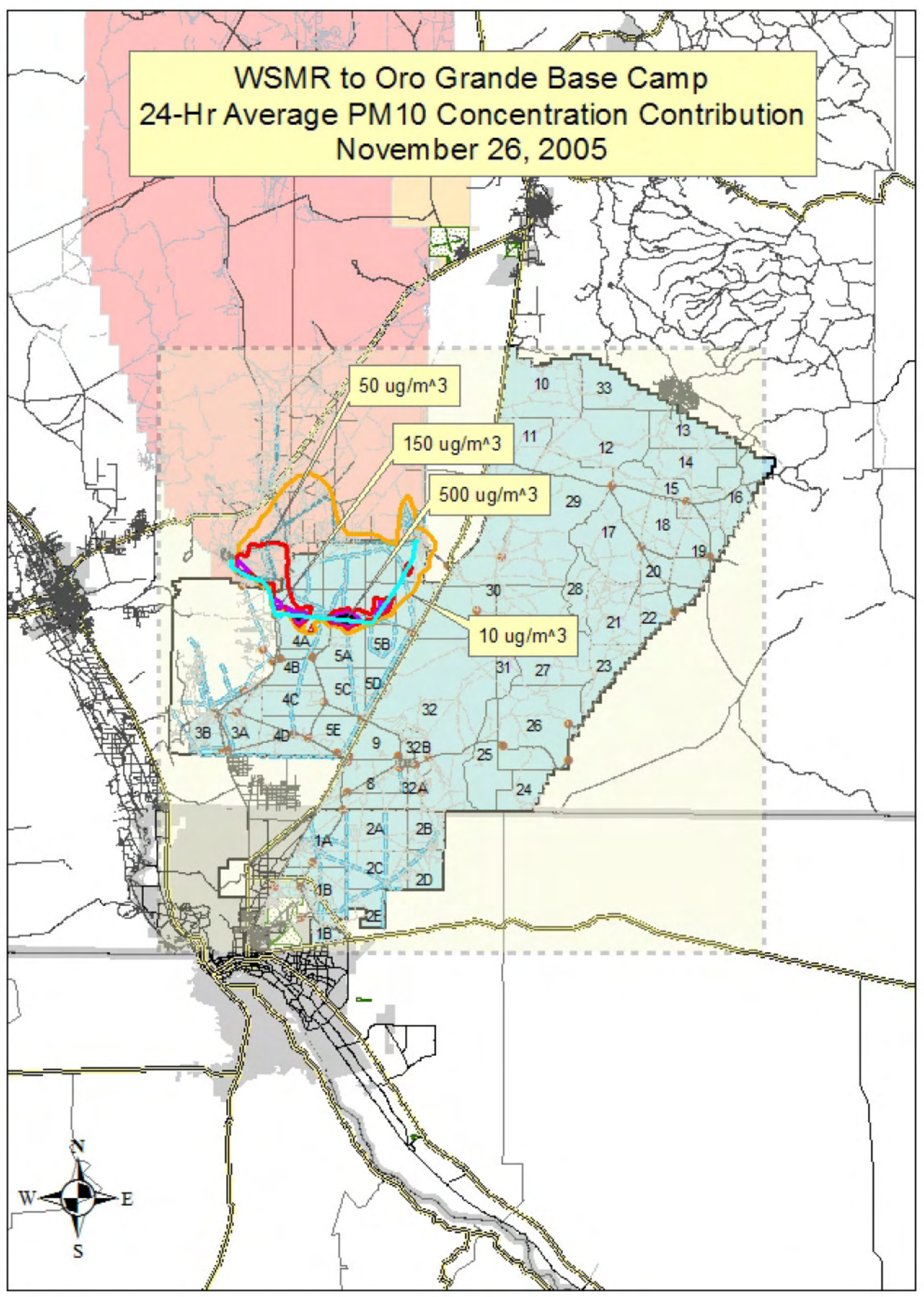




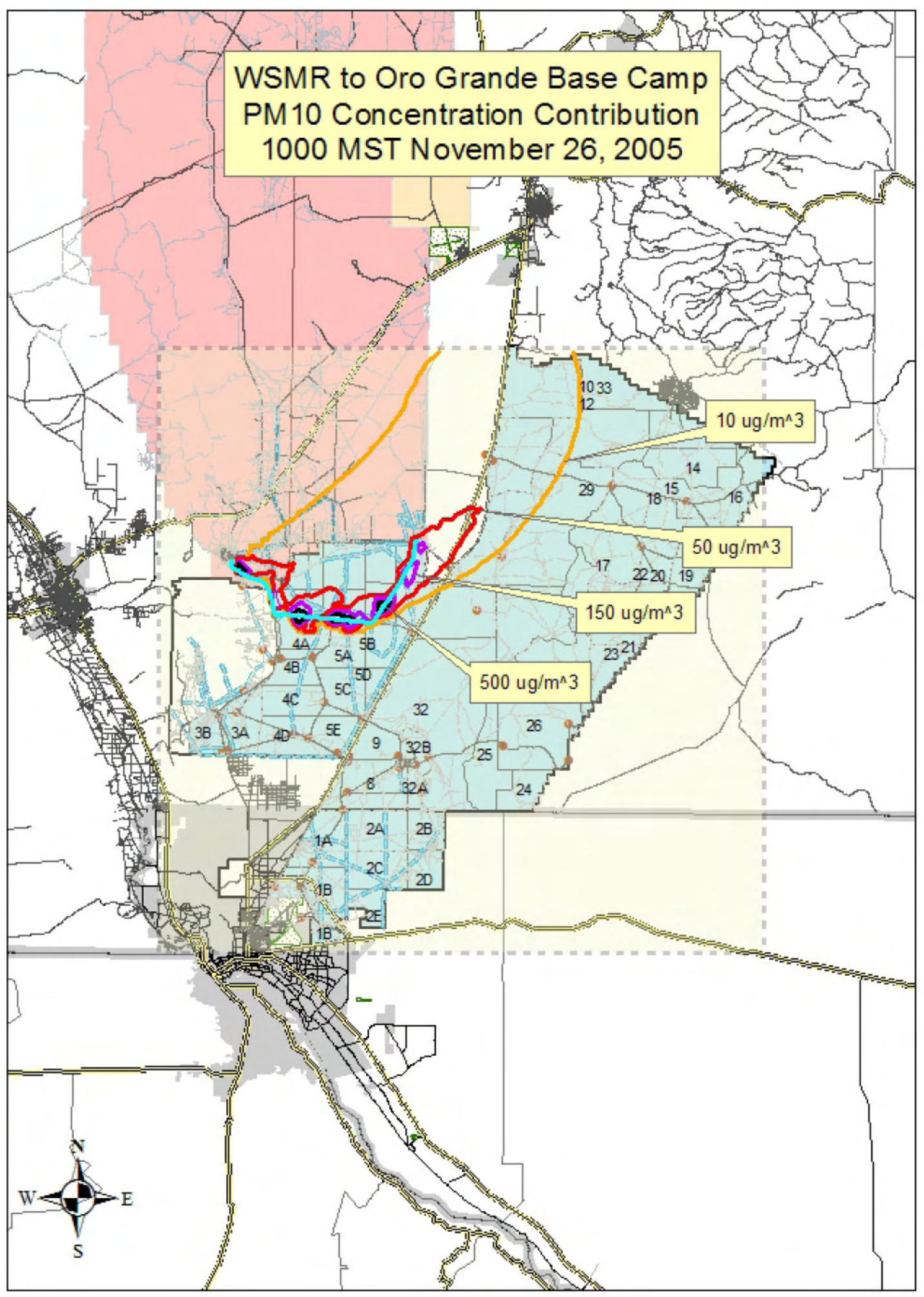




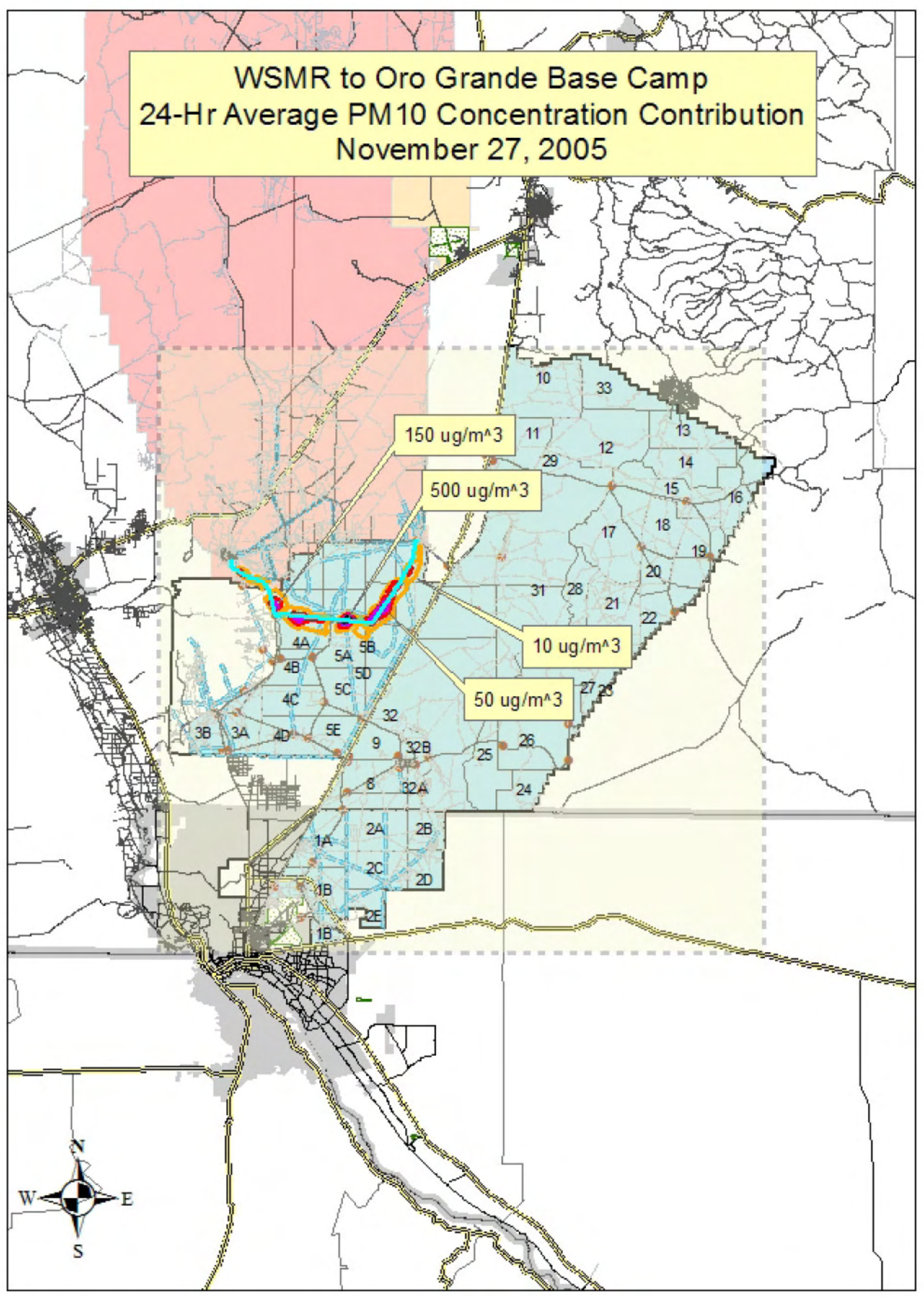




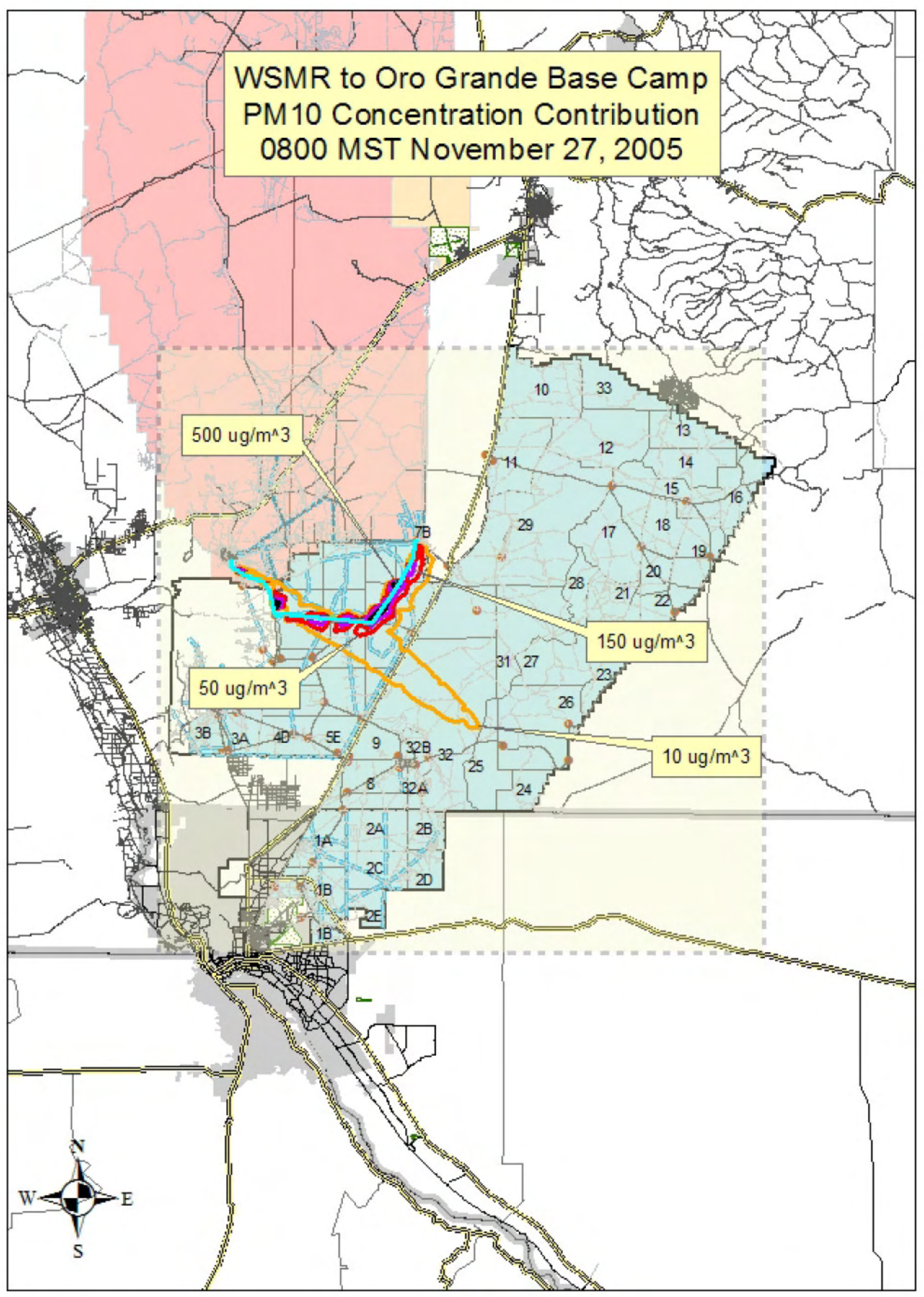




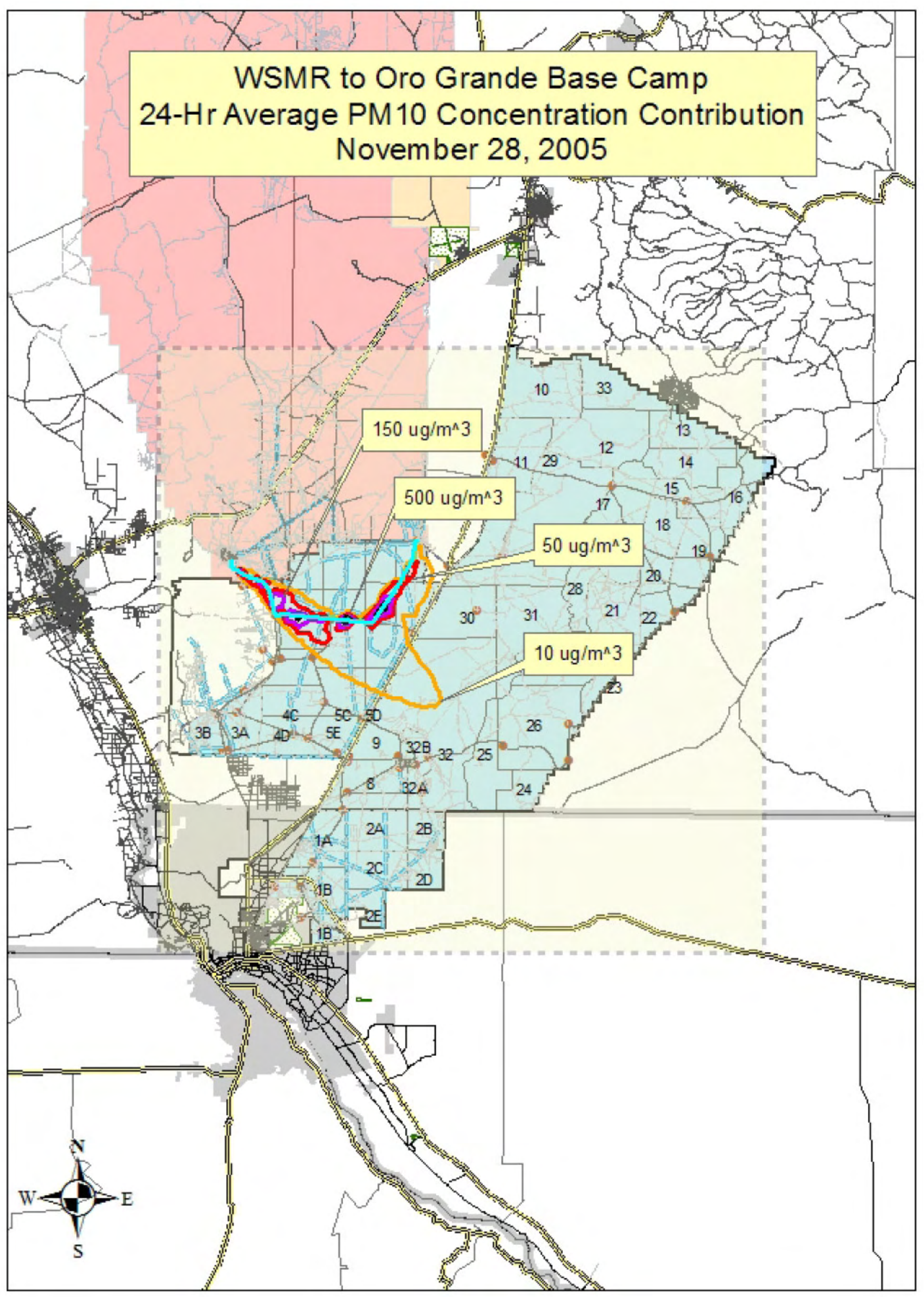




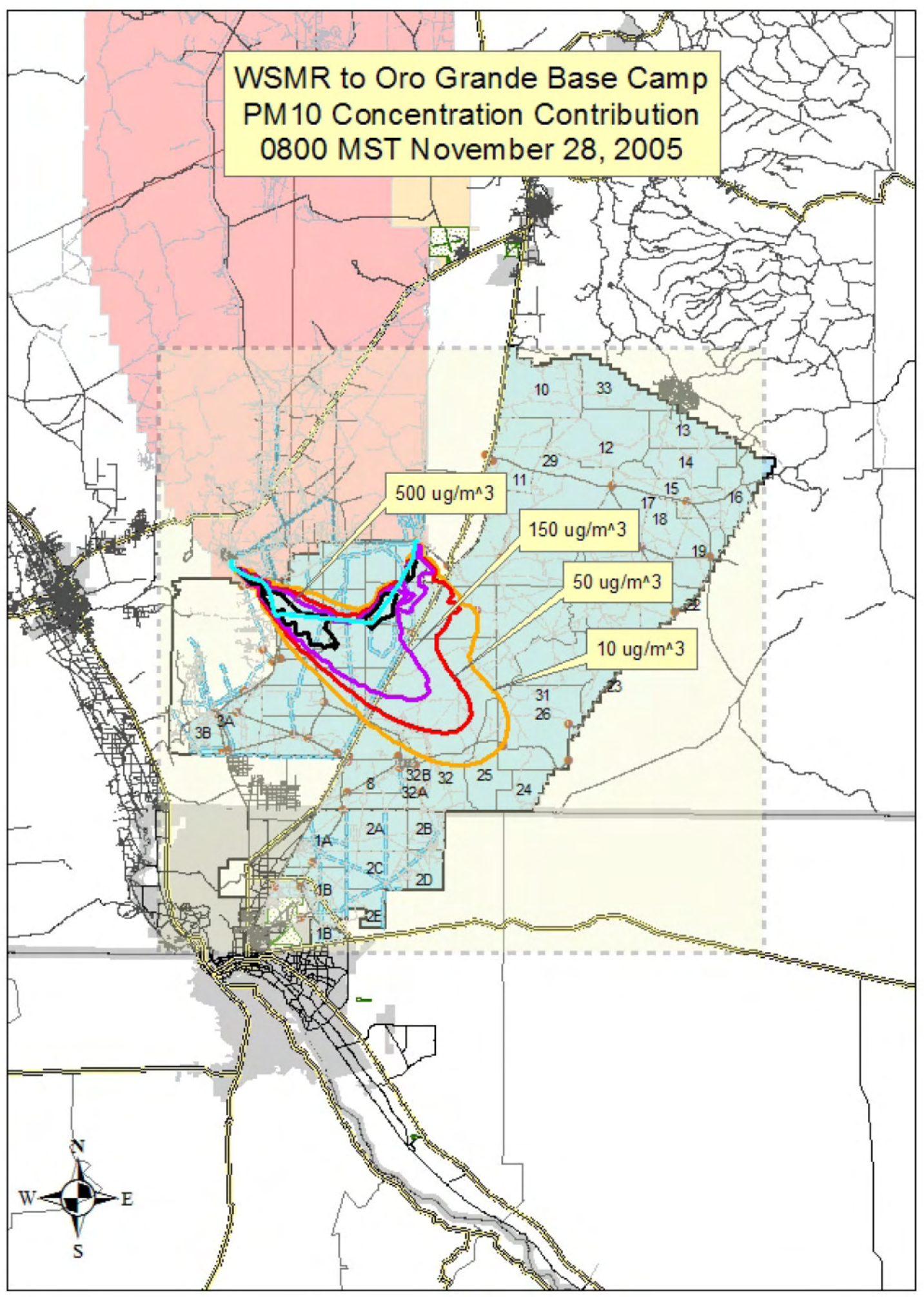




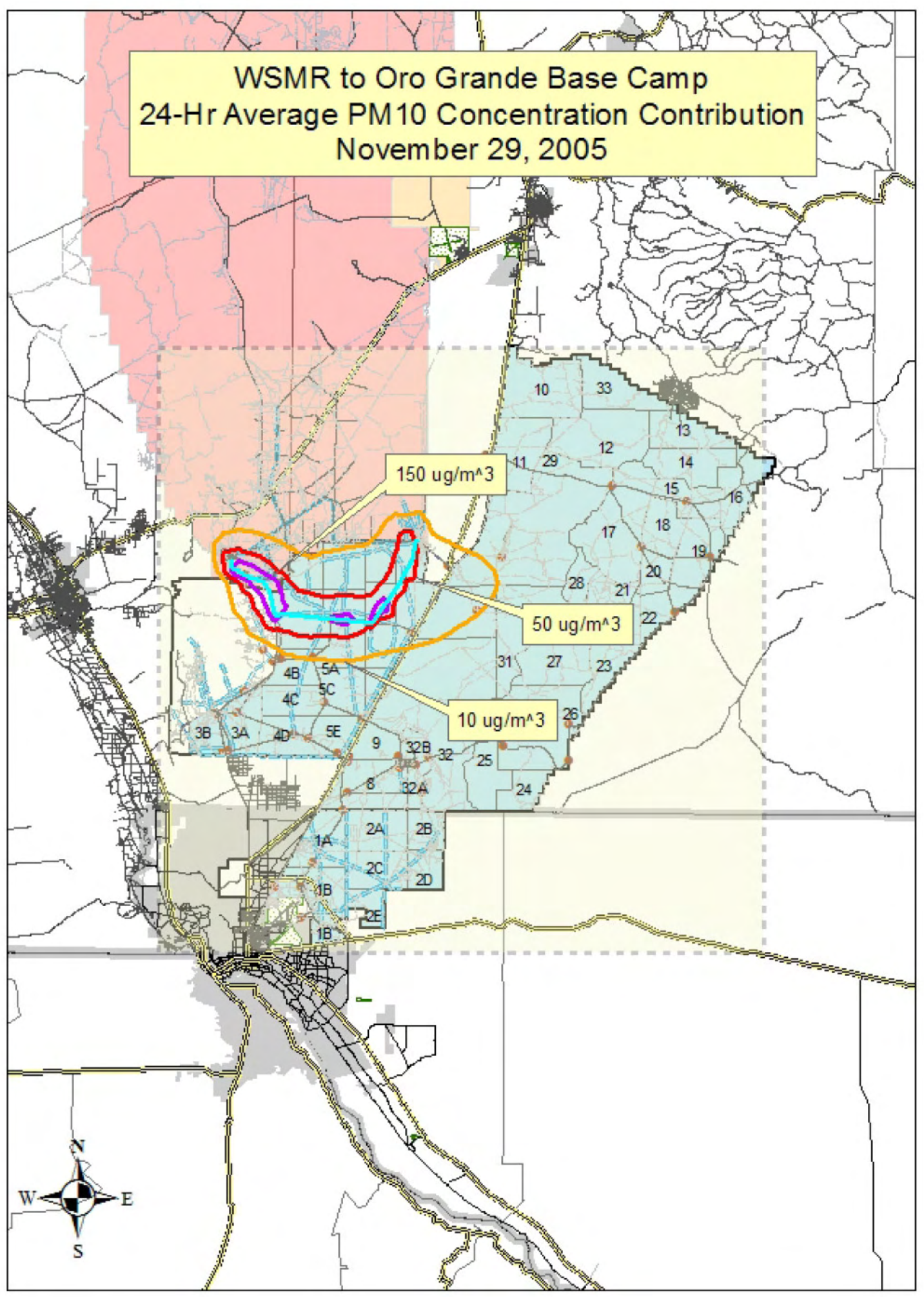




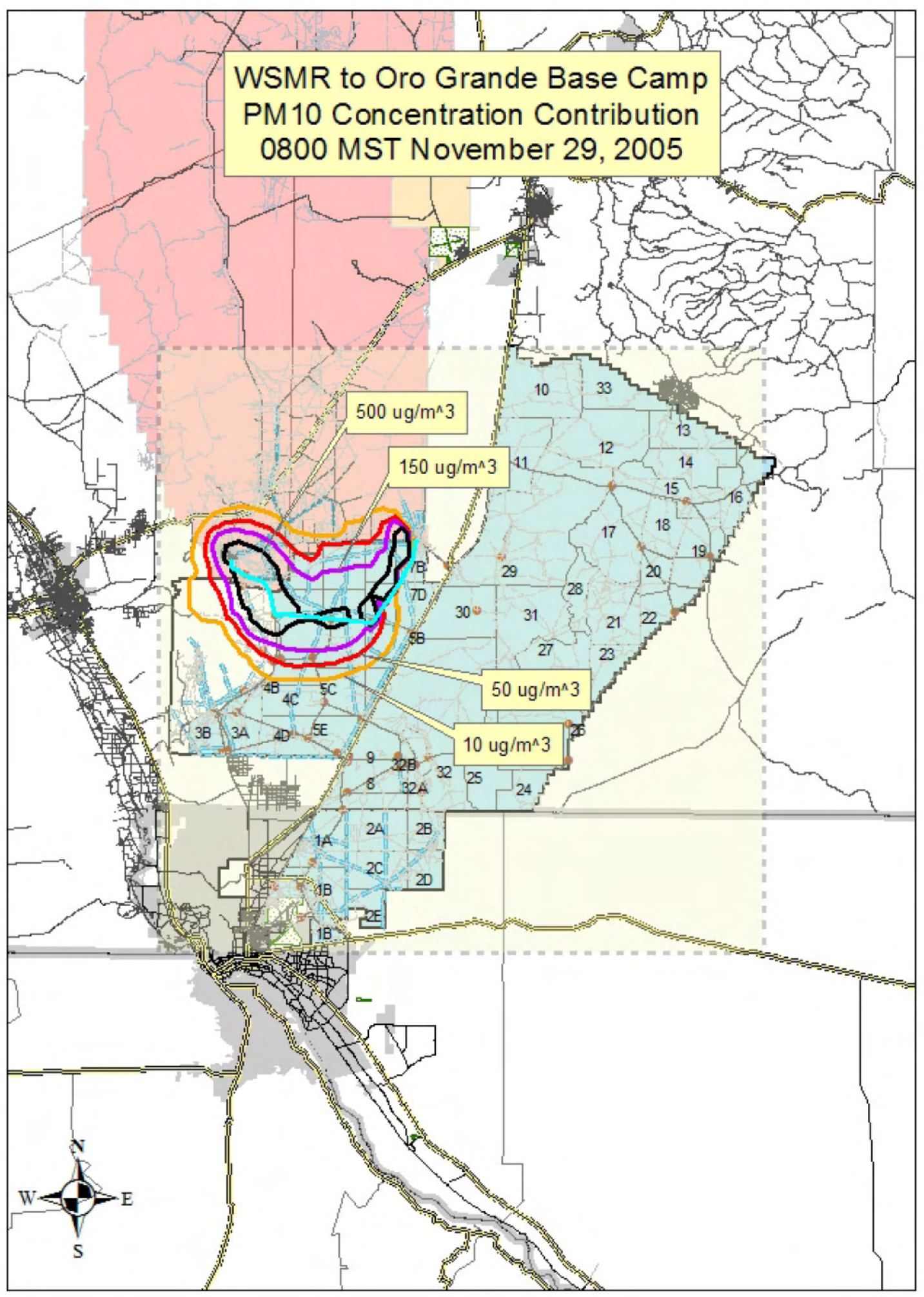





\section{Appendix F}

Simulated $\mathrm{PM}_{10}$ Concentrations for the Move-out from White Sands Missile Range to SHORAD 



\section{Appendix F}

\section{Simulated PM10 Concentrations for the Move-out from White Sands Missile Range to SHORAD}

The following pages present contour maps of simulated PM10 concentrations contributed by WSMR to SHORAD move-out operations to air quality in and around Fort Bliss and WSMR for the 21 days (March 12-16, April 25-30, July 20-24, and November 25-29, 2005) studied in this investigation. For each day, the contour map of the 24-hour-average PM10 concentration contribution is shown first, followed by a contour map of PM10 concentration contributions for a specific hour. The hour listed in the figure header represents the start of the hour, e.g., 1000 MST means the hour from 1000 MST to 1100 MST. Move-out scenario assumptions are summarized in Section 3 of this report. 


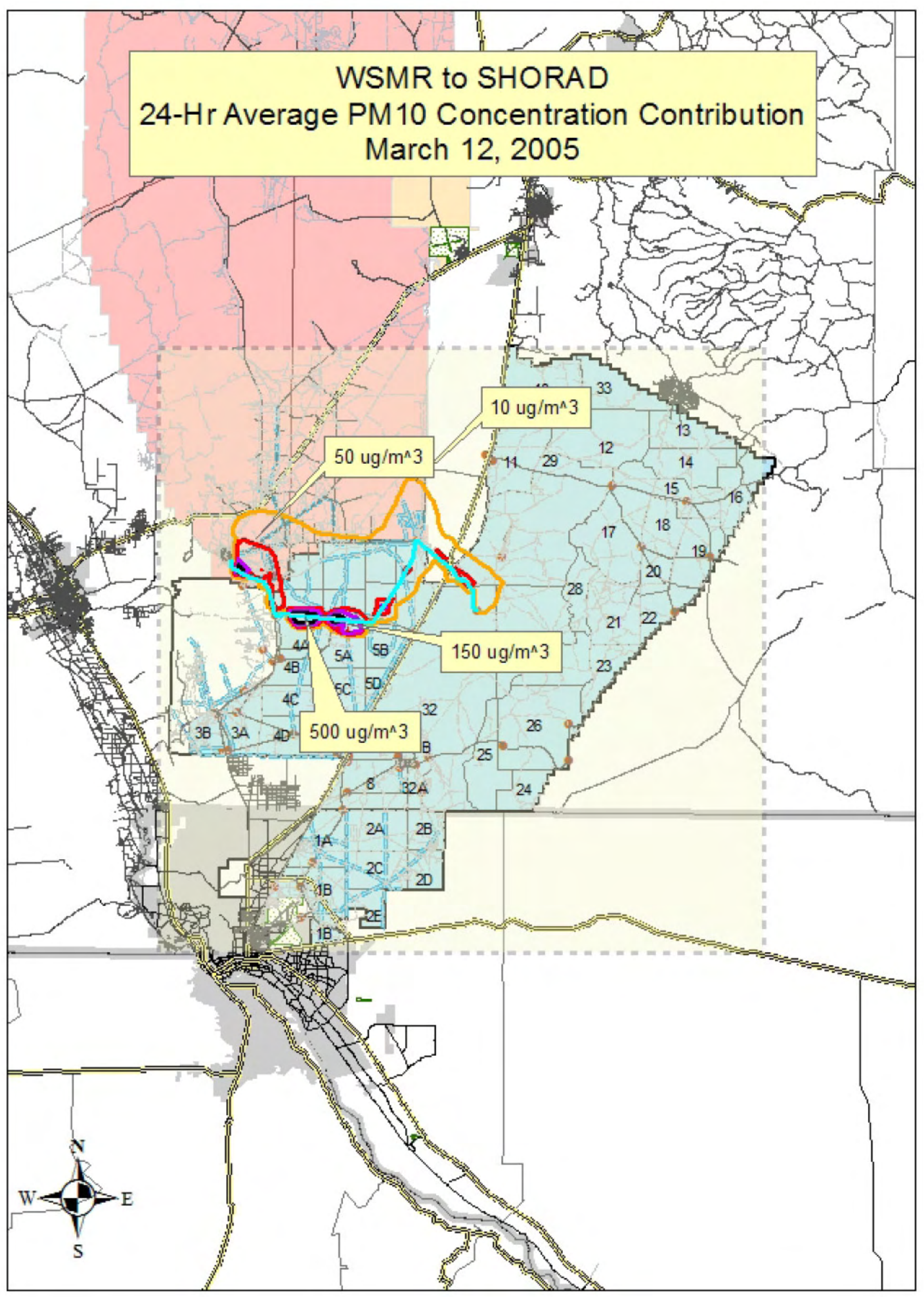




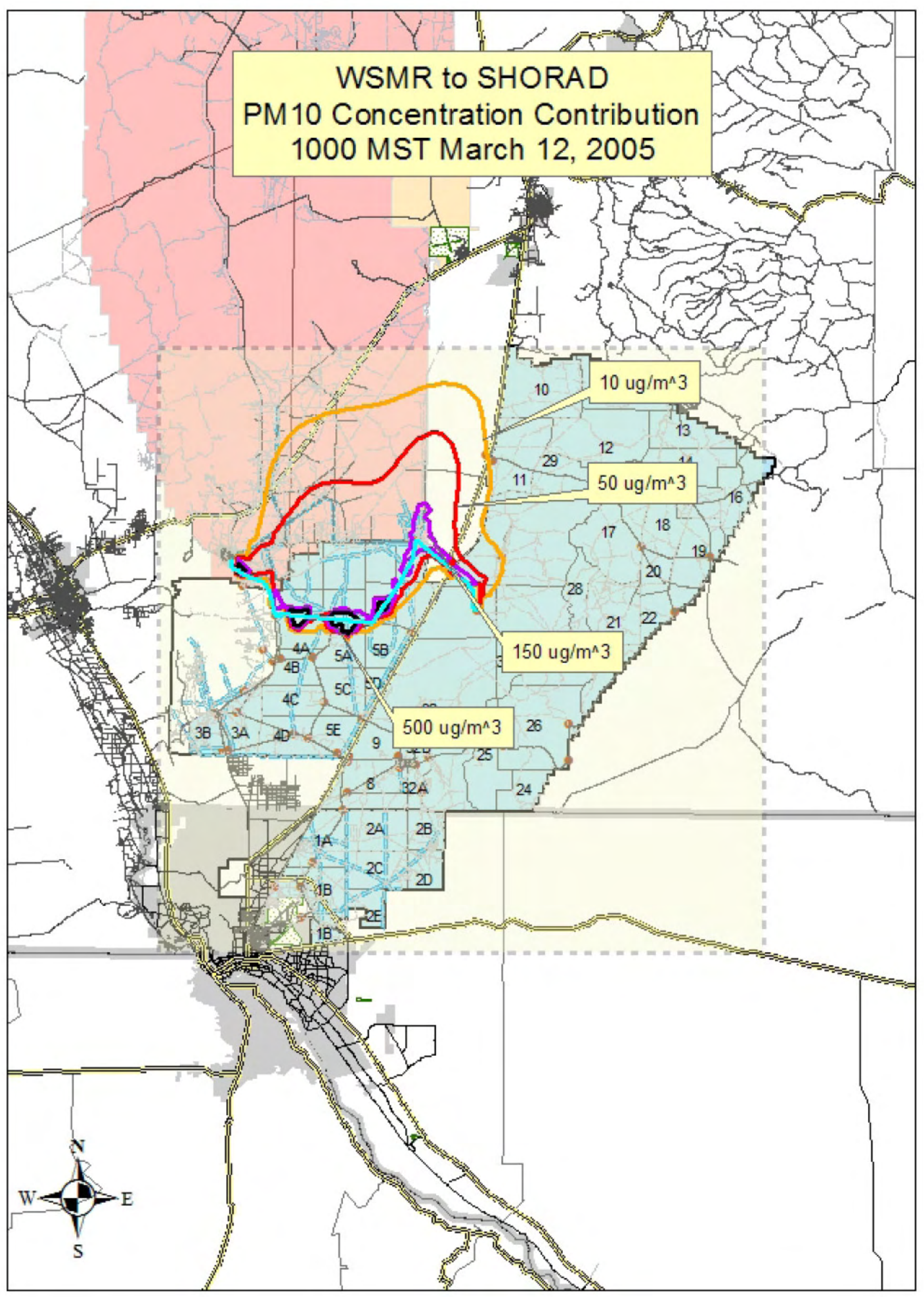




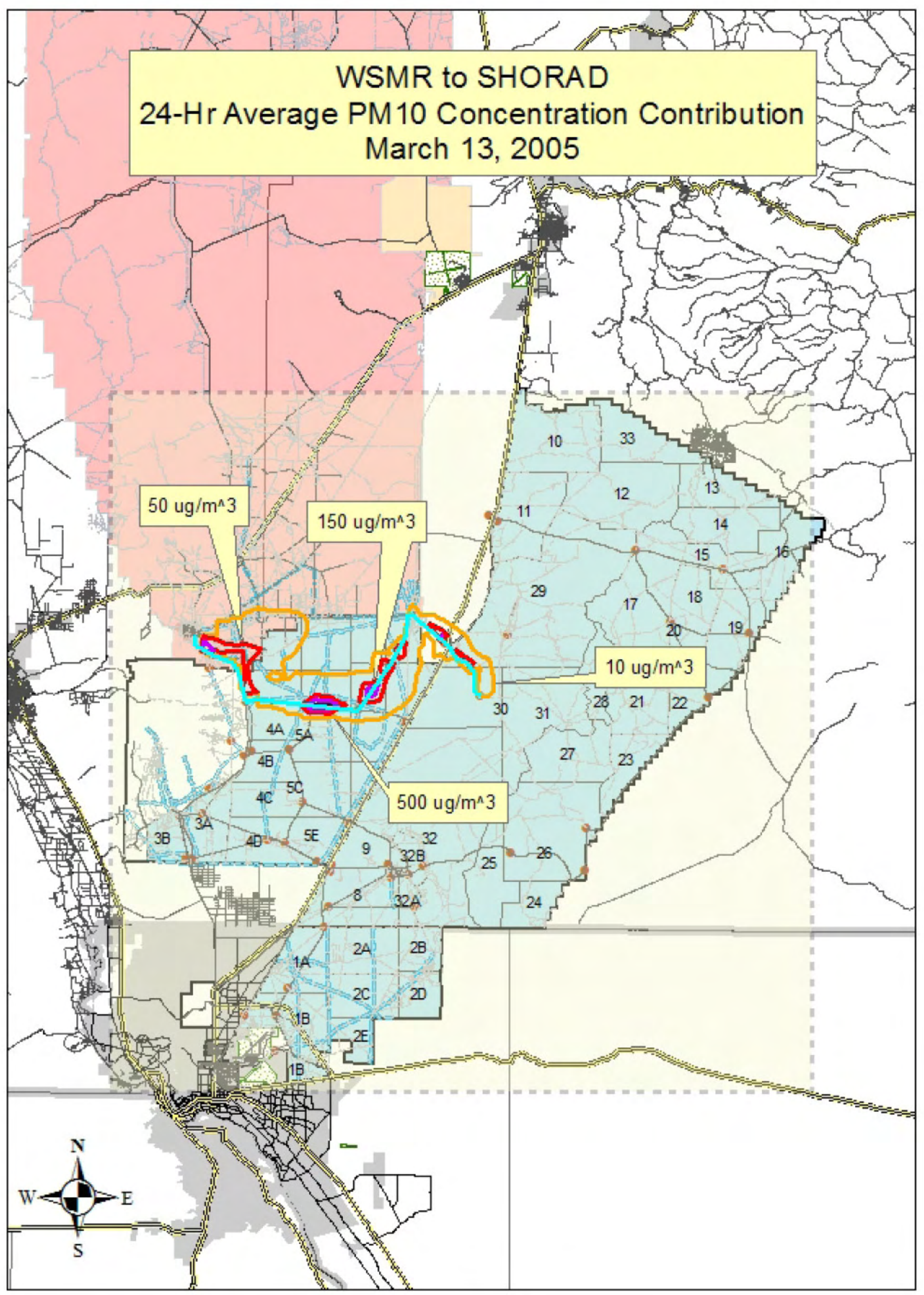




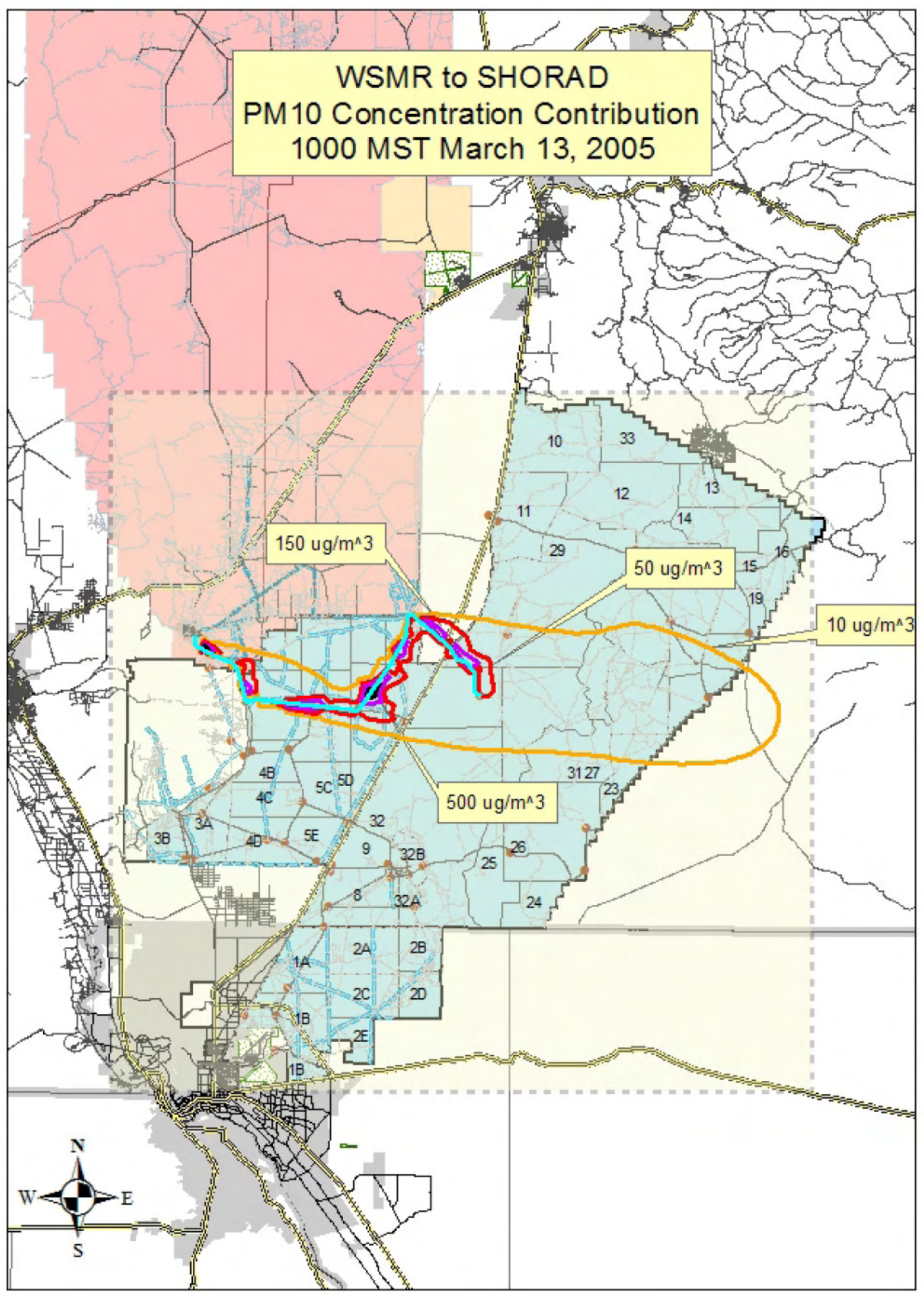




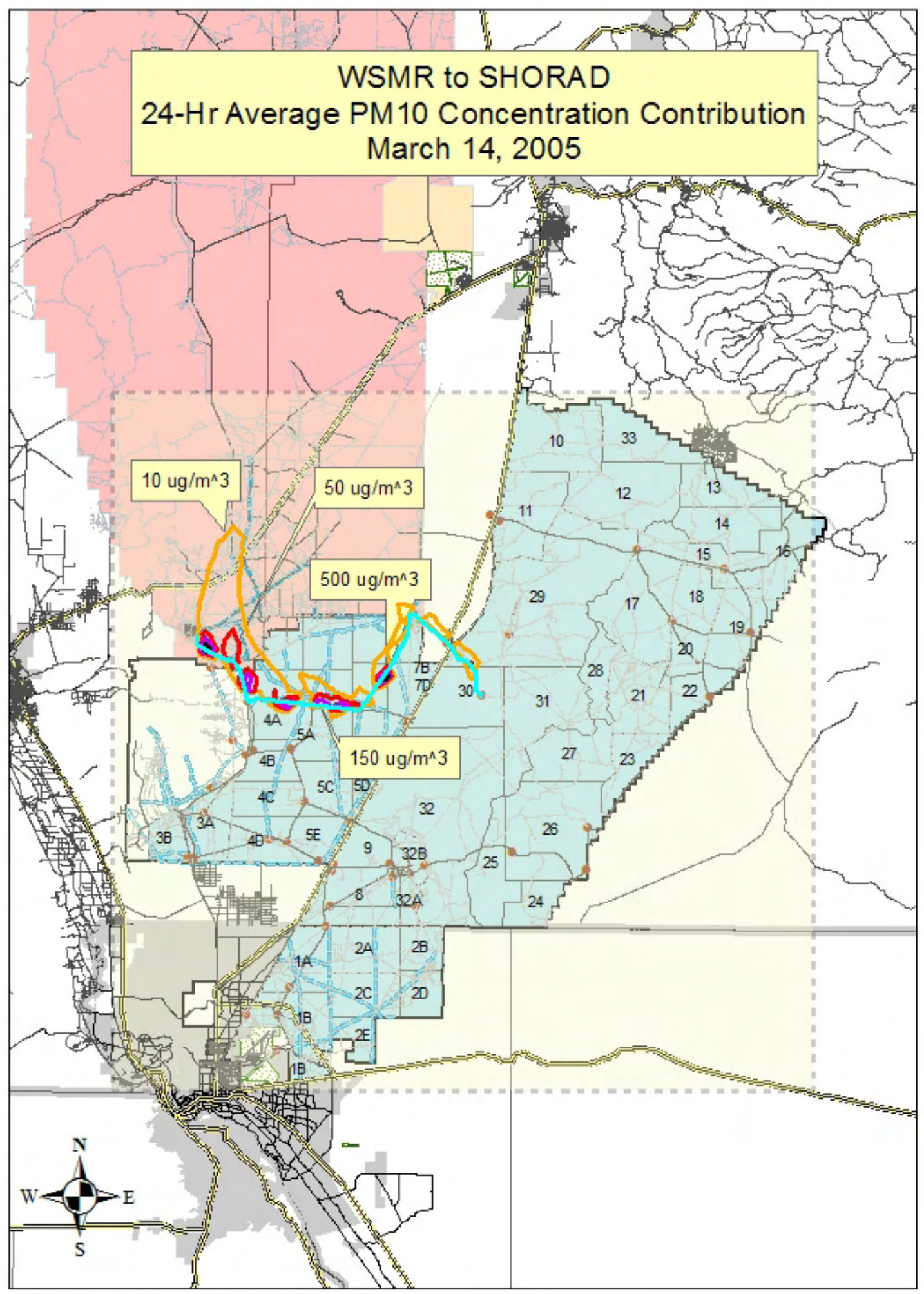




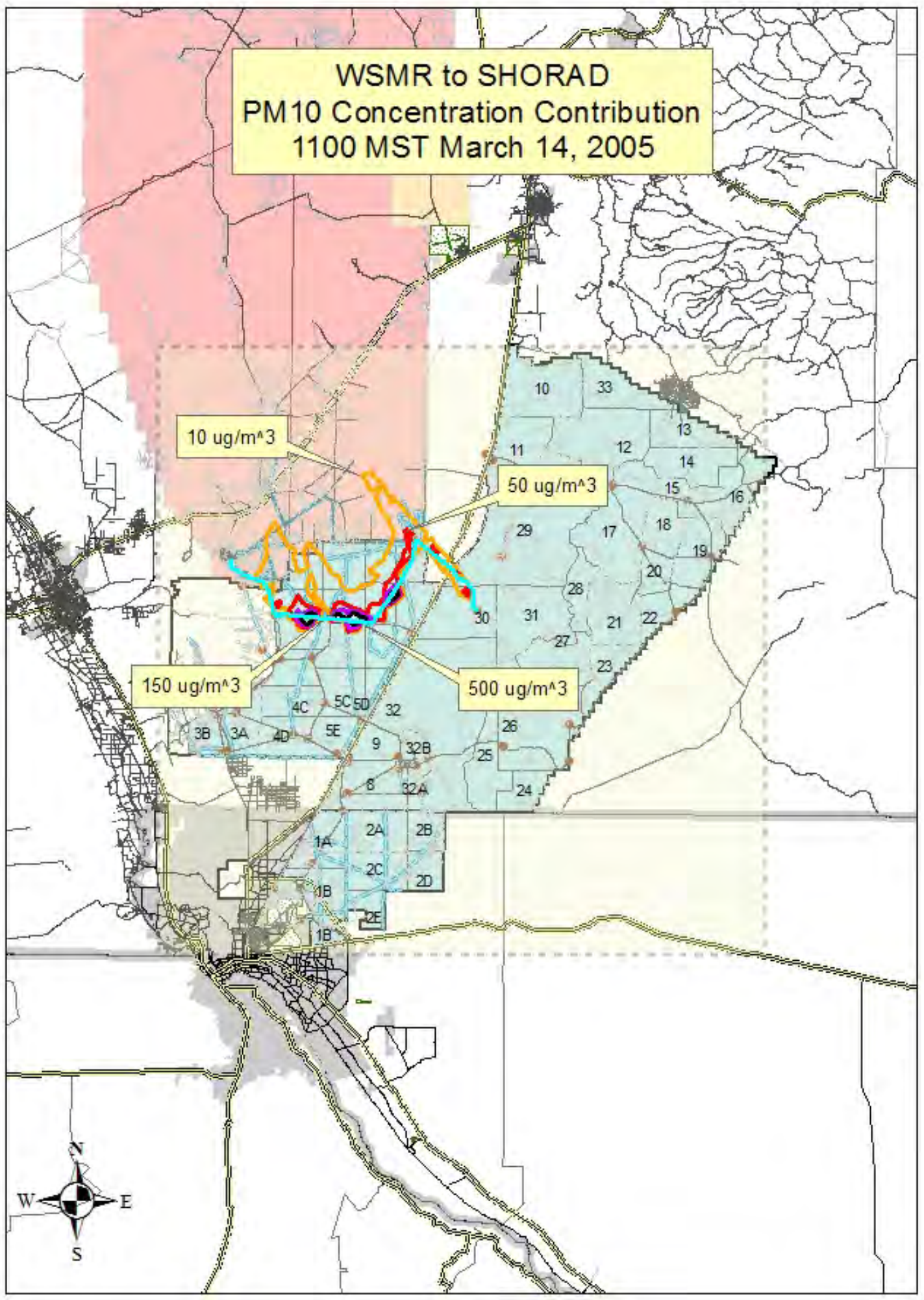




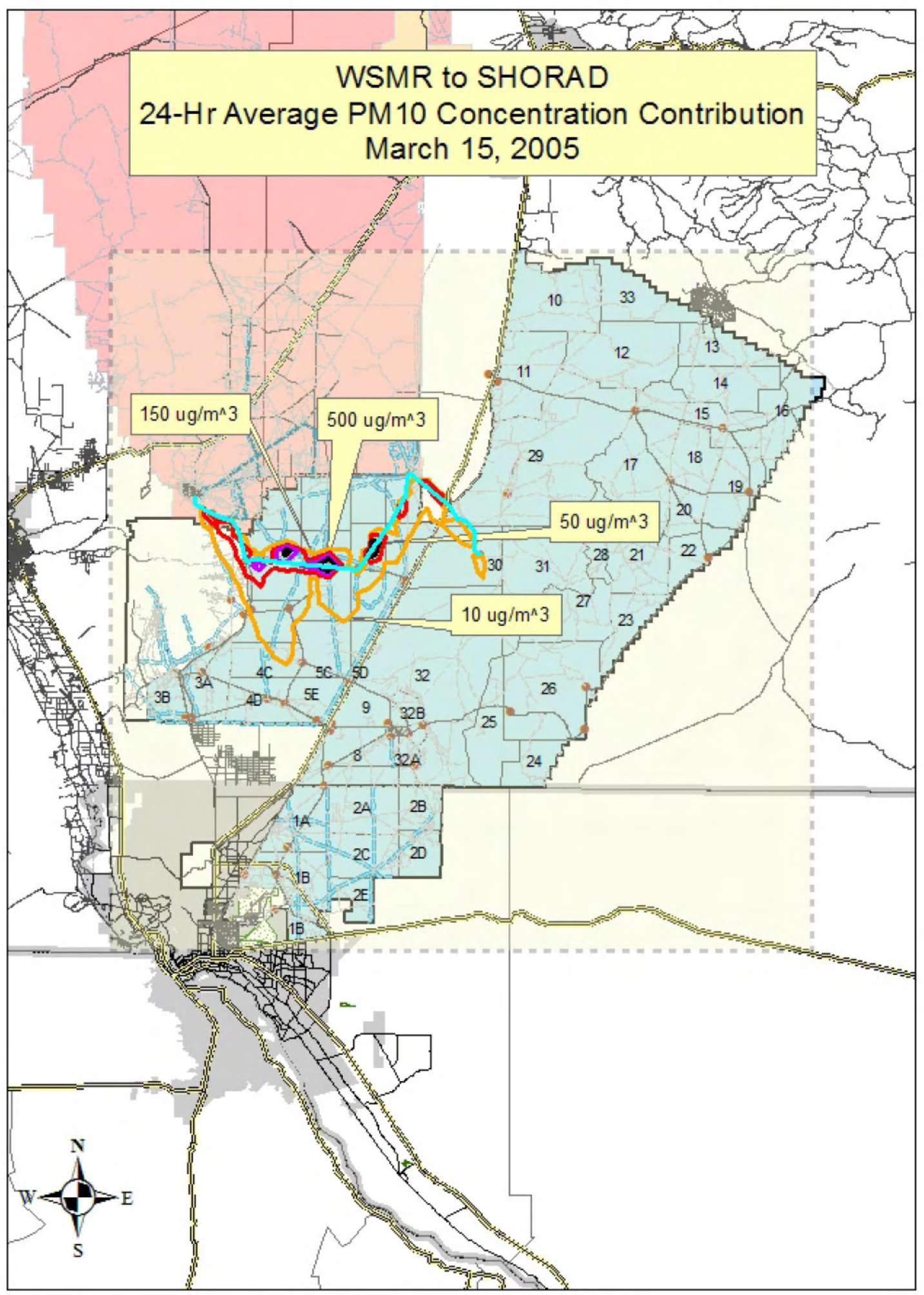




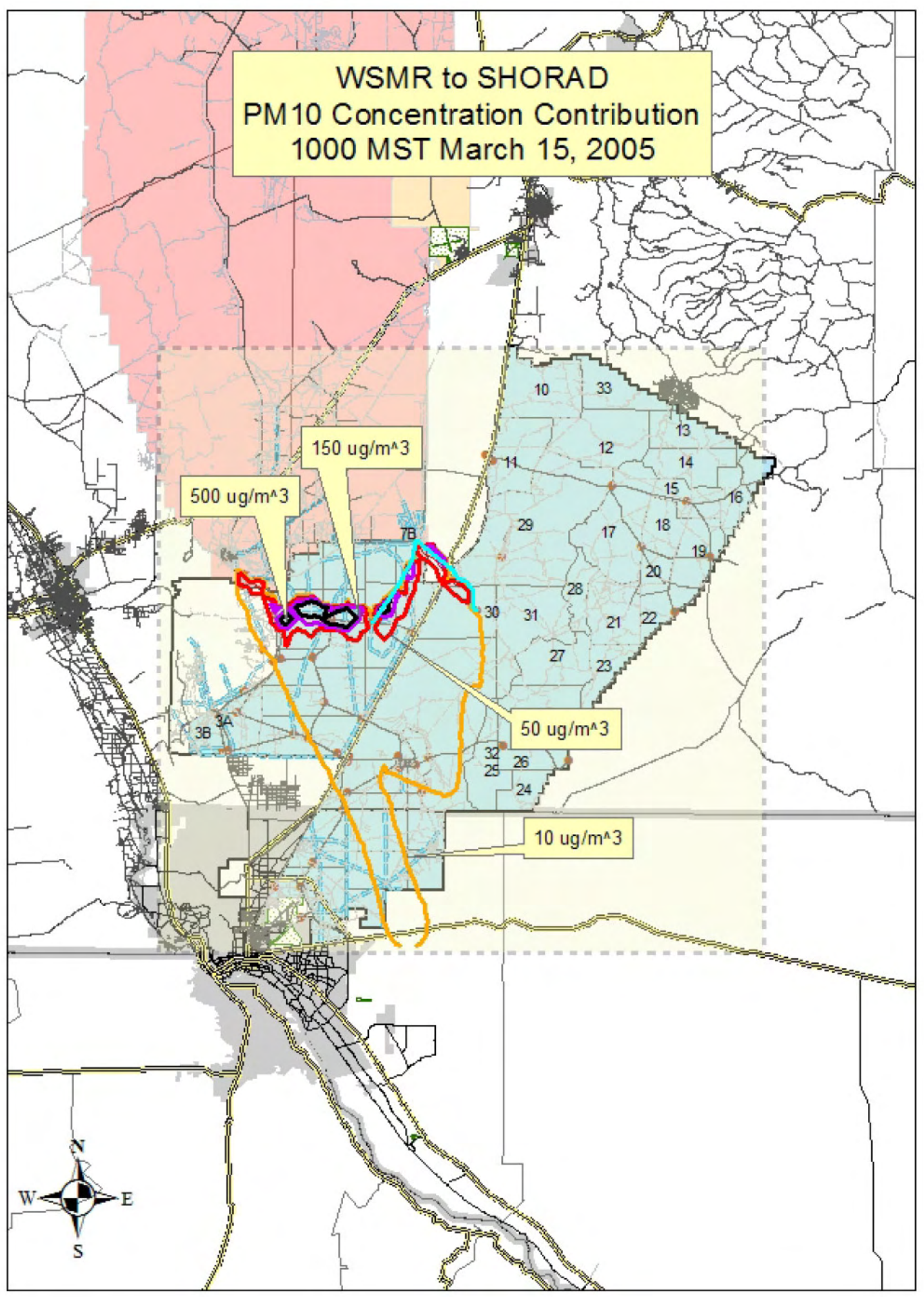




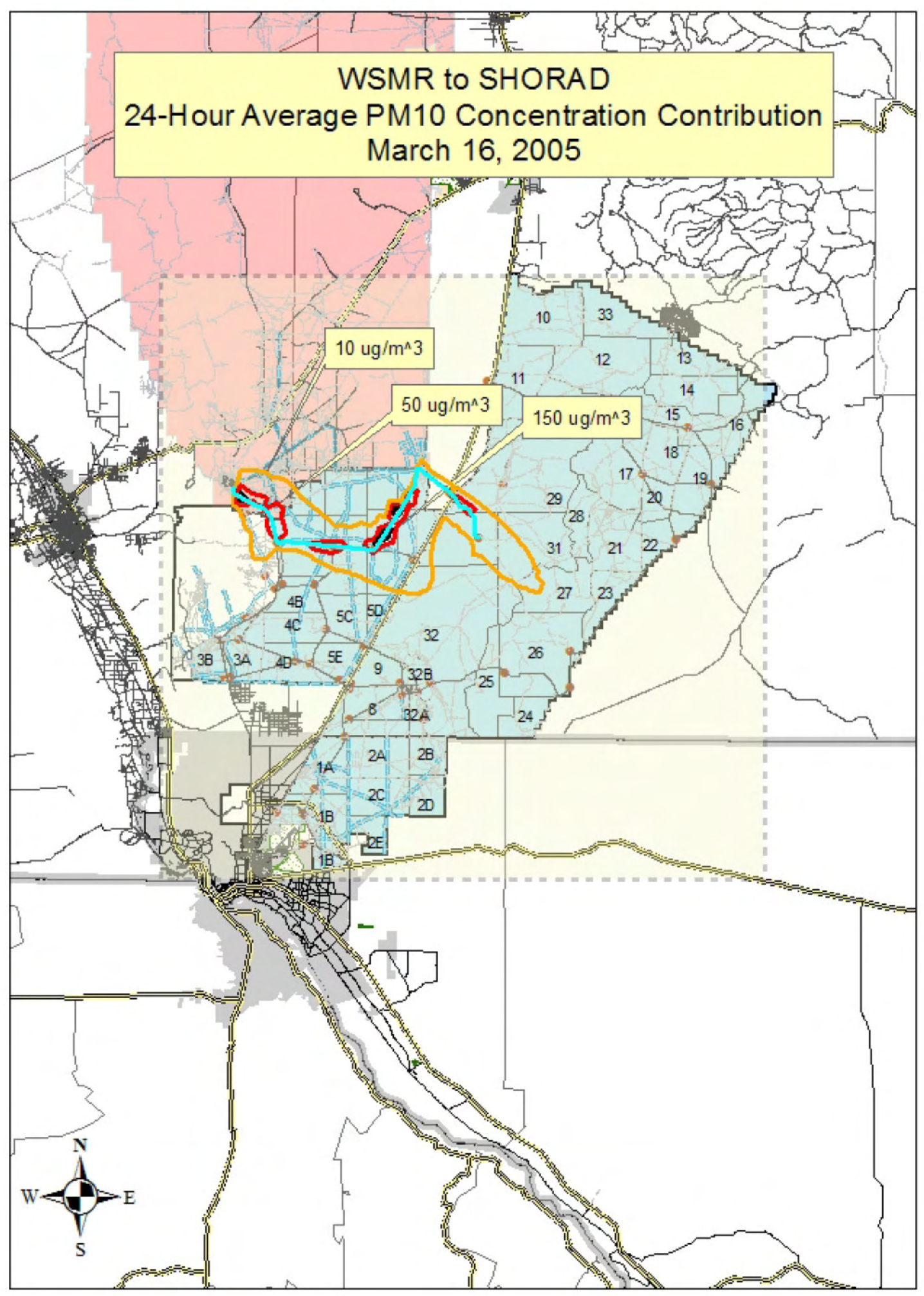




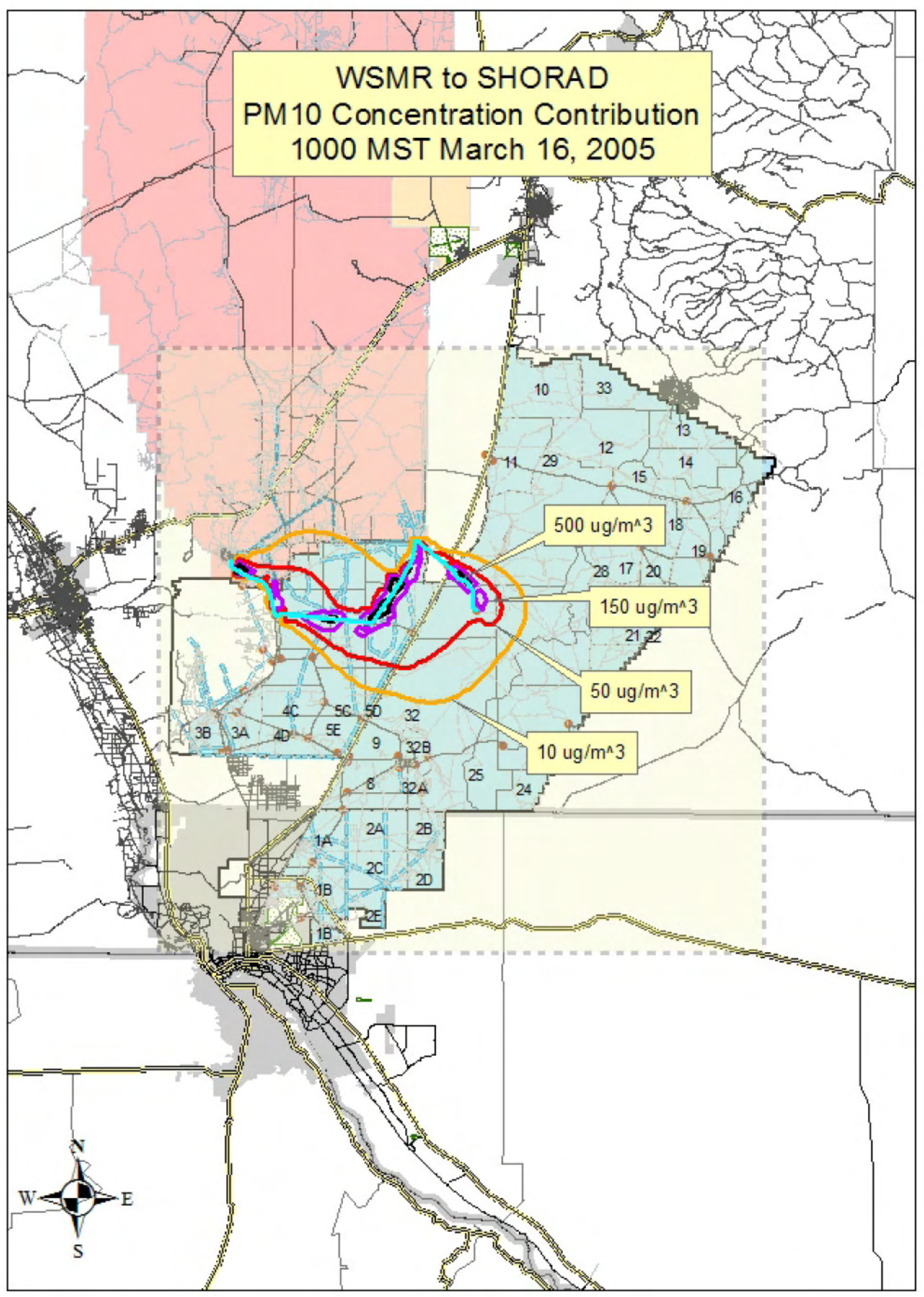




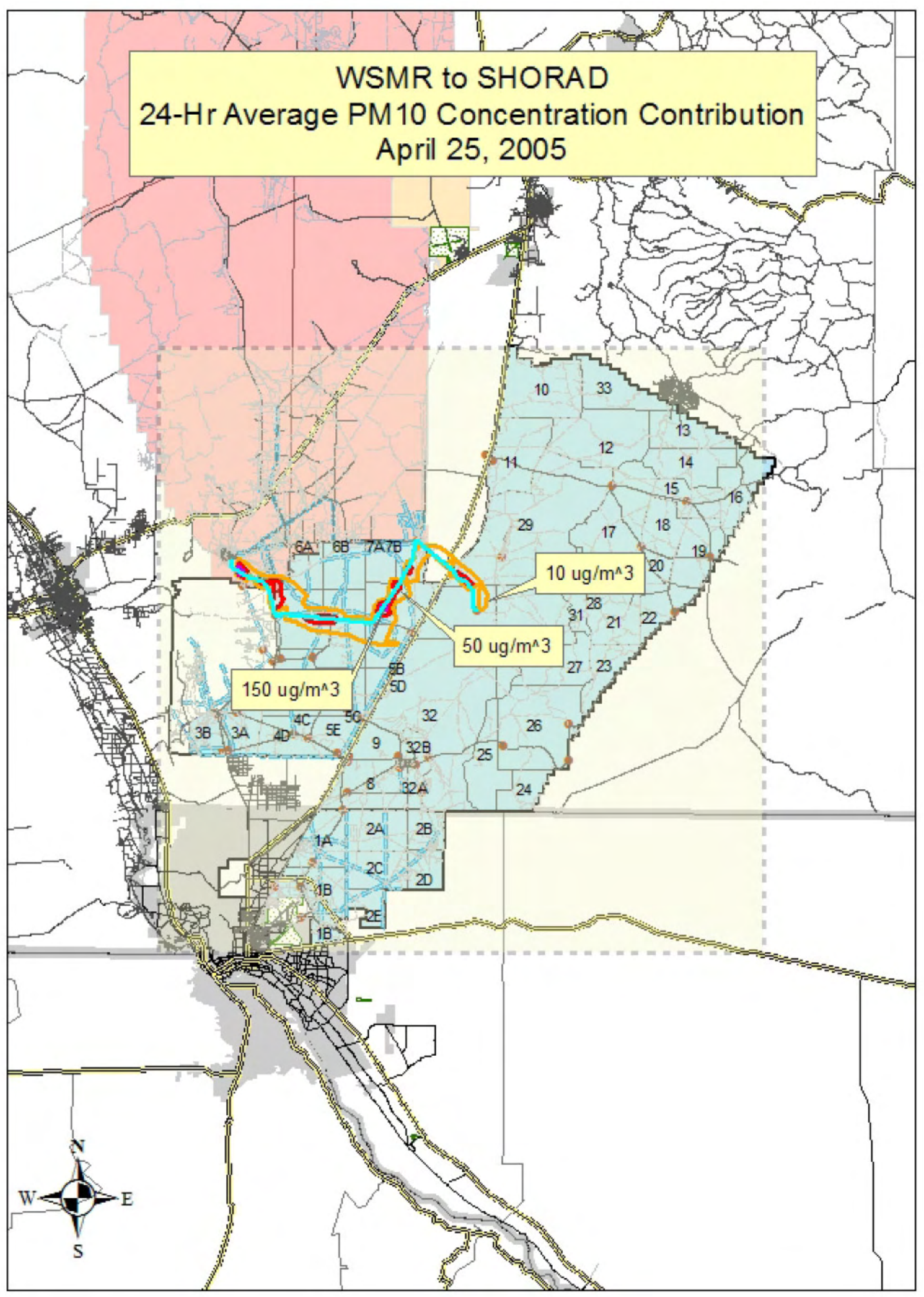




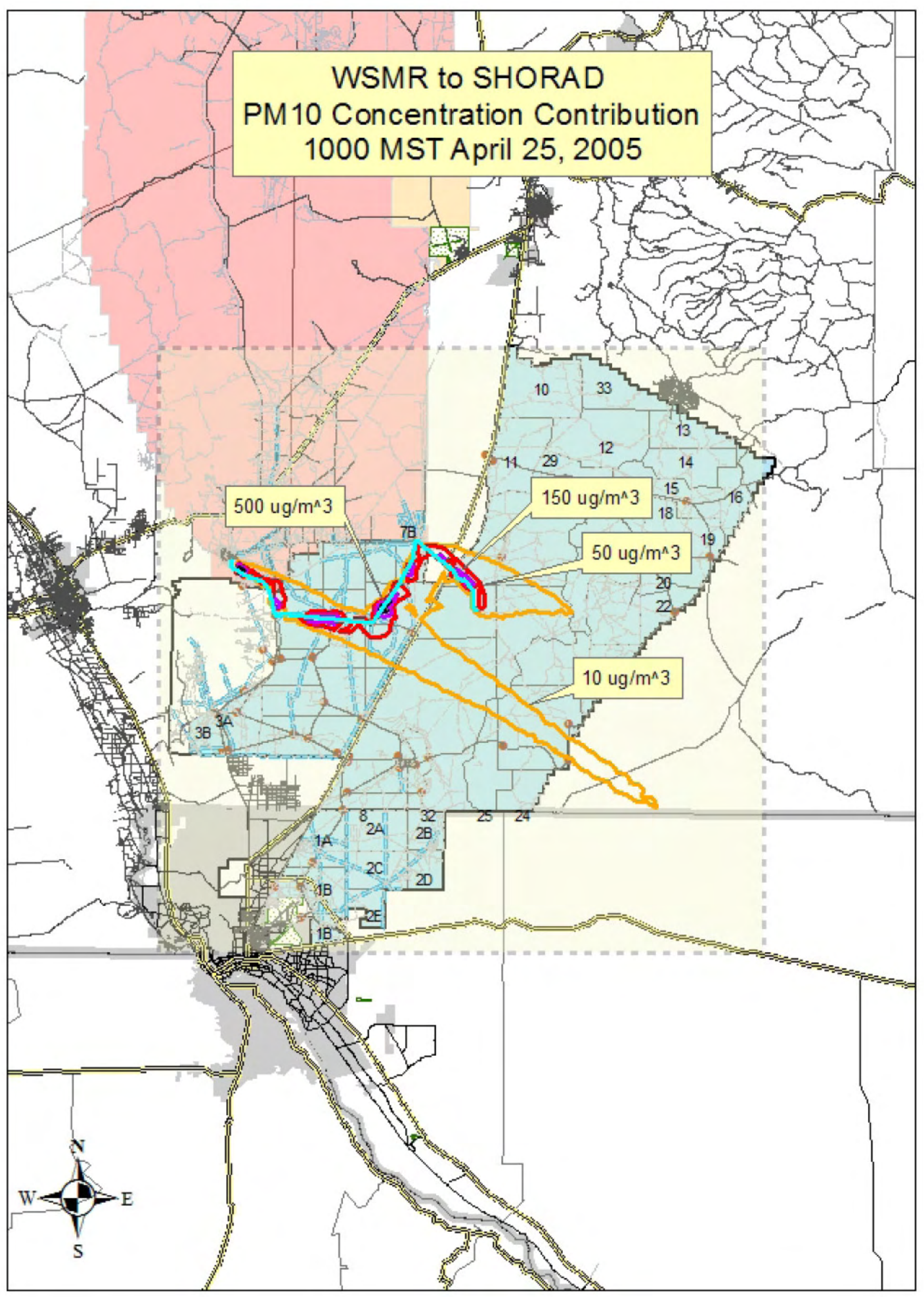




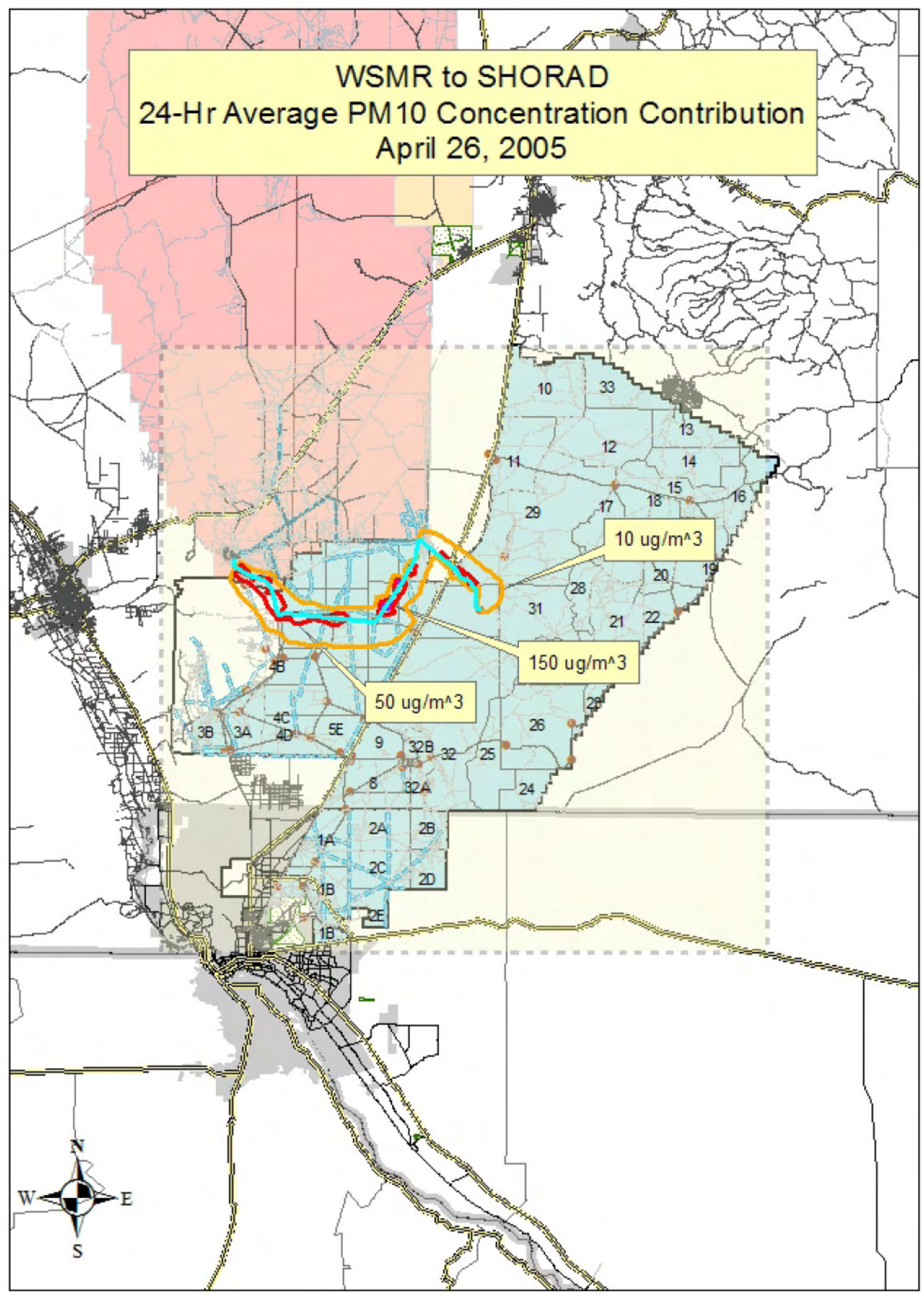




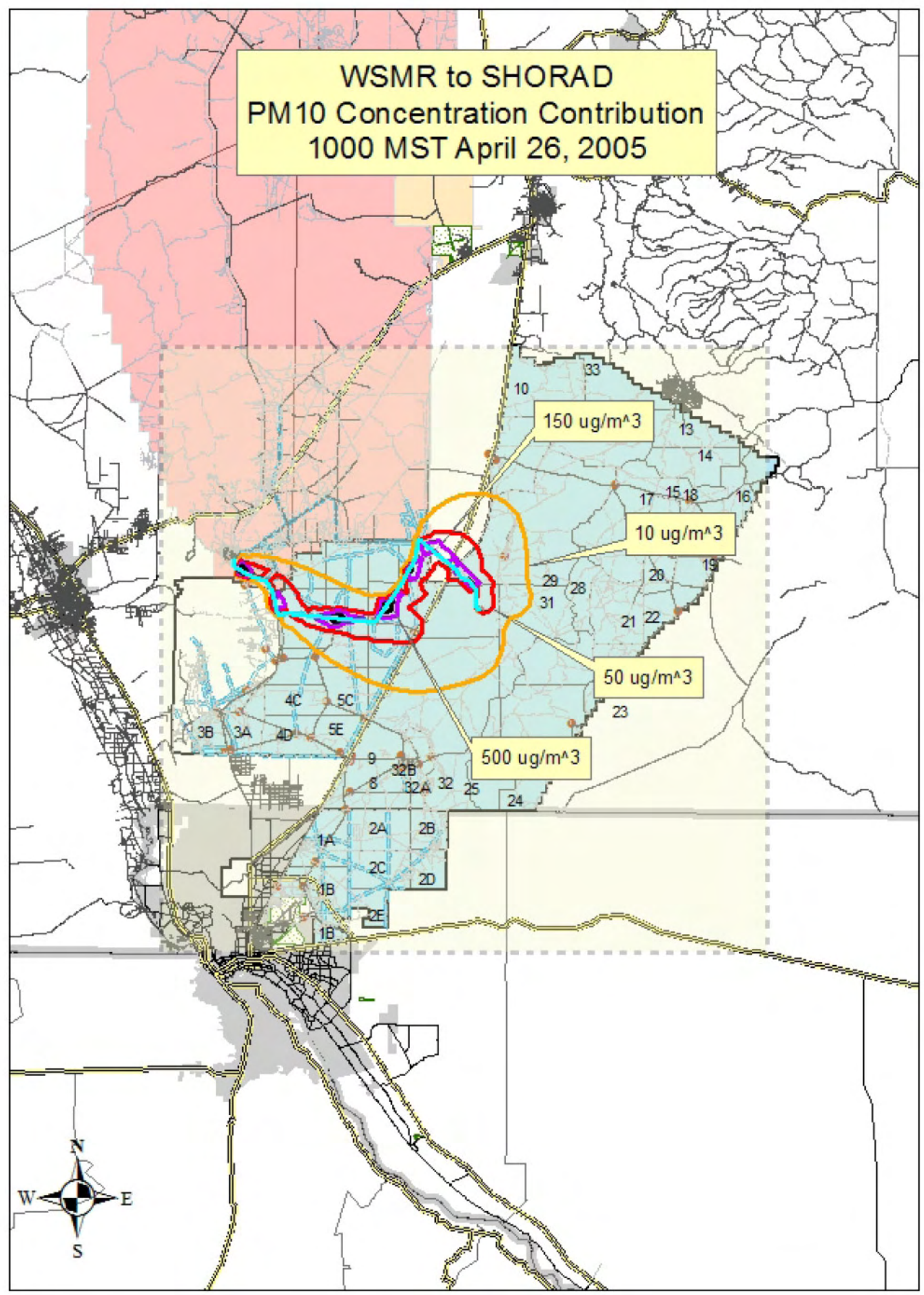




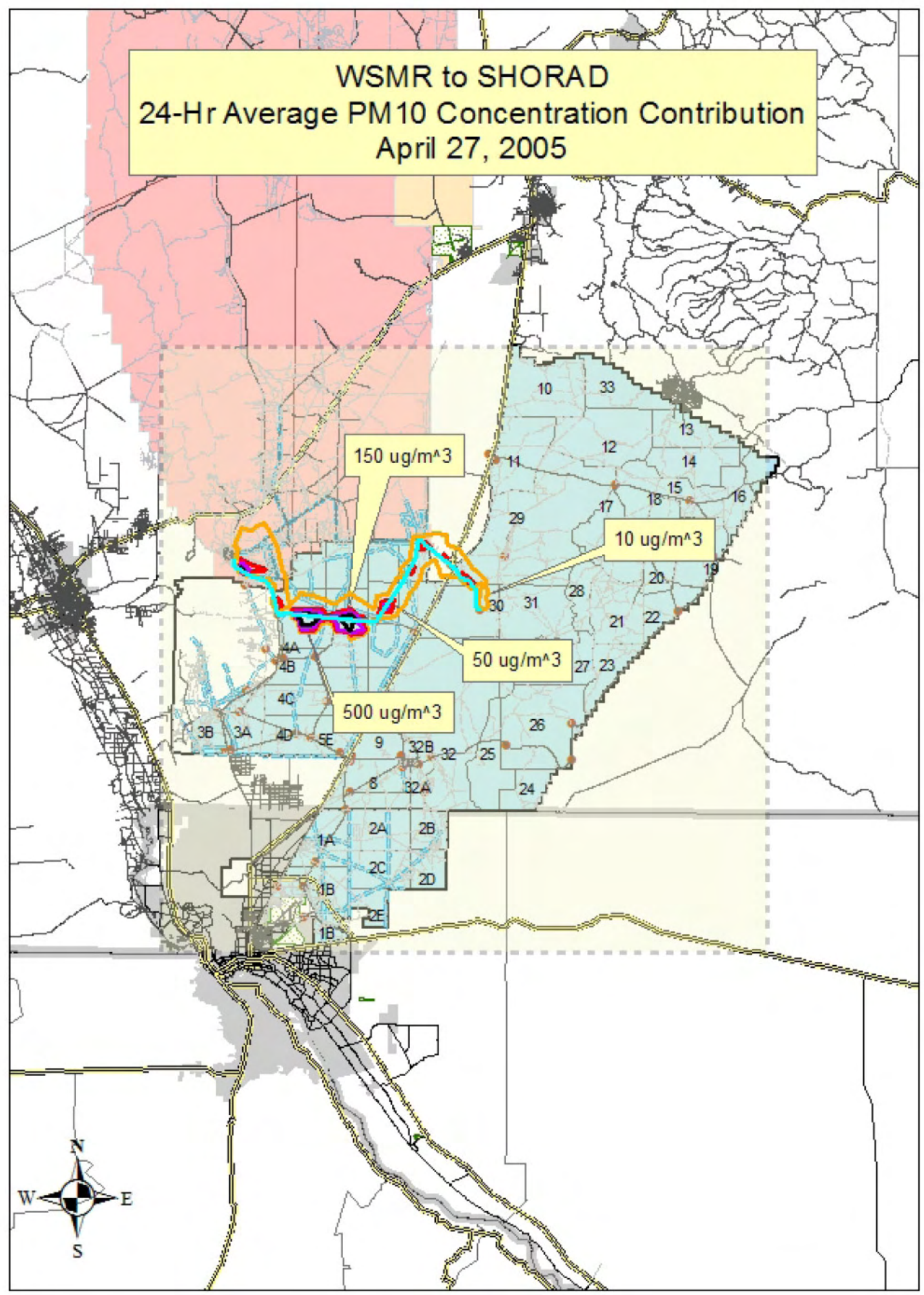




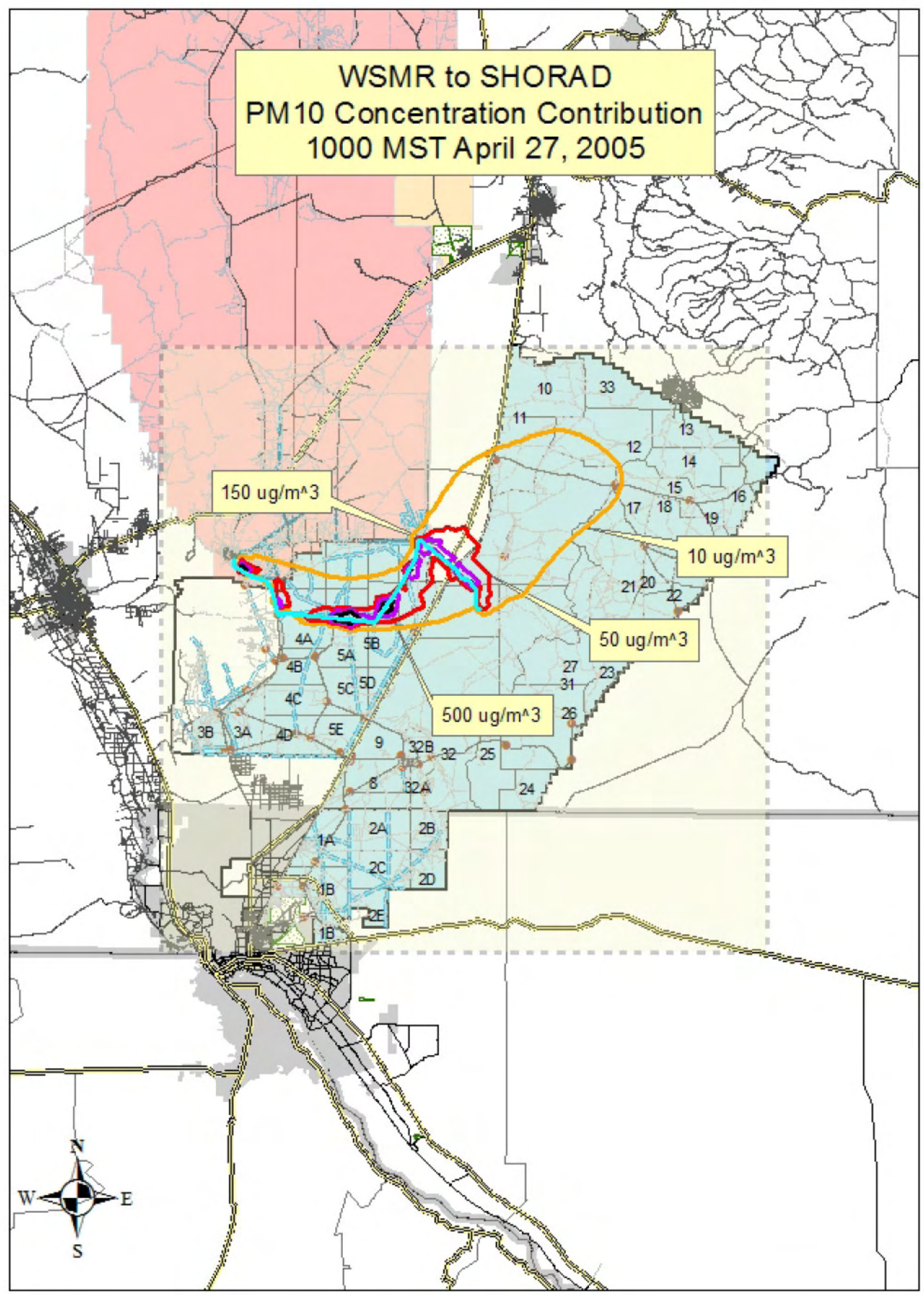




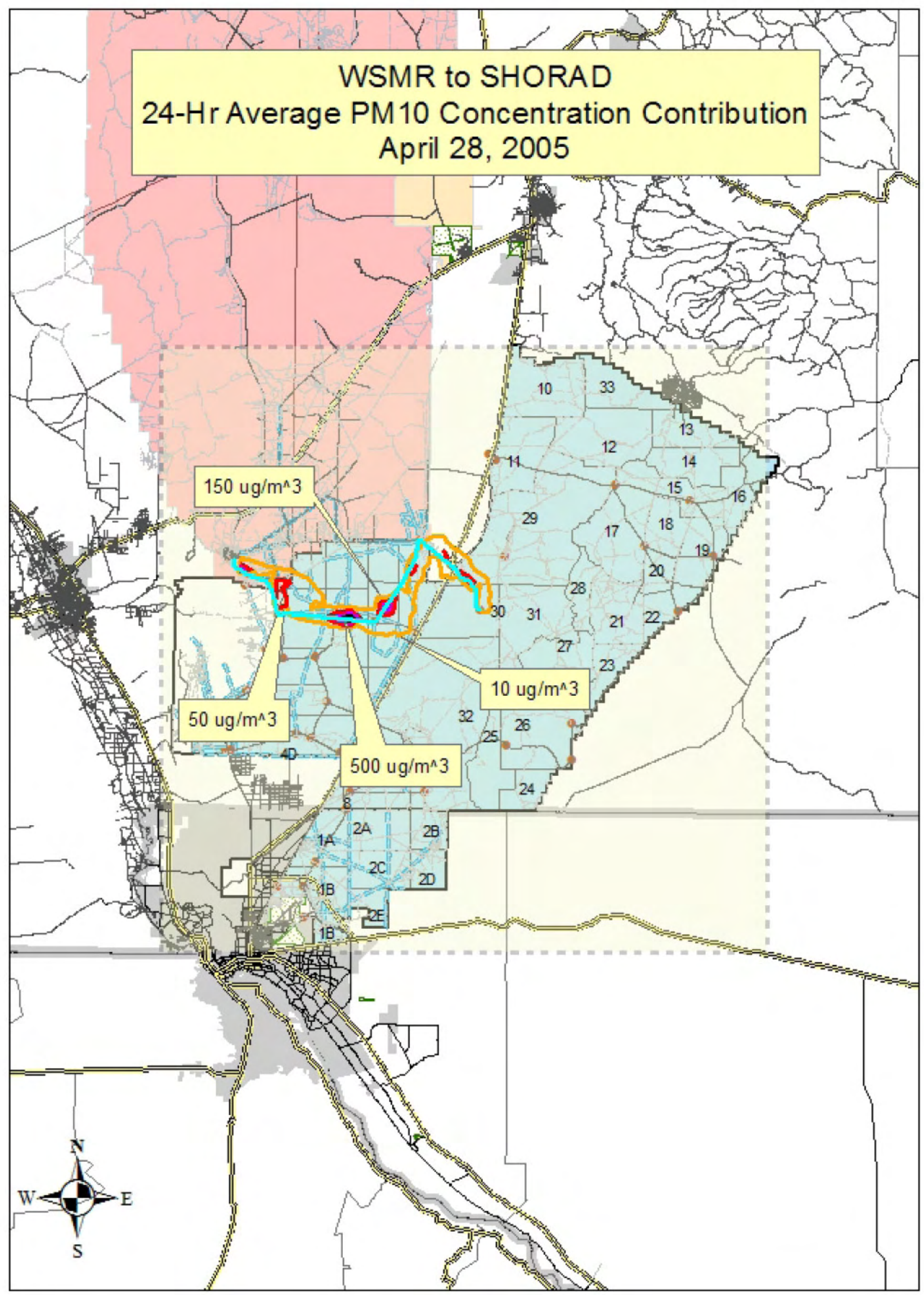




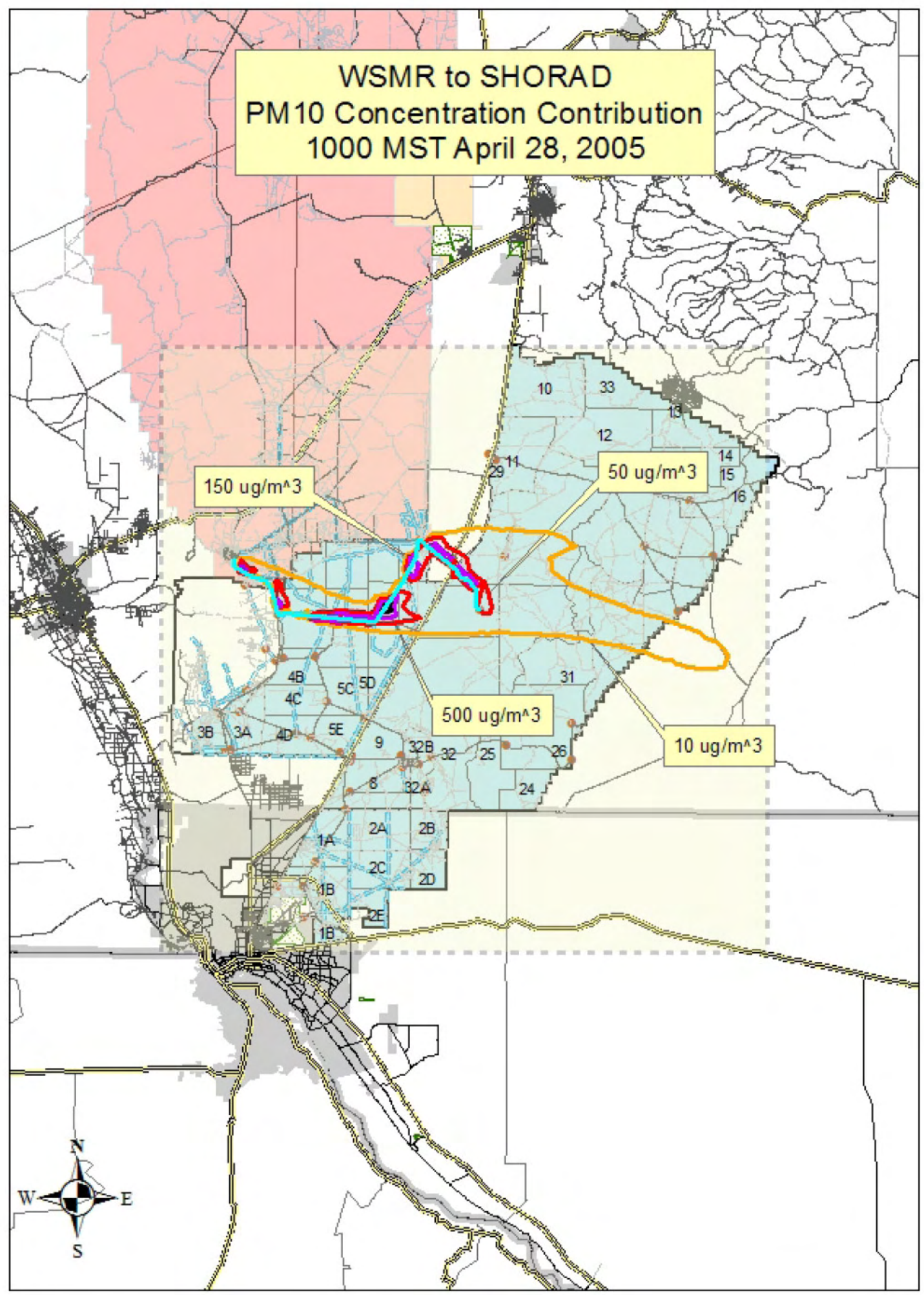




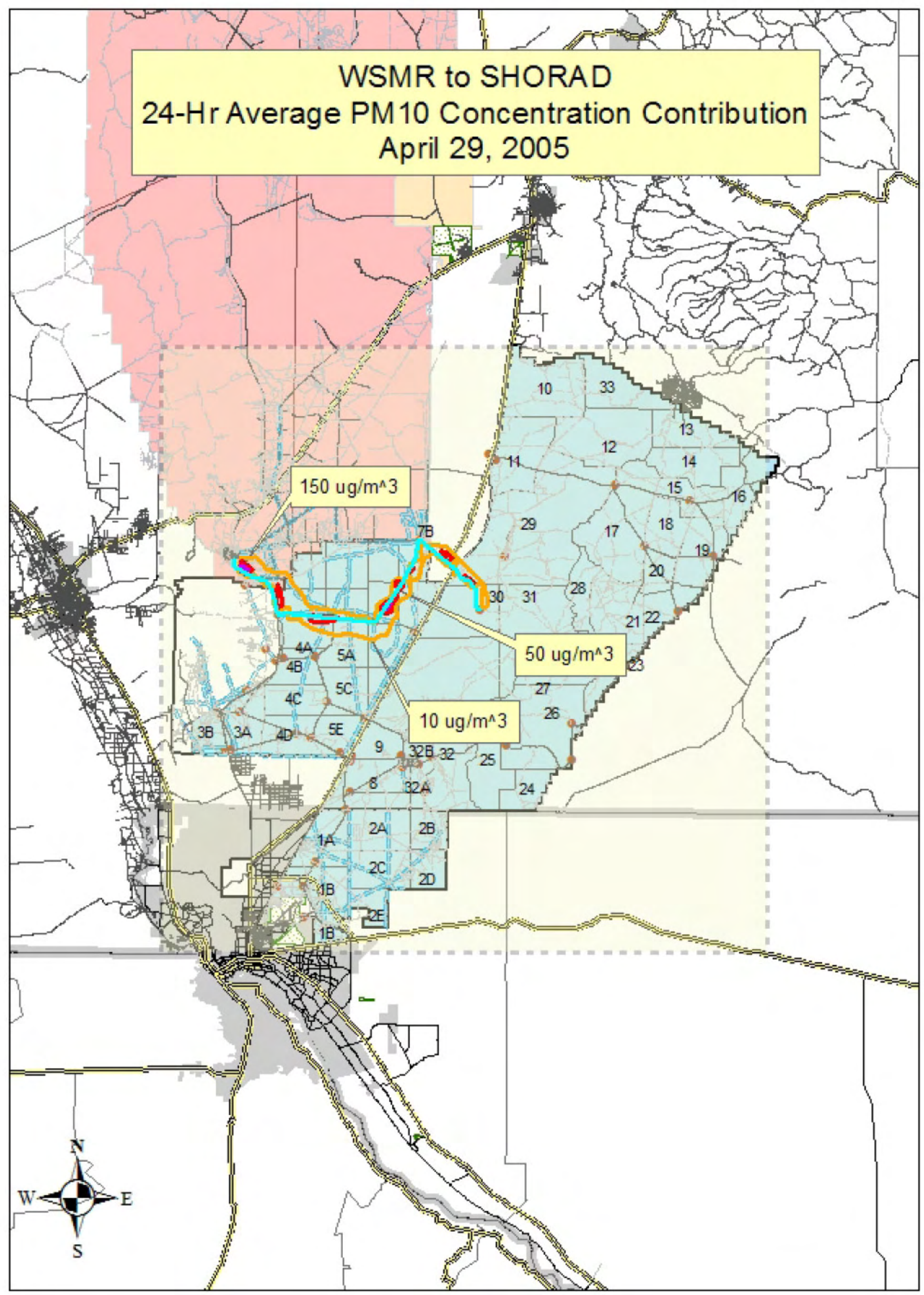




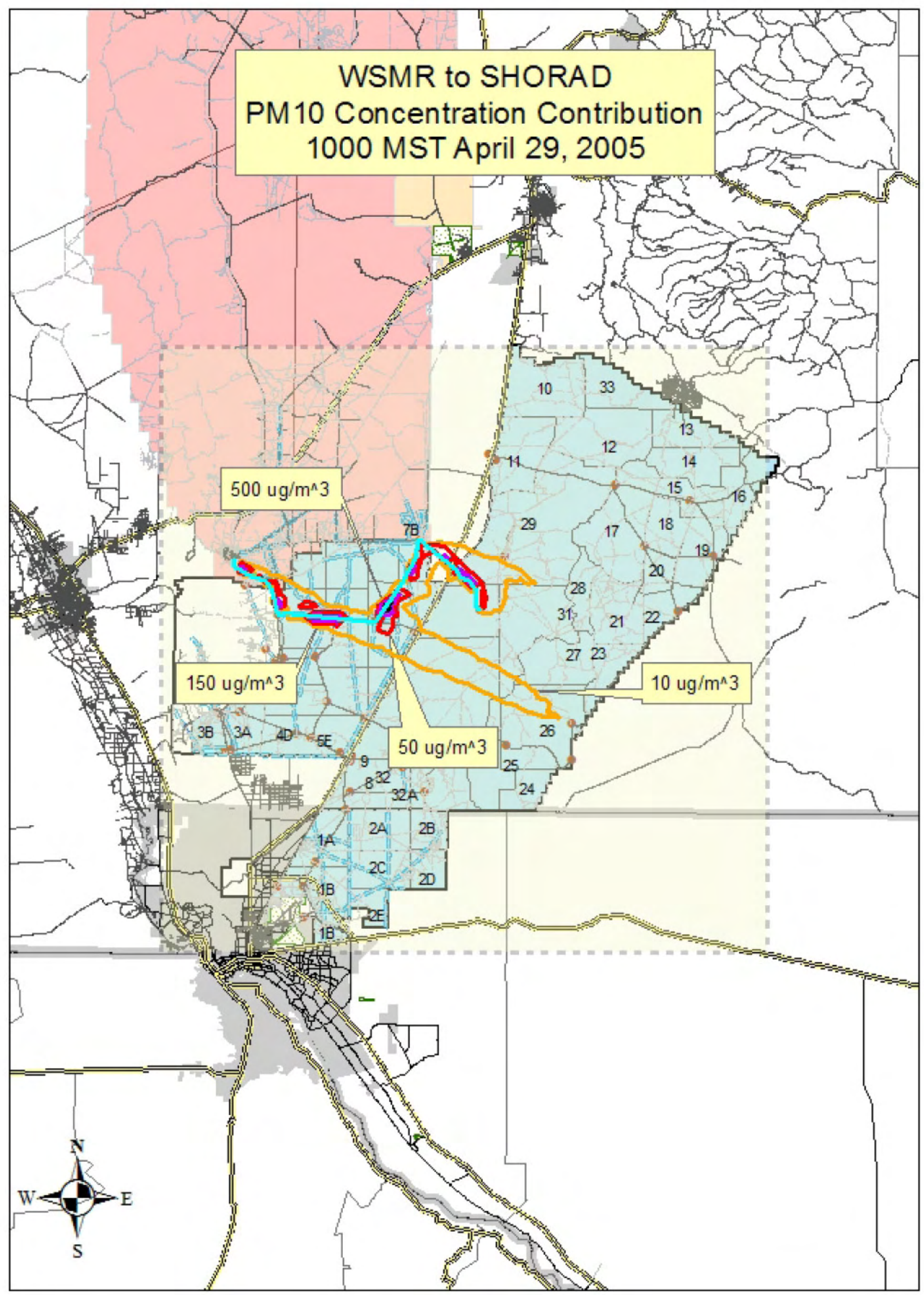




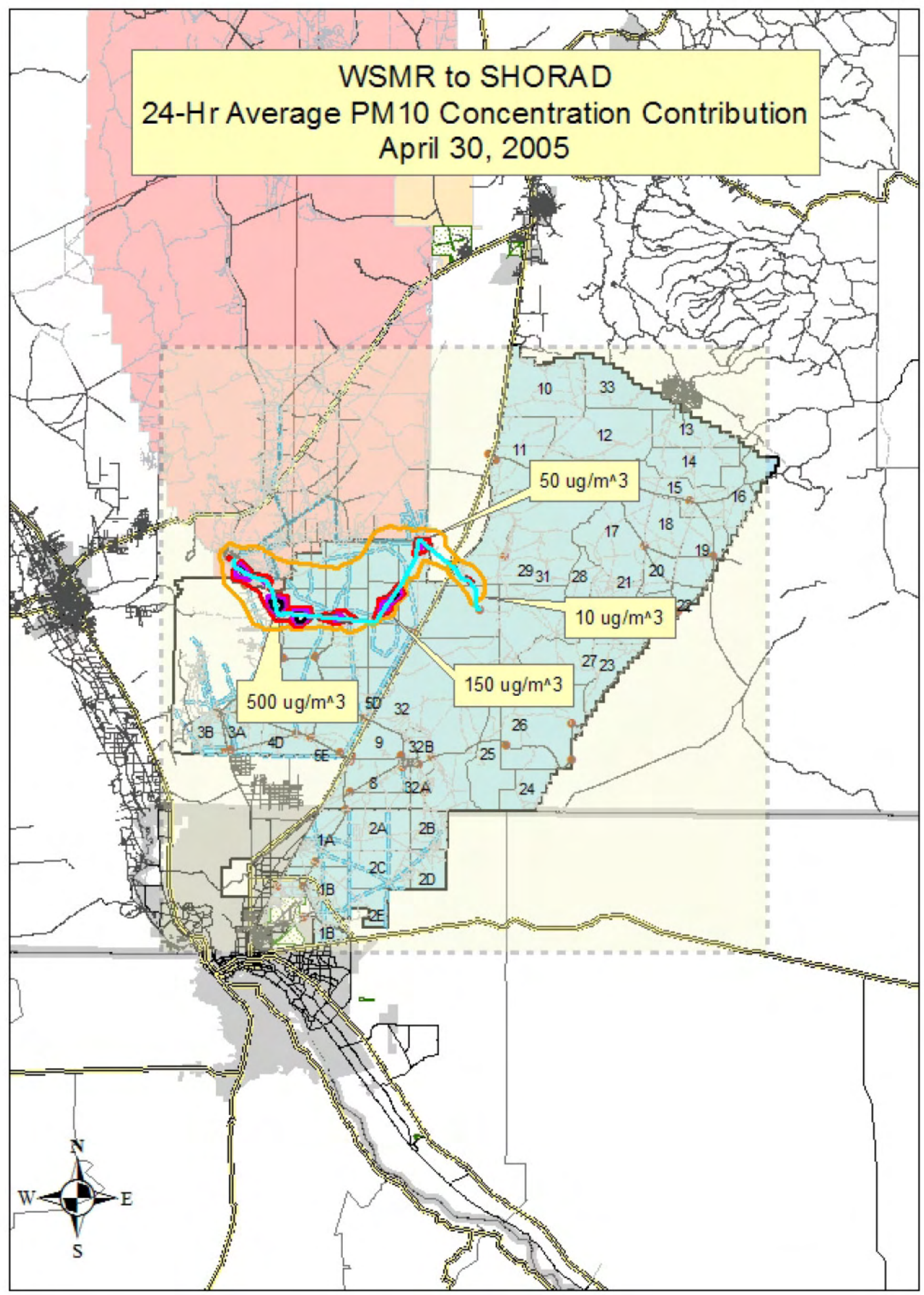




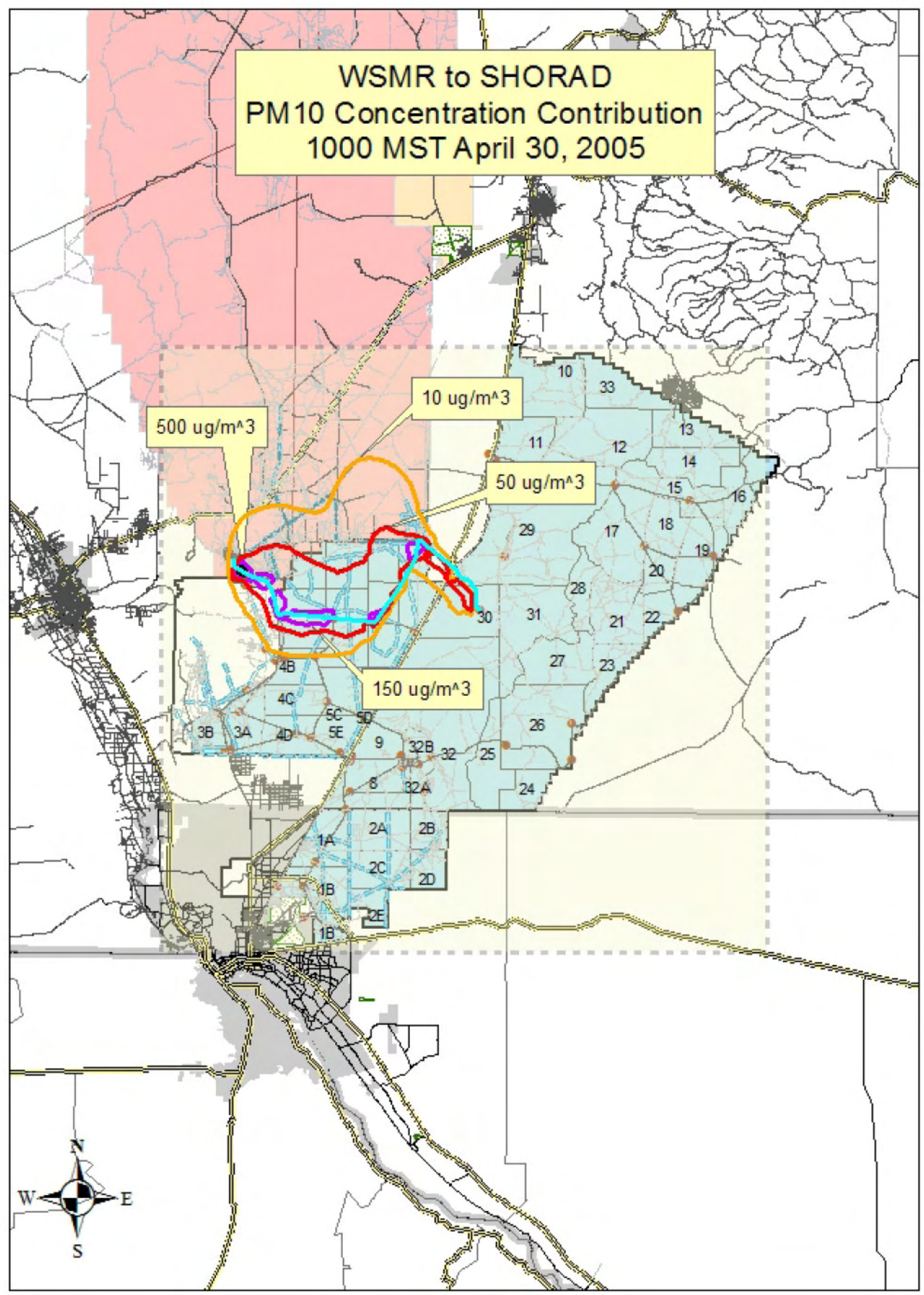




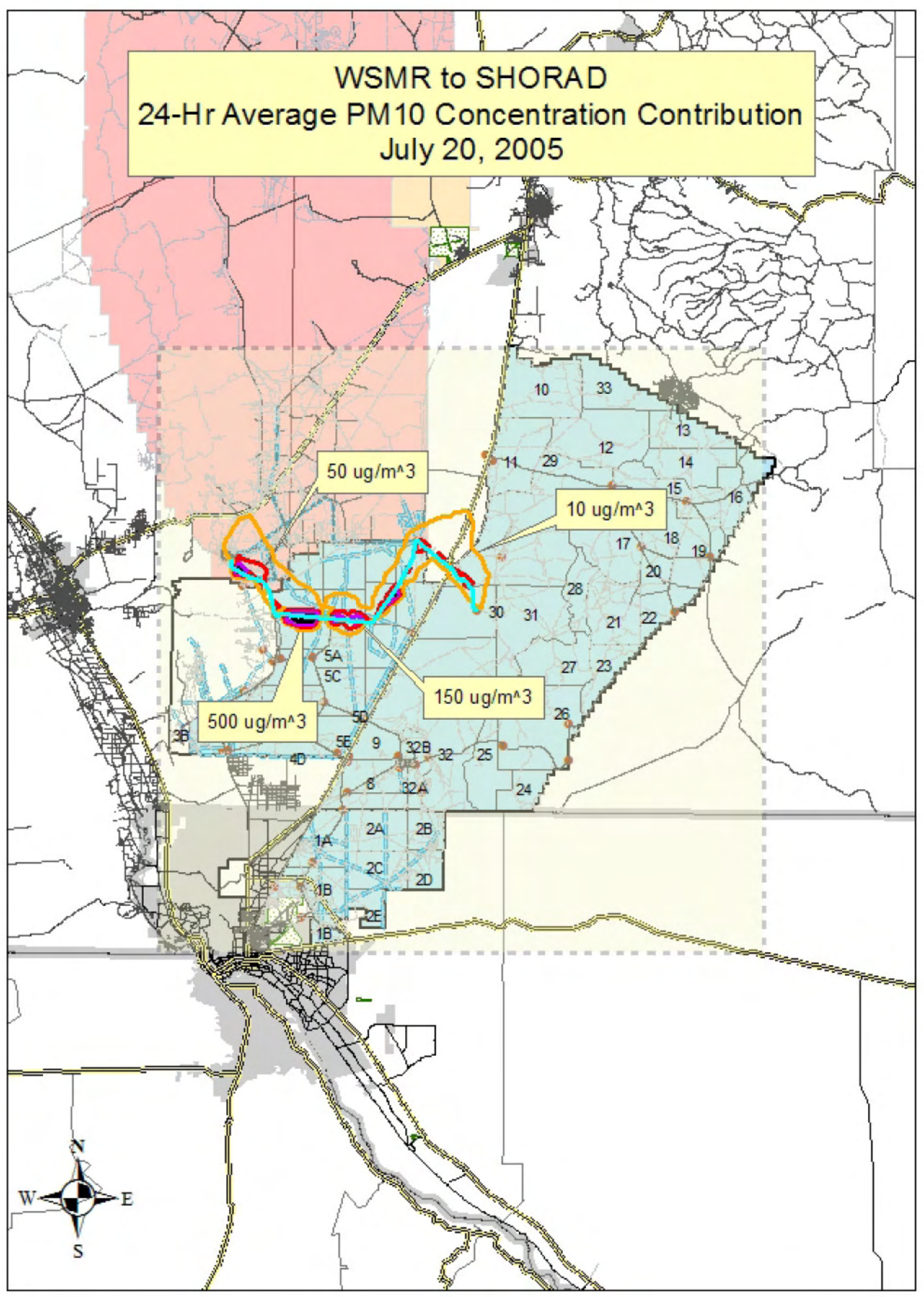




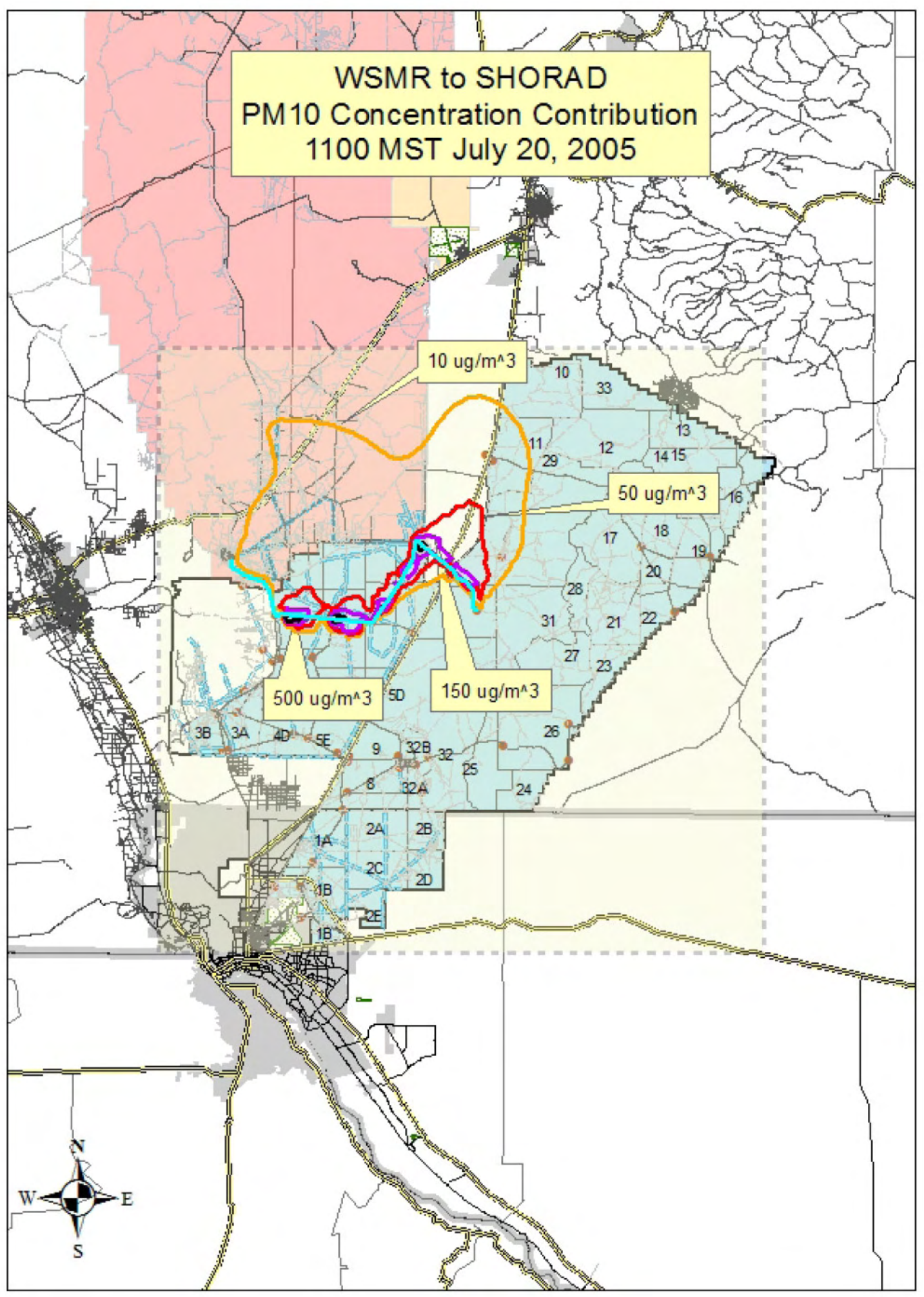




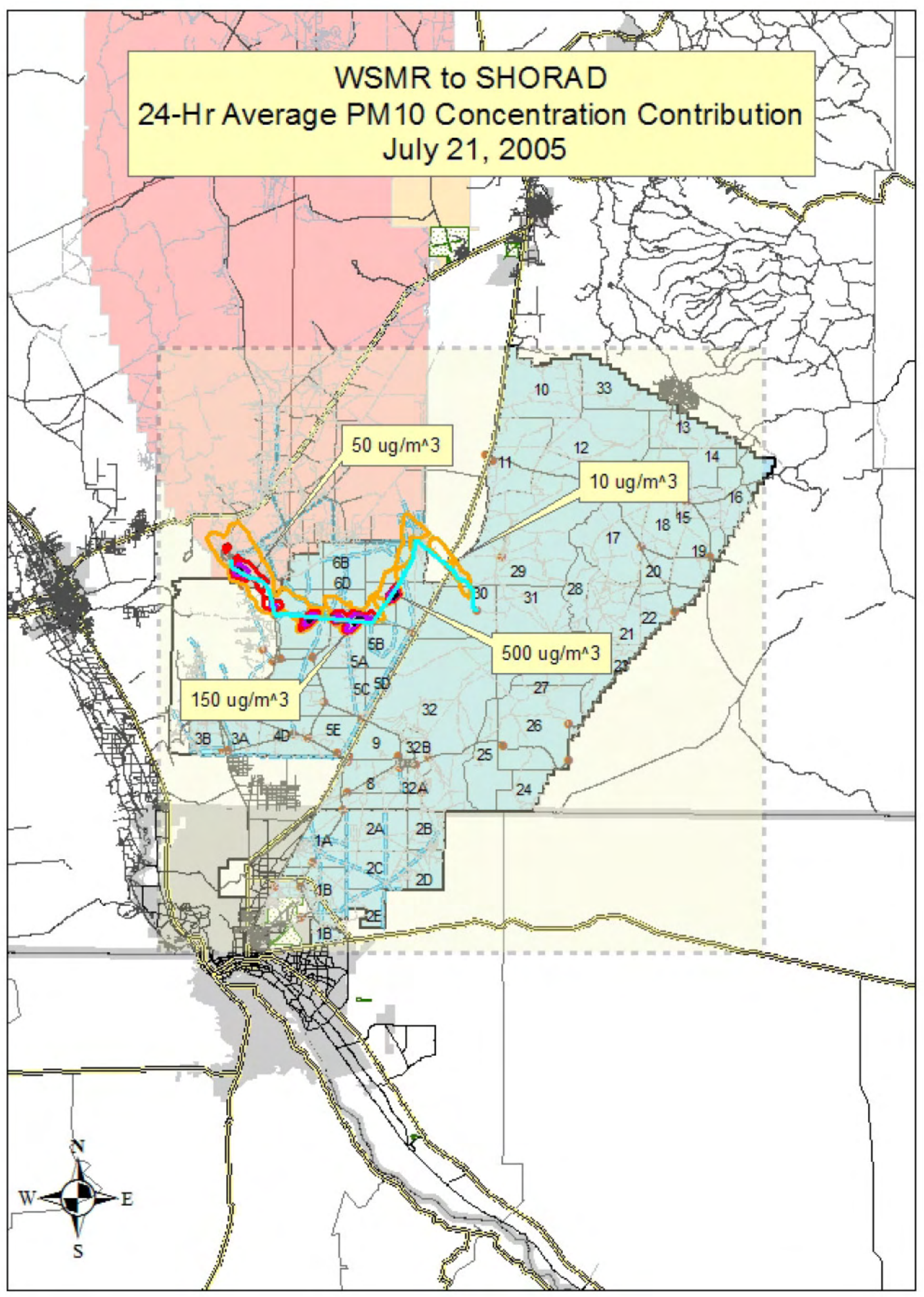




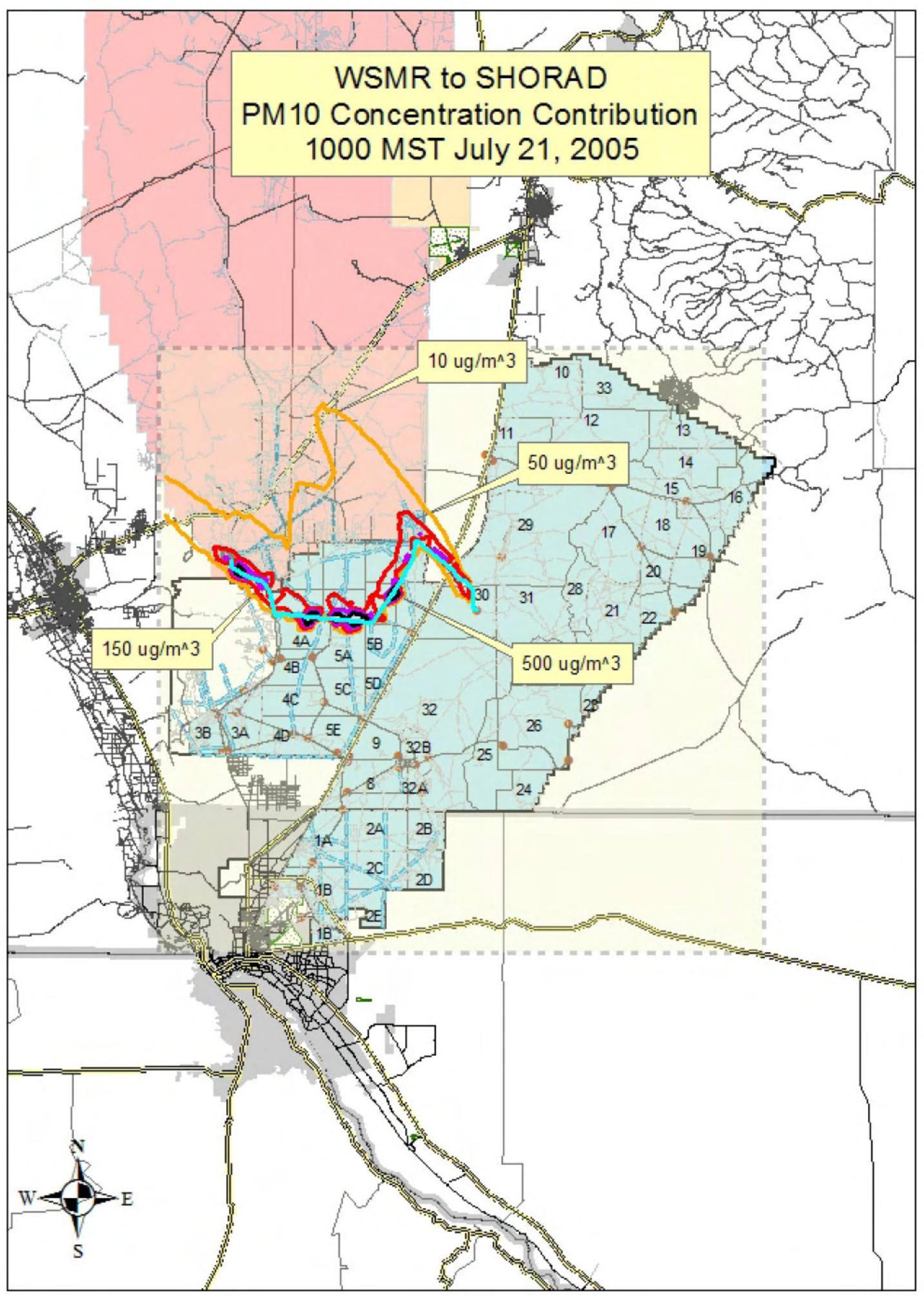




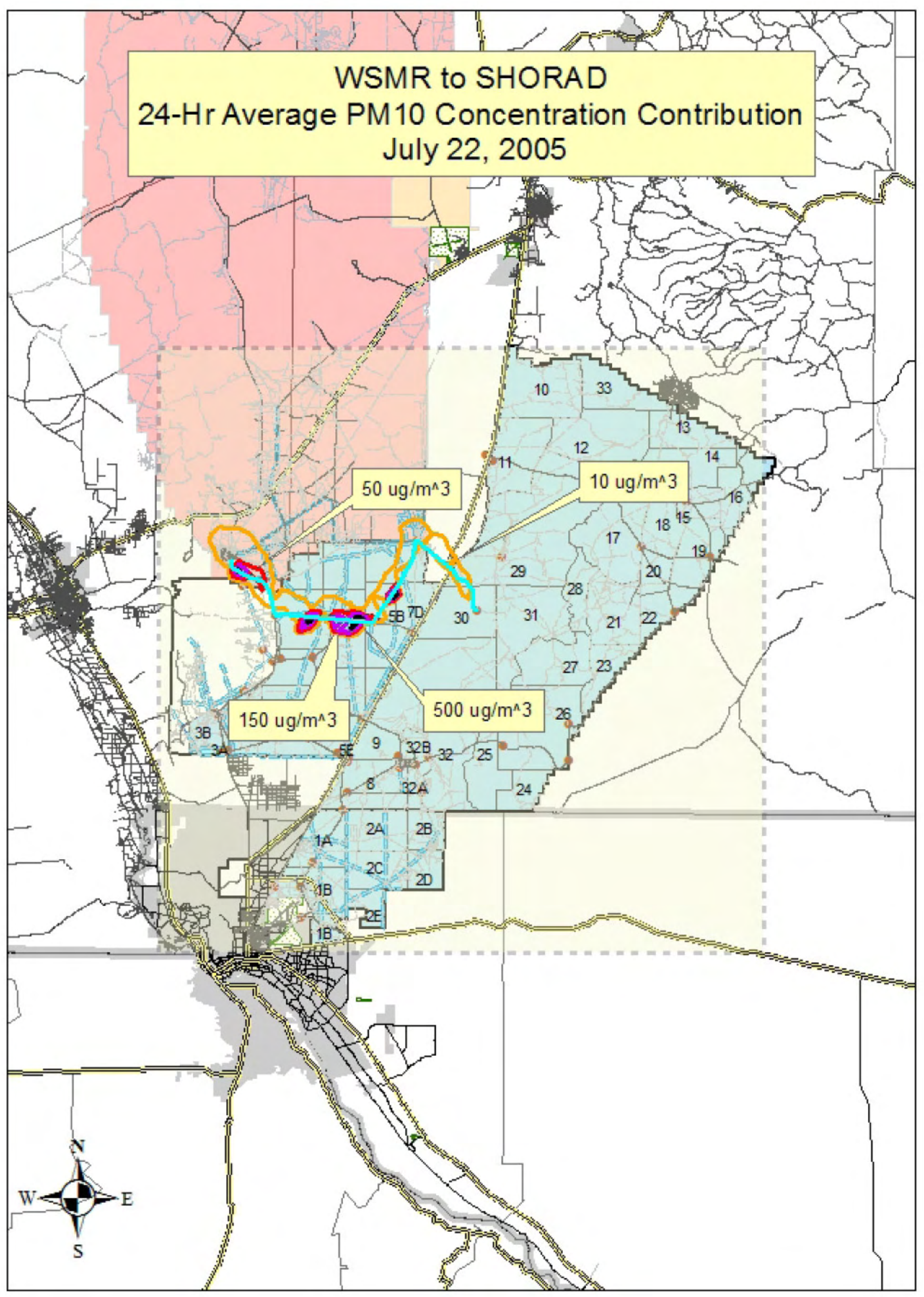




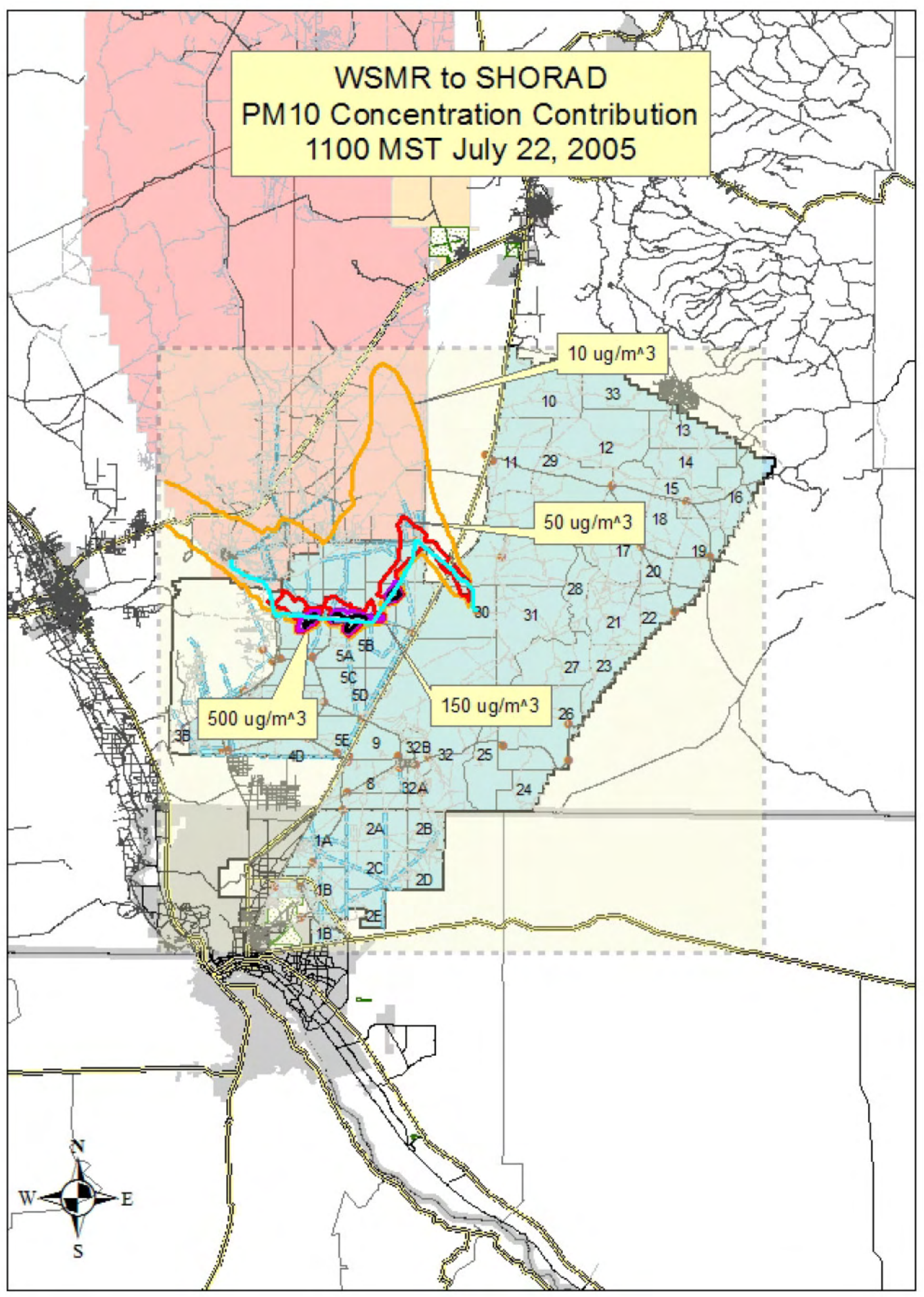




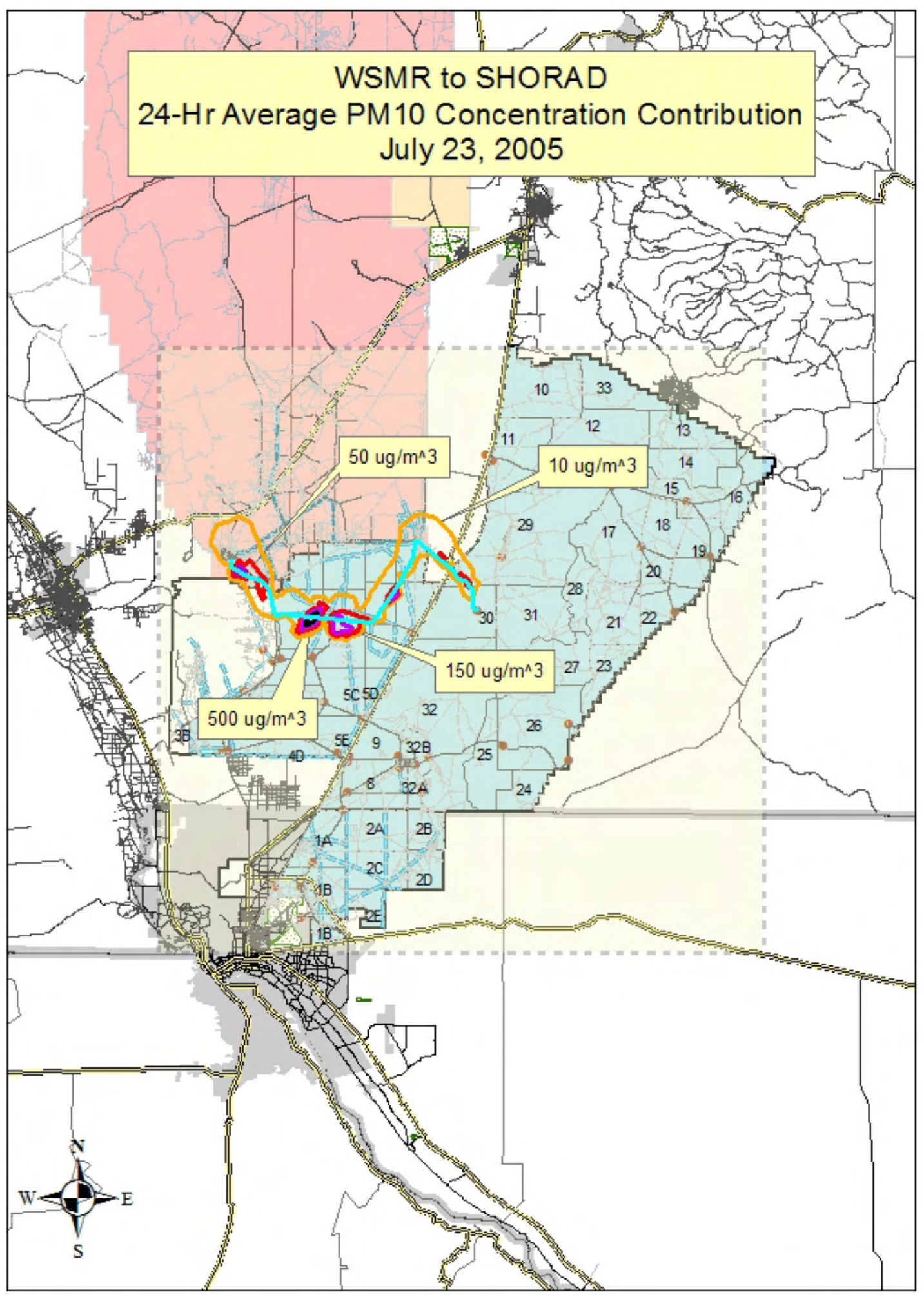




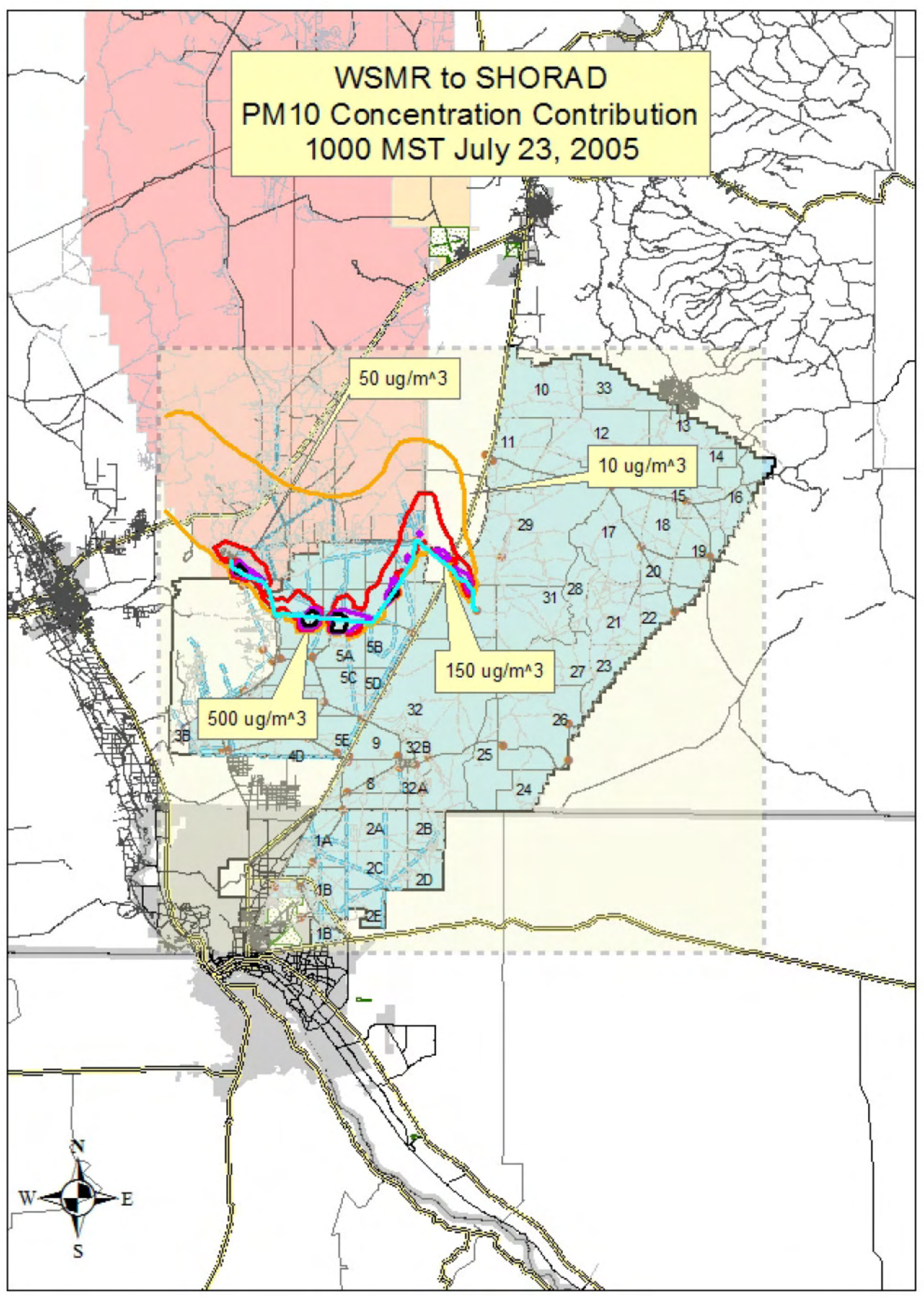




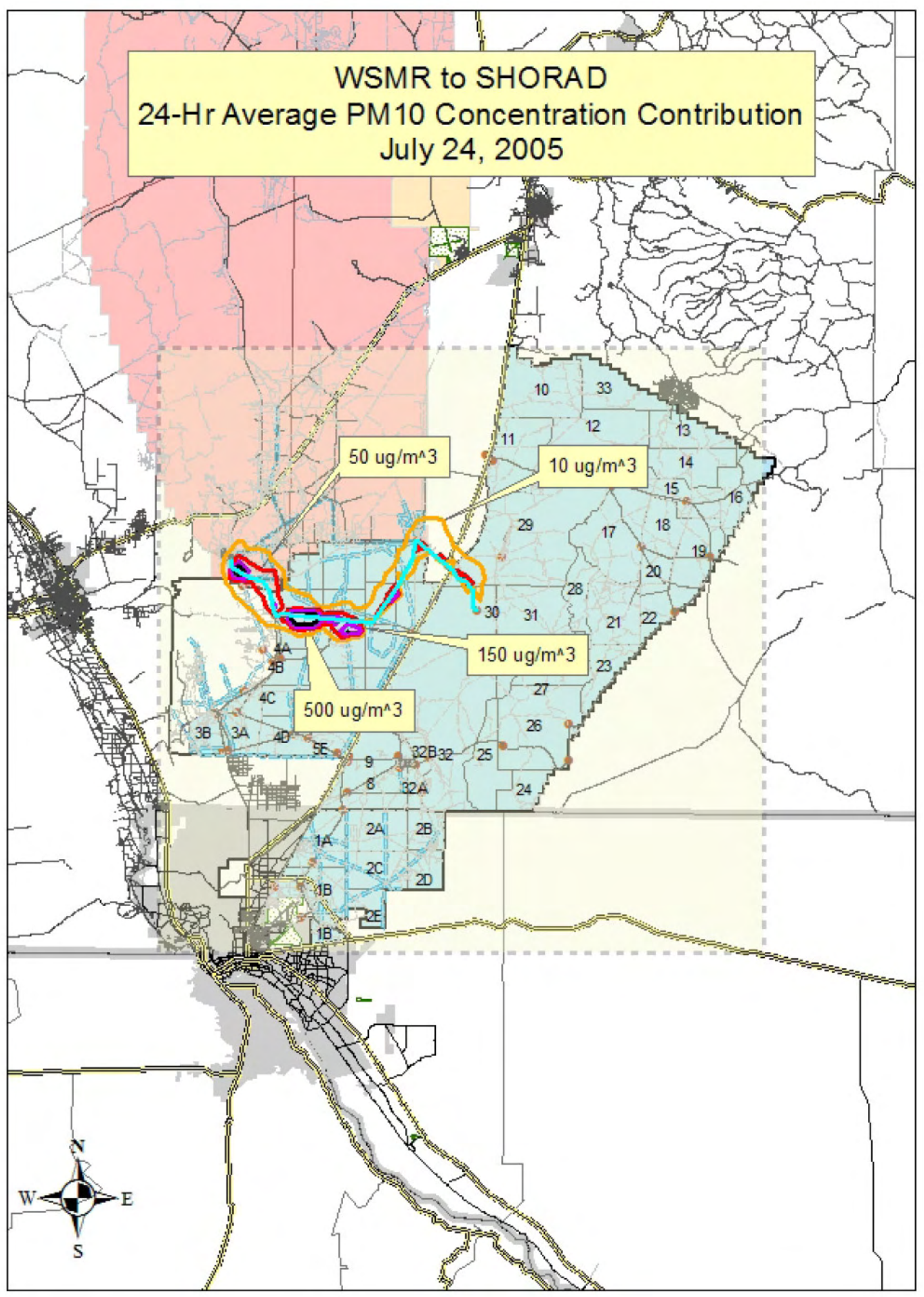




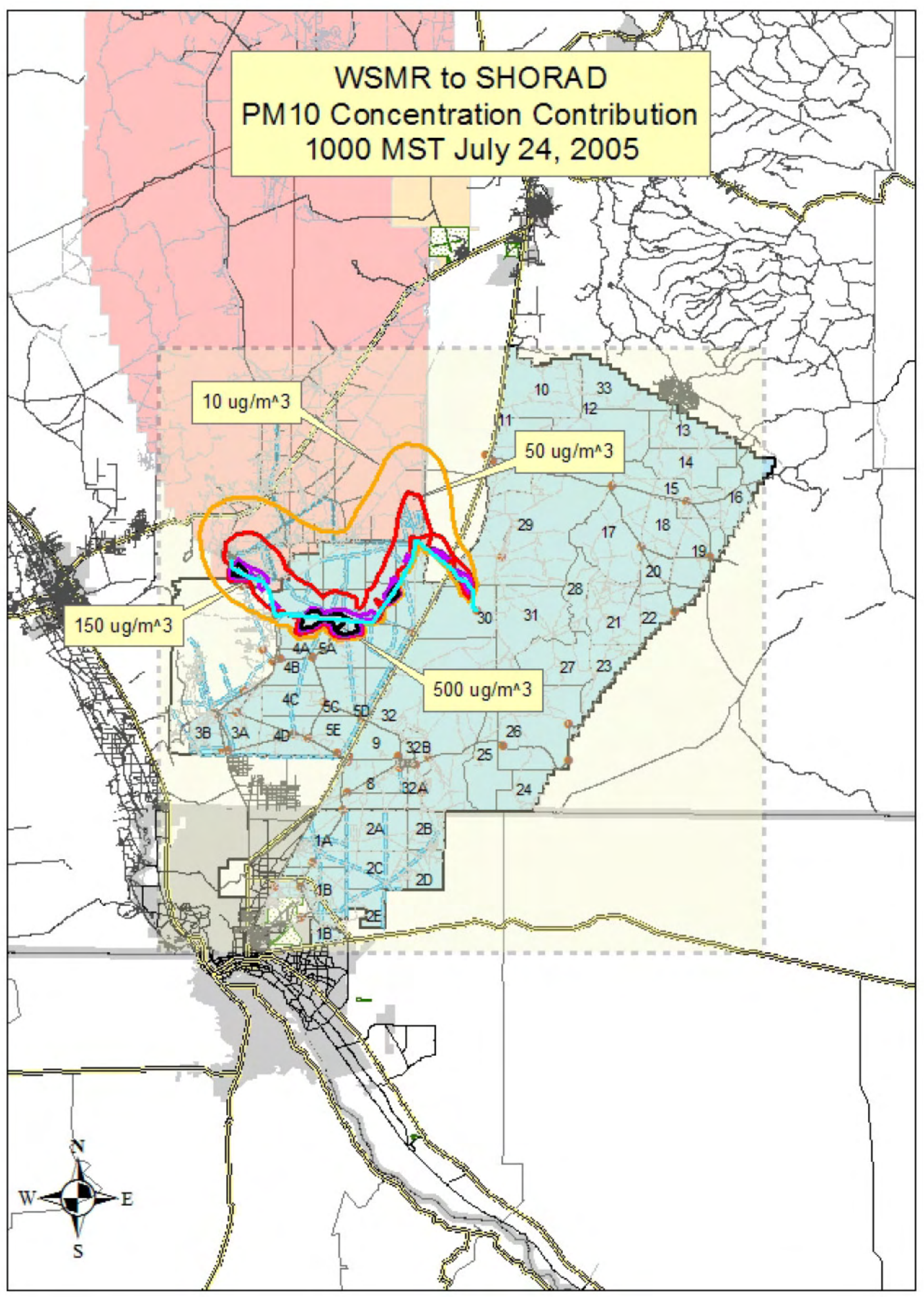




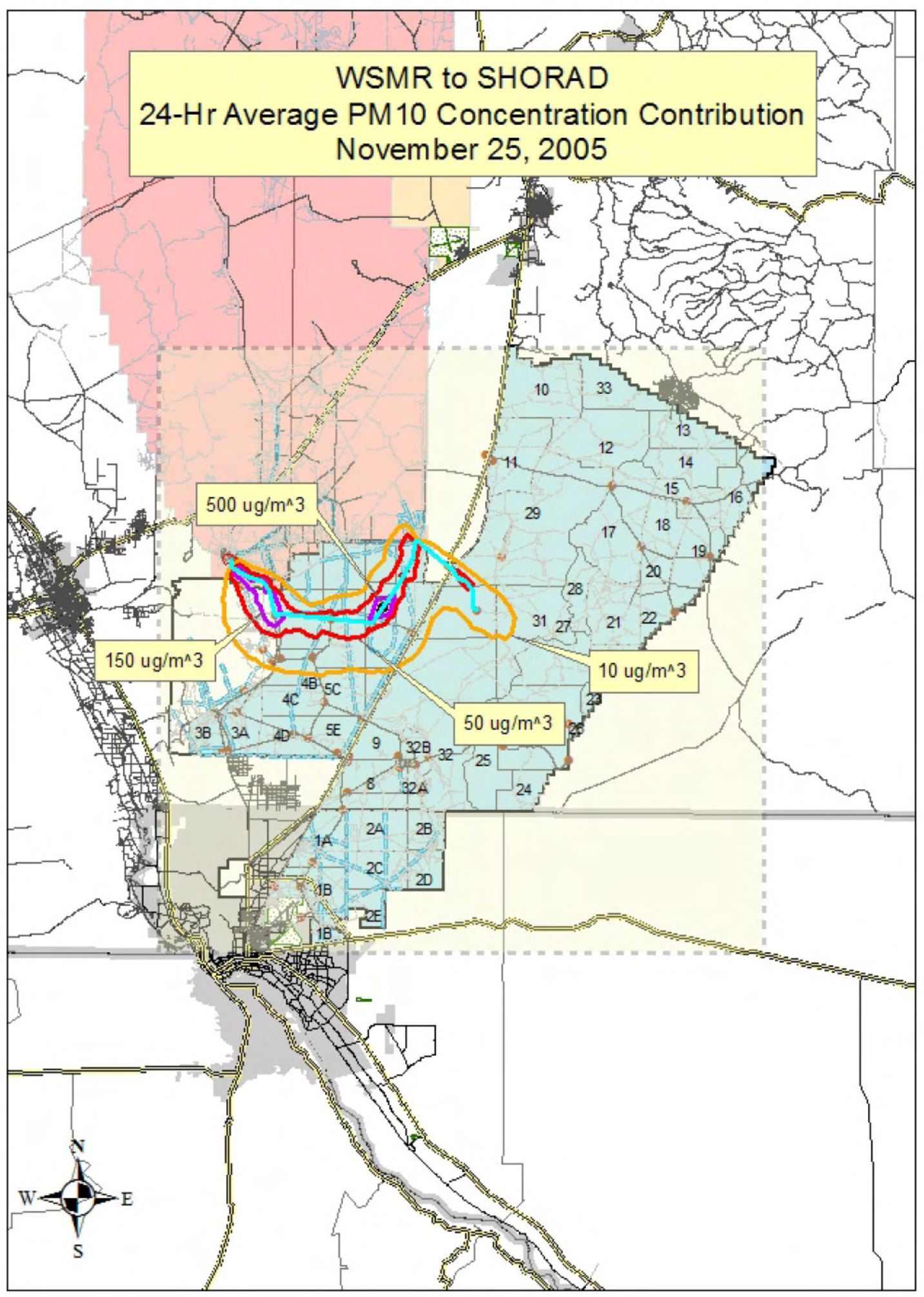




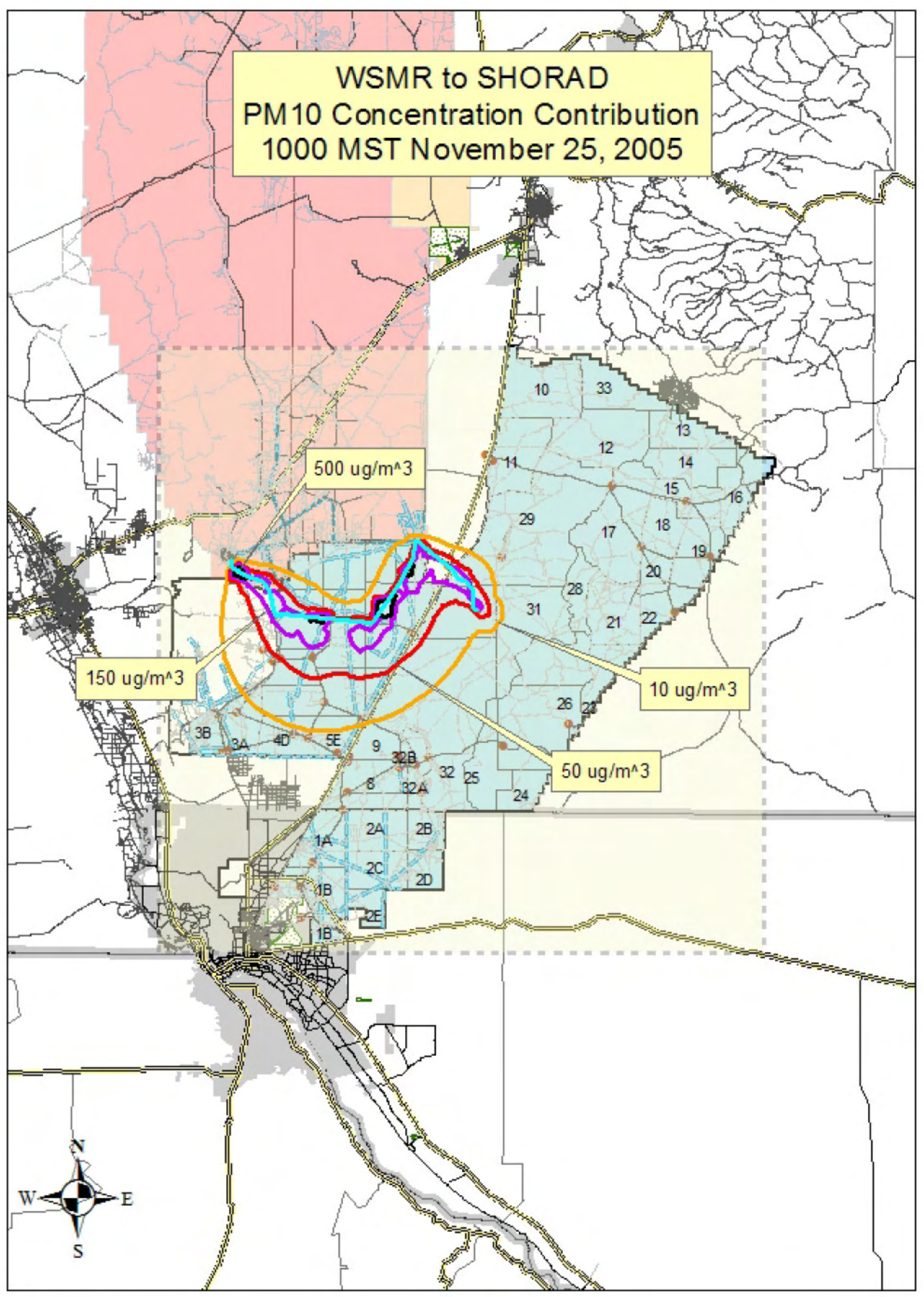




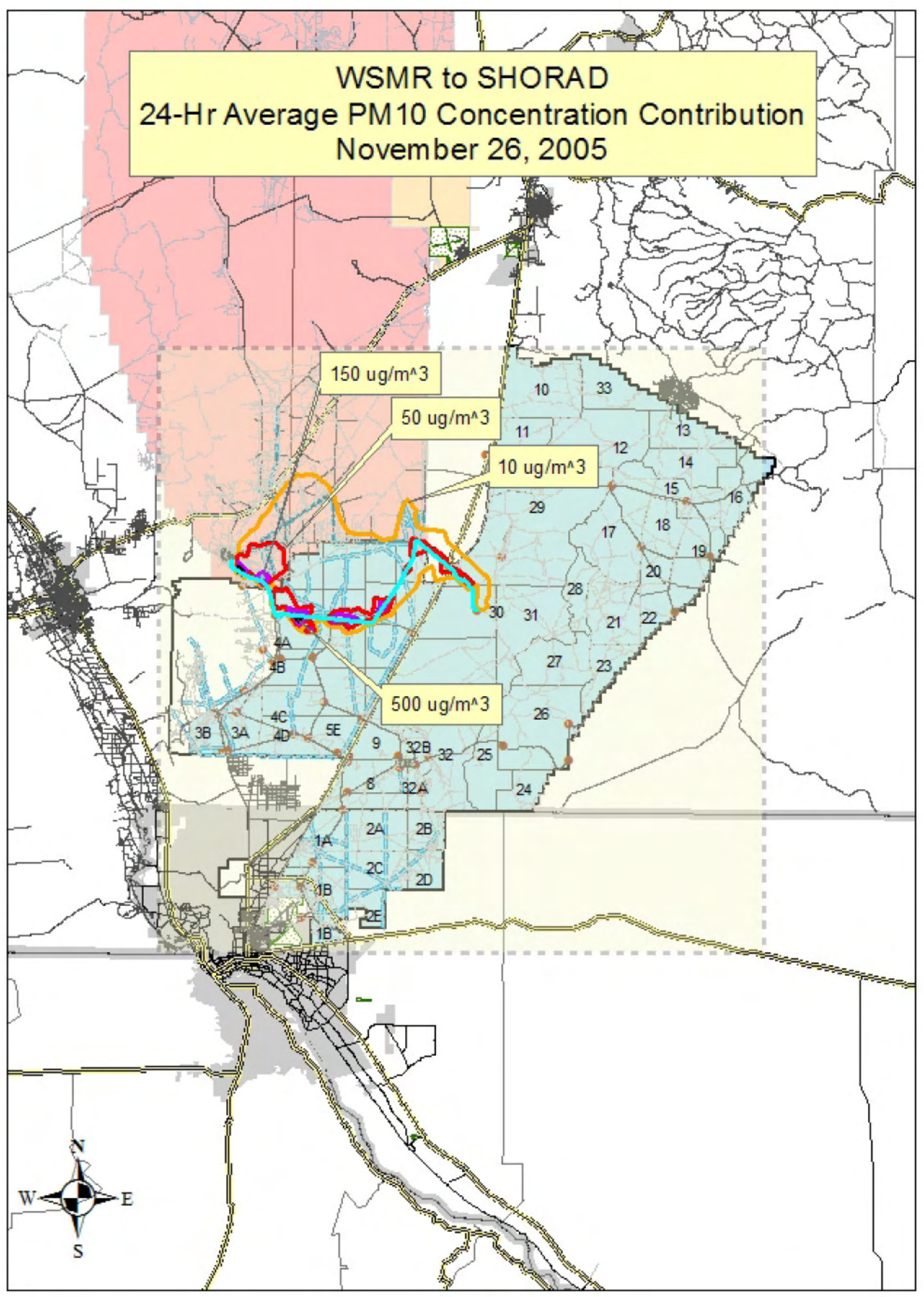




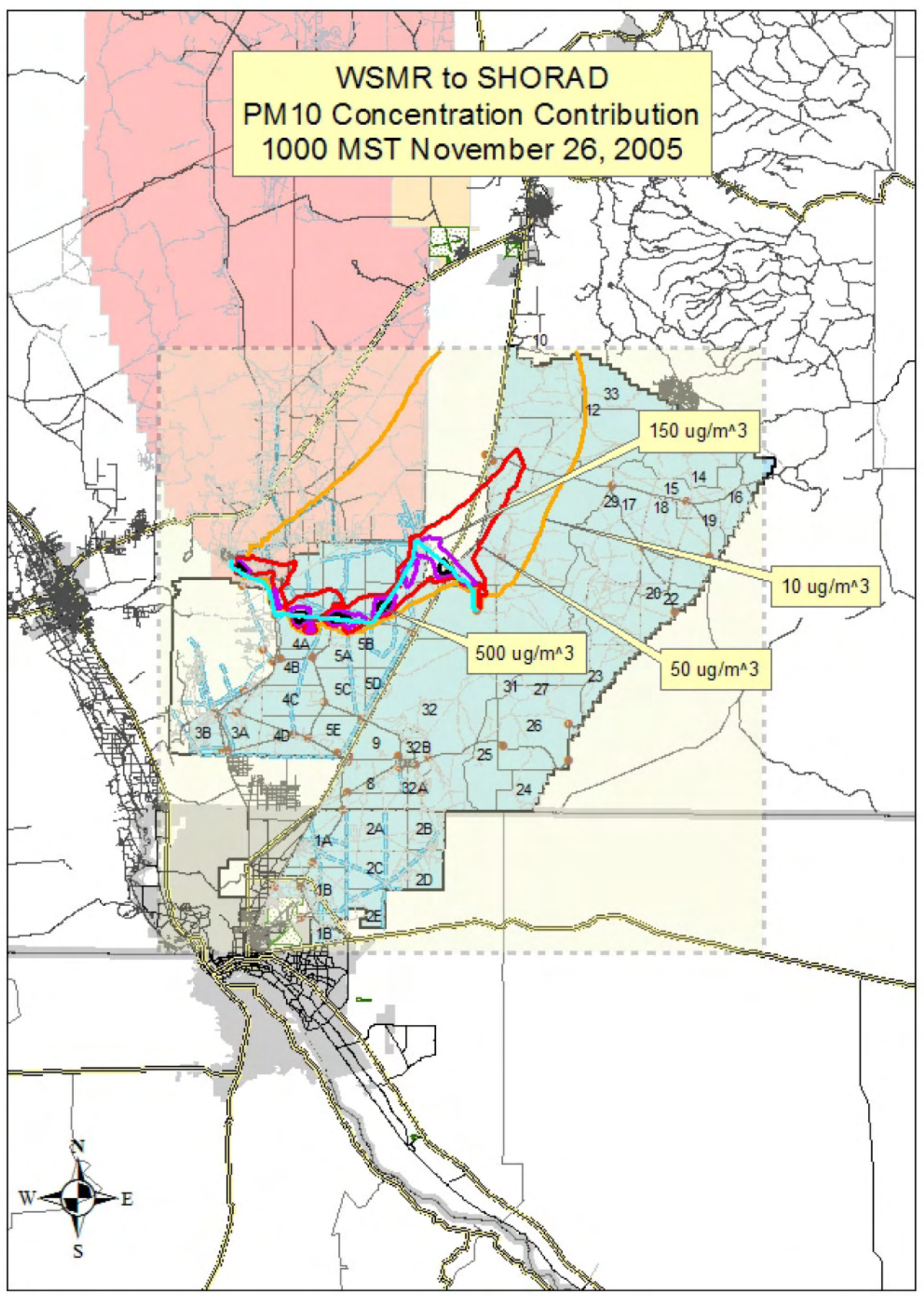




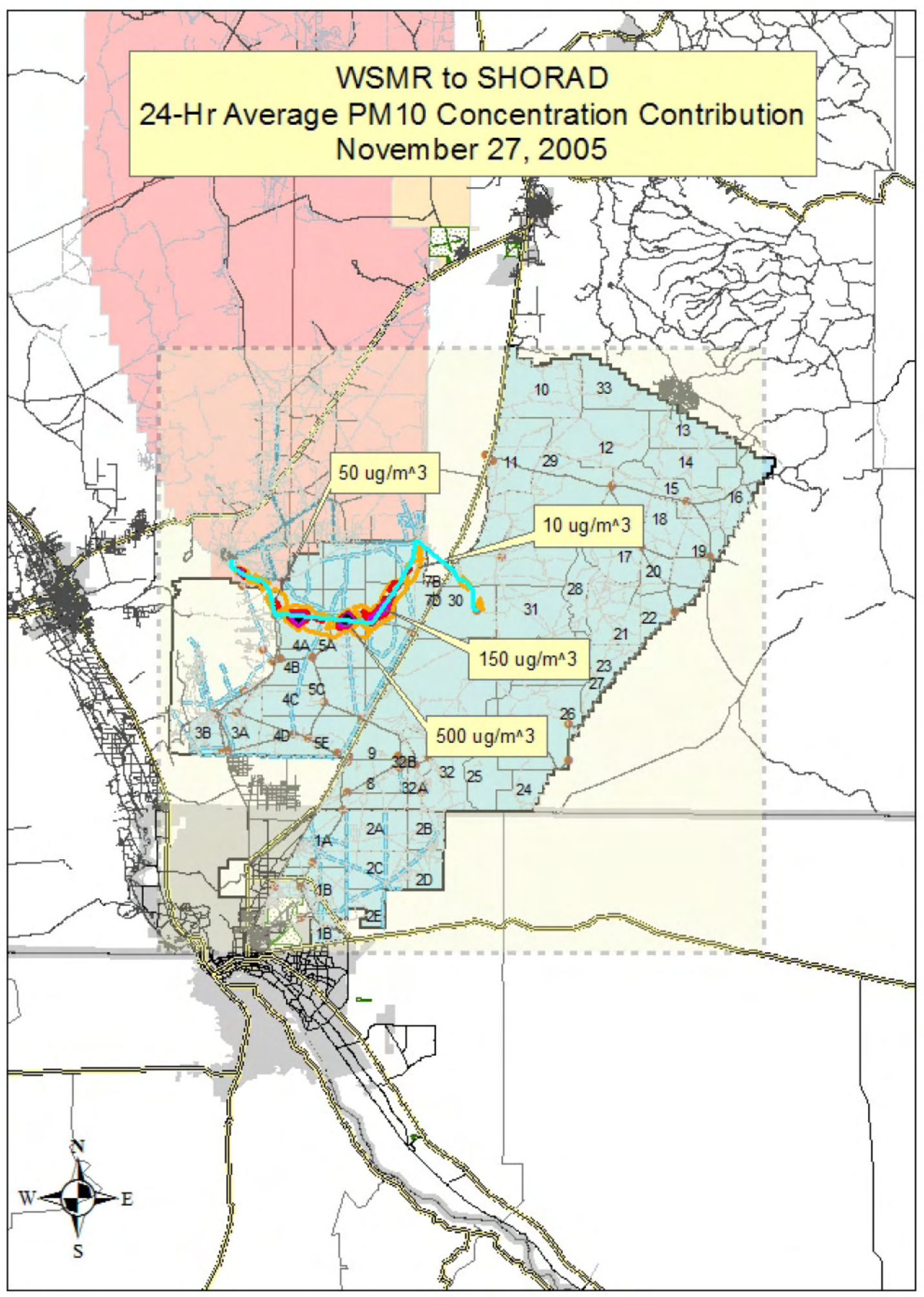




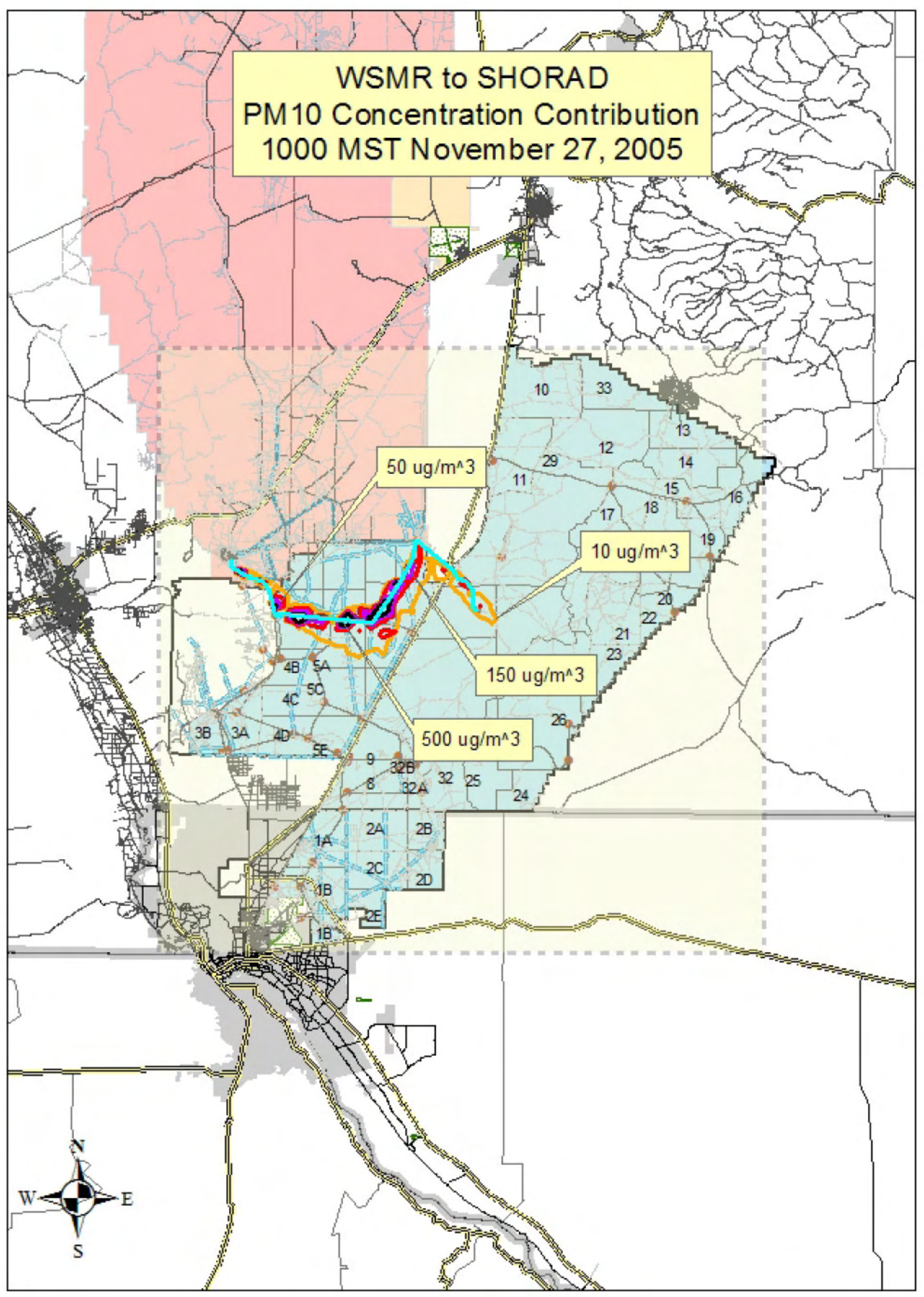




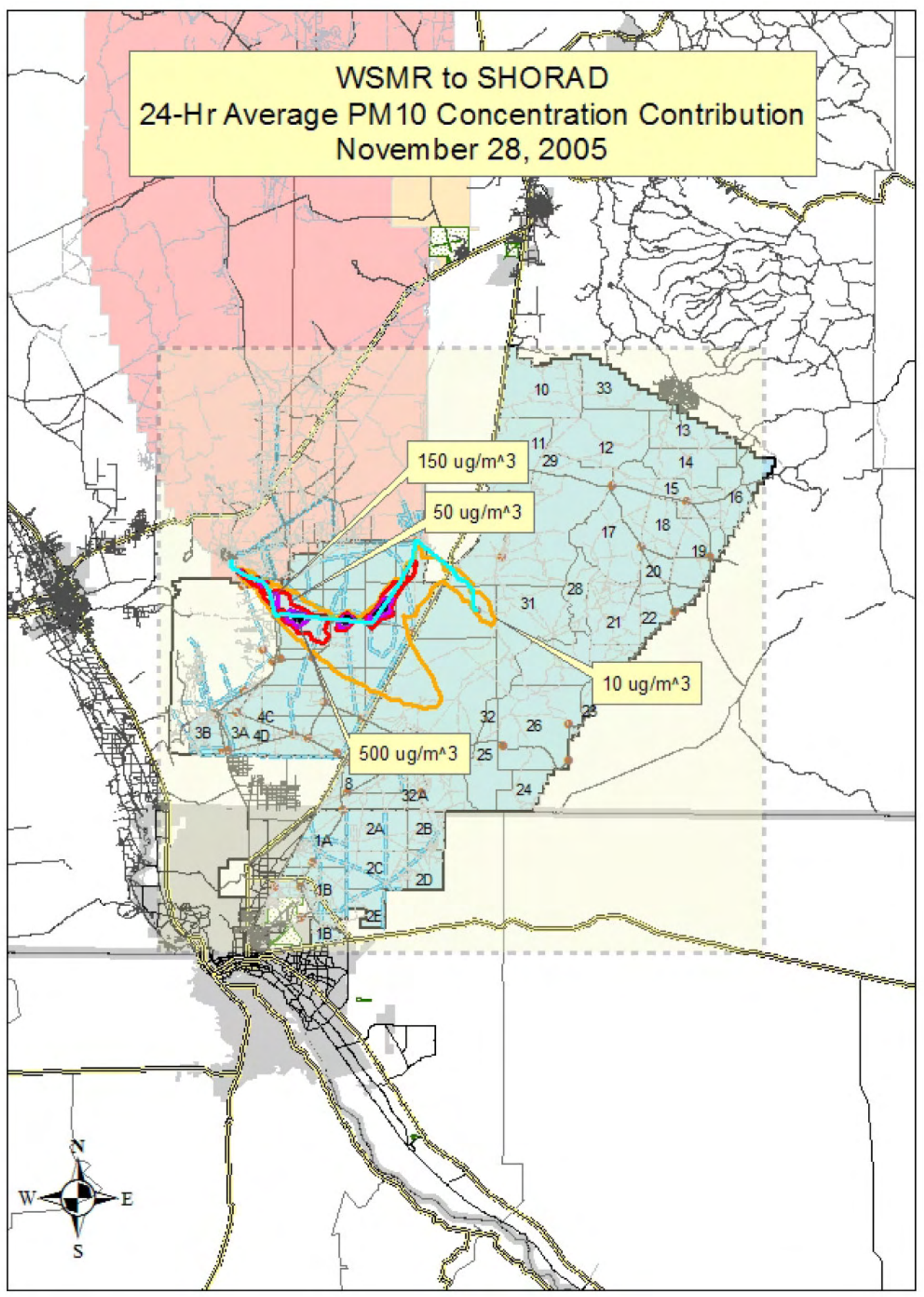




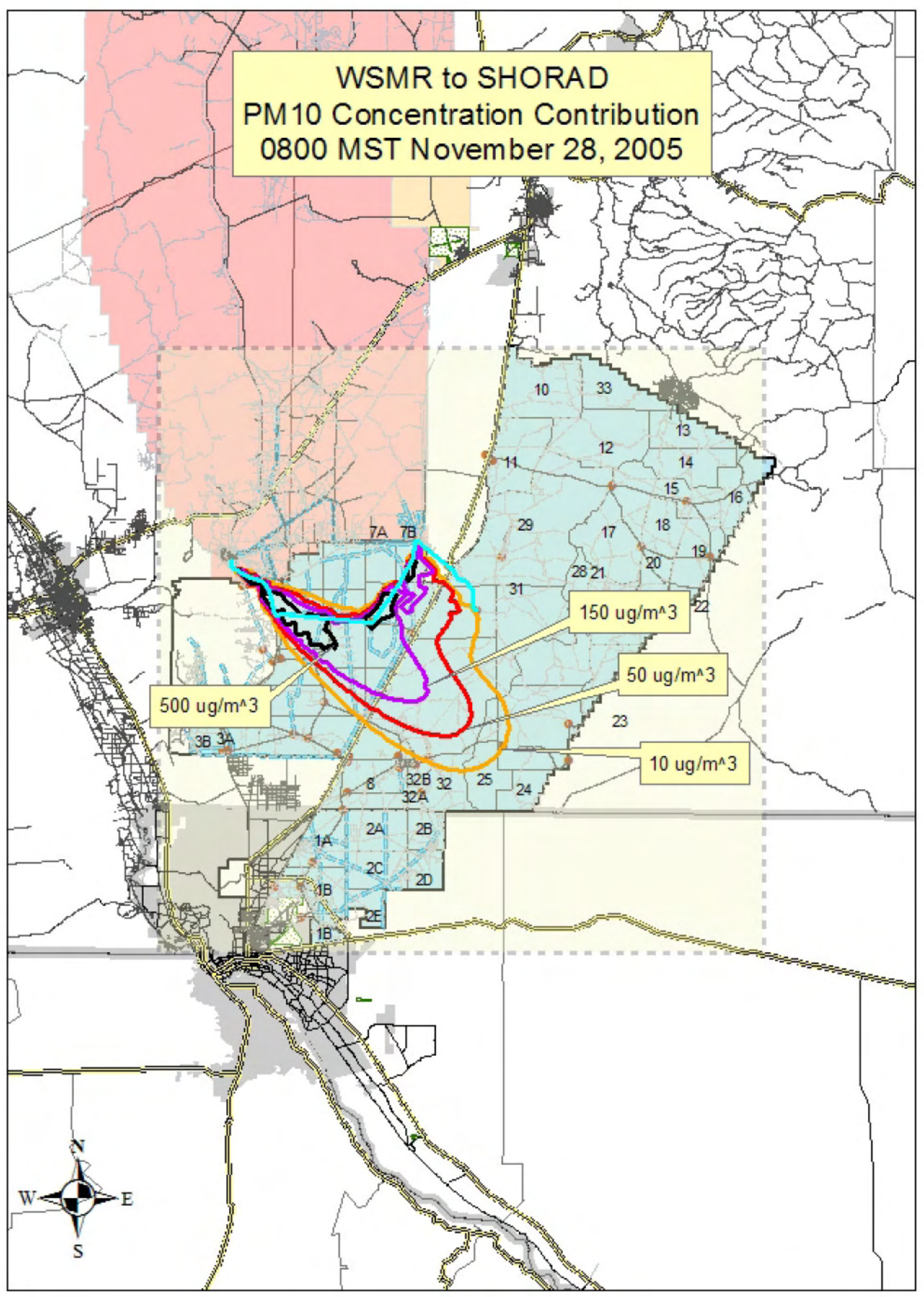




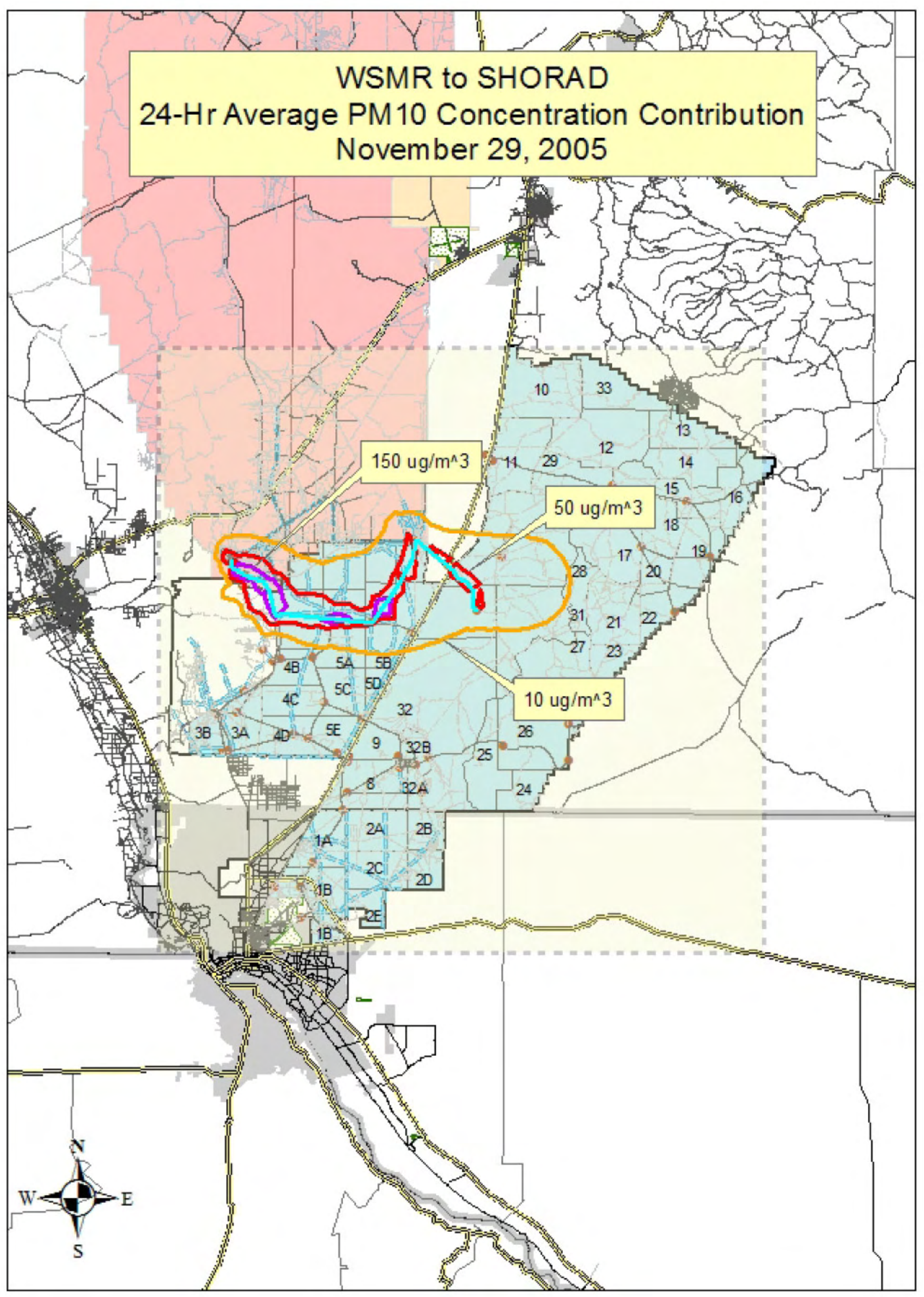




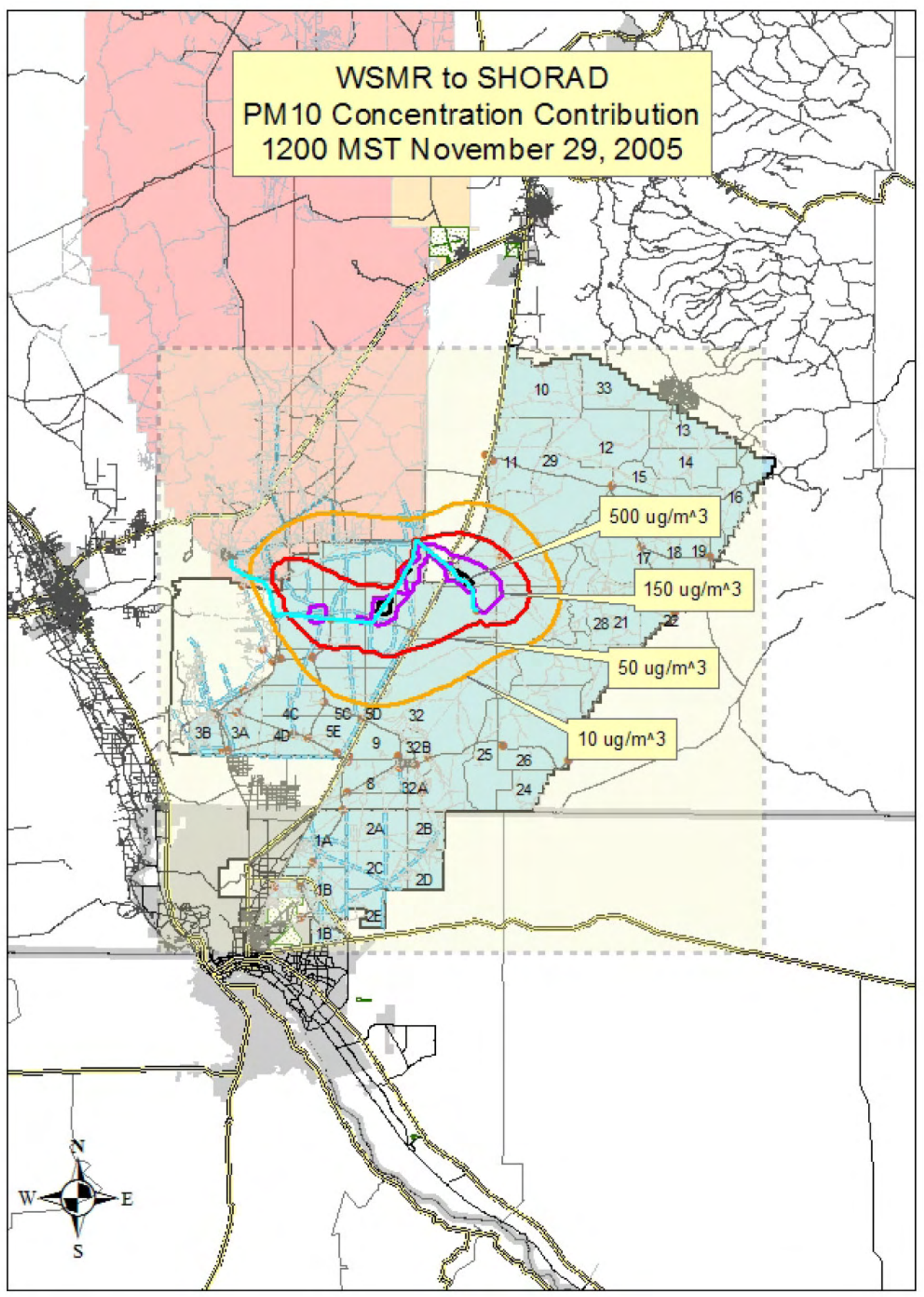





\section{Appendix G}

Simulated $\mathrm{PM}_{10}$ Concentrations for the Move-out from White Sands Missile Range to McGregor Range Camp via Oro Grande 



\section{Appendix G}

\section{Simulated $\mathrm{PM}_{10}$ Concentrations for the Move-out from White Sands Missile Range to McGregor Range Camp via Oro Grande}

The following pages present contour maps of simulated PM10 concentrations contributed by WSMR to McGregor Range Camp via Oro Grande move-out operations to air quality in and around Fort Bliss and WSMR for the 21 days (March 12-16, April 25-30, July 20-24, and November 25-29, 2005) studied in this investigation. For each day, the contour map of the 24-hour-average PM10 concentration contribution is shown first, followed by a contour map of PM10 concentration contributions for a specific hour. The hour listed in the figure header represents the start of the hour, e.g., 1000 MST means the hour from 1000 MST to 1100 MST. Move-out scenario assumptions are summarized in Section 3 of this report. 


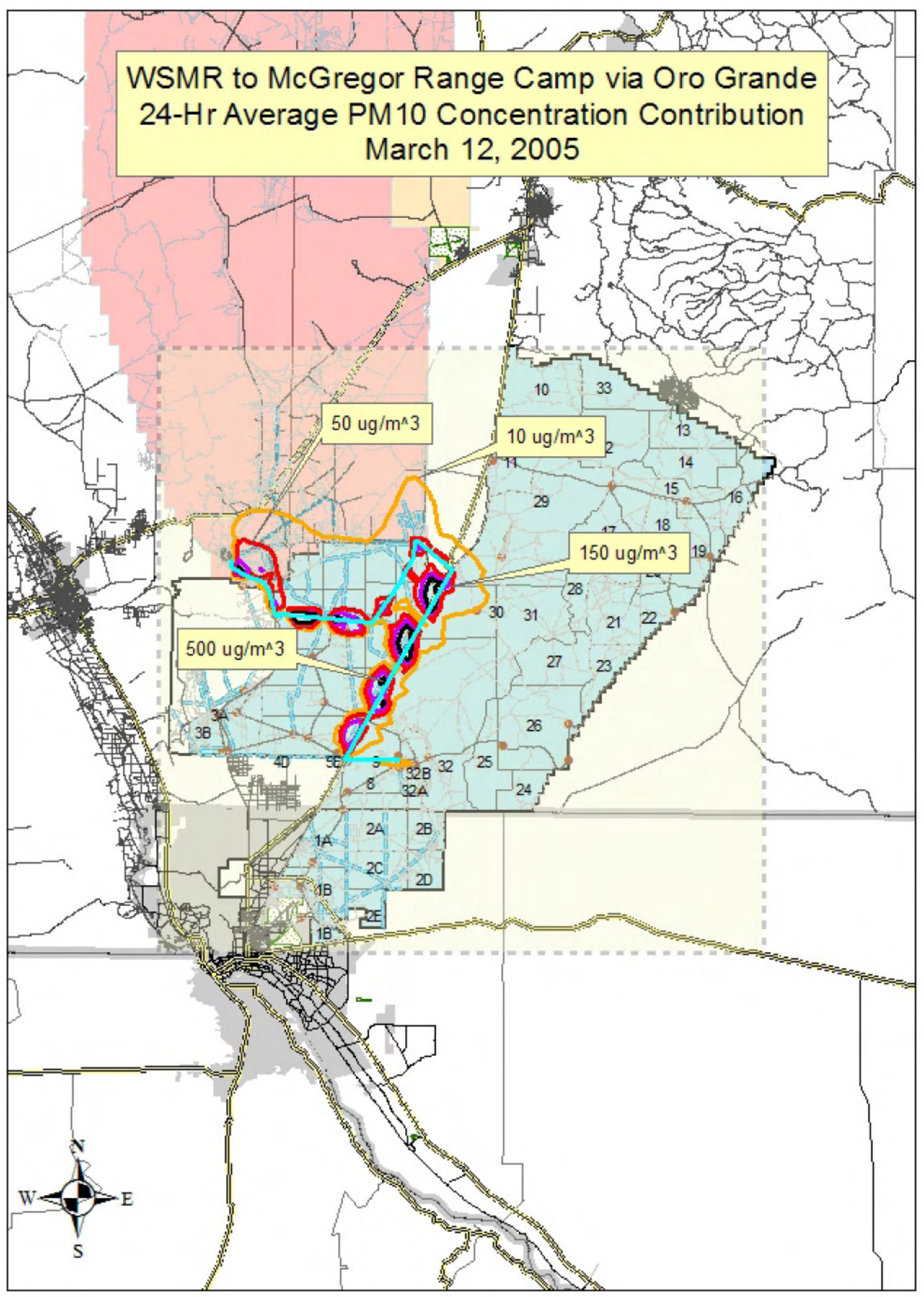




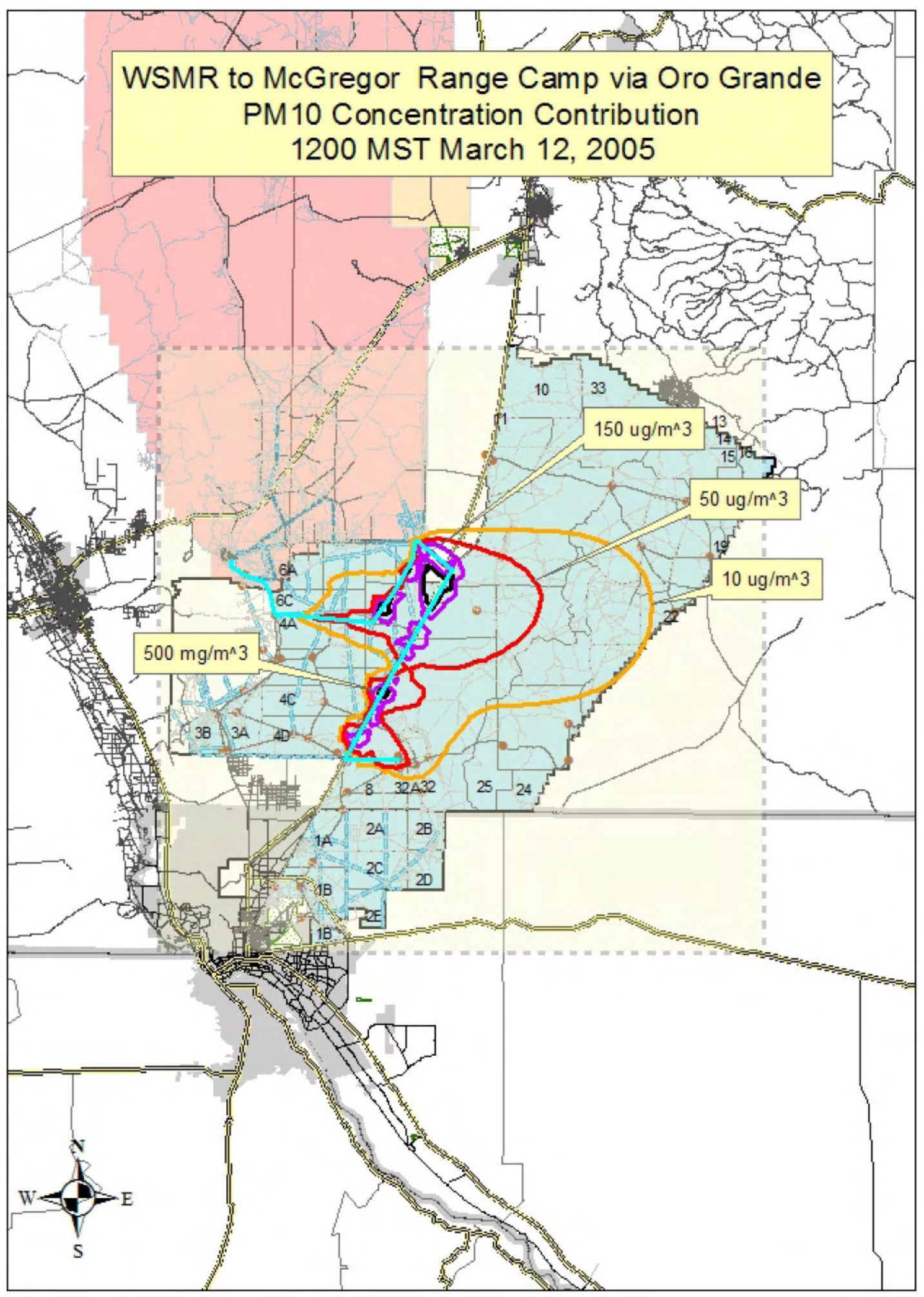




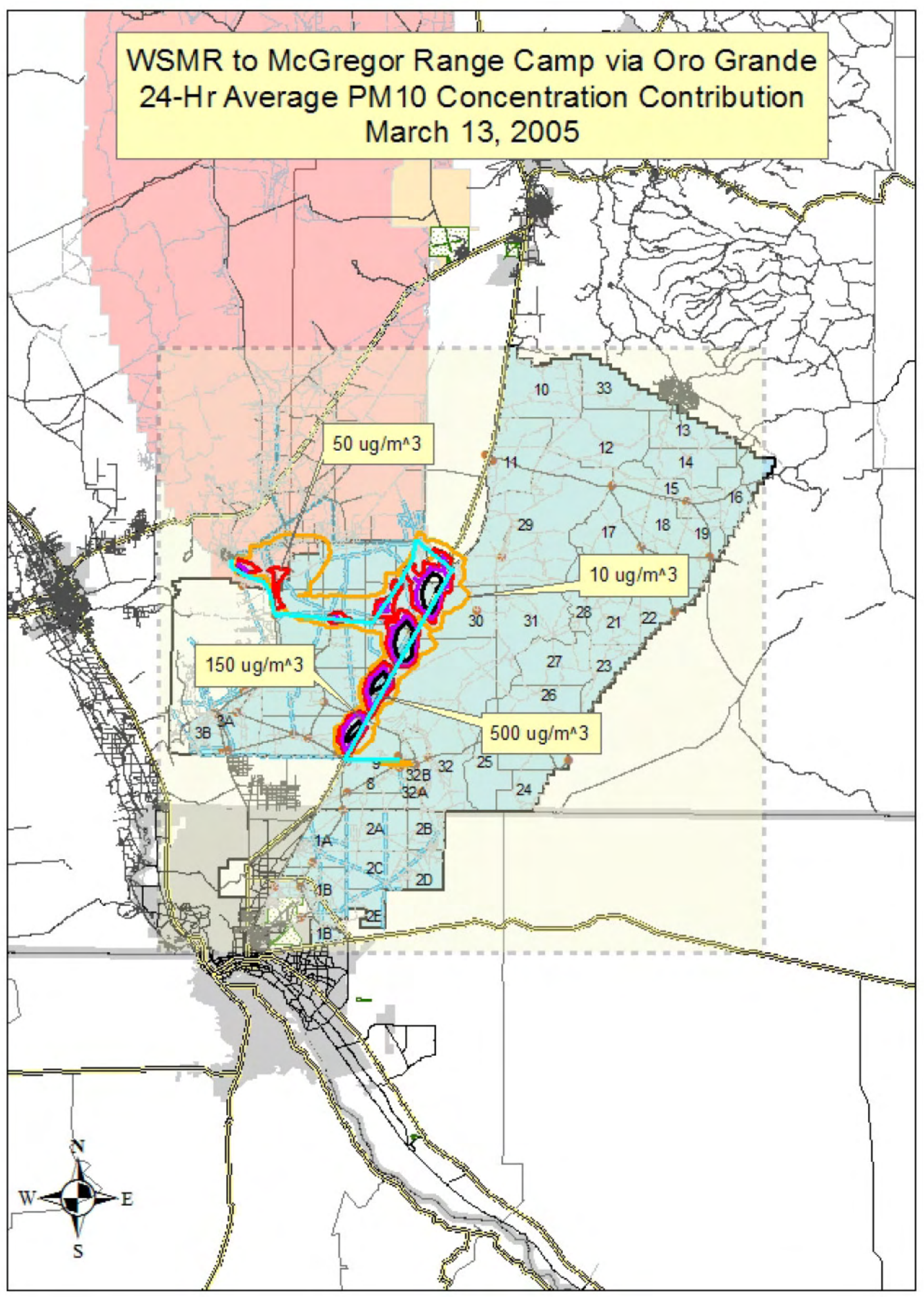




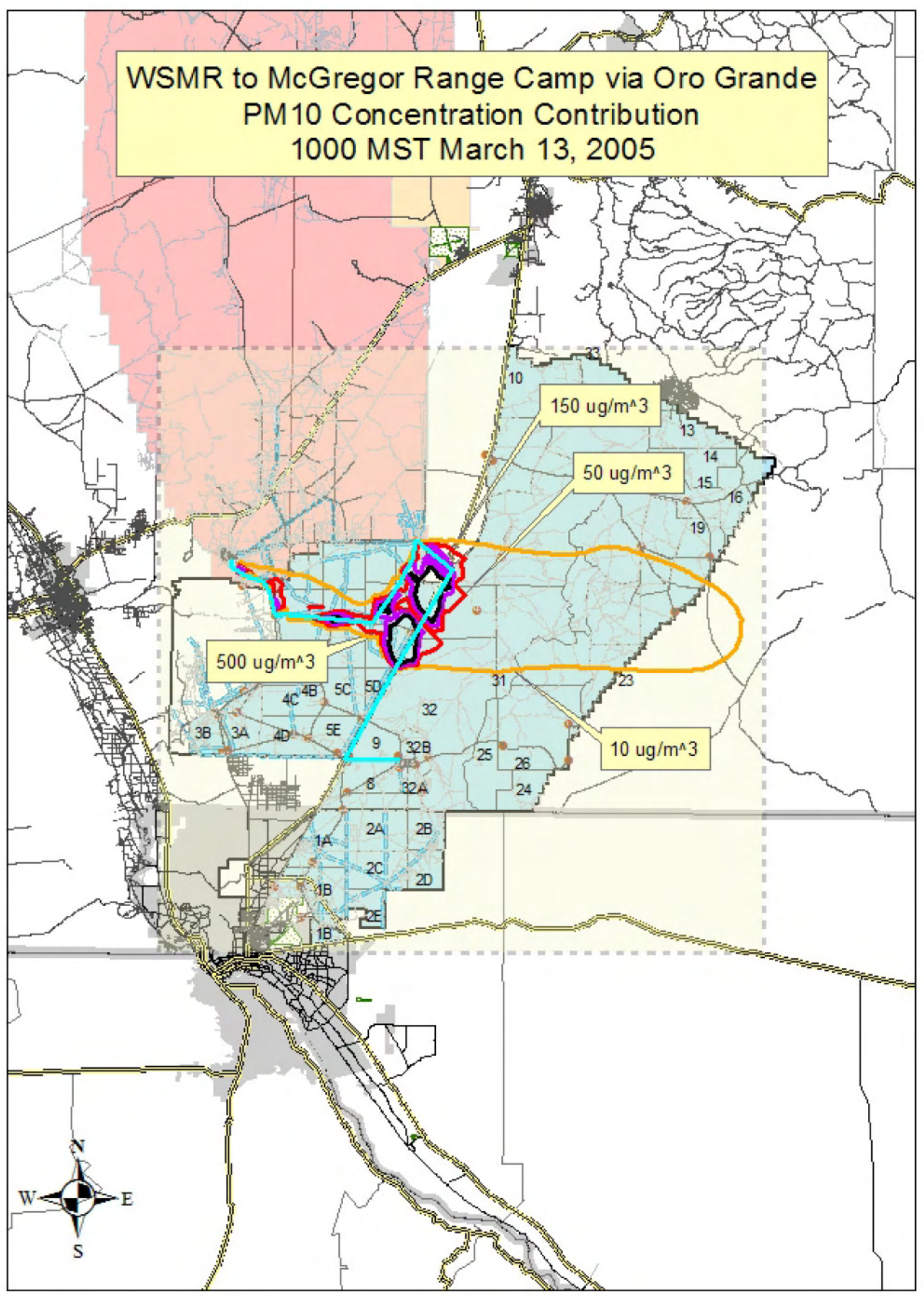




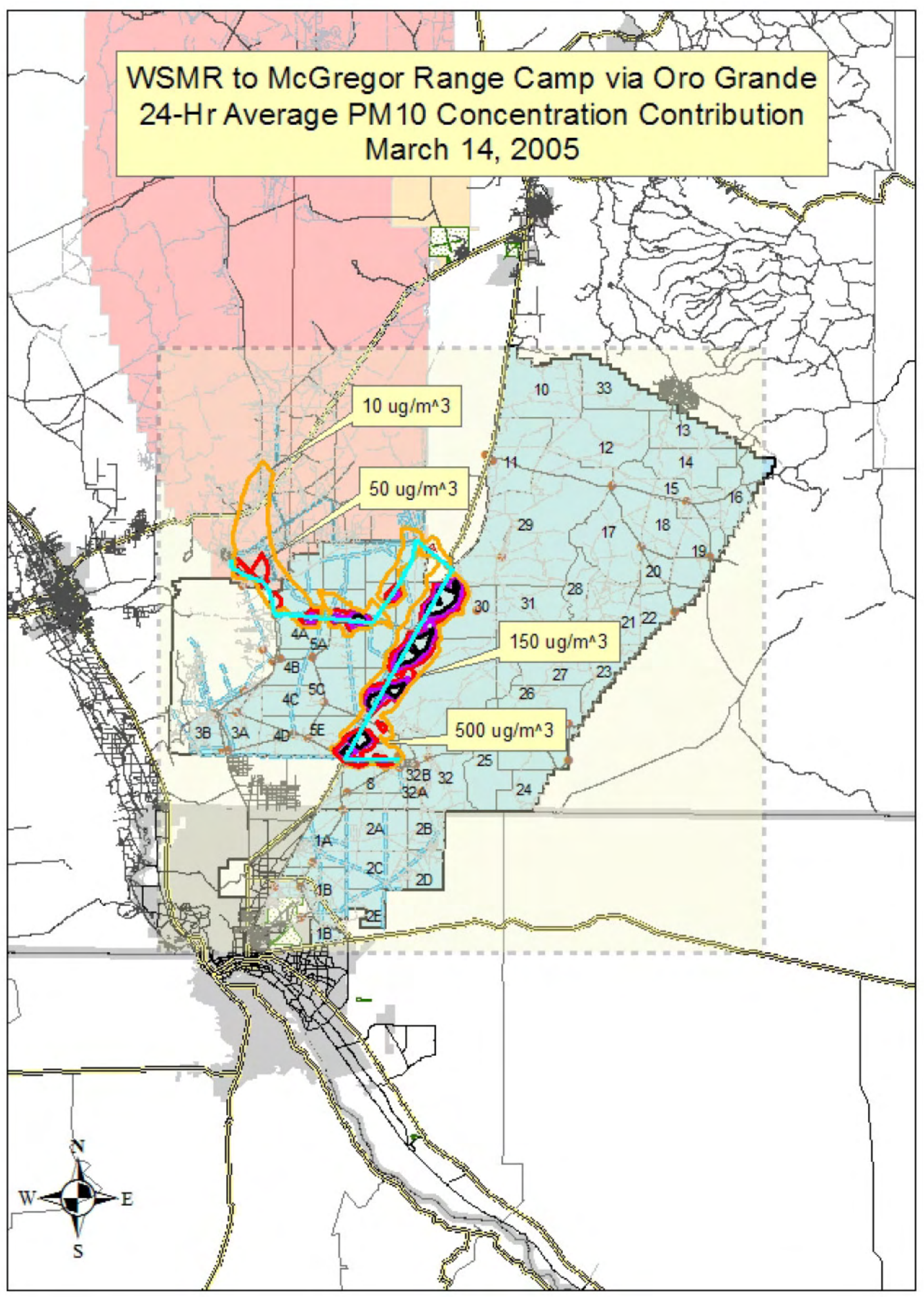




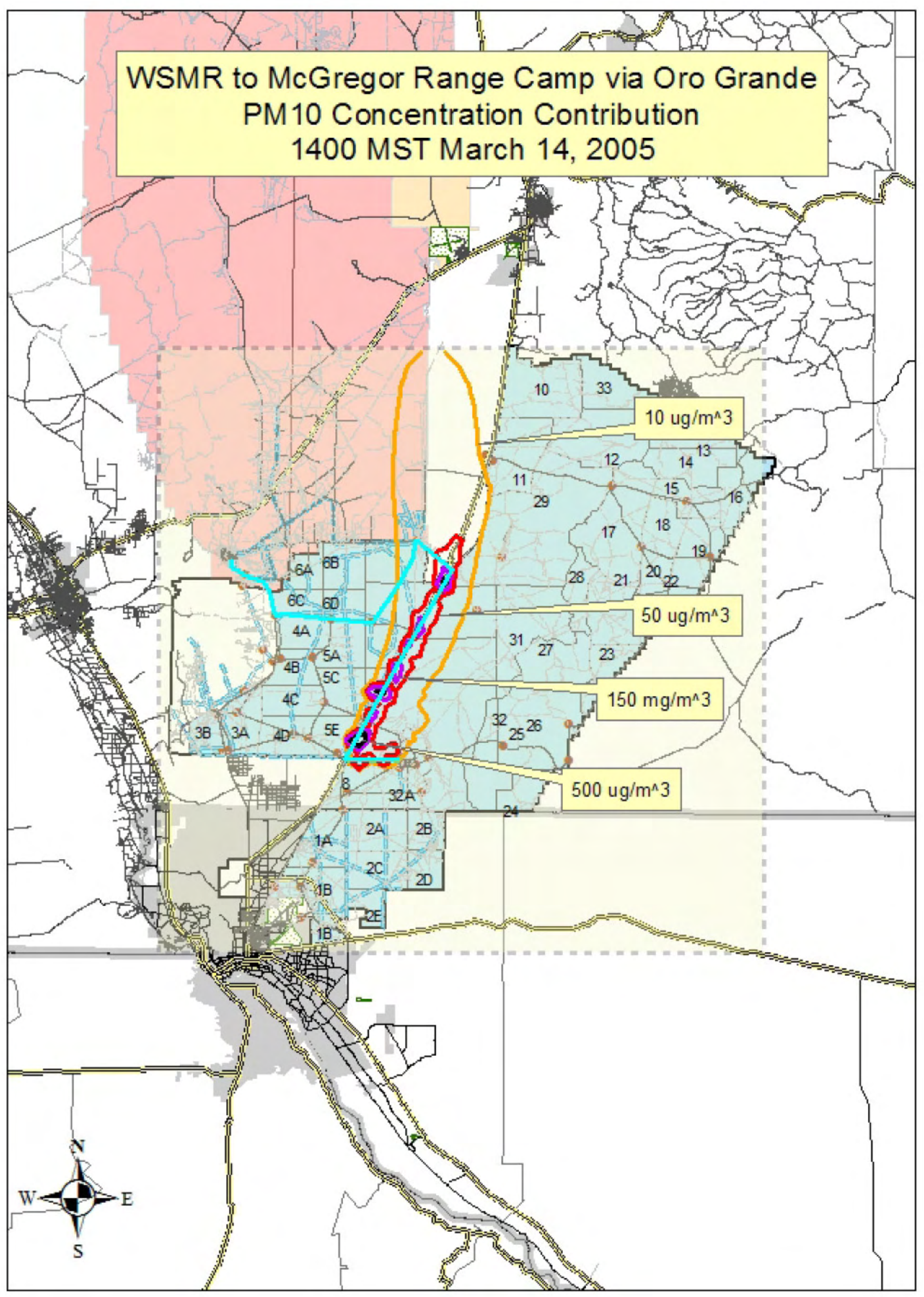




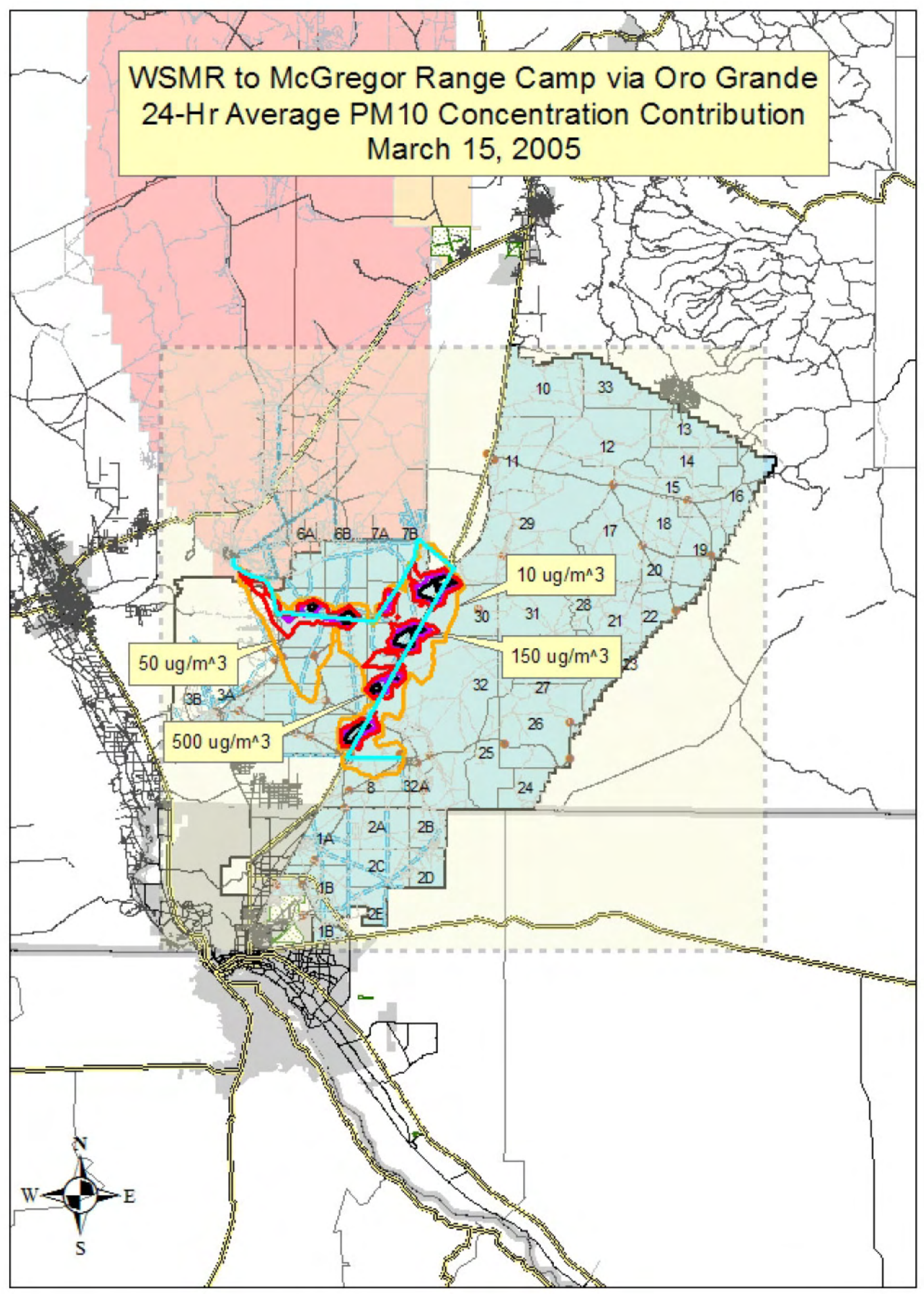




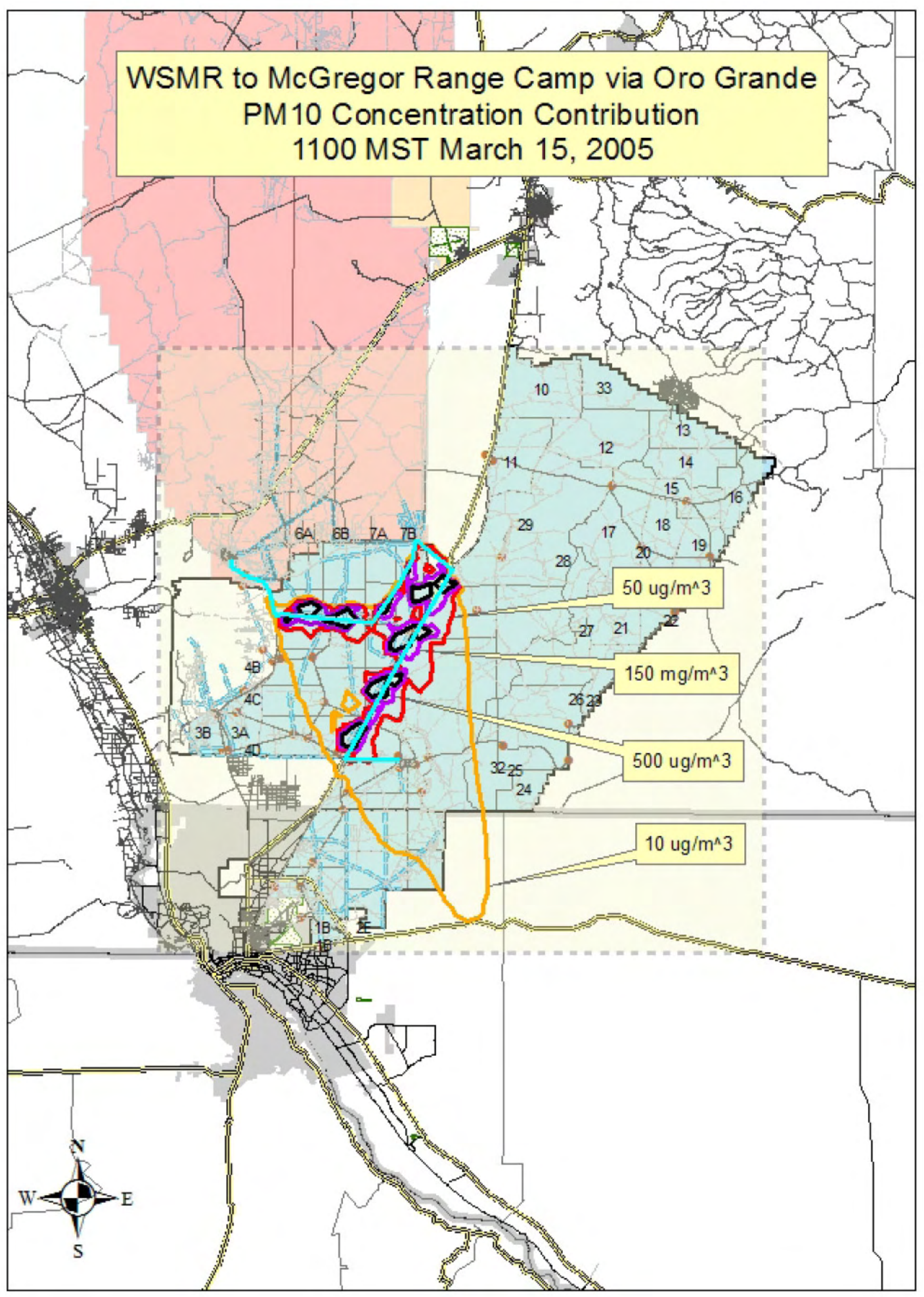




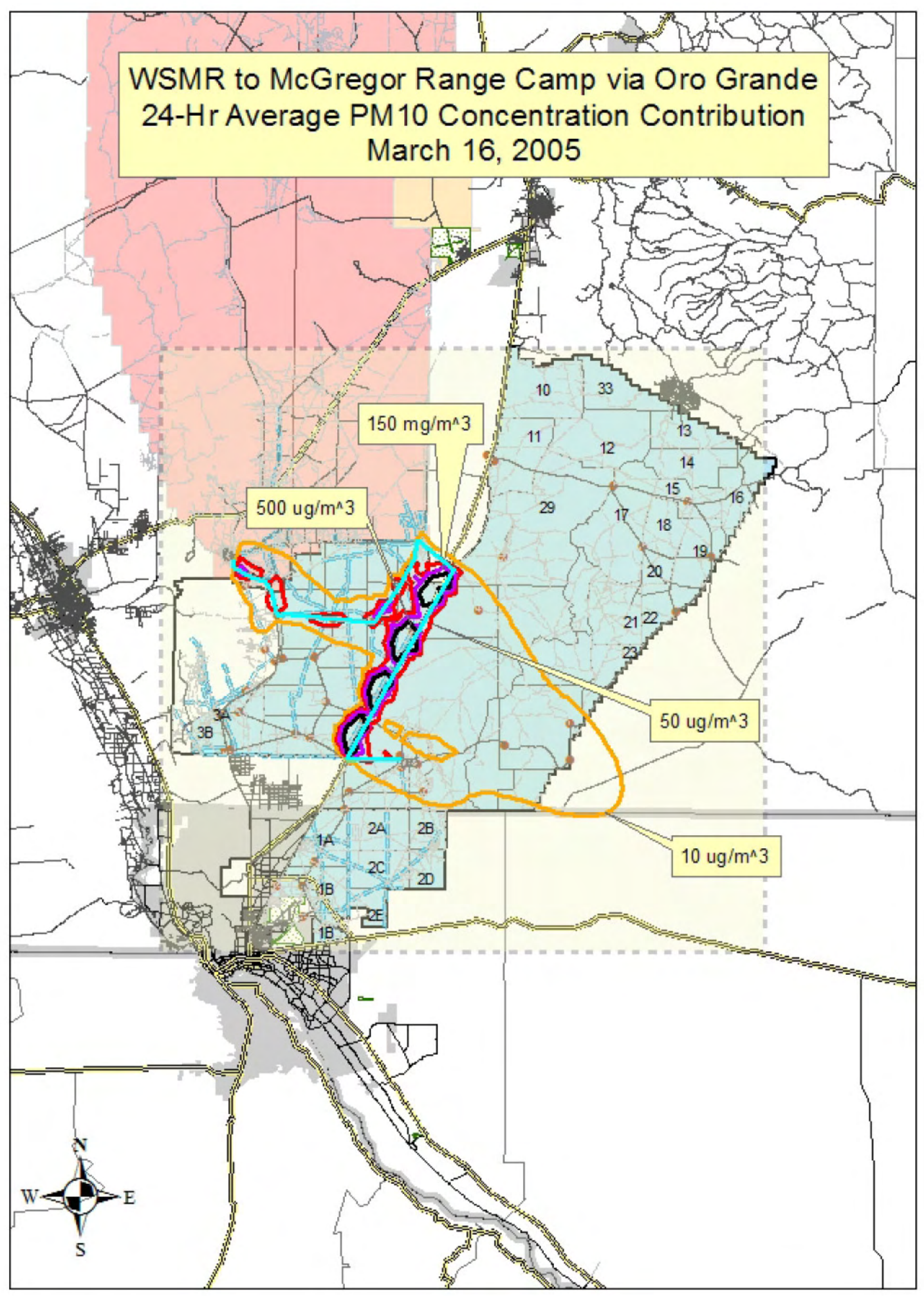

G.10 


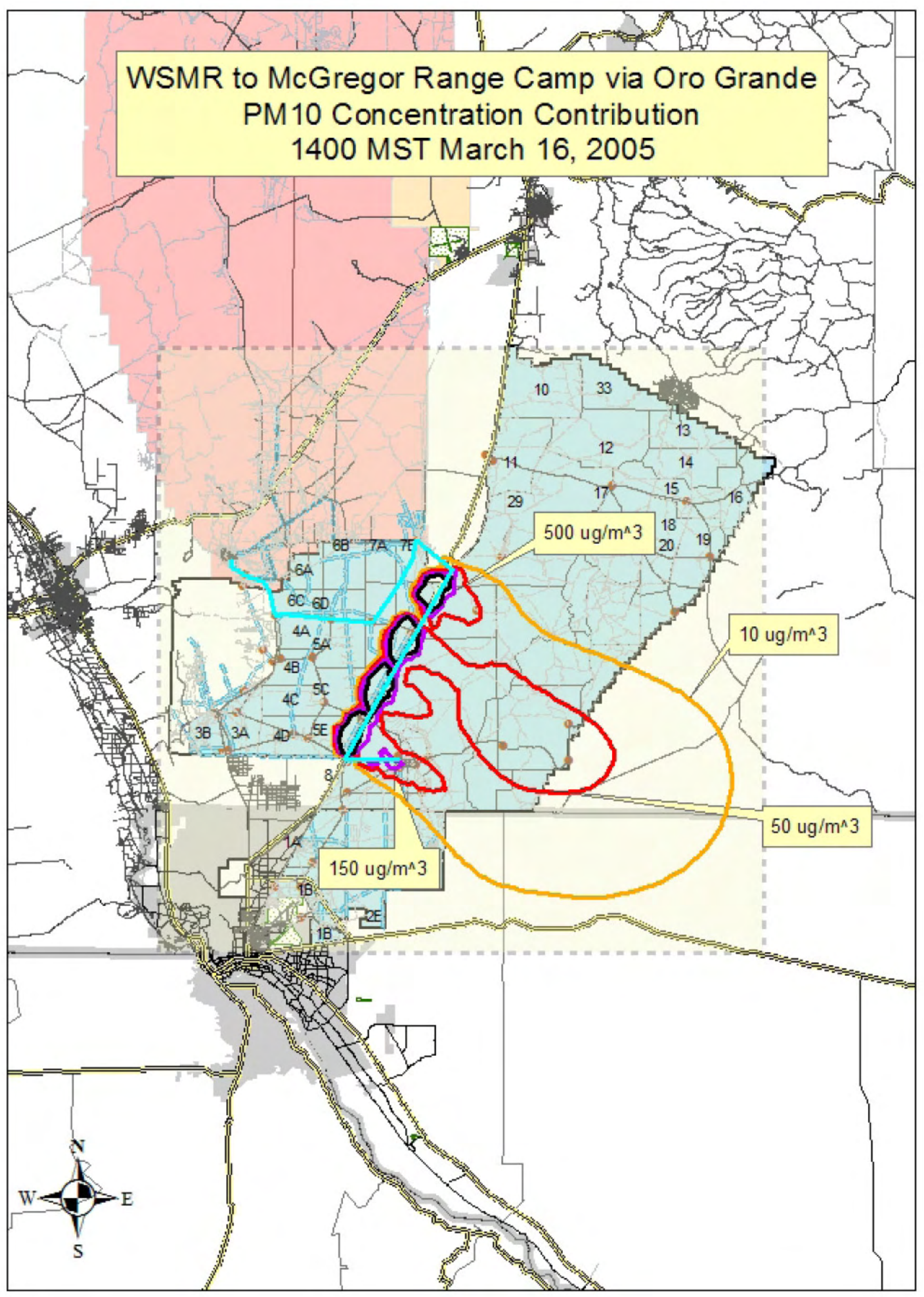




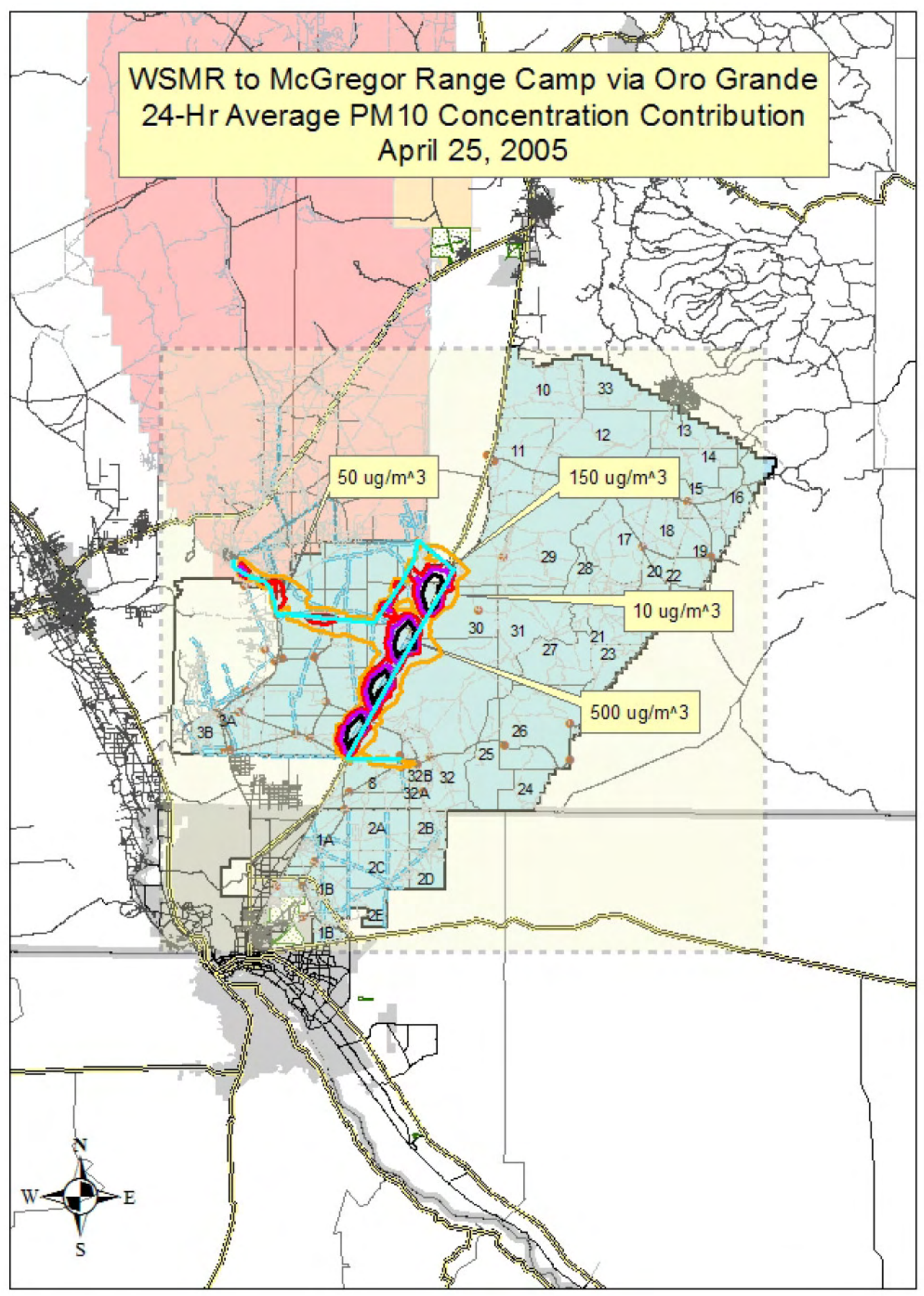

G.12 


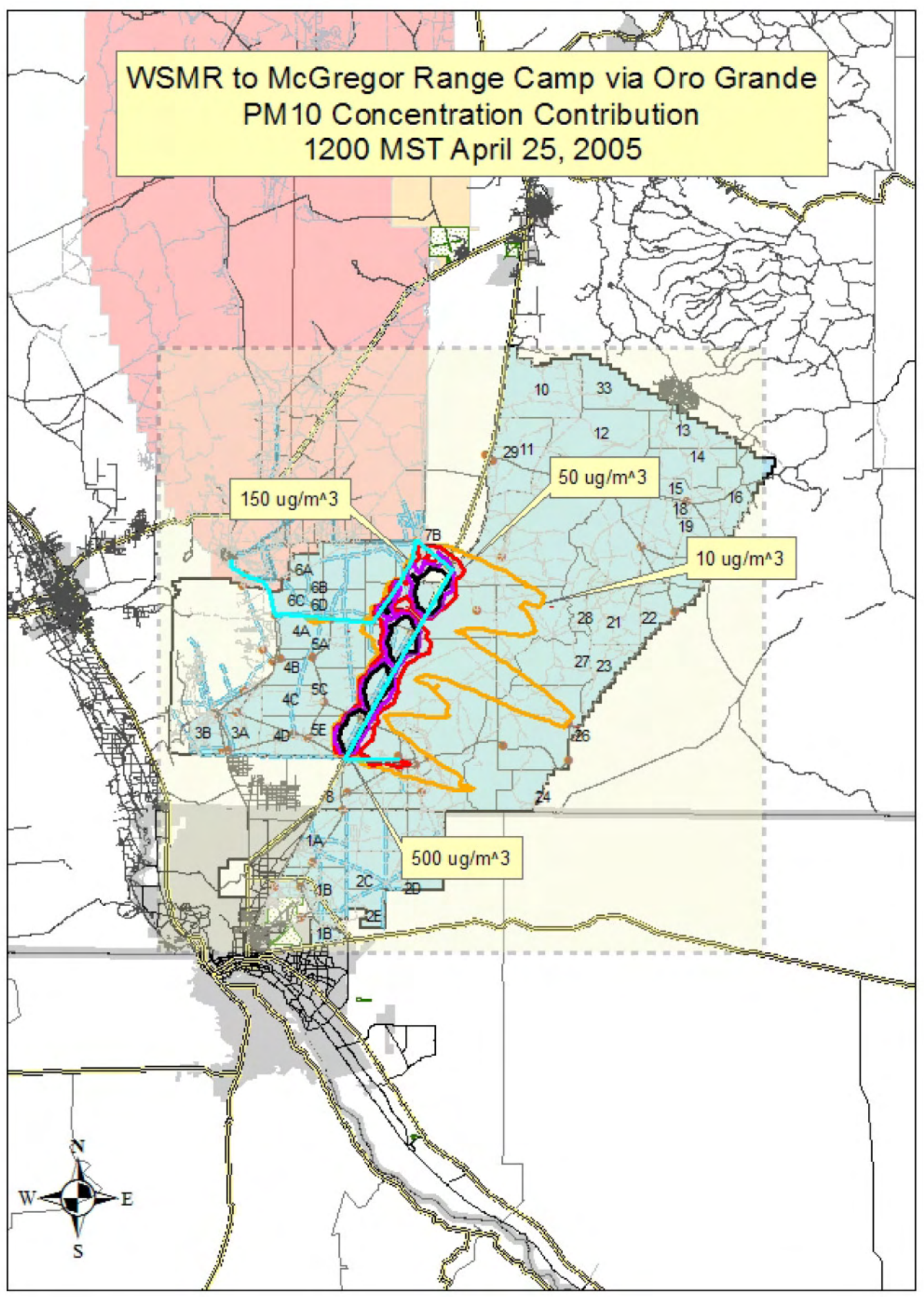

G.13 


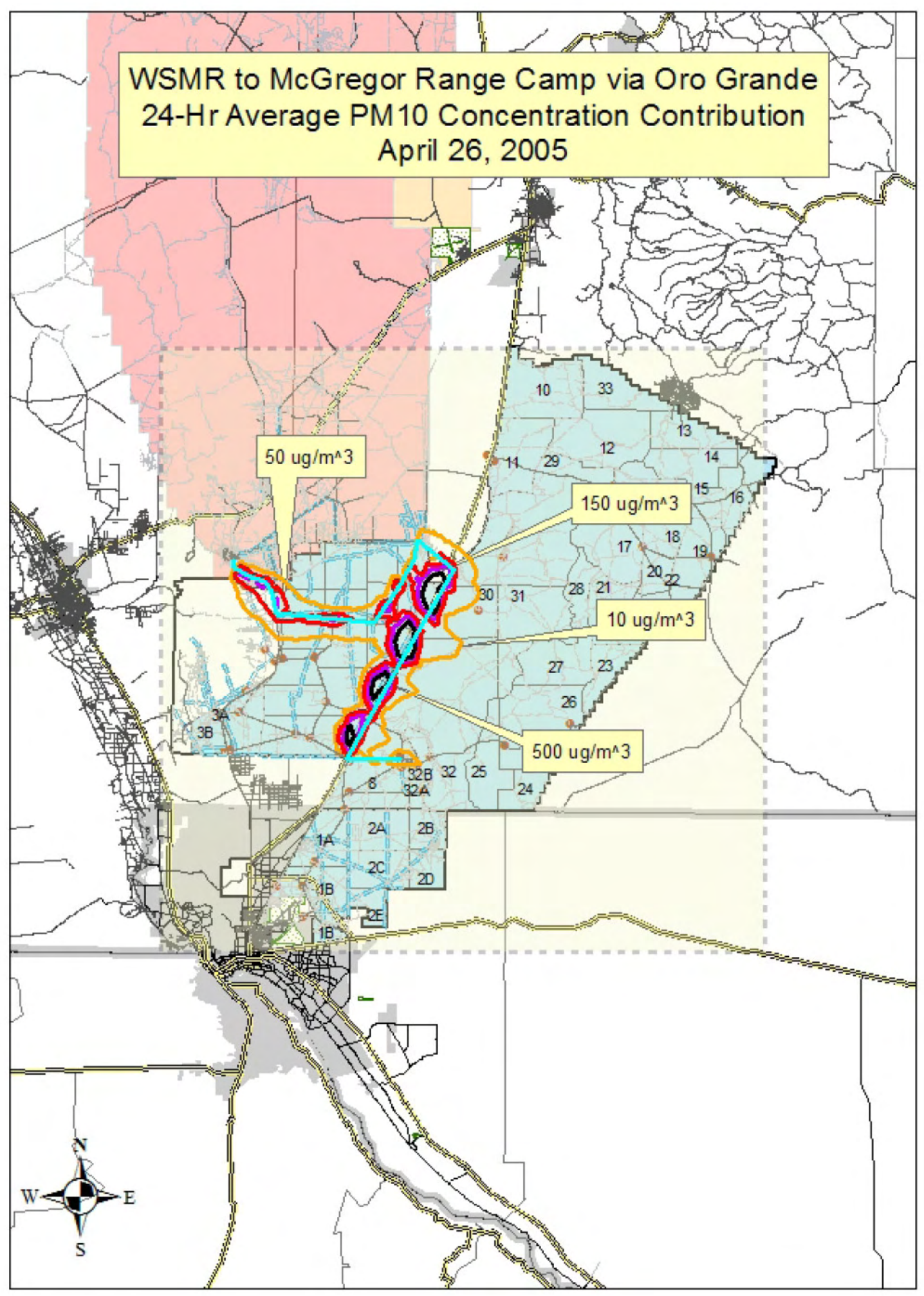




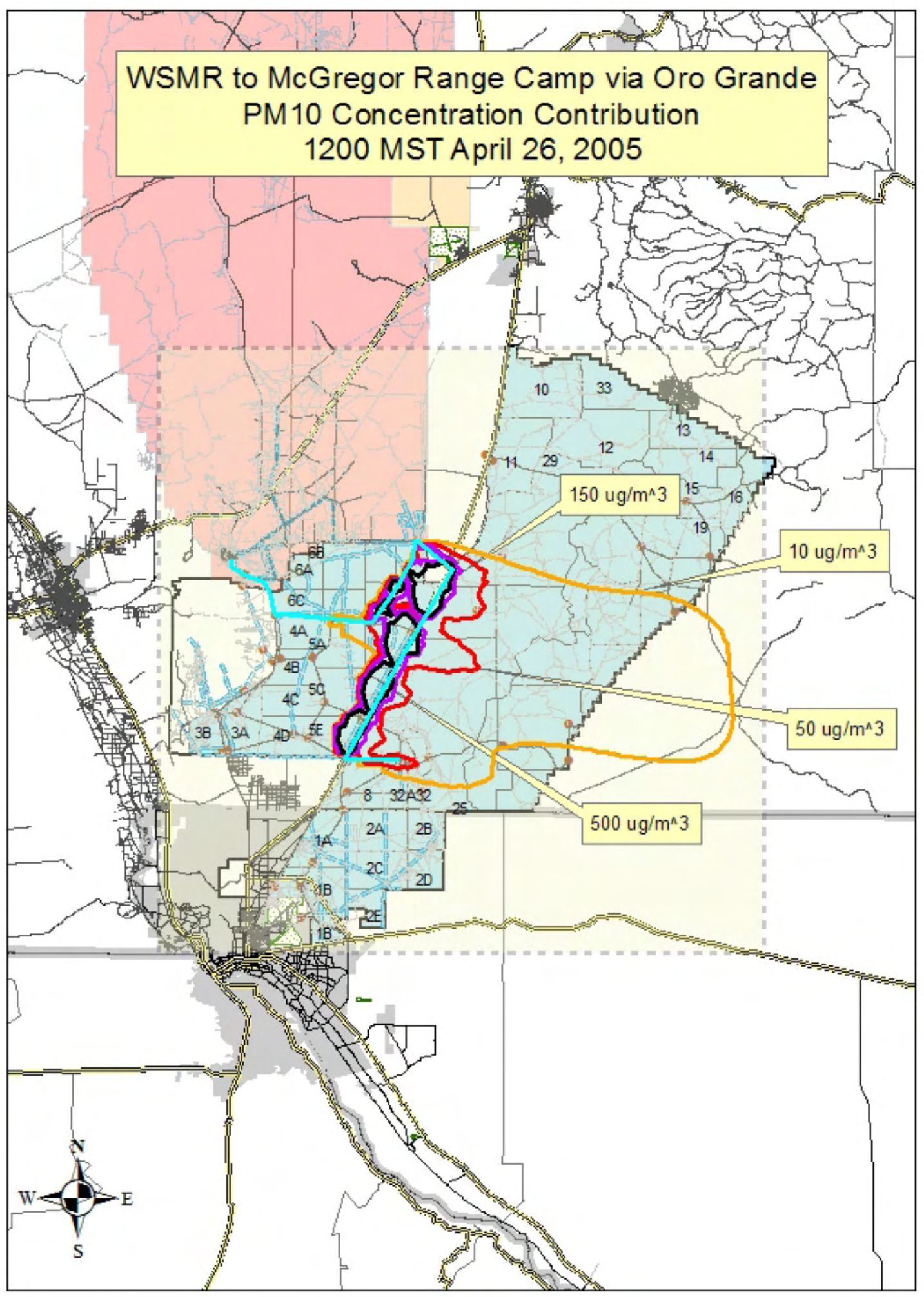

G.15 


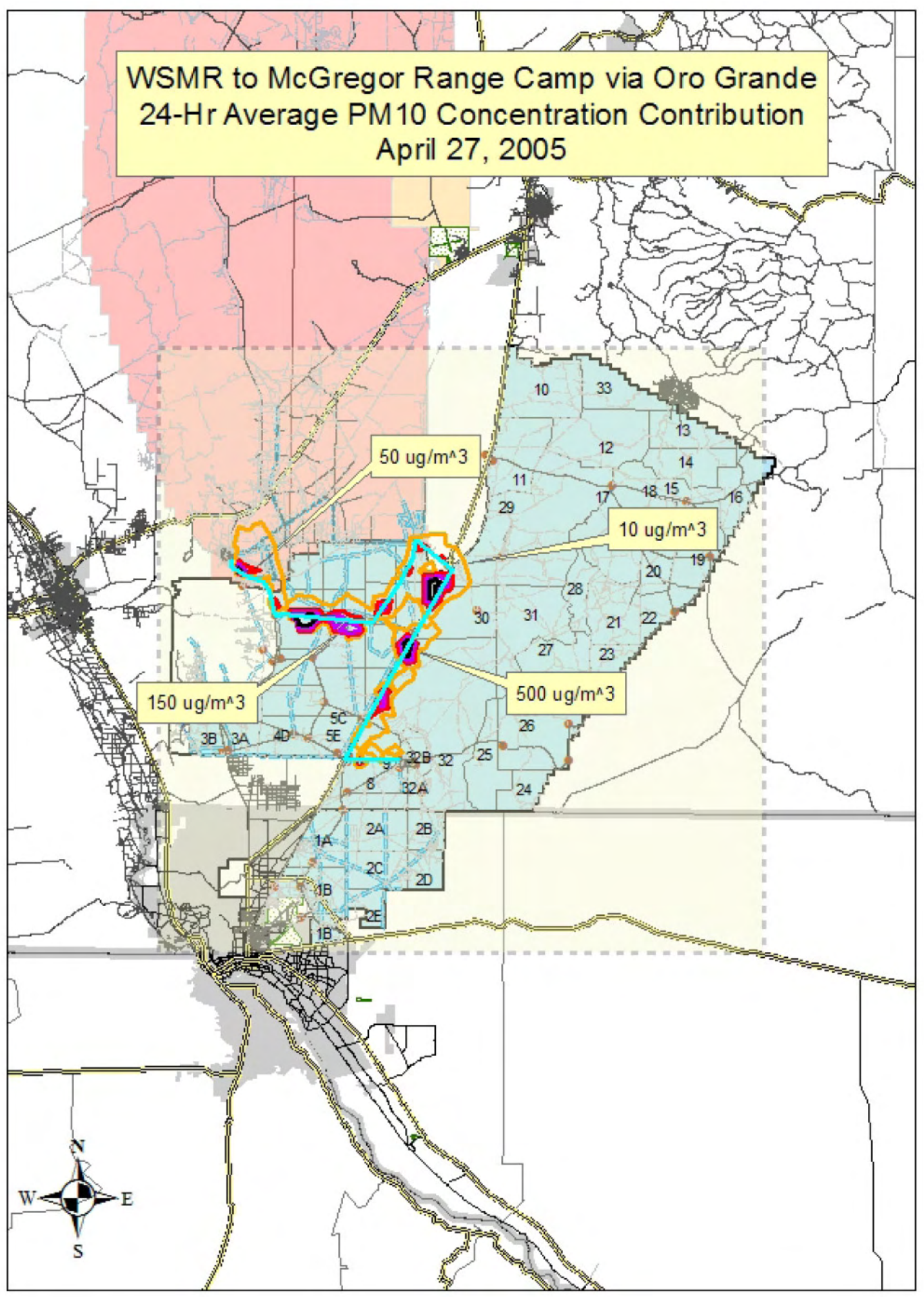

G.16 


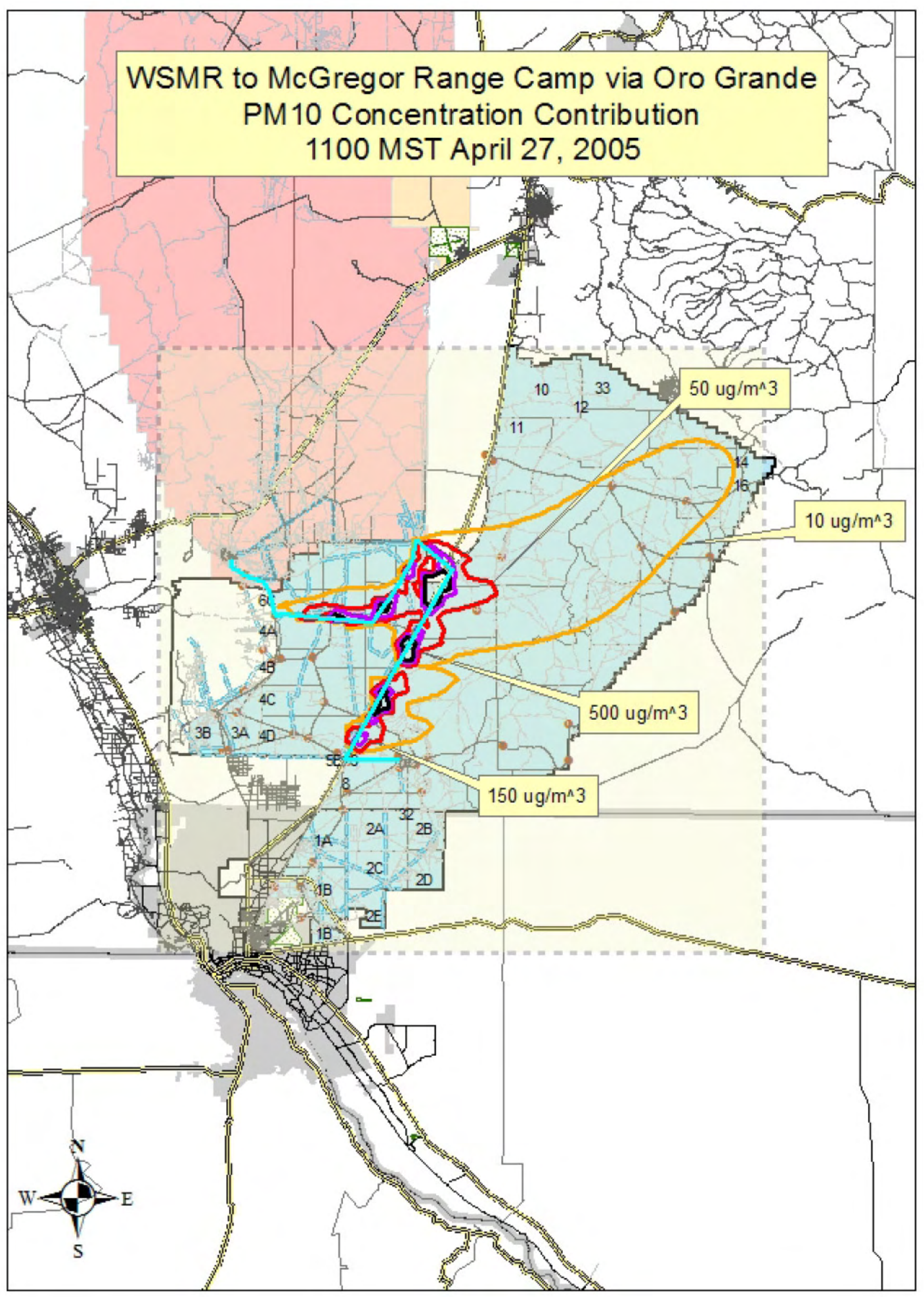




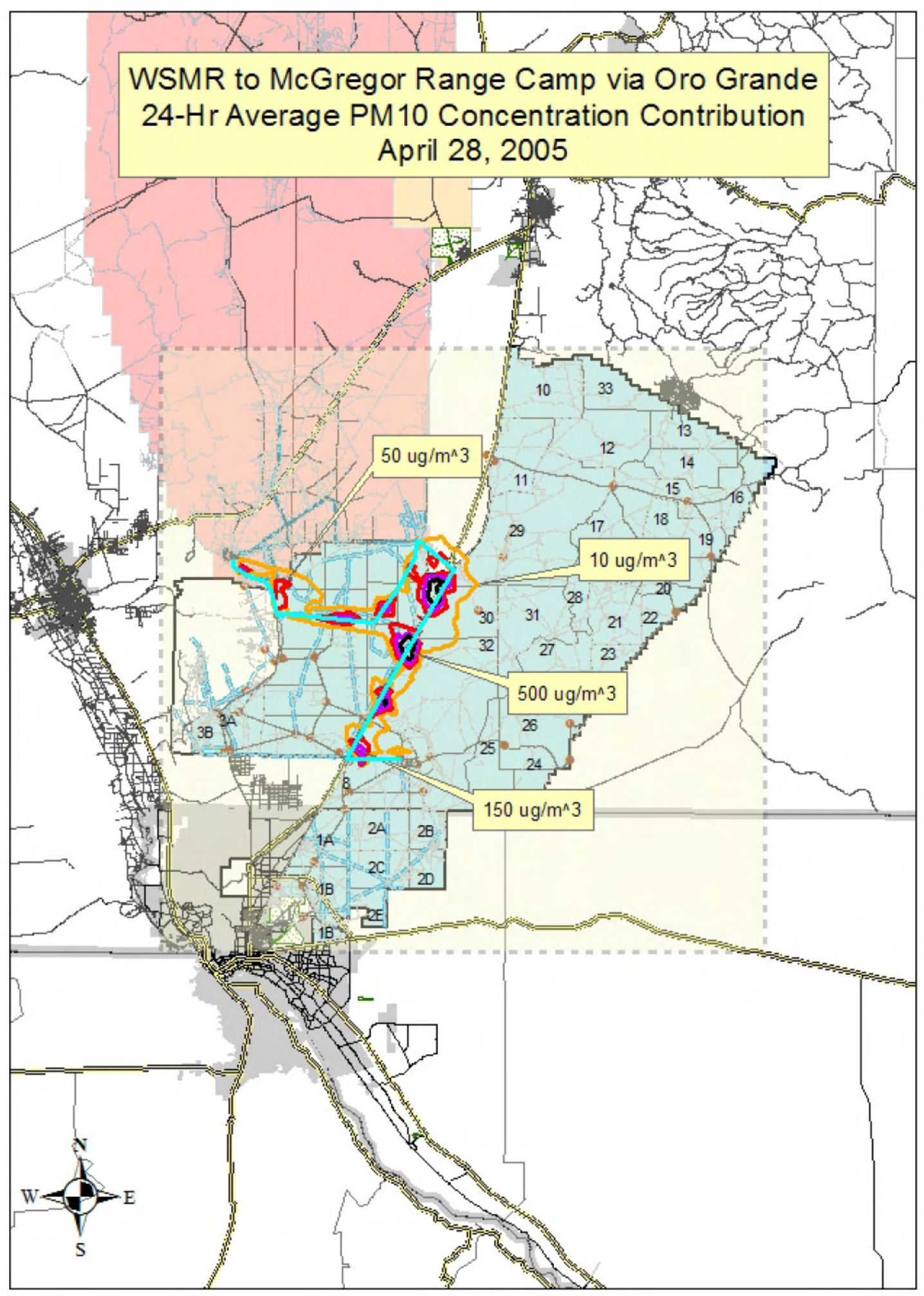

G.18 


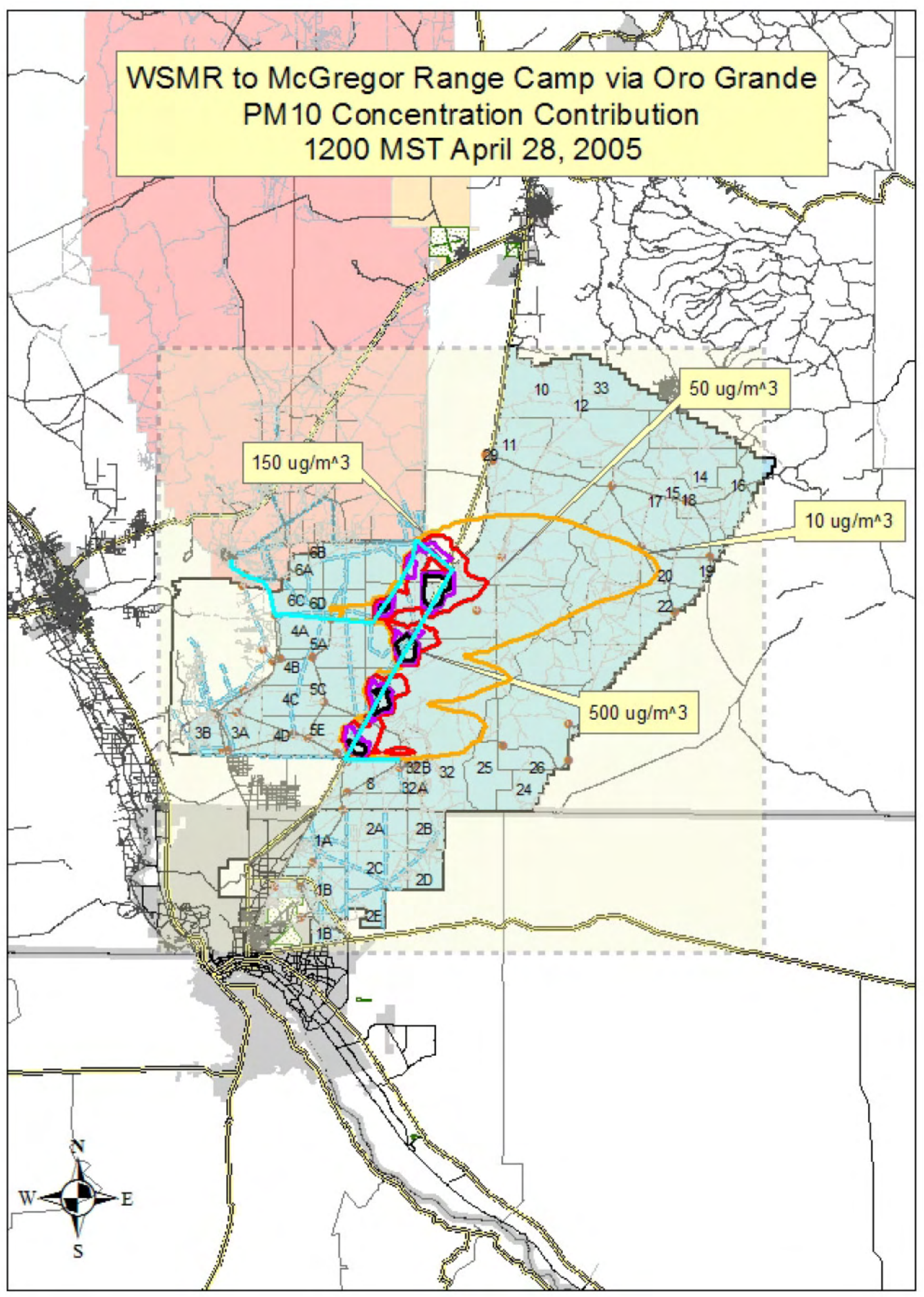

G.19 


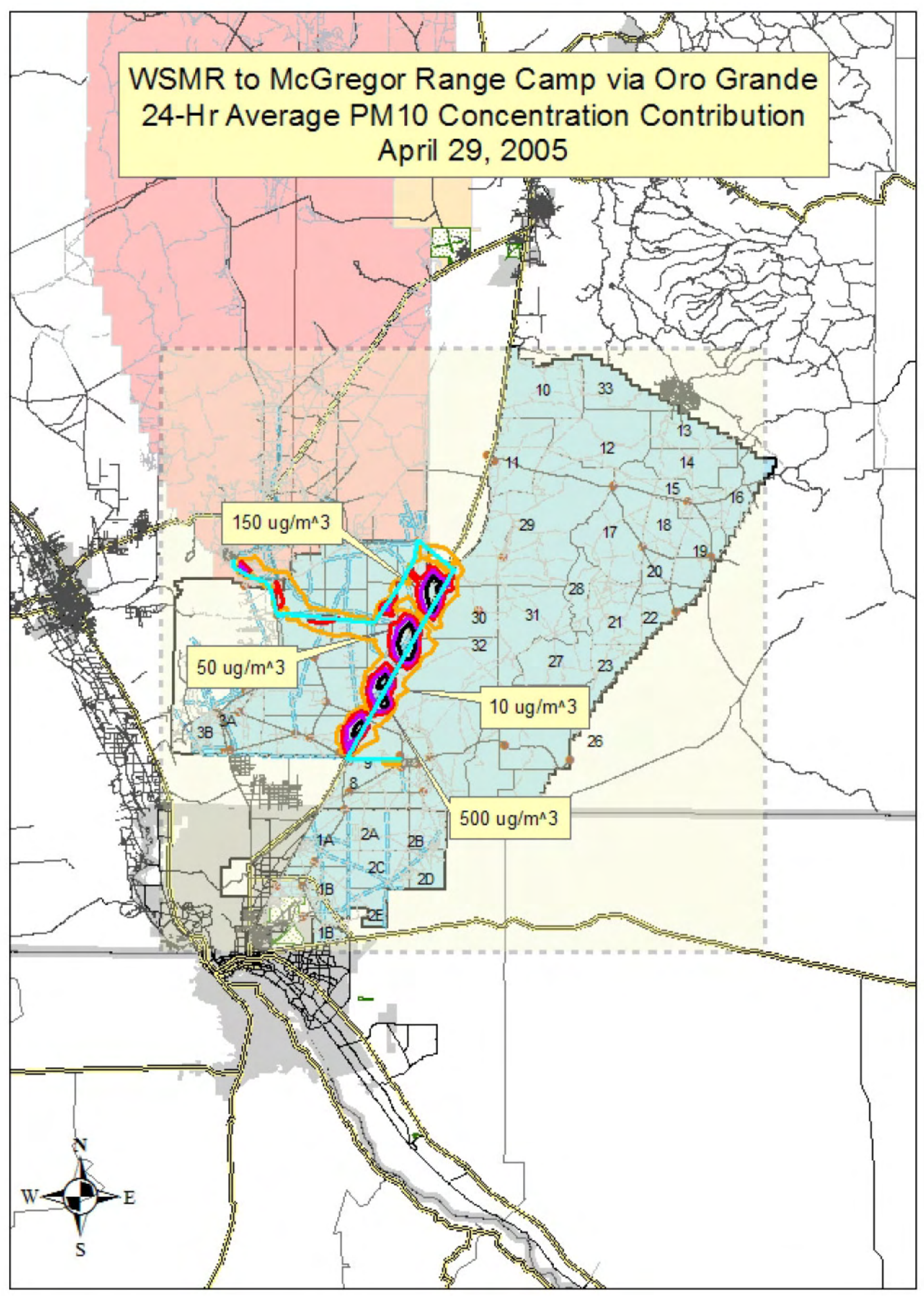




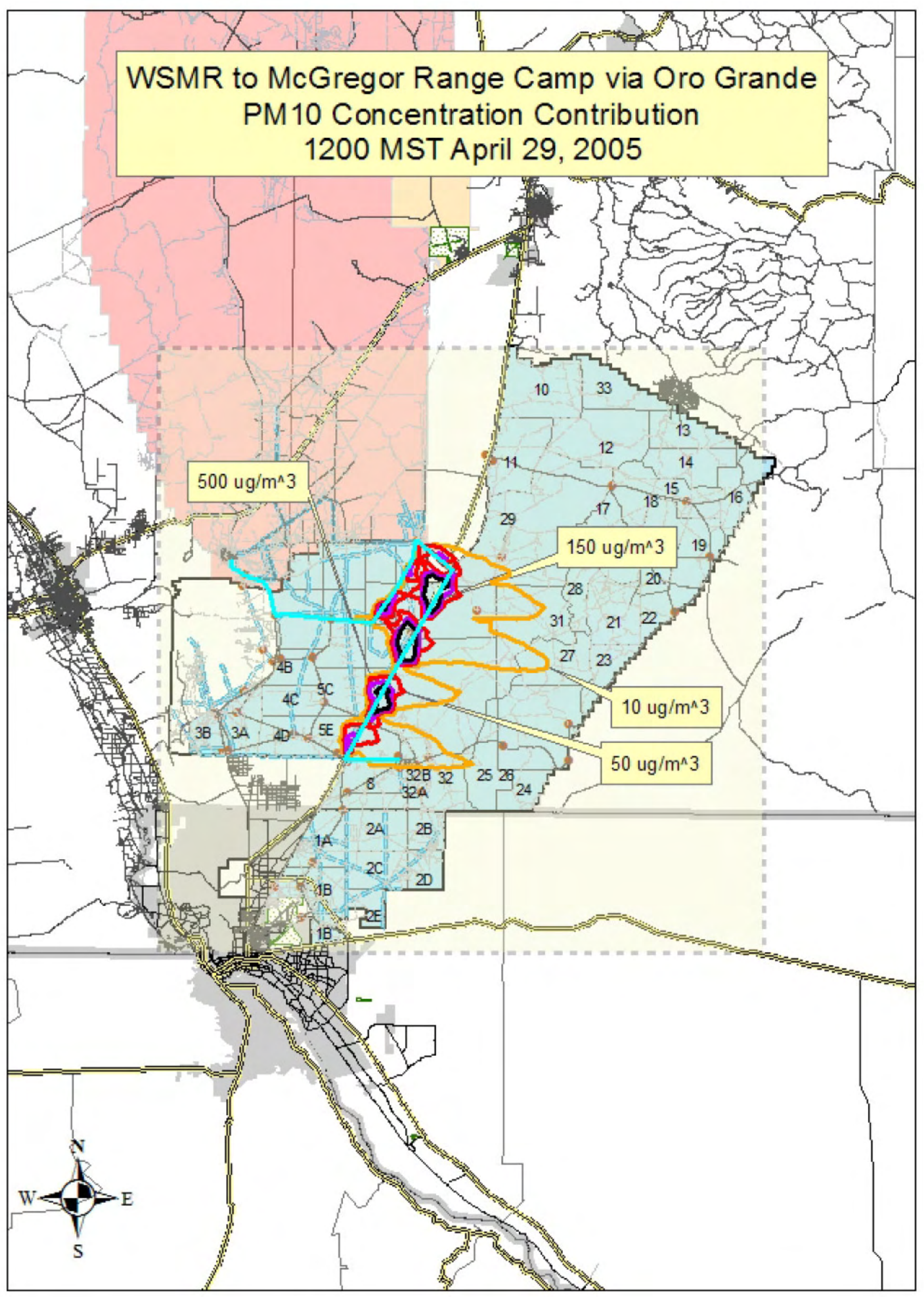




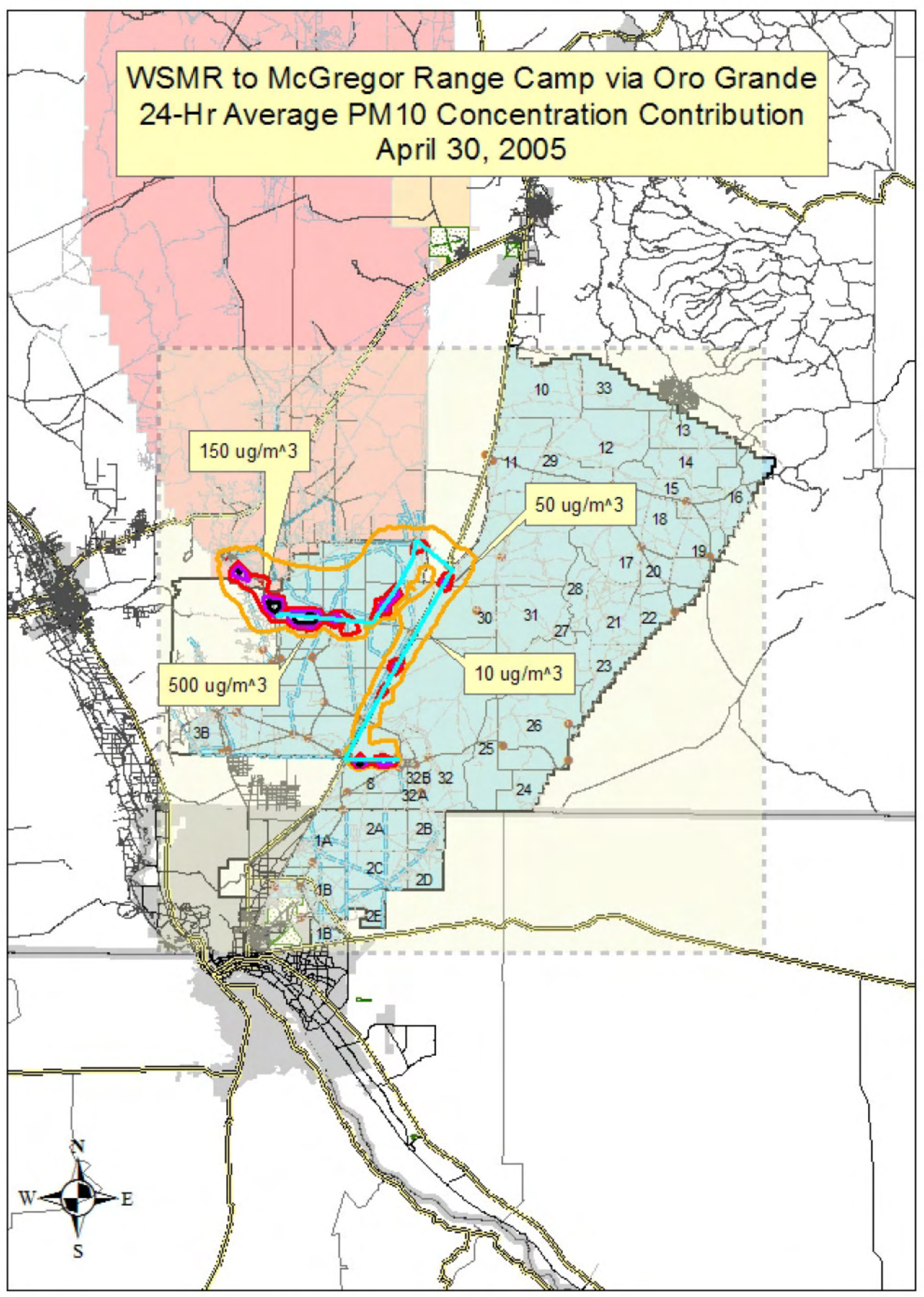




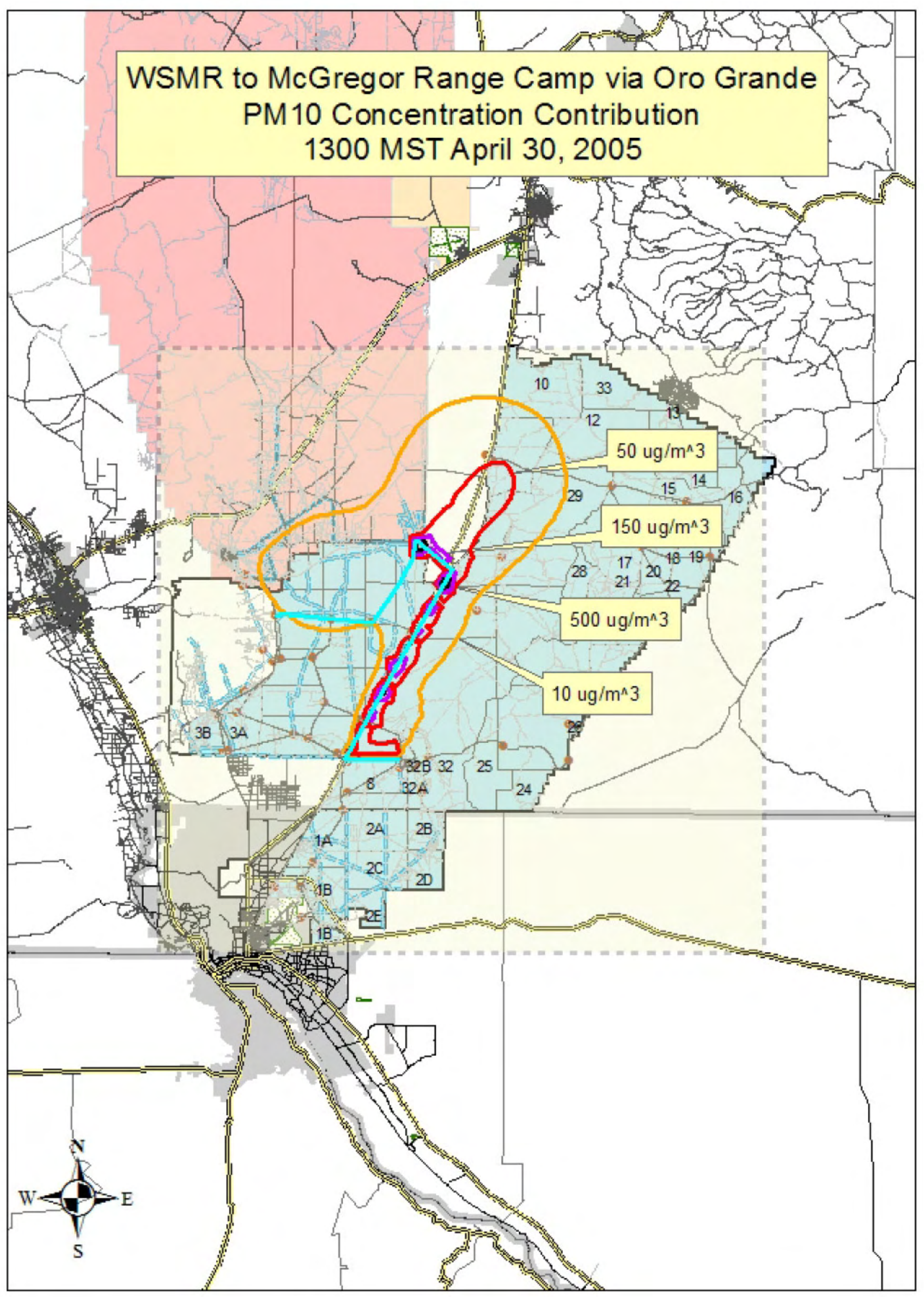




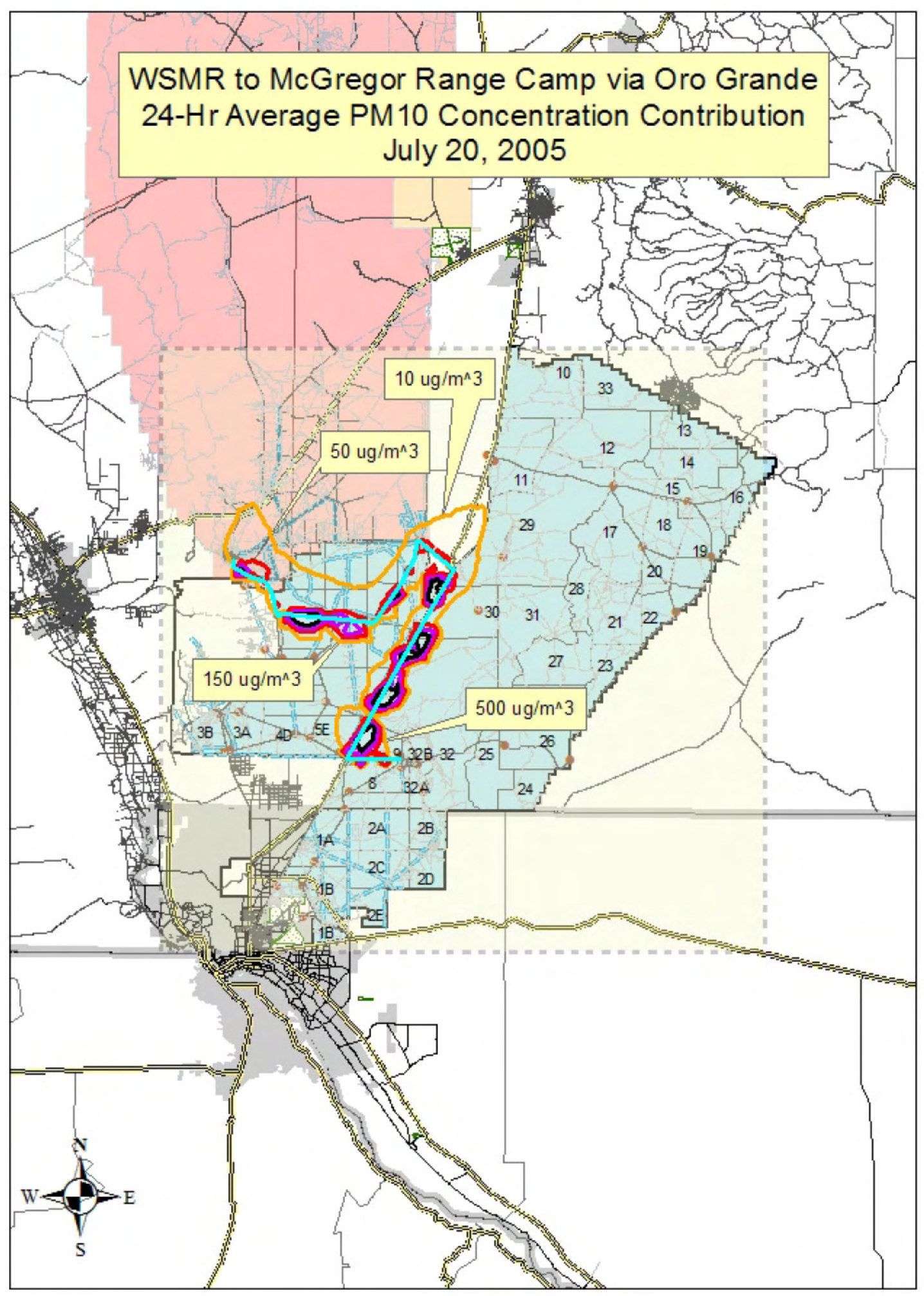




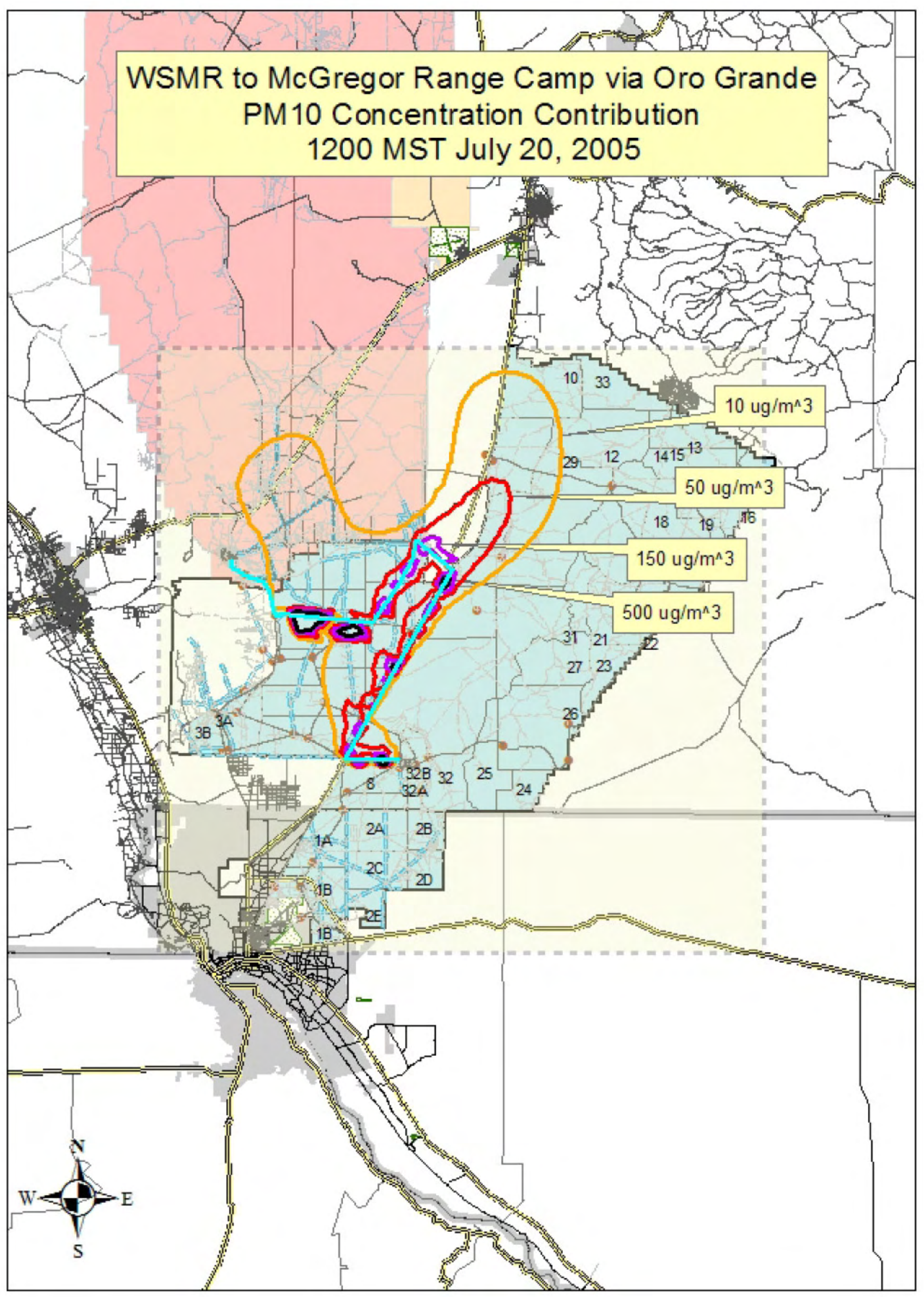




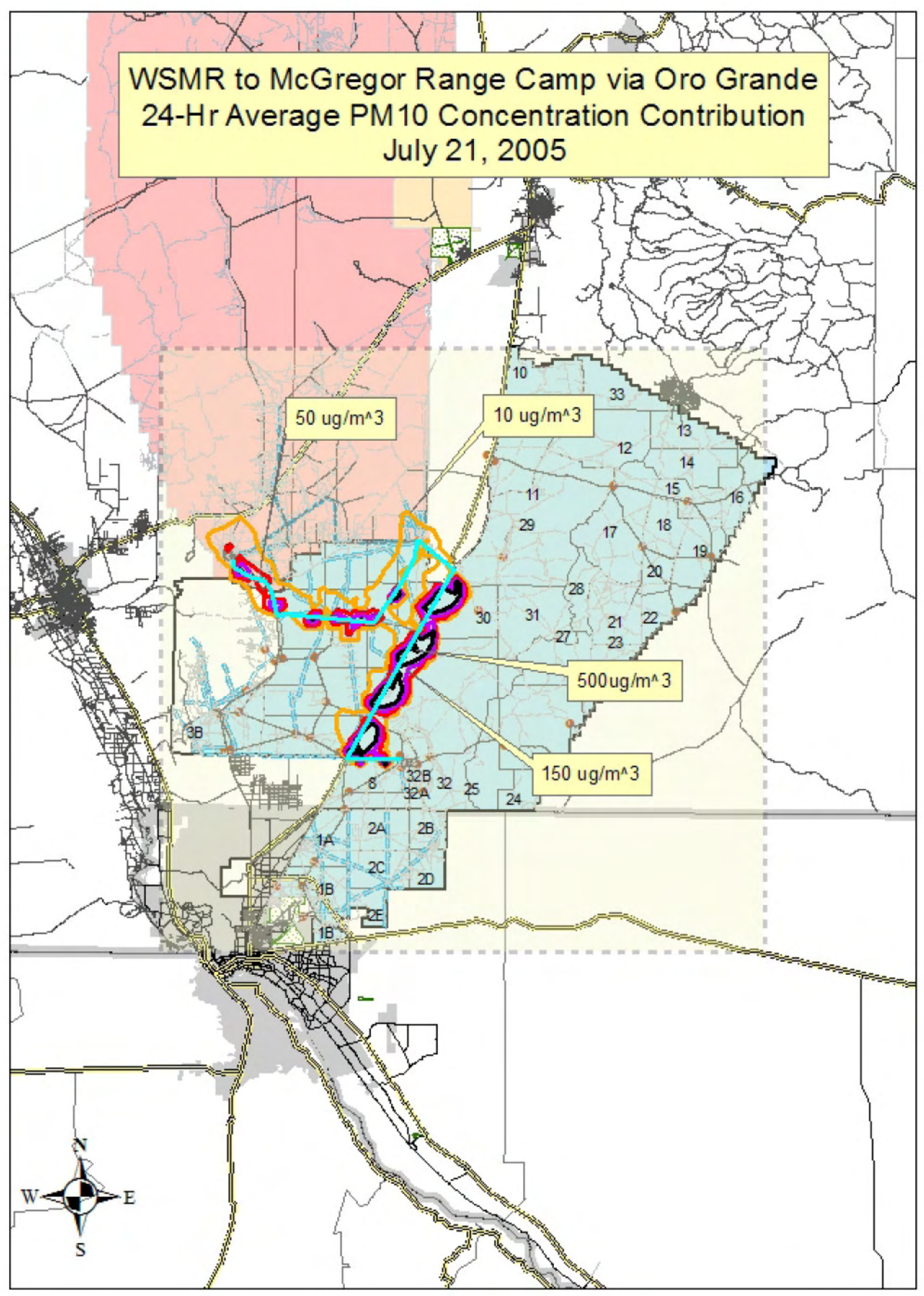




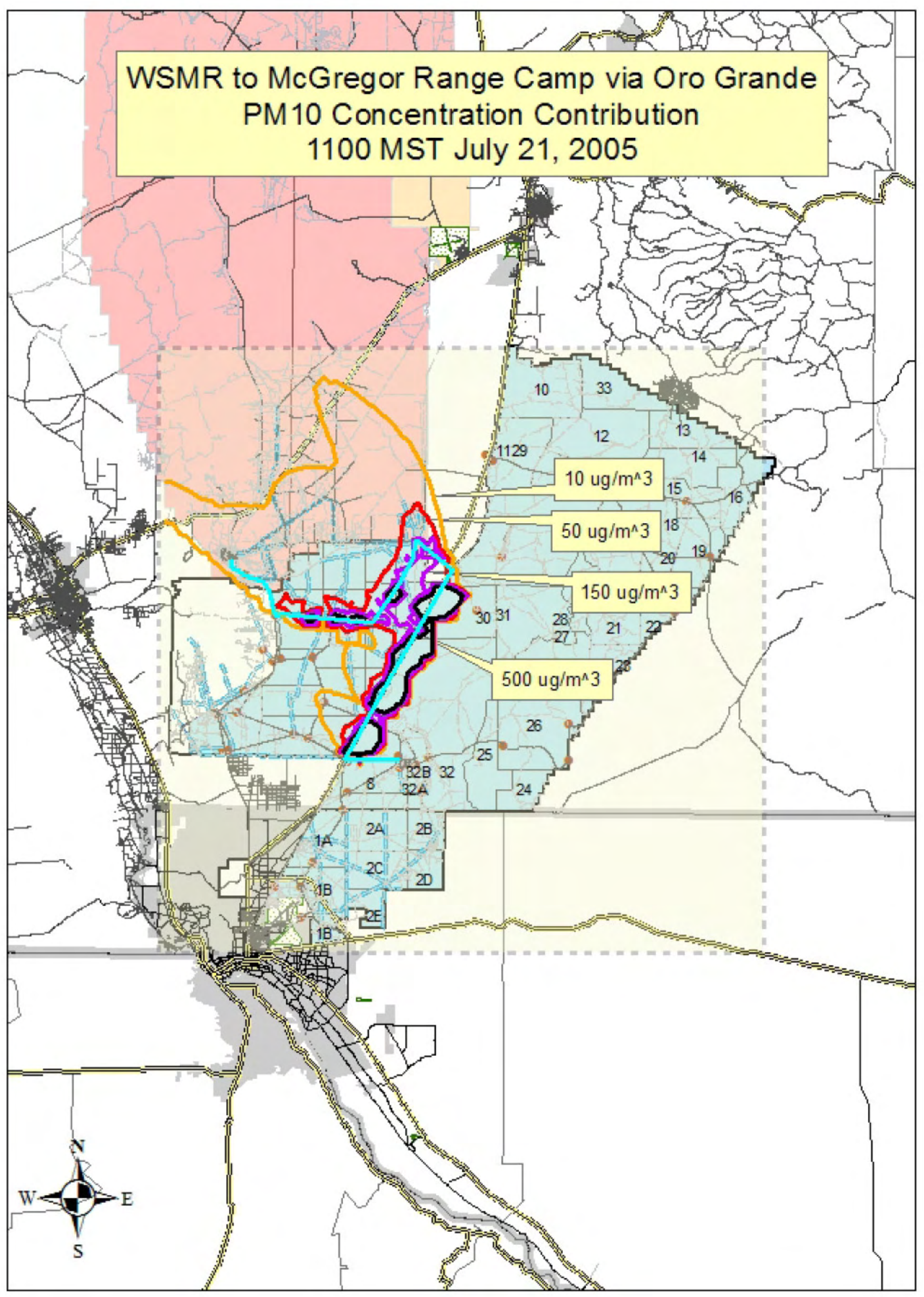




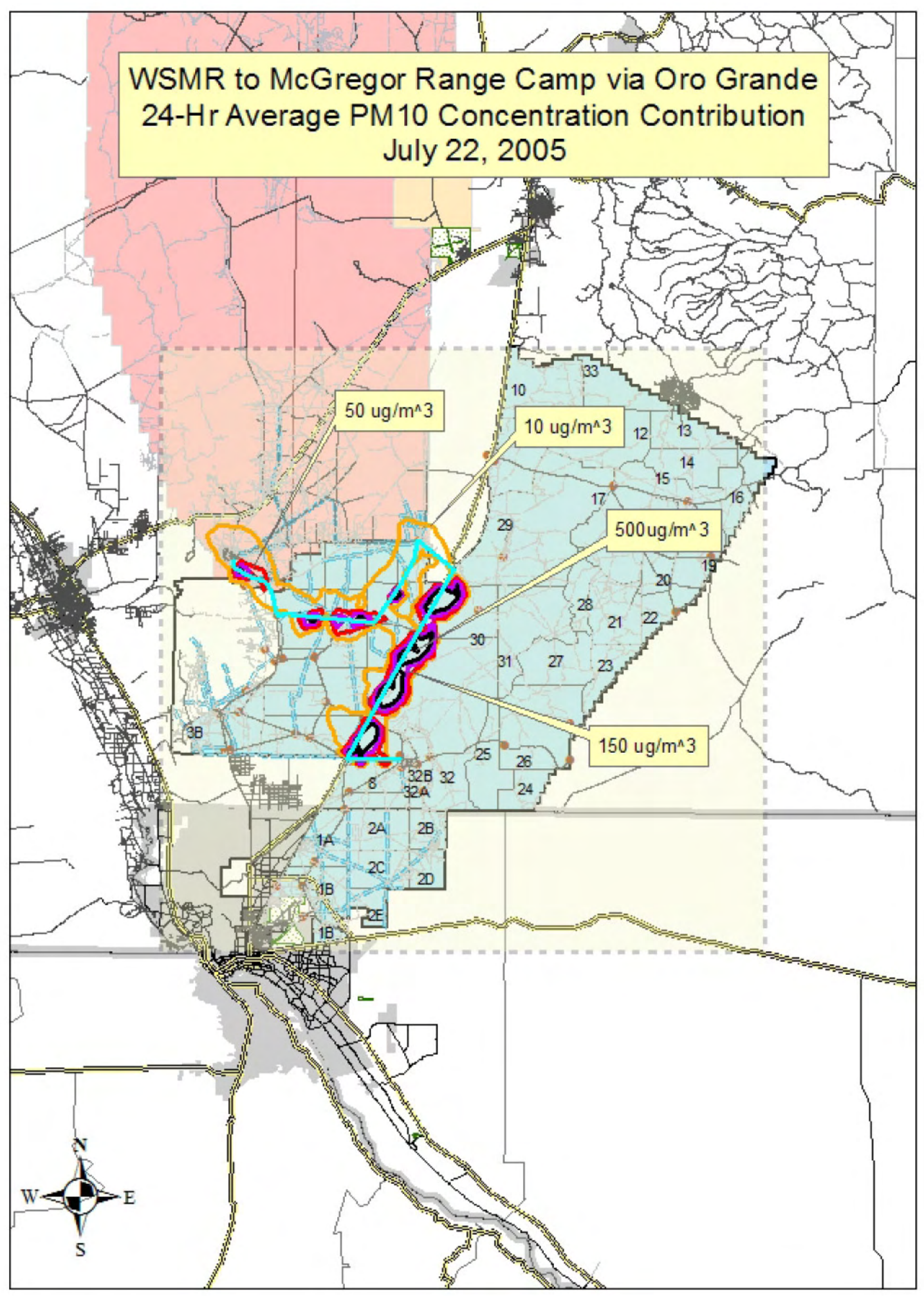




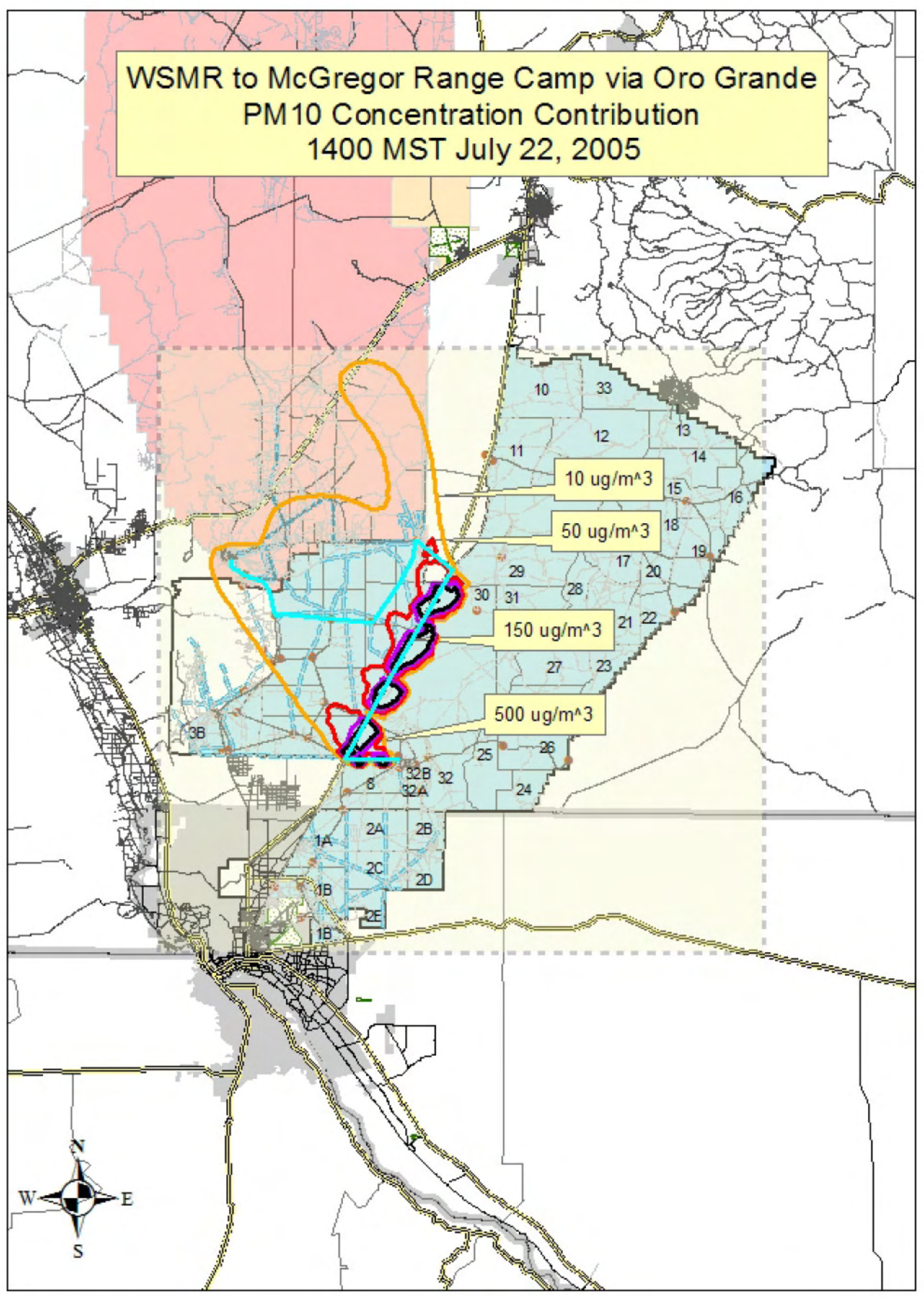




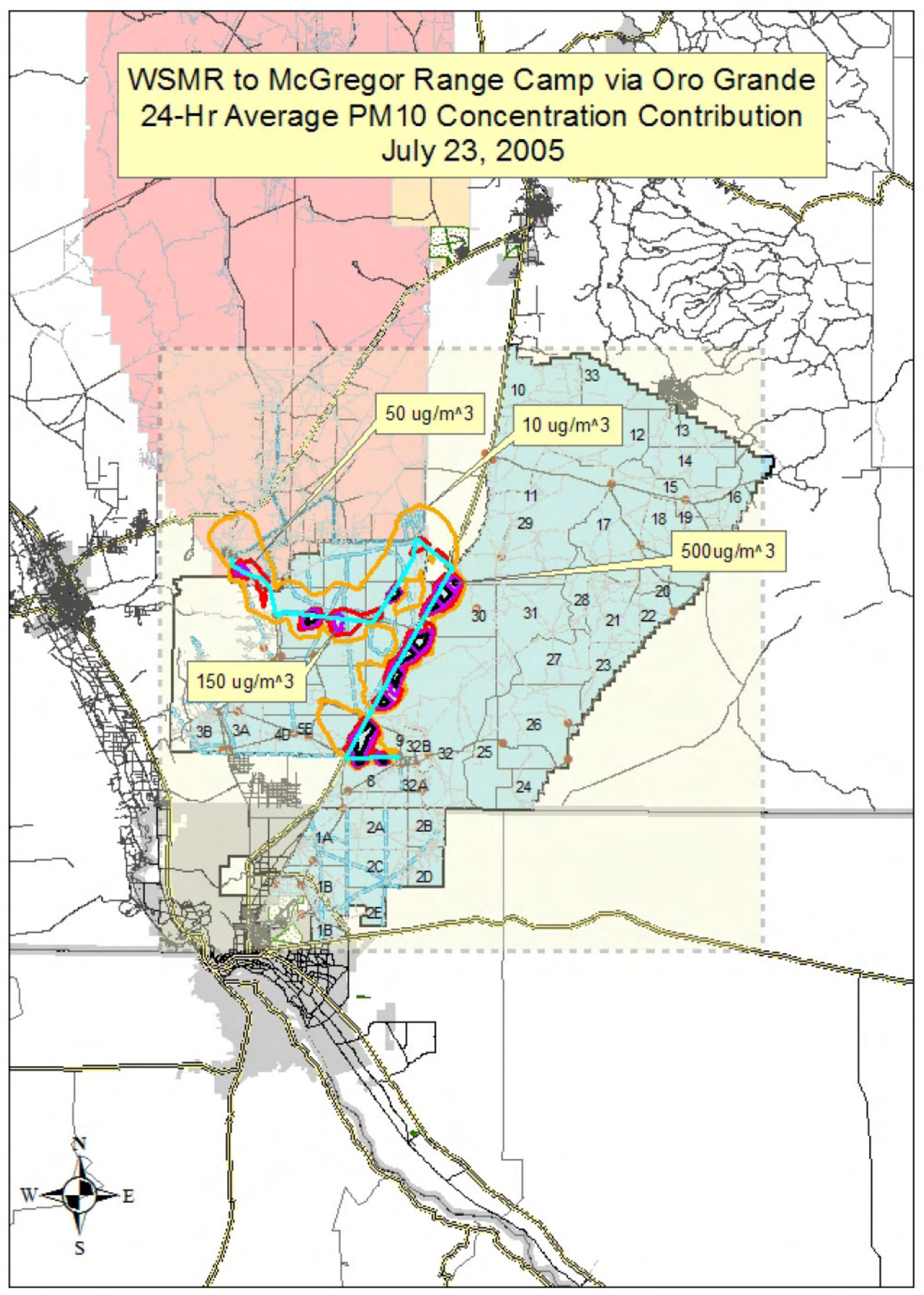




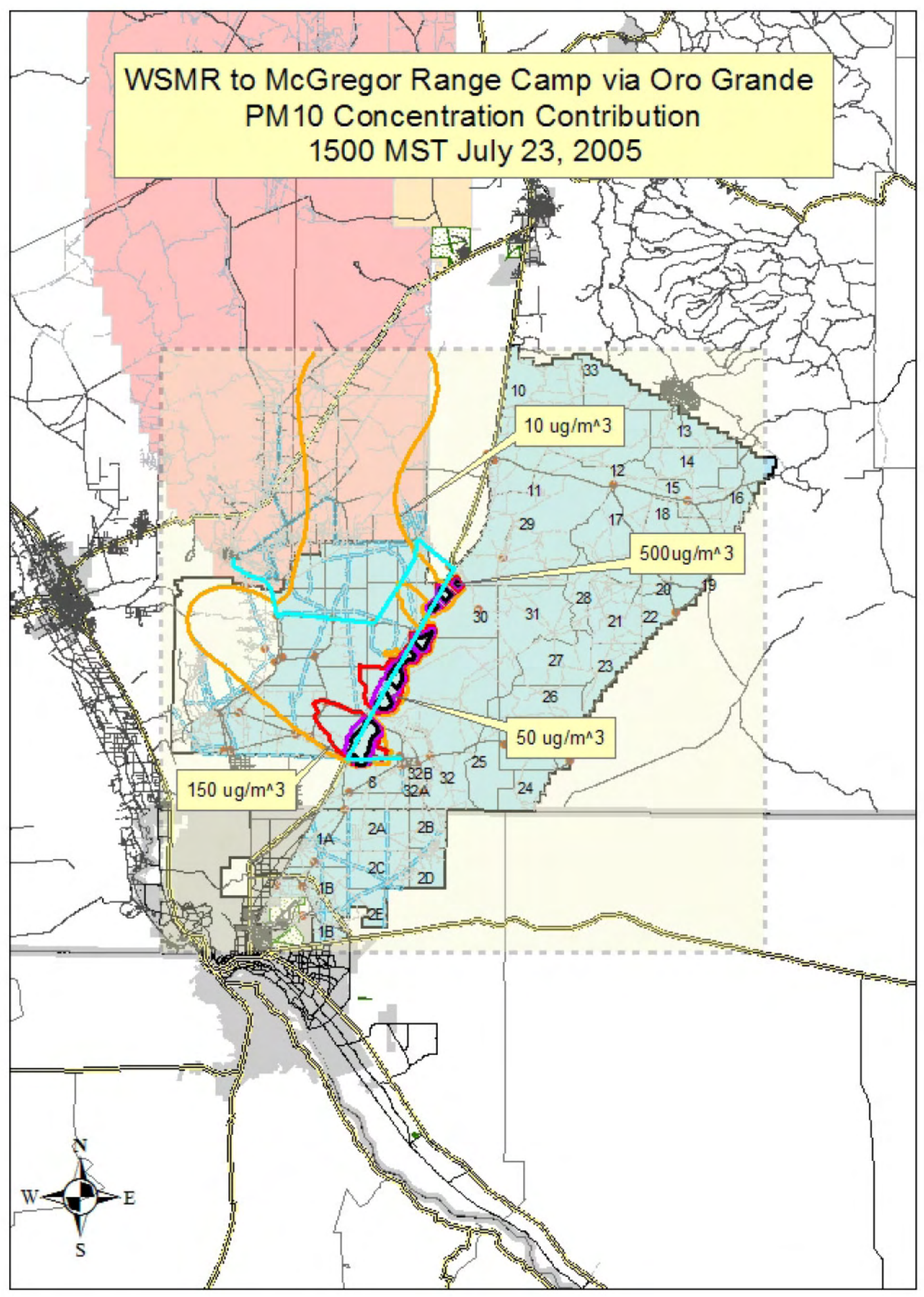




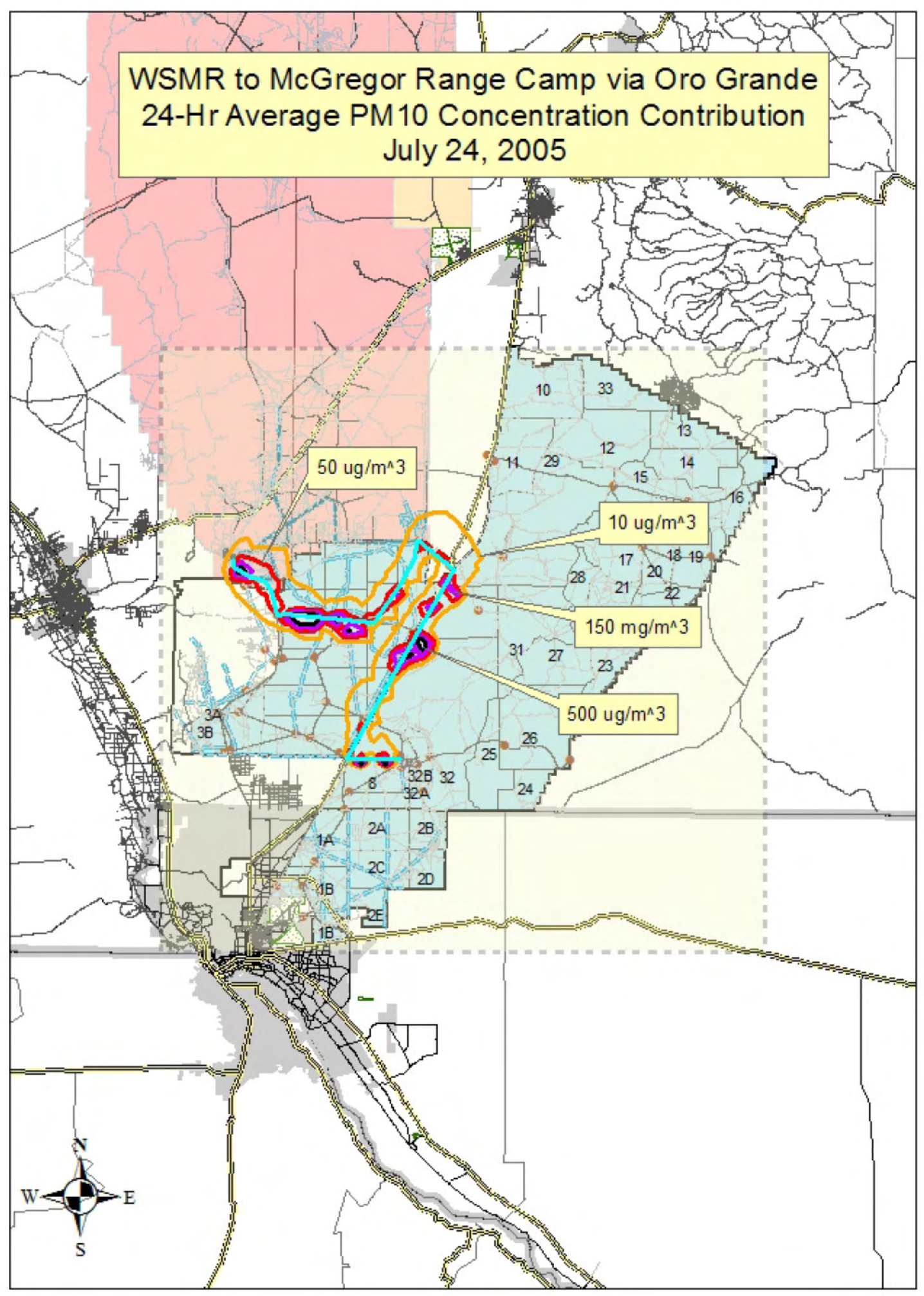




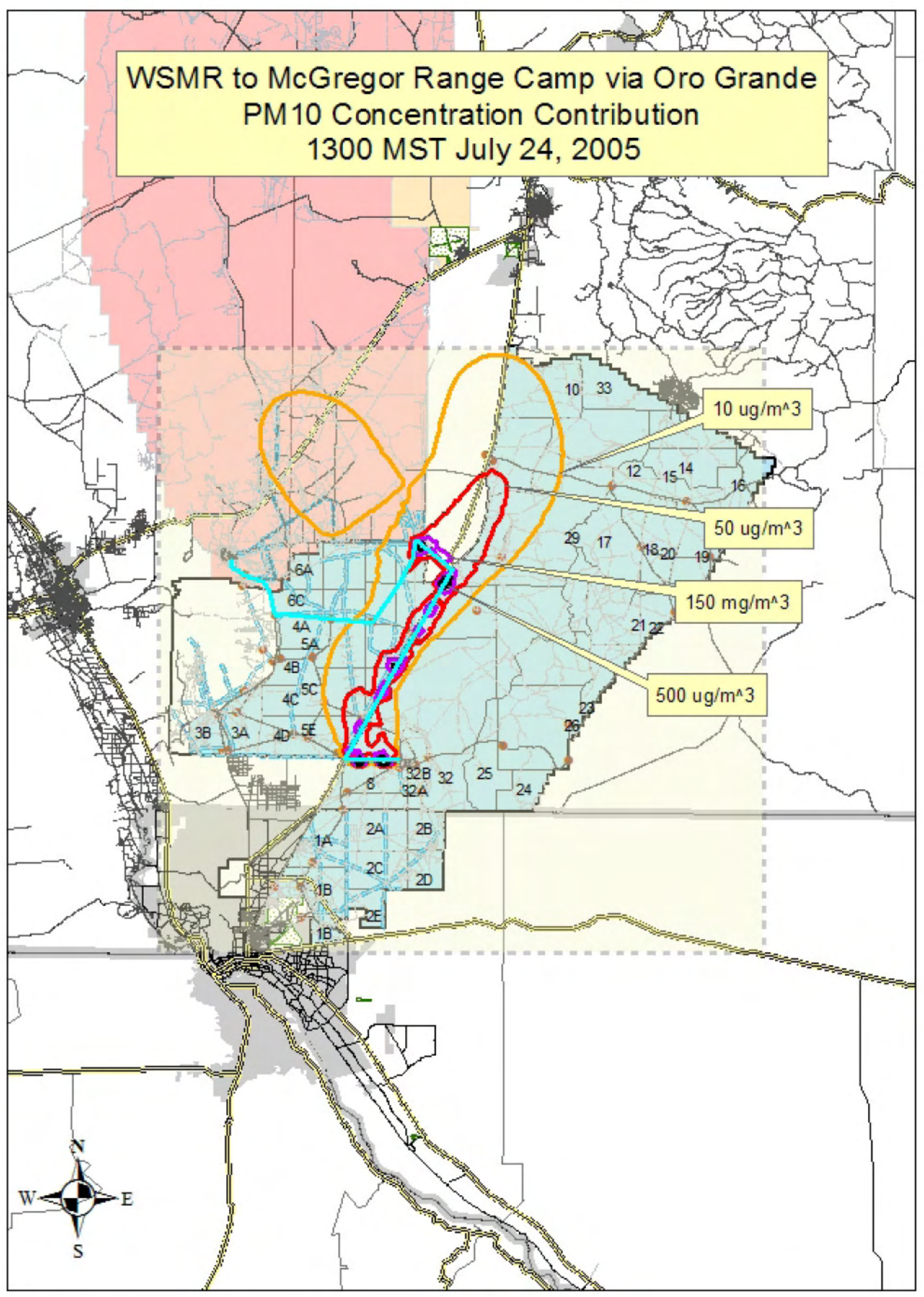




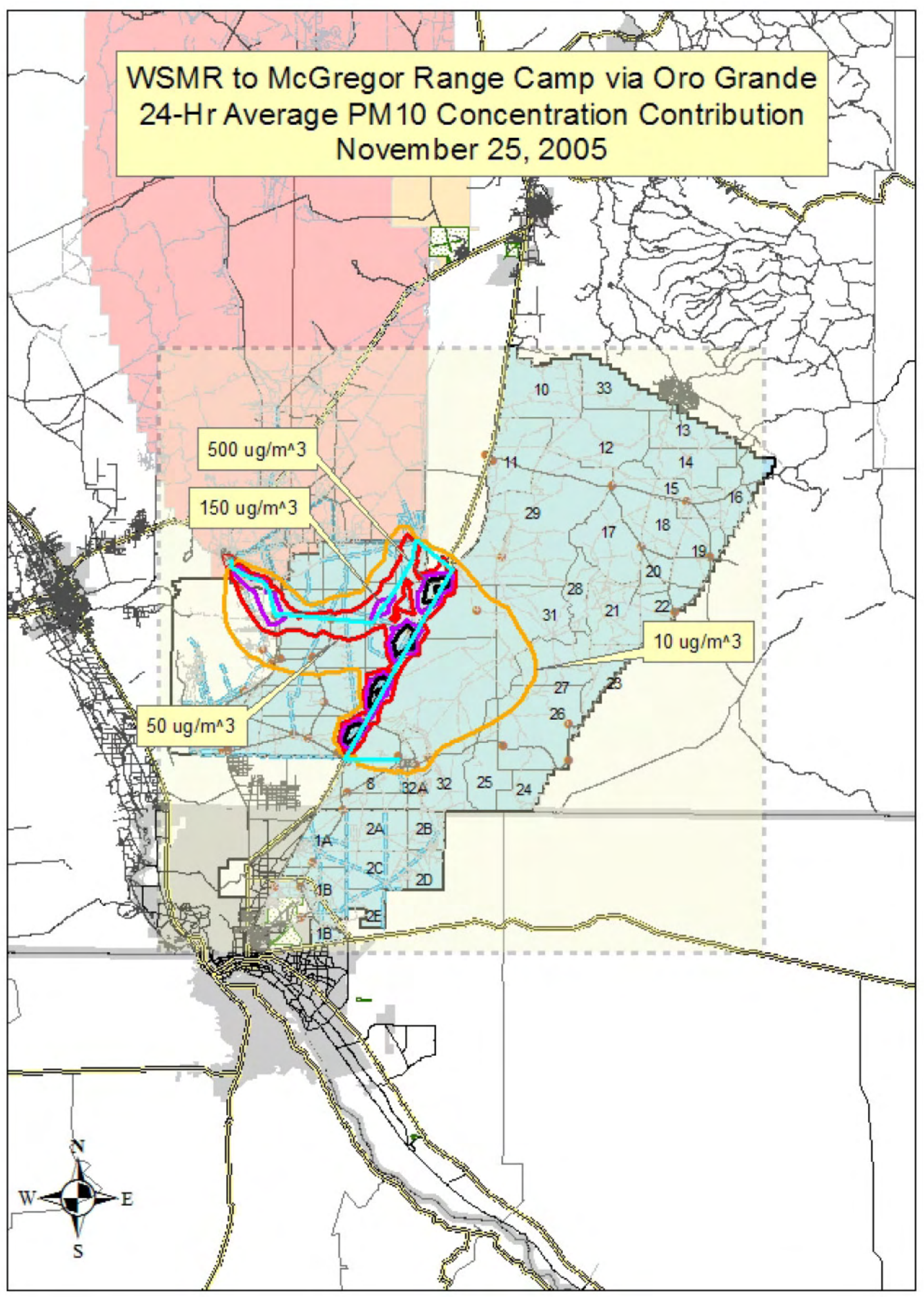




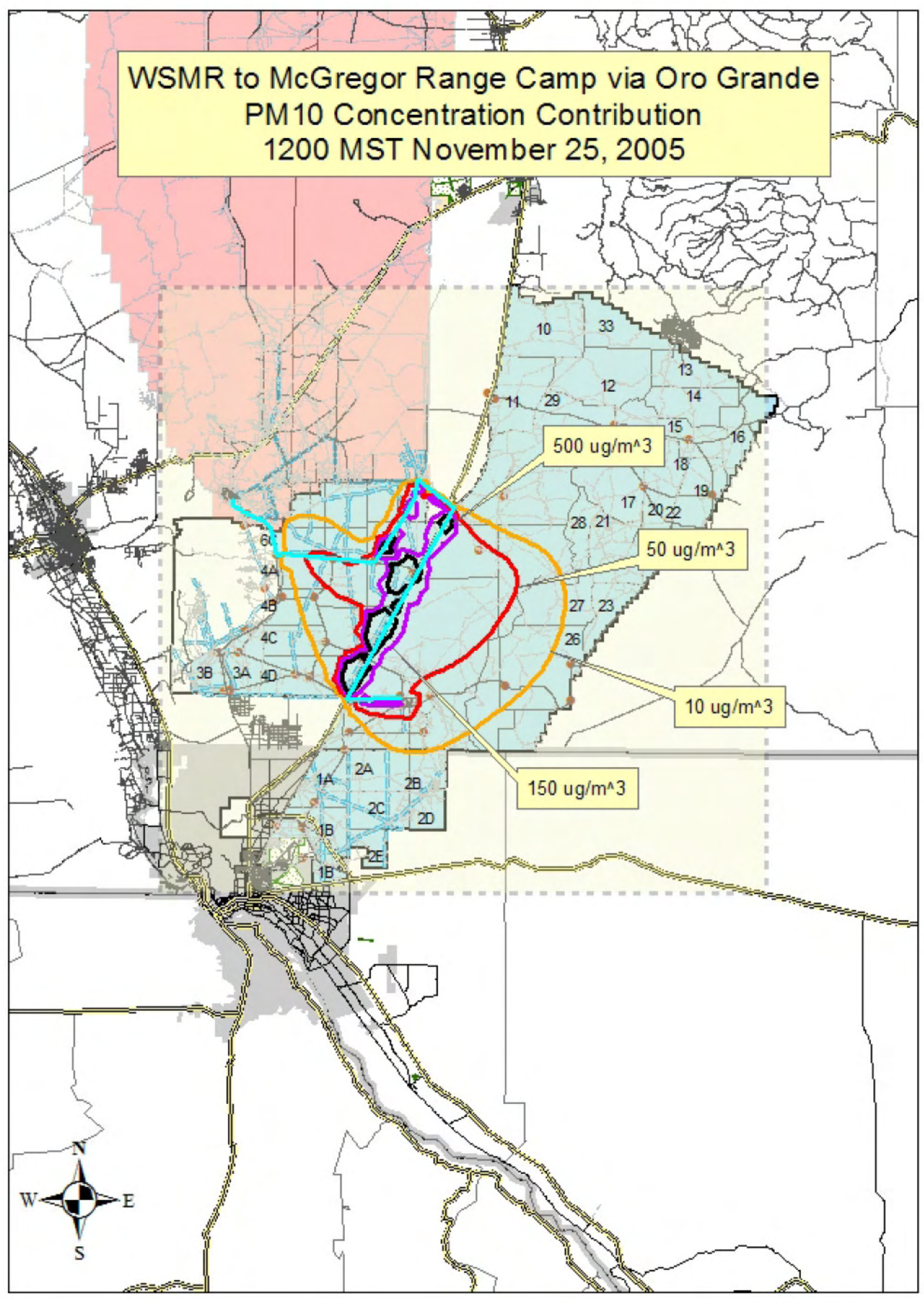




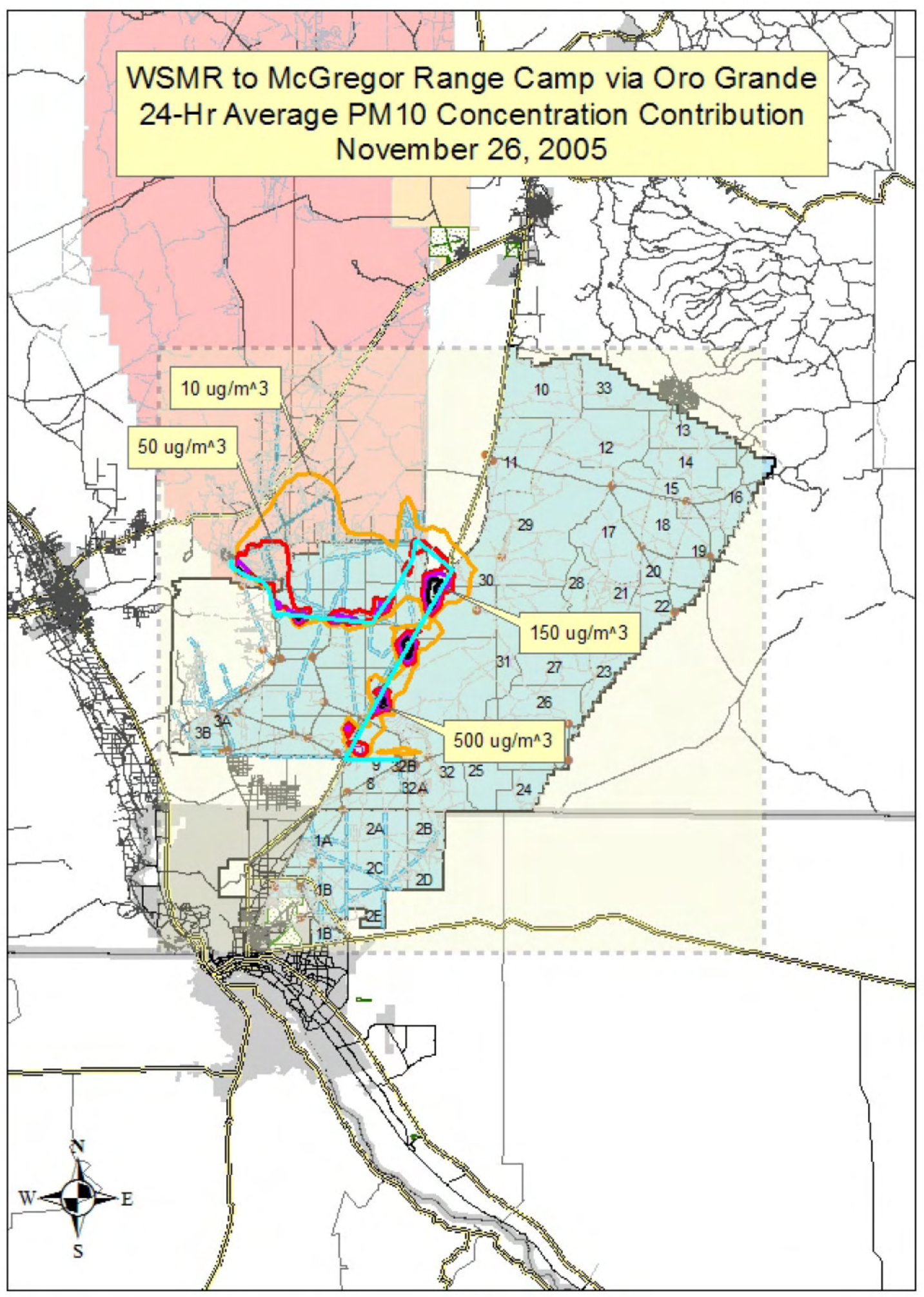




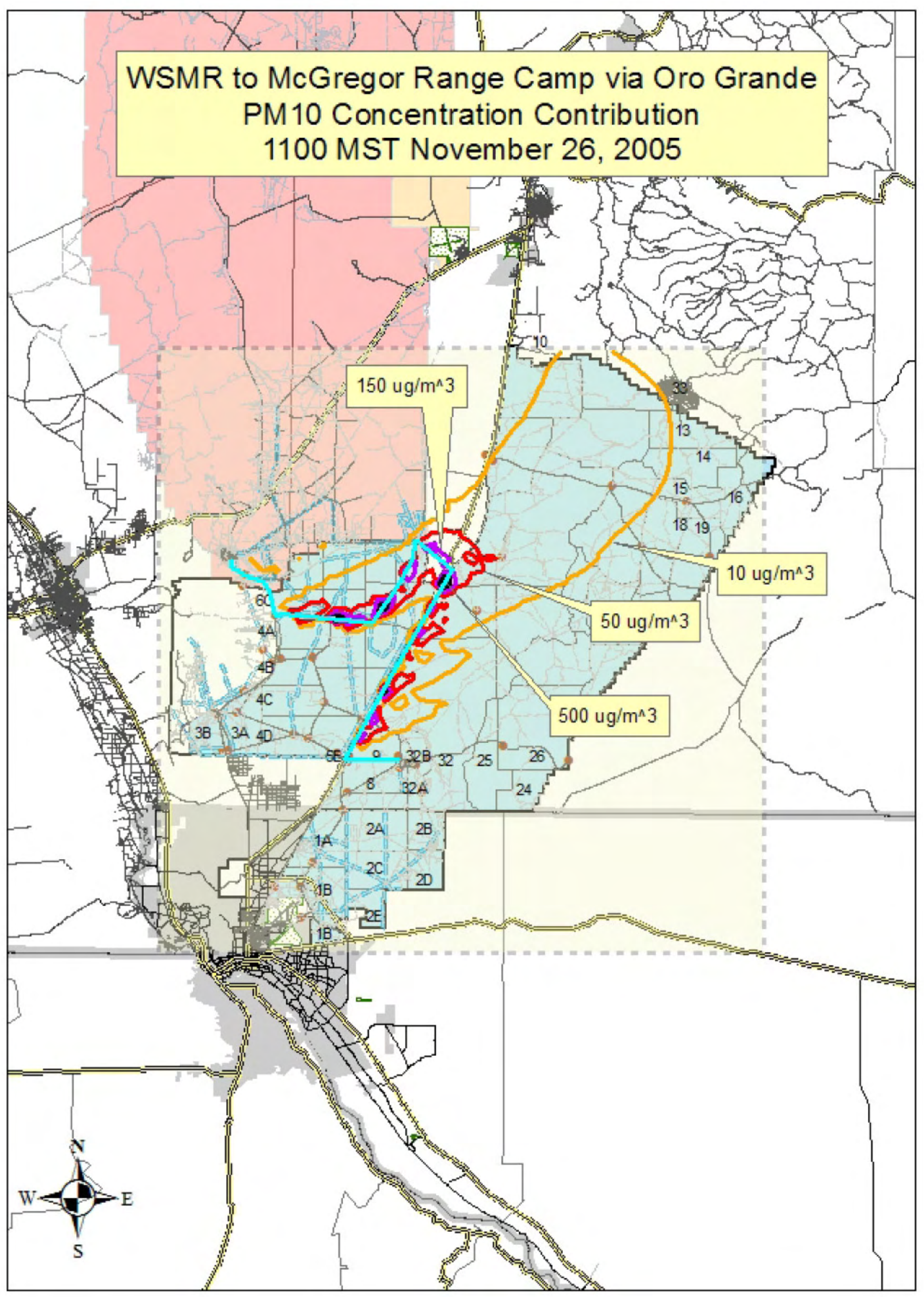




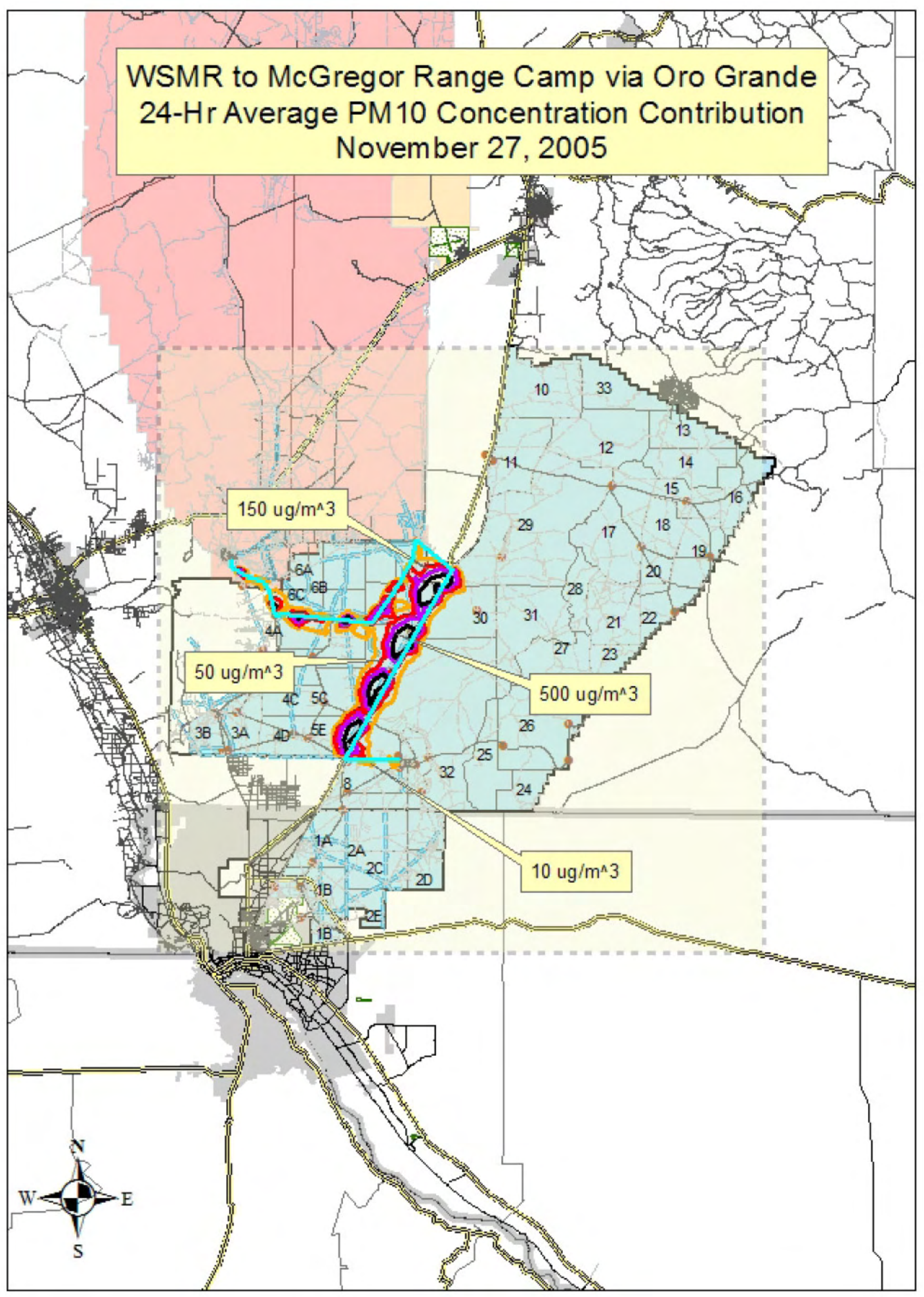




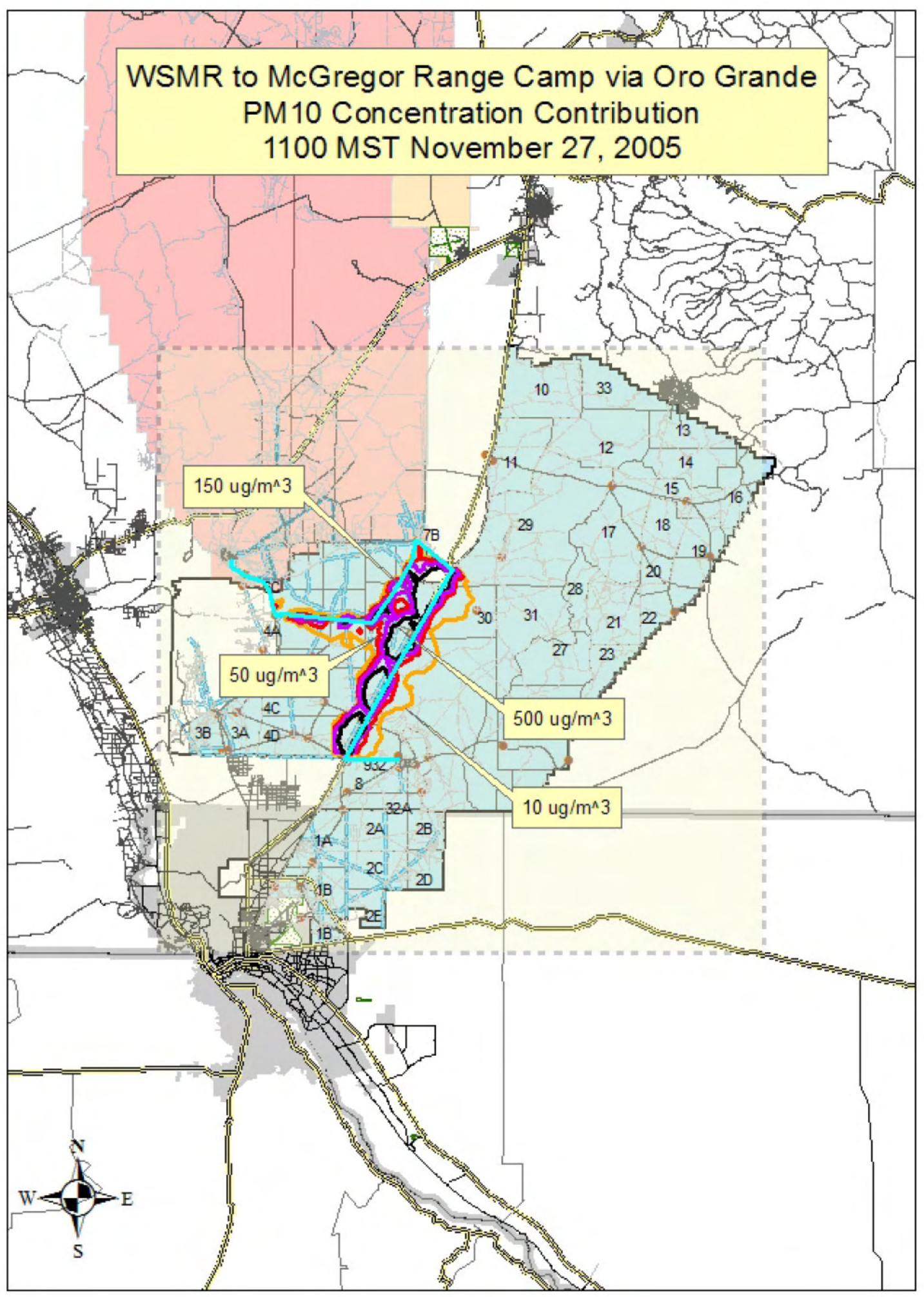




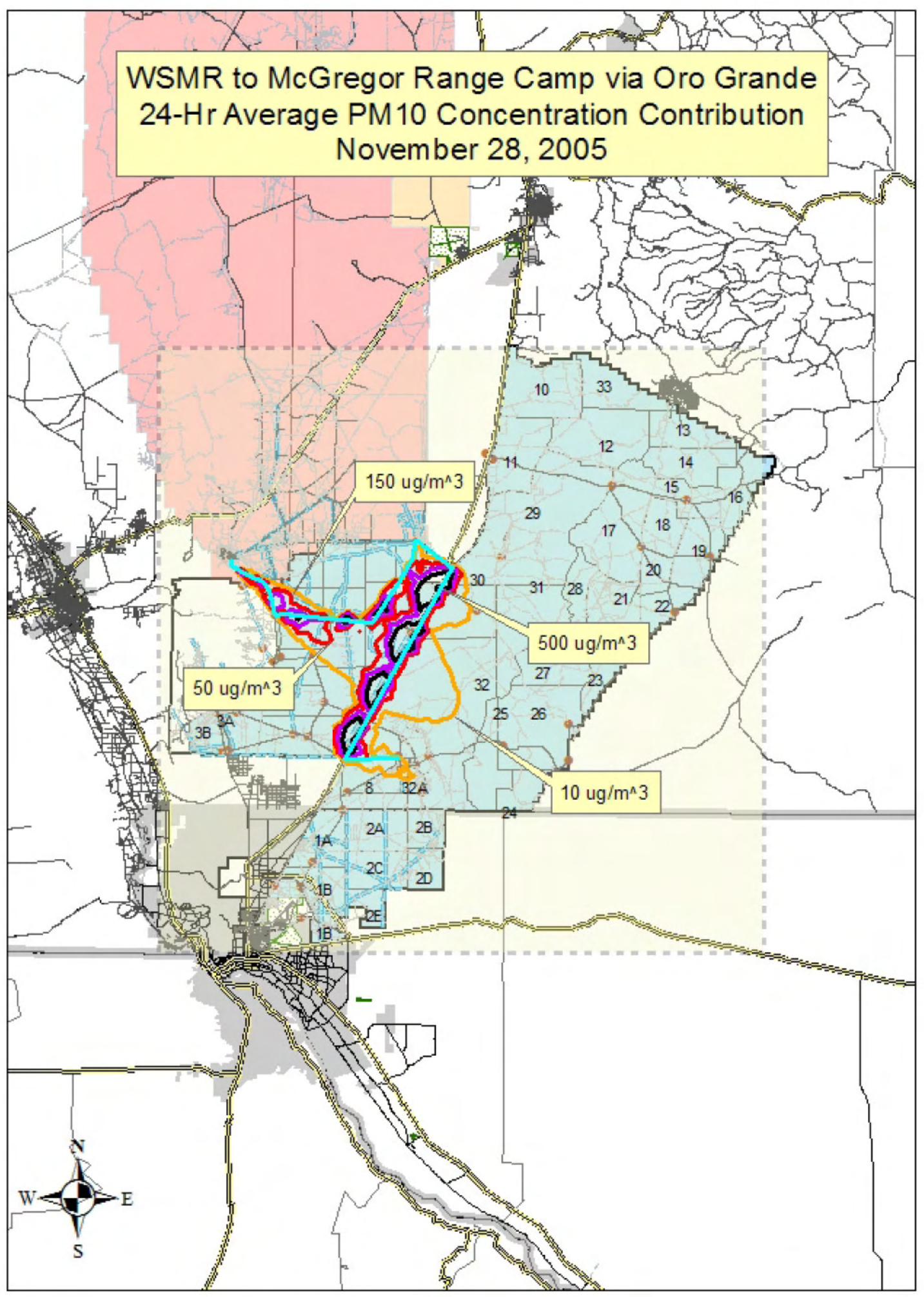




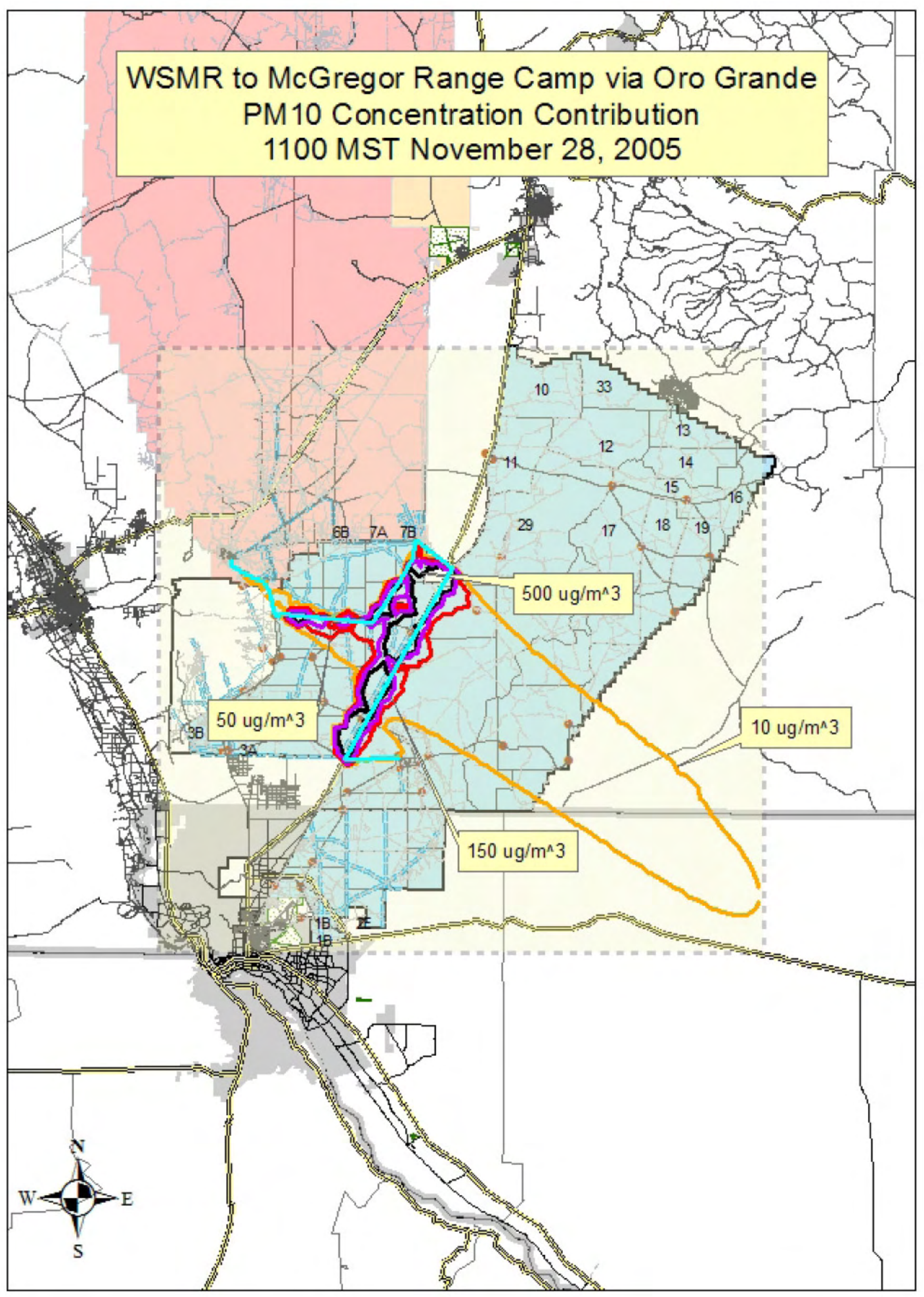




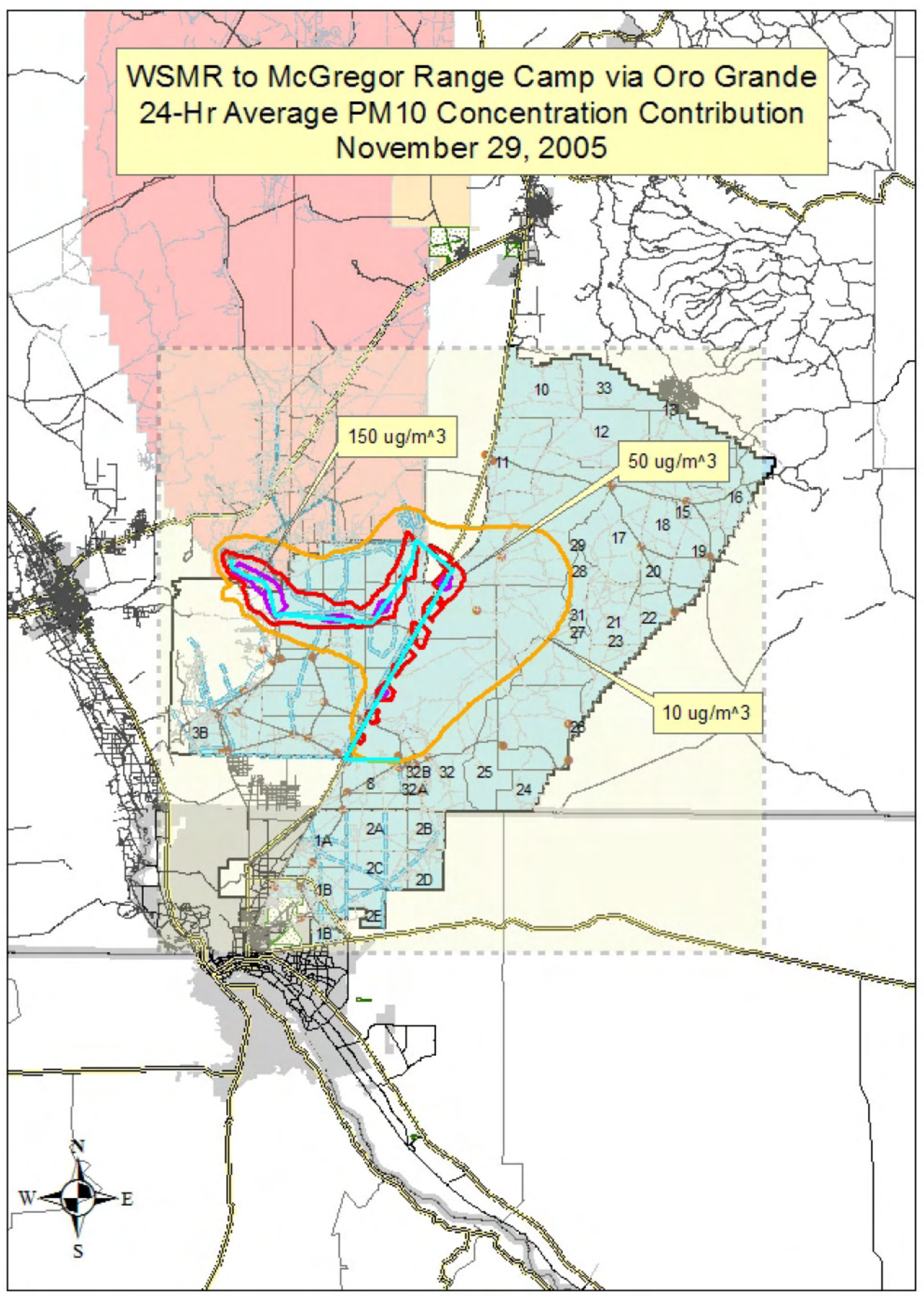




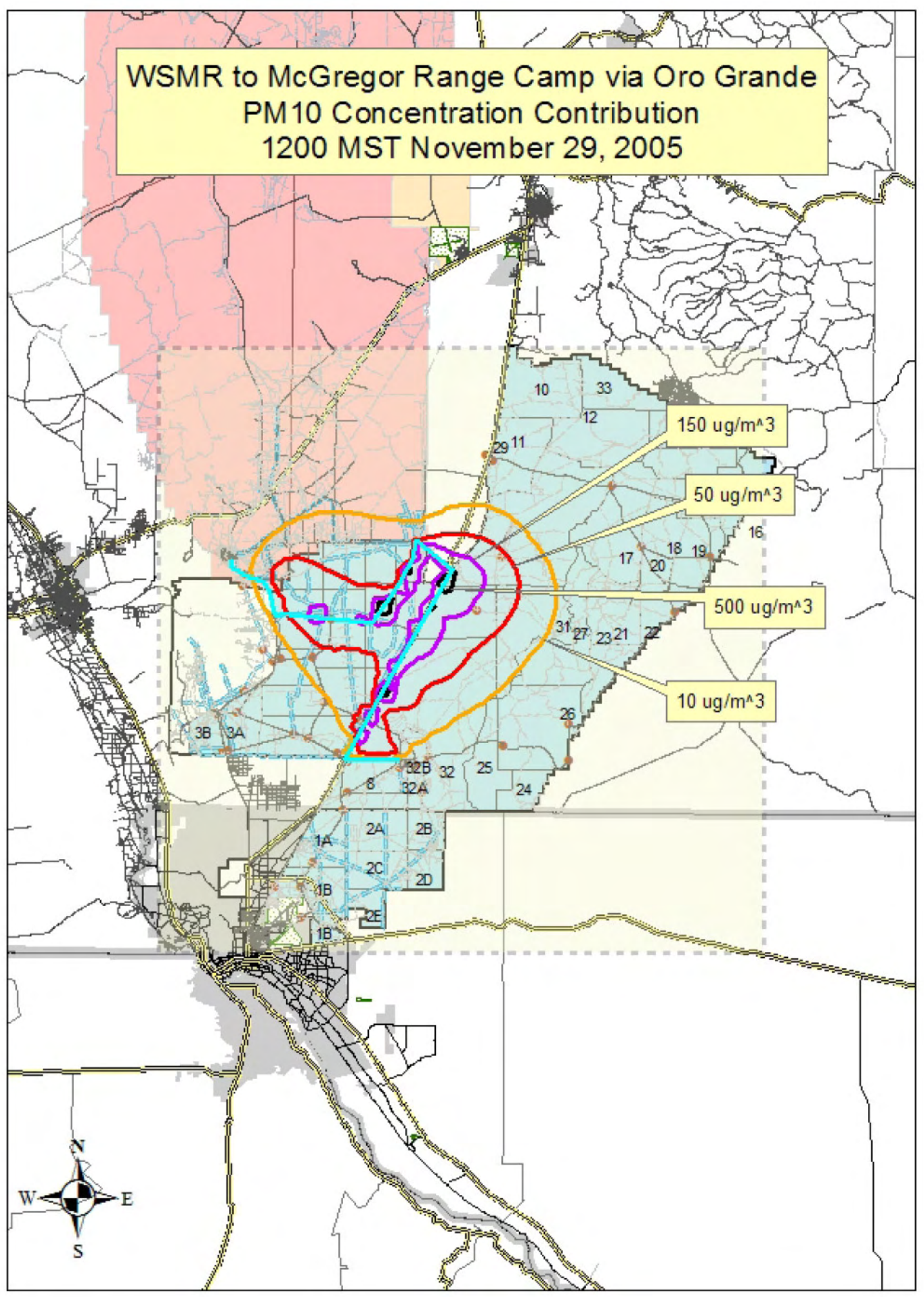





\section{Distribution}

No. of

Copies

2 Lilia Lenhart

Fort Bliss, Environmental Division

IMWE-BLS_PWE, B-622 Attn: Lenhart

Fort Bliss, Texas 79916

(915) 568-5724

Jesus D. Moncada

Corpus Christi Army Depot, Directorate of Security \& Industrial Risk Management

308 Crecy Street, MS-23

Attn: AMSAM-CC-BC-L

Corpus Christi, Texas 78419

(361) 961-2326, Ext. 246

Isaac Trejo

Fort Bliss, Environmental Division

IMWE-BLS_PWE, B-622 Attn: Trejo

Fort Bliss, Texas 79916

(915) 569-6297
No. of

Copies

$5 \quad$ Pacific Northwest National Laboratory

E. G. Chapman (2)

K9-30

W. J. Shaw

K9-30

Information Release (2) P8-55 




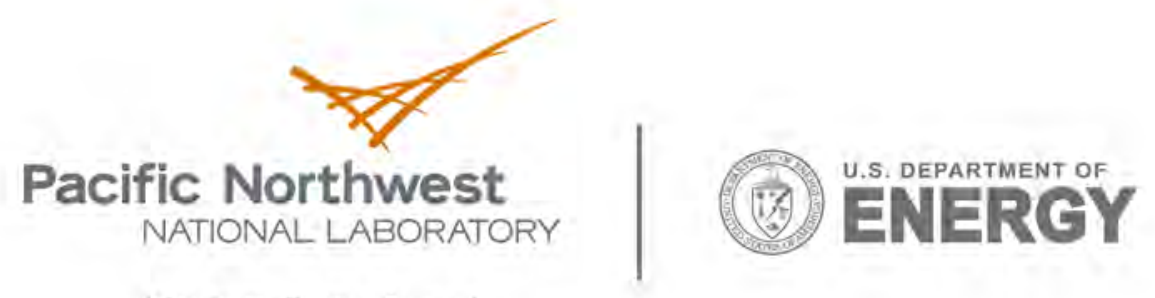

902 Battelle Boulevard

P.O. Box 999

Richland, WA 99352

1-888-375-PNNL (7665)

www.pnl.gov 